\title{
Revenue generation strategies in \\ Sub-Saharan African universities
}

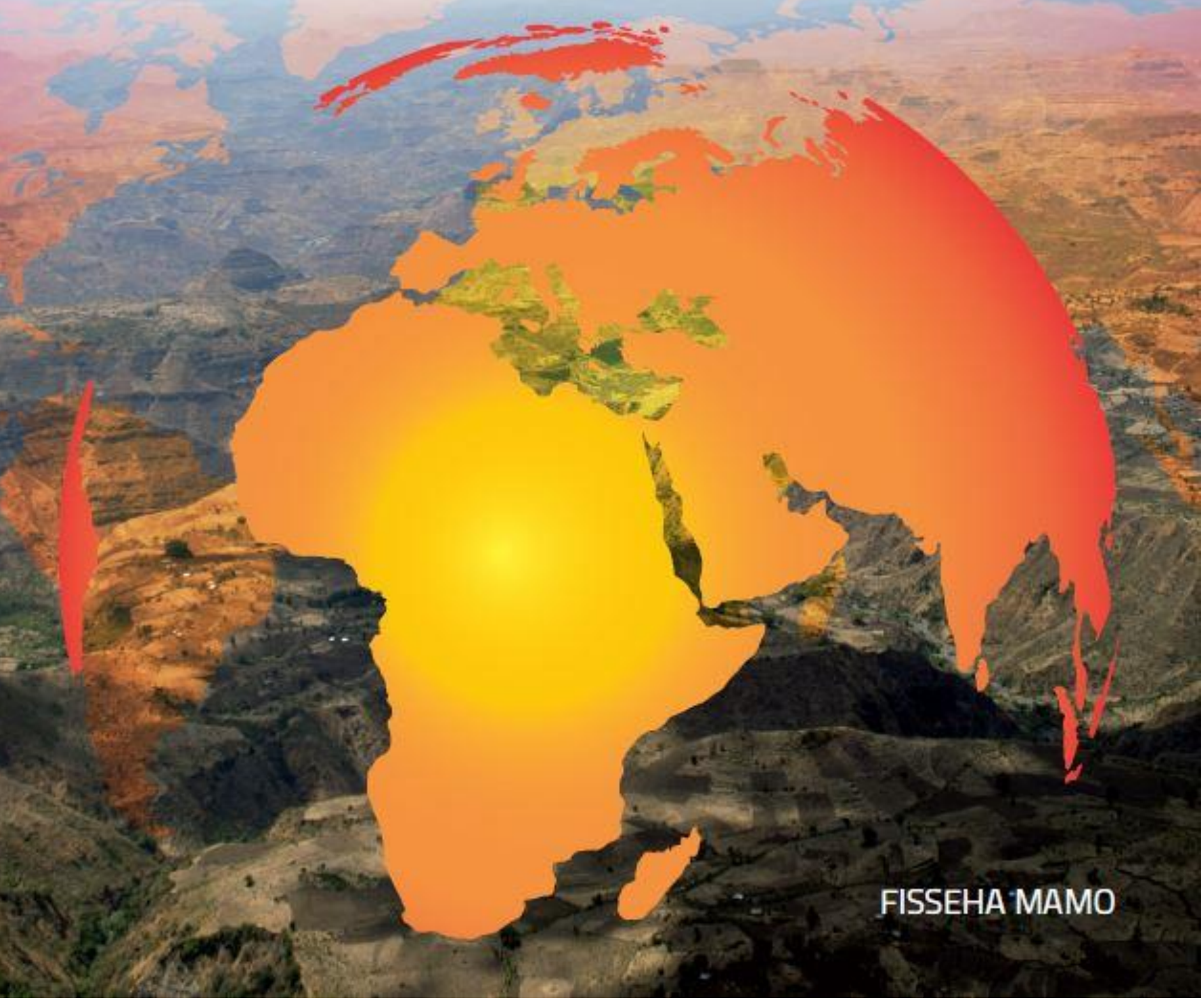


REVENUE GENERATION STRATEGIES IN SUB-SAHARAN AFRICAN UNIVERSITIES 


\title{
REVENUE GENERATION STRATEGIES IN SUB-SAHARAN AFRICAN UNIVERSITIES
}

\section{DISSERTATION}

\author{
to obtain \\ the degree of doctor at the University of Twente, \\ on the authority of the Rector Magnificus, \\ prof. dr. H. Brinksma,
}

on account of the decision of the graduation committee,

to be publicly defended

on 29 April 2015 at 16.45 hrs

by

Fisseha Mamo Gebreyes

born on 15 June 1973

in Shoa, Ethiopia 
This dissertation has been approved by the promotors:

Prof. dr. J. Enders

Dr. B.W.A. Jongbloed

(c) Fisseha Mamo, 2015

All rights reserved. No part of this publication may be reproduced, stored in a retrieval system of any nature, or transmitted in any form or by any means, electronic, mechanical, now known or hereafter invented, including photocopying or recording, without prior written permission of the author.

ISBN 978-90-365-3880-0

DOI $\quad 10.3990 / 1.978903653880-0$

Published by CHEPS/UT, P.O. Box 217, NL-7500 AE Enschede, the Netherlands,

cheps@utwente.nl

Printed by Ipskamp Drukkers, Enschede, the Netherlands

Cover design by WeCre8, Enschede, The Netherlands 
Members of the graduation committee:

Prof.dr. P.B. Boorsma

Prof.dr. P.A.M. Maassen

Prof.dr. R. Naidoo

Prof.dr. R. Torenvlied

This book is dedicated to my beloved father, the late Mamo Gebreyes, who always believed in education, and educated all of his children to the level of higher education without himself attained beyond basic education. His deep love and dedication to his family remains with us forever. 


\section{Preface}

Most African countries choose to pursue more knowledge-intensive growth that magnifies the critical role of higher education in their overall socio-economic development. Nonetheless, universities in Africa face the challenge of balancing the need to raise educational quality with the increasing social demand for access. In this regard, financial sustainability is one of the key challenges for Sub-Saharan Africa's universities. The inception of the topic for my $\mathrm{PhD}$ research traced back to 2007/08, while I was working for the Ministry of Education in Ethiopia as a coordinator for donor funded projects. In this capacity, I had a chance to participate in a series of governance, leadership, and management capacity development training programmes, several policy debates, and strategic planning organized by national and international stakeholders. In such forums, how to devise a financing approach to higher education development that enables the country to raise educational quality during times of ever-rising demand for higher education always was a topic of heated debates. Other matters, such as safeguarding organizational autonomy, equity and relevance were also part of the debates. Particularly, the issue of how public universities might receive extended organizational autonomy, while at the same time being almost fully dependent on the government for their revenues triggered questions that called for an adequate response. This raised my interest in the question of how universities might improve their financial situation while continuing to accommodate the steep rise in student enrolments. I started exploring several possibilities to address this question in a $\mathrm{PhD}$ project abroad. I then contacted Mr. Kees van Dongen, then Director of the Centre for International Cooperation at the Vrije Universiteit Amsterdam, who forwarded my research proposal to CHEPS at the University of Twente. This research centre very much welcomed my initiative and supported a research proposal that was sent to the NUFFIC. CHEPS very much turned out to be the right place for undertaking my $\mathrm{PhD}$ research. It houses many extremely talented and experienced scholars in the field of higher education that could inspire me in my work. I would like to take the opportunity to thank the CHEPS colleagues for helping me realise my ambitions.

The journey of my $\mathrm{PhD}$ research thus began in 2009 in CHEPS. It proved to be route with some ups and downs, and brought me to face a lot of opportunities 
and challenges. The death of my father in 2012, my personal health situation, and the constraints I faced during the field work to collect my data were some of the issues I had to face. On the positive side, I was lucky to get the opportunity to improve as a scholar and a person during the process of writing this book. My PhD research presented many opportunities to establish networks with researchers and colleagues in different parts of the world and allowed me to make new friends.

The long journey of my $\mathrm{PhD}$ research has now come to an end. I managed to answer some of the questions I had in the beginning but realise that many more new ones have emerged along the way. Still, the completion of my study brings me great joy. I feel it holds some important messages that I managed to extract from the large amount of data that was collected for four universities from three Sub-Saharan African countries, namely Ethiopia, Kenya, and South Africa. I was able to better understand opportunities and obstacles for successful revenue generation by universities. This important to help universities in Africa (and elsewhere) ensure their financial sustainability. My book presents a wide range of strategies that universities may employ for improving their financial sustainability in times of huge demands from students and other stakeholders in higher education.

My work could never have been completed without the support of several people whom I owe special thanks. First of all, I am very grateful to my promoter, Professor Jürgen Enders, and my supervisor, Dr. Ben Jongbloed, for the continuous encouragement, invaluable advice and scholarly guidance throughout my study. I would like to thank Professor Enders for being an excellent and caring promoter, providing constructive comments, and bringing in more structure into my ideas and putting the study into perspective. I thank and appreciate Dr. Jongbloed for his critical comments and suggestions, his open door policy, and his patience and persistence when discussing my ideas. He showed enormous dedication throughout my study. Another CHEPS colleague, Paul Benneworth, suggested some important improvements for the final chapter of my thesis. I would also like to acknowledge the academic staff of CHEPS who gave me their sympathy and support during my stay in Enschede. I am grateful to the Jongbloed family (Elvira, Ben, Dylan, and Ruben), Liudvika Leisyte, Hans Vossensteyn, Egbert de Weert, Elke Weyer, Don Westerheijden, Grit Laudel, Harry de Boer, Paul Benneworth, Jon File, Frans Kaiser, Arend Zomer, Andrea Kottmann, Leon Cremonini, and Jenny 
Ngo, for their hospitality, humour, and encouragement. The very professional CHEPS secretariat (Ingrid van der Schoor, Karin van der Tuin and Mae Fastner) and Hilly ter Horst and Mirjam Vaanholt also deserve special thanks for facilitating my flights and providing advice and support. Leanne Benneworth did a great job in proofreading my final manuscript and polishing my English.

I would also like to express my deep appreciation and gratitude to the many people and organizations outside CHEPS that contributed to the realization of my study. First of all, I would like to thank the Ministry of Education of Ethiopia for granting me a study leave to work full-time on my $\mathrm{PhD}$. The Netherlands Universities' Foundation for International Cooperation (NUFFIC) deserves particular acknowledgment for funding my PhD study under its NFP scholarships programme. I am also grateful to the staff members of the international office at the University of Twente for their support services. The outcomes of my study are based on many interviews, documentary evidence, and on site visits to my case study universities. I am greatly indebted to many individuals at the four case study universities for their willingness to participate in the interviews and proving me with crucial information. In every university I received great support 'from the following individuals in arranging visits and organizing interviews: Dr. Tola Baresso of Adama Science and Technology University; Professor Belay Kassa, Professor Kebede W/Tsadik and Dr. Kindie Tesfaye of Haramaya University; Professor Romanus Odhiambo and Dr. Kabare Karanja of Jomo Kenyatta University of Agriculture and Technology: and Dr Sibongile Muthwa, Professsor Heather Nel, Dr. Charles Sheppard, and Dr. Nico Jooste of Nelson Mandela Metropolitan University. They also provided me with invaluable documentary evidence on their universities. I am truly grateful to my friend, Dr. Mulu Nega, for providing me with office space at Addis Ababa University and for proofreading my dissertation chapters. I would also like to thank the Center for Higher Education Transformation in South Africa, notably Dr. Nico Cloete and Ms. Angela Mias, for hosting me in Cape Town in 2011. Mr. James Otieno Jowi of Moi University deserves special thanks for assisting me in the process of granting me a research permit to work in Kenya. I also thank Dr. Tehsome Nekatibebe of Addis Ababa University for his sympathy and encouragement.

Finally, I could not have realized my dreams of doing a $\mathrm{PhD}$ without the unconditional support and unwavering love of my wife and parents. I am extremely grateful to my wife Woinshet Admasu for her uncompromised 
commitment and moral support to pursue my study under any circumstances. I am also grateful to my sons Abem Fisseha and Adonay Fisseha, who brought a fantastic addition to our life and made me finish my $\mathrm{PhD}$, although they are still too young to realize that. Last but not least, words of gratitude should go to my parents - particularly my beloved mother Wizero Ejegayehu Limenih, my brothers (Sisay and Cherinet), and my sisters (Aster, Hana, Rahel and Seblewongel), who always believed in me and supported me morally.

Fisseha Mamo

Addis Ababa, January 2015 


\section{Contents}

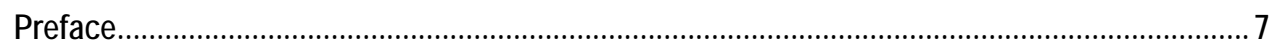

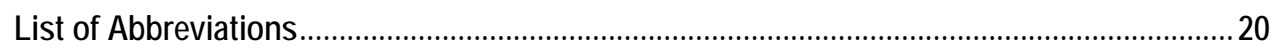

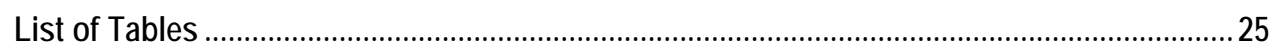

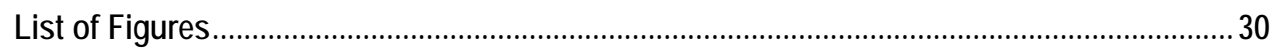

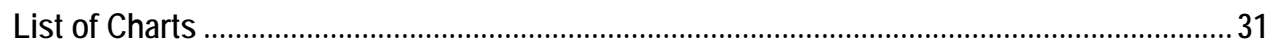

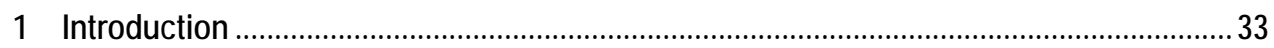

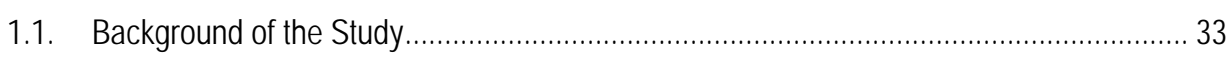

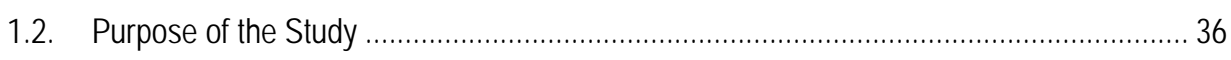

1.3. Research Problem and Research Questions............................................................. 37

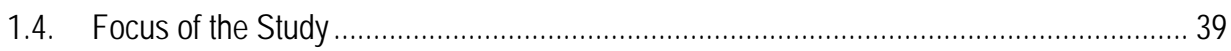

1.5. Theoretical and Methodological Orientation ………………….................................... 39

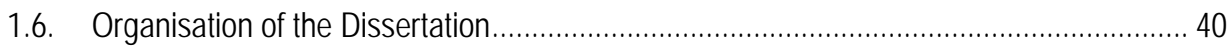

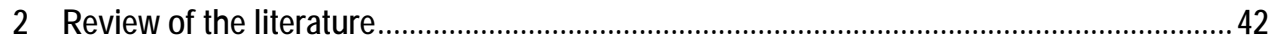

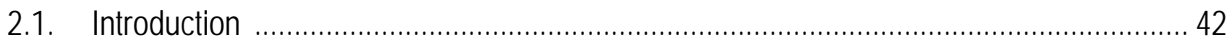

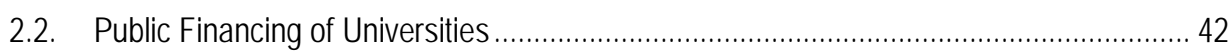

2.3. Challenge of Sustainable Financing for Public Universities........................................... 44

2.4. Potential Solutions for Overcoming Financial Challenges ............................................ 44

2.5. Revenue Generation for Financial Sustainability in Public Universities............................47

2.6. Drivers to Revenue Generation in Public Universities ................................................. 48

2.7. Sources of Revenue for Public universities ............................................................ 49

2.8. Revenue Generation Activities in Public Universities ................................................ 51

2.8.1. Educational services and Short-term courses .................................................... 51

2.8.2. Research and Consultancy Services ................................................................. 52

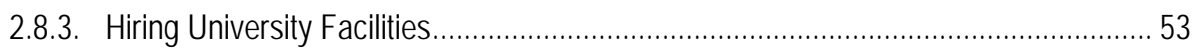

2.8.4. Sales of Goods and Products of Public Universities............................................ 53

2.9. Factors that Enable or Hinder Revenue Generation in Public Universities...................... 53 
2.10.1. Differentiation and Diversification of Services or Products for Revenue Generation.. 62

2.10.2. New Organisational Structures for Revenue Generation. 63

2.10.3. Internal Resource Allocation Mechanisms and Human Resource Policies for Revenue Generation................................................................................... 64

2.11. Effects of Revenue Generation in Public Universities............................................... 65

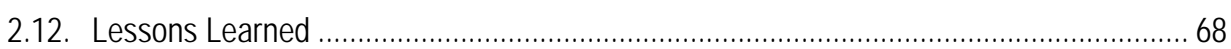

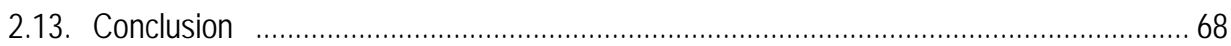

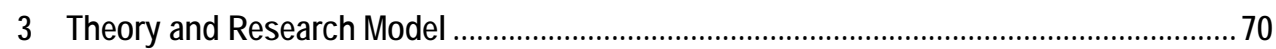

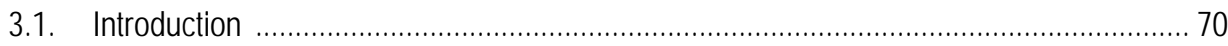

3.2. Resource Dependence Theory: Main Concepts and Critiques......................................... 70

3.3. Application of Resource Dependence Theory ........................................................... 77

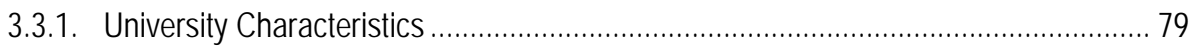

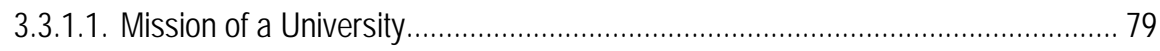

3.3.1.2. Internal Governance of a University ................................................................ 81

3.3.1.3. Leadership of a University ...................................................................... 84

3.3.1.4. Academic and Administrative Support Staff .................................................. 87

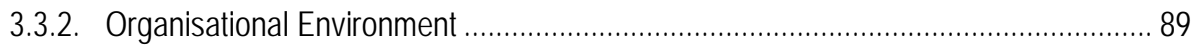

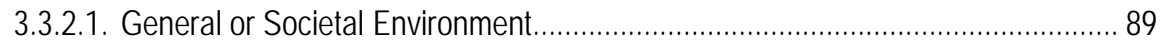

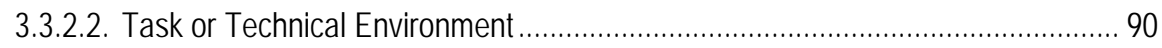

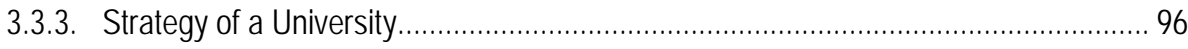

3.3.4. Revenue Generation Activities (RGA) ........................................................... 100

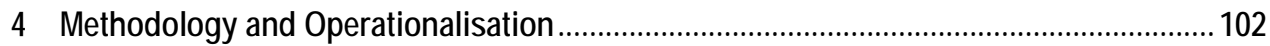

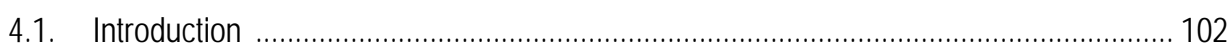

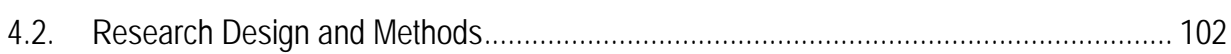

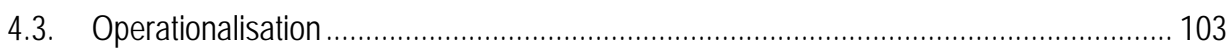

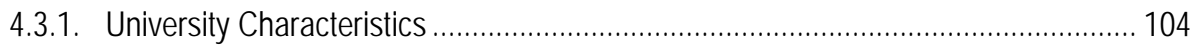

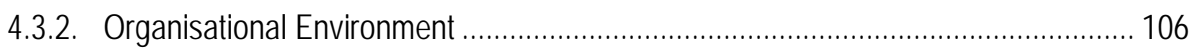

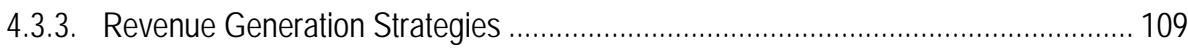




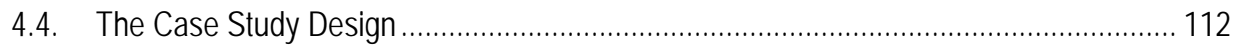

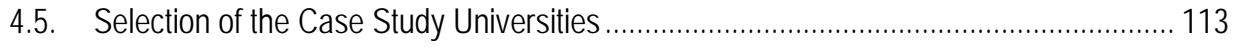

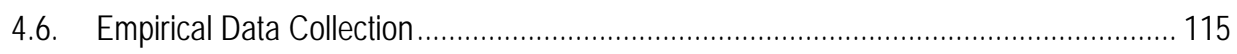

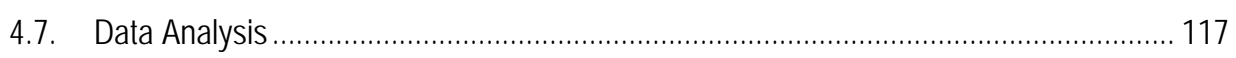

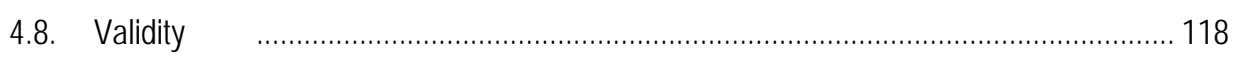

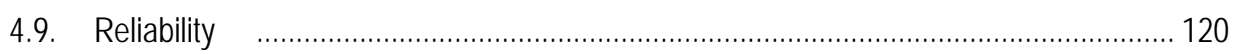

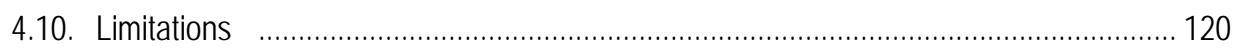

5 The Ethiopian Case Study Universities................................................................. 121

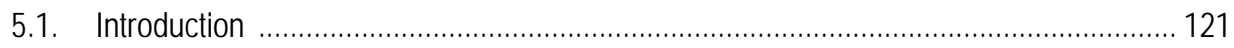

5.2. Demographic and Socio-Economic Context of Ethiopia ......................................... 121

5.3. Ethiopia's Higher Education System at a Glance ............................................. 124

5.3.1. Size and Shape of the Ethiopian Higher Education System................................ 125

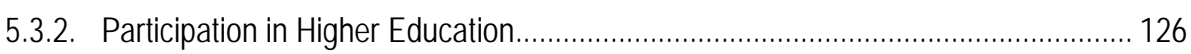

5.3.3. Higher Education Governance and Management in Ethiopia................................ 128

5.3.4. Financing Higher Education in Ethiopia........................................................ 130

5.4. Key Characteristics of the Ethiopian Case Study Universities ..................................... 133

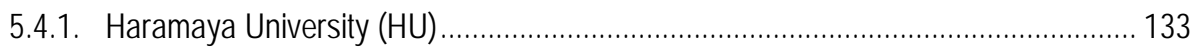

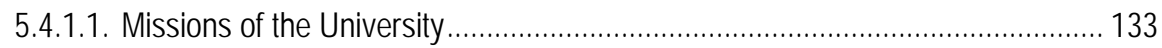

5.4.1.2. Internal Governance and Management of HU............................................. 134

5.4.1.3. Student Population and Areas of Study at Haramaya University ...................... 139

5.4.1.4. Academic and Administrative Support Staff ............................................... 141

5.4.1.5. Sources of Finance for Haramaya University ................................................ 144

5.4.2. Adama Science and Technology University (ASTU) ......................................... 145

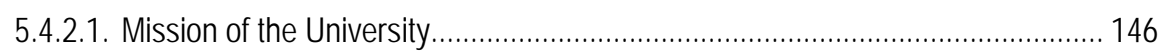

5.4.2.2. Internal Governance and Management of ASTU ........................................... 146

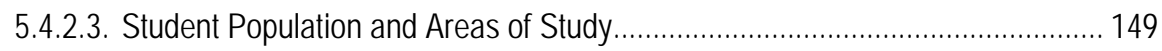

5.4.2.4. Academic and Administrative Support Staff ................................................ 151

5.4.2.5. Sources of Finance for Adama Science and Technology University................. 153 
5.5. External Environment of the Ethiopian Case Study Universities

5.5.1. External Stakeholders in the Ethiopian Case Study Universities.

5.5.2. Stakeholder Salience in Terms of Regulatory Powers

5.5.2.1. The Higher Education Proclamation (650/2009) and Organisational Autonomy 156

5.5.2.2. Other Regulation Tools Used by Bilateral and Multilateral Donors 159

5.5.3. Stakeholder Salience in Terms of Funding..... 161

5.6. Revenue Generation at the Ethiopian Case Study Universities 163

5.6.1. Status of Revenue Generation at ASTU and HU 163

5.6.2. Drivers for Revenue Generation 167

5.6.3. Factors that Enabler or Hinder Revenue Generation at the Ethiopian Case Study Universities

5.6.3.1. External Environmental Factors that Enable or Hinder Revenue Generation .... 170

5.6.3.2. University Specific Factors that Enable or Hinder Revenue Generation. 175

5.7. Revenue Generation Strategies of ASTU and HU 177

5.7.1. Differentiation of Services and Products for Revenue Generation 177

5.7.1.1. Differentiation of Educational Services and Creation of New Academic Units for Revenue Generation 177

5.7.1.2. Differentiation of Research Services and Creation of New Research Entities for Revenue Generation 183

5.7.2. Diversifying Non-Academic Services for Revenue Generation 186

5.7.3. Creation of Administrative Support Structures for Stakeholder Management 187

5.7.4. Decisions Concerning Internal Resource Allocation Mechanisms and Human Resource Policies for Revenue Generation. 193

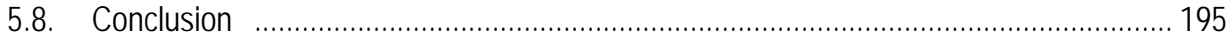

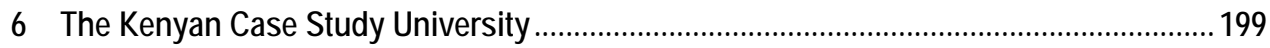

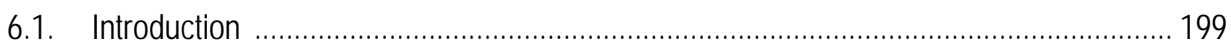

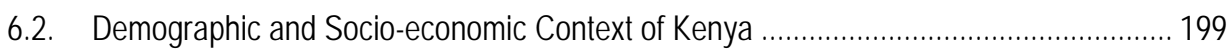

6.3. Higher Education System in Kenya at a Glance .......................................................... 202

6.3.1. Size and Shape of the Kenyan Higher Education System...................................... 202

6.3.2. Participation in University Education ................................................................. 206 
6.3.3. Higher Education Governance and Management in Kenya

6.3.4. Financing Higher Education in Kenya.......................................................... 210

6.4. Key Characteristics - Jomo Kenyatta University of Agriculture and Technology ............ 213

6.4.1. Vision and Mission of Jomo Kenyatta University of Agriculture and Technology ..... 214

6.4.2. Student Population and Areas of Specialisation at JKUAT .................................... 215

6.4.3. Internal Governance and Management at JKUAT .............................................. 217

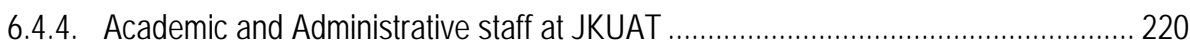

6.4.5. Non-Human Resources and Facilities at JKUAT ................................................... 222

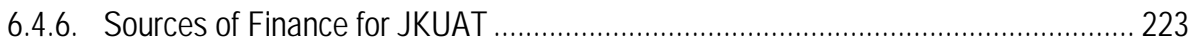

6.5. External Environment of the Kenyan Case Study University ......................................... 225

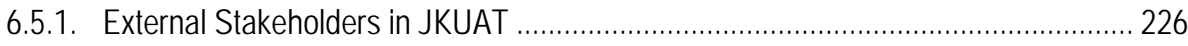

6.5.2. Stakeholder Salience in Terms of Regulatory Powers ..................................... 227

6.5.2.1. The 1994 JKUAT Act and Organisational Autonomy ....................................... 228

6.5.2.2. Other Regulation Tools used by Donors and Professional Organisations ......... 230

6.5.3. Stakeholder Salience in Terms of Funding .................................................. 230

6.6. Revenue Generation at the Kenyan Case Study University ....................................... 233

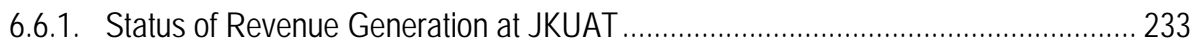

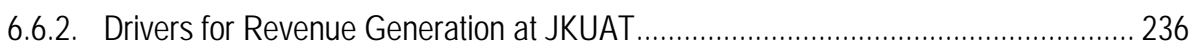

6.6.3. Factors that Enable or Hinder Revenue Generation at the Kenyan Case Study University. 239

6.6.3.1. Environmental Factors that Enable or Hinder Revenue Generation at JKUAT .. 239

6.6.3.2. University Specific Factors that Enable or Hinder Revenue Generation ............ 243

6.7. Revenue Generation Strategies of the Kenyan Case Study University .......................... 244

6.7.1. Differentiation of Services and Products for Revenue Generation .......................... 245

6.7.1.1. Differentiation in Educational Services and Creation of Academic Units for Revenue Generation

6.7.1.2. Differentiation in Research and Consultancy Services and Creation of Research Entities. 249

6.7.1.3. Differentiation of Non-Academic Services and Products for Revenue Generation 251

6.7.2. Creation of Administrative Support Structures for Stakeholder Management 252 
6.7.3. Decisions Concerning Internal Resource Allocation Mechanisms and Human Resource Policies for Revenue Generation.

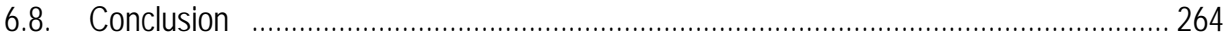

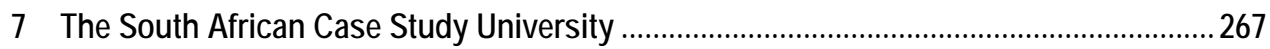

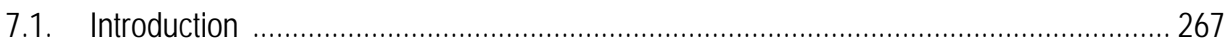

7.2. Socio-Economic, and Political Context of South Africa ............................................ 267

7.3. The South African Higher Education System.............................................................. 270

7.3.1. Size and Shape of the South African Higher Education System ............................. 270

7.3.2. Participation in the South African Higher Education System .................................. 272

7.3.3. Governance and Management of the South African Higher Education ..................... 273

7.3.4. Higher Education Financing in South Africa ........................................................... 275

7.4. Key Characteristics of Nelson Mandela Metropolitan University ................................... 276

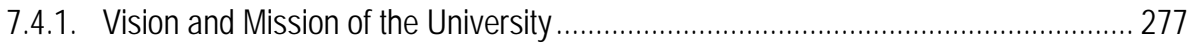

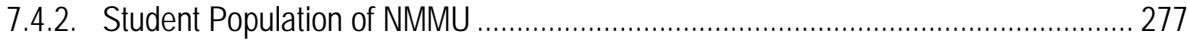

7.4.3. Disciplinary Areas and Academic Units of NMMU ................................................ 279

7.4.4. Internal Governance and Management of NMMU .............................................. 280

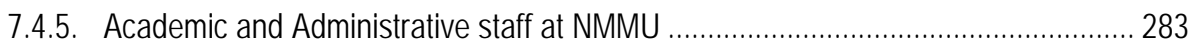

7.4.6. Non-Human Resources or Facilities at NMMU................................................... 285

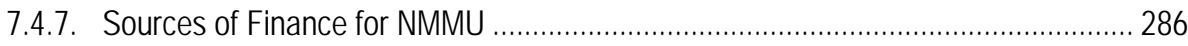

7.5. The External Environment of Nelson Mandela Metropolitan University......................... 287

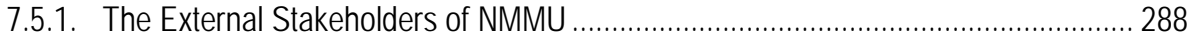

7.5.2. Stakeholder Salience in Terms of Regulatory Powers ......................................... 289

7.5.2.1. The Higher Education Act 101 of 1997 and Organisational Autonomy .............. 290

7.5.2.2. Other Regulation Tools Used by Donors and Professional Organisations......... 292

7.5.3. Stakeholder Salience in Terms of Funding at NMMU........................................ 293

7.6. Revenue Generation by the South African Case Study University ............................... 295

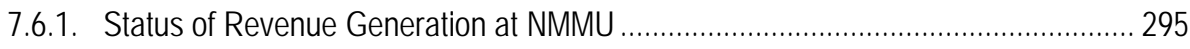

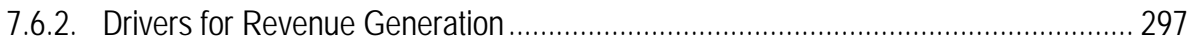

7.6.3. Factors that Enable or Hinder Revenue Generation at NMMU ............................... 299 
7.6.3.1. Environmental Factors that Enable or Hinder Revenue Generation at NMMU .. 300

7.6.3.2. University Specific Factors that Enable or Hinder Revenue Generation at NMMU .

7.7. Revenue Generation Strategies at the South African Case Study University. 309

7.7.1. Differentiation of Products and Services for Revenue Generation 310

7.7.1.1. Differentiation of Educational Services and Creation of Academic Units for Revenue Generation 310

7.7.1.2. Differentiation of Research and Consultancy Services and Creation of Academic Units for Revenue Generation

7.7.1.3. Differentiation of Non-Academic Products and Services for Revenue Generation 318

7.7.2. Creation of Administrative Support Structures for Stakeholder Management .......... 319

7.7.4. Human Resources Policies for Revenue Generation 326

7.8. Conclusion 331

8 Comparative Analysis. .334

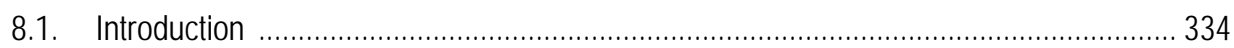

8.2. The environments of the case study universities: similarities and differences................. 334

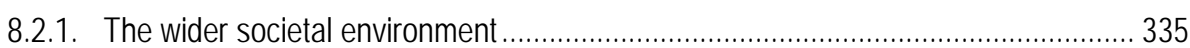

8.2.2. The immediate environment of the four universities: similarities and differences..... 337

8.2.3. Stakeholder salience in terms of funding. 338

8.2.4. Stakeholder salience in terms of regulatory powers .............................................. 341

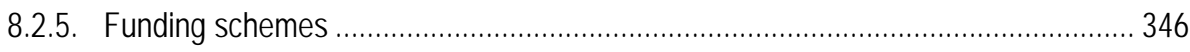

8.3. Characteristics of the case study universities: similarities and differences...................... 348

8.4. Revenue generation in the four case study universities .......................................... 355

8.4.1. Status of Revenue Generation at the Case Study Universities .............................. 355

8.4.2. Drivers of Revenue Generation at the Case Study Universities .............................. 358

8.4.3. Factors that Enable or Hinder Revenue Generation at the Case Study Universities 360

8.4.3.1. Environmental Factors that Enable or Hinder Revenue Generation in the Case Study Universities.

8.4.3.2. University Specific Factors that Enable or Hinder Revenue Generation at the Case Study Universities 
8.5. Revenue Generation Strategies at the Four Case Study Universities 366

8.5.1. Differentiation of Academic and Non-Academic Products and Services for Revenue Generation.....

8.5.1.1. Differentiation of Educational Services and Short Courses for Revenue Generation.

8.5.1.2. Differentiation of Research and Consultancy Services for Revenue Generation 369

8.5.1.3. Differentiation of Non-Academic Products and Services for Revenue Generation. 371

8.5.2. Creation of Administrative Support Structures for Stakeholder Management 373

8.5.3. Decisions Concerning Internal Resource Allocation Mechanisms and Human Resource Policies for Revenue Generation. 380

8.6. Conclusion 382

9 Conclusions and Reflections. 387

9.1. Revenue Generation in Practice in Higher Education in Sub-Saharan Africa 388

9.1.1. Financial Sustainability: Revenue Diversification In a Time of Expanding Student Numbers. 388

9.1.2. The Wicked Issues of Revenue Generation in Universities as Complex Organisations 390

9.1.3. Study Approach, Method and Results 391

9.2. Balancing Growing Student Enrolments and Revenue Generation in Sub-Saharan Africa 393

9.2.1. Enablers For and Barriers to Revenue Generation: a Theoretical Framework 393

9.2.2. Universities' Revenue Generation Practices in Sub-Saharan Africa 396

9.2.2.1. Adapting Strategies 398

9.2.2.2. Altering Strategies 399

9.2.3. Enablers For and Barriers to Revenue Generation 400

9.2.3.1. Enablers and Barriers External to the Universities 400

9.2.3.2. Enablers and Barriers Internal to the Universities 401

9.2.4. Recommendations for Enhancing Revenue Generation 402

9.2.4.1. Effective Revenue Generation by Sub-Saharan African Universities. 403

9.2.4.2. Creating an Optimal Environment for University Revenue Generation 404 
9.3. Reflections on Theory and Policy Practice ………………............................................ 406

9.3.1. Reflections on the Theoretical Framework ....................................................... 406

9.3.1.1. The Value of Resource Dependency Theory for Understanding Revenue Generation in Sub-Saharan African Universities ................................................. 406

9.3.1.2. The Limitations of Resource Dependence Theory ……………………............. 409

9.3.2. Reflections on policy practice ........................................................................... 412

9.4. Coda: Reflections on Methodology and Future Potential Research Avenues ............... 417

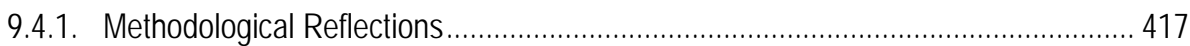

9.4.2. Openings for Further Research ....................................................................... 418

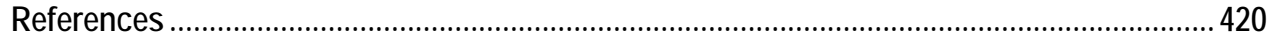

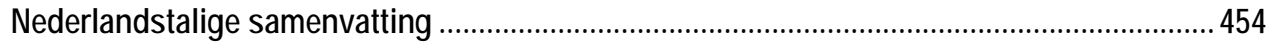

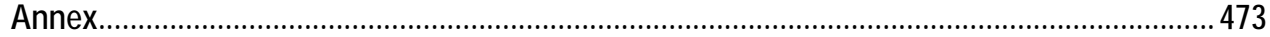




\section{List of Abbreviations}

$\begin{array}{ll}\text { AAB } & \text { Access Assessment Battery } \\ \text { AAU } & \text { Addis Ababa University } \\ \text { AAU } & \text { African Association of University } \\ \text { ACTS } & \text { Automotive Components Technology Station } \\ \text { AMAE } & \text { Asella Model Agricultural Enterprise } \\ \text { ASTU } & \text { Adama Science and Technology University } \\ \text { AUtic } & \text { Technology Innovation Centre } \\ \text { BA } & \text { Bachelor of Arts } \\ \text { BRICS } & \text { Brazil, Russia, India, Chain and South Africa } \\ \text { BSc } & \text { Bachelor of Science } \\ \text { BP } & \text { Business Plan } \\ \text { CAB } & \text { College Academic Board } \\ \text { CAEC } & \text { Centre for Academic Engagement \& Collaboration } \\ \text { CDF } & \text { Constituency Development Fund } \\ \text { CEO } & \text { Chief Executive Officer } \\ \text { CEP } & \text { Continuing Education Programme } \\ \text { CHE } & \text { Commission for Higher Education } \\ \text { CHE } & \text { Council on Higher Education } \\ \text { CHEPS } & \text { Centre for Higher Education Policy Studies } \\ \text { CHET } & \text { Centre for Higher Education Transformation } \\ \text { CMB } & \text { College Management Board } \\ \text { COETEC } & \text { College of Engineering and Technology } \\ \text { COMESA } & \text { Common Market for Eastern and Southern Africa } \\ \text { CoR } & \text { Certificates of Registration } \\ \text { CoP } & \text { Cut off point } \\ \text { CRAC } & \text { Capital Resource Allocation Committee } \\ \text { CTO } & \text { Consultancy and Short-Term Training Office } \\ \text { CUE } & \text { Commission for University Education } \\ \text { DED } & \text { Department of Economic Development } \\ \text { DHET } & \text { Department of Higher Education and Training } \\ \text { DST } & \text { Department of Science and Technology } \\ \text { DTI } & \text { Department of Trade and Industry } \\ \text { DVC-AA } & \text { Deputy Vice Chancellor for Academic Affairs } \\ \text { DVC-APD } & \text { Deputy Vice Chancellor for Administration, Planning, and } \\ & \text { Development } \\ \text { DVC-RPE } & \text { Deputy Vice Chancellor for Research, Production, and } \\ & \text { Extension } \\ & \end{array}$




$\begin{array}{ll}\text { EAC } & \text { East Africa Community } \\ \text { EMT } & \text { Extended Management Team } \\ \text { ESDP } & \text { Education Sector Development Programme } \\ \text { EU } & \text { European Union } \\ \text { EU } & \text { Egerton University } \\ \text { EUA } & \text { European University Association } \\ \text { FB } & \text { Faculty Board } \\ \text { FET } & \text { Further Education and Training } \\ \text { FTI } & \text { Further Training Institute } \\ \text { GDP } & \text { Gross Domestic Product } \\ \text { GER } & \text { Gross Enrolment Ratio } \\ \text { GET } & \text { General Education and Training } \\ \text { GoK } & \text { Government of Kenya } \\ \text { GTP } & \text { Growth and Transformation Plan } \\ \text { HBUs } & \text { Historically Black Universities } \\ \text { HEADS } & \text { Higher Education Access and Development Services } \\ \text { HEI } & \text { Higher Education Institution } \\ \text { HELB } & \text { Higher Education Loans Board } \\ \text { HEQC } & \text { Higher Education Quality Committee } \\ \text { HEQF } & \text { Higher Education Qualifications Framework } \\ \text { HERQA } & \text { Higher Education Relevance and Quality Agency } \\ \text { HESC } & \text { Higher Education Strategy Centre } \\ \text { HRTEM } & \text { High Resolution Transmission Electron Microscopy } \\ \text { HU } & \text { Haramaya University } \\ \text { HWUs } & \text { Historically White Universities } \\ \text { GERD } & \text { Gross Expenditure on Research and Development } \\ \text { GTP } & \text { Growth and Transformation Plan } \\ \text { IBR } & \text { Institute of Biotechnology Research } \\ \text { ICT } & \text { Information Communication Technology } \\ \text { ICSIT } & \text { Institute of Computer Science and Information Technology } \\ \text { IEET } & \text { Institute of Energy \& Environmental Technology } \\ \text { IESA } & \text { International Education Association of South Africa } \\ \text { ITROMID } & \text { Institute of Tropical Medicine and Infectious Diseases } \\ \text { IGA } & \text { Income Generation Activity } \\ \text { IGU } & \text { Income Generation Unit } \\ \text { IMF } & \text { International Monetary Fund } \\ \text { IP } & \text { Intellectual property } \\ \text { IRDP } & \text { Institutional Research Development Programme } \\ \text { IUCEA } & \text { Inter-University Council for East Africa } \\ \text { JAB } & \text { Joints Admissions Board } \\ \text { KEMRI } & \text { Kenya Medical Research Institute } \\ & \end{array}$




$\begin{array}{ll}\text { KJAS } & \text { Kenya Joint Assistance Strategy } \\ \text { JKUAT } & \text { Jomo Kenya University of Agriculture and Technology } \\ \text { JKUATES } & \text { Jomo Kenyatta University of Agriculture and Technology } \\ & \text { Enterprises } \\ \text { KCSE } & \text { Kenyan Certificate Secondary Examination } \\ \text { KM } & \text { Kilometre } \\ \text { KRA } & \text { Kenya Revenue Authority } \\ \text { KTI } & \text { Knowledge and Technology Interchange } \\ \text { KU } & \text { Kenyatta University } \\ \text { LIA } & \text { Letters of Interim Authority } \\ \text { MA } & \text { Master's of Arts } \\ \text { MB } & \text { Managing Board } \\ \text { MCR } & \text { Marketing and Corporate Relations } \\ \text { MMUST } & \text { Masinde Muliro University of Science \& Technology } \\ \text { MoCS } & \text { Ministry of Civil Service } \\ \text { MoE } & \text { Ministry of Education } \\ \text { MoF } & \text { Ministry of Finance } \\ \text { MoFED } & \text { Ministry of Finance and Economic Development } \\ \text { MOHEST } & \text { Ministry of Higher Education, Science, and Technology } \\ \text { MoST } & \text { Ministry of Science and Technology } \\ \text { MSc } & \text { Master's of Sciences } \\ \text { MSU } & \text { Maseno University } \\ \text { MTSF } & \text { Medium Term Strategic Framework } \\ \text { MU } & \text { Moi University } \\ \text { NCBP } & \text { National Capacity Building Program } \\ \text { NCST } & \text { National Council for Science and Technology } \\ \text { NGOs } & \text { Nongovernmental Organizations } \\ \text { NHIF } & \text { National Health Insurance Fund } \\ \text { NMMU } & \text { Nelson Mandela Metropolitan University } \\ \text { NQF } & \text { National Qualifications Framework } \\ \text { NPO } & \text { Not for-profit organisation } \\ \text { NRF } & \text { National Research Foundation } \\ \text { NSFAS } & \text { National Student Financial Aid Scheme } \\ \text { NUFFIC } & \text { Netherlands Organization for International Cooperation in } \\ \text { OECD } & \text { Higher Education } \\ \text { PET } & \text { Organisation for Economic Co-operation and Development } \\ \text { PhD } & \text { Port Elizabeth Technikon } \\ \text { PGDP } & \text { Doctor of Philosophy } \\ \text { PPOA } & \text { Provincial growth and development plan } \\ \text { PRB } & \text { Public Procurement Oversight Authority } \\ & \text { Performance Responsibility Budgeting } \\ & \end{array}$




\begin{tabular}{|c|c|}
\hline QCs & Quality Councils \\
\hline RAM & Resource Allocation Model \\
\hline$R \& D$ & Research and Development \\
\hline RCD & Research Capacity Development \\
\hline RDT & Resource Dependence Theory \\
\hline RIS & Regional system of innovation \\
\hline RM & Research Management \\
\hline RoK & Republic of Kenya \\
\hline RPL & Recognition of Prior Learning \\
\hline RPO & Research and Publication Office \\
\hline RRB & Revenue Responsibility Budgeting \\
\hline RTI & Research, Technology and Innovation \\
\hline SADC & Southern Africa Development Community \\
\hline SAQA & South African Qualifications Authority \\
\hline SAPS & Structural adjustment programmes \\
\hline SARChI & South African Research Chairs Initiative \\
\hline SB & Supervisory Board \\
\hline SMARTEC & Sustainable Materials Research and Technology Centre \\
\hline SP & Summer-in-Service Programme \\
\hline SRF & Strategic Research Fund \\
\hline SLPs & Short learning programmes \\
\hline SSA & Sub-Saharan Africa \\
\hline TIVET & $\begin{array}{l}\text { Technical, Industrial, Vocational and Entrepreneurship } \\
\text { Training }\end{array}$ \\
\hline ToR & Term of Reference \\
\hline TTO & Technology transfer offices \\
\hline TVET & Technical and Vocational Education and Training \\
\hline UCGH & University Cape of Good Hope \\
\hline UEE & University Entrance Examination \\
\hline UK & United Kingdom \\
\hline UNESCO & $\begin{array}{l}\text { United Nations Educational, Scientific, and Cultural } \\
\text { Organization }\end{array}$ \\
\hline UNDP & United Nations Development Programme \\
\hline UNISA & University of South Africa \\
\hline UPE & University of Port Elizabeth \\
\hline UoN & University of Nairobi \\
\hline US & United States \\
\hline USA & United States of America \\
\hline USD & United States Dollar \\
\hline VC & Vice Chancellor \\
\hline $\mathrm{VP}$ & Vice President \\
\hline
\end{tabular}


VPIDCE Vice President for Institutional Development and Corporate Communication

VPRA Vice President for Research Affairs

VRB

Value Responsibility Budgeting

WEF

World Economic Forum

WTO

World Trade Organization 


\section{List of Tables}

Table 4.1: Operationalisation of Box I: University Characteristics........................................... 105

Table 4.2: Operationalisation of Box II: the Societal Environment .................................................... 107

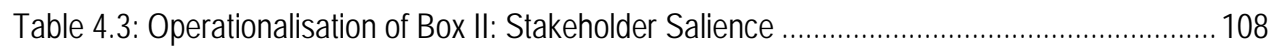

Table 4.4: Operationalisation of Box II: Organisational Autonomy .............................................. 109

Table 4.5: Operationalisation of Scalar: University Strategies for Revenue Generation ................. 111

Table 4.6: Operationalisation of Box III: Revenue Generation Activity......................................... 112

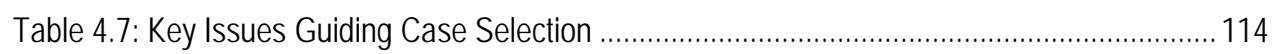

Table 4.8: Number and Position of Interviewees....................................................................116

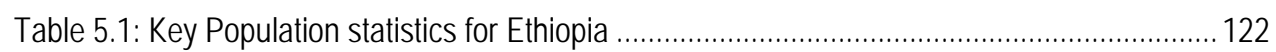

Table 5.2: Selected Economic Development Indicators for Ethiopia.............................................. 123

Table 5.3: Government funding for education and the share allocated to higher education in

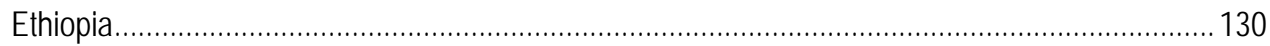

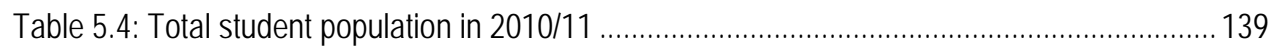

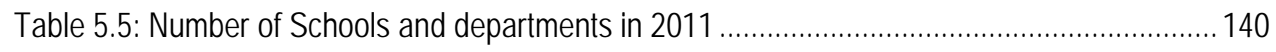

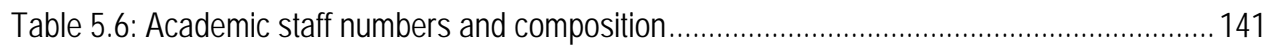

Table 5.7: Academic Staff Volume and Composition by College/Institute in 2011....................... 142

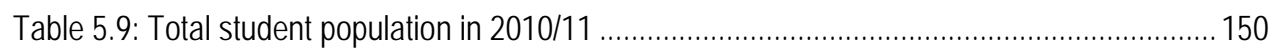

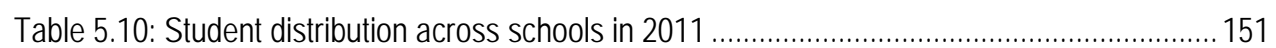

Table 5.11: Number of Academic staff in 2006/07 and 2010/11 .............................................. 152

Table 5.12: Academic Staff Volume and Composition in 2010/11 ............................................ 152

Table 5.13: Revenues by Sources (In million ETB) ........................................................... 153

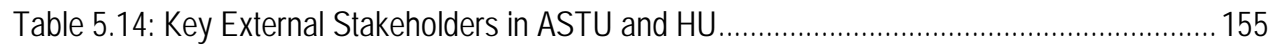

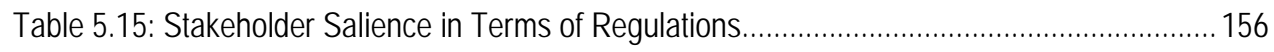

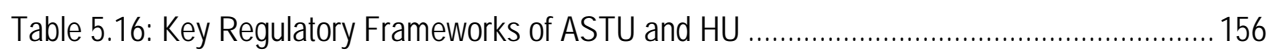

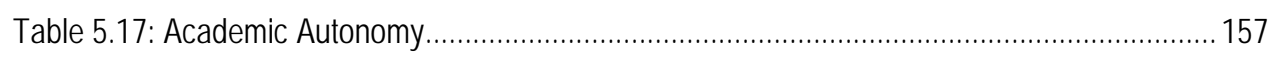

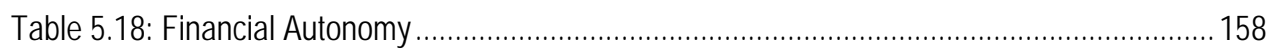




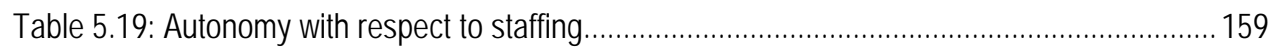

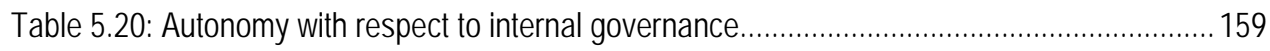

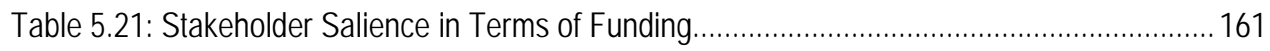

Table 5.22: Sources of Nongovernmental Financial Revenue at HU (in Millions ETB)................. 165

Table 5.23: Sources of Nongovernmental Financial Revenue at ASTU (in Millions ETB) .............166

Table 5.24: Pre-Higher Education System in Ethiopia: Access and Targets.................................. 168

Table 5.25: Donors contributions and commitments (mill USD) ................................................. 173

Table 5.26: Levels of degrees/diploma offered for revenue generation ......................................178

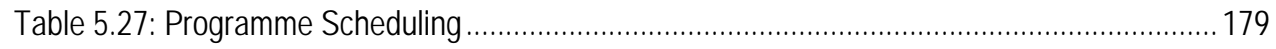

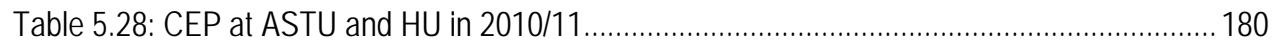

Table 5.29: Summer Programme at ASTU and HU in 2010/11............................................... 182

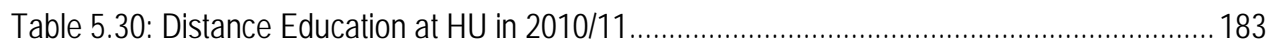

Table 5.31: Diversifying Non-Academic Services for Revenue Generation ................................... 186

Table 5.32: Offices in Charge of Revenue Generation at the Strategic Apex ................................ 188

Table 5.33: Key Support Offices Dealing with Revenue Generation.............................................. 189

Table 5.34: Key Support Offices Dealing with Revenue Generation from Educational Services... 190

Table 5.35: Key Support Offices Dealing with Revenue Generation from Research and

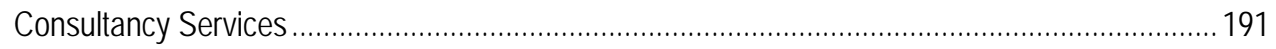

Table 5.36: Key Support Offices Dealing with Revenue Generation from Non-Academic Services 192

Table 6.1: Key Population Statistics for Kenya...................................................................... 200

Table 6.2: Selected Economic Development Indicators for Kenya .............................................. 200

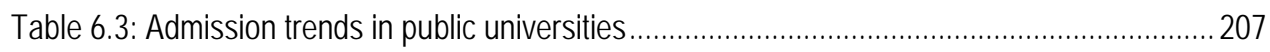

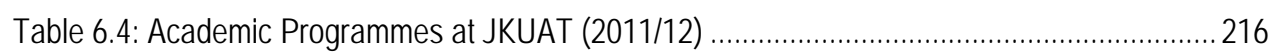

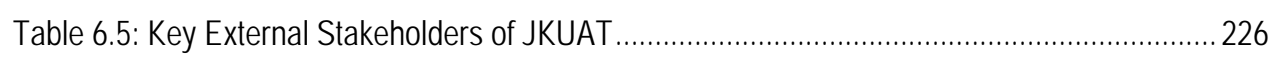

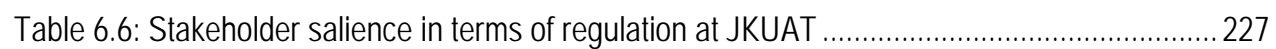

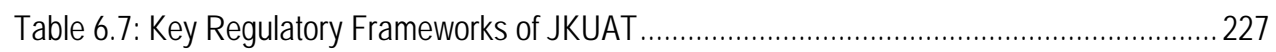

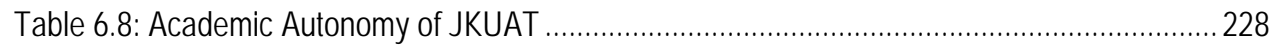

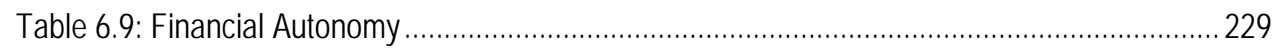

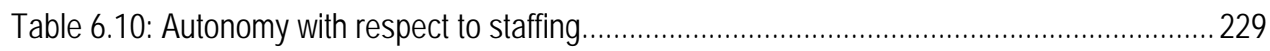




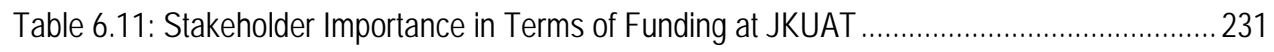

Table 6.12: Nongovernmental Funds by source (in million KShs)............................................ 233

Table 6.13: Student Enrolment in Pre-Higher Education System in Kenya..................................2 237

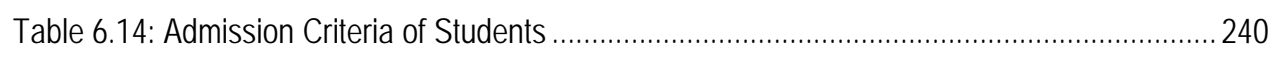

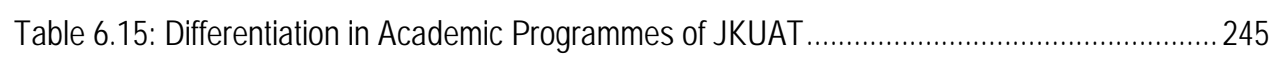

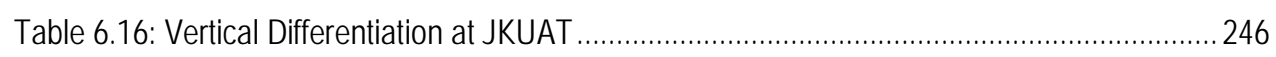

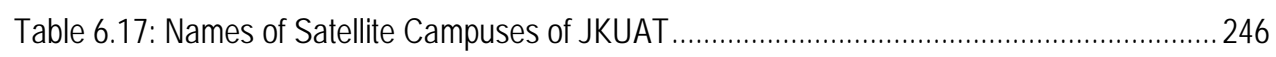

Table 6.18: Constituent Colleges of JKUAT ................................................................... 247

Table 6.19: Diversifying Non-academic Services for Revenue Generation.................................. 251

Table 6.20: Members of IGUs Committee of JKUAT_...................................................... 252

Table 6.21: Crosscutting Offices Fostering Revenue Generation ............................................ 253

Table 6.22: Administrative Entities in Charge of Education and Short-term Courses at JKUAT .... 254

Table 6.23: Administrative Support Entities Fostering Revenue Generation from Research and

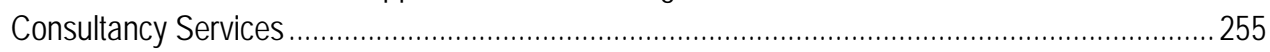

Table 6.24: Entities Fostering Revenue Generation from Non-Academic Services and Products. 258

Table 6.25: Income Distribution for Teaching Services (Internal Actors) ................................... 260

Table 6.26: Sharing Ratios for Research among Internal Actors ............................................... 261

Table 6.27: Income Distribution for Consultancy Services (Internal Actors) …………………...... 262

Table 6.28: Income Distribution for Non-Academic services (Internal Actors) ............................. 263

Table 7.1: Key population statistics of South Africa ........................................................... 268

Table 7.2: Selected economic development indicator of South Africa .......................................... 268

Table 7.3: Higher education organisations and total enrolment in 2010 in South Africa ................ 272

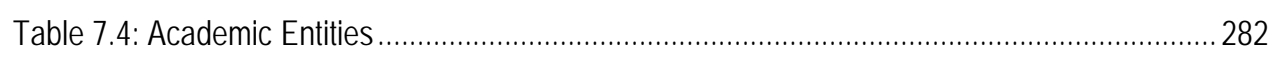

Table 7.5: Number of Rated Researchers per Faculty/Division in 2011.................................... 284

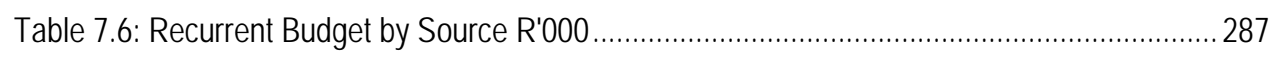

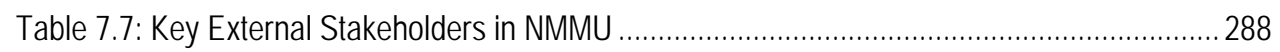

Table 7.8: Stakeholder Salience in terms of Regulatory Powers of NMMU ................................... 289

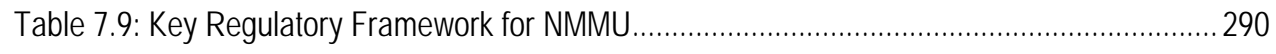

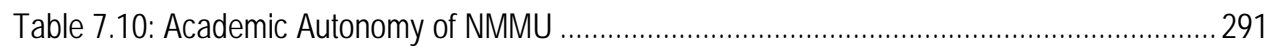




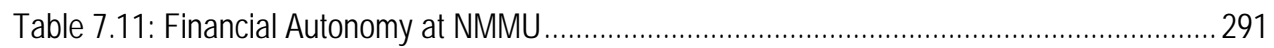

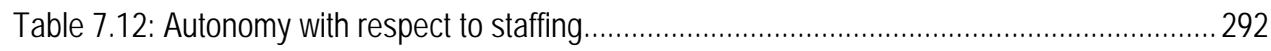

Table 7.13: Stakeholder Importance in Terms of Funding at NMMU ........................................... 293

Table 7.14: Levels of Achievement in Matric Examinations ..........................................................303

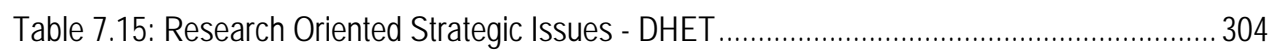

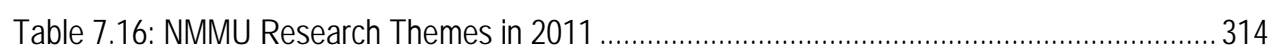

Table 7.17: Diversifying Non-Academic Services for Revenue Generation ....................................318

Table 7.18: Crosscutting Administrative Support Offices for Fostering Revenue Generation.........319

Table 7.19: Administrative Entities in Charge of Education and Short-courses .............................320

Table 7.20: Administrative Support Offices for Fostering Revenue Generation from Research and

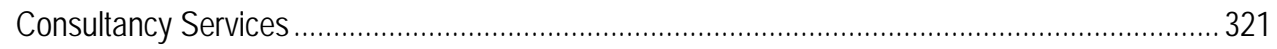

Table 7.21: Entities Fostering Revenue Generation from Non-Academic Services and Products. 323

Table 7.22: NMMU Academic Resource allocation Model ........................................................326

Table 8.1: Key Population statistics for sampled countries ......................................................... 335

Table 8.2: Selected economic development indicators ................................................................ 336

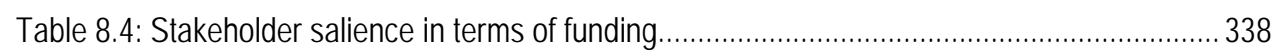

Table 8.5: Aid to higher education, annual average commitments, 2001-06.................................340

Table 8.6: Stakeholder Salience in Terms of Regulations............................................................. 341

Table 8.7: Autonomy with Respect to Academic Matters ........................................................... 343

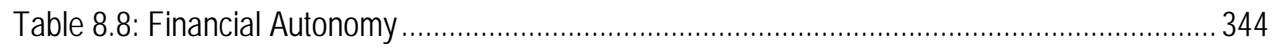

Table 8.9: Autonomy with respect to staffing.......................................................................... 345

Table 8.10: Autonomy with respect to internal governance.................................................... 345

Table 8.11: Methods of Allocating Government Funds to Universities....................................... 347

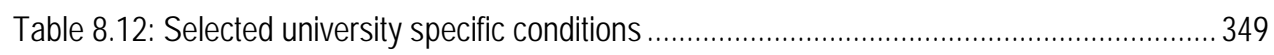

Table 8.13: Discipline mix at case study universities ................................................................ 350

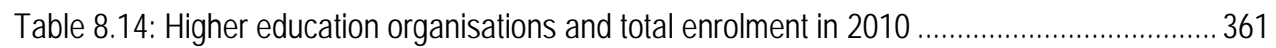

Table 8.15: Levels of degrees, diplomas, and certificates offered at the case study universities .. 367

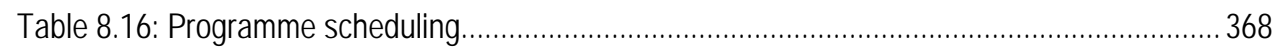

Table 8.15: Diversifying non-academic services for revenue generation .......................................372 
Table 8.16: Office in charge of revenue generation at the strategic apex.......

Table 8.17: Key support offices dealing with revenue generation

Table 8.18: Key support offices dealing with revenue generation from educational services and short-courses.

Table 8.19: Key support offices dealing with revenue generation from research and consultancy services

Table 8.20: Key Support Offices Dealing with Revenue Generation from Non-Academic Services 379 


\section{List of Figures}

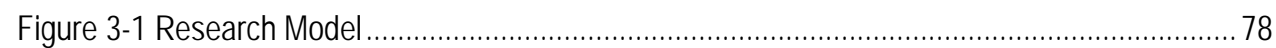

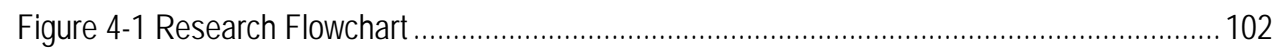

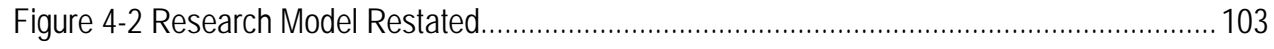

Figure 5-1 Organisational structure of Haramaya University ................................................. 135

Figure 5-2 Organisational Structure of Adama University ...................................................... 147

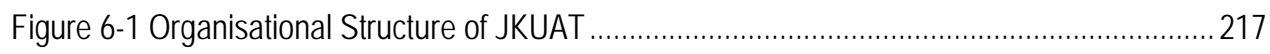

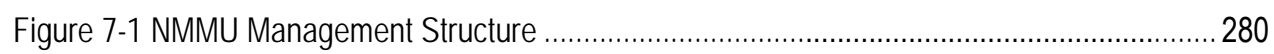

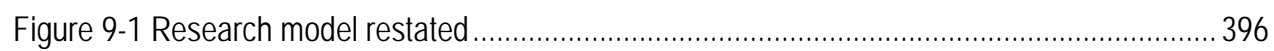




\section{List of Charts}

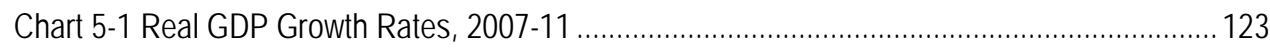

Chart 5-2 Share of Non-governmental Revenue (non-MoFED) over Total Government Recurrent

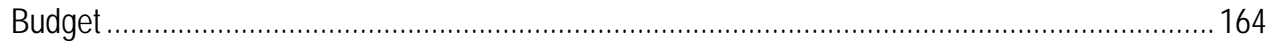

Chart 5-3 Academic Staff Volume and Composition in 2010/11 ................................................176

Chart 5-4 Number of Research Institutes, Centres, and Units at the Case Study Universities ...... 184

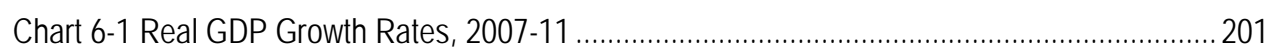

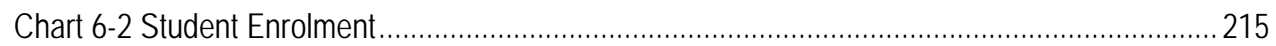

Chart 6-3 Student Population by the level of degree in 2011/12 ...........................................215

Chart 6-4 Academic Staff Qualifications in 2012 ................................................................ 221

Chart 6-5 Administrative Staff Qualifications in 2012 ............................................................. 222

Chart 6-6 Budget Submission and Government funding of JKUAT in KShs (millions)................... 224

Chart 6-7 Governmental and Nongovernmental Revenues in KShs (millions)........................... 225

Chart 6-8 Revenue from Educational Services as a percentage of Nongovernmental Revenue... 234

Chart 6-9 Revenue from Research and Consultancy as a percentage of Nongovernmental

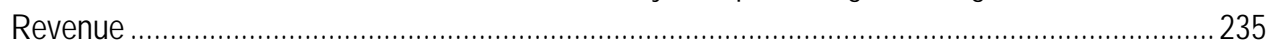

Chart 6-10 Revenue from Non-academic Services as a percentage of Nongovernmental Revenue 236

Chart 6-11 Numbers of Research Institutes, Centres, and Units at JKUAT .................................. 249

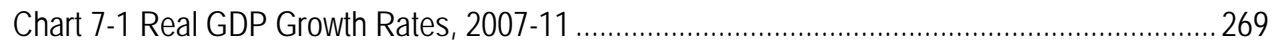

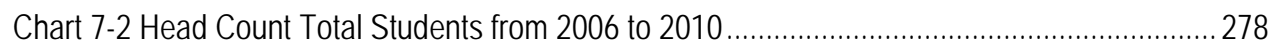

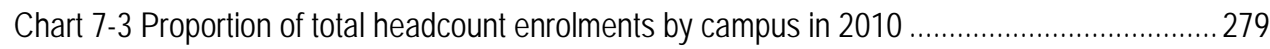

Chart 7-4 Percentage of overall enrolments by major fields of study in $2010 \ldots \ldots \ldots \ldots \ldots \ldots \ldots \ldots \ldots . . .279$

Chart 7-5 Academic Staff Volume and Composition in 2010/11 .............................................. 283

Chart 7-6 The Proportion of Administrative Support Staff by Category in 2011 ......................... 285

Chart 7-7 Revenue from Nongovernmental Sources as a Percentage of Recurrent Budgets ....... 295

Chart 7-8 Revenue from Education Services as a percentage of Nongovernmental Revenue...... 296

Chart 7-9 Revenue from Research and Consultancy Services as a Percentage of Nongovernmental Revenue. 
Chart 7-10 Revenue from Non-academic Services as a Percentage of Nongovernmental Revenue

Chart 7-11 Major flows of funding for R\&D (South Africa, 2009/10) (R millions).......................... 305

Chart 7-12 Total Head Count Enrolment by Qualification Type .............................................. 311

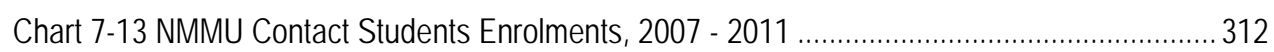

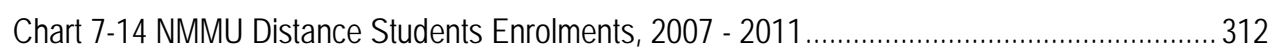

Chart 7-15 NMMU Short Course Students Enrolments, 2007 - 2011.......................................... 313

Chart 7-16 Numbers of Research Institutes, Centres, and Units at NMMU .................................. 315

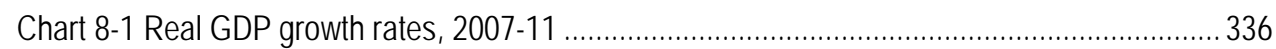

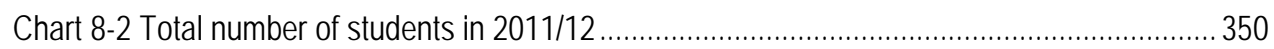

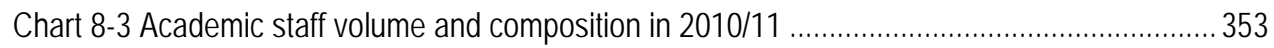

Chart 8-4 Percentage of governmental recurrent budgets and nongovernmental revenue from

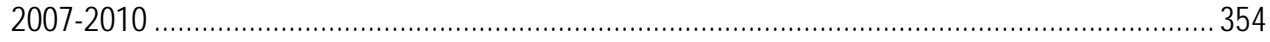

Chart 8-5 Nongovernmental Revenue as a Percentage of Recurrent Budgets............................. 356

Chart 8-6 Revenue from educational services as a percentage of total nongovernmental revenue 357

Chart 8-7 Revenue from research and consultancy services as a percentage of total

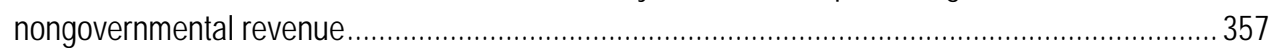

Chart 8-8 Revenue from non-academic services as a percentage of nongovernmental revenue.. 358

Chart 8-9 Number of Research institutes, centres, and units at the case study universities.......... 370 


\section{Introduction}

This chapter presents the background of the study. It begins with an overview of the issues surrounding financing higher education across the globe and in Sub Saharan African in particular. The second section deals with the purpose of the study. The third section presents the study's research problem and research questions, which is followed by an outline of the focus of the study in section four. Section five briefly discusses the theory that informs the study. Finally, the organisation of the dissertation is presented in section six.

\subsection{Background of the Study}

Financial sustainability is one of the key challenges for public universities in both developed and developing countries. The rapid changes in the higher education context across the globe, driven by economic, social, political, and technological forces, have created an unprecedented set of challenges for financing universities (Gumport \& Sporn, 1999; Jongbloed, 2004; Massy, 2003). In today's world, two seemingly contradictory matters/issues dominate the higher education landscape. On the one hand, universities have the potential to act as key catalysts for the overall development of a nation. On the other hand, they are required to operate within increasingly tight financial frameworks caused by decreased government financial support. With regard to the latter, several researchers have studied the financial challenges placing higher education institutions', where they are operating indifferent socio-economic, political and technological environments (EUA, 2011; Clark, 1998, 2004; Massy, 2003; Johnstone, 1998; Jongbloed, 2004; Clark, 2004; OECD, 2008; World Bank, 2010). We would like to recognise the work of Rizzo (2004) on North America; Jongbloed (2004) on continental Europe; Beliakov et al., (1998) on Eastern Europe; Kitaev et al., (2003), Li \& Shen (2003), and Ziderman (2003) on Asia; Sanyal (1998) on North Africa and the Arab States; and Saint (1992), World Bank (2010) and Varghese (2009) in Sub-Saharan Africa countries. The insights in these studies how national governments' capacity for financing higher education systems has fallen significantly. These studies generally conclude that there are poor prospects for public funding catching up with everincreasing higher education expenditures.

In the context of Sub Saharan African countries, universities - like the national anthem, the national flag, and the national currency - were seen as a sign of real independence from colonial forces between the 1950s to 70s. African public 
universities were run as a status apparatus, a parastatal, and the state would continue to be the sole funder of universities. Free university education was a characteristic feature of almost all-African higher education system, and it remained so until the 1980s (Saint, 1992). In the early 1980s, the capacity of African governments to finance public services fell sharply because of a marked decline in economic outputs across the continent (Saint, 1992; see also Altbach \& Teferra, 2004). This meant that higher education had to compete for resources with other public budget priorities (pre-higher education, security, health, etc.). Although higher education was initially fully insulated from these financial cutbacks, eventually it too was forced to absorb sizeable budget reductions (Saint, 1992). As a result, public expenditure per student declined from US\$ 2,800 in 1991 to US\$2,000 in 2006 (see World Bank, 2010). This reduction occurred when the rate of annual public expenditure per student to GDP per capita is 3 for Sub-Saharan African countries. This figure is far greater than the average allocation by OECD countries, which is 0.3 (see OECD, 2008; World Bank, 2010). Governments of Sub-Saharan African countries allocate close to $0.78 \%$ of GDP to higher education ( $20 \%$ of the education budget), while this figure averages around $1.2 \%$ for OECD countries. One can observe that even the current modest expansion in higher education enrolment has made higher education financing more complex and challenging in many Sub Saharan African countries.

The total number of students pursuing higher education in Sub-Saharan African universities has tripled since 1991, climbing from 2.7 million to 9.3 million in 2006 (World Bank, 2010). If the current trend continues, the total number of HE students in the African continent could reach between 18 million and 20 million by 2015. However, public resources allocated to expenditure in the higher education sector only doubled between 1991 and 2006. By 2015, the level of expenditure could be $75 \%$ higher than the volume of public resources that may be mobilised by Sub-Saharan African countries (Ibid). This financial gap indicates that the proportion of government funding in the overall budgets of Sub-Saharan African public higher education organisations continues to drop, at a time when higher education is experiencing rising enrolments (World Bank, 2010; Johnstone \& Marcucci, 2010; Bundy, 2004; Musisi \& Muwanga, 2003; Albrecht \& Ziderman, 1995). Many national governments have made it clear that it will no longer be possible for public universities to rely solely on the state for funding. This indicates that higher education systems often face formidable policy challenges in balancing the need to raise educational quality with increasing demands for access.

Nowadays, financing higher education in Africa is increasingly becoming an important topic in higher education policy debates. It is also often a subject of 
heated policy debate when rapidly rising social demands for higher education have to be met in the context of constrained resources. Many researchers have conveyed an encouraging message on alternative funding options amid this decline in government support for higher education organisations (see Clark, 1998; Massy, 2009). One of the organisational adaptation strategies for universities is to raise more and more of their own revenues to ensure their financial sustainability. Many African higher education systems have recognised the importance of sharing the financial burden of higher education between the public and private sectors (Johnstone, 1998). African governments have encouraged their public higher education organisations to develop their capacity for revenue generation and use their resources economically (Mingat, Ledoux, \& Rakotomalala 2008 cited in World Bank, 2009). According to the World Bank (2010:74), on average African universities' self-generated resources account for approximately $28 \%$ of their recurrent budgets.

Financial sustainability has been the topic of many recent studies. The current pressures on higher education budgets across the world make research on this topic a timely contribution to the ongoing debates on how to fund universities' activities. In recent decades, several African countries have searched for a way to find financial sustainability for their higher education systems. There is now a consensus in several higher education systems that public budget cuts can be mitigated by private funding sources. Revenue generation has consequently been given greater attention as a strategy for financial sustainability. Although the financial challenges for public universities have many similarities between countries, it is not clear how these issues should be addressed in different socioeconomic and political contexts. A review of the existing empirical studies also indicates that revenue generation strategies in higher education organisations in the Sub-Saharan African context are rarely addressed (see Chapter 2). Strategies for overcoming the financial challenge and the implications of the chosen strategies in the African socio-economic and political context are also understudied. Our understanding of revenue generation and the forces that erect barriers to it is still very limited. The relevance and usefulness of revenue generation strategies undertaken by universities in developed countries for use by universities in developing countries is still an area for further investigation. We argue that financial sustainability is a multifaceted phenomenon that is worthy of conceptual and empirical attention. Revenue generation is an area of serious debate, both scholarly and by the public, where various issues of concern have been raised repeatedly (Altbach, 2002; Nafukho, 2004; Sawyerr, 2002a; Scott, 2003; Leslie \& Slaughter, 1997; Williams, 1992, 2003). This suggests that the analysis of revenue generation practices and strategies in the context of 
Sub-Saharan African countries is an area of much interest for empirical research.

\subsection{Purpose of the Study}

Financial sustainability has been one of the key challenges for Sub-Saharan African public universities in the last three decades. The purpose of this study is to contribute to our understanding of how Sub-Saharan African public universities can improve their financial sustainability by diversifying their resources while continuing to accommodate growth in higher education enrolment. The reasons for undertaking this research in the context of SubSaharan African public universities are fivefold. Firstly, this study is conducted in Sub-Saharan African countries, where there is rapid growth in enrolment and strong commitment to public financing for higher education, alongside a simultaneous decline in public expenditure per student with clear financial challenges. Studying such complex higher education contexts can bring important inputs and insights for policy makers, university leaders, and other stakeholders who seek to establish higher education systems that can ensure financial sustainability, while accommodating growth in student populations.

Secondly, the current drastic pressures on higher education budgets across SubSaharan African countries (see World Bank, 2010) make this research a timely contribution to the ongoing debates on how to fund universities' activities, by looking at the potential of complementary revenue sources. This research will thus throw light on areas of serious debate on revenue generation by several stakeholders. We argue that those public universities that have a better insight into their financial structures and income flows will be better able to fulfil their multiple missions and respond to the current challenges in an increasingly complex and global environment.

Thirdly, we study revenue generation at public universities in Sub-Saharan countries in the context of resource dependence theory (Pfeffer \& Salancik, 1978). The application of the resource dependence perspective offers an opportunity to identify external and internal factors that influence revenue generation strategies in the context of Sub-Saharan African public universities. The theoretical perspective and empirical data together may help to achieve a better understanding of revenue generation strategies and activities among stakeholders.

Fourthly, this study has been conducted using a cross-national comparative case study approach. We aim to explore how public universities in three SubSaharan African countries are trying to address the common challenges of 
resource reduction from public sources. This approach helps to place the findings in a comparative perspective and to identify which enablers and barriers are particularly relevant for universities operating in different settings. This research helps us to better understand how public universities operating in different regulatory frameworks and within different national settings have tried to reduce resource dependence on government funding, by looking at two Ethiopian universities, one university in Kenya and one in South Africa.

Finally, this study also offers practical contributions. The study provides an updated overview of the state of play in revenue generation in Sub-Saharan African public universities. It aims to generate some operational knowledge for university leaders and managers who seek to start revenue generation and broaden the funding base of their organisations. The findings of our research on success factors and framework conditions for revenue generation will also allow governmental actors to raise awareness among public and private stakeholders about the need to improve the external conditions that enable public universities to diversify their financial structures. It identifies best and transferable practices that may improve the framework conditions for universities and their ability to act strategically in this area.

\subsection{Research Problem and Research Questions}

As indicated in the previous paragraphs, in most African countries the current rates of expansion in enrolments in higher education will not be financially sustainable in the future due to the narrow tax base of African countries that translates into limited public resources. Under such financial challenges, public universities are forced to engage in revenue generation to improve their financial sustainability and ensure their survival. The issue of whether and how these universities manage to implement effective revenue generation strategies that lead to financial sustainability in rapidly changing environments is particularly interesting. We do not have a full understanding of the internal conditions within universities or the external factors in their environments that enable (or erect barriers to) revenue generation in the context of Sub-Saharan African public universities. Thus, the central research question of this dissertation may be stated as:

How can Sub-Saharan African public universities improve their financial sustainability by diversifying their resources while continuing to accommodate the growth in higher education enrolment?

This fundamental research problem is further broken down into four basic research questions: 
1. What theory can assist us in understanding the enablers for and barriers to revenue generation in Sub-Saharan African universities?

This research question will be addressed through the conceptual lens derived from resource dependence theory in Chapter 3. It explains how public universities as organisations, particularly their senior managers, respond to changes in external environments in seeking resources from various stakeholders in order to continue their operations and secure their organisations' survival. This perspective enables us to analyse which internal characteristics and conditions of universities and which factors in their external environment allow universities to successfully develop new funding sources.

2. What is the actual practice of revenue generation in Sub-Saharan African public universities?

This question will be addressed through a review of the literature on financing higher education organisations in Chapter 2. In addition, empirical data will be presented in Chapters 5 to 8 . We examine current practices of revenue generation in Sub-Saharan African public universities, taking into account the significant differences that exist among countries (i.e. Ethiopia, Kenya, and South Africa) and within universities operating in different regulatory frameworks. Drawing on experiences from around the world, the research also identifies a range of revenue generation strategies that could be considered for tackling the financing challenges.

3. What are the enablers for and barriers to revenue generation in SubSaharan African public universities?

Theoretically, this question will be approached through resource dependence theory in Chapter 3. Empirically, Chapters 2 to 9 collectively contribute to identifying enablers for and barriers to revenue generation in Sub-Saharan African public universities. Chapters 2, 8 and 9 intend to provide answers to this question. This helps to identify the external and internal enablers for and barriers to successful revenue generation strategies.

4. Given what we know from theory and international practice, how can barriers be overcome and enablers be introduced for revenue generation in Sub-Saharan African universities?

This question is addressed in Chapter 9. We try to identify some good practice that may help to improve the framework conditions for universities and their ability to act strategically in the area of revenue generation. 


\subsection{Focus of the Study}

The empirical focus of this study is delimited to an analysis of revenue generation strategies of Sub-Saharan African public universities. Our research provides an analysis of the status of revenue generation and identifies the external and internal enablers for and barriers to the development of successful revenue generation strategies. Firstly, this research is not primarily concerned with the impact of revenue generation by universities on their organisational environments, which are mainly manifested in terms of obtaining trust and legitimacy in our research model (see Fig. 3.1). Although we recognise the impact of revenue generation on the environment in the form of improving regional development, university-industry linkages, human capacity building, etc., we cannot exhaustively and critically analyse these issues within the scope of this research. Secondly, this research does not seek to empirically address the implications and impact of revenue generation on universities themselves in terms of learning and adaption by universities (see Fig. 3.1). We do not aim to analyse if not totally ignoring, the implications of revenue generation for the quality, and productivity of higher education organisations in terms of improving education and training and research.

\subsection{Theoretical and Methodological Orientation}

This research argues that to survive, universities as organisations must engage in exchanges with other environmental actors (i.e. stakeholders) for acquiring resources. In return for resources, universities produce acceptable products and services for the environment. This interaction between the universities and their external stakeholders creates dependencies. It is argued that universities can respond to environmental demands by either formulating strategies which aim to comply with environmental demands, or strategies which attempt to avoid these demands and/or to (re-)shape the conditions that they are confronted with.

A theoretical framework derived from resource dependence theory (RDT) guides our research. This theory provides useful conceptual tools for understanding organisational responses to financial challenges (Pfeffer \& Salancik, 1978; Aldrich \& Pfeffer, 1976; Davis \& Cobb, 2009). It also helps to explain how the organisational environment influences revenue generation strategies and activities in universities. The theory assumes an active role for individual universities in their struggle for survival (Aldrich, 1979; Pfeffer \& Salancik, 1978; Scott, 1992b). This implies that universities may actively influence their environment. From the resource dependence perspective, universities can address resource dependence difficulties related to state 
funding issues by competing for resources from alternative (including private) sources (Clark, 1998; Sporn, 1999; Leslie \& Slaughter, 1997; Wangenge-Ouma, 2011). Resource dependence theory may contribute to the detailed analysis of such adaptation or altering strategies. Using RDT as a lens, we attempt to identify enablers for and barrier to revenue generation at four universities in three countries.

As the nature of revenue generation in higher education organisations is complex, dynamic and multidimensional, involving a large number of actors inside and outside of the university organisation, a case-study method is wellsuited to investigating the issue in its real-life context (see also Stake, 2000:43; Yin, 1994:1-13). This case study method is particularly helpful when the context of the organisation and the organisational environment is important (Hartley, 1994) and especially when the boundaries between phenomenon and context are not clear. Our intention in choosing the case study method is that every case may serve a specific purpose within the research (Yin, 2003; Stake, 2003). More specifically, a multiple case study design is used in this study as it offers opportunities for exploring the issues for different sets of socio-economic and legal circumstances as well as for a diverse set of university characteristics.

\subsection{Organisation of the Dissertation}

This dissertation is organised into nine chapters. Chapter 2, following this introductory chapter, contains a review of existing research work related to revenue generation, both at the international level and at the specific level of Sub-Saharan African countries. This chapter presents what we know about revenue generation across the globe, and what issues need more investigation. Chapter 3 attempts to present a theory that can help to explore relations and interactions between organisations and their environment: resource dependence theory. Specifically, the chapter discusses how the theoretical approach of the study has been applied, and what links there are between the theoretical framework and revenue generation strategies of public universities. The main elements of the conceptual framework of the study are operationalised in Chapter 4. Revenue generation strategies and activities constitute the dependent variables of our study. The factors drawn from the organisational environment of the case study universities and the key characteristics of the universities themselves form the independent variables of the research. This chapter also presents our research design and discusses methods, data sources, sampling instruments and data analysis techniques.

Chapters 5 to 7 present the empirical findings of the four case study universities located in three countries (Ethiopia, Kenya, and South Africa). Chapter 5 is 
concerned with the presentation and analysis of data collected from two Ethiopian case study universities (Adama Science and Technology University (ASTU) and Haramaya University (HU)) in line with the theoretical framework in Chapter 3 and the operationalisation of key variables in Chapter 4. Chapters 6 and 7 present the analysis of data on the Kenyan case study university (Jomo Kenyatta University of Agriculture and Technology (JKUAT) and the South African case study university Nelson Mandela Metropolitan University (NMMU), respectively. Chapter 8 provides a comparative analysis of the four cases. Finally, Chapter 9 presents the summary and conclusions of the study. It discusses the major research findings, draws conclusions, and reflects on the applied theoretical framework and empirical approach of the study. The chapter includes some remarks on methodology and discusses the limitations of our research and makes suggestions for further research. 


\section{Review of the literature}

\subsection{Introduction}

This Chapter argues that financial sustainability is one of the key challenges for African universities today. The Chapter aims to provide readers with an overview of the literature on revenue generation in public universities both globally and in Sub-Saharan African in particular. It tries to offer an operational definition of revenue generation, analyses its drivers, the current state of play, and its effects. It also explores the conditions that have enabled some countries to put in place a successful revenue generation system. Finally, it highlights "roadmaps" or strategies for revenue generation in public universities. From the outset, we would like to inform readers that this literature review is mainly about financing public universities in developed countries because of limited scholarly research in the African context.

\subsection{Public Financing of Universities}

In many countries, particularly in Europe and Africa, universities are predominantly public organisations. The major explanations are that public institutes do not have a profit motive, and that (part of the) decision authority rests with their national governments instead of the individual organisations. More importantly, public universities receive more of their revenue from their national governments than private universities. They are also legally recognised as public organisations in their national settings, and are often exempt from most forms of taxation (see Levy, 1986a; Geiger, 1991; Massy, 2003; Hauptman, 2007). Governments all over the world intervene heavily in the higher education sector because of market failures and a concern with income redistribution (see Jongbloed, 2004; Begg et al., 1991; Canton \& van der Meer, 2001). The market failures include human capital spill overs (Gemmell, 1997; Lucas, 1988), capital market constraints (Shea, 2000), risk/insurance market imperfections (Oosterbeek, 1995), and imperfect information/transparency problems (Jongbloed, 2004). The connection between higher education and income redistribution (Teulings, 2000; Goldin \& Margo, 1992), and the impact of tax distortions (Tang \& Van Ewijk, 2000) could be additional reasons for governments to offer full financial support for higher education systems.

Higher education in Africa was mainly imported from Europe and is relatively young. A majority of first generation African universities were established in 
1950 (Beverwijk, 2005). During the 50s and 60s, young and small African higher education organisations were seen as symbols of prestige; and their main aims were to help build up the nation's capacity to develop and manage their resources, alleviate the poverty of the majority of the people and close the gap between African countries and the developed world. African governments made substantial investments in their higher education organisations, covering the entire cost of establishment - buildings, equipment, and other facilities including offering tuition free education as well as stipends and free full board to students (Saint, 1992; Sawyerr, 2004; World Bank 2004). From the late 1970s ${ }^{1}$ on, full government funding for public universities in Africa has become challenging because of the continent's rate of population growth and economic hardship (Johnstone, 1998, 2001; Sawyerr, 2004). The rapid population growth has raised social demand for higher education, resulting in the challenge of sustainable financing (see World Bank, 2010). For instance, the mean ratio between the average increase in the number of students and the increase in resources from 1991 and 2006 is 1.45 (Ibid). However, there has still been a rapid increase in both the number of public universities and enrolment in higher education throughout the African continent, which appears to have a further negative impact on resources per student (Sawyerr, 2004; Beverwijk, 2005). From a starting point of six universities in the 1960s (Eisemon, 1992), by 2010 there were at least 1015 higher education institutions (HEIs) across Africa (Fifth Edition of the Guide to Higher Education in Africa, 2010)2 ${ }^{2}$. According to Hauptman (2007), the fundamental financing challenge now facing higher education systems around the world is the real or perceived crunch of enrolments growing faster than resources.

The severity of this challenge varies across the globe, with countries in SubSaharan Africa being the most affected. The current literature on higher education reinforces the view that public funding can only support high-quality university education when the system is relatively modest and inevitably elitist (Barr, 1998; Massy, 2003; Williams, 2009; Jongbloed, 2003; Court, 1999;

1 Most African countries entered a phase of economic decline (i.e., a decline in export volumes, a relative decline in the price of primary products, and inflation), accompanied in some areas by drought, famine and severe ecological degradation, political instability or wars, demographic issues, and national debt crisis (debt overhang and debt serving), beginning in the late 1970s.

2 The Guide to Higher Education in Africa is published by the International Association of Universities (IAU) in partnership with the Association of African Universities (AAU) and the IAU/UNESCO Centre on Higher Education and is considered to be the most comprehensive listing of higher education institutions across Africa. 
Heyneman, 1999; Oketch, 2000). The main challenge facing African governments is how to build human capital through continued and sustained investment in education.

\subsection{Challenge of Sustainable Financing for Public Universities}

Many scholars have reported that public universities around the globe face financial challenges (see Clark, 1998 \& 2004; Jonhstone, 1998; Leslie \& Leslie \& Slaughter, 1997; Rizzo, 2004; Jongbloed, 2004; Beliakov et al., 1998; Kitaev et al., 2003; Shen \& Li, 2003; Ziderman , 2003; Sanyal, 1998; Saint, 1992; World Bank, 2010; Varghese, 2009). Despite government declarations of intent to increase spending on higher education, it is not very likely that public expenditure will grow significantly across the globe. We are, of course, aware that the priority given to higher education in the context of overall public expenditure on education varies considerably from country to country. The financial challenge is very severe in the case of Sub-Saharan African countries, where there are significant economic challenges. For instance, public expenditure per student in Africa declined from US\$ 2,800 in 1991 to US\$2,000 in 2006 (see World Bank, 2010; Hauptman, 2007).

Currently, governments of Sub-Saharan African countries allocate close to $0.78 \%$ of GDP to higher education ( $20 \%$ of the education budget). For SubSaharan African countries, the rate of annual public expenditure per student to GDP per capita is 3 . This figure is far greater than the average allocation by OCED countries, which is 0.3 (see OECD, 2008; World Bank, 2010). According to the World Bank (2010), the capacity for public investment in higher education at the national level meets only $33-40 \%$ of total requirements in Africa as a whole (20-25\% of the requirements in low-income countries). Financial sustainability has thus become one of the key challenges for African's universities today (World Bank, 2010). In the pages that follow, we raise the question, "What happens to universities that depend on public funding when this funding is reduced?"

\subsection{Potential Solutions for Overcoming Financial Challenges}

Public universities around the globe have faced financial challenges amid rising social demands for higher education. A number of potential solutions are suggested for continuing and sustaining the expansion of higher education enrolment in many countries around the globe (see Johnstone, 1998; Mingat, Ledoux, \& Rakotomalala, 2008 cited in World Bank, 2009). The most obvious solution is to provide additional funding to accommodate the growing demand 
for higher education. As indicated in previous paragraphs, most countries are not in a position to increase their public funding sufficiently to keep up with the expanding growth in demand. As observed by Hauptman (2007), the decline in spending per student in recent years has more often been a function of the difficulty in keeping up with extraordinary increases in demand than a lack of commitment to providing resources, which have typically grown in real terms (see Beverwijk, 2005; World Bank, 2009; World Bank, 2010). Thus, many African Countries are already overstretched and additional government funding can rarely be found.

The second potential solution for closing the gap between enrolment and resource projections is to cap the growth in enrolments. If the number of places available in higher education were limited by available funds, the students most likely to be affected by enrolment rationing would be those from more disadvantaged families, since individuals from more affluent families would have alternatives in the fee-paying sector or through higher education abroad. More importantly, it may be difficult to achieve economic competitiveness by capping human capital growth that complements the creation of productive capacity, as technological change is increasingly skill based (see OECD, 2008; World Bank, 2009; World Bank, 2010). In addition, the current spread of information and communication technology (ICT) is strengthening the demand for a highly qualified labour force. Generally, given that Sub-Saharan African countries have the lowest higher education gross enrolment ${ }^{3}$ ratio in the region and a more skill-intensive route to development, capping the growth in enrolments is not an attractive policy. Higher education is the most durable investment that Africa needs for enhancing its overall development (see World Bank, 2010).

The third solution for expanding higher education is liberalisation and privatisation. This means opening the education markets to domestic and transnational providers with the goal of increasing the accessibility of national education markets to foreign providers. Overall, a growth in private providers can be observed, linked to the growing demand for higher education that the public sector in many Sub-Saharan Africa countries is unable to fully respond to. However the impact across countries in Sub-Saharan African countries is not

3 Five percent Sub Sahara Africa average (Materu, 2007). Countries in which less than one-fifth of the high school cohort moves beyond the secondary level are regarded as elite systems; those with up to half of high school graduates continuing are defined as mass systems; whereas those systems in which more than half of high school graduates continue their education are regarded as being universal (Hauptman, 2007). 
as expected (Altbach \&Teferra, 2004; Saint, 1992). The experience so far shows that domestic private and foreign providers encounter all manner of problems, which are linked to establishment requirements, tax legislation, accreditation, the recognition of awarded diplomas, etc.(NCITE, 2000 cited in van der Wende, 2002). While trade liberation demands conditions for economic and social development including more highly educated citizens, globalisation increases pressure on governments to reduce their steering role in and financial contribution to education. This is a double challenge and contradictory that poor countries will have little autonomy or competitive potential in the globalised world (Altbach, 2001; van der Wende, 2002).

As the fourth solution, Hauptman (2007) and Woodhall (1995) suggest seeking efficiencies in the delivery of education and services to close the gap between enrolment and resource projections by using the existing resources more efficiently, and reducing waste or unproductive use of resources. Efficiency in operation implies reductions in the cost of production (Bleiklie et al., 2000). A focus on efficiency leads to attention to staff-student ratios, to student repetition and dropout rates, and to outsourcing non-academic services such as security, maintenance, and grounds keeping. Trends towards this have been observed in many Sub-Saharan African universities. For example, inefficient staff/student ratios pointed out two decades ago (World Bank, 1988) have largely disappeared as the result of surging enrolments combined with staff recruitment and retention difficulties (World Bank, 2009). In fact, overcrowding has frequently replaced underutilisation as a major management challenge on many campuses.

The fifth solution is cost sharing, which means attracting additional resources that enable further expansion of higher education in Africa. Growing demand for higher education coupled with scarce public resources has driven many governments to require students and their families to contribute to the costs of higher education (Johnstone, 1998). The case for greater private contributions is often tied to the returns that students can expect from obtaining a degree, such as increased earnings, a lower risk of unemployment and relatively good employment conditions (World Bank, 2002). Private contributions improve efficiency in higher education (Jongbloed, 2004). Introducing market forces encourages students to make better study choices and makes higher education organisations more responsive to students' demands (Vossensteyn, 2005). Many countries have moved from a system in which the government bears all or most of the financial responsibility, for example, for food, lodging and instructional expenses, to a greater share of the actual costs of instruction and full cost of food and lodging being borne by parents and students (Johnstone, 2004; World Bank, 2004). However, in Ethiopia, for example, Saint (2003) concluded that 
very low levels of family resources mean that completion of secondary education requires a major financial effort for each child, and that the potential for cost sharing at the university level is severely limited.

The sixth possibility is that public universities may be given the freedom to engage in a number of revenue generating activities that lead to benefits in terms of enriching educational programmes and strengthening research (Jongbloed, 2003; Clark, 1998; Massy, 2009; Liu, 2007; Riechi, 2003; Ouma, 2007). Public universities are advised to improve their financial viability and sustainability by reducing the instability of their funding through revenue generation (Chabotar, 1989). Consequently, universities have been put under continuing pressure to diversify their revenue base and reduce their dependence on public funding (OECD, 2008). We shall discuss revenue generation in public universities in more details in the subsequent sections.

\subsection{Revenue Generation for Financial Sustainability in Public Universities}

Before we move on to discussing revenue generation as a tool for ensuring the financial sustainability of public universities, we clarify what we understand by 'revenue'. Revenue is an income that an organisation (university in our case) receives from its normal business activities, usually from the sale of services and goods in the form of cash or cash equivalents (Johnson, 1995; Galskiewicz \& Marsden, 1978). Revenue generation is fundamentally about innovation and risk taking in anticipation of subsequent benefits (Shattock, 2003; Williams, 2009; Kirby, 2002a). Neither the innovations and risks nor the expected benefits need necessarily be financial, but it is rare for them to have no economic dimension (see Jongbloed, 2003). In this research, revenue generation is understood as acquiring resources from diverse sources (other than the core governmental budgets) in order to contribute to balancing the revenue structure of a public university or public universities.

Several authors in the field of higher education have been interested in revenue generation by public universities (Clark, 1998; Leslie \& Slaughter, 1997; Sporn, 1995a; Shattock, 2003; Jongbloed, 2004; Tolbert, 1985; Trow, 1983). This chapter is mostly based on their work. University success has always depended on capacity to secure resources to achieve their core missions (Ernste, 2007).While public universities still call for additional financial support from public authorities, they also seek to engage in revenue generation in order to increase and diversify alternative sources of funding. Public authorities seem to be growing more aware of the need for higher education organisations to develop a reasonably diversified funding structure, attracting funding from other 
sources including the private sector (EUA, 2011; Clark, 1998; Massy 2009; Jacobs, 1974; Gumport \& Sporn, 1999).

Several scholars suggest that revenue generation is one tool for ensuring financial sustainability in higher education policies (Clark, 1998; Leslie \& Leslie \& Slaughter, 1997; Mamdani, 2007; Massy, 2009; Ouma, 2007; EUA, 2011; Rothaermel et al., 2007). Several scholars (Clark, 2004; Court, 1999; Ouma, 2007; Mamdani, 2007; Nafukho, 2002; Saint, 1992) have studied revenue generation in the context of African public universities as well. The message of this research is that revenue generation is used as a financial sustainability strategy across a wide range of national systems and institutions throughout the world (Clark, 1998; Clark, 2004; Saint, 1992; Hatch, 1997; Dill, 1958; Massy, 2009; OECD, 2008; Jongbloed, 2003), where the conditions in which public universities operate permit it.

\subsection{Drivers to Revenue Generation in Public Universities}

Several drivers for revenue generation in public universities have been identified. The general economic context is an important driver for revenue generation, as pressures on public budgets lead to reductions in public funding (see Gumport \& Sporn, 1999; Court, 1999). Public universities that are deprived of critical resources will seek new resources (Pfeffer \& Salancik, 1978). In other words, shortfalls in government funding have increasingly encouraged universities to engage in a variety of revenue generation activities for acquiring vital resources (Shattock, 2003; Clark, 1998; Massy, 2009; Ouma, 2007; Hinchliffe, 1985; Nafukho, 2004, 1996; Oketch, 2003; Altbach \& Teferra, 2004; TFHES, 2000; World Bank, 1994, 1988, 1986; Cameron, 1983; EUA, 2011). Financial stringency and financial opportunities have been the main drivers of entrepreneurial activity in the case study institutions (Williams, 2009).

Globalisation and internationalisation also constitute drivers of revenue generation and diversification (Guerrero-Cano, Kirby, \& Urbano, 2006). The globalisation ${ }^{4}$ paradigm vis-à-vis the worldwide proliferation of neo-liberal

4 Two tensions for developing countries created by globalisation have been identified. First, the nation state is expected to create the conditions for economic and social development within the framework of trade liberalisation, predominately through producing more and better educated citizens and increasing knowledge production, which is a prized commodity in the global economy. Second, the pressure to reduce the role and contribution of central government in education. The double-edged challenge is to produce more graduates with high-level knowledge skills, but with 
policies, which emphasises reduction of state subsidisation of higher education and shifting costs to "the market" and consumers (Marginson \& Rhoades, 2002) drives public universities to acquire resources from diverse sources. Globalisation has encouraged higher education to become more business-like, as public universities are encouraged to seek additional funding from non-state sources (see Sawyerr, 2004; Akin Aina 1994; Mwiria, Kilemi \& Ng'ethe, Njuguna, 2003; Vaira, 2004). This simultaneously creates new opportunities and expands the field of competition for universities, which need financial means to improve their attractiveness. Similarly, internationalisation represents a substantial cost for universities, particularly in research, but it also creates new revenue possibilities, for instance through fostering "cross border" research collaboration. This has also become a more important way of increasing revenue in recent years. A case in point is the European Framework Programmes for Research, which has provided a strong incentive to increase collaborative research activities across many countries.

Risk management constitutes one of the major drivers for income diversification for public universities (Clark, 1998; Massy, 2009; EAU, 2011). Spreading financial risks is a common approach among public universities. This is particularly the case in the light of the consequences of the economic crisis and pessimistic expectations regarding future trends in funding coming from "traditional" governmental sources. Developing additional funding streams becomes necessary to mitigate the negative consequences of a sudden drop in income or to fuel further growth of the institution's activities. Revenue generation supports the expansion of organisational missions, by providing new resources to foster the achievement of new or pre-existing tasks (Clark, 1998). Universities are increasingly central to future growth and to the consolidation of the knowledge society. Revenue generation contributes to strengthening the university's research and educational capacities (EUA, 2011). Aside from research and teaching, universities may seek to generate additional revenue to improve internal processes, quality standards, or internationalisation activities.

\subsection{Sources of Revenue for Public universities}

There are many examples of public universities interacting with an increased number and variety of stakeholders for acquiring resources (see Clark, 1998 \& 2004; Massy, 2003\&2009; Jongbloed, 2004; Dill \& Sporn 1995; Enders 2004;

less direct government support per graduate (Caronyon, 1999 cited in Maassen and Cloete, 2006). 
OECD 2007; Enders, Jongbloed \& Salerno, 2008). Normally, sources of revenue for public universities vary from country to country or from one university to another and even within one university among units and sub-units over time. Although national governments remain the most important funders for public universities across the globe (Hauptman, 2009), there are three additional major sources of revenue for public universities (Hearn, 2003; see also Clark, 1998). These include: (i) other ministries, regional and local governments; (ii) private entities (e.g. firms, students, NGOs, philanthropic foundations, professional associations, communities, business (industrial) firms; investment revenue), and (iii) international donor organisations (Williams, 2009; Clark, 1998; Dill \& Sporn, 1995a; Gumport \& Pusser, 1997; Osborn, 1971). These sources of resources are not solely passive providers of resources; they may demand a more active voice in the university's running to improve the value of their share and their benefits (Benneworth \& Jongbloed, 2009). They may also expect something in terms of the economic and social functions of the university and its services in terms of teaching, research and knowledge transfer (Enders, Jongbloed, \& Salerno, 2008).

Most public universities earn resources from governmental authorities other than the core ministry (Clark, 1998, 2004). These actors can provide resources for a public university to serve the needs of their territories (Goddard\& Puukka, 2008) in terms of supplying human capital to the regional or local labour market, providing technology and research outputs, and contributing to sociocultural and policy development (Castells, 1996; Etzkowitz \& Leydesdorff 1997; Enders \& Fulton 2002). Universities can interact with these actors in areas like health, industry, culture, and territorial development as well as in the areas of training and research.

Public universities also receive resources from individuals and private entities that include non-profit organisations and private enterprises, as indicated in the second category of sources of revenue for public universities. Students and their parents are the main source of revenue for public universities who can spend on education according to their assessments of private benefits, their prosperity and their demands (Vossensteyn, 2005). Across the globe, student financial contributions or fees have the potential to constitute a large, predictable, income source, giving the university the ability to invest over the long term (EUA, 2011; OECD, 2008). Industrial firms can enter into exchanges with public universities after having estimated their economic returns, which are linked to their market incentives to engage in new technologies and apply new scientific knowledge (OECD, 2002; Clark, 2001). Most industrial firms interact with nearby universities when seeking advice on matters of technological and organisational innovations, conducting contract and joint research, and getting training 
courses customised to their needs (Gulbrandsen \& Smeby, 2005; Jongbloed \& Van der Sijde 2008).

A variety of donors such as bilateral countries and multilateral organisations form the third sources of revenue for public universities (World Bank, 2010; Teshome, 2005; Johnstone, 1998; Liu, 2007). Funds from donors are mostly received in the form of grants and/or loans. In exchange for their resources, most donors can ask for certain education and research services, require performance reports, or generally expect universities to meet the conditionality associated with the resources provided.

\subsection{Revenue Generation Activities in Public Universities}

A need to diversify resources implies that universities are required to undertake a variety of revenue generating activities (Clark,1998; Shattock, 2003; Jongbloed, 2003; Johnstone, 1998; Leslie \& Slaughter, 1997; Williams, 1992; Liu, 2007; CHET, 2011; EUA, 2011; Hearn, 2003) apart from the teaching and research that are funded by core-funding. Revenue generation activities by public universities are categorised in four domains (Hearn, 2003; Clark, 1998; Ouma, 2007; Williams, 1992:39), which are discussed below.

\subsubsection{Educational services and Short-term courses}

Educational services and short-term training is the first category of revenue generation activity for public universities. Many public universities have been responding to external opportunities aggressively, targeting such diverse student markets as corporate learners, professional enhancement learners, degree-completion adult learners, pre-university learners, remediation and testpreparation learners, and recreational learners (Hearn, 2003). These educational services focus not only on students seeking degree programmes but also on students seeking non-degrees pre-and post-baccalaureate certification (see Hearn, 2003; Levine, 2000a; Schneider, 1999; Ouma, 2007; Williams, 1992). Some universities have benefited financially from creative state-level mechanisms to stimulate workforce training and development in the form of short-term or long-term programmes for industry and other stakeholders. Many public universities have moved towards offering special versions of high-demand courses at high tuition levels. Such efforts can include evening courses, summer courses, short courses, online courses, credentialing programs in areas demanded by the labour force and offerings abroad (Hinchcliff, 2000). Vocational master's programmes where short courses can be linked as modules 
can fall under this category (Douglas, 2008). Currently, the demand for education greatly exceeds the supply (Geiger, 1991).

\subsubsection{Research and Consultancy Services}

The second category of revenue generation activities for public universities is their research (basic and applied) and consultancy services. Many universities are repackaging and reorganising their research and analysis capabilities, often in pursuit of revenue (Clark, 1998). Prominent initiatives involve business incubators, technology transfer offices, research and technology centres and parks, small business development centres, and research collaborations with private industry and the government. Some scholars suggest that more revenue comes from more applied and problem-solving research (Lee, 1996; OwenSmith \& Powell, 1998; Anderson et al., 2001; Gulbrandsen \& Smeby, 2005). Profit oriented firms may be more interested in applied research, the benefits of which are relatively easy to appropriate, than in basic research. Conversely, basic research is hard to appropriate privately. And yet, other scholars find no empirical evidence that the shift towards more applied research occurs at the expense of basic research (Callaert et al., 2004). In practice, research contracts cover most of the research and development work undertaken for various external stakeholders in order to generate revenue (Williams, 1992; Leslie \& Slaughter, 1997).

Some of the revenue generation activities in this category may be organised into separate university-owned spin-off companies. Money can be earned from patents and licences, direct consultancy or commercial research partners (Jacobet al., 2003). Consultancy is one stage further than contract research from core academic activities. It is normally undertaken primarily for financial gain. Joint research projects or commissioned research seem to be among the most common forms of cooperation between public universities and their regions and are likely the important sources of nongovernmental resources and colearning (Benneworth \& Sanderson, 2009). In this regard, several universities have been establishing science parks for fostering their revenue generation agenda, b). One of the main purposes of science parks is to enhance technology transfer through spin-offs, research collaborations, and informal points of accessibility to various resources, including human resources (Massey et al., 1992; Vedovello, 1997; Siegel et al., 2003c). In recent decades, many universities have designated an adjacent land area and established a research park (Bozeman et al., 2000). 


\subsubsection{Hiring University Facilities}

Several universities are increasingly privatising their facilities with the aim of enhancing revenues. Revenue can be received from leasing university property to private entities or by the exploitation of university facilities for commercial purposes (Geiger, 2002; Kirp \& Roberts, 2002). Many universities obtain such revenues through rental, residences, catering, consultancy, libraries, museums, training centres or resource centres, printing and binderies, sport facilities, language centres, scientific test equipment, etc. Thus, universities have considerable opportunities to exploit their facilities for generating revenue.

\subsubsection{Sales of Goods and Products of Public Universities}

Universities can also generate revenues through retail. This may include sales of diverse university products and services to diverse customers. In more advanced universities, it consists of patenting and licensing, creating incubators, science parks, and university spinouts, and investing equity in startups, among others (Mowery et al., 2004; Siegel, 2006a).

\subsection{Factors that Enable or Hinder Revenue Generation in Public Universities}

Revenue generation by public universities is influenced by a number of factors. Scholars have recognised that the process of university revenue generation is influenced by external factors (Etzkowitz, 2003), most notably laws and policies (Mowery et al., 2001; Jacob et al., 2003), the surrounding industry (Gulbrandsen \& Smeby, 2005), regional conditions (Friedman \& Silberman, 2003), and funding and incentives in the organisational environment. They have also reported that unique characteristics of an individual university can influence their revenue generation. The principal features of the environment impacting on universities include social, political, economic, and technological trends that the university faces (see Sporn, 2001; Duczmal, 2006; Gulbrandsen \& Smeby, 2005; Trow, 1973; Gumport \& Sporn, 1999; Massy, 1996). Political parties and public decisionmaking bodies can influence the role of universities in national development. Whether or not universities have a role in national development strategies or policies may enable or obstruct their revenue generation capacity (CHET, 2011:13-20; Boucher et al., 2003; Charles 2003, 2006; IHEP 2007; Arbo \& Benneworth 2008). Enders (2007) points out that a dictatorial and totalitarian political system can restrict teaching and research (see also Court, 1999; Duczmal, 2006). Social trends mainly relate to demographic patterns that might determine the number and types of student body in universities (OECD, 2008). 
While some countries (particularly developing countries) face the situation of growing demand for university education due to rapid expansion in their youth population, others (mostly developed countries) face decreases in domestic enrolments.

The overall growth of the national economy will generally enable universities to generate additional revenues from the environment (Court, 1999; Arbo \& Benneworth 2008). Studies show that an increase in GDP per capita influences the demand for university education (OECD, 1993, 1998). Economic trends also include the unemployment levels of university graduates, opportunities for employment for those without university level education, the economic structure, and even faculty and staff labour markets that affect a given university's responses to external demands and expectations (Dill, 2003). For example, industrialism and other forms of modern economic growth require job skills of an increasing range and complexity (Ramirez, Riddle, 1991). The technological revolution currently underway entails significant changes for many universities and it can be considered a major trigger for expanding and diversifying sources of revenue for public universities by expanding opportunities for education services. Information technology and modern telecommunication, including computers, accompanied by increasingly sophisticated software is another important enabler for revenue generation as they have significant impacts on how students learn, how professors teach and conduct research, and how administrators manage the university (Chun \& Gumport, 1999).

National governments can steer the behaviour of public universities towards certain goals through policies or laws and funding (Jongbloed, 2004). Several scholars have identified that the regulatory frameworks or laws in which public universities operate influence their revenue generation efforts (Jongbloed, 2004; OECD, 2008; EUA, 2011). For instance, universities will not be able to pursue additional revenue generation if the regulatory frameworks in which they operate do not allow them to do so (OECD, 2008; EUA, 2011). A formal requirement for regional engagement in the national legislation can be an enabling force to adopt the third mission in universities' core activities. The Bayh-Dole Act (1980) of the USA provides a good example of this (Mowery \& Sampat, 2005). The regulatory frameworks often define the rules of the game by which various stakeholders interact and exchange resources (Becher \& Kogan, 1992:82; Jongbloed, 2004; OECD, 2008; Gornitzka \& Maassen, 2000).

National governments can provide incentives for university-stakeholder collaborations using diverse policy instruments (Varghese, 2004; Davies, 2001). These include: (1) subsidies to co-finance collaborations; (2) subsidies for formal 
collaborations may drive out equally or more efficient informal contacts; and (3) governments may be tempted to use R\&D policies for subsidising national firms, and policy competition may render the national policies ineffective (Fogel \& Gnyawalli, 1994; Abbot \& Doucouliagos, 2003; Mok, 2005). Funding models for education production can, for example, influence the revenue generation efforts of public universities as the funding models have their own incentive structures (Massy, 2003). Vouchers or student loans could improve access to higher education because the investment in higher education made by the student is less dependent on initial (including parents') wealth. Such a funding system is an important enabler for revenue generation as university students are less concerned about paying for their education.

Several scholars have identified the organisational autonomy ${ }^{5}$ of public universities as a key condition for successful revenue generation and diversification and for their long-term financial sustainability (EUA, 2011; Massy, 2003; Hasan, 2007; Jongbloed, 2004; Askling et.al. 1999; Varghese, 2004; Goedegebuure et al., 1994). Not all aspects of organisational autonomy are equally important for influencing revenue generation strategies or activities in universities (EUA, 2011). Procedural autonomy ${ }^{6}$ (i.e. financial and staffing autonomy) is highly associated with revenue generation activities or marketorientation (De Vries \& Koelman, 1999; Jongbloed, 2004:341; Williams, 1992; EUA, 2011). This may be because universities by their very nature are bottomheavy organisations that have traditionally been self-governing centres of education and research with adequate substantive autonomy (Dill \& Sporn, 1995).

Financial incentives can encourage universities to meet certain conditional policy goals, including implementation of revenue generation strategies and activities (Jongbloed, 2004). Several resource allocation mechanisms such as line-item budgeting, block grant $^{7}$, targeted funds ${ }^{8}$, indirect funding ${ }^{9}$,

5 See OECD (2008:81) for an overview of the different aspects typically associated with institutional autonomy.

6 See also Berdahl (1990) to distinguish between procedural and substantive autonomy.

7 A large sum of money granted by government authorities to HEIs without strings attached as to the way it is to be spent.

8 An amount of money awarded by government authorities to HEIs with a particular purpose.

9 Extra funding allocated to HEIs in proportion to the "best" entering students the HEIs are able to attract. 
competitive funding ${ }^{10}$, etc. can be employed in allocating government funds to universities to achieve certain policy goals (OECD, 2008). These funding mechanisms can enable or erect barriers to revenue generation of public universities (Massy, 1996; Massy, 2003; Hauptman \& Salmi, 2006; Williams, 1992). For example, governments can foster partnerships between the academic and business communities, support national (local or regional) economy development objectives, undertake R\&D activities on certain thematic areas, make universities offer lifelong learning programmes and admit students from disadvantaged parts of society, etc. using targeted funding mechanisms (Williams, 1992; Harman \& Harman, 2003). Generally, the shift from 'budgets itemised by function' towards 'budgets itemised by performance targets' or output-oriented funding marks the road to revenue generation (Canton \& van der Meer, 2001; Koelman \& Venniker, 2001; Hauptman \& Salmi, 2006). The underlying rationale is that public universities themselves know best how and where to use their resources to meet their objectives (Williams, 1995).

Many authors show that the nature of competition and the number of competitors in the task environment can influence revenue generation in public universities (Dill, 2003). The intensity of rivalry for the higher education market can be influenced by several factors. These include: (i) the number or concentration of competitors; (ii) their similarities or differences in programmes; (iii) a slow growth of the higher education market in terms of student numbers; and (iv) the costs of switching from one university to another (Duczmal, 2006; Mansfield, 1991; Begg, Dornbusch, \& Fischer, 1991; Dill, 2003; Jongbloed, 2003). Some of the key competitors for a public university consist of private and public providers of post-secondary education, R\&D institutes in government organisations and industrial firms, private companies, etc., which are part of a common industry providing academic degrees, research and services (Dill, 2003; Clark, 1998; Massy,2003; Enders, Jongbloed \& Salerno, 2008; Salmi, 2007). These factors can either enable or erect barriers to revenue generation in public universities.

Several research outputs have also revealed that revenue generation by public universities can be influenced by university specific factors. Engaging in different missions ${ }^{11}$ may lead to addressing the demands and expectations of

10 A process by which a HEI is selected from among contestants for allocation of limited resources.

11 Universities may follow different academic traditions such as the German, the French and the British ones, but an American perspective is also relevant since US universities provide the important bridging of European and American developments (Jónasson, 2008; see Enders, 2007).The German tradition or the 
several of stakeholders, which in turn leads to revenue generation (Shattock, 2003; Davis, 2001). The inclusion of research as a legitimate function of a university in the 19th and 20th century has created opportunities for innovations in the economy and society, which has resulted in revenue generation (Etzkowitz (1998, 2003 and 2004), Etzkowitz \& Leydesdorff, 2000; Etzkowitz et al., 2000; Schulte, 2004). The development of business ideas through academic spin-offs for the commercialisation of research (Clarysse \& Moray, 2004; Link \& Scott, 2005; Lockett et al., 2005; Allen \& O'Shea, 2005), academic spin-out (Lockett \& Wright, 2005; Birley \& Nicolau, 2003; Di Gregorio \& Shane, 2003), and academic spill over (Chiesa \& Piccaluga, 2004; Audretsch \& Lehmann, 2005; Audretsch et al., 2005) can lead to acquiring resources from stakeholders.Many scholars suggest that revenue generation is generally encouraged when governments promote and support third mission activities (Etzkowitz, 1993; Ropke, 1998; Laukkanen, 2000; Clark, 1983; Massy, 2003:12-15; Etzkowitz et al., 2000; Etzkowitz 2003).

A university's behaviour can be influenced by the actions of various internal players who would seek to control its decisions and actions (Mintzberg, 1983). These actors have certain powers ${ }^{12} /$ authority (see Thompson, 1995; French \& Raven, 1960) by which they seek to produce and influence decisions on university issues. One of the core enablers in relation to revenue generation is commitment by university senior leaders (Clark, 2001:19; Massy, 1996:185). The attitudes and character of the head of a public university contributes greatly to levels of revenue generation. Leadership cannot be restricted to a single post or

Humboldtian tradition (after Wilhelm von Humboldt) set the stage for the researchteaching nexus that we now take for granted as a fundamental characteristic of the university. In the French or Napoleonic tradition, the main role of a university focuses on the teaching mission. In the British tradition, the Newman perspective, the key role of a university is to offer the most suitable environment for learning, by guaranteeing close interaction between students and tutors to provide an education that favours the formation of the student's character and mind so that he or she Master's the intelligence processes needed for a successful life. In this tradition, students are not trained only for a narrow profession. The American tradition can be regarded as merging German and British perspectives and ideas, with a significant addition, the 'land-grant' universities created in the second half of the 19th century. In this perspective, a university makes a clear distinction between undergraduate and graduate education (Newman inspiring undergraduate studies and Humboldt the graduate programmes). Thus, from early on, education, research and application, are seen in the US as distinct university roles that formalise education, research, and service as the core missions of a university (Clark, 1983).

12 Reward, coercive, legitimate, charismatic or personal, information, connection and expert power. 
even to a team or subset of colleagues in the centre, but rather dispersed around a university including at upper, middle, and operational level management (Shattock, 2003; Sporn, 2001). Clark (1998), the most cited writer on the entrepreneurial university, advocates a "strengthened steering core" that stretches from highly personal leadership to highly collective or group-based leadership (see also Sporn, 1999; Shattock, 2003). As universities increasingly need to demonstrate their effectiveness in meeting the demands of various stakeholders, the need for strong organisational leadership emerges (Lapworth, 2004; Stamoulas, 2006; Shattock 2004; Clark, 1998; Maak 2007; Bryman 2007). As put by Askling et al., (1999), "universities can no longer afford amateurish leadership in accordance with the traditional collegial model." Clark (1998), however, warns against the dictator, the tyrant, the authoritarian leadership figure who cannot be a permanent feature in entrepreneurial universities. Several authors on African higher education systems point out a need for knowledgeable and strong leaders of universities for successful reforms in public universities in Africa (Abagi, 2001; Banya \& Elu, 2001; Cooksey et al., 2003; Musisi, 2001; Musisi \& Muwanga, 2003; Saint, 1992; TFHES, 2000).

The senior leaders of universities define internal regulations for determining the detailed mechanisms of management of education and research including human and financial management (Gornitzka \& Maassen, 1998). Accordingly, the leadership may integrate the differentiated units through various mechanisms (e.g. policies, resource allocation mechanisms, reward systems, etc.) in order to trigger adequate responses from internal actors (Maassen \& Potman, 1990). According to Davies (2001), revenue generation needs to be incorporated in the role of the university community (as appropriate) implying explicit job descriptions, rewards, and incentives. Monetary and/or nonmonetary rewards will further enhance revenue generation (Kirby, 2005; Massy, 2003). The leadership of public universities has the ability to implement or drop or change organisational policies (Davies, 2001) that may inhibit revenue generation strategies and activities. The levels of commitment of the leadership can be detected from the hierarchical positions of revenue generation offices and their accountability (Allison \& Zelikow, 1999: 143).

A leadership style that combines the traditional academic model of collective collegial decision-making and market coordination in terms of stronger organisational leadership is an important enabler for revenue generation by public universities (Dill, 1992a; Clark, 2004). Collegial leadership can be achieved by greater devolution of decision making to academic departments and extensive use of committees for ensuring participation in decision-making (Clark, 1998). There has also been a broad trend towards the appointment of professional administrators reporting to a small senior executive team (Graham, 
2002; Kirp, 2003; Zhou, 2008; Berglund 2008), which is seen by many as weakening democracy in public universities and marginalising the concept of a community of scholars. Professionalised management is seen as a necessary condition for higher education organisations to respond to both external ${ }^{13}$ and internal ${ }^{14}$ pressures and demands adequately (Cloete \& Maassen, 2006; Brennan \& Shah, 1994). In this situation, the managerial ethos is oriented to organisational governance, leadership and planning (Subotzky, 1999) and requires a university manager with professionalised, leadership and full-time job personal characteristics (Dill, 1995; Henkel, 1997; Sporn, 2001; Sotirakou, 2004).

The governance structures of a university are of paramount importance in influencing organisational responses to external pressures (Stensaker, 2004; Covalski \& Dirsmith, 1988; Sporn, 2001; Neave, 1998; Bauer et al., 2006; Middlehurst, 2004; McNay, 1995) in terms of revenue generation. Research outputs show that the entrepreneurial university model, an intermediate coordination between the collegial and the market models (see Clark, 1979 for Clark's triangle of coordination), offers more opportunities for revenue generation (see Clark, 1998; Jónasson, 2008; Considine \& Marginson, 2000; Sporn, 1999). In terms of the centralisation and decentralisation of universities, while many studies argue for a greater devolution of decision-making to the operational level (Brennan \& Shah, 1994), others do not (see Clark, 1998). According to Eastman (2007:10), decentralising resource allocation from central administration to faculty or whatever level gives cost centres greater incentives to control costs and engage in revenue generation (Davies, 2001:35). Many authors call for a decentralised organisational management for fostering revenue generation (Etzkowitz et al., 2000; Gumport \& Pusser, 1995; Gumport \& Sporn, 1999). On the other hand, taking the case of Warwick University, Clark (1998:21) suggests that a centralised structure, which is supported by a set of interrelated and interlocked central committees, can be an important enabler for revenue generation. Mamdani (2007) strongly warns against extensive decentralisation of universities, which he equates with absolute commercialisation.

13 External demands range from new policy initiatives and new government legislation to opportunities for the formation of industry, commerce or community partnerships.

14 Internally, greater planning and more efficient allocation of resources are required, as well as the provision of incentives for academic to respond to opportunities or markets. 
Any university must have acquired required resources (human and nonhuman) for its operations to achieve its chosen strategies (Dill, 2003; Mahoney, 1995) including its revenue generation agenda. Creating and disseminating good quality useful knowledge in the higher education setting depends on knowledge embedded in people (Gibbons et al., 1994) to a large extent (academic staff, researchers, etc.), as well as other inputs such as technologies, books and networks (Spaapen et al., 2007; Marginson, 2007; Beyer, 1982:171). Academic staff holding higher scientific degrees (notably PhDs), who are committed and adequately compensated are the heart of universities, without whom higher education organisations cannot function properly (Altbach, 1991; CHET, 2011; Clark, 1998). The demand for a given university is mostly dependent on its prestige, reputation, and educational programmes (Clark, 1983:163). According to Enders (2007), the overall reputation and status of a university is dependent on the publically acknowledged qualifications and expertise of its academia (see also Clark, 1998; CHET, 2011; Massy, 2003; Lynton, 1995; Shattock, 2003). Qualified academic staff are a crucial ingredient for meeting the demands and expectations of a variety of stakeholders (Dill, 2003:143; Shattock, 2003:121, citing Fombrun, 1996:73), which leads to revenue generation. In this respect, highly valued universities (or their prestige) bring various sets of higher rewards ${ }^{15}$ : better students, better working conditions, higher personal reputation, and more generous financing (Clark, 1998 \& 2001). Equally, revenue generation from diverse stakeholders with different demands brings about a huge amount of additional administrative work at all levels within a university (Clark, 1998; Sporn, 1999; Kirby, 2006). Several scholars argue that professional managers (Mintizberg, 1983; Clark, 1998; Cloete \& Maassen, 2006) in the areas of financial management, marketing, strategic planning, and human resource management (Coaldrake \& Stedman, 1999) are important prerequisites for revenue generation (Gumport \& Sporn, 1999). Universities must also have reasonable capacity in terms of their non-human resources, such as laboratories, workshops, classrooms, libraries and other facilities in order to assist the academic staff engaging in revenue generation (see Shattock, 2003). For instance, higher education organisations with limited research facilities are not likely to attract external funding for research, just as those whose programmes are perceived to have limited education inputs are likely to find it difficult to attract fee-paying students (Cameron, 1983).

Several research outputs show that revenue generation typically spreads unevenly within universities that have widely divergent fields of study (Clark, 1998; Fairweather, 1988; Leslie \& Slaughter, 1997; Williams, 1992). Scholars

\footnotetext{
${ }^{15}$ Matthew effect
} 
argue that the advent of natural sciences ${ }^{16}$ in universities have enhanced their economic significance and social importance (see Jónasson, 2008). Clark (1998:141) points out that science and technology departments commonly become revenue generation areas (entrepreneurial) first and most fully. Social sciences departments, aside from economics and business, find revenue generation difficult and commonly lag behind. However, a study by David Court on Makarer University showed that social sciences could also take a lead in terms of revenue generation (Court, 1999; Clark, 2003), in a context where a capacity for initial investment is limited. Interdisciplinary and multidisciplinary (Mode2) ways of configuring knowledge can be considered as better enablers for revenue generation than traditional disciplines (Mode1) as the former leads to interaction with a range of stakeholders (Gibbons et al., 1994; Dooley \& Kirk 2007; Koivula \& Rinne , 2009; Etzkowitz, 2004).

Many authors report that internal resource allocation mechanisms and management influence revenue generation in public universities (Massy, 1996; Jongbloed, 2004). According to Massy (1996), Performance Responsibility Budgeting (PRB), Revenue Responsibility Budgeting (RRB), and Value Responsibility Budgeting (VRB) models of allocating resources within universities can enable or erect barriers to revenue generation. RRB in particular extends sensitivity to market forces down through the organisation, since operating unit budgets depend on their ability to generate revenue, and therefore encourages entrepreneurial culture (Massy, 1996: 35-36; William, 1992). In terms of resource management, when financial decisions are taken by the central administration and all income earned is retained by the centre, there is very little incentive for departments or individual members of staff to proactively seek external revenue. Some scholars suggest that severe financial stringency can inhibit creative entrepreneurialism because many innovations require some initial investment and usually some financial risks that public universities that are severely short of money cannot afford to take. Money is important, but while the need for resources often stimulates entrepreneurial knowledge transfer, extreme financial stringency is often seen as an inhibiting factor in that it makes it difficult to take risks and staff have to devote so much of their time to mainstream teaching that they have little energy for new initiatives. Any organisation with an assured income at a level that is adequate in relation to its needs and aspirations has little motivation to undertake risky innovations. In contrast, when the assured income is inadequate to meet the

16 Germany was the first of the European states to assimilate science into the universities. The fruits of this were seen already by the middle of the 19th century, in terms of trained scientists, texts and apparatus. 
goals of an organisation, incentives are created to seek new sources of revenue and this often means developing new ideas and taking risks to implement them.

\subsection{Revenue Generation Strategies for Public Universities}

At the beginning of this chapter, we argued that the survival of a university depends on its responsiveness to external demands from multiple stakeholders (Oliver, 1991). In response to these demands, leaders of public universities seek to manage and strategically respond to external dependencies to ensure the continued survival of the university, reduce the effects created by external constraints on internal organisational discretion, and maximize the autonomy and discretion available to them (Aldrich \& Pfeffer, 1976; Thompson, 1995:7; Porter, 1979). Formulation of strategies depends on how a university learns about its environment and attends to it, and how it selects and processes information to give meaning to the environment (Chaffee, 1985; Gumport \& Sporn, 1999; Pettigrew \& Whipp, 1991; Fahey \& Narayanan, 1986). Gathering quality and comprehensive information through scanning the environment is an entry point for setting strategies (Fahey, King, \& Narayanan, 1981; Pfeffer \& Salancik, 1978; Gumport \& Sporn, 1999). Some of the key revenue generation strategies for public universities are discussed below.

\subsubsection{Differentiation and Diversification of Services or Products for Revenue Generation}

One of the strategies for revenue generation in public universities is to differentiate and diversify its products and services physically, mentally, and psychologically in order to address the needs and expectations of various customers (Huisman, 1995; Clark, 1979). Clark has identified two dimensions of differentiation (vertical and horizontal differentiation) which respond to the increase in the variety of the student population, the growth of the labour market for higher education graduates, and the emergence of new disciplines (Clark, 1979). Vertical differentiation is all about tiers within organisations. It addresses the demands and expectations of students seeking degree programs (BA, MA/MSc, and $\mathrm{PhD}$ ), and those seeking non-degree pre-and postbaccalaureate certification. Horizontal differentiation is about opening different areas of study at a certain tier (Clark, 1995; Dill, 1992b; Lawrence \& Lorsch, 1986). The differentiation strategy can encompass a variety of pedagogical forms or modes of delivery (e.g. distance, summer, weekend, evening, etc.) to provide opportunities to attract new customers and motivate traditional customers to remain loyal to their services (Jongbloed, 2003). Similarly, public 
universities can differentiate and diversify their research to basic research and applied research in various areas (e.g. health, education, agriculture, business, etc.) targeting diverse stakeholders (see Dill, 1992a:16). The differentiation strategy includes non-academic services and products such as auxiliary enterprises, real estate, facility rentals, and other university research products (Hearn, 2003).

\subsubsection{New Organisational Structures for Revenue Generation}

New organisational structures (both academic and administrative) are necessary to generate funds from new sources (Tolbert, 1985; Bergmann, 1991; Gumport \& Pusser, 1995; Guskin, 1994a; Leslie, 1995). Public universities may use a strategy of creating new functions, structures, and units that enable them to embark on successful revenue generation activities (Clark, 1998; Jacob et al., 2003; Bergmann, 1991; Gumport \& Pusser, 1995; Guskin, 1994a; Leslie, 1995). The organisational structures for revenue generation include both new academic units and outreach administrative support offices that promote contract research, contract education, and consultancy. Examples of outreach administrative units include technology transfer offices (TTO), industrial contact or liaison offices, intellectual property development, start-up firms, business incubators, research parks, continuing education, international offices and donor project coordination offices including fundraising and alumni affairs (see Lockett et al., 2004; Ylinenpää 2001; Baldini et al., 2006). The increased demand for accountability from diverse stakeholders has expanded universities' administrative support structures (Gumport \& Pusser, 1997). The support units enable the universities to manage resource dependencies between the university and its stakeholders (Clark, 1998; Gumport \& Sporn, 1999; Massy, 2003).The academic units include interdisciplinary or multidisciplinary research centres that work side by side with academic departments to reach a variety of stakeholders.

To foster a revenue generation agenda, academic and administrative structures need to be integrated and coordinated (Dill, 1995b; Galbraith, 1977) by establishing effective communication systems. We can differentiate between internal and external communication (EUA, 2011). External communication can make all stakeholders aware of the range of activities undertaken by universities. It ensures the stakeholders know about a given university. External communication makes the much needed link between internal activities and the outside world. Internally, the whole university community needs to be involved and be aware of the university's purposes, aims, and actions. Internal communication plays a crucial role in achieving cooperation from diverse actors 
(e.g. leadership, academic staff, etc.) and it is critical in implementing efficiency measures.

\subsubsection{Internal Resource Allocation Mechanisms and Human Resource Policies for Revenue Generation}

Several scholars have shown that internal resource allocation mechanisms can be used as a strategy for steering a university towards certain goals (World Bank, 2010; Williams, 1992).Various funding mechanisms such as line item budgeting, performance responsibility budgeting, revenue responsibility budgeting, and value responsibility budgeting may be used as incentives to foster revenue generation (Massy, 1996). In this regard, block budgeting (in which the centre allocates general funds to units in blocks and units are responsible for balancing their budgets), modified block budgeting (in which block grants are supplemented by specific revenue-sharing arrangements) and responsibility centre budgeting (RCB) are increasingly prevalent in enhancing universities' engagement in revenue generation. As Massy (1996:455) has observed, RCB "extends the sensitivity to market forces down through the organization".

Many activities to increase and generate new revenue sources need more and new expertise, which may or may not exist within the university (EUA, 2011). Kirby (2005) argues that one of the strategic actions intended to promote revenue generation in universities is related to recruitment, promotion, recognition and reward, and endorsement (see Bernasconi, 2005; Miclea, 2004). Universities may recruit professionals from the labour market or invest in staff development to acquire these skills. Public universities will have to be increasingly flexible in the management of their human resources; for example, in the recruitment of academics and administrative support staff, including the setting of more competitive salaries (OECD, 2008; EUA, 2011). There is also a need to design a set of incentive mechanisms (financial and non-financial) in order to increase the commitment of the academic community to revenue generation. A diversity of incentive mechanisms exists, mostly operating at two levels, either by rewarding staff directly (Henrekson \& Rosenberg, 2001; Jensen \& Thursby, 2001; Friedman \& Silberman, 2003; Debackere \& Veugelers, 2005) or through providing incentives at faculty/institute level (EUA, 2011). Incentives to academic and administrative support staff help to reduce resistance and contribute to successful implementation of revenue generation. There are two kinds of rewards: intrinsic and extrinsic. Intrinsic rewards stem from a person's own value system - psychological payoffs based on what he or she thinks is important or enjoys doing (e.g. employee recognition programmes). Others that 
may be financial in nature, such as salary increases (Mcinnis, 2001; Clark, 1983; Judge \& Robbins, 2008), confer extrinsic rewards.

\subsubsection{Creating Alliances/Consortia with Other Universities and Co-opting Stakeholders Universities' Governance}

Public universities are required to create networks, conglomerates, and strategic alliances with other organisations in their environments such as industry, government and other institutions (Sporn, 2001; Etzkowitz et al., 2000) in order to further their revenue generation agenda. The alliances aim to mobilise academic staff or researchers and/or other resources such as capital and equipment and facilities from partner organisations to undertake joint education programmes and/or research projects in order to coalesce efforts around specific issues to achieve a revenue generation aim (OECD, 2008). Additionally, alliances will take place in a context where one party will resell a focal university's courses in new markets. Many alliance-based efforts can help to create a new business environment in which a university is connected to outside organisations. A pact or treaty will guide the alliance in the process of advancing common goals and securing common interests. Additionally, universities can involve people from key stakeholders in their governance in order to enhance linkages with the economy. This strategy will increase the openness of universities vis-à-vis their environment or their stakeholders (e.g. industry, regional, and local community, etc.). As a result, they may enhance their responsiveness to the needs of stakeholders and thereby create an opportunity for revenue generation (OECD, 2008:129-130; Sporn, 2001).

\subsection{Effects of Revenue Generation in Public Universities}

Revenue generation enhances universities' economic contributions, potentially overshadowing broader societal contributions (OECD, 2007). Engaging in interactions with diverse stakeholders can expand the core missions of public universities by including activities outside of the ivory tower, with the goal of transforming inventions into innovations for the betterment of society. However there are concerns about the potential problems with and hidden costs of revenue diversification, which policy makers and university leaders should be aware of (Liu, 2007:34; Mamdani, 2007; Carroll, 2006; Musisi \& Muwanga, 2003; Obong, 2004; Jongbloed, 2004; Massy, 2009). Revenue generation is frequently described as having a "seamy side", the distasteful consequences of a financially driven organisational system. Preoccupation with entrepreneurial activities may cause money to be the driving force of the 
university, rather than educational excellence (Mohrman, 2003). If pushed too far, revenue diversification may alter the fundamental teaching and research missions of a university (Obong, 2004; Newman, 2000, Albrecht \& Ziderman, 1995). For example, it can raise costs on campus, redistribute academic power, shift academic priorities, and reduce the sense of community (Leslie \& Slaughter, 1997). The amount of time devoted to revenue generation may distract faculty from teaching and basic research. Moreover, inequalities in ability to generate revenues among institutions and unequal distribution of revenue over different departments within institutions will occur (Liu, 2007:36). Direct competition with private business, consultancy firms, and/or other commercial education and research providers may create conflicts of interest, unfair competition and market distortion, especially when commercial businesses argue that publically funded institutions use government grants to engage in cross-subsidisation and under-pricing (Jongbloed, 2003).

Moreover, high-powered incentives for revenue generation are believed to produce graduates who are narrowly prepared for job-markets. When educational quality is difficult to observe and the reputation mechanism works insufficiently, revenue generation from educational services brings the danger of falling standards. In particular, schools have an incentive to let pass students just below the critical border. The average quality of graduates is reduced when more of these so-called infra-marginal students receive their certificates. When education funding does not depend on education output and the effort academics put into education is hard to verify, strong financial incentives for research may come at the cost of the quality of education. The same applies to the transfer of knowledge, which is a legal task, but is rarely explicitly rewarded. When universities substitute short-term applied "industrial" research for basic research due to closer ties with industry, this might hamper long-term research productivity, diminish spill overs from academic research, and eventually even harm long-term national innovativeness. Individual academics may systematically become entrepreneurs whose stature and relevance are somehow determined by the amount of revenue they are able to raise.

Jongbloed (2004:103) has extensively discussed the problems associated with 'hybrid ${ }^{17 \text { ' }}$ organisations. While the hybrid organisations can generate revenue through their commercial activities, this can also be regarded as one of their

17 Organisations which operate in both the public and the private domains, fulfilling public duties as well as developing commercial market activities. In simple language, organisations containing public and private elements. 
disadvantages. They are accused of cross-subsidisation ${ }^{18}$ and under-pricing. Market activities may bring large benefits for those who are involved, leading them to disregard their core missions. Market forces also put pressure on faculty to teach on financially remunerative programmes. They (market forces) also guide academics to steer their organisations towards a commercially profitable mission (mission drift). Gordon Winston (1997) and Clark Kerr, 1988 (cited in Massy, 2003) have described the tension between academic values and market forces as "university as church" or "the Acropolis" against and university as "car dealer" or "the Agora". In the former case, public universities exist to produce value based on grounds of both equity and efficiency, and hence only public funds could provide the resources needed. In the latter case, driven by the market, universities allow no cross subsidies for programmes that do not have a market demand. The fate of the 'endangered' programmes might, at best, be to be downsized or suffer a major financial setback or be deleted from a list (Massy, 1996:46-47). This is mainly discussed as the sacrifice of quality standards in the interests of cutting costs or generating more surpluses; unethical advertising for business by universities; failures of consumer protection; standard courses of education, which are demonstrably unsuited or un-adapted to particular client groups (local, industrial, or international students). These and others pose challenges of crisis prevention and reputation protection in potentially all revenue generation domains.

The practical issue for the government is how to deal with the challenges and risks of hybrid higher education organisations. According to Jongbloed (2004), government cannot prohibit the existence of the hybrid organisation; the only option available for the government seems to be to find ways of regulating it. The regulations should ensure that the public duty (teaching and research) of the higher education organisations is not endangered and students should not become victims of revenue generation activities. The regulations should ensure that there is no unfair competition between higher education organisations and private enterprises due to cross-subsidisation. This means that there should be distinct agreements between stakeholders on the nature and proportion of the commercial activities. Higher education organisations have to be accountable for their public duties as well as their commercial activities. There is a need to have internal (organisational level) as well as external regulatory arrangements for marketisation. This would seem to argue for robust quality processes for audit and assurance and evaluation by government agencies to guarantee integrity at various levels (see Fielden 2007). A range of accountability assuring

18 Subsidise commercial activities by using public revenues that lead to charging lower prices than those of private competitors. 
mechanisms could help to achieve this: licensing requirements, academic audits, quality assurance reviews, accreditations, learning assessment tests, professional qualification exams, financial audits, performance-based budgeting, and public reports covering outputs and achievements (World Bank, 2009: 83; Materu, 2007; Goedegebuure et al. (1994); Hauptman (2007); De Boer, 2000).

\subsection{Lessons Learned}

In this chapter, we have learnt that environmental forces on higher education have led public universities to engage in revenue generation from a variety of stakeholders (Clark, 1998). Revenue generation is thus generally understood within the complex environment of public policies, and in relation to the demands which the environments place on public universities (Keast, 1995). Equally, the chapter clearly indicates that the efforts of public universities to generate revenue have been affected by internal factors (Bergmann, 1991; Gumport \& Pusser, 1995; Guskin, 1994a; Leslie, 1995). Earning their own resource goes hand in hand with university specific factors such as missions, leadership and management, human and nonhuman resources, fields of study, etc.. This implies that not all universities have the same potential to find new income sources. This chapter notes that many environmental factors connected to funding and policies, as well as university specific characteristics, can facilitate or restrict revenue generation in public universities. Establishing a balance between environmental demands and internal factors in public universities is an important issue in formulating strategies to manage the relationship between public universities and their environments. The chapter has also hinted that current research in the area of revenue generation lacks complexity in models and richness in data to help understand the interdependent processes across many different actors, agents, and higher education organisations involved in revenue generation. As a result, the subject of revenue diversification by organisations of higher learning is under theorised.

\subsection{Conclusion}

This chapter has examined the status of revenue generation in universities. The review of literature shows that all higher education systems face the challenge of designing sustainable funding models. As a result, external funds are increasingly becoming the most critical resource for universities operating at different stages of socio-economic development, in different political 
environments and at different levels of industrial and technological development. Revenue generation is now one of the financial sustainability strategies for public universities across the world. This chapter outlined that many universities around the world have already diversified their income structure to some degree. In this respect, African universities' self-generated resources on average account for approximately $28 \%$ of their recurrent budgets (World Bank, 2010:74). Many new revenue streams can draw on the instructional and research operations of the universities, as well as nonacademic operations. Usually, substantive philosophical debate needs to accompany a choice to generate revenue from academic services. No such deep debate may be required for non-academic services and products such as facility renting. In this chapter, we indicate that revenue generation is influenced by university specific factors as well as by the external conditions. Based on their specific internal and external conditions, universities create revenue generation strategies by capitalising on their strengths to use environmental opportunities and overcoming their weaknesses and environmental threats. Although revenue generation is one of the mechanisms to achieve financial sustainability, it cannot replace sufficient public funding. 


\section{Theory and Research Model}

\subsection{Introduction}

In this chapter, we will address the first research question: What theory can assist us in understanding the enablers for and barriers to revenue generation for public universities? Based on a discussion of Resource Dependence Theory (RDT) ${ }^{19}$, we will develop our theoretical framework which will help to identify enablers for and barriers to revenue generation in a university. We first introduce the major elements and concepts of RDT, and then outline the potential criticisms of the theory. Finally, we present our research model.

\subsection{Resource Dependence Theory: Main Concepts and Critiques}

RDT is characterised by an open system framework. The fundamental assumption of this perspective is that organisations require resources to survive (Pfeffer \& Salancik, 1978) and ultimately organisational actions are directed at securing survival: "The key to organizational survival is the ability to acquire and maintain resources" (Pfeffer \& Salancik, 1978: 2). For its survival, the organisation must engage in an exchange with its environment. The environment of an organisation contains scarce and valued resources essential to organisational survival. In order to acquire an uninterrupted flow of resources from the environment, the focal organisation is expected to offer acceptable products or services to the organisations it depends on. This mutual benefit creates dependencies between the organisation and its environment (Johnson, 1995). The organisation's environment encompasses different people, groups, organisations or regulations that influence organisational survival. This means that an organisation often faces conflicting demands from the environment. The challenge to the organisation is which groups to attend to and which to ignore. In short, RDT stress the dependency relations between organisations and their environment, power positions of different organisations, and strategic alternatives for those in organisational leadership (Pfeffer \& Salancik, 1978).

RDT makes a distinction between an organisation and its environment. According to Pfeffer \& Salancik (1978:36), an organisation is defined as "a

19 RDT is also referred to as the Resource Dependence Perspective (Pfeffer \& Salancik, 2003:xiii). 
coalition of groups and interests, each attempting to obtain something from the collectivity by interacting with others, and each with its own preferences and objectives". Internally, as stated in the Handbook of Theory and Research (Smart, 1999), "organisations consist of participants not organised as a unitary hierarchy or as an organic entity, but as a loosely linked coalition of shifting interest groups" (see also Cyert \& March, 1992; Pfeffer \& Salancik, 1978; Weick, 1976). Individuals and groups in an organisation are aligned by providing inducements or rewards (or satisfaction) from their resource providers, and in return for these inducements, they contribute to the mission of the organisation (Pfeffer \& Salancik, 1978). In RDT, organisations are viewed as active and they can partially determine the selection of customers (resource providers) and the terms of exchange for resources (Pfeffer \& Salancik, 1978:1).

What does the environment of an organisation mean in RDT? As described by Pfeffer \& Salancik (1978:12), the concept of environment is elusive since it includes every actor in the world which has an effect on the activities or outcomes of the focal organisation. We follow Molm's (2001:260-261) definition of actors as participants in exchange. An actor can be an individual person, a corporate group, or an organisation. In other words, 'actors' refers to both 'organisational actors' and 'organisations' as actors. However, not every actor confronting the focal organisation from the environment affects it. Nor is every actor in the environment viewed as important by the organisation. The most important environmental actors are those groups, individuals, coalitions and organisations that provide and/or govern resources necessary to an organisation, and that aim to influence an organisation and its resources (Pfeffer \& Salancik, 2003:258-259). These influential groups, individuals, coalitions and organisations could be viewed as stakeholders. According to Freeman (1984:46), a stakeholder refers to "any group or individual who can affect or is affected by the achievement of the organization's objectives" (see also Johnson \& Scholes, 1999). External stakeholders, according to Mitroff (1983), exert their influence and power over resource recipients to promote their own demands or expectations.

The environment of an organisation can be understood as a technical (task) and an institutional environment (Scott, 1992a; Scott, 2003:211). While the technical or task environment refers to sources of inputs, markets for outputs, information and know-how, competitors and regulators, the institutional environment is concerned with social \& cultural values and political environments (see also Pfeffer \& Salancik, 2003:190; Scott, 1992a). The technical environment is a place where organisations produce a product or service that is exchanged in a market and the organisations are rewarded for effective and efficient performance (Scott, 1987:126). On the other hand, the institutional 
environment shapes the structure of political, social, and economic incentives, and thereby limits the scope of strategic choices available to individuals and organisations (DiMaggio \& Powell, 1983; Scott \& Meyer, 1991). Scott argues that the technical and institutional aspects are best viewed as dimensions of environments, but not as dichotomies since the boundary between the two is blurred and one aspect does not exclude connections to the other (see also Pfeffer \& Salancik, 2003:190). The environment within which the organisation is embedded offers not only opportunities to act, but simultaneously imposes constraints on actions. Hence, the environment plays a major role in resource dependence because of its effect on the organisation.

In short, the environment is conceptualised in terms of other organisations with which the focal organization interacts for acquiring resources (Levine \& White, 1961; Thompson, 1967; Pfeffer \& Salancik, 1978). Environments define both the resources needed by organisations and the constraints which limit the options for organisational activity. In RDT, the most important environmental stakeholders are those organisations that govern resources necessary to the focal organisation (Pfeffer \& Salancik, 2003). RDT holds that those who provide resources to organisations have the capability of exercising power over resource recipients to promote their own demands or expectations. This theory argues that the environment is not only taken as a given that the focal organisation must adapt to, but the focal organisation can also try to change that environment (Pfeffer \& Salancik, 1978:222).

One of the fundamental assumptions of RDT is that no organisation is completely self-contained or in complete control of the conditions of its own existence (Pfeffer \& Salancik, 1978:19). Nor are organisations totally autonomous entities pursuing desired ends at their own discretion. For their survival, organisations must engage in exchanges and transactions with other groups or organisations in their environment (Scott, 1992; Hall 1999:279). The exchanges between the focal organisation and external stakeholders involve resources (Pfeffer \& Salancik, 1978). We follow Barney \& Arikan's (2001:138) definition of resources as the "tangible and intangible assets firms (organizations) use to conceive of and implement their strategies." These resources may be monetary, physical, human, information or involve social legitimacy, all assets that are essential for the continued survival and success of an organisation (Pfeffer \& Salancik, 1978:43; Johnson, 1995; Galskiewicz \& Marsden, 1978). Monetary resources involve financial means. Physical resources include raw materials, production equipment and infrastructural assets. Human resources refer to all the personnel in an organisation. Information involves knowledge about the environment of the focal organisation, based upon which this organisation can produce outputs desirable to other 
organisations. Legitimacy is defined as a generalised perception or assumption that the actions of an entity are desirable, proper, or appropriate within some socially constructed system of norms, values, beliefs, and definitions (Enders, Jongbloed, \& Salerno, 2008; Suchman, 1995:574).

One of the important issues in RDT is the availability and accessibility of the above-mentioned resources (see Hall, 1999). Resource providers in the environment may have the capability of exercising power over their resource recipients to enforce their demands and interests. Power is defined as a relationship among social actors in which one social actor, $\mathrm{A}$, can get another social actor, B, to do something that B would not have otherwise done (Pfeffer, 1981; Dahl, 1957; Weber, 1947). The bases for power are: coercive (force/threat), utilitarian (incentives), and normative (symbolic influences) (Etzioni, 1964). There are two dimensions of resource exchange by which resource providers may impact on organisations: the relative magnitude of exchange and the criticality of the resource to the recipient (Pfeffer \& Salancik, 1978:46). Relative magnitude is measured in terms of the share of resources provided. An organisation receiving resources from only one source will be heavily dependent upon that source, which consequently may exercise great power over the organisation. Dependence is here defined as the product of the importance of a given resource to the organisation and the extent to which it is controlled by external actors. Criticality is the degree to which the organisation may continue to function in the absence of the resource. For instance, if there is a sole provider of a critical resource, the resource recipient has little power to bargain and its dependence on the resource provider is very high. If there are several providers of a critical resource, the organisation has a choice and consequently is less dependent on one resource provider (Pfeffer \& Salancik, 1978:51-52 \&237).

For the resource recipient, it is important to know where the resources will come from and who will be determining the allocation of possible resources. The goal of the resource recipient is obtaining resources and securing the resources to survive. On the other hand, resource providers, just like the focal organisation, aim to achieve influence and control in order to further their own demands and to initiate actions for meeting their interests in return for resources (Pfeffer \& Salancik, 2003:259-261). Resource recipients are expected to offer acceptable products or services to organisations they depend on. The more attractive the resources of an organisation are to others the more demands the organisation will face, so it will be able to make others dependent on its resources. The interdependence between an organisation and its stakeholders can create problems of uncertainty or unpredictability for the organisation. The flow of resources may at times be unpredictable or might not be continually 
available at all (Johnson, 1995; Scott, 1992b). The number of transaction partners could also vary over time. The focal organisation might be facing various opportunities and threats from its environment. In the higher education landscape, for example, decreased government support for students, devolution or decentralisation of responsibility to the university level, international competition (e.g. for funds, faculty, and students), governmental regulations to improve quality in teaching and learning, changing student demographics, and new technologies can create a new environment for universities (Gumport \& Sporn, 1999). This new environment may be pushed by the economic, political, and technological forces of the wider societal environment, and may signal a need for adaption for a HEI.

In an effort to meet these environmental demands, organisations work to achieve two related objectives: 1 ) acquiring resources while minimising their dependence on other organisations, and 2) controlling resources to maximise the dependence of other organisations on themselves (Pfeffer and Salancik, 1978). In either case, organisations have an interest in reducing uncertainty in their dependencies on other organisations.

For any given organisation to be effective in securing resources, it will need to produce acceptable outcomes for the organisations it depends upon. This will persuade organisations in the environment of the focal organisation to dispense resources to the focal organisation. The selection of customers and the terms of exchange are partly determined by the focal organisation. RDT assumes that organisational decision makers have a certain autonomy (Hall, 1999: 281) or discretion that may permit the organisation to adapt to contingencies or to alter conditions (Pfeffer \& Salancik, 1978:271). Organisations will attempt to obtain more power and autonomy, thereby limiting their dependencies and reducing uncertainty regarding external pressures and demands (Pfeffer \& Salancik, 1978; Aldrich \& Pfeffer, 1975; Thompson, 1967; Johnson, 1997:7). By autonomy, we mean an organisation's capacity to determine its own actions through independent choice within a system (Ballou, 1998). "Organizations seek to avoid dependencies and external control and, at the same time, to shape their own contexts and retain their autonomy for independent action" (Pfeffer \& Salancik, 2003:16). Organisational dependence is subject to the degree of discretion the organisation has over the resources generated in the exchange relations with its environment.

According to Pfeffer \& Salancik (1978), organisations will develop a strategy that will secure the largest amount of resources for the longest time possible. In doing so, organisations aim to secure a steady flow of resources, anticipate developments in the environment, respond to threats and opportunities in their 
environment, expand their resource base, and decrease uncertainty regarding the acquisition of resources. An organisation's dependence on its environment is shaped by its adaption strategies as well as by the demands and expectations of other organisations in its environment. RDT defines adaptation as strategies to deal with external constraints. To set strategies for adaptation, good information about organisation's environment (the context) will be required. This can be made available by scanning the environment. Pfeffer and Salancik suggest two adaptive responses to compensate for dependence (see Oliver, 1991 for more strategies). On the one hand, organisations can adapt and change to fit environmental requirements. On the other hand, organisations can attempt to alter the environment so that it fits the organisation's capabilities. Organisations are therefore viewed as active (Oliver, 1991). One of the main contributions of RDT is a detailed analysis of adaptation strategies. Pfeffer \& Salancik (1978:262268) suggest a form of leadership that includes symbolic, responsive, and discretionary features in this regard (see also Aldrich, 1979). In the symbolic role, the role of management derives from a belief in personal causation as opposed to environmental determinism.

In the responsive role, the administrators (leaders) respond to the demands and constraints confronting the organisation. Pfeffer \& Salancik (1978:266) state, "The most appropriate activity of the responsive manager is not developing appropriate actions but deciding which demands to heed and which to reject". Organisational decision makers try to acquire and process information about the environment and the possible consequences of alternative actions with the goal of finding the most favourable and profitable solution prior to decision making. Since administrators can make choices about the environment based on information obtained from environmental scanning, their decisions may be more suitable for given environments. Organisational leaders or decisionmakers may also take actions to modify or change the environment to which their organisation responds (ibid, p267). Organisations may attempt to manipulate the environment to their own advantage (Pfeffer \& Salancik, 1978:279-280). "This discretionary role of management is involved when we think of organizations merging, lobbying, co-opting, and doing all the various things that alter the interdependencies confronted by the organization" (Ibid p267). It also includes engaging in political activities to influence matters such as regulations, the use of interlocking directors, joint ventures, normative constraints on activity and coordination achieved through more centralised structures or through cooperation or the movement of personnel among organisations (Pfeffer \& Salancik, 1978:183).

Given these strategies for dealing with the environment, RDT also refers to certain limitations on choices. There may be legal, financial, or economic 
barriers that prevent an organisation from moving into a particular area, putting limitations on the choice of actions. Pfeffer and Salancik (2003) have noticed that the view that organisations are constrained by their political, legal, economic and social environments is only partially correct. For instance, governments can supply money to organisations, either through the purchase of goods and services or through the provision of various grants and cash subsidies. On the other hand, they can influence the organisation through legal mechanisms, protecting markets from foreign competition or protecting customers from unfair prices, etc. Internally, organisations and people within the organisation might be reluctant to change their behaviour because they prefer the status quo. More importantly, past commitments may include investment in equipment and personnel that cannot be changed overnight. Therefore, investments in equipment and personnel can lead to behaviour which deviates from the optimal behaviour that organisations in the environment would prefer. If the organisation wants to influence the environment, it has to have the resources and capacity for that in terms of size, prestige, (man) power, or money.

Like any organisational theory, RDT has its critics. First, RDT has been criticised for perceiving organisations as rational actors, which maximise their resources. In other words, it is criticised for overlooking the unconscious imitation of behaviour by organisations and normatively based conformity that mitigates or limits autonomous decision-making (Tolbert \& Zucker, 1996:177). However, we argue that RDT also offers insights how organisations act to achieve social legitimacy through a process involving identification with other legitimate social actors or through normative based conformity (Pfeffer \& Salancik, 1978). Second, some criticise RDT for paying little attention to the internal aspects of an organisation (Donaldson, 1995:161). For instance, Johnson (1995) pointed out that RDT is insufficient to explain power relations within organisations. He argues that the theory pays little (or no) attention to middle or operational levels of management and concentrates on the strategic aspects of upper-level management (see also Hall, 1999). In order to deal with this criticism, we broadly define management as the structure and processes within universities for implementing and executing decisions made by academic governance. In our research, decision makers embrace central managerial groups, middle management, and academic departments.We believe that, through the inclusion of all administrative tiers, this comprehensive definition permits a more comprehensive perspective on the role of management. 


\subsection{Application of Resource Dependence Theory}

We are now in a position to apply RDT to our research. RDT offers explanations of the relationship between a university as an organisation and its environment. Seen through the lens of RDT, for its survival a university must engage in an exchange with the environment. An organisational environment is critical in providing a variety of resources such as finance, material resources, information, personnel, and legitimacy to a university for its survival. The environment will, in return for these resources, try to limit the choices and actions of a resource recipient university. The environment thus plays a major role in resource dependence because of its effect on the university. Yet, a university is viewed as an active organisation (Oliver, 1991) that can partly determine the selection of stakeholders and the terms of exchange. The focal university can also work to reduce uncertainty and ensure survival by maximising the dependence of other environmental actors on themselves. Accordingly, the environment may consume universities' outputs like academic degrees and other educational and research services. For instance, the fact that a university degree is needed to practise certain professions can be seen as a control over the environment. In short, the university's need to acquire resources and the environment's demands for specific products and services from a university create interdependence between these actors. The university and its environment are thus reciprocally interdependent. We will analyse a university-environment relationship in this research in order to identify the enablers for and barriers to revenue generation for a university.

The university-environment exchange relations may be influenced and shaped by a variety of external and university specific factors (Gumport \& Sporn, 1999). Our analyses of the external environment will consider a thorough assessment of the general and task environments in which the focal university operates (Aldrich, 1979; Pfeffer \& Salancik, 1978; Scott, 1992b). While the general environment consists of broad forces that affect all universities, the task environment includes specific external features that influence a particular university (Oliver, 1991; Tolbert, 1985; Meyer \& Scott, 1983). In this environment, a multitude of demands may be present which potentially enable or obstruct the exchange relationships of a university with its environment. RDT is therefore useful to examine how the environment plays a role in the focal university's resource dependencies. Additionally, we seek to examine the strengths and weakness of a university that shape the relationship it maintains with other actors in the environment. In short, RDT focuses on how particular social actors within the environment may exercise power over a university to enforce their demands and the ways in which the university can respond to those environmental actors. Both environmental demands and internal aspects 
(characteristics) of a university can enable or erect barriers to revenue generation strategies and activities that the university pursues.

Our discussion of RDT helps us to identify the main building blocks for the research model (see Figure 3.1 below). The research model distinguishes between the university (box I), organisational environment (box II), the interaction between box I and box II as captured by a bi-directional relationship, the link between the interaction and revenue generation activity, which is shown by a scalar, and finally revenue generation activity (box III). The university's strategies and revenue generation activity make up the dependent variables. Although the strategies and the revenue generation activity are part of the university, they are shown separately in the model for analysis purpose only. Other potential relationships, the impact of revenue generation activities on the organisational environment and the university itself are shown as trust and learning respectively. These are indicated by dashed lines. Although in our research we recognise the relationships shown by the dashed or dotted lines, we have restricted ourselves to studying only the main arrows (i.e. the solid ones). Hence, the dotted lines portray relationships outside the scope of this study.

Figure 3-1 Research Model

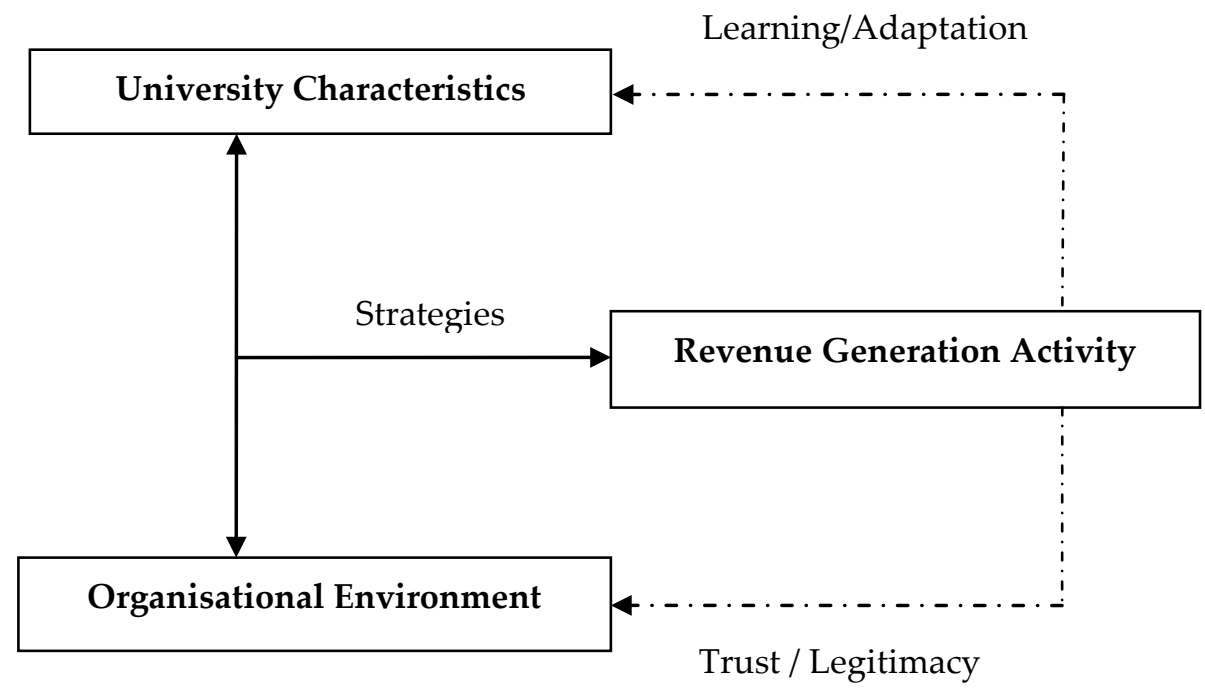




\subsubsection{University Characteristics}

The first component of our model is a university. There is currently no single universally accepted definition of a university (OECD, 2005). The term university carries with it varying connotations, depending on the specific educational system in which it is based. We thereby offer this working definition. A university is defined as "a complex higher education organisation that is formally authorised by its national government to offer and confer advanced degrees." This study is only concerned with public universities. A public university is here understood as a university that is legally recognised as a public university by its government(s). A public university may have public ownership, and it may be predominantly funded by public means through government (see Geiger, 1991; Levy, 1986a). Private ${ }^{20}$ universities are thus beyond the scope of this study. For simplicity, we refer to a "public university" or "public universities" as a "university" or "universities" throughout this study. A few characteristics of a university such as missions, internal governance, leadership and the academic core are discussed in this section.

\subsubsection{Mission of a University}

The starting point in an organisation is its mission statement. The mission statement provides a springboard for establishing more specific objectives and strategies. The performance of the university has to be assessed against its mission. In the simplest language, the mission highlights the actual activity that lies at the core of university life. The mission thus appears to be something that the university is collectively striving to achieve or claim as a legitimate objective. The widely accepted core mission of a university is "education, research, and service" (Clark, 1983; Massy, 2003:12-15; Etzkowitz et al., 2000; Etzkowitz 2003). Through education, universities are preparing generations of students to become productive members of the workforce. Through research, they create valuable knowledge that serves as the foundation for many major technological advances. Universities can also disseminate knowledge that can be applied to the problems of society and economy (engagement). These core missions represent the university's over-riding purpose, which provides direction and guidance in the process of decision-making and also in formulating and implementing strategies. In other words, the mission statement ensures organisation members are less likely drift towards unnecessary

20 Private universities further divide into not-for-profit and for-profit universities. While not-for-profit may be church-sponsored or have charitable foundation status, for-profit universities tend to rely principally on tuition fees to sustain themselves. 
activities and more likely to concentrate on those actions that contribute to the overall effectiveness of the organisation (Shattock, 2003). The mission statement generally describes how and in which aspects those outside the university might work with those inside it. The demands of stakeholders will rain upon a university vis-à-vis its core missions; viz., teaching, research and community services. All university stakeholders will, at least theoretically, subscribe to the realisation of the mission. Functioning as per the core mission will thus allow a university to garner and sustain organisational legitimacy.

Universities may, however, follow different traditions that shape their core missions. From 1800 to the present, we can see the development of three main academic traditions: the German, the French and the British, while an American perspective is also relevant since US universities provide the important bridging of European and American developments (Jónasson, 2008; see Enders, 2007). The German tradition, or the Humboldtian tradition (after Wilhelm von Humboldt), set the stage for the research-teaching nexus that we now take for granted as a fundamental characteristic of the university. In French, or Napoleonic, tradition the role of a university focuses on the teaching mission. In the British, or Newman, perspective the key role of a university is to offer the most suitable environment for learning, by guaranteeing close interaction between students and tutors, providing an education that favours the formation of the student's character and mind so that he or she Master's the intelligence processes needed for a successful life. In this tradition, students are not trained only for a narrow profession. The American tradition can be regarded as merging German and British perspectives and ideas, with a significant addition of the 'land-grant' universities created in the second half of the 19th century. In this perspective, a university makes a clear distinction between undergraduate and graduate education (Newman inspiring undergraduate studies and Humboldt the graduate programmes). Thus, from early on, education, research and application are seen in the US as distinct university roles, which formalise education, research, and service as the core missions of a university (Clark, 1983).

Despite the obvious and important differences between the four university models, they have a strong family resemblance. Many universities that emerged from both Humboldtian and Napoleonic traditions are now given a role in nation building, a function that has evolved towards economic development. However, we assert that the four models just outlined still influence the extent to which a given university involves itself in a certain mission. Some universities might concentrate on research while others hardly do any at all. Even within the research mission, some universities focus on knowledge for its own sake (e.g. basic research), while others focus on applied knowledge. The 
same holds true for the teaching side. Some universities give many advanced degrees and others concentrate almost completely on the first major degrees. Some universities still operate in a supply-driven fashion, dominated by the disciplines, while others are more led by external demands. The inclusion of the third mission, as in the USA perspective, enhances linkages between universities and their surrounding regions and communities. Generally, the more the university engages in various missions, the more it can meet the demands and expectations of its diverse stakeholders. Aligning the missions of a university with the demands of external stakeholders is thus crucial for revenue generation.

\subsubsection{Internal Governance of a University}

A university's governance structures are of paramount importance in understanding how internal powers and interests may influence organisational responses to external pressures (Stensaker, 2004; Covalski \& Dirsmith, 1988). A university's governance arrangements can be understood as "the formal and informal arrangements or structures that allow universities to make decisions and take action" (Sporn, 2001). Governance means processes aimed at coordination, stability and structure in a world of actors of different sizes, power and resources. Internal governance refers to the institutional arrangements within universities (e.g. lines of authority, decision-making processes, financing, and staffing). In the higher education landscape, the internal governance of a university embraces the roles and responsibilities of actors like governing boards, university presidents, senates, academic deans, department chairs, staff and usually some form of student representative organisation. The internal governance of a university can often be described as influenced by the steering role of states. The extent to which universities have autonomy over their internal governance arrangements is critically dependent upon the attitudes which governments may take to their governance. Maassen \& van Vught (1994) propose two very influential models regarding the role of the government in higher education governance: state control (central direct detailed regulation of all key aspects) and state supervision (steering at arm's length, assuring quality and accountability) (De Boer, 2000).

We can also conceptualise models of institutional governance in terms of academic traditions or Clark's classic 'triangle of coordination' (Clark, 1983). This may offer a good starting point for looking at the internal governance of universities. Based on Clark's triangle of coordination, namely, the state, the market, and the academic oligarchy, four alternative models of institutional governance can be identified: collegial, bureaucratic, market, and 
entrepreneurial models (Clark, 1979; Clark, 1998; McNay, 1999; Mintzberg, 1979; de Boer \& Goedegebuure, 2009). These models depict the degree to which the authority, power and responsibility for decision-making are diffused within a university (Neave, 1998; Bauer et al., 2006). Firstly, the collegial model can be illustrated by the classic concepts of the German and English traditions. This model seeks to ensure freedom in research and training in order to protect the moral and intellectual autonomy of academia from political and economic powers. The primary source of authority is professional expertise (Mintzberg 1983) which is often built on the active participation of members of the academic community (Berdahl 1999; Jónasson, 2008). Accordingly, a decisive role is given to the academia, as universities are 'bottom-heavy' organisations (Clark, 1983; Berdahl 1999). The possible drawbacks of this model are that its great emphasis on the protection of academic freedom may negatively influence collective action at a university level. To put it another way, the collegial model leaves a weak role for leadership (Cohen \& March, 1974) and a university is therefore less responsive to the public interest in general and to the demands of its external stakeholders in particular. In the bureaucratic coordination model, fragmented parts of a university are organised within a hierarchy of decisionmaking bodies through common regulations and procedures (McNay, 1999). This appears to coincide with the Napoleonic university model (Jónasson, 2008) and may be insufficiently receptive to the needs of academics for creativity and flexibility (Berdahl, 1999). The market coordination model emphasises freedom of choice for personnel and clientele and thereby indirectly promotes flexibility and adaptability. This model leaves weak public control over universities. Finally, the entrepreneurial university model is an intermediate coordination between the collegial and market models (Clark, 1998). It looks more like the USA perspective (Jónasson, 2008).

The traditional models of university governance - with collegial decisionmaking structures - have increasingly been criticised by stakeholders. They are considered to have critical weaknesses and be incompatible with changing environments. Many scholars argue that the traditional collegial authority structures and decision-making procedures are too slow to respond to new challenges, and not flexible enough in the changing environment of higher education (Clark, 1998; Considine \& Marginson, 2000; Sporn, 1999). Managerialism has therefore been introduced into the higher education landscape. Several pieces of research analyse changes in the internal governance of a university and the rise of managerialism (Amaral et al., 2002; Goedegebuure et al., 1994).This shift is mainly due to the new competitive environment faced by universities throughout the world, which has required them to publically demonstrate their efficiency and effectiveness (Amaral et al., 
2002). Supporters of the management oriented governance concept argue that decisions made by individuals who can be responsible for any actions are a necessary precondition for autonomy and effective long-term resource allocation. This managerialism emphasises an executive and strong leadership at the expense of the professional role in decision-making. It stresses 'economy, efficiency, and effectiveness' (Currie et al., 2003:98) in response to the ever more targeted nature of public funding as well as increased university autonomy and accountability. More efficient and effective university internal governance and organisation structures are widely recommended (Lapworth, 2004; Middlehurst, 2004; Salter, 2004; Jacobs \& vander Ploeg, 2006). Internally however, a university consists of individual actors or departments as actors not organised as a unitary hierarchy or an organic entity, but as a loosely linked group, with individuals often highly committed to their profession than to the overall goals of that particular university (Clark, 1983; Dill, 2007). Each department is a world in itself. Key internal stakeholders, particularly academic staff, seek appropriate representation on faculty boards or senates or in central administration (Shattock, 2003). Due to the gap between administrative and academic values, the top-down approach or new managerialism might receive inadequate support from teachers and researchers who commonly advocate freedom in education and research.

In many countries, an autonomous and self-regulating institution with strong leaders is the ideal model of institutional governance (Clark, 1998; Sporn, 1999). It is more the entrepreneurial university model, which combines the traditional academic model of collective collegial decision-making with market coordination in terms of stronger institutional leadership. In other words, responding to the multiple and intricate demands for university education and research, as well as regional and international engagement, requires academic participation in major decision-making related to the core missions of a university and strong institutional leadership for effective and efficient coordination. Decentralisation of power including reduction of hierarchies, introduction of market mechanisms, reduction of regulation, and emphasis on the principles of efficiency and effectiveness become evident in these institutions (Gumport \& Pusser, 1995; Gumport \& Sporn, 1999). It is assumed that a high degree of autonomy, responsibility and accountability results in changes in the steering modalities of universities, making internal actors more responsive to the demands of stakeholders (Mets \& Peterson, 1987). In aligning the immediate interests of particular internal actors with the overall university missions, emphasis is placed on various steering tools such as regulations, incentives, or control mechanisms. 
The steering mechanisms include internal resource allocation mechanisms (Massy, 1996), human resource policies (OECD, 2008), and the reward systems (Kirby, 2006). The internal resource allocation mechanisms refer to how money is internally allocated to cost centres. There are different approaches to this: line item budgeting, performance responsibility budgeting, revenue responsibility budgeting, and value responsibility budgeting, among others (Massy, 1996). In terms of human resource policies, there are two key issues: ceilings on the number of staff and the characteristics of employment contracts. The former is about who (e.g. centre, faculty or department) determines the number of staff employed. The latter refers to qualification requirements, salary scales, tenure, working hours, performance measurement, and terms of promotion. Additionally, based on objective evaluation mechanisms (e.g. regulation on entrepreneurial behaviour), monetary and non-monetary rewards are provided to individual staff and/or faculties or departments. We argue that the steering tools used for coordination of a university's overall tasks university may enable actors to or obstruct them from moving into a particular area by putting limitations on the choice of actions.

\subsubsection{Leadership of a University}

According to Mintzberg (1983), a university's behaviour can be influenced by the actions of various internal players who seek to control its decisions and actions. The internal actors may include top management (presidents), middle management (deans), operational level management (department chairs), administrative officers (supervisors, directors), academic staff, support staff, and students. These actors do have certain powers ${ }^{21}$ authority (see Thompson, 1995:170 for types of power; French \& Raven, 1960) and autonomy by which they seek to produce and influence decisions on the university issues. For example, using their expert power, researchers and teachers want to maximise their degree of freedom of research and teaching and opportunities for free decision making. This implies that autonomy of the academic disciplines often makes top-down approaches difficult. Some key internal actors can also define the general framework of rules and internal regulations for determining the detailed mechanisms of management of education and research including human and financial management. According to Gornitzka \& Maassen (1998:16), of all internal actors, the leadership plays the major role in how a given university meets external demands and expectations (see Clark, 1998 for the strengthened steering core). The leadership refers to the structure (positions,

21 Reward, coercive, legitimate, charismatic or personal, information, connection and expert power. 
offices, and formal roles) and processes through which individuals seek to influence decisions (Sporn, 2001). Leadership cannot be restricted to a single post or even to a team or subset of colleagues in the centre, but rather is dispersed around a university (Shattock, 2003:92).The task of the leadership is mainly to influence and persuade others in a desired direction, usually towards the accomplishment of a specific task or performance goal (Nadler \& Tushman, 1997). In our view, leadership is inclusive of upper, middle and operational level management. This would include departmental chairs, deans, administrative directors, and presidents (Shattock, 2003).

In a university, differentiation and integration can help to understand university behaviour in general and leadership roles in particular (Clark, 1995; Dill, 1997a). According to Dill (1992a:16), "As specialization and differentiation are the universal characteristics of academic organization, so integration is the universal challenge of academic administration". In this regard, universities are defined as loosely coupled systems (Weick, 1976) or organised anarchies (Cohen \& March, 1974). This differentiation or loose coupling can help the university to create the potential for survival through innovations by independent and highly skilled units that meet the demands of its various stakeholders simultaneously. And yet, the importance of integration through collaboration and cooperation among units and individual members or actors intensifies as the organisational environment forces a university to meet the demands of key stakeholders such as regulatory agencies that seek to increase quality, improve effectiveness, lower costs, and provide access. A compelling rationale for the management of these challenges positions the leadership in the central mediating role, determining the potential costs and benefits of any course of action. The leadership positions itself in an expanded role as managers having authority over a broader domain of organisational decisionmaking, as well as in representing the organisation's purposes and priorities to its environment. The leadership becomes more important because they are mainly responsible for the development and implementation of strategies that help to reduce dependency relationships with the environment. Accordingly, the leadership plays two key roles. On the one hand, they serve as a buffer between the environment and the core activities of the university. On the other hand, they try to integrate the differentiated units through various mechanisms (e.g. policies, resource allocation mechanisms, reward systems) in order to trigger adequate responses from internal actors (Maassen \& Potman, 1990).

Building on our review of RDT, the leadership may be seen as an active agent positioning the university in a struggle for survival. It may spend its resources scanning, forecasting, and repositioning the university within a changing environment. Using power vested upon them, leaders represent and act on the 
behalf of their organisations. They use their power to get other internal actors do something that these actors would not have otherwise done. This power has granted them a unique position to persuade other actors to move towards desired goals. The bases for power are: coercive (force/threat), utilitarian (incentives), and normative (symbolic influences). In exercising their coercive power, the leadership will have to outline acceptable and unacceptable behaviour. They will have to have means for identifying non-compliance and often will use coercive forces to achieve compliance. They will display the ability to install or drop or change organisational policies (Davies, 2001) for realising certain goals, i.e., generating revenues in our case. Leaders can also emphasise financial incentives and rewards for promoting a particular agenda. Internal resource allocation mechanisms are used as an instrument for steering a university towards certain goals. With regard to normative power, the norms of academic professionalism, for instance, can be considered as a means of steering a university towards a desired direction. The ethical norms of the professoriate ensure that academics spend their time and attention maintaining academic standards and quality.

Given the power bases outlined above, the leadership may exercise strategic choice within the constraints imposed by their organisational environment but also with the enablement this environment provides (Gornitzka \& Maassen, 1998). As universities increasingly need to demonstrate their effectiveness at meeting the demands of various stakeholders, the need for strong institutional leadership emerges (Lapworth, 2004; Stamoulas, 2006). Clark (1998), the most cited writer on the entrepreneurial university, advocates a "strengthened steering core" that stretches from highly personal leadership to highly collective or group-based leadership (see Johnstone et al., 1998; Sporn, 1999). This strong university leadership embraces central managerial groups (e.g. presidents), deans, and some department chairs as well as senior administrators like the registrar, director of finance, director of human resource management, and director of estates (Shattock, 2003). As Askling et al., (1999) put it, "universities can no longer afford amateurish leadership in accordance with the traditional collegial model." Burton Clark, however, warns against the dictator, the tyrant, the authoritarian leadership figure who cannot be a permanent feature in entrepreneurial universities.

A need for revenue generation from diverse stakeholders with different demands may bring a huge amount of additional administrative work at all levels within a university. Such an environment requires managerial skills among universities' leaders, to make quick decisions and implement them flexibly (Coaldrake \& Stedman, 1999). This requirement is often apparent for a wide range of specialist skills in areas such as financial management, 
marketing, strategic planning, and human resource management. In addition, managers at different levels are being asked to become more professional, through more vigilant leadership (Gumport \& Sporn, 1999). Accordingly, several scholars argue for professionalisation of university management and leadership (Mintzberg, 1983; Clark, 1998; Cloete \& Maassen, 2006; Sporn, 200). Another significant issue in relation to revenue generation is the commitment of the leadership. According to Massy (1996:185), when moving to a new form of revenue, commitment at the top is vital. The leadership can speak and act for the university as a whole in repositioning it within resource dependencies. As an integral part of its commitments, the leadership will display the ability to install or drop or change organisational policies (Davies, 2001) that may inhibit revenue generation strategies and activities. This commitment will be evident in terms of resource allocation (e.g. money, time, infrastructure, and staff). It can also be shown in the degree of attention paid to revenue generation in a university's strategic and operational plans and the hierarchical positions of revenue generation offices and their accountability (Allison \& Zelikow, 1999: 143)

\subsubsection{Academic and Administrative Support Staff}

Universities are highly specialised human-intensive institutions that are organised according to the structures of academic disciplines (Becher \& Kogan, 1992; Becher \& Trower, 2001; Gibbons, 1998). Academic departments are the operating base of a university where teaching, research, and community services are done (Clark, 1998). Academic departments hold together both social sciences (e.g. law and theology), which were the main focus during the creation of universities in the Middle Ages (Clark, 1983), and natural sciences ${ }^{22}$, that emerged as disciplines within universities around 600 years after they were first founded (Bernal, 1969). Scholars argue that the advent of natural sciences in universities enhanced their economic significance and social importance (Jónasson, 2008). As noted by Clark (1998:141), science and technology departments commonly become revenue generation areas (entrepreneurial) first and most fully. Social science departments, aside from economic and business, find revenue generation difficult and commonly lag behind. Gibbons et al. (1994) argue that, be it in social science or natural science, academic departments are configured around traditional disciplines (Mode1) and some

22 Germany was the first of the European states to assimilate science into the universities. The fruits of this were seen already by the middle of the 19th century, in terms of trained scientists, texts and apparatus. 
interdisciplinary and multidisciplinary fields (Mode2). Most universities are still organised according to Mode 1, but these structures are being complemented or to some extent changed to Mode 2. The main change is that knowledge production and dissemination, research and teaching, involve interaction with a variety of other knowledge producers (specialists) working in teams on problems in a complex applications oriented environment.

The creation and dissemination of knowledge requires people who are expert at configuring knowledge relevant to a wide range of contexts (Gibbons et al., 1994). According to Spaapen et al., (2007) and Marginson (2007), an important element for creating and disseminating good quality useful knowledge may to a large extent be dependent on knowledge embedded in people (academic staff, researchers, etc.), alongside other inputs such as technologies, books and networks. A university will have to acquire these resources to achieve its chosen strategies (Dill, 2003; Mahoney, 1995). The presence of a skilled workforce is one of the critical factors of production in any organisation. Many scholars argue that the backbone of the university's business is its academic core (Clark, 1998; CHET, 2011; Massy, 2003; Lynton, 1995) and everything else, like administrative functions, laboratories, and libraries, exists to assist the academics in their work (see Shattock, 2003). As Beyer says (1982:171), "it is because faculty members meet several crucial needs of universities that universities value their services and are highly dependent on them." Similarly, Shattock (2003) states that the performance of a university depends strongly on intellectual ability, technical training, individual creativity, and the motivation of academia. The overall reputation and status of a university may be dependent on the publically acknowledged qualifications and expertise of its academics (Enders, 2007). The strength of the academic core is thus a crucial ingredient for meeting demands and expectations of a variety of stakeholders (Dill, 2003:143; Shattock, 2003:121, citing Fombrun, 1996:73).

In particular, academics holding higher scientific degrees, well committed and adequately compensated, may be considered as the heart of the university without whom the university cannot function properly (Altbach, 1991). Thus, no university can be fully successful without a strong academic core since the academic core has the dominant influence on the quality of teaching and research (CHET, 2011; Clark, 1998). In fact, organisations do not interact with other organisations in the strict meaning of the word, but individuals with the required knowledge and skills interact with those of another organisation for acquiring resources. According to Clark (1998), it is the heart land, or the academic core in the language of CHET (2011), that will have to be strong enough to interact with external stakeholders to promote new programmes and relationships promoting third stream income (see CHET, 2011). 


\subsubsection{Organisational Environment}

An organisational environment consists of an infinite set of elements outside the boundaries of a university. Many organisations, groups and associations of individuals, and broad forces in the organisational environment may affect a university's ability to acquire and maintain resources (Dill \& Sporn, 1995a; Gumport \& Pusser, 1997; see Osborn, 1971, for a more complete discussion). The survival of universities, therefore, depends on responsiveness to multiple external demands and expectations. Since universities operate in an environment that is not only highly institutionalised but also somewhat competitive, we will consider many dimensions of the organisational environment in our analysis (see Scott, 1992a; Scott, 2003:211). Universities are often subject to intense regulation by governments and under strong market competition. The analysis of organisational environment will begin with an assessment of the general environment followed by the task environment.

\subsubsection{General or Societal Environment}

As universities operate in a particular environment, and are an integral part of a national economy, so their operation and performance are influenced by a variety of external conditions. The principal features of the general or societal environment impacting on universities include social, political, economic, and technological trends and events (see Sporn, 2001; Duczmal, 2006; Gulbrandsen \& Smeby, 2005; Trow, 1973; Gumport \& Sporn, 1999; Massy, 1996). Each set of forces can enable or obstruct the revenue generation strategies and activities of a university.

Social trends mainly relate to demographic patterns that might determine the number and types of student body in universities (OECD, 2008). While some countries (particularly developing countries) face the situation of growing demand for university education due to a rapid expansion in their youth populations, others (mostly developed countries) face decreases in domestic enrolments. An additional social factor may be linked to the creation of demand for various types of education from different types of students (e.g. young, mature, etc.). These scenarios will affect the demand for university education.

Political trends are the system of authority that governs a given country or geographic region in which the university is located. Political parties and public decision-making bodies can influence the role of universities in national development (CHET, 2011). For example, Enders (2007) points out that dictatorial and totalitarian political systems can restrict teaching and research (see Court, 1999). Likewise, Duczmal (2006) suggests that the growth of 
universities is linked to the rise of political democracy, while more authoritarian regimes and less representative policies block higher education growth. Whether or not universities have a role in national development strategies or polices may enable or obstruct their revenue generation capacity (CHET, 2011:13-20).

Economic trends can affect the financial stability of universities. Like any other public organisation, universities have to obtain a certain share of GDP in order to survive. While recessions generally constrain state budgets and generate pressures likely to reduce appropriations to universities, economic growth may lead to substantial funding increases from governments. The overall growth of the national economy will generally enable universities to generate additional revenue from the environment (Court, 1999). Studies show that an increase in GDP per capita increases the private rate of return for higher education graduates (OECD, 1993, 1998), which in turn influences the demands for university education. Economic trends also include unemployment levels for university graduates, opportunities for employment for those without university level education, the economic structure, and even faculty and staff labour markets that affect a given university's responses to external demands and expectations (Dill, 2003). For example, industrialism and other forms of modern economic growth are seen as requiring job skills of an increasing range and complexity (Ramirez, Riddle, 1991).

The technological revolution currently underway entails significant changes for many universities and it can be considered as a major trigger for changes. Information technology and modern telecommunication including computers, accompanied by increasingly sophisticated software will have a significant impact on how students learn, how professors teach and conduct research, and how administrators manage the university (Chun \& Gumport, 1999). In other words, they alter and enlarge the traditional tasks of teaching and research. They change methods of cooperation within and between universities and with other organisations and overall governance modes, as well as the way the individual university is operated and managed.

In short, trends in society, politics, the economy, and technology are translated into environmental demands for universities, and thereby enable or obstruct the structure and growth of the university.

\subsubsection{Task or Technical Environment}

A task environment is understood as a place where the products or services (i.e. academic degrees and other educational and research services) of a university are exchanged in a market such that the university is rewarded for effective and 
efficient control of its work process and thereby goal attainment (Meyer \& Scott, 1983:140; Dill, 1958:410). As no university is self-sufficient, it is forced to enter into exchange relations with other actors, entities, and organisations in its task environment to acquire resources. In seeking resources, a university engages in transactions with various organisations and groups of individuals in its task environment (Jacobs, 1974; Gumport \& Sporn, 1999). The task environment consists of regulatory agencies, key suppliers, product consumers (customers), and competitors (Hatch, 1997:65; Dill, 1958:424) who can all be conceptualised as stakeholders (See Enders, Jongbloed, Jongbloed, \& Salerno, 2008:7). In this section, we will firstly discuss the demands and (potential) resources of a university's external stakeholders, then address external regulations and incentives and the degree of rivalry in the task environment.

\subsection{Demands and (potential) resources of Stakeholders}

According to RDT, the survival of a university depends on its responsiveness to external demands from multiple stakeholders. A stakeholder is defined as "any group or individual who can affect or is affected by the achievement of the firm's objectives"' (Freeman 1984: 16). Since we are here dealing with the organisational environment, our discussions focus only on external stakeholders. The external stakeholders of a university consist of a variety of organisations and groups of individuals that may influence or be influenced by the realisation of the university's missions. They include students, governments, donors, industrial firms, buffer organisations, regional and local communities, and NGOs, among others (see Enders, Jongbloed, \& Salerno, 2008 for the complete list of stakeholders). Government bodies include the Ministry of Education and Ministry of Finance (or buffer organisation) that supervise and allocate funds, as well as quality assurance agencies that are crucial in providing assessments of the quality of education and research performed by a university. Donors are bilateral countries or multilateral organisations that mostly offer donations in the form of grants and or loans. Non-profit organisations and private enterprises are organisations with whom a university engages in education and research activities. These organisations can be industrial firms or public organisations including regional and local communities that are interested in the knowledge and services of a university. Universities can interact with them on areas like health, industry, culture, territorial development as well as training and research. These stakeholders possess resources vital for the survival of a university. Resources may include monetary, physical, human, information and social legitimacy that are essential for the continued survival and success of a university (Pfeffer \& Salancik, 1978:43; Galskiewicz \& Marsden, 1978; Barney \& Arikan, 2001:138). 
These stakeholders are, like the university itself, interest driven (Oliver, 1991). As new stakeholders contribute, their demands and expectations of what they need to get in return readily become new constraints (Clark, 1998). They will expect something, for instance, in terms of the economic and social functions it carries out, or services in terms of teaching, research and knowledge transfer (Enders, Jongbloed, \& Salerno, 2008).

RDT assumes that a university is able to know the demands of its stakeholders and can draw the line between what it is willing to do or not do to meet those demands. Governments provide resources to higher education to protect and benefit the public at large through equality of opportunity, income and wealth redistribution, protecting the interests of future generations, and innovation for promoting wider social goals or national interests (Jongbloed, 2004:91-92; see Begg et al., 1991:50-55). Local and regional governments can support a university in serving the needs of their territories (Goddard \& Puukka, 2008) in supply of human capital to the regional or local labour market, in provision of technology and research outputs, and in contributions to socio-cultural and policy development (Castells, 1996; Etzkowitz \& Leydesdorff 1997; Enders \& Fulton 2002). Students and their parents can also spend money on education according to their assessment of private benefits, their prosperity, and their demands (Vossensteyn, 2005). Students want good, solid teaching that provides them with competence and knowledge, which will be of use when entering working life. Industrial firms will be influenced mainly by estimates of economic returns that are linked to their market incentives to engage in new technologies and apply new scientific knowledge (OECD, 2002; Clark, 2001). They will interact with at nearby universities when seeking advice on matters of technological and organisational innovation, conducting contract and joint research, and seeking training on courses customised for the needs of industry (Gulbrandsen \& Smeby, 2005; Jongbloed \& Van der Sijde 2008). Donors can ask for certain education and research services, require performance reports, or generally ask universities to meet the conditionality associated with the resources provided (World Bank, 2010; Teshome, 2005; Johnstone, 1998; Liu, 2007).

Since these stakeholders value the attributes of the products or services differently, the focal university may find itself in a jungle of conflicting requirements (Gornitzka, 1999). However, the focal university will prioritise the claims of its crucial stakeholders over those of other competing interests. According to RDT, the most important stakeholders engage in a relatively high magnitude of exchange and/or provide critical resources to the university (Pfeffer \& Salancik, 1978:46). Relative magnitude is measured in terms of the share of resources provided to the focal university by a given stakeholder. The 
criticality is the degree to which the university may continue to function in the absence of the resource(s) from a given stakeholder. The supply of valued resources leads to the emergence of power relations between resource providers and the focal university. We argue that not all stakeholders are equally able to constrain a university's behaviour. Some are relatively trivial or peripheral, while others are critical for both parties (Enders, Jongbloed, \& Salerno, 2008). Key stakeholders can obtain a certain power to enforce their demands. For example, public universities in most countries are still heavily financially dependent upon their governments, so the attention they pay to the demands of their governments is logically high. Governments use their power to control the behaviour of the resource-dependent university. In summary, we expect the choices and actions of the focal university to be somewhat constrained or enabled by the demands and expectation of its diverse stakeholders.

\subsection{Regulatory agencies: external regulations and incentives}

Regulation may be defined as government-imposed restrictions affecting organisations' freedom to exercise their rights and liberties (Jongbloed, 2004). In the higher education landscape, regulation can commonly be exercised by regulatory agencies such as the Ministry of Education, Ministry of Finance, buffer organisations, and quality agencies (Benneworth, \& Jongbloed, 2009; Jongbloed, 2004). Government's regulation in university affairs can take several forms: 'regulation by directive or law', 'regulation by incentive or finance', and 'instruments of information' (Jongbloed, 2004). Regulation by law stipulates the extent to which a government seeks to control universities (Jongbloed, 2004; OECD, 2008). The law often defines the rules of the game by which various stakeholders interact and exchange resources (Becher \& Kogan, 1992:82; OECD, 2008; Gornitzka \& Maassen, 2000:268). Universities are expected to demonstrate conformity with rules and regulations in order to get legitimacy and social approval (DiMaggio \& Powell, 1983) that lead to an uninterrupted flow of resources. Maassen \& van Vught (1994) outline two very influential models regarding the level of government intervention in higher education: state control and state supervision (see also De Boer, 2000). In the state control model, governments centrally impose detailed and stringent rules and extensive control mechanisms for directly regulating all key aspects, including organisational structures and the responsibilities of internal actors (Ibid, p38). The role of a university is essentially limited to the implementation of decisions centrally imposed by the government. In contrast, in the state supervision model a government sees itself as a supervisor, steering from a distance and using broad terms of regulation (Neave \& van Vught, 1994: 9). This model enables universities to control their daily functions and management. In this model, decentralization of responsibilities to the university level is promoted, 
but often alongside stricter reporting systems and quality measures for accountability (De Boer, 2000). While the state control model legally limits institutional autonomy, the state supervision model grants more autonomy at institutional level.

Institutional autonomy ${ }^{23}$ is defined as the degree of freedom the university has to steer itself (Jongbloed, 2003; Askling et.al. 1999). Many scholars suggest that autonomy is a pre-requisite for responding to the demands of stakeholders, including revenue generation activities (Massy, 2003; Hasan, 2007; Jongbloed, 2004). However, some authors argue that not all aspects of institutional autonomy have an equally important influence on revenue generation strategies or activities in universities. For instance, universities in Europe and the USA have traditionally been self-governing centres of education and research without a market-orientation in a modern sense (Dill \& Sporn, 1995:1). De Vries \& Koelman (1999:168) argue that procedural autonomy ${ }^{24}$ (i.e., financial autonomy and autonomy in staffing matters) is highly associated with revenue generation activities or market-orientation (see Jongbloed, 2004:341; Williams, 1992; EUA, 2011). Moreover, universities will only be able to pursue additional revenue generation strategies if the regulatory framework in which they operate allows them to do so (OECD, 2008). For example, a formal requirement for regional engagement enshrined in national legislation can be an enabling force to adopt the third mission in universities' core activities. The Bayh-Dole Act (1980) in the USA provides a good example of this (Mowery \& Sampat, 2005).

Regulation by incentive or finance can be used to encourage universities to meet certain conditional policy goals, including implementation of revenue generation strategies and activities (Jongbloed, 2004). There is an increasing interest in linking funding of universities to education and research production. Various funding mechanisms by which the national governments make finance available to universities can be thus identified: output or performance based funding, targeted funding, competitive funding, etc. (Massy, 1996; Hauptman \& Salmi, 2006; Williams, 1992:141). For example, using targeted funding, governments can foster partnerships between the academic and business communities, support national local or regional economic development objectives, undertake $R \& D$ activities in certain thematic areas and make

23 See OECD (2008:81) for an overview of the different aspects typically associated with institutional autonomy.

24 See also Berdahl (1990) to distinguish between procedural and substantive autonomy. 
universities offer lifelong learning programmes and admit students from disadvantaged backgrounds(Williams, 1992; Harman \& Harman, 2003). Money can also be supplied to universities through the purchase of goods and services, or through the provision of various grants and cash subsidies (Pfeffer \& Salancik, 2003:190). Generally, the shift from 'budgets itemised by function' towards 'budgets itemised by performance targets' marks the road to revenue generation (Canton \& van der Meer, 2001; Koelman \& Venniker, 2001; Hauptman \& Salmi, 2006). The latter gives universities more flexibility and autonomy than line-item arrangements, enabling them to determine their preferred distribution of funds in accordance with their particular mission.

The third type of regulation is by using 'instruments of information'. Market mechanisms lead to outcomes that are more efficient when information on the relative prices and quality of the services can be accessed and interpreted easily. An average consumer of educational and research services has, however, often faced 'ex ante uncertainty about the quality of its products' (Jongbloed, 2004; Dill, 2003). Even after purchase or consumption, it is common to be unaware of the 'real' quality of the good. The problem of information asymmetry can cause market failures (Jongbloed, 2004) that might have impacts on the relationships between the focal university and its stakeholders (see Coase, 1960). Hence, governments may impose 'consumer protection' regulation to check on the quality of academic programmes and research (see Jongbloed, 2004; also Cave 1994) as part and parcel of enforcing accountability. Regulatory bodies (e.g. Ministry of Education, quality agencies, professional organisations, etc.) disseminate useful information such as consumer guides, evaluation reports, quality assessment reports, rankings, and performance indicators (OECD, 2008; Jongbloed, 2004; Cave 1994) to enhance the exchange between the focal university and its stakeholders. The regulatory bodies may require universities to publish timely and accurate performance information in their yearly reports to inform their stakeholders about their performance, costs, and quality of the teaching and research.

\subsection{Competitors: degree of rivalry}

The final external factor in the task environment is the degree of rivalry. We consider competitors to be stakeholders in a university (see Enders, Jongbloed, \& Salerno, 2008), but with unique roles in the task environment. It is clear that the focal university is not the only player in the knowledge production process. Nor is it the only education and research organisation that produces and provides information and knowledge to society at large (Salmi, 2007). Private and public providers of post-secondary education (e.g., universities and colleges), R\&D offices in government organisations and industrial firms and 
private companies, among others, can all be considered to be part of a common industry providing academic degrees, research and services (Dill, 2003; Clark, 1998; Massy, 2003; Jongbloed, 2003). These stakeholders compete with the focal university for resources, for example, students, research support, faculty members and financial contributions, public funds and donor support (Dill, 2003). They share resources provided by customers and suppliers. Thus, competitors can generally influence and constraint the capacity of the focal university to acquire resources. The intensity of rivalry for the higher education market or simply competition for resources can be influenced by several factors (Duczmal, 2006:78 adapting from Mansfield, 1991; Begg et.al, 1991; Dill, 2003:138; Jongbloed, 2003) which include:

- The number or concentration of competitors: a large number of higher education institutions of roughly equal size and providing similar programmes increases rivalry, because more providers must compete for the same student segments and inputs.

- Programme similarities or differences: a low degree of product differentiation among higher education providers is associated with higher levels of rivalry. The more similar providers are located in one region, the higher the levels of rivalry between them.

- A slow growth of the higher education market in terms of student numbers causes institutions to fight for market share. In an expanding market, providers are more easily able to increase their revenues and student enrolments, while a shrinking market makes rivalry more intense.

- Switching costs: the presence of low costs for students to switch from one university to another increases rivalry. When a student can easily change university or college, there is a greater struggle to capture and hold students within the university.

\subsubsection{Strategy of a University}

Revenue generation strategy makes up our first dependent variable. Section 4.3.3 of Chapter 4 provides some definitions of a strategy. Strategies are defined as "the direction and scope of an organization to achieve advantages in an environment through its configuration of resources and competences" (Thompson, 1995:7). The essence of strategy formulation is coping with competition to defend a university against environmental forces, and thereby create opportunities for superior performance (Porter, 1979). Strategy may be set at various levels, i.e., corporate strategy; competitive strategies for each business area; and functional strategies, which provide the competitiveness 
(Thompson, 1995:9). For instance, the corporate strategists or the central leadership will find a position for a university where it can best defend itself against environmental forces or can influence them in its favour (Porter, 1979). Strategy can be thus understood as a planned, intentional effort that seeks to align a university's structures and polices with a set of goals that the university wants to achieve.

RDT suggests that the organisational environment is not treated as "objective realities" (Pfeffer \& Salancik, 1978). It becomes known through the process of enactment. We argue that how the context of a university is defined depends on how it is perceived, how attention is given to certain aspects, and how the context is interpreted. How a university learns about its environment and attends to it and how it selects and processes information to give meaning to the environment are all-important aspects of how the context of a university affects its actions. Generally, good information about the context of a university will be required for formulating sound strategies. According to Pfeffer \& Salancik (1978: 74-77), organisations can obtain systematised information about their environment through 'environmental scanning'. Scanning the environment is here understood to be a process of gathering, analysing, and dispensing information in order to (i) lessen the randomness of information flowing into the organisation and (ii) provide knowledge about changing external conditions for leaders. A university is also expected to constantly assess its organisational environment and internal conditions for formulating strategies of acquiring resources. It must delve below the surface, assess environmental trends, interpret, and explain the implications of those trends for the university. In particular, the organisational leadership must stay attuned to multiple environments, with primary attention paid to those resources on which the university has the greatest dependence (Gumport \& Sporn, 1999). An understanding of the external environment is a critical piece in the puzzle of a university's strategy formulation.

The quality and comprehensiveness of information gathered through scanning the environment may be dependent on the composition of the scanning units and the frequency of data collection (Fahey, King, \& Narayanan, 1981; Pfeffer \& Salancik, 1978:74-77). An organisation like a university, operating in complex environment, needs many scanning units, which collectively possess a wide range of skills and expertise in order to attain multiple facets of the environment (Pfeffer \& Salancik, 1978:269; Gumport \& Sporn, 1999). It is also argued that a university that continually scan events in its environment can develop appropriate strategies in a timely way (Fahey, King, \& Narayanan, 1981). The scanning activity consists of an internal appraisal of the focal university and an external appraisal of the organisational environment (Keller, 
1983).The internal appraisal focuses on identifying the strengths and weaknesses of a university. The external appraisal seeks to identify opportunities and threats in the environment. These appraisals may highlight the critical strengths and weaknesses of the focal university, indicate the positioning of the university in the higher education industry, clarify the areas where strategic changes may yield the greatest payoff, and highlight the places where university trends promise to hold the greatest significance as either opportunities or threats (Chaffee, 1985; Gumport \& Sporn, 1999; Pettigrew \& Whipp, 1991for formulating strategies; Fahey \& Narayanan, 1986).

Pfeffer and Salancik (1978) suggest two strategic responses that organisations may enact in response to demands towards the organisational environment (see also Scott, 1987b: 181-194; Thompson, 1967; Oliver, 1991 for more strategic responses). On the one hand, a university can adapt and change to fit environmental requirements. In this strategy, the leadership may perceive the demands and expectations of stakeholders confronting the university, and then adjust the university accordingly in order to manage the university's relationships with its environment (Gumport \& Sporn, 1999). This does not mean that the leadership is responsive to all demands, but its main role is to decide which demands to heed and which to reject. The adaption strategy can take quite different specific forms:

- Differentiation in education and research products and services: Through training or education, universities are expected to offer opportunities in areas demanded by the labour force to diverse group of learners at costrecovering (or higher) tuition fee levels. These efforts will focus not only on students seeking degree programmes (BA, MA/MSc, and $\mathrm{PhD}$ ), but also on students seeking non-degree pre-and post-baccalaureate certification, for examples, short courses, summer courses, etc. They may target new markets of diverse learners (e.g. professional enhancement learners, adult learners, etc.) through a variety of pedagogical forms or modes (e.g. distance, summer, weekend, evening, etc.). Universities can also engage in a variety of research undertakings like basic and applied research in various areas (e.g. health, education, agriculture, business, etc.). The development of research activities includes the creation of spinout companies, contractual research with private partners or participation in regional or international research programmes.

- Introducing financial and non-financial incentives: designing a set of incentive mechanisms (financial and non-financial) in order to increase the commitment of the academic community to revenue generation activities. A diversity of incentive mechanisms exists, mostly operating at two levels, 
by rewarding staff either directly or through providing incentives at faculty/institute level. While financial incentives to staff may include incentives in individual salaries based on revenue generation performance, non-financial incentives may be concerned with linking revenue generation performance to promotion. At faculty level, different types of financial incentives may be introduced: targeted-funding for new initiatives or investment in facilities, project-based funding (mostly competitive), and even co-funding (matching funds). Generally, formulabased funding is seen as a driver for universities to search for additional revenue. The incentive mechanisms can include setting a fair distribution factor (e.g. revenue generation policies) between the centre, faculty, and individuals who will be engaging in revenue generation activities.

- Creating new functions, structures and units: These structures enable universities to embark on successful revenue generation activities from education and research. They include both administrative offices and academic units (Clark, 1998). Outreach administrative units consist of technology transfer offices (TTO), industrial contact, intellectual property development, start-up firms, business incubators, research parks, continuing education, international offices and donor projects coordination offices including fundraising and alumni affairs, among others. The academic units include interdisciplinary or multidisciplinary research centres that work side by side with academic departments. These arrangements can be established to manage resource dependencies between the university and its stakeholders (Clark, 1998; Gumport \& Sporn, 1999; Massy, 2003).

- Communication or advertising: communication makes all stakeholders aware of the range of activities undertaken by universities. It ensures the stakeholders know about a given university and make appropriate decisions about funding options. Communication can be analysed at different scales: internal and external. In the process of revenue generation, the whole university community needs to be involved and be aware of the purposes, aims and actions being pursued. Internal communication plays a crucial role in achieving cooperation from diverse actors (e.g. leadership, academic staff, etc.) and it is critical to implementing efficiency measures. Through external communication, a university makes the much needed link between its internal activities and the outside world.

On the other hand, a university can attempt to alter the environment so that it fits the organisation's capabilities. In this case, the leadership may take actions to modify the environment to which the focal university responds. The 
university leadership may focus on altering the system of constraints and dependencies confronting the university (Gumport \& Sporn, 1999; Sporn, 1999). This altering strategy includes:

- Lobbing for re-regulation \& revised policies: universities lobby for a regulatory framework, which allows them to pursue revenue generation activities. For instance, based on the current perceived degree of autonomy, universities will ask or lobby for additional autonomy, particularly in terms of staffing and financial autonomy. This re-regulation may create a new environment for revenue generation.

- Creating alliances/consortia with other universities: two or more universities may coalesce efforts around specific issues to achieve a revenue generation aim. This might pool various resources, for examples, human resources (e.g. knowledge), capital or equipment and facilities, for achieving a common goal. Additionally, alliances may take place in a context where one party resells a focal university's courses in new markets. Many alliance-based efforts can help to create a new business environment through which a university is connected to outside organisations. A pact or treaty will lead the alliance in the process of advancing common goals and securing common interests.

- Selecting board members: this involves bringing more people from key stakeholders into the governance of a university to enhance both linkages with the economy and internal efficiency. This creates more openness between universities and their environment. Universities may open up to their stakeholders (e.g. industry, regional and local community, etc.) which may enhance universities' responsiveness to the needs of stakeholders (OECD, 2008:129-130; Sporn, 2001).

\subsubsection{Revenue Generation Activities (RGA)}

Our last dependent variable is concerned with revenue generation activities. RDT suggests that organisations deprived of critical revenue will seek new resources. In other words, shortfalls in government funding have increasingly encouraged universities to engage in a variety of revenue generation activities for acquiring vital resources (Shattock, 2003). These resources include monetary revenues (student fees, fees for research \& consultancy services), in-kind resources, and immaterial resources (e.g. legitimacy) (Johnson, 1995; Galskiewicz \& Marsden, 1978). A need for diversifying resources implies that universities are required to undertake a variety of revenue generating activities. By revenue generation activities, we refer to any activities undertaken to 
generate revenues in return for education and research services, contract work, the sale of goods and any other activity not funded through recurrent income received from public authorities for the university's regular teaching and research tasks (Shattock, 2003; Johnstone, 1998; Williams, 1992; Leslie \& Slaughter, 1997). We can identify three main sources of revenue: a) national, regional and local governments; b) private entities (e.g. firms, dual track students, NGOs, philanthropic foundations, professional associations, communities, business (industrial) firms); and c) international organisations (governments and donor organisations from abroad).

Many scholars (e.g. Clark, 1998; Shattock, 2003; Liu, 2007; Johstone, 1998; Jongbloed, 2003; CHET, 2011; EUA, 2011;Williams, 1992; Leslie \& Slaughter, 1997) have identified revenue generation activities in universities. We can categorise these revenue generation activities as follows:

a) Activities related to educational services: universities may provide educational services that focus not only on students seeking degree programmes but also on students seeking non-degree pre-and postbaccalaureate certification (see Levine, 2000a; Schneider, 1999). This may include short courses for industry and other stakeholders. Vocational Master's programmes where short courses can be linked as modules fall under this category.

b) Activities related to research: some universities will generate revenue from research contracts (Williams, 1992; Leslie \& Slaughter, 1997), money earned from patents and licences, direct consultancy or commercial research partners. Some of these activities may be organised into separate university-owned spin-off companies. In practice, research contracts cover most of the research and development work undertaken for various external stakeholders.

c) The exploitation of university facilities for commercial purposes: revenue can be generated by leasing university property to private entities. Many universities will invest in their facilities to obtain revenue from such facilities as rental, residences, catering, consultancy, libraries, museums, training centres or resource centres, printing and binderies, sport facilities, language centres, scientific test equipment, etc. All offer possibilities for earned income. Thus, universities have considerable opportunities to exploit their facilities to generate income.

d) Sales of goods and services: universities can also generate revenue from the retail business. This may include bookshops, letting space to banks, hairdressing, pharmacy, sales of agricultural and industry products, etc. 


\section{$4 \quad$ Methodology and Operationalisation}

\subsection{Introduction}

This chapter presents the methodological considerations of the study. It begins with the operationalisation of variables contained in the research model. The second section presents the methods, the case selection, data collection instruments, and techniques for analysis. Finally, the validity and reliability of the data are briefly discussed. The chapter outlines how the study was carried out in order to obtain answers to its basic questions.

\subsection{Research Design and Methods}

This study aims at answering the question of how Sub-Saharan African public universities can improve their financial sustainability by diversifying their own resources on the one hand and continuing to accommodate the growth in higher education enrolment on the other. The unit of analysis of this study is the university. Fig. 4.1 below presents the research procedures of the study.

\section{Figure 4-1 Research Flowchart}

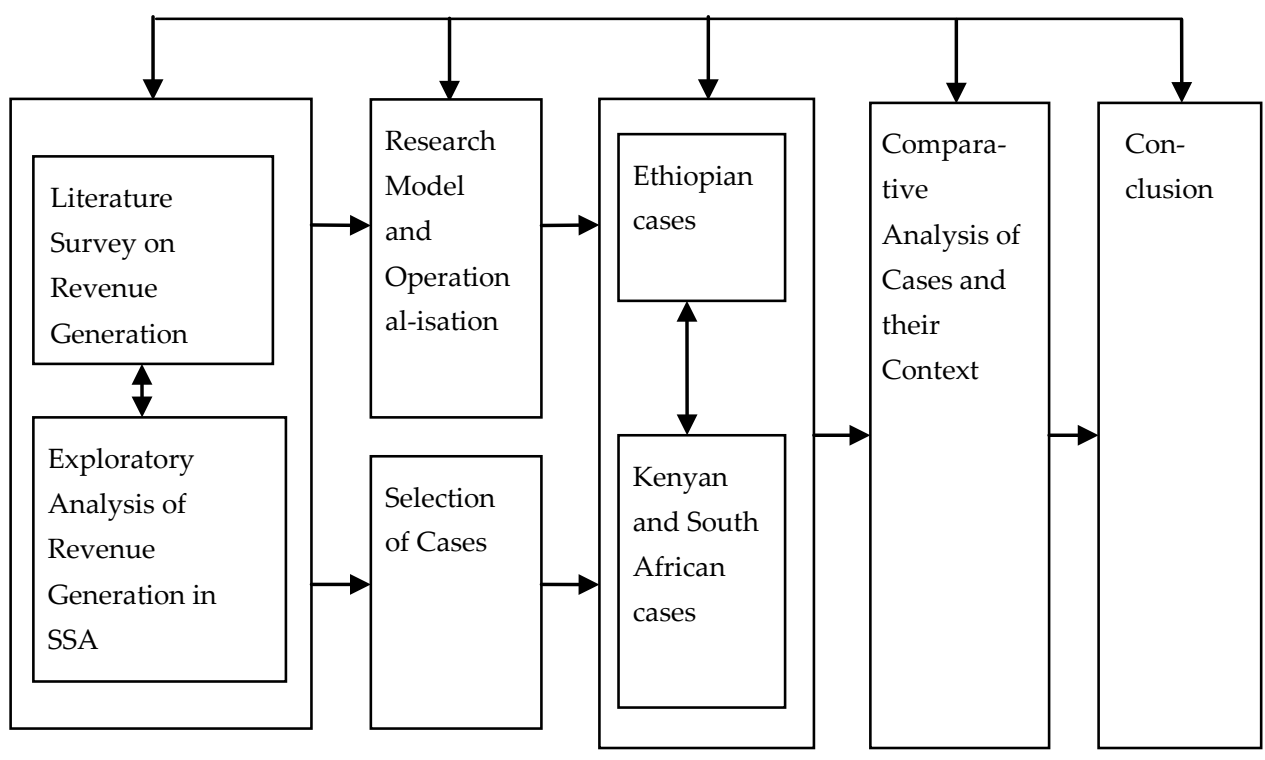

As indicated in Fig 4.1 above, this study consists of five major parts. The first part presents the current higher education environment. Accordingly, we have 
presented the literature survey on revenue generation and the theory suitable for this research in Chapters 2 and 3. The main function of the theory discussed in Chapter 3 is to provide us with a lens through which the relationships of universities with their environments and the impacts of these relationships on revenue generation can be explored. The theoretical model for the study provides us with variables which are later evaluated empirically. Methodologically, we follow a case study approach combined with a comparative analysis. In Chapters 5 to 7 , we conduct an in-depth case analysis of the four case study universities. As this research is primarily about revenue generation in Ethiopian public universities, the two Ethiopian case study universities are at the centre of the research. The other case study universities in Kenya and South Africa provide comparisons and lessons for Ethiopian universities. In Chapter 8, we perform a comparative analysis of the four universities, to explore similarities and differences in their revenue generation strategies and activities, environments, and other university specific conditions. This enables us to identify the environmental and university characteristics that explain similarities and differences in revenue generation strategies and activities. Finally, Chapter 9 presents the summary, conclusions of the study and reflections.

\subsection{Operationalisation}

The theoretical model we discussed in Chapter 3 contains four major variables: university characteristics, organisational environment, revenue generation strategies, and revenue generation activities, as indicated in Fig. 4.2 below.

\section{Figure 4-2 Research Model Restated}

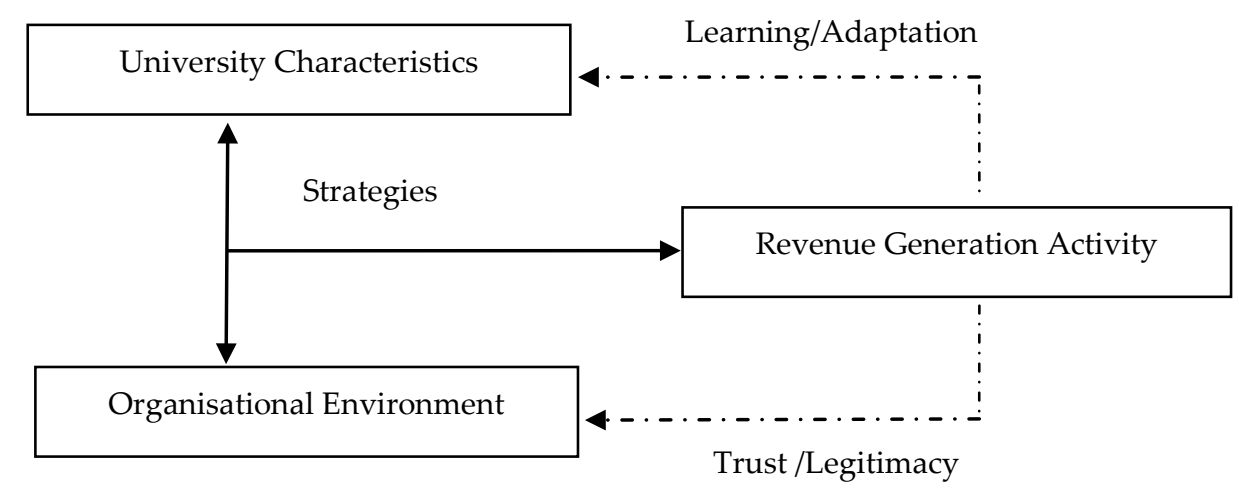


In this section, we briefly elaborate and operationalise the main variables and their constituent parts. We begin with the independent variable - university characteristics - in section 4.3.1, followed by the organisational environment in section 4.3.2, and then continue with the dependent variables, i.e. the strategies for revenue generation in section 4.3.3 and revenue generation activities in section 4.3.4. Other potential relationships indicated above as trust and learning, are not operationalised here as they are beyond the scope of this research.

\subsubsection{University Characteristics}

The first set of independent variables deals with the characteristics of a university. As universities are complex organisations, their success in attaining certain goals (e.g. revenue generation) is contingent upon their unique characteristics (see Chapter 3). In this research, four variables measure the variation between universities: mission, disciplinary configurations/specialisations, internal governance and leadership, and human and non-human resources. We are interested in the mission of a university since the mission statement of a university can show the degree of attention paid towards revenue generation. The disciplinary configuration or specialisations of a university, which consist of the academic programmes and research areas in which the university is active, may affect the propensity of the university to mobilise resources from certain stakeholders in its environment. Internal governance is defined in terms of the positions and responsibilities in the governance structure of a university. The internal policies, regulations, and structures related to revenue generation are indications of the willingness of a university to support its revenue generation strategies and activities. As stated in Chapter 3, the specific policies, regulations, and structures affect the degree to which a given university engages in revenue generation. The university leadership's commitment to revenue generation is of crucial importance, since the leadership plays a major role in how a university meets external demands and expectations (Gornitzka \& Maassen, 1998). The leadership is here defined as the structure (positions, offices, and formal roles) and processes through which individuals seek to influence decisions (Sporn, 2001). In this research, leadership is not restricted to a single post or even to a team or subset of colleagues in the centres, but rather dispersed within a university (Shattock, 2003:92). It is inclusive of upper, middle, and operational level management (Shattock, 2003). The task of the leadership is mainly to influence and persuade others in a desired direction (Nadler \& Tushman, 1997), usually towards the accomplishment of specific tasks (e.g. revenue generation). 
Human and nonhuman resources: A university needs to acquire adequate human and nonhuman resources to achieve its chosen strategies for revenue generation (Dill, 2003; Mahoney, 1995; Spaapen et al., 2007; Marginson, 2007). Human resources consist of both academic and administrative support staff. The most important element for creating and disseminating good quality useful knowledge in a university may be the knowledge embedded in academic staff. The presence of a skilled workforce is one of the critical factors of production in any organisations. Specifically, academics holding higher scientific degrees (e.g. $\mathrm{PhD}$ ), well committed, and adequately compensated may be considered as the heart of the university without whom the university cannot function properly (Altbach, 1991). Other inputs like financial resources and physical resources such as technologies, books and networks, also shape the decisions and choices of a university (Dill, 2003). Each of these variables is operationalised in Table 4.1 below.

Table 4.1: Operationalisation of University Characteristics

\begin{tabular}{ll}
\hline Variables & Indicators \\
\hline Mission Statement & $\begin{array}{l}\text { Degree of attention paid to revenue generation in the } \\
\text { university's mission statement. }\end{array}$ \\
\hline $\begin{array}{l}\text { Disciplinary } \\
\text { configuration or }\end{array}$ & $\begin{array}{l}\text { Main units (e.g. departments, research centres, support } \\
\text { units) for education, research and community services } \\
\text { Degree programmes offered. } \\
\text { Disciplinary areas and specialisations in research. }\end{array}$ \\
\hline $\begin{array}{l}\text { Internal Governance } \\
\text { and Leadership }\end{array}$ & $\begin{array}{l}\text { Main decision-making bodies (e.g. board, senate, } \\
\text { council). } \\
\text { The degree of centralised or decentralised decision- } \\
\text { making procedures in the university. } \\
\text { Positions in charge of revenue generation in the } \\
\text { university. } \\
\text { Degree of attention paid to revenue generation in the } \\
\text { university's strategic and operational plans. }\end{array}$ \\
\hline $\begin{array}{l}\text { Human and Non- } \\
\text { Human Resources }\end{array}$ & $\begin{array}{l}\text { Total budget (for recurrent and capital items) and its } \\
\text { composition. } \\
\text { Academic staff volume and composition (incl. share } \\
\text { wistribution across disciplinary areas). }\end{array}$ \\
\hline
\end{tabular}




\begin{tabular}{ll}
\hline Variables & Indicators \\
\hline & Support staff volume and level of training. \\
& Education and research equipment and facilities \\
& owned by the university. \\
\hline
\end{tabular}

\subsubsection{Organisational Environment}

The organizational environment of a university is operationalised by three major variables: societal environment, stakeholder salience, and organisational autonomy. The general or societal environment impacting on a university includes social, political, and economic events that the university faces (see Sporn, 2001; Duczmal, 2006; Gulbrandsen \& Smeby, 2005; Trow, 1973; Gumport \& Sporn, 1999; Massy, 1996). Social trends mainly relate to demographic patterns that may determine the number and types of student body in universities (OECD, 2008). Economic trends can affect the financial stability of universities. Like any other public organisation, universities have to obtain a certain share of budget from their national government. The overall growth of the national economy generally enables universities to generate additional revenue from the environment (Court, 1999). Economic trends also include the national economic structure (Dill, 2003) that influences the range and complexity job skills (Ramirez, Riddle, 1991). Political trends are described in terms of the system of authority that governs the country in which the case study university is located. Political parties and public decision-making bodies can influence the role of universities in national development. Whether or not universities have a role in national development strategies or polices may enable or obstruct their revenue generation capacities (CHET, 2011). The societal environment is operationalised in Table 4.2 below. 
Table 4.2: Operationalisation of the Societal Environment

\begin{tabular}{ll}
\hline Variables & Indicators \\
\hline & - Number of pre-higher education graduates. \\
- Size of the secondary education system and transition \\
rates between secondary and higher education. \\
- Number of undergraduate degree offering higher \\
education institutions in a country.
\end{tabular}

In the environment of a university, different types of stakeholders such as regulators, suppliers, customers, and competitors may be distinguished (Freeman, 1984:16; see also Enders, Jongbloed, \& Salerno, 2008; Dill \& Sporn, 1995a; Gumport \& Pusser, 1997; Osborn, 1971; Porter, 1980). A given stakeholder is relevant for the university only if there is some expectation on both sides (i.e. the university and the stakeholder) that some service can be rendered or a mutually beneficial exchange can take place (Enders, Jongbloed, \& Salerno, 2008). Each type of stakeholder holds a different set of resources and may place different demands on the university. Not every stakeholder confronting the university has an equal effect on the organisation. Nor is every stakeholder in the environment viewed as important by the university. In explaining the attention paid to the various stakeholders in the environment of the university, we take into account the issue of stakeholder salience. Stakeholder salience is defined as the degree to which a university gives priority to competing stakeholder claims. In this research, the identification of the main stakeholder groups depends on two factors: the relative magnitude of exchange (funding) and the power of a given stakeholder to influence the university through regulation (see Pfeffer \& Salancik, 1978). We operationalise the external stakeholder and their salience to a university in Table 4.3 below. 
Table 4.3: Operationalisation of Stakeholder Salience

\begin{tabular}{|c|c|}
\hline Variables & Indicators \\
\hline $\begin{array}{l}\text { External stakeholders } \\
\text { and their degree of } \\
\text { importance (or } \\
\text { stakeholder salience) }\end{array}$ & $\begin{array}{l}\text { 1. Public authorities and regulatory bodies at } \\
\text { national level (ministries, funding agencies, } \\
\text { intermediary bodies, regulatory agencies; } \\
\text { accreditation agencies). } \\
\text { 2. Regional and local authorities. } \\
\text { 3. Donors (NGOs, international organisations such } \\
\text { as World Bank; individual governments, EU, } \\
\text { etc.). } \\
\text { 4. Students (and their parents /households). } \\
\text { 5. Business \& Industry (and their representative } \\
\text { organisations, e.g. employers' organisations). } \\
\text { 6. Other education institutions (national \& } \\
\text { international; secondary \& tertiary education } \\
\text { providers; public \& private) and their } \\
\text { representative bodies. }\end{array}$ \\
\hline
\end{tabular}

Regulation may be defined as a restriction affecting organisations' freedom to exercise their rights and liberties (Jongbloed, 2004). More specifically, it stipulates the extent to which a regulatory body seeks to control a university (Jongbloed, 2004; Becher \& Kogan, 1992; OECD, 2008; Gornitzka \& Maassen, 2000). In this research, regulation is understood as a law that affects the university's freedom to operate. The law, among other things, defines the autonomy or the degree of freedom the university has to steer itself (see OECD, 2008; Jongbloed, 2004; EUA, 2010; Anderson \& Johnson 1998; Ashby \& Anderson 1966; Berdahl 1990; Verhoest et al., 2004). It is the relationship between the state and universities (Dill 2001; Ordorika 2003). Four basic dimensions of autonomy are operationalised in Table 4.4 below. 
Table 4.4: Operationalisation of Organisational Autonomy

\begin{tabular}{ll}
\hline Variables & Indicators \\
\hline Financial Autonomy & $\begin{array}{l}\text { Acquiring and allocating funding, deciding on tuition } \\
\text { fees, accumulating surplus, lump-sum or block grant } \\
\text { funding, setting prices for research \& consultancy } \\
\text { services, own buildings, borrowing money from } \\
\text { banks, and leasing of university facilities. }\end{array}$ \\
Staffing Autonomy & $\begin{array}{l}\text { Responsibility for recruitment, promotions, dismissal, } \\
\text { and salaries- }\end{array}$ \\
Organisational & $\begin{array}{l}\text { Setting university internal governance and decision- } \\
\text { making structures/bodies, and introducing academic } \\
\text { structures (faculties, departments, research centres). }\end{array}$ \\
Deciding on degree supply, curriculum and methods \\
Academic Autonomy \\
of teaching, student admission and numbers, \\
deciding on areas, scope, aims and methods of \\
research.
\end{tabular}

\subsubsection{Revenue Generation Strategies}

Strategies that universities employ to pursue revenue generation make up our first dependent variable. The concept of strategy has been adopted from the military, and later adapted for use in business and public organisations including universities. There is very little agreement as to the meaning of strategy (Steiner, 1979). Chandler (1962) defined strategy as the determination of the basic long-term goals and objectives of an enterprise, and the adoption of courses of action and allocation of resources for carrying out these goals. For Mintzberg (1994), strategy is a plan, a pattern, a position, and a perspective. He indicated that strategy could also be a ploy, a manoeuvre intended to outwit a competitor. Bryson (1996) defines strategy as a pattern of purposes, policies, programmes, actions, decisions, or resource allocations that define what an organisation is, what it does, and why it does it. Andrews (1980) depicts corporate strategy as the pattern of decisions in a company that determines and reveals its objectives, purposes, or goals, produces the principal policies and plans for achieving those goals, and defines the range of business the company is to pursue, the kind of economic and human organisation it is or intends to be, and the nature of the economic and non-economic contribution it intends to make to its shareholders, employees, customers, and communities. Porter (1996) describes competitive strategy as a combination of the ends (goals) for which 
the firm is striving and the means (policies) by which it is seeking to get there. Tregoe \& Zimmerman (1980) define strategy as the framework which guides those choices that determine the nature and direction of an organisation.

Although there are many similarities in the definitions above, there are also some important differences. Strategy is thus generally a broad and ambiguous topic. What, then, is strategy in this research? Strategy is understood as the direction and scope of universities' efforts to achieve advantages in an environment through their configuration of resources and competences. It is concerned with how the university will achieve its revenue generation aims (see De Boer \& Dennert, 2002) by making choices with regard to direction, allocation of people, and allocation of means and money. It is concerned with decisions pertaining to choices between products and services, customers and markets and how actors are incentivised financially and non-financially. We operationalise strategy as indicated in Table 4.5 below. 
Table 4.5: Operationalisation of University Strategies for Revenue Generation

\begin{tabular}{ll}
\hline Variables & Indicators \\
\hline & $\begin{array}{l}\text { Initiating differentiation of academic (education and research) } \\
\text { services, and non-academic services and products. }\end{array}$ \\
\cline { 2 - 2 } & $\begin{array}{l}\text { Setting up dedicated academic units such as departments, } \\
\text { education and research centres, continuing education, etc. }\end{array}$ \\
\cline { 2 - 2 } & Setting up dedicated organisational support units such as a \\
Technology Transfer Office, a unit for fundraising \& donations, \\
etc.
\end{tabular}

\subsubsection{Revenue Generation Activities (RGA)}

Our second dependent variable is concerned with the actual revenue generation activities. A revenue generation activity is a specific task that the university does as a response to its resource providers for revenue generation. Table 4.6 presents the operationalisation of revenue generation activities in a university. 
Table 4.6: Operationalisation of Revenue Generation Activity

\begin{tabular}{|c|c|}
\hline Variables & Indicators \\
\hline \multirow{3}{*}{ Activity } & $\begin{array}{l}\text { Actual education activity aiming at revenue generation (e.g. } \\
\text { teaching students in degree programmes and non-degree } \\
\text { pre-and post-baccalaureate certification, short courses for } \\
\text { industry and vocational Master's programmes). }\end{array}$ \\
\hline & $\begin{array}{l}\text { Actual research conducted for various external } \\
\text { stakeholders to acquire nongovernmental resources (e.g. } \\
\text { research contract, and consultancy activities; the } \\
\text { commercialisation of intellectual property such as patents } \\
\text { and licenses). }\end{array}$ \\
\hline & $\begin{array}{l}\text { Actual non-academic services rendered and products sold } \\
\text { with the aim of revenue generation (e.g. the exploitation of } \\
\text { university facilities through renting residences, catering } \\
\text { revenue, libraries, training centres or resource centres, } \\
\text { printing and binderies, sport facilities, language centres, } \\
\text { scientific test equipment/facilities, museums, etc. for } \\
\text { commercial purposes, sales of goods and services including } \\
\text { retail businesses such as bookshops, sale of agricultural and } \\
\text { industry products, etc.). }\end{array}$ \\
\hline
\end{tabular}

\subsection{The Case Study Design}

As revenue generation in a university is a complex, dynamic and multidimensional phenomenon involving different actors from inside and outside of the organisation, this study follows a case study design. In this study, we focus on both the phenomena of revenue generation and the context in which it exists. A case study can be defined as (Yin, 1994: 23.), "an empirical inquiry that investigates a contemporary phenomenon within its real-life context, especially when the boundaries between phenomenon and context are not clearly evident and in which multiple sources of evidence are used." Hartley (1994:212-213) recommended the case study method for situations where the context of organisational environment is important. The case study method enables researchers to collect practical and context-dependent knowledge for an in-depth understanding of the cases (see Yin 2003:2; Flyvbjerg 2006:5; Hartley, cited in Kohtamaeki, 2009). We employ a multiple case study design. The multiple case study design is a logical choice for exploring the research problem relating to diverse socio-economic and legal bases as well as 
unique university characteristics. Multiple cases allow us to study revenue generation strategies across different cases, where explanatory variables and context may differ across the cases. This will provide evidence that is often convincing and make the study more robust (Yin, 2003), and will increase the credibility of the findings (Miles \& Huberman, 1994:29; Grix, 2004:53-55).

\subsection{Selection of the Case Study Universities}

Four universities in three countries were selected for investigating revenue generation strategies in Sub-Saharan African public universities. The selection of the countries is based on the idea of "purposive sampling" in order to acquire rich information (see Patton, 1987). The main criterion for selecting the countries was their different levels of development in higher education. According to the World Economic Forum (2011/12), the South African Higher Education and Training was ranked 73 out of 142 countries whereas Kenya and Ethiopia ranked 94 and 132 respectively. As Patton put it (1987), studying such dissimilar countries can give a complete picture of the problem under investigation and provide lessons that might be helpful in improving the existing conditions for revenue generation in universities. Secondly, these countries differ significantly in the opportunities they provide for universities to generate revenue. South Africa is a relatively advanced or efficiency-driven economy, which may create more opportunities for universities to generate their own revenues from diverse sources, particularly research and consultancy. Kenya and Ethiopia are factor-driven economies, which might have relatively limited conditions for universities to mobilise resources from diversified sources. This does not mean that there is no dissimilarity between the Ethiopian and Kenyan contexts, however. The Kenyan and South African case study universities provide inspiration for strengthening the revenue generation efforts of public universities in Ethiopia.

The sampling procedure used for the selection of case study universities was a purposive sampling technique (see Silverman, 2000:104; Patton, 2002:45-48), which is one of the most widely used methods in qualitative studies. The literature survey has guided the selection of cases and the construction of the research model on revenue generation. The selection of case study universities in this research is for 'theoretical representativeness', not based on statistical representativeness (Billiet, 1996:139-140). Two public universities, Adama Science and Technology University (ASTU) and Haramaya University (HU), were selected from Ethiopia. Jomo Kenyatta University of Agriculture and Technology (JKUAT) from Kenya and Nelson Mandela Metropolitan University (NMMU) from South Africa were chosen for the case study. The four 
universities were selected based on three criteria. The first is that they had engaged in revenue generation by the time that data were collected for this study. Secondly, all the selected universities are comprehensive universities in their national definition. Thirdly, the case study universities are not legally prohibited from generating nongovernmental revenues. Additional criteria used for selection of the universities are indicated in Table 4.7 below.

Table 4.7: Key Issues Guiding Case Selection

\begin{tabular}{|c|c|c|c|c|}
\hline Position & ASTU & HU & JKUAT & NMMU \\
\hline Type of University & $\begin{array}{l}\text { Compre- } \\
\text { hensive }\end{array}$ & $\begin{array}{l}\text { Compre- } \\
\text { hensive }\end{array}$ & $\begin{array}{l}\text { Compre- } \\
\text { hensive }\end{array}$ & $\begin{array}{l}\text { Compre- } \\
\text { hensive }\end{array}$ \\
\hline Mission & $\begin{array}{l}\text { Teaching, } \\
\text { Research, } \\
\text { and } \\
\text { Community } \\
\text { services }\end{array}$ & $\begin{array}{c}\text { Teaching, } \\
\text { Research, } \\
\text { and } \\
\text { Community } \\
\text { services }\end{array}$ & $\begin{array}{c}\text { Teaching, } \\
\text { Research, } \\
\text { and } \\
\text { Community } \\
\text { services }\end{array}$ & $\begin{array}{l}\text { Teaching, } \\
\text { Research, and } \\
\text { Community } \\
\text { services }\end{array}$ \\
\hline $\begin{array}{l}\text { Total student } \\
\text { population in } \\
2010 / 11\end{array}$ & 19,516 & 30,634 & 20,000 & 26,119 \\
\hline Founded & 1983 & 1952 & 1994 & 2005 \\
\hline Emerged as & $\begin{array}{l}\text { Technical } \\
\text { University }\end{array}$ & $\begin{array}{l}\text { Agricultural } \\
\text { University }\end{array}$ & $\begin{array}{l}\text { Agricultural } \\
\text { and } \\
\text { Technology } \\
\text { University }\end{array}$ & $\begin{array}{l}\text { Technical } \\
\text { University }\end{array}$ \\
\hline Location & Urban & Rural & Rural & Urban \\
\hline $\begin{array}{l}\text { Key source of } \\
\text { nongovernmental } \\
\text { revenue }\end{array}$ & $\begin{array}{l}\text { Student } \\
\text { tuition fees }\end{array}$ & $\begin{array}{c}\text { Student } \\
\text { tuition fees }\end{array}$ & $\begin{array}{c}\text { Student } \\
\text { tuition fees }\end{array}$ & $\begin{array}{l}\text { Student tuition } \\
\text { fees }\end{array}$ \\
\hline $\begin{array}{l}\text { Ratio of earned } \\
\text { revenue from } \\
\text { nongovernmental } \\
\text { source to total } \\
\text { recurrent budget } \\
\text { received from } \\
\text { governmental } \\
\text { source in } 2011\end{array}$ & $<1$ & $<1$ & $>1$ & $>1$ \\
\hline $\begin{array}{l}\text { National } \\
\text { regulation of the }\end{array}$ & Allowed & Allowed & Neutral & Allowed \\
\hline
\end{tabular}




\begin{tabular}{l|llll}
\hline Position & ASTU & HU & JKUAT & NMMU \\
\hline $\begin{array}{l}\text { university on } \\
\text { revenue } \\
\text { generation in } 2011\end{array}$ & & & & \\
\hline
\end{tabular}

A senor expert from the World Bank and experts from CHET in South Africa, who are all active in studying higher education in Africa, agreed with the nomination of these as the units of analysis in this research.

\subsection{Empirical Data Collection}

Multiple sources of evidence under the rationale of triangulation (Yin, 2003:97) guided the logic behind data collection. Data collection included:

- Literature survey: this primarily focused on identifying suitable theory to assist us in understanding the enablers for and barriers to revenue generation for Sub-Saharan African universities.

- $\quad$ Desk research / exploratory study of revenue generation in Sub-Saharan Africa and beyond. The review of literature in Chapter 2 was carried out to map the status of revenue generation in Sub-Saharan African universities in particular and in the globe in general. As part of this task, a three-week visit was paid to CHET in South Africa to search for documents on Sub-Saharan African universities (see Chapter 2), and to get feedback on the research model and theoretical framework of this research apart from the visit to South Africa for a large-scale data collection.

- Analysis of data in the four case studies: this includes interviews with key figures from the universities, documentary evidence from the universities and other stakeholders in the environments, and on-looker observation on the campuses of case study universities.

This study relies heavily, though far from exclusively, on evidence collected from the case study universities. Based on the research problem and research questions set and the epistemological assumptions of the current research, we decided to collect data through interviews (Yin 2003:89; Hartley, 1994:210). In the data collection process, we relied on a semi-structured interview guide (Yin, 2003:90; Grix, 2004) that was prepared based on the variables identified for this research (see Annex I).This semi-structured interview guide enables us to gain a better understanding of the significance of the views and experiences of the 
informants. Requests for interviews were sent to each university by email and included an introduction to the research topic and its purpose. The research consisted of two rounds of one-to-two week visits in the case of Ethiopian universities, and a two-week visit in the case of Kenyan and South African universities. Several respondents (see Table 4.8) who were directly or indirectly involved in revenue generation agenda of the case study universities were included in the interviews.

Table 4.8: Number and Position of Interviewees

\begin{tabular}{lcccc}
\hline Position & ASTU & HU & JKUAT & NMMU \\
\hline Vice presidents/Deputy & 2 & 3 & 1 & 1 \\
vice chancellors & 3 & 3 & 2 & - \\
Deans & 2 & 1 & 3 & 4 \\
Directors & 2 & 2 & 2 & 1 \\
Registrar & 3 & 2 & 2 & 1 \\
Department Heads & 3 & 3 & 3 & 2 \\
Academic Staff & 1 & 1 & 1 & 1 \\
Finance officers & 1 & 1 & - & - \\
Human resource officers & 3 & 4 & 1 & 2 \\
Other administrative & 20 & 19 & 15 & 13 \\
support personnel & & & & \\
\hline Total & & & & \\
\hline
\end{tabular}

The involvement of a variety of interviewees from different positions within the case study universities enabled us to obtain rich information. Importantly, it helped us to triangulate the interview data by interviewing multiple respondents within the universities. The participation of senior staff members created opportunities to gain a better understanding on the status, philosophy, and development of revenue generation in their respective universities. All interviewees were asked for permission for their interviews to be tape-recorded and for notes to be taken. Whenever possible and necessary, the interviewees were asked to support their statements with documentary evidence. In some cases, respondents were approached for a second or third time by phone or electronic mail to provide additional data. The majority of the data collection occurred in 2011/12. Most of the primary data covered what had happened in 
the last five to six years in terms of revenue generation in the case study universities.

Gathering and analysing information about a large number of aspects of each case study university is an essential feature in case study research (see Gomm \& Hammersley, 2000:3-4). We analyse the multitude of revenue generation paths, routes, and strategies based on the opinions of interviewees, financial data, strategic plans, laws, policies and university web pages, and thereby seek to analyse these from the point of view of our theoretical model to answer the research questions. National development strategies (such as the Growth and Transformation Plan of Ethiopia, Vision 2030 of Kenya, and Medium Term Strategic Framework (MTSF) of South Africa and its Vision 2030), institutional strategic and annual plans, institutional physical and financial reports, website text, internal policies and regulations, organisational structures, national policy documents, statistical information, reports by the World Economic Forum, and other research documents from the World Bank, CHET, and the African Association of Universities were reviewed and analysed. The documentary evidence allows us to understand and make judgements about visions and strategies, laws and regulations, operational practices and protocols, rewards and incentives, problems and 'windows' of opportunity, organisational models, human resource issues, methods of leadership and communication as well as revenue generation activities in universities. Furthermore, we observed what was happening in the offices, classrooms, laboratories, and paths of the university campuses. The collection of data from different sources (i.e. individual informants, documentary evidence, and observation and photographs) through different techniques was an important step towards triangulation and answering the research questions.

\subsection{Data Analysis}

In this research, we conduct 'within case' analysis as well as 'cross case' analysis. We undertook three types of analysis: (i) content analysis, (ii) analysis at the level of the individual case study university, and (iii) comparative analysis across the four case study universities. First, content analysis involves identifying coherent and important examples, themes, and patterns in the data. The interview transcripts were read several times, concentrating on content analysis (Patton, 1987:149) to identify those ideas, issues, or concepts that go together. These activities were carried out based on informants' responses guided by the theoretical framework. Secondly, we prepared the individual case study reports on the basis of the content analysis. Case data consists of all the interview data, the observation data, and the documentary evidence. 
Interview data were analysed and categorised using the concepts and operationalisations of the research model. A peer review and structured analysis were considered to enhance the validity of the data categorisation by coding and interpretation (Corbin \& Strauss, 1990; Richards, 2005). For the sake of parsimony, citations that best represented a category or opinion presented by the majority of the interviewees was used. The category headings are the basis for the data analysis (Holliday, 2002:99-100; Marshall \& Rossman, 1997:111).

The analysis process has gone through several rounds of data reduction to extract the information needed for brief organisational narratives. After a number of drafts, we managed to construct written analyses for each of the individual case study universities using the theoretical framework for the research in Chapter 3 and the operationalisations of the key variables indicated in this chapter. During the analysis of different categories, we raised theoretically oriented questions about items in the data and thought in terms of the propositions of the study about the conditions and consequences of changes in the organisational and/or socio-economic environment for university's responses (Strauss, 1987, 2003). Some of the questions were "What are the perceived barriers and obstacles to revenue generation in public universities operating in different settings? What is already facilitating revenue generation at the case study universities, and what is done to further revenue generation? To what extent have university specific factors and their environment enabled or constrained revenue generation in the four case study universities?" The within case analyses provide inputs for the comparative analysis. In the comparative analysis of the four case study universities, we compare the levels and types of revenue generation strategies and activities of the four case study universities and identify those environmental factors and university specific conditions that influence revenue generation in different settings. In this regard, we look at revenue generation strategies in all cases, and at what factors account for the chosen strategies and their success.

\subsection{Validity}

Though the concepts of validity and reliability developed within the quantitative tradition that requires strict procedures, they can still be employed within the qualitative study as hallmarks to check whether the information is adequate. According to Judd, Smith, \& Kidder (1991:29) validity is the degree to which the allotted instruments convincingly measure, explore, or describe the phenomenon in hand. There are three criteria to assess validity viz. internal, external and construct validity of studies (see Yin, 2003:35-38 and 116; Denzin \& Lincoln, 2003:35). The criteria of validities have been taken into consideration in 
this research. To increase the validity, the study used multiple sources of evidence and discussed the controversial definitions. We used the triangulation technique to enhance the validity of interpretation. Following Patton (1990: 464), we applied data source and method triangulation extensively in the study. In this regard, a comparison of data gained through interviews, documents, and literature was made in order to nuance the interpretations presented in the study. In addition, we compared the views inspired by different theoretical perspectives.

External validity is observed throughout the study. This is the extent to which research findings can be replicated or generalised. Yin (2003:34) defines external validity as "establishing the domain to which a study's findings can be generalized." The critical point of the validity in sample case studies is whether the empirical data obtained and the interpretations of that data do indeed respond to the research questions (Denzin \& Lincoln, 2003; Patton, 2002; Silverman, 2000). The goal of this research is to achieve theoretical generalisation, not statistical generalisation. Based on the case study material a revenue generation strategy typology is drawn up, where 'types' of revenue generation strategy are recognised based on the literature on the one hand and the empirical data on the other. These types are internally homogeneous (the cases are mutually as close as possible) and externally heterogeneous (the differences between the types are as large as possible) (Kluge, 2000). This typology construction is based on knowledge from the literature, but is further refined and expanded according to the empirical research. Kluge (2000) summarises the movement of typology construction together in a 'model or empirically grounded type construction': development of relevant analysing dimensions; grouping the cases and analysis of empirical regularities; analysis of meaningful relationships and type construction; and characterisation of the constructed types.

The typology of strategies is also deployed to construct the protocol of the case studies. This guides the research design, i.e.; "the logical sequence that connects the empirical data to a study's initial research questions and, ultimately, to its conclusions "(Yin, 1994: 28-29), that determines which questions are studied, which data are relevant and have to be collected and how the results are analysed and interpreted. The theoretical framework helps us identify relevant information. Later on, it is also important for the generalisation of the results of the case studies. It guides the case, transcending, abstracting and re-describing the cases studied, the properties and mechanisms that emerge from the analysis of the specific research materials - the cases (Sayer, 1992). As well as input for the revenue generation strategy typology, the cases provide insight into experiences of revenue generation in Sub-Saharan African (SSA) universities, as 
well as into the experiences of researchers and users with thresholds and obstacles, bottlenecks and challenges. The interviews with respondents also provide insights for strengthening revenue generation policies. These insights are complemented by an analysis of national policy instruments to encourage and support the revenue generation agenda in Sub-Saharan Africa and beyond.

\subsection{Reliability}

Reliability concerns the degree to which the analysis or findings can be repeated by another researcher. Kirk \& Miller (1986:19) define it as the "extent to which a measurement procedure yields the same answer however and whenever it is carried out". A systematic error is the crucial threat to reliability; thus, the study has to be thoroughly planned. In the current study, accuracy is maintained during instrument development and at the stage of data collection by referring to truthful materials. Although it is difficult to take identical measurements within a qualitative research, we documented and described the research actions during the research process, and notes were taken of recordings at the data collection stage. The supervisors of the research commented on the interview checklists. A colleague from Addis Ababa University was invited to code the same text to increase inter-coder reliability during the data coding process. Attention was paid to improving the reading and analysis as much as possible by overcoming the linguistic and cultural background differences of the research author and those interviewees from Kenya and South Africa.

\subsection{Limitations}

The key limitation of this research is that it did not gather data from external stakeholders such as policy-makers, business, donors, students, and other government representatives. In order to mitigate the impacts of this limitation on the findings of the research, we collected data from national laws, regulations and national development strategies and plans, which should more or less represent the views of these external actors. 


\section{$5 \quad$ The Ethiopian Case Study Universities}

\subsection{Introduction}

This chapter pulls together a wide range of data on the national development context of Ethiopia, its higher education system, and the Ethiopian case study universities, in order to answer the basic questions of the study. To aid the reader both in understanding the country-specific chapters (5-7) and in comparing the findings across the three countries (see chapter 8), this chapter is structured in line with the theoretical framework and research model discussed in Chapter 3, and the operationalisation of variables in Chapter 4. Following this introductory section, we provide background information about the demographic and socio-economic context of Ethiopia. In the third section, the evolution and structure of the Ethiopian higher education system, in terms of its size and shape, governance and management, and financing, are examined. The key characteristics of Adama Science and Technology University (ASTU) and Haramaya University (HU) are provided in section four, in line with the variables given in Table 4.1. The fifth section of this chapter explores the external environments of the Ethiopian case study universities, to determine stakeholder salience in terms of regulatory powers and funding. We investigate the drivers, enablers for, and barriers to revenue generation by ASTU and HU in section six. In section seven, we analyse the revenue generation strategies of the Ethiopian case study universities. Finally, we draw the conclusions of the chapter.

\subsection{Demographic and Socio-Economic Context of Ethiopia}

The Federal Democratic Republic of Ethiopia (hereafter Ethiopia) is a landlocked country located in the Horn of Africa with an area of 1.1 million square kilometres. The country is bordered by Eritrea to the north, Djibouti and Somalia to the east, Sudan and South Sudan to the west, and Kenya to the south. Ethiopia comprises the Federal Government and the State members. It is divided into nine ethnically based regional states ${ }^{25}$ and two chartered cities $^{26}$ (see Article 47 of the Ethiopian Constitution). The Ethiopian higher education system and organisations operate in a rapidly changing

25 The regional states are Oromo, Amhara, South Nations, Nationalities and Peoples, Tigray, Somali, Afar, Benishangul Gumuz, Gambela, and Harari.

26 Addis Ababa and Dire Dawa. 
environment. Changes in the demographic and socio-economic context of the country place new demands and pressures on the system in general and specific universities in particular. Ethiopia is currently the second most populous country in Africa, after Nigeria, with a $2.6 \%$ annual population growth rate (see Table 5.1).

Table 5.1: Key Population statistics for Ethiopia

\begin{tabular}{lllll}
\hline $\begin{array}{l}\text { Total } \\
\begin{array}{l}\text { Population } \\
(2010) \text { in }\end{array}\end{array}$ & $\begin{array}{l}\text { Proportion of } \\
\text { population } \\
\text { below the } \\
\text { age of } 15\end{array}$ & $\begin{array}{l}\text { Proportion of } \\
\text { population } \\
\text { between } \\
15 \text { and } 64\end{array}$ & $\begin{array}{l}\text { Proportion of } \\
\text { population } \\
65 \text { or older }\end{array}$ & $\begin{array}{l}\text { Population } \\
\text { annual } \\
\text { growth rate }\end{array}$ \\
\hline 85.0 & $41.5 \%$ & $55.2 \%$ & $3.3 \%$ & $2.6 \%$ \\
\hline
\end{tabular}

Source: UNPF, 2010

According to the Central Statistics Agency of Ethiopia (2008), the primary school age population (6-14 years) and the secondary age population (15-18 years) contain $27 \%$ and $11 \%$ of the total population of the country, respectively. The higher education age cohort (19- 23 years) accounts for $9 \%$ of the total population. We shall return to the pre-higher education system in section 5.6.2. Here it suffices to say that the higher education environment has been operating with a fast growing youth population that may create increased demands for university education.

Similarly, Ethiopia's higher education system operates in a rapidly changing economic environment. Although Ethiopia is still one of the poorest nations in the world, the country has recently recorded strong economic performances after remaining in recession for decades. Table 5.2 provides data on GDP (or income) per capita and other selected economic development indicators for Ethiopia (see World Economic Forum, 2011-12). 
Table 5.2: Selected Economic Development Indicators for Ethiopia

\begin{tabular}{llll}
\hline $\begin{array}{l}\text { Gross domestic } \\
\text { product per capita in } \\
\begin{array}{l}\text { current US dollars } \\
(2010)\end{array}\end{array}$ & $\begin{array}{l}\text { Rank out of } \\
\text { countries }\end{array}$ & $\begin{array}{l}\text { Stage of } \\
\text { development } \\
(2011-12)\end{array}$ & $\begin{array}{l}\text { Overall } \\
\text { competitive } \\
\text { ranking (out of 142 } \\
\text { countries) }\end{array}$ \\
\hline 350 & 106 & Factor-driven 27 & 106 \\
\hline
\end{tabular}

Source: WEF 2011-2012

Over the past 20-25 years, the Ethiopian economy has changed a great deal, with a transformation from a centrally planned economy into a market economy. A set of proclamations, policies and plans intended to move the economy in a market direction were introduced and implemented. The government of Ethiopia implemented a Sustainable Development and Poverty Reduction Programme (2000/01-2004/05) and a Plan for Accelerated and Sustained Development to End Poverty (2005/06-2009/10) for stabilising the economy, promoting structural reforms, and putting the country on the right path to reducing poverty. As a result, Ethiopia has become one of the fastest growing non-oil economies in Africa, with double-digit growth (MoFED, 2010) in the last decade. Chart 5-1 below depicts the economic growth of Ethiopia from 2007-2011.

Chart 5-1 Real GDP Growth Rates, 2007-11

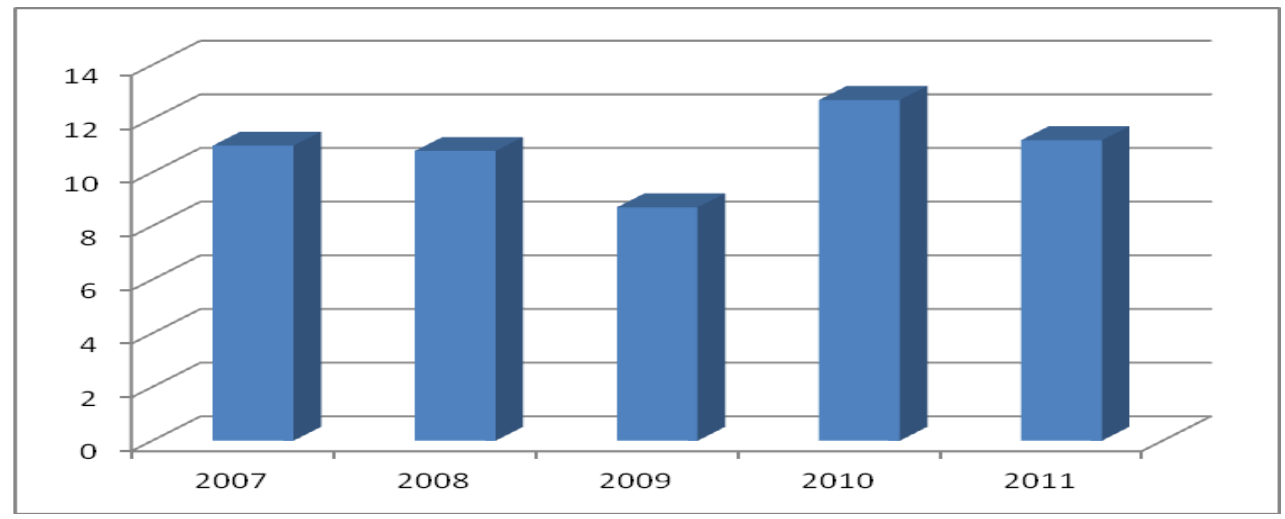

Source: accessed on 25 April 2013: http://www.africaneconomicoutlook.org/en/datastatistics/table-2-real-gdp-growth-rates-2003-2013/ or African Economic Outlook.

27 Ethiopia competes based on its factor endowments - primarily unskilled labour and natural resources. Companies compete based on price and sell basic products or commodities, with their low productivity reflected in low wages. 
Yet Ethiopia is a rural economy that is largely based on subsistence agriculture. The agricultural sector is the major driver of the economy and is a source of income for the majority (80\%) of the population. In 2009/10, this sector contributed about $41.6 \%$ to total real GDP, generated about $90 \%$ of export earnings, and supplied about $70 \%$ of the country's raw material requirements for agro-based large and medium sized industries. The service and industrial sectors respectively contributed $45.5 \%$ and $12.9 \%$ of the overall real GDP in the same year (MoFED, 2010:4). The economy in Ethiopia has been dominated by the public sector with little private enterprise. The state has subsidised and regulated both the production process and consumption. In 2010/11, the government of Ethiopia started to implement a Growth and Transformation Plan $(G T P)^{28}$ (2010/11-2014/15). According to MoFED (2010), the industrial sector will become the major driver of the economy by 2015 (pp56-63). The recent economic growth has led to substantial funding increases for higher education from the government treasury (see Section 5.3.4), which has resulted in the establishment of several public universities (see Section 5.3.1). The shift from an agriculture-led to an industry-led economy is expected to shift the structure of the labour market towards services, trade, and knowledgeintensive industries, where most employment positions require higher education degrees. A devolution of power to lower tiers ${ }^{29}$ of the government (see Chapter 5 of the Constitution, 1994), the relative political stability of the country, and a need for building the overall implementation capacity of regional states all enhance the role of higher education in national development strategies. The Ethiopian socio-economic and political context may cause multiple facets of partnerships between universities and regional states in order to sustain the overall growth of Ethiopia.

\subsection{Ethiopia's Higher Education System at a Glance}

As has been shown in section 5.2, the socio-economic context in which Ethiopian higher education organisations operate has been changing rapidly. The environmental changes have translated into specific demands on universities to contribute to the development of the country through education and research (see MoE, 1997; MoE, 1997a; MoE, 1997b; MoE, 2002; MoFED, 2002; MoE, 2004a; World Bank, 2004; MoE, 2004; MoE, 2005; MoE, 2008; MoE,

28 This national planning document has identified key macroeconomic and sectoral targets (MoFED, 2010:34-37).

29 Ethiopia has a three-tiered federalist system of government: the federal government; nine administrative regions and two chartered city administrations; and over 800 Woredas and sub-cities. 
2010). Ethiopian higher education organisations have been asked to expand access, improve quality, reduce costs, and ensure effectiveness. In an effort to meet these demands, universities in Ethiopia have been heavily steered by the government, using various regulatory frameworks (see Table 5.16). According to a Higher Education Proclamation of Ethiopia (650/2009, Article 2, No.8 and Article 19), higher education is defined as education in the arts and sciences offered to undergraduate and graduate students who attend degree programmes through regular, continuing, and distance or virtual education (see Higher Education Proclamation). In the following section, we briefly provide some data on the Ethiopian higher education system, focusing on its size and shape, governance and management, and financing.

\subsubsection{Size and Shape of the Ethiopian Higher Education System}

Ethiopia's experience with modern higher education is a recent phenomenon. Modern higher education commenced with the creation of Trinity College with the assistance of Canadian Jesuits during Haile Selassie's regime in 1949 (Lulat, 2003). This College was upgraded to the University College of Addis Ababa in 1950. The University College became Haile Selassie I University in 1961, and was then renamed as Addis Ababa University (AAU) following the abolition of the Monarchy in 1974. Two additional colleges were upgraded to the status of university between 1961 and 1991: Alemaya Agricultural University (1985) and Asmara University (1991). Asmara University dropped out of the list of Ethiopian universities following Eretria's separation from Ethiopia in 1993. Until 1999, Ethiopia had two universities (Addis Ababa and Alemaya) and seventeen colleges (Habtamu Wondimu, 2003).

The push from expanding pre-higher education access (see section 5.6) and growing demand for higher education graduates in the Ethiopian economy, alongside pressure from the international community, have contributed to the increased government interest in expanding access to higher education. In 1999, several colleges in different regions of the country were merged to form universities. Bahir Dar, Debub (now Hawassa), Jimma, and Mekelle universities were officially created by amalgamating colleges in the towns of Bahir Dar, Awassa, Jimma and Mekelle and their vicinities. Most of the organisations in this category served as colleges for an extended period, supervised by an old established place (often Addis Ababa University). From 2004 to 2007, without going through a merger process, five additional higher education organizations - Gondar (2004), Arba Minch (2004), Adama (2005), Ambo (2007), and Dilla (2007) - were upgraded to full university standing. Despite opening access to 
students from all over the country, almost all established universities were still located in the major cities and towns.

Limited expansion in terms of geographical distribution and student enrolments appeared to make the Ethiopian government very impatient about establishing universities from organisation already acting as colleges. Eleven new universities were established from scratch in 2007. These universities held the name of 'university' without fulfilling minimum national standards set by the law (see Proclamation 650/2009, Article 11, No. 1(a-d)). Given this special opportunity, they have served to expand access to higher education (see Section 5.3.2). Ten new additional universities started admitting students in 2012. Thirty-one public universities are now under the auspice of the Ministry of Education (MoE). All but two were established after 1999. There are also five higher education organisations under the auspice of different governmental bodies (not MoE). These include Ethiopian Civil Service University, Defense University College, Ethiopian Police University College, Telecommunication and Information Technology College, and Kotebe Teachers Education College. Moreover, Ethiopia is now home to private higher education organisations. Since the mid-1990s, private higher education institutions have been allowed to operate in the country. Three institutions, Alfa Distance Education College, the Ethiopian Adventist College, and Harar Sewotch-le-Sewotch Technical College, started operating in 1996 (see Wondwosen Tamrat, 2008). Currently 65 accredited private higher education institutions are operating in different parts of the country (MoE, 2011). The growth in the number of universities in Ethiopia makes it one of the fastest growing higher education organisations in the world.

\subsubsection{Participation in Higher Education}

The growth in the number of the Ethiopian higher education organisations has led to a rapid expansion in student enrolments. Ethiopia's higher education participation rate (GER) increased from 3.6\% in 1999 to $6 \%$ in 2010/11 with an average annual growth rate of $23 \%(\mathrm{MoE}, 2011)$. This figure is very close to the average for Sub-Saharan Africa (around 6\%). The total number of higher education students rose from 120,384 in $2004 / 05$ to 467,843 in 2010/11. In 2010/11, the private higher education institutions accounted for $79,314(17 \%)$ of the total student population. In terms of educational programmes, about $447,693(96 \%)$ students were enrolled in undergraduate programmes and the rest 20,150 (4\%) students were enrolled for postgraduate studies. Of all postgraduate enrolees of 2010/11, 19,361(96\%) students were enrolled for Master's degrees and the remaining $789(4 \%)$ were PhDs. Only ten public 
universities and two private higher education institutions ran graduate programmes in that year. The private sector's share of the postgraduate enrolees was $875(1.1 \%)$. No private higher education institutions offer $\mathrm{PhD}$ level training.

The rapid growth in higher education enrolments is not unlike what happened in most Western European states in the late 1970s until the early 1990s and in Central and Eastern Europe in the 1990s after the fall of the Berlin Wall. Ethiopia's higher education system can still be described as the system financed by the entire population, but it is available to only a tiny minority amid excess demands for university education. A structure of dual track tuition fees has been in place in Ethiopia for decades. This system has operated as something of a safety valve in terms of balancing public expenditure and societal expectations. In 2011, while 51\% of the total student population was regular (directly placed by the MoE), the remaining $49 \%$ were full cost paying programmes such as evening (13.3\%), summer (20.4\%), and distance education (9.1\%). The latter groups are taught in entirely separate classes from their counterpart regular students. The government of Ethiopia has, once again, set ambitious targets to reach 467,000 in gross admissions for undergraduate programmes by 2015, up from 185,788 students in 2010 (MoFED,2010:89-90).

Despite expanding access rapidly, the Ethiopian higher education system has faced serious challenges that include, among others, issues of financing ${ }^{30}$, relevance, quality, and overall governance and management $(\mathrm{MoE}, 1997 ; \mathrm{MoE}$, 2004a; World Bank, 2004; MoE, 2004; MoE, 2005; MoE, 2008; MoE, 2010; Mulu Nega, 2012). Although the number of academic staff doubled from 8,355 in $2006 / 07$ to 17,402 in 2010/11, the breakdown of full time academic staff by highest academic qualification was $6 \%$ PhD holders, 50\% Master's, and the remaining 44\% Bachelor holders in 2010/11 (MoE, 2011:63). This is far lower than the national standards require (30\% $\mathrm{PhD}, 50 \% \mathrm{MA} / \mathrm{MSc}$, and $20 \% \mathrm{BA} / \mathrm{BSc})$. There is a consensus among stakeholders that the quality of higher education in the country is deteriorating because of an inability to meet the requirements for good quality inputs such as staff, equipment, books, and adequately prepared students (Mulu Nega, 2012).

30 Annual recurrent public expenditure per student is less than $\$ 600$, a $30 \%$ reduction over the last two decades. It is far less than the average of $\$ 10,000$ per student for OECD countries. 


\subsubsection{Higher Education Governance and Management in Ethiopia}

Governance of higher education can concern both the internal (organisational) and external (system) governance of higher education organisations. In this section, we focus on external governance, which refers to the institutional arrangements on the macro- or system-level. The internal governance of the Ethiopian case study universities will be discussed in sections 5.4.1.2 and 5.4.2.2. Public universities in Ethiopia are mainly steered by higher education proclamation 650/2009, and this law urges them to place a premium on effectiveness, efficiency, and public accountability (see Article 53 No. 1(j)). Higher Education governance and management in Ethiopia takes place through interconnected policy levels with a substantial number of actors influencing agenda setting, policy development, policy determination, policy implementation, and evaluation. The House of Peoples' Representatives, the Council of Ministers, the Ministry of Education (MoE), the Ministry of Finance and Economic Development (MoFED), the Ministry of Civil Service (MoCS), the Ministry of Science and Technology (MoST), the Higher Education Strategy Centre (HESC), and Higher Education Relevance and Quality Agency (HERQA) are all key regulatory bodies for higher education in Ethiopia (see section 5.5).

These public authorities set regulatory frameworks for steering the Ethiopian higher education system in general and individual universities in particular toward societal goals for higher education. The House of Peoples' Representatives and the Council of Ministers set out the general legal framework for the development of higher education in Ethiopia. As the key regulatory authorities, these two actors collectively determine and approve higher education law and budget (See Article 55 of the Constitution of Ethiopia). In particular, the Council of Ministers (as the most important executive government organ) holds responsibility for preparing and presenting higher education law to the parliament (see Article 74 Constitution, 1994). For instance, a public higher education institution financed by the Federal Government can only be established by the regulation of the Council of Ministers (Proclamation 650/2009 Article 5, No.1). A regulation for cost sharing is another example of this (No.154/2008).

The Federal Ministry of Education of Ethiopia is the highest responsible body for defining and ensuring Ethiopia's higher education system's responsiveness to the public interest. The MoE is mandated to steer the higher education system and organizations within the broad legal and policy framework (see Article 88 No. 1-13 of the Proclamation 650/2009). Duties and responsibilities of the ministry include: defining the relevant and minimum national educational quality standards, determining the requirements for degrees, ensuring the 
implementation of the national policy and strategy on higher education, ensuring fair and just student placement, determining key criteria for student admissions, determining criteria and standard procedures for government funding of institutions, issuing directives on higher education affairs, aligning higher education programmes with labour market demands, and appointing the president and board members.

The Ministry of Finance and Economic Development (MoFED) is one of the important stakeholders in the Ethiopian higher education landscape. MoFED prepares and administers the higher education budget from the government treasury and supports public universities in negotiating, mobilising, and signing foreign development assistances and loans with bilateral countries and multilateral organisations (Proclamation, 651/2001). It determines the budget ceiling of each public university, makes a budget call, organises budget hearings, recommends the annual budgets for each public university, submits the draft budgets for review and endorsement by the highest executive and legislative bodies, and finally monitors the implementation of the proclaimed budget. In terms of human resource policies and management, the Ministry of Civil Service (MoCS) is an important stakeholder for issuing directives regarding the planning of administrative support staff at public universities. The MoST's main role is to register technologies generated in the processes of executing research projects.

HESC and the HERQA are intermediary bodies between universities and the government with responsibility for overseeing quality assurance and the expansion of university education by ensuring the sustainability, affordability and relevance of academic programmes (See Articles 89 and 90 of the Proclamation 650/2009 for HERQA's and HESC's powers and duties respectively). The establishment of these intermediary bodies resembles what Neave referred to as the "Evaluative State" (Neave, 1998) or Power called the "Audit Society" (Power, 1994). However, these are yet to be realised in the Ethiopian higher education landscape. For instance, the establishment of public universities through governmental regulations did not make them subject to the accreditation process of HERQA. The heavy involvement of the government itself in planning, budgetary matters and maintaining the quality of public universities has denied these organisations an active role as stipulated in the Higher Education Proclamation (650/2009). HERQA, for instance, presides over matters of accreditation in private higher education organisations only. 


\subsubsection{Financing Higher Education in Ethiopia}

The rising demand for higher education necessitates huge investments in the Ethiopian higher education system. The investment comes from the government treasury, and a variety of revenue generating initiatives including funding from donors in the form of loans and assistance. The government of Ethiopia is seriously committed to spending on higher education, as indicated in Table 5.3 below.

Table 5.3: Government funding for education and the share allocated to higher education in Ethiopia

\begin{tabular}{lccc}
\hline Category & $\mathbf{2 0 0 0 / 0 1}$ & $\mathbf{2 0 0 5 / 0 6}$ & $\mathbf{2 0 1 0 / 1 1}$ \\
\hline $\begin{array}{l}\text { Education share of GDP (\%) } \\
\begin{array}{l}\text { Education share of Government } \\
\text { Budget (\%) }\end{array}\end{array}$ & 2.80 & 3.20 & 7.00 \\
$\begin{array}{l}\text { Higher Education share of Education } \\
\text { Budget (\%) }\end{array}$ & 18.40 & 17.80 & 25.90 \\
\hline
\end{tabular}

This $7 \%$ of GDP financial investment in education is higher than the 3.9\% average for Sub-Saharan Africa. The $31.7 \%$ share of the education budget devoted to higher education is almost twice the $15 \%$ to $20 \%$ range used as a World Bank guideline (World Bank, 2002). Placed in the international context, the Ethiopian higher education system takes a very high percentage of the education budget from the government (See World Bank, 2010). However, annual recurrent expenditure per university student is roughly Birr 12,750 (US\$750) with the university providing food, lodging, and health care to students. It becomes Birr 10,812 (US\$636) when student welfare subsidies for students are excluded (World Bank, 2004). The university community often considers this level of funding for public universities to be low.

The government of Ethiopia provides both recurrent and capital budgets to its public higher education organisations through the Ministry of Finance and Economic Development (MoFED). By and large, the funds are allocated through a negotiated funding model that is based on detailed line-by-line budgets. The allocation procedure is based on the previous year's allocations, augmented by across-the-board incremental increases whenever possible. According to data obtained from MoFED (our own calculations), Ethiopian public universities received an average of around $62 \%$ of the total budget they requested from 2006 to 2011. Funding for research from the government treasury is often insignificant or totally unavailable because of soaring student enrolment that 
favoured allocations to teaching instead of research, and to undergraduate instead of postgraduate training. The inadequacy of funding has limited universities' ability to invest in infrastructure, research facilities, and equipment, thereby hindering their overall research capacity. The consequences of this situation are evident when one considers the minimal contribution of Ethiopian universities to international academic research (see World Bank, 2010). Notwithstanding the fact that education and research are combined and produced together within single university by sharing resources, the complementarities between them are more obvious for postgraduate programmes than for undergraduate education, on which Ethiopian public universities are currently focusing (see section 5.3.2). As of 2012/2013 fiscal year, the government of Ethiopia slightly modified its budget allocation mechanism by providing money to learning and teaching, research and development, consultancy and community services, and management and administration.

The Ethiopian higher education landscape has been subject to four public higher education funding policies. These include the period of free higher education (prior to 2003), the period of cost sharing, the period of revenue generation, and a shift in resource allocation mechanisms. The latter three policies were introduced in a 2003 higher education proclamation (351/2003). Prior to 2003, public higher education in Ethiopia was mostly free, with the government covering almost all costs such as tuition fees and living expenses. The notion that the government had to provide its people with higher education "free" of charge was a dominant feature. It was argued that unless the government subsidised higher education, many students (particularly from poor families) would be unable to benefit from it, and ensuring free-higher education was seen as the surest method for the government to achieve the goal of social equity. The social rates of returns (externalities) of higher education as the epicentre of social and economic development promoted full government funding of higher education. In practice, however, the policy of free higher education has never been realized in Ethiopia because household financing for higher education in Ethiopia has been the norm for quite sometimes (with the start of the continuing education programme in the then University College of Addis Ababa in 1952). As charging fees were not politically feasible during the previous regimes, private financing of higher education had never been legally acknowledged up until 2003. Hence, the idea of higher education as a public service was overwhelmingly the dominant model.

In 2003, the government of Ethiopia introduced the cost sharing scheme (see Article 92 of Proclamation (650/2009), and also see Regulation No. 154/2008) for undergraduate regular students who have achieved above a certain cut-off point on a University Entrance Examination (UEE), and who are allowed to 
access no-obligatory payment places as they learn. They are required to share full costs related to board and lodging (the cost of housing, food, and other student living expenses was previously borne largely by government) and a minimum of $15 \%$ of tuition related costs through a graduate tax scheme or in services (Regulation No.154/2008 Article 4 No.1). This graduate tax scheme is an income-contingent repayment obligation that awards low-cost places to a limited number of students (undergraduate regular students) based on their performance on the above exam. In 2011, about 51\% of the total student population was regular (government-sponsored) and allowed to pay their higher education expenses through the graduate tax scheme. The other group $(49 \%)$ was fee-paying students who have achieved lower marks in the entrance exams (the UEE) and are admitted to available places on a fee-paying basis (pay as you learn). The existing fee-paying structure seems to trigger debate as it assumes that there are no externalities accruing from the education of students who receive no public support for their tuition or who are not allowed to benefit from the cost-sharing scheme.

The second major policy shift was a change of budget allocation mechanism (Article 62 Nos. 1-2) of the government from the existing line item budgeting to block-grant budgeting. Although block grant budgeting has been legally approved as the budget allocation mechanism for public funding, it has never been implemented to date. Instead, the government began to allocate budgets to public universities in four categories, which consist of learning and teaching, research and development, consultancy and community services, and management and administration as of 2012/2013 fiscal year.

Thirdly, the government made a broad policy shift in allowing public universities to engage in income generation initiatives (see Articles 66 and 67). As a sign of its commitment to revenue generation by public universities, the government went to the extent of allocating an initial capital fund for operating revenue generation activities (See Higher Education proclamation 650/2009, Article 66, No.3). Public universities were engaged in revenue generation from different sources prior to this legal requirement. Ethiopian public universities generate resources from a variety of sources such as student tuition fees, donors, regional and local states, campus services (hiring facilities), agricultural products, consultancy, industrial firms, etc. (see Section 5.5). Although the amounts earned from these activities are difficult to document due to inadequate record keeping and a perceived fear of facing budget reductions, on average Ethiopian public universities generate approximately $5 \%-10 \%$ of their total recurrent budget. The amounts of income generated varies from university to university, ranging from $20 \%$ to $35 \%$ of the total recurrent budget in some relatively established 'old' universities to less than $3 \%$ in newly opened 'young' 
universities. The major source of the revenue is currently tuition fees, followed by donor contributions. We shall discuss the revenue generation strategies and activities of the Ethiopian case study universities in more details later.

\subsection{Key Characteristics of the Ethiopian Case Study Universities}

In this section, interviews and documentary data concerning university specific factors are presented following the research model in Chapter 3 and the operationalisation of key variables in Chapter 4 . The section begins with the key characteristics of Haramaya University (HU), followed by those of Adama Science and Technology University (ASTU).

\subsubsection{Haramaya University (HU)}

Haramaya University is the second oldest higher education organisation in Ethiopia. It opened its doors to students in 1954/55. Located in a typical rural setting about $510 \mathrm{kms}$ from Addis Ababa at a distance of about $20 \mathrm{kms}$ and $40 \mathrm{kms}$ from the towns of Harar and Dire Dawa, some might argue that the location was hardly a favourable environment for a university. Alemaya town itself is a minor place that offers little cosmopolitan life to attract senior academic and administrative staff compared to other areas in Ethiopia hosting public universities. The university has operated as College of Agriculture and Mechanical Arts (1954-1984), Agricultural University (1985-1994), and Comprehensive University (1996 to present). Haramaya University relied heavily on Oklahoma State University in the USA for the overall operation of the organisation from 1954 to 1963. Because of its long association with the Oklahoma State University, $\mathrm{HU}$ has possibly developed a particular educational culture, particularly in the area of research of its founding college, Agriculture. From the start the university had the special features of a "campus college" with all academic, administrative, and service units brought together in one place. Currently, HU consists of three campuses in the towns of Haramaya, Harar and Chrio.

\subsubsection{Missions of the University}

According to its strategic plan, the vision of $\mathrm{HU}$ is "to be among the leading universities recognised nationally and internationally for excellence in teachinglearning, research and community services." The university's mission statement is "to produce competent graduates in a wide spectrum of academic disciplines through quality education; to undertake academically rigorous and socially meaningful cutting edge applied and basic research in national priority areas, 
and to disseminate knowledge and technologies and provide community services." The goal of HU is to evolve as an autonomous and independent graduate and research university with competitive national and international quality and relevance standards in its academic, research and community service endeavours. The university wants to focus primarily on research projects that transfer technology for the benefit of society through better products and services, improved life for farmers, and economic development. The commercialisation of products and services is one mechanism to that end. The university opts for establishing a 40:40:20 ratio of academic, research and community engagement responsibilities as an operation principle for realising its missions (Haramaya University, 2008b: 96). Moreover, HU values the need for partnership with external entities, community engagement, commercialisation, and revenue generation (Haramaya University, 2008a:55; Haramaya University, 2008b:29, 102).

\subsubsection{Internal Governance and Management of HU}

The 2009 higher education proclamation (650/2009) of Ethiopia states that the governance and management of public universities is based on corporate governance models. This suggests that public universities are mainly considered to be stakeholder organisations rather than a republic of scholars. Fig. 1 below depicts the multilevel internal governance of $\mathrm{HU}$, which is more or less organised according to Articles 43 to 57 of the higher education proclamation 650/2009. 
Figure 5-1 Organisational structure of Haramaya University

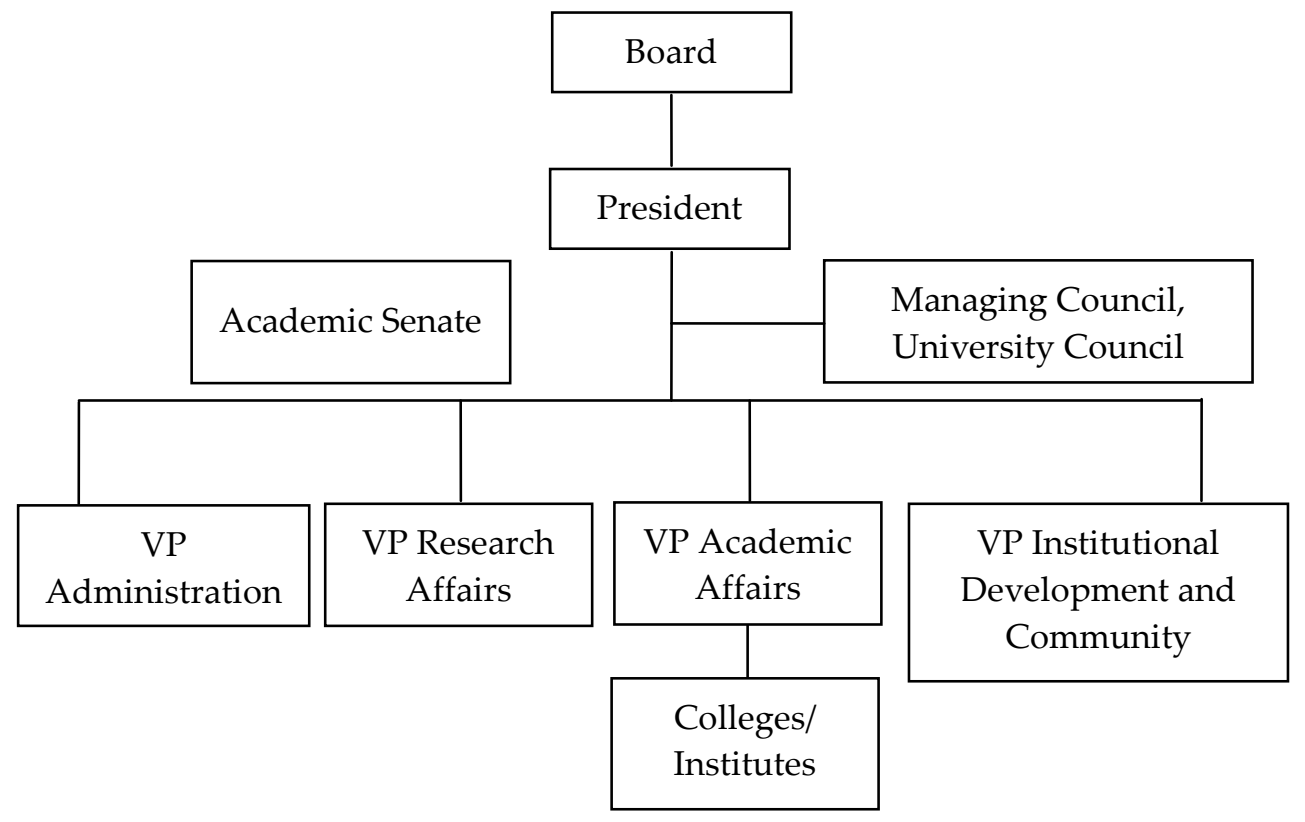

The board of the university is the supreme governing body of the university (see Article 44 No. $1(\mathrm{a}-\mathrm{v})$ ) and is answerable to the MoE. It composed of seven ${ }^{31}$ voting members who are mainly drawn from government offices (heavyweight politicians from Regional States and Federal ministries), senior members of governing political party, and representatives from the private sector. The heavy presence of the government in the university's governance continues, despite the buzzwords in political debates such as organisational autonomy, and academic freedom and excellence. The board, among others, approves $\mathrm{HU}^{\prime}$ s strategic and operational plans and the budget, policies, promotions of academic staff to the rank of professorship, and the university's internal regulations. It nominates the president for appointment by the MoE, and appoints the vice presidents itself. The board also rescinds decisions made by the president or the senate when it feels that the decisions compromise organisational missions. According to one university leader, the previous power of the MoE has now been transferred by law to the board of the

31 MoE selects and appoints the board chairperson and three additional voting members to the board, and the president, in consultation with the university council and the senate nominates three other voting members of the board and submits their list for appointment to the Minister of Education. 
university, which can be considered to be MoE's 'twin' or 'cousin', as it is heavily dominated by the government's office holders.

The Senate is the leading body of the university for academic matters (see Proclamation 650/2009 Article 49 Nos.1-12), and is accountable to the university president. Its members include president, vice presidents, deans, academic programmes officer, public relations directorate, registrar, and two representatives each from academic staff and students. Traditionally, the academic senate of an Ethiopian pubic university had extended responsibilities for making decisions on academic matters as well as on financial and structural aspects. Following the ratification of the proclamation (650/2009), however, the power of academic senate has been substantially modified and limited to an advisory role. In other words, the decision-making power of the senate has been largely limited to accrediting academic programmes and their curricula, supervising academic units to ensure the relevance and quality of education and research, approving the employment of academic staff with the rank of professor, and approving the opening, closure or merger of academic units. Most deans and department heads who participated in the interviews told us that the reduction of the authority of the senate to only academic affairs negates the 'collective wisdom and collegial decision-making on which the very idea of a university is based.'

The president of the university is a chief executive officer (CEO) and an academic leader (see Article 53 No.1). The MoE appoints the president. The president as the CEO, among others, directs and administers the university to achieve its missions; connects the organisation internationally as well as with federal and state organisations, agencies, business and industry, and associations; manages finance, and ensures the implementation of the higher education law (see Article 53 No.1 (a-z)). This indicates that the position of the president has strengthened significantly. Former responsibilities of the senate and some of those of the MoE have been legally transferred to the president, which leads to a concentration of executive authority in the office of the president. This is particularly true for formal powers. However, in practice, the president does not always have the opportunity to fully exploit - his enhanced powers. The vice presidents who participated in the interviews told us that MoE's interference in aspects of academic management such as curriculum design and recruiting graduate assistants undermines the enhanced powers of the president. Similarly, within the university, this steering philosophy (the president as the CEO) seemed to be less popular, as most internal actors still demand collegial leadership. 
The president ${ }^{32}$ of HU is assisted by four Vice Presidents: Academic Affairs, Research Affairs, Institutional Development and Community Engagement, and Administration and Students Affairs ${ }^{33}$. Under the university president and the four vice presidents, twenty-five different offices were established. The Vice President for Academic Affairs ${ }^{34}$ is responsible for planning, directing and supervising the activities of academic units and programmes of the university. Colleges and institutes/centres are organised under this vice president. While deans head the colleges, the four offices (see the footnote) are managed by their respective directors. Since 2009, former faculties (in some cases departments) have been merged into colleges and institutes to form active teams who could smoothly collaborate on cross-disciplinary subjects. Schools and departments are still the building blocks of the university, where teaching and research are housed and performed. Although in most public universities in Ethiopia research and teaching are intertwined within one vice president's office, HU established a separate office of the Vice President for Research Affairs (VPRA) ${ }^{35}$ in 2009. The senior university leaders described this move as a sign of according research sufficient priority as per Article 24 of the Proclamation 650/2009.

Community service was a founding mission of $\mathrm{HU}$, but was subordinated to the teaching and research missions of the university until 2009. HU has not maintained institutionally defined programmes and associated staff positions for its outreach mission. In 2009, the office of Vice President for Institutional Development and Community Engagement (VPIDCE) was created to promote the community and consultancy services of the university. The creation of this

32 In addition to the four vice presidents, the offices of Diversity, Affirmative Action Programmes and Legal Affairs, Institutional Quality Assurance and Internal Auditing, Strategic Planning, and Monitoring \& Evaluation, Institutional Transformation and Advancement, Alumni Relations and Endowment Fund, and the University Relations offices are directly answerable to the president and are headed by directors.

33 Consists of Finance, Procurement and Property Management, Human Resource Management, Estate and Facilities Management, and Student Services. All are headed by their own directors.

34 In addition to Colleges and Institutes, the vice president for academic affairs is responsible for offices like ICT, Student Academic Support Service, Programme Development and Promotion, and Library and Information Service.

35 Consists of five offices; namely: Research Groups, Research Partnerships, Research Promotion and Marketing, Research Facilities, and Student Research that are headed by their own directors. The office for Research Promotion and Marketing consists of two officers: Knowledge and Technology Transfer Officer and a Research Commercialisation Officer. 
structure was an attempt to end the peripheral role of community service in the university system. This senior leadership position also offers policy leadership for revenue generation by the university. The VPIDCE encompasses such offices as Development Work, Service Learning, University Enterprises, Consultancy and Short-Term Training, Enterprise Promotion and Marketing, and Legal Support and Intellectual Rights Protection. These outreach administrative units aim to promote contract education, contract research, short-term training, and consultancy to link the university with its external stakeholders with the ultimate goal of generating and diversifying income. We will return to this issue under revenue generation strategies (see Section 5.8)

Two other important presidential advisory bodies that are prescribed by law are the managing council (Article 56 No. 1) and the university council (Article 57). The former council includes the president, the vice presidents, and other officers in charge of university-wide student affairs. This council advises the president on strategic issues; and serves as a forum for monitoring, coordination, and evaluation of the university's operations. The latter council consists of the managing council, all deans, directors, members of the senate standing committee, the chief librarian, the registrar, other key academic officers, and representatives of academic staff and students (Article 57 No. 1 of the proclamation 650/2009). It advises the president on organisational proposals regarding plans, budgets, organisational structures, academic programmes, agreements of cooperation, and on division, merger, and closure of academic units. These two councils are yet to become operational at HU. As it stands today, HU has over 15 standing or ad hoc committees which are spin-offs from the university Board, Senate and the (vice) Presidents. These committees try to ensure collegial steerage or reinforce strong academic traditions by bringing academic points of view into decision-making circles.

Each college or institute is organised into one or more department(s) and/or school(s) (see Table 5.5). They have a dean and an academic council (or academic commission) accountable to the dean. The members of the academic commission are the dean (chair), deputy deans, heads of departments, associate registrar, a representative of students, a representative of academic staff, and other offices such as postgraduate coordination office, continuing and distance education contact point, and research and publication officer. At the operational level is a school or a department with its head (see Section 5.5.3c). A department assembly is another governance structure, which consists of all full-time academic staff and is chaired by the department head. The assembly deliberates on and submits proposals about programmes, plans, curricula, courses, certification, staff promotions, teaching materials, examination, and students' status to the academic commission. 


\subsubsection{Student Population and Areas of Study at Haramaya University}

Since its establishment, HU has enjoyed a consistent growth in its student population. Beginning with a tiny enrolment of less than 100 students in 1954, the University enrolled 30,634 students in 2011 as indicate in Table 5.4.

Table 5.4: Total student population in 2010/11

\begin{tabular}{lccccc}
\hline $\begin{array}{l}\text { Level of } \\
\text { Education }\end{array}$ & Regular & $\begin{array}{l}\text { Continuing } \\
\text { Education } \\
\text { (Evening) }\end{array}$ & Summer & Distance & $\begin{array}{l}\text { Grand } \\
\text { Total }\end{array}$ \\
\hline $\begin{array}{l}\text { Undergraduate } \\
\begin{array}{l}\text { Postgraduate } \\
\text { (Master's) }\end{array}\end{array}$ & 14914 & 2013 & 6292 & 4551 & 27770 \\
$\begin{array}{l}\text { Postgraduate } \\
\text { (PhD) }\end{array}$ & 1310 & 460 & 997 & & 2767 \\
\hline Total & 97 & & & & 97 \\
\hline
\end{tabular}

Source: Haramaya University, 2011

As indicated in Table 5.4, 90.7\% of students were enrolled in undergraduate programmes, while the remaining $9.3 \%$ were enrolled in postgraduate study in 2011. In terms of educational programmes, HU was limited to agricultural fields ${ }^{36}$ between 1954 and 1996. Since 1996, the University has diversified its academic programmes into non-agricultural fields (see Table 5.5) in response to shortages of skilled labour in the country. In particular, the MoE strongly pressed the university to diversify its programmes into non-agricultural fields, as reported by a dean and a department head who participated in the interviews. In 2011, HU had 61 undergraduate, 56 Master's and $13 \mathrm{PhD}$ programmes in its twelve colleges, three institutes and six research centres.

36 Two instances could, however, be noted where HU had attempted to offer nonagricultural curricula (Home Economics in 1967, and Biology and Chemistry in 1978) at diploma level. These programmes were fully phased out in 1984, and were substituted by three new agricultural fields at the same level. 
Table 5.5: Number of Schools and departments in 2011

\begin{tabular}{|c|c|c|c|}
\hline College/School & School & Department & $\begin{array}{c}\text { Year of } \\
\text { foundation }\end{array}$ \\
\hline $\begin{array}{l}\text { Agriculture and Environmental } \\
\text { Studies }\end{array}$ & 4 & 1 & 1954 \\
\hline Business and Economics & - & 5 & 2002 \\
\hline Computing and Informatics & 1 & 4 & 2008 \\
\hline Health Sciences & 1 & 2 & 1996 \\
\hline Social Sciences and Humanities & 1 & 5 & 1996 \\
\hline Medical Sciences & 2 & 1 & 2007 \\
\hline Law & - & - & 2002 \\
\hline Veterinary Medicine & - & - & 2003 \\
\hline Natural and Computational Sciences & - & 5 & 1996 \\
\hline Institute of Technology & 1 & 3 & 2004 \\
\hline Education and Behavioural Sciences & - & 3 & 1997 \\
\hline Continuing and Distance Education ${ }^{37}$ & - & - & 1963 \\
\hline School of Graduate Studies38 & 1 & - & 1979 \\
\hline Total & 11 & 29 & \\
\hline
\end{tabular}

Source: Haramaya University, 2011

Research is the founding mission of HU. Although research output has lagged behind the educational accomplishments of the university (see Haramaya University, 2008b), it (research) was not totally left out. The university has predominantly undertaken research in agricultural fields (more than 95\% of research outputs). The newly opened colleges (since 2003) are yet to develop their research capacity in terms of human and non-human resources. In 2008, for instance, less than $10 \%$ of HU's academic staff (Master's and PhD holders) engaged in some sort of research, and this achievement was, on average, estimated at one mega research project per twenty six academic staff

37 Continuing Education Programme, Summer-in-service Programme, and Distance Education Programme Coordination office were established across all colleges and institutes.

38 Postgraduate coordination office across all colleges and institutes. 
(Haramaya university, 2008:98). The 'young colleges ${ }^{39}$ suffer from a shortage of academic staff holding higher scientific degrees (see Section 5.4.1.4). HU was not able to lie down academic departments that are strong on research performance and outcomes. The university devised a strategy that includes organising thematic areas, changes in research organisation and management, increasing academic staff time spent on research from $25 \%$ to $40 \%$, a minimum target of one publication per academic staff member per year, and five active research projects in a research group per year. As outlined in its strategic plan, by 2010 about $25 \%$ of HU's academic staff held competitive national and international research grants and the research income of the university had increased by $50 \%$ (Haramaya, 2008b:29 \& iv). Limited research infrastructure and capacity was the cause of not meeting the targets mentioned above.

\subsubsection{Academic and Administrative Support Staff}

As universities are generally labour intensive, the knowledge and experience of their staff are of paramount importance in achieving organisational missions (see Chapter 3). The creation and dissemination of useful knowledge is dependent on knowledge embedded in people, largely in academic staff and researchers. Table 5.6 below presents HU's academic staff numbers and qualifications from 2006/07 to 2010/11.

Table 5.6: Academic staff numbers and composition

\begin{tabular}{lccccc}
\hline \multirow{2}{*}{ Degree Level } & \multicolumn{5}{c}{ Number of Academic Staff } \\
\cline { 2 - 6 } & $2006 / 07$ & $2007 / 08$ & $2008 / 09$ & $2009 / 10$ & $2010 / 11$ \\
\hline PhD & 74 & 78 & 74 & 62 & 100 \\
MA/MSc/MD/MED/DV & 150 & 156 & 187 & 219 & 235 \\
M & 177 & 216 & 242 & 293 & 498 \\
BA/BSc/BED/LLB & 401 & 450 & 503 & 574 & 833 \\
Total &
\end{tabular}

Source: Haramaya University (2006/07-2010/11)

In 2011, HU had 833 academic staff, of whom 93\% were Ethiopians and 7\% were expatriate staff. The 65 expatriate instructors (17 Master's and $48 \mathrm{PhD}$ ) came from India, the Philippines, European countries, and the USA. From 2006 to 2011 , the number of academic staff grew by $182 \%$. There was a particularly

39 Includes Law, Business and Economics, Veterinary Medicine, Health Sciences, Education and Technology 
rapid growth $(181 \%)$ in the number of staff with first-degrees. The number of Master's and $\mathrm{PhD}$ holders grew by $57 \%$ and $36 \%$, respectively in the same period. The proportion of academic staff with doctorates is close to $12 \%$, which is below the average for universities having a strong focus on research and postgraduate studies. As shown in Table 5.7 below, HU suffers from shortages of experienced senior staff (particularly PhD holders) across its colleges, although variations do exist between the colleges.

Table 5.7: Academic Staff Volume and Composition by College/Institute in 2011

\begin{tabular}{|c|c|c|c|c|c|c|c|}
\hline \multirow{2}{*}{ College/Institute } & \multicolumn{2}{|c|}{ Bachelor's } & \multicolumn{2}{|c|}{ Master's } & \multicolumn{2}{|c|}{ PhD } & \multirow{2}{*}{ Total } \\
\hline & Number & $\%$ & Number & $\%$ & Number & $\%$ & \\
\hline $\begin{array}{l}\text { Engineering and } \\
\text { Technology }\end{array}$ & 58 & 71 & 18 & 22 & 6 & 7 & 82 \\
\hline $\begin{array}{l}\text { Natural and } \\
\text { Computational } \\
\text { Sciences }\end{array}$ & 55 & 48 & 43 & 37 & 17 & 15 & 115 \\
\hline $\begin{array}{l}\text { Medicine and } \\
\text { Health Sciences }\end{array}$ & 118 & 97 & & 0 & 4 & 3 & 122 \\
\hline $\begin{array}{l}\text { Agricultural and } \\
\text { Environmental } \\
\text { Sciences }\end{array}$ & 53 & 35 & 56 & 37 & 44 & 29 & 153 \\
\hline $\begin{array}{l}\text { Business and } \\
\text { Economics }\end{array}$ & 62 & 78 & 16 & 20 & 1 & 1 & 79 \\
\hline $\begin{array}{l}\text { Social Science and } \\
\text { Humanities }\end{array}$ & 34 & 36 & 52 & 55 & 8 & 9 & 94 \\
\hline $\begin{array}{l}\text { Computing } \\
\text { Informatics }\end{array}$ & 48 & 76 & 11 & 17 & 4 & 6 & 63 \\
\hline Law & 19 & 66 & 6 & 21 & 4 & 14 & 29 \\
\hline $\begin{array}{l}\text { Educational and } \\
\text { Behavioural Science }\end{array}$ & 6 & 20 & 21 & 70 & 3 & 10 & 30 \\
\hline $\begin{array}{l}\text { Veterinary } \\
\text { Medicine }\end{array}$ & 18 & 67 & & 0 & 9 & 33 & 27 \\
\hline $\begin{array}{l}\text { Chiro Campus } \\
\text { Academic staff }\end{array}$ & 27 & 69 & 12 & 31 & & 0 & 39 \\
\hline Grand Total & 498 & 60 & 235 & 28 & 100 & 12 & 833 \\
\hline
\end{tabular}

Source: Haramaya University, 2011 
One senior university leader and several deans and department heads told us that attracting and retaining qualified staff is more challenging in disciplines like computer sciences, engineering, law, business and economics, where the private sector offers much higher salaries and/or better career prospects. In its recent strategic plan document (2004:10), HU identified high staff turnover and difficulty in attracting qualified and experienced staff as one of the key challenges caused by its location disadvantage. From 2006-2010, for instance, the number of PhD holders was substantially "eroded" (see Table 5.6) due to the exodus of talent from the university. Even when academic staff are loyal to the organisation, many teachers supplement their incomes by providing services to other organisations, which may negatively influence the implementation of organisational goals. The low proportion of the academic staff with $\mathrm{PhD}$ qualifications and their limited engagement in core tasks are a critical challenge to imparting good quality education and publishing in internationally recognised peer-reviewed journal or books. As one senior academic and the senior university leaders reported during the interviews, the bachelor holders who are now forming the academic core of the university are not sufficiently qualified to independently teach and conduct research. Shortages of senior staff in the areas of science and technology are increasingly becoming a challenge to realising the recently initiated government Conversion Plan.

In $2011 \mathrm{HU}$ had more than 2000 administrative support staff ${ }^{40}$ (both full time and part-time), nearly twice the number of academic staff. The university is the largest employer of support staff within its local labour market, and hence it is an important economic contributor in a rural area. There is however a shortage of professional administrative support staff. Most of the administrative support staff, including those who work in the finance, procurement, and staffing offices, lack managerial expertise/competence. According to the academic interviewees, the support staff are inexperienced, not business-minded, and insufficiently qualified for the positions they hold. They are incapable of managing and communicating on a tight schedule either within the university or between the university and its stakeholders. The poor performance of the support staff is greatly hampering the university's attainment of its mission (Haramaya University, 2008c). The senior university leaders who participated in the interviews pointed out that attracting and retaining talented support staff is the biggest challenge under the existing pay scales for civil servants.

40 Includes such as administrative staff, technical support staff, and other nonacademic professionals in its teaching hospital. 


\subsubsection{Sources of Finance for Haramaya University}

As indicated in section 5.3.4, financial support for $\mathrm{HU}$ comes from both main governmental allocation and other nongovernmental (particularly non-MoFED) sources. Between 2006 and 2011, the total revenue of the university increased by $269 \%$ in nominal terms, as shown in Table 5.8 below.

Table 5.8: Financial sources for HU (in million ETB)

\begin{tabular}{lcccccc}
\hline Source & $\mathbf{2 0 0 6}$ & $\mathbf{2 0 0 7}$ & $\mathbf{2 0 0 8}$ & $\mathbf{2 0 0 9}$ & $\mathbf{2 0 1 0}$ & $\mathbf{2 0 1 1}$ \\
\hline Government & 165.44 & 175.43 & 220.67 & 320.53 & 480.68 & 677.53 \\
Recurrent & 70.01 & 90.98 & 109.05 & 144.13 & 198.25 & 251.32 \\
Capital & 95.43 & 84.45 & 111.62 & 176.40 & 282.43 & 426.21 \\
$\begin{array}{l}\text { All other sources } \\
\text { (nongovernmental) }\end{array}$ & 29.75 & 32.1 & 42.71 & 51.30 & 53.12 & 54.58 \\
\hline Total & 195.19 & 207.53 & 263.38 & 371.83 & 533.8 & 732.11 \\
\hline
\end{tabular}

Sources: Budget Proclamations (2006-2011) and Finance, Procurement and Property Management department of $\mathrm{HU}$

The biggest proportion of the university's revenue comes from the government treasury and therefore $\mathrm{HU}$ is heavily dependent on the government for its funding. The federal government of Ethiopia covers both operating and investment budgets. It provides about $80 \%$ the operating and almost $100 \%$ of the investment budgets for the university. As shown in Table 5.8, the main state allocation to HU grew by 310\% between 2006 and 2011(the recurrent and capital budget increased by $259 \%$ and $348 \%$, respectively). The enrolment expansion and a series of construction works necessitated this growth. Nonetheless, HU did not receive the full budget it requested from the government treasury. Between 2006 and 2011, for instance, the university secured only $60 \%$ of the recurrent budget and $62 \%$ of the capital budget it had requested (our own calculations based on the raw data obtained from MoFED). According to the head of Finance, Procurement and Property Management, the entire processes of budget preparation - a sequence of submission, review, and approval steps that rise through the university hierarchy and up MoFED and government hierarchies - is little more than an annual ritual.

As discussed in section 5.3.4, the most common model of allocating recurrent budget to the university is to use the previous year as a baseline and make incremental changes based on general considerations such as student services, staff salaries, inflation rates, and other operational expenses. Significant portions (about $20 \%$ ) of the recurrent budget are allotted to student welfare. 
About 15\% covers students' food. The budget earmarked for student welfare is insufficient to cover all expenses, as reported by the senior university leaders. Staff salaries take about 39\% of the entire recurrent budget. The university community generally perceives their salaries as low. There has been no government budget allocated for research over the period of 2006-2011. Paradoxically, HU cannot fully utilise its annual budget. Budget "flow backs", the paradox between insufficient budgets and budget flow backs to governmental treasury at the end of the fiscal year, are very common and apparent at the university. HU also generates considerable financial resources (see Table 5.8) from a variety of sources (5.22). We shall return to this issue in section 5.7 .

\subsubsection{Adama Science and Technology University (ASTU)}

Adama Science and Technology University (ASTU) is one of the young universities in Ethiopia. The university was established in Adama town in Oromia regional state with funding from the World Bank in 1993. Adama town ${ }^{41}$ is the second most economically significant and industrial town in Ethiopia, after Addis Ababa. This university has had four different names since its foundation: Nazareth Technical College (1993-1994), Nazareth College of Technical Teacher Education (1994/95 to 2006), Adama University (2006/07 to May 2011), and Adama Science and Technology University (May 2011 to present). ASTU has two campuses in Adama and Asella towns, which are 75 $\mathrm{km}$ apart. One of the objectives of ASTU is to help produce technical teachers for TVET colleges and schools, in its role as the only technical university in the nation. In 2007, the Ethiopian government decided to transform Adama University into the model University for Ethiopia and a Centre of Excellence in Technology, according to a strategic document known as 'Setting up Adama University-A framework ${ }^{42}$ (Eichele, 2007). Although the university was known as Adama University during the data collection period, we have used the university's latest name in this study. The key characteristics of the university are presented below.

41 Adama Town is situated along the main road to Djibouti seaport (the main import and export route for Ethiopia) about $100 \mathrm{kms}$ to the South East of Addis Ababa. Its closeness to the capital city of the country makes Adama town a commercial, conference and recreational centre.

42 It presents the overall transformation of $\mathrm{AU}$ into a model university for Ethiopia (http://www.adama-university.net/docs/Framework_Rel_1.1.1.pdf). This framework is a state-led revolution from the top, and is widely known as the 'Bible of Adama University'. It recommended completely restructuring AU. 


\subsubsection{Mission of the University}

According to the framework of Adama University, the university aspires to be an education and training institution providing students with all-round personal development as well as professional knowledge and skills through practice-oriented programmes. The university strives to undertake research, particularly of an applied nature. It facilitates the participation of its staff and students in community development activities. It also endeavours to link itself to the international network of universities and to support international economic links. The fundamental objectives of the university are i) economic development and University-Enterprise cooperation; ii) excellence in teaching, learning and applied research; iii) attracting international university partnerships and networks; and iv) being a Centre of Vocational Teacher Education in Ethiopia (see Eichele, 2007:5).

\subsubsection{Internal Governance and Management of ASTU}

The 2009 higher education proclamation and the framework of Adama University seek to bring industrial and business management structures and decision-making processes into ASTU in order to create greater efficiency and effectiveness in its operations. The framework acknowledged that the environment of ASTU is volatile, complex and increasingly demanding. As a result, there was a need for strong strategic capacity, management by objectives, and swift and flexible decision-making capabilities, in order to transform the university into the model University for Ethiopia (see Eichele, 2007). Figure 5-2 below shows the organisational structure of Adama University. 
Figure 5-2 Organisational Structure of Adama University

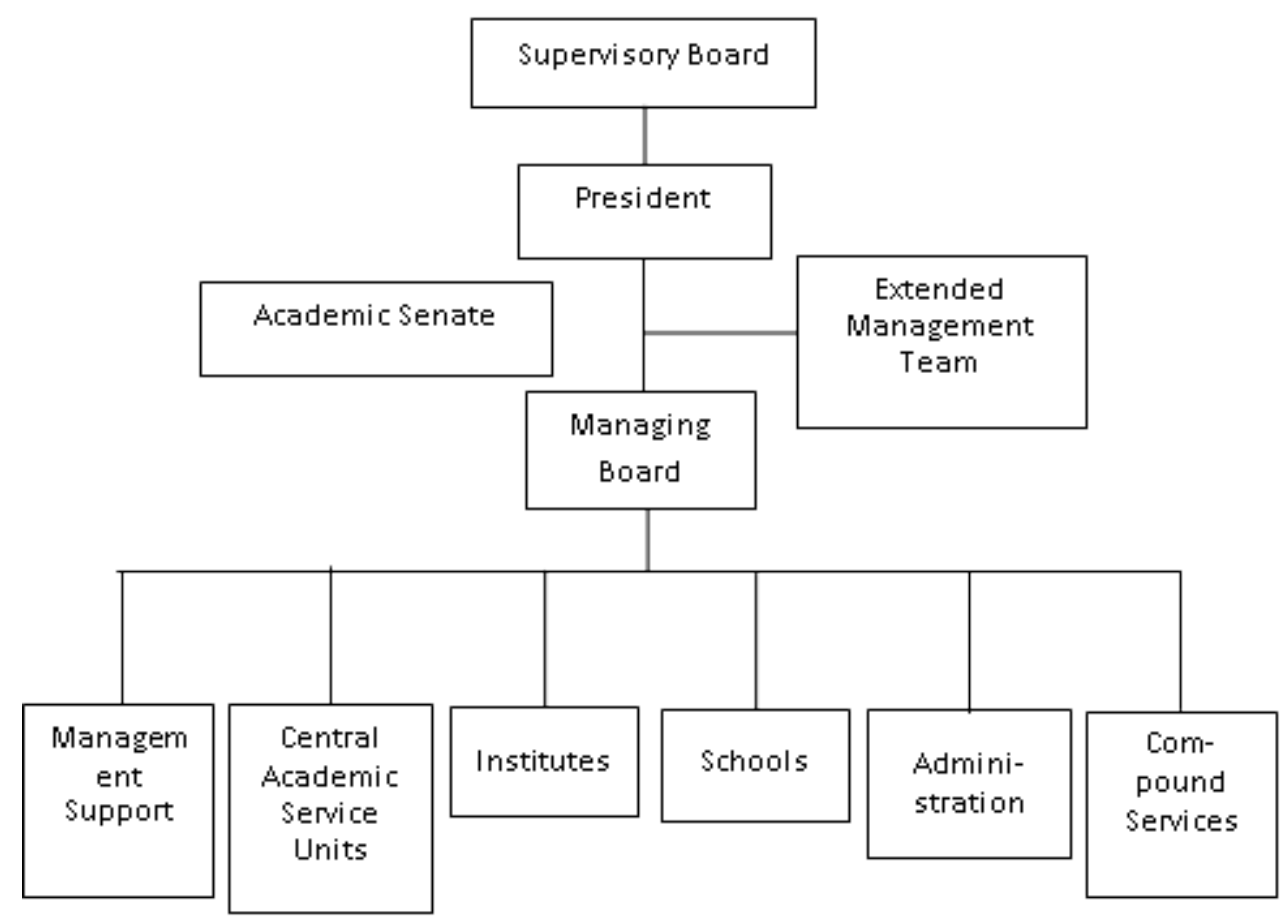

The internal governance and management of ASTU is based on the corporate governance model. The Supervisory Board (SB) is the supreme governing body of the university that ensures the university complies with national laws and regulations. The Board consists of seven members who are drawn from the government authorities, professionals, and industry in order to mobilise a range of constituencies as constructive contributors to ASTU's governance. This SB sets the goals of the university and approves policies, objectives, strategies, corporate reorganisation and procedures, introduction or termination of curricula, staffing, and financial matters. This governance structure theoretically illustrates how the SB has embraced this more strategic leadership role, leaving daily management to executive teams. The Senate is a mandatory body in an Ethiopian university structure. ASTU's academic senate is composed of the president (Head), the vice presidents, one elected representative from professors in each school, one elected member of scientific staff from each school, two elected other staff representatives and two elected student representatives. The Senate issues directives related to academic affairs such as student administration, selection of academic heads, and employment and promotion of academic staff. The role of the Senate has been a relative weak in 
deciding financial and staffing matters. The SB and the president have replaced the power of academically dominated senate.

The president of ASTU is the Chief Executive Officer (CEO) of the organisation. A German professor, Herbert Eichele, was appointed to head the university for the period of 2008 and 2011. The president has an extended right to authorise a decision by advisory bodies and the right to block or change it when he feels it is unacceptable (Eichele, 2008:69). He is the final authority on all aspects of daily organisation, staffing, strategic, and budgetary affairs. He has a veto right over majority votes by self-governing bodies. As a result, traditional notions of collegiality and consensus-based decision-making have increasingly come under pressure. Three vice presidents assist the president: VP for Academic Affairs and Undergraduate Studies, VP for Research and Postgraduate Studies, and VP for International Relations, Corporate Communications and Fund Raising. The Vice President for Academic Affairs and Undergraduate Studies is responsible for leading the teaching-learning process, as well as curriculum and academic staffing. The Research and Postgraduate Studies Vice President has responsibility for starting up relevant research activities and searching for domestic and international research funds and development partners. Offices like Knowledge and Technology Interchange (KTI), Research and Publication Office (RPO), and Technology Innovation Centre (AUtic) report to this VP. The Vice President for International Relations, Corporate Communications, and Fund Raising deals with building the image of the university and soliciting resources from diverse stakeholders. This VP is required to play a facilitation role in revenue generation, with a focus on proactively initiating fast growing business cases (Eichele, 2008:66).

The president and his vice presidents constitute the Managing Board (MB), forming the top management team of the university. The MB leads the university in academic and administrative affairs such as setting strategic and operational aims, and deciding all internal affairs. All heads of operational units (schools, institutes, and other administrative units) within ASTU are bound to the standards and targets set by the MB. The Extended Management Team (EMT) is composed of the MB, the Deans, the Head of Administration, and the Head of Compound Services. Headed by the president, the MB exchanges information, discusses budgetary, administrative, cooperative and strategic affairs, proposes and agrees on appropriate measures, and advises the president.

Seven schools are the basic entities in charge of executing higher learning and research within ASTU. Each school is headed by a Dean and is accountable to the MB. The school board, whose members are the Dean, the Vice Dean and the 
Heads of Departments, governs each school. In principle, the school's board is in charge of making the best use of the budget and resources assigned to the school. In practice, however, the school or its board has little influence on financial matters. Each school is further divided into departments and each department has a Head of Department. The 7 schools and their 22 departments are the building blocks of the university. In addition to its traditional academic departments, ASTU has seven institutes ${ }^{43}$. These institutes are self-contained operational units acting as a legal part of ASTU and cooperate closely with the university's schools, departments, and administration to share resources. A great number of units exist at the University to provide support to the university's primary processes, education, and research. These units are organised in 18 subunits $^{44}$. However the managing board (specifically the president) still has control over financial and legal decisions. In short, decisions concerning finance, procurement, and human resource matters are highly centralised at ASTU and often operate in a "top down" fashion.

\subsubsection{Student Population and Areas of Study}

ASTU has enjoyed a consistent growth in its student population since its establishment. Total enrolment has more than doubled, from 9084 in 2006/07 to 19516 in 2010/11 (see Table 5.9 below).

43 namely: Adama Institute of Sustainable Energy (AISE), Research Institute for Tropical Medicine, Further Training Institute (FTI), Artificial Insemination Institute of Asella (AIIA), Asella Model Agricultural Enterprise (AMAE), Institute of Continuing and Distance Education (ICDE), and Adama Cisco Local Academy (ACLA)

44 Management Support Functions include Auditing/Controlling, Strategic Planning, Legal Matters, Public Relations, Grievance Committee, and Safety. The Central Administration consists of Finance and Accounting, Human Resource, Enrollment and Examinations, and Social Services. The Compound Services is organised into Construction and Maintenance, General Services, and Security. The Central Academic Service units consist of International Office, Workshop, Computer Centre, Pedagogical Skills Support, Library, Culture, Leisure and Sports (see Herbert Eichele, 2008:12-24). 
Table 5.9: Total student population in $2010 / 11$

\begin{tabular}{lcccc}
\hline Level & Regular & $\begin{array}{c}\text { CEP } \\
\text { (Extension) }\end{array}$ & Summer & $\begin{array}{c}\text { Grand } \\
\text { Total }\end{array}$ \\
\hline $\begin{array}{l}\text { Diploma } \\
\begin{array}{l}\text { Undergraduate } \\
\text { (Bachelor) }\end{array}\end{array}$ & 527 & 527 \\
$\begin{array}{l}\text { Postgraduate (Master's) } \\
\text { Postgraduate (PhD) }\end{array}$ & 767 & 3676 & 3972 & 18202 \\
\hline Total & 20 & & 3972 & 19516 \\
\hline
\end{tabular}

Source: MoE Annual Abstract, 2011

In 2011, about $96 \%$ of the students were enrolled on undergraduate programme, while $4 \%$ were enrolled for postgraduate studies. Postgraduate studies leading to Master's and PhD degrees at ASTU were first available in 2008 in 13 academic programmes at three schools. While 60\% of the total student population were regular students, the remaining $40 \%$ were full-cost paying students. In terms of areas of study, the university awards degrees in more than 50 disciplines. The distribution of students among the seven schools of ASTU in 2011 is shown in Table 5.10 below. 
Table 5.10: Student distribution across schools in 2011

\begin{tabular}{lccc}
\hline School $^{45}$ & Department & $\begin{array}{c}\text { Year of } \\
\text { foundation }\end{array}$ & $\begin{array}{c}\text { Share of } \\
\text { students } \\
\text { (\%) }\end{array}$ \\
\hline $\begin{array}{l}\text { Engineering and Information } \\
\text { Technologies }\end{array}$ & 7 & 1993 & 40 \\
Business & 5 & 2003 & 20 \\
Agriculture & 4 & 2009 & 4 \\
Health and Hospital & 1 & 2009 & 2 \\
Humanities and Law & 7 & 2005 & 22 \\
Educational Science and & 3 & 1993 & 6 \\
Technology Teacher Education & 6 & 2005 & 6 \\
Natural Sciences & 22 & & 100 \\
\hline Total & 6 & & 6 \\
\hline
\end{tabular}

Source: MoE Annual Abstract, 2011

Although research is the founding mission of ASTU, the university has not created a discipline-centred academic base that is strong on research. According to the deans and department heads, ASTU's research capacity and infrastructure in terms of human and non-human resources is very limited and weak in all its schools.

\subsubsection{Academic and Administrative Support Staff}

The expansion of the university and the opening of several new programmes caused a rapid increase in the number of employees at ASTU. The number of academic staff grew by 182\% between 2006 and 2011, as indicated in Table 5.11. In 2011, ASTU had 961 academic staff of whom 95.6\% were Ethiopians and 4.4\% were expatriate staff from Germany, the UK, Cuba, India, Ireland, the Philippines and the United States. Full professors from Europe, particularly from Germany, made up six of the seven deans at ASTU.

45 Asella campuses host two schools: the School of Health and Hospital and the School of Agriculture. The former school includes the Asella Referral Hospital while the latter used to be an agricultural college. The university has also opened satellite campuses in Bishoftu and Addis Ababa, to run continuing education programmes. Five of the seven schools of AU are located at Adama campus (the main campus). 
Table 5.11: Number of Academic staff in 2006/07 and 2010/11

\begin{tabular}{|c|c|c|c|c|c|c|c|c|c|}
\hline \multirow[b]{2}{*}{$\begin{array}{l}\text { Academic } \\
\text { Staff }\end{array}$} & \multicolumn{4}{|c|}{$2006 / 07$} & \multicolumn{5}{|c|}{$2010 / 11$} \\
\hline & $\begin{array}{l}\text { Bachelor } \\
\quad \text { (or } \\
\text { below) }\end{array}$ & Master's & PhD & Total & \multicolumn{2}{|c|}{ Bachelor } & Master's & PhD & Total \\
\hline Ethiopian & 185 & 111 & \multicolumn{2}{|l|}{6} & \multicolumn{2}{|c|}{482} & 412 & 25 & 919 \\
\hline $\begin{array}{l}\text { Expa- } \\
\text { triate }\end{array}$ & 1 & 33 & \multicolumn{2}{|l|}{5} & \multicolumn{2}{|l|}{1} & 17 & 24 & 42 \\
\hline Total & 186 & 144 & 11 & 341 & \multicolumn{2}{|c|}{483} & 429 & 49 & 961 \\
\hline \multicolumn{10}{|c|}{ Sources: MoE Annual Abstracts, 2006/07 and 2010/11 } \\
\hline \multicolumn{10}{|c|}{$\begin{array}{l}\text { Table } 5.12 \text { below shows ASTU's staff composition in terms of academic rank in } \\
\text { 2011. There are shortages of senior and experienced academic staff across all the } \\
\text { schools. }\end{array}$} \\
\hline \multirow{2}{*}{ Band } & & \multicolumn{3}{|c|}{ Bachelors } & \multicolumn{2}{|c|}{ Master's } & \multicolumn{2}{|c|}{ PhD } & \multirow{2}{*}{ Total } \\
\hline & & Num & ber & $\%$ & Number & $\%$ & Number & $\%$ & \\
\hline \multicolumn{2}{|c|}{$\begin{array}{l}\text { Engineering and } \\
\text { Technology }\end{array}$} & \multicolumn{2}{|c|}{249} & 65 & 122 & 32 & 13 & 3 & 384 \\
\hline \multicolumn{2}{|c|}{$\begin{array}{l}\text { Natural and } \\
\text { Computational Science }\end{array}$} & \multicolumn{2}{|c|}{22} & 26 & 58 & 67 & 6 & 7 & 86 \\
\hline $\begin{array}{l}\text { Medicine } \\
\text { Sciences }\end{array}$ & nd Health & 73 & & 60 & 44 & 36 & 5 & 4 & 122 \\
\hline $\begin{array}{l}\text { Agricultur } \\
\text { Sciences }\end{array}$ & and Life & 36 & & 51 & 29 & 41 & 5 & 7 & 70 \\
\hline $\begin{array}{l}\text { Business a } \\
\text { Economic }\end{array}$ & & 71 & & 47 & 69 & 46 & 11 & 7 & 151 \\
\hline Social and & Humanities & 32 & & 22 & 107 & 72 & 9 & 6 & 148 \\
\hline Total & & 483 & & 50 & 429 & 45 & 49 & 5 & 961 \\
\hline
\end{tabular}

Source: MoE Annual Abstracts 2010/11 
With respect to administrative support staff (i.e.; support staff, technical support staff, and technical staff), ASTU had 2205 support staff (both full time and part-time) in 2011. The creation of several new academic units and other specialised support structures such as marketing, human resource management, management accounting, and ICT development office meant that adequate management support and professional expertise were needed. Unlike other public universities in Ethiopia, ASTU was granted autonomy in setting salaries for its key administrative support staff such as Heads of Administration, Compound Services, Management Support Services, ICT, and assistant to the president (see Eichele, 2007). This special status enabled the university to attract and retain senior professional managers to these positions. Nonetheless, the university suffers from a lack of managerial expertise and competence in most support units. For instance, ASTU is unable to attract technical assistants for its laboratories and workshops. Lack of managerial expertise and competence has also been widely observed in newly established research institutes as well as in the Institute of Continuing and Distance Education. The absence of managerial capacity at the university has led to a growing number of administrative tasks being performed by the senior academic staff, at the expense of teaching and research.

\subsubsection{Sources of Finance for Adama Science and Technology University}

ASTU acquires its financial revenue from both governmental and nongovernmental sources as shown in Table 5.13.

Table 5.13: Revenues by Sources (in million ETB)

\begin{tabular}{lccccc}
\hline Source & $\mathbf{2 0 0 7}$ & $\mathbf{2 0 0 8}$ & $\mathbf{2 0 0 9}$ & $\mathbf{2 0 1 0}$ & $\mathbf{2 0 1 1}$ \\
\hline Government & 147.46 & 180.31 & 264.20 & 352.27 & 399.85 \\
Recurrent & 69.86 & 74.24 & 158.00 & 227.27 & 274.67 \\
Capital & 77.60 & 106.07 & 106.20 & 125.00 & 125.18 \\
$\begin{array}{l}\text { All other Sources } \\
\text { (nongovernmental) }\end{array}$ & 12.44 & 14.35 & 20.90 & 24.27 & 26.05 \\
\hline Total & 159.90 & 194.66 & 285.10 & 376.54 & 425.90 \\
\hline
\end{tabular}

Source: Budget Proclamations (2006-2011)

The federal government of Ethiopia provides about $85 \%$ of the university's recurrent (operating) and almost 100\% of the capital budgets through line item budgeting. This suggests that ASTU is heavily dependent on the government for its continued survival and operation. Between 2007 and 2011, the 
university's annual budget from the government treasury increased by $171 \%$. However, ASTU secured on average only $62 \%$ of the total requested budget (our own calculations based on the raw data obtained from MoFED) over this period. The approved recurrent budget as a percentage of the requested budget reduced from $77 \%$ in 2006 to $50 \%$ in 2011 . This rapid decline in the approved budget in relation to the requested budget is a signal of the financial challenge (austerity) from the government treasury. There has been no budget allocated for research from the government over the period of 2007-2011. Additionally, ASTU has diversified its funding base to a variety of nongovernmental (particularly non-MoFED) sources (see Table 5.21). We shall discuss the nongovernmental sources of the university's revenue in more details later.

\subsection{External Environment of the Ethiopian Case Study Universities}

As we indicated in section 5.2, the environment in which the Ethiopian case study universities operate has been rapidly changing in the last decades. As a result, the Ethiopian case study universities are increasingly expected to satisfy the needs of the economy and society, meet requirements for accountability, and build closer links with a variety of stakeholders. Some of the expectations are expanding access to university education, improving quality and achieving cost containment and efficiency. Growing constraints on public funding, together with the expansion of higher education and the emergence of new demands, have encouraged the development of new regulatory frameworks and the emergence of new stakeholders in the Ethiopian higher education landscape. In this section, we will identify the external stakeholders in the Ethiopian case study universities, and then attempt to determine stakeholder salience in terms of their regulatory powers and funding as perceived by the interviewees.

\subsubsection{External Stakeholders in the Ethiopian Case Study Universities}

The findings in this study have identified several key external stakeholders (see Table 5.14 below) that influence the behaviour and actions of the Ethiopian case study universities. 
Table 5.14: Key External Stakeholders in ASTU and HU

\begin{tabular}{ll}
\hline Public Authorities & Other than Public Authorities \\
\hline $\begin{array}{l}\text { The House of Peoples' } \\
\text { Representatives }\end{array}$ & Students and their families \\
$\begin{array}{l}\text { The Council of Ministers } \\
\text { Ministry of Education (MoE) }\end{array}$ & $\begin{array}{l}\text { Donors (bilateral and multilateral) } \\
\text { Professional associations }\end{array}$ \\
$\begin{array}{l}\text { Ministry of Finance and Economic } \\
\text { Development (MOFED) }\end{array}$ & $\begin{array}{l}\text { Nongovernmental Organisations } \\
\text { (NGOs) }\end{array}$ \\
$\begin{array}{l}\text { Ministry of Civil Service (MoCS) } \\
\text { Ministry of Science and Technology }\end{array}$ & $\begin{array}{l}\text { Private higher education institutions } \\
\text { (MoST) }\end{array}$ \\
$\begin{array}{l}\text { Higher Education Strategy Centre } \\
\text { (HESC) }\end{array}$ \\
$\begin{array}{l}\text { Higher Eductror (Business and } \\
\text { Quality Agency (HERQA) }\end{array}$ \\
\hline
\end{tabular}

These stakeholders are regulators, suppliers, customers, and/or competitors of the universities. We briefly presented the duties and responsibilities of the public authority stakeholders (see section 5.3.3) in Table 5.14. One of the common characteristics of the stakeholders is that they can all exert some sort of pressure on the actions and behaviours of the universities in order to promote their demands and expectations. However not all stakeholders are, equally powerful and important for universities in terms of issuing sanctions and offering rewards. In explaining who really matters to ASTU and HU, we further analyse stakeholder salience in terms of regulatory powers and funding as follows.

\subsubsection{Stakeholder Salience in Terms of Regulatory Powers}

The government, donors, and professional associations all have regulatory powers over the Ethiopian case study universities. Table 5.15 below presents the salience of the three stakeholders to ASTU and HU in terms of regulatory powers as perceived by the interviewees. 
Table 5.15: Stakeholder Salience in Terms of Regulations

\begin{tabular}{|c|c|c|}
\hline Stakeholder & ASTU & HU \\
\hline Government & ++++ & ++++ \\
\hline Donors & +++ & +++ \\
\hline Professional associations & + & + \\
\hline
\end{tabular}

The Ethiopian federal government is the most salient stakeholder for ASTU and HU. This stakeholder includes all stakeholders that are categorised under 'public authorities' in Table 5.14. The most common regulation tools that public authorities use to influence the behaviour and actions of the Ethiopian case study universities are outlined in Table 5.16 below.

Table 5.16: Key Regulatory Frameworks of ASTU and HU

\begin{tabular}{|l|l|}
\hline $\begin{array}{l}\text { Higher Education Proclamations (No. } \\
650 / 2009)\end{array}$ & The Graduate Mix Policy (MoE, 2008) \\
\hline $\begin{array}{l}\text { Education Sector Development } \\
\text { Program ESDP IV (2010/11-2014/15) }\end{array}$ & Budget Administration (2010) \\
\hline $\begin{array}{l}\text { Growth and Transformation Plan } \\
(2010 / 11-2014 / 15)\end{array}$ & Public Procurement law (2005) \\
\hline $\begin{array}{l}\text { Higher Education Cost-Sharing } \\
\text { Council of Ministers Regulation (No. } \\
\text { 154/2008) }\end{array}$ & $\begin{array}{l}\text { Federal Civil Servants Proclamation } \\
\text { (No. 515/2007) }\end{array}$ \\
\hline Disbursement directive (2010) & \\
\hline
\end{tabular}

Additionally, ASTU was steered by its 'framework' from 2008 to 2012. One of the most prominent regulatory frameworks in the higher education landscape of Ethiopia is the Higher Education Proclamation 650/2009. This proclamation defines the autonomy of the Ethiopian case study universities. In the following subsection, we provide a more detailed picture of the status of organisational autonomy at ASTU and HU, in order to explore the link between revenue generation and the degree of organisational autonomy.

\subsubsection{The Higher Education Proclamation (650/2009) and Organisational Autonomy}

The 2009 Higher Education Proclamation (650/2009) is the legal framework for the operation of the higher education system in Ethiopia. This proclamation 
allows public universities in Ethiopia to mobilise income from nongovernmental sources (see Articles 66 and 67; Article 62, No.2). This law defines the degree of freedom that the Ethiopian case study universities have to steer themselves. On the basis of the analysis of data obtained from documentary evidence and interviews, we analyse the degree of autonomy (see Table 4.4) ASTU and HU have to carry out certain tasks including their revenue generation agenda. Table 5.17 below shows the status of academic autonomy at ASTU and HU (see Articles 19, 24, 25, and 39 of the Proclamation 650/2009).

Table 5.17: Academic Autonomy

\begin{tabular}{lcc}
\hline Aspect & ASTU & HU \\
\hline $\begin{array}{l}\text { Freedom to select and admit parallel undergraduate } \\
\text { students (BA/BSc) and postgraduate students }\end{array}$ & + & + \\
(MA/MSc and PhD) & & - \\
$\begin{array}{l}\text { Freedom to select and admit regular students } \\
\text { Freedom to decide on parallel student numbers }\end{array}$ & + & + \\
$\begin{array}{l}\text { Freedom to introduce degree programmes } \\
\text { Freedom to terminate degree programmes }\end{array}$ & + & + \\
$\begin{array}{l}\text { Freedom to design programmes } \\
\text { Freedom to decide modes of instruction and } \\
\text { delivery }\end{array}$ & + & + \\
$\begin{array}{l}\text { Ability to charge tuition fees for government } \\
\text { sponsored students }\end{array}$ & + & - \\
$\begin{array}{l}\text { Ability to charge tuition fees for nongovernment } \\
\text { sponsored students }\end{array}$ & + & + \\
$\begin{array}{l}\text { Freedom to set priorities for research } \\
\text { Ability to determine the price of research and }\end{array}$ & + \\
consultancy works & + & + \\
$\begin{array}{l}\text { Freedom to generate revenue from their research } \\
\text { outputs and consultancy services }\end{array}$ & + & + \\
\hline
\end{tabular}

Key: + present - absent

The Conversion Plan ${ }^{46}$, which seeks to achieve a 70/30 enrolment ratio in favour of science and technology in the undergraduate mix, could also influence the

46 Each university is urged to enrol $40 \%$ of their students in engineering and technology, 20\% in natural and computational sciences, $20 \%$ in business and 
academic autonomy of the case study universities (see MoE, 2008). Generally, the Ethiopian case study universities are granted a good deal of academic autonomy in their corporate form to determine the 'what of academe'. Table 5.18 presents the level of financial autonomy of the Ethiopian case study universities.

Table 5.18: Financial Autonomy

\begin{tabular}{lcc}
\hline Aspect & ASTU & HU \\
\hline Generation and deployment of monetary resources & + & + \\
Ability to keep financial surpluses & - & - \\
$\begin{array}{l}\text { Ability to charge tuition fees to government } \\
\text { sponsored students }\end{array}$ & - & - \\
$\begin{array}{l}\text { Ability to charge tuition fees to nongovernment } \\
\text { sponsored students }\end{array}$ & + & + \\
Lump-sum or block grant funding & - & - \\
$\begin{array}{l}\text { Ability to set prices for research \& consultancy } \\
\text { services }\end{array}$ & + & + \\
Ability to own buildings & + & + \\
Ability to borrow money & - & - \\
Ability to lease university facilities & + & + \\
\hline
\end{tabular}
Key: + YES - NO

The degree of financial autonomy shows that on average, financial autonomy is perceived as being lower than academic and organisational autonomy at ASTU and HU (see Articles 17, 25, 26, 44, 62, 66, 67, and 91 of the Proclamation $650 / 2009$ ). The universities are not legally allowed to move funds between budget heads without passing stringent approval procedures. Nor are they able to borrow money to expand their revenue generation.

Table 5.19 below presents the degree of perceived autonomy of ASTU and HU in terms of staffing (see also Articles 30, 31, 32, 33, 34, 35, and 36 of the Proclamation 650/2009).

economics, $10 \%$ in social sciences and humanities, $5 \%$ in medicine and health sciences, and $5 \%$ in agriculture and natural resources. 
Table 5.19: Autonomy with respect to staffing

\begin{tabular}{lcc}
\hline Aspect & ASTU & HU \\
\hline Freedom to decide on recruitment & + & + \\
Freedom to decide on promotion of academic staff & + & + \\
Freedom to decide on promotion of administrative staff & - & + \\
Freedom to decide on dismissal of staff & + & - \\
Freedom to set salaries for academic staff & - & - \\
Freedom to set salaries for administrative staff & + & + \\
Determine working conditions for staff & + & + \\
\hline
\end{tabular}

Key: + YES - NO

The empirical findings show that the civil servant status of the administrative staff (see Civil Servants Proclamation (No. 515/2007) and the inability to control the overall salary costs limits the staffing autonomy of the Ethiopian case study universities (Article 31, no.1(e) of the Proclamation 650/2009).

The Ethiopian case study universities have been granted autonomy with respect to internal governance (see Articles 17, 43, 49, and 53 of the Proclamation 659/2009) as shown in Table 5.20.

Table 5.20: Autonomy with respect to internal governance

\begin{tabular}{lcc}
\hline Aspect & ASTU & HU \\
\hline $\begin{array}{l}\text { Freedom to decide on internal governance and decision- } \\
\text { making structures/bodies }\end{array}$ & + & + \\
$\begin{array}{l}\text { Freedom to introduce new academic structures } \\
\text { (faculties, departments, research centres) }\end{array}$ & + & + \\
\hline Key: +YES - NO & &
\end{tabular}

\subsubsection{Other Regulation Tools Used by Bilateral and Multilateral Donors}

Donors steer the Ethiopian case study universities indirectly. The most common regulation tools that these actors use to influence the Ethiopian higher education system are policy conditionalities, reporting requirements, and technical assistance and research outputs. Many so-called policy conditionalities associated with external assistance steer the behaviour and actions of the Ethiopian case study universities. Donors employ several resource allocation mechanisms; for example, competitive funding or categorical funding, that can move the behaviours and actions of a university 
towards certain goals. An example of this is the World Bank funded PostSecondary Education Project, which has five conditions for accessing an Institutional Development Grant (see World Bank, 2005: Cr. 3984) and two resource allocation methods (i.e. competitive funding and earmarked funding). In terms of reporting requirements, a complex format has been used by donors for reporting physical and financial performance, causing poor performance in disbursement and utilisation of funds. As preconditions for disbursements, some donors insist on allocating a great majority of the funds to technical assistance (e.g. compulsory employment of experts) from their countries. Some donors provide funds for research promoting their priorities rather than for solving the practical problems of the university or the country. Overlooking these issues, the senior university leaders reported that the majority of projects with development partners are as demanding as public funding. In addition, meeting conditions for funding was described as restrictive by several interview respondents.

Donors can also influence the higher education system of Ethiopia in particular and developing countries in general through technical assistance (MoE, 2004a; MoE, 2002; MoE, 1997a: MoFED, 2002). The agenda of a reduction in central state regulation and intervention and the trend towards evaluation of performance and outcomes steering of the Ethiopian higher education system were, for example, disseminated and promoted by multilateral agencies like the World Bank, IMF, UNESCO, and EU. Funding is the first instrument by which these donors make their agenda attractive, mainly by binding their financial loans and assistance to the conformity with their requirements. One example of this is the World Bank funded Post-Secondary Education Project in Ethiopia (see World Bank, 2005: Cr. 3984). Additionally, several faculties and departments within the two case study universities have received technical support from similar departments or faculties at other foreign universities. The curricula, teaching methodology, facilities, assessment of students and promotion of staff have all been influenced by the Western education system ${ }^{47}$. Furthermore, donors steer the higher education systems of developing countries through their research outputs. For instance, a research study on "rates of return of studies" by economists at the World Bank and the consequent conclusion that the highest rates of return for Africa came from primary-level education (Lulat, 1988) caused a relative neglect of higher

47 Very recently, the curricula of medicine, engineering, and law were reviewed with the help of the UK, Germany, and the Netherlands respectively. Joint research with European and American universities is very common at public universities in Ethiopia. 
education in Africa. The 1980s new loan policies by the World Bank and the Structural Adjustment Programme also resulted in a deep financial cut to the African higher education sector.

\subsubsection{Stakeholder Salience in Terms of Funding}

The results of this study revealed that many stakeholders use funds as steering tools for their demands and expectations. As stated in the theory (Chapter 3), the steering effectiveness of this tool depends on the volume (potential) of funds that the case study universities receive in return for meeting the demands and expectations of stakeholders. Table 5.21 presents the relative importance of the various stakeholders of ASTU and HU in terms of the magnitude of exchanges as perceived by the interviewees.

Table 5.21: Stakeholder Salience in Terms of Funding

\begin{tabular}{lcc}
\hline Stakeholder & ASTU & HU \\
\hline Public Authorities & ++++ & ++++ \\
Students (and their parents) & +++ & +++ \\
Donors (bilateral and multilateral) & ++ & ++ \\
Ministries, Regional and Local Authorities & ++ & +++ \\
Business \& Industry & + & + \\
\hline Key: ++++ the most salient $\quad+++$ more salient & ++ salient & + less salient
\end{tabular}

The Federal Government of Ethiopia provides the highest volume of resources to ASTU and HU (see sections 5.3.4, 5.4.1.6, and 5.4.2.6). Thus, the government is the most salient stakeholder for the Ethiopian case study universities. The second most salient stakeholder for ASTU and HU is the students (see Tables 5.22 and 5.23). Full-fee paying students in particular bear the costs of their education, and the Ethiopian case study universities thus acquire resources from them. In return for their money, students are more concerned about the quality and economic relevance of their studies (see MoE, 2010; MoFED, 2010:89).

The third stakeholder category is the donors ${ }^{48}$ (both bilateral countries and multilateral organisations). Major bilateral donors that provide resources to

48 During their establishment, almost all public universities received assistances from donors. For instance, Trinity College (now Addis Ababa University) from the 
Ethiopian universities include the Netherlands, Sweden, the UK, Germany, Norway, Ireland, Italy, France, Belgium and Austria. The multilateral donors consist of the World Bank, European Commission, African Development Bank, UNESCO, and UNDP. These donors are not unitary actors. They have their own demands and expectations in return for resources. Their annual share of direct and indirect support for the Ethiopian higher education system from 2001-06 was US\$ 11.3 million a year (World Bank, 2010: 98). Over the period 2004-10/11, the country obtained two significant grants as on-budget support ${ }^{49}$. The World Bank allocated US\$40 million for a project spanning 2005-2009, while another US\$ 18 million was obtained from the Dutch government through NUFFIC. Donors' average annual contribution to Ethiopian higher education was estimated to be around $6.4 \%$ of the total higher education budget in this period (our own calculations based on the raw data obtained from MoFED). In 2009/10, for instance, total donor financing to education was estimated at around $\$ 340$ million, with around $5 \%$ of this going to higher education. The percentage of revenue from donors ranges from over $12 \%$ in some well-established 'old' universities to close to zero in young 'Greenfield' universities (see Tables 5.21and 5.22 for ASTU and HU). Ethiopia is the fourth largest recipient of foreign aid from external donors in Africa. Nevertheless, when seen in terms of the total amount of aid per student, Ethiopia ranks far lower than several African countries. There is a plan by the Federal Ministry of Education (MoE, 2010:103) to mobilise a total of US\$ 302 million from donors for the entire education system in 2011/12 (see Table 5.23).

The fourth stakeholder group is the Ministries and regional and local authorities (Tables 5.21and 5.22). These stakeholders provide resources to the Ethiopian case study universities in exchange for receiving education, research, consultancy or short-course services from the universities. The Ethiopian government has increasingly been recognising the important role of universities as strategic assets in innovation and economic competitiveness, and as problem-

Canadian Jesuits, Alemaya College of Agriculture and Mechanical Arts and Jimma College of Agriculture from the USA government, Gondar College of Health Science from WHO, UNICEF and the USA government, Bahir Dar Polytechnic Institute from the USSR, Bahir Dar College of Teachers Education from UNESCO and UNDP, and Nazareth Technical College from the World Bank, and new universities from the Netherlands and Germany. The higher education system of the country has thus been heavily influenced by the European and American higher education systems (Teshome, 2007:145).

49 While the on-budget support addresses the higher education sector in a holistic way and supports national strategies, the off-budget aid includes external funding that directly benefits individual universities or researcher(s). 
solvers for the socio-economic issues affecting the country, regional states, and their hometowns (see MoFED, 2010). Thus, this stakeholder group is perceived as a potential source of resources for universities in the future. The absence of large-scale and research-intensive industries in Ethiopia makes industrial firms the least important stakeholder group for the Ethiopian case study universities. There is very limited evidence for the involvement of small ${ }^{50}$ industry firms in funding public universities in Ethiopia.

\subsection{Revenue Generation at the Ethiopian Case Study Universities}

This section analyses the interdependence between the Ethiopian case study universities and their environment for acquiring resources. First, it presents the volume of resources that ASTU and HU received from their stakeholders between 2006 and 2011. It also briefly discusses what the resource providers received in return for their resources. Second, it presents the findings of the data analysis about drivers for revenue generation. The final part of the section explores key enablers and barriers for revenue generation at the Ethiopian case study universities.

\subsubsection{Status of Revenue Generation at ASTU and HU}

With varying degrees of success for revenue generation, the Ethiopian case study universities offer both academic and non-academic services and products to their stakeholders to acquire resources. The academic services include educational services mostly at the undergraduate level, short-term courses, and research and consultancy. However, earned resources from actual research and postgraduate education formed an insignificant part of the universities' income (see Eichele, 2007:64-66; Haramaya university, 2008b:57-69). The non-academic services consist of cafeteria services, facility rental, conference services, and selling agricultural products. Chart 5-2 below depicts the share of nongovernmental revenue in the total recurrent budgets from 2007 to 2010.

50 The median employment level of 50 leading firms in the country is about 500; while all but two have over 100 employees. Ethiopia has, in total, 43 firms with over 500 employees, and another 408 firms employing between 50 and 500 (Sutton and Kellow, 2010). 
Chart 5-2 Share of Non-governmental Revenue (non-MoFED) over Total Government Recurrent Budget

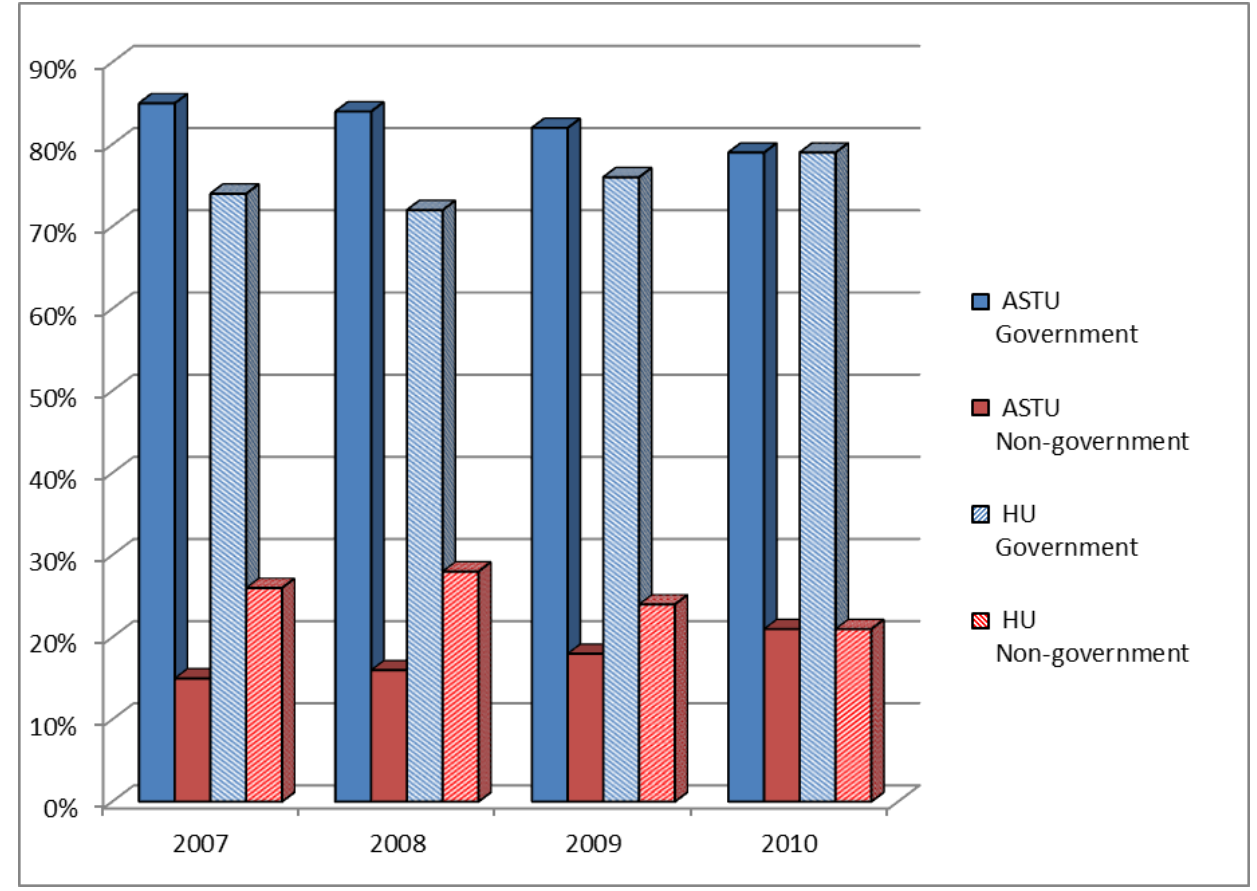

From the onset, we must acknowledge the substantial lack of transparency on the financial data. On the side of the university, there is a fear of seeing its budget allocations decrease by the amount generated. Disclosing data on generated income may be lead to "punishment for good deeds". Thus, information on such revenues is very sensitive, and is often undisclosed. When disclosed, the figures are often unreliable. The nongovernmental revenue accounts for nearly $15 \%-20 \%$ of the total recurrent income (see Tables 5.21 and 5.22 below). Although ASTU and HU have been mobilising non-monetary (in kind) revenues from donors in the form of books, computers, and the like, we have not managed to obtain reliable information on this sort of support. Table 5.22 below indicates the main subcategories and sources of nongovernmental revenues at $\mathrm{HU}$. 
Table 5.22: Sources of Nongovernmental Financial Revenue at HU (in Millions ETB)

\begin{tabular}{lcccccc}
\hline Source & $\mathbf{2 0 0 6}$ & $\mathbf{2 0 0 7}$ & $\mathbf{2 0 0 8}$ & $\mathbf{2 0 0 9}$ & $\mathbf{2 0 1 0}$ & $\mathbf{2 0 1 1}$ \\
\hline Student fees & 11.00 & 14.18 & 20.45 & 26.01 & 25.18 & 25.65 \\
$\begin{array}{l}\text { Donors (bilateral } \\
\text { and multilateral) }\end{array}$ & 13.10 & 12.14 & 15.09 & 16.17 & 17.12 & 17.38 \\
$\begin{array}{l}\text { Ministries, regional } \\
\text { states and local } \\
\text { government }\end{array}$ & 4.55 & 4.36 & 5.47 & 6.34 & 7.05 & 7.43 \\
$\begin{array}{l}\text { All other sources } \\
\text { Total }\end{array}$ & 1.10 & 1.42 & 1.70 & 2.78 & 3.77 & 4.12 \\
\hline
\end{tabular}

Source: Haramaya university: Finance, Procurement, and Property Management Department of HU

From 2006-2011, the highest proportion of nongovernmental revenues for Haramaya University comes from students fees (47\%), followed by donors $(35 \%)$. In this period, the university received a substantial amount (app. $12 \%$ to $15 \%$ ) of its recurrent budget from multilateral and bilateral donors. The university also obtained some funds (app. 13\%) from other ministries, regional states, and local authorities in return for capacity building training. HU obtained around $6 \%$ of its nongovernment revenues from internal and external stakeholders using conference facilities and cafeteria services and buying agricultural products, research by-products, and improved seeds. By 2011, the university planned to cover at least $30 \%$ of its recurrent expenses from nongovernmental revenue (Haramaya university, 2008b:36).

Table 5.23 below indicates the main subcategories and sources of nongovernmental revenues at ASTU. 
Table 5.23: Sources of Nongovernmental Financial Revenue at ASTU (in Millions ETB)

\begin{tabular}{lccccc}
\hline Source & $\mathbf{2 0 0 7}$ & $\mathbf{2 0 0 8}$ & $\mathbf{2 0 0 9}$ & $\mathbf{2 0 1 0}$ & $\mathbf{2 0 1 1}$ \\
\hline $\begin{array}{l}\text { Student fees } \\
\begin{array}{l}\text { Donors (bilateral and } \\
\text { multilateral) }\end{array}\end{array}$ & 6.60 & 5.60 & 8.20 & 8.35 & 9.24 \\
$\begin{array}{l}\text { Ministries, regional } \\
\text { states and local }\end{array}$ & 1.04 & 1.43 & 2.00 & 2.60 & 3.01 \\
government 51 & 0.30 & 0.42 & 0.50 & 0.70 & 0.90 \\
$\begin{array}{l}\text { Industrial firms } \\
\text { All other sources }\end{array}$ & 0.50 & 0.70 & 2.80 & 4.50 & 5.30 \\
Total & 12.44 & 14.35 & 20.90 & 24.27 & 26.05 \\
\hline
\end{tabular}

Source: Finance and Accounting Department and Ministry of Education

The highest proportion of nongovernmental revenues at ASTU comes from student fees $(37 \%)$, followed by donors $(36 \%)$. The university also obtained funds from ministries, regional states and local authorities (10\%) and industrial firms (3\%). A variety of other customers paid to use university facilities and cafeteria services, and this together with sales of agricultural products accounted for around $14 \%$ of nongovernmental revenue. According to the recent ASTU strategic plan, nongovernmental revenue will reach 100 million ETB by 2015/16 (ASTU, 2011:48-55). Although the nongovernmental revenue of the two universities has shown significant growth, this obviously does not compare with the share that direct public funding continues to represent in the universities' revenue structures. As it stands today, the Ethiopian case study universities received most of the nongovernmental resources from student tuition fees. Substantial funds were obtained from donors without having the research capacity to sustain that trend. This suggests that the Ethiopian case study universities are still far from diversifying their revenue streams by implementing significantly differentiated revenue generation activities.

${ }^{51}$ Including municipalities 


\subsubsection{Drivers for Revenue Generation}

An analysis of interview and documentary data shows that the overall socioeconomic context of Ethiopia, the rapid expansion of the education system (see Table 5.20), risk management, flexibility in the internal resource allocation mechanism, and the move to create entrepreneurial universities have become the most important drivers of revenue generation at the Ethiopian case study universities. The general economic context of Ethiopia is an important driver for revenue generation by public universities (see section 5.2). Ethiopia aspires to progress towards becoming a middle-income economy by 2020-23 (MoE, 2010:6; MoFED, 2010:87). The realisation of this goal is subject to the capacity of the country to diversify its economy into services, trade, and knowledge-intensive industries (see section 5.2). The existing economic environment of the country has, as reported by the interview respondents, given rise to new requirements for skills and competencies, as more jobs require higher education degrees (MoFED, 2010: 87; see Article 4 of Proclamation 650/2009). This finding is in line with the dominant functional theory that links higher education expansion to the socio-economic development process of industrialisation and modernisation. Moreover, economic growth in terms of a higher Gross Domestic Product per person can further increase student enrolments (see Chart 5-1).

The most important driver for revenue generation in the context of Ethiopia is the consequences of the continued expansion of the demand for higher education in the country. The current rapid growth in enrolments in pre-higher education and higher education means many clients who are entitled to various types of higher education services. Graduates from the preparatory schools and TVET drive the Ethiopian case study universities to expand their educational services at the undergraduate level. Table 5.24 below shows the expansion of the pre-higher education system in Ethiopia from 2007 to 2011, and the targets set for 2015. 
Table 5.24: Pre-Higher Education System in Ethiopia: Access and Targets

\begin{tabular}{|c|c|c|c|c|c|c|c|}
\hline \multirow{2}{*}{$\begin{array}{l}\text { Education } \\
\text { Level }\end{array}$} & \multicolumn{2}{|c|}{2007} & \multicolumn{2}{|c|}{2011} & \multirow{2}{*}{ 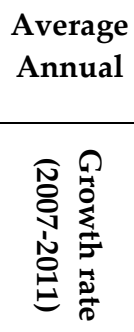 } & \multicolumn{2}{|c|}{ Target for 2015} \\
\hline & 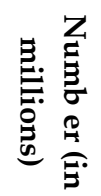 & 畟 & 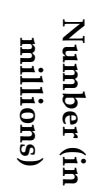 & 田 & & 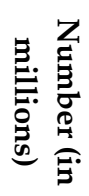 & 悬 \\
\hline Pre-primary & 0.23 & $3.1 \%$ & 0.38 & $5.2 \%$ & $15.0 \%$ & N/A & $20 \%$ \\
\hline $\begin{array}{l}\text { Primary (1-8 } \\
\text { grades) }\end{array}$ & 14.00 & $91.7 \%$ & 16.70 & $96.4 \%$ & $4.5 \%$ & N/A & $100 \%$ \\
\hline $\begin{array}{l}\text { Secondary } \\
\text { (9-12 grades) }\end{array}$ & 1.40 & $22.0 \%$ & 1.75 & $23.7 \%$ & $5.8 \%$ & N/A & \\
\hline $\begin{array}{l}\text { 1st Cycle (9- } \\
\text { 10grades) }\end{array}$ & 1.22 & $37.3 \%$ & 1.46 & $38.4 \%$ & $4.5 \%$ & N/A & $62 \%$ \\
\hline $\begin{array}{l}\text { 2nd Cycle } \\
\text { (11-12grades) }\end{array}$ & 0.18 & $5.5 \%$ & 0.29 & $8.1 \%$ & $13.2 \%$ & 0.36 & $9.5 \%$ \\
\hline TVET & 0.19 & $\mathrm{~N} / \mathrm{A}$ & 0.37 & $\mathrm{~N} / \mathrm{A}$ & $18.1 \%$ & 1.13 & $\mathrm{~N} / \mathrm{A}$ \\
\hline $\begin{array}{l}\text { Teacher } \\
\text { Education } \\
\text { (Diploma) }\end{array}$ & 0.07 & $\mathrm{~N} / \mathrm{A}$ & 0.16 & N/A & $32.5 \%$ & N/A & N/A \\
\hline
\end{tabular}

Source: MoE Statistics Annual Abstract 2010/11 and MoFED, 2010

As this table shows, the most significant suppliers of undergraduate students to universities in Ethiopia, the preparatory schools (grades 11-12) and TVET, rapidly increased in size from 2007 to 2011. By 2015, there will be 0.36 million students at preparatory schools and 1.13 million at TVET institutions (MoE, 2010). According to MoFED (2010), around 31\% of these students will get access to higher education. Ethiopia plans to achieve an annual intake of 467,000 undergraduate students (an increase of 150\% compared to 2009/10) by 2015 (MoE, 2010:64; MoFED, 2010:89). This scenario drives the Ethiopian case study universities to offer educational services to a variety of students in return for resources. 
The decade-long rapid expansion in both the number of HE organisations and the number of undergraduate students (see sections 5.3.1 and 5.3.2) has led to there being many more potential candidates for postgraduate education. For instance, 75,348 students graduated with bachelor degrees in 2011. According to MoFED (2010), the annual intake for postgraduate programmes (Master's degrees and PhDs) will reach 16,100 students by 2015, up from 10,734 in 2009/10. Similarly, the recent national capacity-building programme at the three levels of government (federal, regional, and local levels) necessitates frequent refresher training. The growth of knowledge (the creation of subfields) itself and a need for keeping pace with discoveries and innovations make universities key providers of life-long learning, carrying out re-education (retraining) and continuous professional development to persistently build the implementation capacity of the country (see MoFED, 2010:96-99; Tegegne Egziabher, 2007).

Risk mitigation is another important driver for the Ethiopian case study universities' engagement in revenue generation. There is now a wide spread understanding among stakeholders in public universities that public funding alone will not be sufficient to respond to the growing demand for higher education, while delivering a level of quality that provides students with the skills necessary to succeed in current and future labour markets. The senior university leaders from the two universities reported that income received from the main government treasury had been unable to cover all their requirements for resources in recent years. As a result, heavy dependence on a single funder (e.g. public funding) becomes a risky situation. Mitigating the risks of relying on one single revenue source is thus one of the most important drivers for revenue generation. Additionally, earned revenues can help avoid or reduce the administrative burden that often comes with public funding. The senior university leaders from the two universities and their finance officers told us that non-governmental income is comparatively easy to manage and can be allocated internally without many restrictions. This suggests that revenue generation is an important leverage for implementing a home-grown agenda, which is an important driver for revenue generation. To be more specific, revenue generation is a crucial part of maintaining the autonomy of ASTU and $\mathrm{HU}$, and the universities' freedom of manoeuver. We recognise a worldwide movement towards creating entrepreneurial universities (see Clark, 1998) as another driver for revenue generation. 


\subsubsection{Factors that Enabler or Hinder Revenue Generation at the Ethiopian Case Study Universities}

The findings in this chapter suggest that revenue generation in public universities is influenced by both environmental factors and university-specific conditions. Data from the interview respondents and documentary evidence has identified several enablers for and barriers to revenue generation within and outside ASTU and HU. We will analyse these in the following subsections.

\subsubsection{External Environmental Factors that Enable or Hinder Revenue Generation}

The environmental factors that enable or obstruct revenue generation at the Ethiopian case study universities are linked to the overall socio-economic and political context of Ethiopia, the degree of organisational autonomy, financial incentives, and the nature of stakeholders in the universities. From the societal environment of the case study university, the current rapid economic growth, the political stability of the country, and devolution of power to regional states and Woredas (see Section 5.2) all create an enabling environment for expansion of university education. The recent rapid economic growth has substantially increased the enrolment capacity of all Ethiopian public universities including ASTU and HU. This devolution of powers to Regional States and Woredas (districts) administrations (Article 52 of the Constitution, 1995) and the need for national capacity building have been gradually leading several ministries or regional states (or Woreads) towards being key service partners for public universities (MoFED, 2010:96-98). The information communication technological expansion underway in Ethiopia has also created opportunities to offer education services by transcending the obstacles of time and location.

A number of enablers for and barriers to revenue generation at the Ethiopian case study universities are embedded in their regulatory frameworks. In this regard, one of the prominent regulatory frameworks, the Higher Education Proclamation 650/2009, allows public universities in Ethiopia to mobilise income from non-governmental sources (see Articles 66 and 67; Article 62, No.2). This law, in addition to legalising income generation, implicitly warned the higher education organisations of the danger of financial dependence on the government. The proclamation further states that the initial capital required for the establishment of the revenue generation enterprise may come from a budget allocated by government (see Article 66, no.3). It allows a public university to use or keep the net profits of income generated in the pursuit of its mission and objectives (Article 66 No.5). Likewise, the MoE's Education Sector Development programme (ESDP IV) urges Ethiopian public universities to generate a 
minimum of $5 \%$ of their overall budget from non-governmental sources $(\mathrm{MoE}$, 2010:63).

The results of this chapter revealed that the degree of organisational autonomy granted by the regulatory framework in which the Ethiopian case study universities operate (see Chapters 2 and 3) influences their revenue generation agenda. The data from the interviews and documentary evidence revealed that the high degree of academic and organisational autonomy of the Ethiopian case study universities are key enablers for ASTU and HU to attract income from additional funding sources (see section 5.5.2). One of the important enablers is the existence of diversified criteria for the admission ${ }^{52}$ of full-cost paying students (Article 39, No.3 (a\&c) and No.5 of Proclamation 650/2009) by the universities themselves. The ability to admit as many fee-paying students as they wish is another enabler. The freedom to deliver fee-based short-term training by setting their own standards \& curricula (Article 19 No.3), as well as the capacity to determine modes of delivery are also enablers for engaging in revenue generation activities.

Autonomy in financial and staffing matters (see Section 5.5.2), and particularly freedom in the generation and deployment of monetary resources, the ability to charge tuition fees for non-government sponsored students, freedom of pricing for research \& consultancy services and freedom in recruiting and promotion of academic staff are all important enablers for revenue generation. This study also identified a number of hurdles within the regulatory framework which hinder revenue generation at ASTU and HU. These include the inability to borrow money from financial markets, line item budgeting, the inability to use virement between budget headings, and the inability to set the salary levels of academic and administrative staff (see Budget Administration 2010; Disbursement directive 2010). Another serious barrier for revenue generation at

52 Students who achieved higher in the UEE are directly admitted for undergraduate studies to any public university. Those who pass the UEE but are not admitted to the public universities through the MoE have the option of enrolling as full fee-paying students in public universities, seeking admission at private higher education organisations or joining overseas universities. These students are required to satisfy admission criteria set by the individual university or academic departments. TVET graduates with pertinent qualifications, and who satisfy the entrance qualifications assessment set by the admitting university can join the undergraduate continuing, summer and distance programmes. Adults can be enrolled in universities under special admission procedures to be issued by senate. 
the Ethiopian case study universities is bureaucratic procurement ${ }^{53}$ methods (e.g. an international competitive bid requires about 18 months to finalise) that cause budget 'flow backs' to the central treasury (see Public Procurement law,2005). An additional barrier to revenue generation is the inability of public universities to present a performance bond ${ }^{54}$ to a party in a contract as a guarantee against their failure to meet obligations specified in the contract. Staffing autonomy, and particularly the inability to set salary levels for academic and administrative staff, was also found to be a barrier to revenue generation (see Civil Servants Proclamation, 515/2007).

The availability or absence of financial incentives in the environment of the Ethiopian case study universities influences their revenue generation efforts. The absence of a loan scheme for full-fee paying higher education students (particularly those students who are academically able but financially challenged) is an important barrier to revenue generation (see section 5.3.4). Nonetheless, the Ethiopian government annually commits some funds (through the National Capacity Building Program $(\mathrm{NCBP})^{55}$ ) to strengthening the skills of civil servants, semi-skilled workers, and private sector entities through education and training (MoFED, 2010:96). A need for improving institutional and human capacity in both the Federal government and regional states has played a role in fostering partnerships between the university and other stakeholders in the environment (see Tegegne Egziabher, 2007). A good example is the teachers'-in-service training (widely known as summer-inservice programme) programme, where universities have provided targeted programmes for schoolteachers to upgrade their qualifications since 1997.

The lack of or very limited provision of government funding allocations for research at ASTU and HU is an important barrier to revenue generation. This shortage of public funding for research has limited the ability of ASTU and HU to invest in their research facilities and equipment and therefore hinders their overall research capacity. However, various bilateral and multilateral donors, and NGOs are the main sources of funds for research at ASTU and HU, offsetting some of the lack of government funding for research (see Section 5.5.3). From 2001-06, the Ethiopian higher education system received USD $\$ 11.3$

53 Tendering or advertisement takes 30 working days for national competitive bidding and 45 working days for international competitive bidding.

54 A surety bond issued by an insurance company or a bank to guarantee satisfactory completion of a project by the university.

55 Targets (i) federal civil service reforms, (ii) regional capacity building, and (iii) local government restructuring and empowerment for supporting the current decentralisation of power to regional states and local governments. 
million a year (World Bank, 2010). In 2009/10, for instance, total donor financing to education was estimated at around $\$ 340$ million, with around $5 \%$ going to higher education. Donor contributions and commitments between 2010/11 and 2014/15 are shown in Table 5.25 below.

Table 5.25: Donors contributions and commitments (mill USD)

\begin{tabular}{lcccccc}
\hline Category & $\mathbf{2 0 0 9 / 1 0}$ & $\mathbf{2 0 1 0 / 1 1}$ & $\mathbf{2 0 1 1 / 1 2}$ & $\mathbf{2 0 1 2 / 1 3}$ & $\mathbf{2 0 1 3 / 1 4}$ & $\mathbf{2 0 1 4 / 1 5}$ \\
\hline On-budget & 101 & 202 & 55 & 75 & 69 & 35 \\
Off-budget & 73 & 142 & 144 & 125 & 7 & 0 \\
$\begin{array}{l}\text { PBS to } \\
\text { education }\end{array}$ & 167 & 109 & 104 & 76 & 0 & 0 \\
\hline Total & 342 & 453 & 302 & 277 & 76 & 35 \\
\hline
\end{tabular}

Source: ESDP IV, MoE, 2010:103

Funds from donors can come as 'on-budget' or 'off-budget' support. The former is a priority for the university, where donors and the university focus on the implementation of clearly set university-owned policies and strategies. The latter (off-budget) support is mostly based on donors' project priorities (mostly not aligned with the requirements of the recipient universities). A common way of funding research is off-budget support that encompasses dozens of projects, amounting to less than US\$100,000 and usually provided either directly to a university or to faculties/departments within a given university or even to an individual researcher or group of researchers within a faculty. These research projects are usually fragmented, leading to the implementation of a variety of uncoordinated projects by an individual faculty or a group of academics, increasing the administrative or transaction costs for universities. Detailed and stringent financial and activity reports are generally required for research grants, which were reported to be an unattractive aspect of receiving the funds. Our interview respondents from HU told us that the absence of a well-defined national technology registration system discourages the academic staff from generating new technologies that lead to revenue generation (see Haramaya university, 2008b:7).

Unlike universities in developed and industrialised countries, ASTU and HU do not have many opportunities to attract income from the private sector, such as industrial firms and businesses. Industry covers a very small fraction of university research expenditures, due to the virtually non-existent presence of big research-intensive industrial firms that allocate money for research (see 
Section 5.5.3). Medium-sized and large firms are also not well developed (Tilman Altenburg, 2010; Sutton and Kellow, 2010). The relatively large industries in Ethiopia are subsidiaries of international companies, which draw upon the in-house R\&D capabilities of their parent company. Most industrial firms are very limited in articulating their needs, knowledge absorption, and capacity to pay for the services rendered. Moreover, they do not have a tradition of collaborating with universities. The key challenges are that all or most technology is imported, and R\&D concepts are not fully understood by the personnel of the small industrial firms. The underdevelopment of manufacturing sector in Ethiopia is generally an important barrier to revenue generation from industrial firms. ASTU and HU do not have equality of opportunities for cooperation with industry; due to their geographical settings (see Section 5.4). Unlike HU, ASTU is in a relatively concentrated area of industrial firms ${ }^{56}$, which enables the university to attract some revenue from these industrial firms.

Higher education organisations in Ethiopia have several suppliers and competitors. The rapid expansion of small public and private undergraduate universities across the country creates opportunities to have ample postgraduate students (Master's and $\mathrm{PhD}$ ) at the relatively established major universities. Moreover, the Ethiopian case study universities can form alliances with other organisations in the environment. On the other hand, there have been some competitions among higher education organisations, for students, staff, and research projects. The competition for undergraduate students seems to be growing, due to a low degree of product differentiation following the 70:30 policy of the federal Ministry of Education (see MoE, 2008), and an attempt to harmonise curricula at a national level. The establishment of two or more higher education organisations in the same town/city might contribute to competition for the student market. The participation of several public universities (e.g. Arba Minch, Bahir Dar, Harmaya, Jimma and Mekelle) in the provision of distance ${ }^{57}$ education signals competition for the same student market.

56 In a $100 \mathrm{~km}$ radius from the campus, a number of small to large-scale industrial firms such as sugar factories, milk and food processing companies, aluminium sulphate and sulphuric acid factory, soap factory, malt factory, tannery, defence engineering and metal corporation, metal and metallurgy, pulp and paper factory, textiles factories, car assembling companies, etc. are situated.

57 Was fully under the control of private HEIs prior to 2007. 


\subsubsection{University Specific Factors that Enable or Hinder Revenue Generation}

The findings of this research identify a number of internal factors that enable or hinder revenue generation at the Ethiopian case study universities. As indicated in Tables 5.5 and 5.8, ASTU and HU offer a broad range of courses in order to accommodate a very heterogeneous group of students. Differentiation in academic programmes can enable the two universities to create a better fit between the education given and the interests and talents of potential students. Thus, it is a step towards revenue generation from different types of students. The senior leaders of the Ethiopian case study universities were highly committed to revenue generation. For instance, HU planned to gradually generate up to $80 \%$ of its fund requirements (Haramaya university, 2008a:1), while ASTU strives to generate Birr 100 million by 2015. Revenue generation is part of the overall academic strategy of both the universities, and is also a strategic priority. This is believed to have created more awareness of the need to engaging in revenue generation and thereby improved the university community's commitment to revenue generation.

In terms of the internal governance structures and decision-making processes, HU has typically maintained a 'deliberative' structure of committees in order to develop a strong central leadership fused with the traditional academic approach. The established communication between HU's central administration and its different units (most often colleges) is an enabler for the implementation of a consistent revenue generation strategy. At $\mathrm{ASTU}^{58}$, the university president himself was in charge of major decisions related to revenue generation (see section 5.4.2.2). Such personal leadership faces opposition from the academic community. The experience of ASTU clearly shows that revenue generation will not prosper in a top-down approach. Additionally, the leadership of ASTU and HU play a great role in creating a positive climate for revenue generation through financial support. Any promising revenue generation initiatives, be it new activities or expanding existing programmes, have been given seed money, mostly in the form of loans. This enables the universities to increase revenue generation. However, the volume of the seed money provided is small and this was reported to be a key barrier to expanding revenue generation.

As shown in Chart 5-3 below, most faculties and colleges at the Ethiopian case study universities have poorly qualified staff, who are best characterised as young, inexperienced, and often insufficiently trained for carrying out postgraduate teaching, research or/and other service tasks. As a result, the two

58 In the case of ASTU, however, almost all decisions are made by the managing board (notably the president). 
universities do not have a discipline-centred academic base that could be a strong foundation for research. The young and inexperienced academic staff at ASTU and HU have found it difficult to form collaborations with other universities, either in Ethiopia or overseas.

Chart 5-3 Academic Staff Volume and Composition in 2010/11

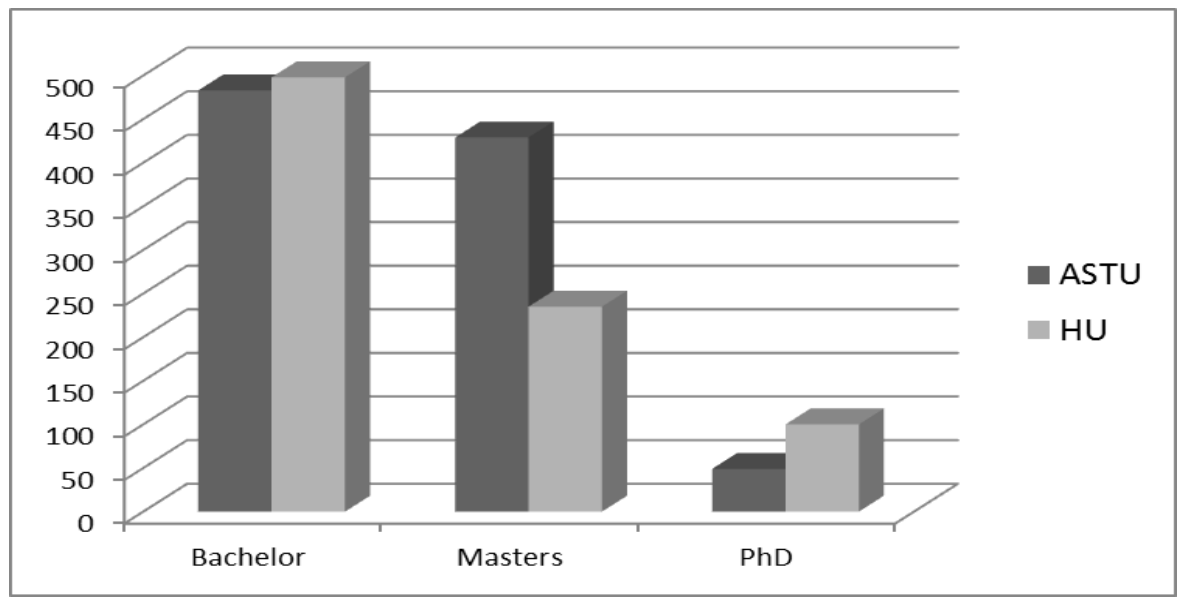

Shortages of qualified staff, more than the lack of funds, are an obstacle to generating revenue from research and postgraduate education. Equally, the heavy involvement of the tiny senior academic staff in undergraduate teaching and administrative tasks limits their opportunities for engaging in research and PhD supervision. Moreover, academic staff often spend limited time on their main job because they use second jobs and/or moonlighting to compensate for their low salaries.

ASTU and HU also suffer from a lack of managerial expertise and competence that leads to unprofessional management of revenue generating activities. This is an important barrier to revenue generation. The two universities have been unable to attract and retain high quality professional managers who can carry out the task of stakeholder management effectively and efficiently. The universities have grown aware of the need for specialised professional management to reduce the administrative burden on academics and free them to concentrate on their core tasks (education and research), which lead to revenue generation. Several senior academics who could have been performing education and research tasks are too heavily involved in administrative tasks that could otherwise be carried out by specialised support staff. To varying degrees ASTU and HU both reported a lack of adequate facilities as a major barrier to revenue generation. The universities still operate with inadequate laboratories, workshops, and library stock. Years of neglect in financing 
university research have left ASTU and HU with weak research infrastructures and equipment, and made them reliant on donor funding for research. Although the government has heavily invested in physical infrastructure, this capacity has generally not evolved as rapidly as anticipated, thus limiting its ability to help meet the demands of stakeholders in the areas of research and consultancy.

\subsection{Revenue Generation Strategies of ASTU and HU}

The main objective of this section is to analyse the revenue generation strategies of the Ethiopian case study universities. Some of the strategies discussed below are not necessarily undertaken by the universities with the objective of revenue generation, even if they offer a potential for it.

\subsubsection{Differentiation of Services and Products for Revenue Generation}

One of the prominent strategies for revenue generation is a differentiation of academic and non-academic services and products at ASTU and HU. The Ethiopian case study universities have set revenue generation strategies to foster their education services, research and consultancy services, and nonacademic services and products in relation to their missions. In the analysis, we would emphasise what revenue generation strategies were pursued by the Ethiopian case study universities against the above mentioned revenue generation activities below.

\subsubsection{Differentiation of Educational Services and Creation of New Academic Units for Revenue Generation}

One of ASTU and HU's strategies for revenue generation is vertical and horizontal differentiation of educational services to address the requirements of heterogeneous students (see section 5.6). As part of their vertical differentiation, ASTU and HU have been targeting not only students seeking degree programmes, but also students seeking non-degree pre- and post-baccalaureate certification (see Table 5.26 below). 
Table 5.26: Levels of degrees/diploma offered for revenue generation

\begin{tabular}{ll}
\hline ASTU & HU \\
\hline Bridging Course & First Degree \\
First Degree & Master's \\
& $\mathrm{PhD}$ \\
\hline
\end{tabular}

Table 5.26 above shows that ASTU did not offer educational services for revenue generation at Master's and $\mathrm{PhD}$ level. Even at $\mathrm{HU}$, more differentiation or proliferation of the programmes was observed in undergraduate programmes than postgraduate programmes (see Tables 5.28, 5.29 and 5.30). The college of agriculture and life sciences of $\mathrm{HU}$, where the university has more senior staff and better non-human resources, offers educational services at the postgraduate level. This vertical differentiation strategy enables HU to overcome stiff competition for full-cost paying students from newly established Dire Dawa and Jijiga universities, which are in its vicinity. Although the current higher education landscape of Ethiopia provides important opportunities for offering postgraduate studies in the areas of computer sciences, law, business and economic studies, as reported by the deans who participated in the interviews, the two universities are unable to exploit those opportunities due to their limited human and non-human resources.

ASTU provides bridging courses for those students whose average matriculation grade may be below the minimum required for automatic university admission or who may have scored the required minimum grade but had inferior grades in subjects considered core for the course desired by the student Bridging courses are primarily designed to enhance access to university education, but the inner motive of the university is to guarantee a constant flow of students for acquiring resources. The bridging courses are horizontally differentiated into mathematics, English, biology, chemistry, and physics, in order to reach as many high school leavers as possible.

ASTU and HU distinguish between student populations via their terms of study (regular or part-time students) and/or locations of study (main campuses or satellite campuses), as indicated in Table 5.27 below. 
Table 5.27: Programme Scheduling

\begin{tabular}{ll}
\hline ASTU & HU \\
\hline Evening & Evening \\
Weekend & Weekend \\
Summer & Summer \\
& Distance \\
\hline
\end{tabular}

This strategy of distinguishing customers by study time enables the universities to overcome their inadequate facilities in terms of lecture halls, library, offices, laboratories, and other educational inputs, by efficiently using the facilities' idle time. Moreover, it offers flexible routes into higher education by scheduling programmes at times which enable students to continue working and supporting a family.

ASTU and HU introduced continuing education programmes (CEP) in 1994/95 and 1980/81, respectively. The CEP operates a tri-semester scheduling equally distributed over periods of 15 weeks with a course load of 9-12 credit hours, which is different from the regular courses running on a bi-semester basis with a course load of a minimum of 15 credit hours. Table 5.28 indicates the status of CEP at the Ethiopian case study universities in 2010/11. 
Table 5.28: CEP at ASTU and HU in 2010/11

\begin{tabular}{|c|c|c|c|c|c|c|c|c|c|}
\hline \multirow[b]{3}{*}{ Academic Unit } & \multicolumn{6}{|l|}{ HU } & \multicolumn{3}{|l|}{ ASTU } \\
\hline & \multicolumn{3}{|c|}{ Undergraduate } & \multicolumn{3}{|c|}{ Postgraduate } & \multicolumn{3}{|c|}{ Undergraduate } \\
\hline & $\begin{array}{l}\# \\
\text { Progr } \\
\text { amm } \\
\text { es }\end{array}$ & $\begin{array}{l}\# \\
\text { Stud } \\
\text { ents }\end{array}$ & $\%$ & $\begin{array}{l}\# \\
\text { Progr } \\
\text { amm } \\
\text { es }\end{array}$ & $\begin{array}{l}\# \\
\text { Stud } \\
\text { ents }\end{array}$ & $\%$ & $\begin{array}{l}\# \\
\text { Progr } \\
\text { amm } \\
\text { es }\end{array}$ & $\begin{array}{l}\# \\
\text { Stud } \\
\text { ents }\end{array}$ & $\%$ \\
\hline $\begin{array}{l}\text { Engineering } \\
\text { and Technology }\end{array}$ & 3 & 285 & 14 & & & & 12 & 1087 & 30 \\
\hline $\begin{array}{l}\text { Natural and } \\
\text { Computational } \\
\text { Science }\end{array}$ & & & & & & & 2 & 97 & 2.6 \\
\hline $\begin{array}{l}\text { Medicine and } \\
\text { Health Sciences }\end{array}$ & 1 & 223 & 11 & & & & & & \\
\hline $\begin{array}{l}\text { Agricultural } \\
\text { and Life } \\
\text { Sciences }\end{array}$ & 1 & 485 & 24 & 3 & 383 & 83 & 2 & 27 & 0.7 \\
\hline $\begin{array}{l}\text { Business and } \\
\text { Economics }\end{array}$ & 3 & 579 & 29 & & & & 5 & 1196 & 33 \\
\hline $\begin{array}{l}\text { Social and } \\
\text { Humanities }\end{array}$ & 2 & 441 & 22 & 1 & 77 & 17 & 5 & 1269 & 35 \\
\hline Total & 10 & 2013 & $\begin{array}{c}10 \\
0\end{array}$ & 4 & 460 & 100 & 26 & 3676 & 100 \\
\hline
\end{tabular}

Source: MoE Annual Abstract, 2010/11

Moving educational services closer to their newly found 'customers' is an important strategy for expanding the CEPs for both ASTU and HU. The two universities have established new campuses in strategic locations in order to accommodate the soaring demands for higher education. While HU established satellite campuses in Haramaya, Harar, Dire Dawa, Chiro, and Jijiga, ASTU opened satellite campuses in Addis Ababa (Wingate), Bishoftu, and Assela. Forming franchises or collaborating with other middle-level colleges or postsecondary providers is the key strategy that the universities have followed in order to reduce costs and improve services, and thereby perhaps generate more revenue from the CEP. For instance, HU collaborates with Jijiga 
University ${ }^{59}$ and Somali Regional Government for building the implementation capacity in the region. In this alliance arrangement, Haramaya University assigns professionals; Jijiga University provides facilities such as lecture halls, library facilities, laboratory spaces, etc.; and Somali regional state recruits and sponsors students.

Similarly, the Ethiopian case study universities introduced a Summer-in-Service Programme (SP) in 1997 in response to the demands of the Federal Ministry of Education and Regional Education Bureaus for upgrading the academic qualification of teachers during the school vacation period (July to September for 8-10 weeks). Following the approval of the National Capacity Building Programme and the creation of capacity building offices (as the federal ministry and regional capacity bureaus), the SP was horizontally differentiated into noneducation fields of study. The SP uses the idle time of the facilities and work force for generating funds. Table 5.29 presents the status of SP in 2011.

${ }^{59}$ Situated in Somali region. 
Table 5.29: Summer Programme at ASTU and HU in 2010/11

\begin{tabular}{|c|c|c|c|c|c|c|c|c|c|}
\hline \multirow{3}{*}{$\begin{array}{l}\text { Academic } \\
\text { Unit }\end{array}$} & \multicolumn{6}{|c|}{ HU } & \multirow{2}{*}{\multicolumn{3}{|c|}{$\frac{\text { ASTU }}{\text { Undergraduate }}$}} \\
\hline & \multicolumn{3}{|c|}{ Undergraduate } & \multicolumn{3}{|c|}{ Postgraduate } & & & \\
\hline & $\begin{array}{l}\text { No. } \\
\text { Progr } \\
\text { amm } \\
\text { es }\end{array}$ & $\begin{array}{l}\text { No. } \\
\text { Stud } \\
\text { ents }\end{array}$ & $\%$ & $\begin{array}{l}\text { No. } \\
\text { Progr } \\
\text { amm } \\
\text { es }\end{array}$ & $\begin{array}{l}\text { No. } \\
\text { Stud } \\
\text { ents }\end{array}$ & $\%$ & $\begin{array}{l}\text { No. } \\
\text { Progr } \\
\text { amm } \\
\text { es }\end{array}$ & $\begin{array}{l}\text { No. } \\
\text { Stud } \\
\text { ents }\end{array}$ & $\%$ \\
\hline $\begin{array}{l}\text { Engineering } \\
\text { and } \\
\text { Technology }\end{array}$ & 1 & 224 & 4 & 5 & 78 & 8 & 11 & 420 & 11 \\
\hline $\begin{array}{l}\text { Natural and } \\
\text { Computatio } \\
\text { nal Science }\end{array}$ & 5 & 1531 & 24 & 7 & 340 & 34 & 5 & 1124 & 29 \\
\hline $\begin{array}{l}\text { Medicine } \\
\text { and Health } \\
\text { Sciences }\end{array}$ & 3 & 761 & 12 & & & & & & \\
\hline $\begin{array}{l}\text { Agricultural } \\
\text { and Life } \\
\text { Sciences }\end{array}$ & 6 & 1308 & 21 & 13 & 258 & 26 & & & \\
\hline $\begin{array}{l}\text { Business } \\
\text { and } \\
\text { Economics }\end{array}$ & 3 & 575 & 9 & & & & 2 & 109 & 3 \\
\hline $\begin{array}{l}\text { Social and } \\
\text { Humanities }\end{array}$ & 8 & 1893 & 30 & 4 & 321 & 32 & 14 & 2219 & 57 \\
\hline Total & 26 & 6292 & 100 & 29 & 997 & 100 & 42 & 3872 & 100 \\
\hline
\end{tabular}

Source: MoE Annual Abstract, 2011

According to the senior university leaders and deans, the lack of academics who are trained at $\mathrm{PhD}$ level and inadequate laboratories and workshops have hindered the vertical differentiation of CEP and SP (Tables 5.28 and 5.29). Although visiting professors and lecturers from in country and overseas universities often teach block courses on postgraduate regular programmes at $\mathrm{HU}$, the same approach has not been applied to CEP and SP because of their time schedules. 
HU opened its distance Education programmes in three colleges, based on the experiences and lessons learned from running a USAID funded Basic Education System Overhaul project (upgrading 1200 primary school teachers) in 2003 (see Table 5.30 below).

Table 5.30: Distance Education at HU in 2010/11

\begin{tabular}{lccc}
\hline Band & $\begin{array}{c}\text { Number of } \\
\text { Programmes }\end{array}$ & $\begin{array}{c}\text { Number of } \\
\text { Students }\end{array}$ & \% \\
\hline $\begin{array}{l}\text { Agricultural and Life } \\
\text { Sciences }\end{array}$ & 4 & 1423 & 31 \\
Business and Economics & 2 & 2179 & 48 \\
Social and Humanities & 1 & 949 & 21 \\
\hline Total & 7 & 4551 & 100 \\
\hline
\end{tabular}

Source: MoE Annual Abstract, 2010/11

\subsubsection{Differentiation of Research Services and Creation of New Research Entities for Revenue Generation}

As indicated in section 5.4, research is the founding mission of the Ethiopian case study universities, although it is underrepresented and underperformed. Revenue generation from research activity is almost non-existent at the two universities except at HU's College of Agriculture and Environmental Studies. The College of Agriculture and Environmental Studies accounts for about 95\% of the research outputs of HU. The reasons for low performance in research are attributed to shortages of qualified academic staff at PhD level, limited national budget allocations for research, heavy administrative and teaching loads for academics, and inadequate non-human resources such as machinery, laboratories and workshops (see Haramaya University, 2008b). Nonetheless, the Ethiopian case study universities have diversified their research areas ${ }^{60}$ in their

60 ASTU mainly desires to conduct research in areas of energy, tropical medicine, technical and vocational education, agriculture, and ICT. The university undertakes some projects in the fields of photovoltaic (PV) technologies, thermal solar energy, wind energy, biomass energy utilisation for briquette charcoal making, biogas and gasification, and small hydropower development. In addition to its agricultural research, HU has gradually included research in other areas such as law, social sciences, educational sciences, languages, health, and environment. Nonetheless, HU is still heavily involved in agricultural research that covers such themes as agricultural mechanisation, food sciences and post-harvest technology, dry-land agriculture and agrometeorology, highland and lowland pulses improvement 
strategic plans in order to meet the research requirements of the environment (see Sections 5.6). They have also established several additional academic entities that promote contract education, contract research, and consultancy in order to respond to emerging external opportunities for revenue generation as shown in Chart 5-4 below.

\section{Chart 5-4 Number of Research Institutes, Centres, and Units at the Case} Study Universities

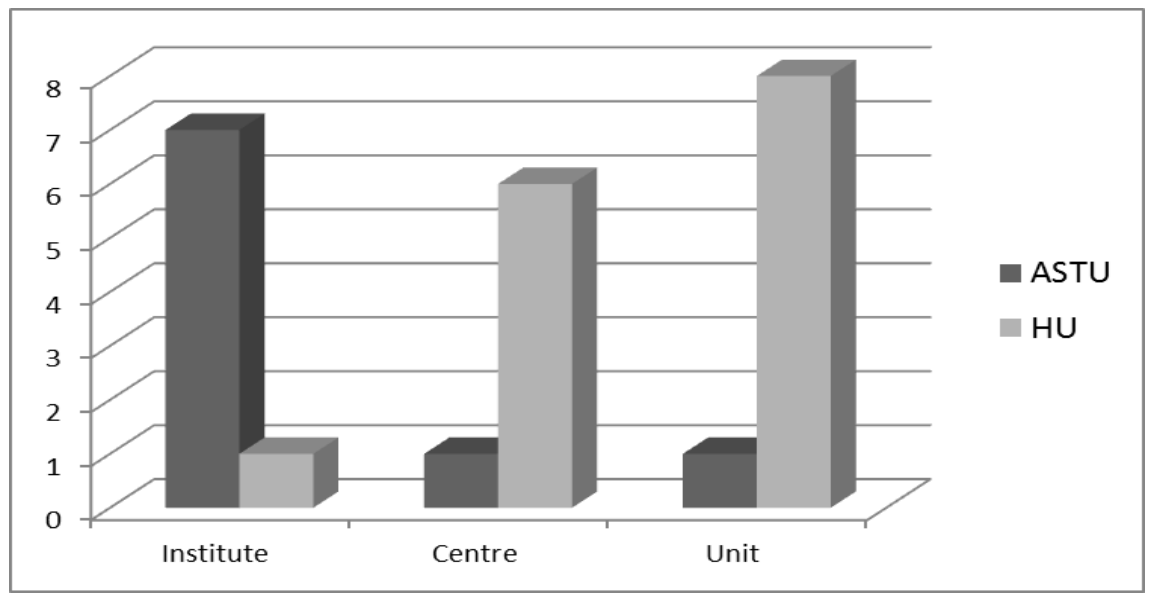

These academic entities were expected to reach across old university boundaries and link the universities with various stakeholders to promote collaborative and interdisciplinary approaches. The entities are considered to be a way of establishing stable and enduring relationships with stakeholders in order to develop predictable flows of resources. They work closely with traditional academic departments by sharing resources, but actually operate much like mediating bodies situated between the university and its external stakeholders. Internally, they work closely with academic staff/researchers in forming collaborations between academic staff and/or between faculty members in different disciplines (i.e. they bring together a new mix of people to solve new problems in unusual ways); and externally they serve as venues for

programme, soil and water conservation, fruits and vegetable improvement programme, oil crops improvement programme, wheat improvement programme, maize improvement programme, sorghum improvement programme, root and tuber crops improvement programme, forestry improvement programme, beef cattle improvement programme, camel improvement programme, small ruminants improvement programme, poultry improvement programme, dairy cattle improvement programme, animal health improvement programme, feeds and nutrition, and fisheries and other aquatic lives. 
collaboration between the universities and their stakeholders. As it stands today, the development of several research entities (see Chart 5-4 above) at ASTU and HU without having adequate supporting research capacity is a cost rather than a profit for the universities. This illustrates how the senior university leaders of ASTU and HU have, under conditions of uncertainty, imitated the behaviour of other research-intensive universities that they knew and trusted.

One of the strategies formulated to augment the two universities' inadequate human and non-human resources $\mathrm{s}$ was to form research alliances ${ }^{61}$ with incountry and overseas organisations. The major incentive for the formation of these alliances was to gain access to funding. According to the senior university leaders and deans who we interviewed, the alliance strategy did not work as intended, because there was inadequate in-house capacity in terms of qualified human resource (notably at PhD level) to effectively and efficiently collaborate with alliance organisations. The College of Agriculture and Environmental Studies at HU offers evidence that it is able to raise revenue because of its strong senior academic staff at PhD level and well-established alliances with several universities and research institutes.

61 ASTU has alliances with: British Council, ecbp German Development Cooperation, ELIP/ELIC, Embassy of the Federal Republic of Germany in Addis Ababa, German Academic Exchange Service, German Development Service, German Technical Cooperation, International Leadership Institute, KfW Bank engruppe, UNECO, VSO, Andhra University/India/, Bayreuth University/Germany/, Budapest Tech/Hungary/, Georg-Simon-Ohm University of Applied Sciences Nuremberg/Germany/, Institute for Housing and Urban Development Studies/The Netherlands, Johannes Gutenberg University Mainz/Germany, Leeds Metropolitan University/UK, University College of Engineering \& Technology Malaysia, University of Applied Sciences Rosenheim/Germany, Rostock University/Germany, Shanghai Institute of Technology/China, University of Tasmania in Australia, Tomsk State University in Russia, Victoria University of Wellington in New Zealand, and Western Michigan University in USA are alliance organizations (accessed in May, 2011: http://www.adama-university.net/index.php?id=766). The way that ASTU moved into external alliances and networks with other universities signified the importance of the social contacts or 'social capital' of the president and various European deans. Similarly, HU formed alliances with a number of organisations such as NUFFIC, SIDA/SAREC, DAAD, Sasakaw Global/Winrock International, Austrian Development Council, the Carter Center, Irish Aid, NORAGRIC, USIS, British Council, IFISH, VSO, six universities in the USA, five universities in Europe and two universities in Asia. HU also works and collaborates with several multilateral organisations such as the World Bank, UNDP, FAO, CGIAR, ECA, WHO, and International Livestock Research Institute. 


\subsubsection{Diversifying Non-Academic Services for Revenue Generation}

A number and of non-academic services and products (see Table 5.31) are assets that could provide additional revenue for the Ethiopian case study universities.

Table 5.31: Diversifying Non-Academic Services for Revenue Generation

\begin{tabular}{lcc}
\hline Revenue Generation Activity & ASTU & HU \\
\hline Academic credentials & $\checkmark$ & $\checkmark$ \\
ID card & $\checkmark$ & $\checkmark$ \\
Bookshops & - & $\checkmark$ \\
Agricultural products ${ }^{2}$ & $\checkmark$ & $\checkmark$ \\
Conference hall and venue hire & $\checkmark$ & $\checkmark$ \\
Medical services & $\checkmark$ & $\checkmark$ \\
Material or sampling testing in laboratories & $\checkmark$ & $\checkmark$ \\
Residences or housing services (guest houses & $\checkmark$ & $\checkmark$ \\
and dormitories) & $\checkmark$ & $\checkmark$ \\
Sport facilities & $\checkmark$ & $\checkmark$ \\
Leasing university property & $\bullet$ & $\checkmark$ \\
Museum & $\checkmark$ & $\checkmark$ \\
Catering services & $\checkmark$ & $\checkmark$ \\
Repair and maintenance of furniture & $\checkmark$ & $\checkmark$ \\
Day care centre and model schools & $\bullet$ & \\
\hline Key: Not Available $\checkmark$ Available &
\end{tabular}

The growth of ASTU and HU in terms of student population, academic staff and administrative support staff has necessitated engaging in these on-campus services in order to meet the demands of their internal and external customers. Notably, agricultural products and conference services play a dual role in terms of revenue generation. First, they are important sources of revenue for the universities by themselves. Second, they enable academic units to generate

62 ASTU engages in large scale agricultural production such as meat, dairy, grains, honey, horticultural crops, fruits, etc.. HU sells agricultural products including poultry and poultry products, dairy products, live beef animals and beef, pig and pork, small live animals (sheep and goats) and products, horticulture products, improved seeds and the like to in- and off-campus communities. 
revenue from short-term courses that are organised on campuses, through cafeteria services. The absent or inadequate basic facilities near HU did not lead to unfair competition with private-sector businesses that could have raised legal and philosophical issues. Although the Ethiopian case study universities are, in principle, committed to running non-academic services and products with full costs plus a contribution to the general pot of earned revenue, they never even cover their full costs. According to the heads of the Finance Departments of ASTU and HU, there is often no financial return in running non-academic service and sometimes the universities incur losses. Almost all cafeterias on campuses, for instance, promote the notion of "feed yourself from the work place". The unofficial principle is to create an enabling working environment for the academic community to reducing staff turnover by high subsidies for the products and services.

A strategy of establishing university enterprise was pursued for refraining the universities from entering into direct competition with private enterprises at ASTU and HU (see Haramaya university, 2008b:57-69; Eichele, 2007). At HU, thirteen different enterprises were proposed or established as the university's investment machines for technology commercialisation and assistance in transferring technology and expertise to clients. ASTU established Asella Model Agricultural Enterprise (AMAE) as an income generating enterprise with its own legal persona. It envisages AMAE operating as a certified organic model farm in Ethiopia and processing (agro-processing) the farm produce into certified organic food products based on relevant ISO standards for domestic and foreign markets. ASTU also created business-incubators or science and technology parks as one of their initiatives to improve research and consultancy; they also facilitate academic start-up firms in order to take advantage of low-cost real estate to provide affordable rentals to aspiring commercial enterprises. The inadequate research capacity at the Ethiopian case study universities has limited the operation of all these enterprises.

\subsubsection{Creation of Administrative Support Structures for Stakeholder Management}

The Ethiopian case study universities created strategies for a structured approach to stakeholder management. Two broad organisational approaches were identified: (i) using the existing organisational structures to enhance efficiency and reduce costs, and (ii) establishing new organisational structures dedicated to revenue generation. Table 5.32 below shows which offices are in charge of revenue generation at the strategic apex of ASTU and HU. 
Table 5.32: Offices in Charge of Revenue Generation at the Strategic Apex

\begin{tabular}{lll}
\hline University & Level & Position \\
\hline \multirow{2}{*}{ ASTU } & Vice & International Relations, Corporate \\
& President & Communications, and Fund Raising \\
\multirow{2}{*}{ HU } & Vice & Institutional Development and Community \\
& President & Engagement \\
\hline
\end{tabular}

The presidents of ASTU and HU are the lead people responsible for the revenue generation agenda at their respective universities. The vice-presidents indicated in Table 5.32 assist the presidents in revenue generation matters. According to Eichele (2007:66), the office of the Vice President for International Relations, Corporate Communication and Fund Raising is mandated to proactively initiate fast growing business cases and to make an unbureaucratic, responsive, low-barrier support system a reality. At HU, the vice president responsible for revenue generation is assisted by a kind of revenue generation committee or a team comprising different members of the university community for collective steerage (see Haramaya University, 2008 a, b, c, \&d). Additionally, the participation of regional authorities on the governing boards ${ }^{63}$ of the universities created opportunities to collaborate on capacity building programmes, and led to additional resources for ASTU and HU, as reported by the senior leaders of the universities.

Table 5.33 below shows the crosscutting offices that ensure a structured approach to stakeholder management for fostering revenue generation at the Ethiopian case study universities.

63 The members of ASTU's Supervisory Board are drawn from Minister of Civil Service, Minister of Education, Director of Oromia Regional State TVET Agency, and representatives from private organisations such as entrepreneurs and the President of Adama Chamber of Commerce. The current board members of HU are drawn from regional states (Oromia, Harari, Somaile and Dire Dawa), a representative from Ministry of Agriculture and Rural Development, a representative from MoE, and two representatives from the governing political party EPRDF. 
Table 5.33: Key Support Offices Dealing with Revenue Generation

\begin{tabular}{ll}
\hline ASTU & HU \\
\hline - Finance and Accounting & - Finance, Procurement and Property \\
- Human Resources & Management \\
- Legal Matters & - Human Resource Management \\
- Public Relations & - Strategic Planning, Monitoring, and \\
- International Offices & Evaluation \\
& - Promotion and Marketing \\
& - Legal Support and Intellectual \\
& Right Protection \\
\hline
\end{tabular}

The positions in Table 5.33 have not necessarily been established by the universities solely with the objective of generating revenue, but they offer support for revenue generation. By optimising tasks in the given structures, the senior university leaders try to achieve efficiency without extensive decentralisation of their financial, human resource and procurement management to faculty and departmental levels. The offices undertake such activities as conducting needs identification studies, marketing university services and products, developing a corporate image for the university, supporting proposal writing and costing, providing legal and contracting support, and handling finance and human resource matters. All the offices collectively deal with stakeholders in the environments in order to facilitate linkages at different levels and address issues of accountability (i.e., in terms of compliance and reporting) once such linkages are made. The Ethiopian case study universities intensively communicate with internal and external stakeholders in order to ensure sustainable flows of resources to the universities. ASTU and HU advertise their programmes heavily in print and electronic media, websites and through fora such as agricultural shows, trade fairs, and exhibitions as well as by directly addressing high school students. One or more units devoted to these tasks perform marketing activities along with academic departments and faculties. Internal communication targets the broader university community in order to achieve cooperation between the leadership, academic staff, and administrative staff on the purposes, aims, and actions pursued to raise non-governmental revenue.

Table 5.34 below lists the outreach support offices for fostering revenue generation from educational services. 
Table 5.34: Key Support Offices Dealing with Revenue Generation from Educational Services

\begin{tabular}{ll}
\hline ASTU & HU \\
\hline - Vice President for Academic Affairs & - Vice President for Academic Affairs \\
and Undergraduate Studies & - College of Continuing and Distance \\
- Institute of Continuing and Distance & Education \\
Education & - Consultancy and Short-Term \\
- Further Training Institute & Training Office \\
\hline
\end{tabular}

A university-wide College of Continuing and Distance Education at HU and Institute of Continuing and Distance Education at ASTU deal with revenue generation from educational services. These offices operate in collaboration with a focal point at each school to coordinate programmes for fee-paying students. Moreover, the Institute of ASTU and the College of HU work closely with the offices in Table 5.33 on financial matters and other issues such as procurement and human resource management. The Consultancy and ShortTerm Training Office (CTO) at HU and the Further Training Institute (FTI) at ASTU mainly manage the short courses. The inability to produce performance bond to guarantee the satisfactory completion of short-term training and/or consultancy forces the two universities to undertake these revenue generation activities only for those stakeholders who are willing to operate without a bond.

ASTU and HU use different offices to help raise revenue from research and consultancy services, as shown in Table 5.35 below. 
Table 5.35: Key Support Offices Dealing with Revenue Generation from Research and Consultancy Services

\begin{tabular}{ll}
\hline ASTU & HU \\
\hline - Vice President for Research and & - Vice President for Research Affairs \\
Postgraduate Studies & - Research Group \\
- Knowledge and Technology & - Research Partnerships \\
Interchange & - Research Promotion and Marketing \\
- Research and Publication Office & - Legal Support and Intellectual \\
- Technology Innovation Centre & Right Protection \\
(AUtic) & - Consultancy and Short-Term \\
& Training Office \\
& - Estate and Facility Management \\
& - Bridging Committee \\
\hline
\end{tabular}

The administrative support offices shown in Table 5.35 were not necessarily established by the universities solely to generate revenue, but they offer support for revenue generation. They are both outward facing and inward facing. As far as the outside world is concerned, they are expected to serve as a liaison between the universities and their stakeholders, and seek to match faculty expertise with the research needs of stakeholders in the environment. Units such as Knowledge and Technology Interchange at ASTU and Research Partnerships at HU work to form collaborations with other universities and research organisations to offset the lack of qualified staff and adequate research facilities. They also search for domestic and international research funds from diverse development partners or donors. HU approaches its stakeholders to identify their research needs through workshops, annual meetings, etc. or using its 'bridging committee'. This bridging committee, in collaboration with regional states and individual farmers, identifies proposed areas of research during its annual meeting. The KTI supports ASTU's academic and administrative staff in acquisition and contracting projects, counsels them about funding opportunities and assists them in writing funding applications and intermediate and final reports in third party funded projects. $A U$ tic aims to help build successful companies with sustainable growth and provide services that lower development costs and accelerate the implementation process for ASTU's entrepreneurs. Similarly, the Research Partnerships department of HU is 
organised into a Knowledge and Technology Transfer Office and a Research Commercialisation Office that are responsible for creating linkages with national and international institutions and tracking research grants worldwide.

Inward-facing functions include the dissemination of information to internal actors (academic and administrative staff) and stimulating academic units' involvement in research and consultancy. The support functions include proposal writing support, contracting support, financial management, advertising, human resource management, linkages, and the like. The universities chose to use their existing organisational units (see Table 5.32) to manage stakeholders in order to foster revenue generation from research and consultancy services. The administrative support structures indicated in Table 5.35 could have paid off if the case study universities had been researchoriented universities with core qualified faculty. Opening such offices is less cost-effective at ASTU and HU, and the move is simply an isomorphic approach in which the universities try to replicate the practices of more prestigious research-intensive universities. Revenue generation from research commercialisation is overstated at the two Ethiopian case study universities, causing significant administrative costs.

Revenue generation from non-academic activities also requires a wide range of specialist skills (Table 5.36).

Table 5.36: Key Support Offices Dealing with Revenue Generation from Non-Academic Services

\begin{tabular}{ll}
\hline ASTU & HU \\
\hline - Vice President for International & - Vice President for Institutional \\
Relations, Corporate & Development and Community \\
Communication and Fund Raising & engagement \\
- International Office & - Farm Management Office \\
- Social Services & - Resource Centre (food preparation, \\
- Compound services & refreshment centre, and gymnasium \\
& and sport centre) \\
\hline
\end{tabular}

The office of vice presidents/deputy vice chancellors is in charge of offering overall policy leadership for fostering revenue from non-academic services. Many offices linked to non-academic services and products have been established. Offices indicated in Table 5.36 are involved in generating revenue from non-academic services to reduce costs and improve efficiency. ASTU uses 
its Social Services Department and Compound Services Department to operate student and staff-related services like cafeterias, refectories or lounges and provide catering, medical and clinical services as well as develop and maintain ASTU facilities.

\subsubsection{Decisions Concerning Internal Resource Allocation Mechanisms and Human Resource Policies for Revenue Generation}

The Ethiopian case study universities have formulated strategies to help align internal actors with their revenue generation agenda. University authorities have a number of possible levers to foster revenue generation through internal allocation of human, physical, and financial resources. The availability of considerable resources becomes a sine qua non condition for revenue generation in universities. We will now analyse how ASTU and HU have made resources available to their revenue generation activities, and how they have incentivised actors to participate in revenue generation. An entry point for any revenue generation activities is a Business Plan (BP) or Terms of Reference (ToR) that broadly describe the business, market and marketing strategy, production details (e.g. requirements and costs, forecasts of production vis-à-vis sales, and financial start up and operational costs), human resources (e.g. responsibilities and pay), risk management strategy, and action plan. Seed money is allocated to revenue generation activities according to the accepted business plan. The source for the seed money is revenue from other revenue generation activities (mainly from education and non-academic services and products), as ASTU and HU cannot directly use their main state budgets for revenue generation. Cross subsidising across the academic units by taxing rich programmes to aid less fortunate ones is the norm at the two universities. Using the internal resource allocation mechanism to foster revenue generation has been hampered as the universities often face a shortage of money for engaging large-scale revenue generation activities, which require huge initial investment in qualified academic staff, state-of-the art laboratories, workshops, textbooks, etc. Their inability to borrow money from capital market exacerbates the problems.

Wherever an approved business plan proposes additional expertise, the Ethiopian case study universities can recruit professionals from outside or invest in the development of staff to acquire these skills. In most cases however, part-timers (mostly Master's holders) run educational activity for revenue generation. ASTU and $\mathrm{HU}$ also invite guest lecturers from national universities as well as public and private organisations to offset the shortage of qualified staff for their postgraduate provision. Attracting and retaining qualified staff 
(e.g. PhD holders) in those disciplines for which the private sector or international organisations offer much higher salaries and/or better career prospects (e.g. business and economics, law, medicine, and engineering and technology) is difficult. Attracting professional managers (in the areas of finance, marketing, project management, and human resource management, etc.) is also almost impossible for HU under the existing pay scales. The senior academic staff work in the administrative staff offices of the universities (notably at HU) to overcome shortages of managerial expertise, at the cost of research and educational activities. ASTU lobbied for additional autonomy, particularly in terms of setting salaries for senior administrative support staff, to overcome these challenges. This improved its stakeholder management to some degrees. Inadequate procurement and recruitment capacity at the Ethiopian case study universities also significantly affect their resource allocation for revenue generation.

The Ethiopian case study universities are well aware that the university community will only engage in revenue generation as long as they perceive its usefulness and have the opportunity to enjoy monetary and nonmonetary rewards from it. They embed internal reward mechanisms in order to increase their academic community's commitment to revenue generation. An academic who is involved in teaching fee-paying students and/or short-term training at the two universities is financially rewarded for his/her contributions on an hourly basis, as per an agreed scale which also takes into account their academic rank. While this monetary reward has encouraged junior academic staff to participate more and more in teaching full fee-paying students, most senior academics have become increasingly reluctant to teach fee-paying students due to the limited financial benefits. In terms of non-financial rewards, ASTU and HU do not employ revenue generation as a major criterion for the internal promotion or career advancement of academic staff. Promotions depend mostly on the traditional education and research missions. Nor is revenue generation used as a criterion for appointing new staff externally. Nor is evidence sought on a candidate's record of accomplishment in revenue generation. The vast majority of academic staff still consider revenue generation to be peripheral to their traditional roles.

With respect to research projects, financial or nonfinancial incentives benefit researchers, units and/or the university according to their project agreements. In most projects, about $80-85 \%$ of the total project costs go to the implementation of the project, while the remaining $15-20 \%$ becomes a levy to cover central costs. This distribution factor between administrative and implementation costs depends on the type of research and the volume of the funding attracted by the researcher(s). This implies that the amount of levy is 
left to ad hoc negotiations between senior university leaders and project initiators. For instance, at $\mathrm{HU}$, revenue generated from commercialisation of technology is shared between the technology owner (75\%) and the university (25\%). As prestige maximising organisations (Winston, 1994), universities naturally possess an overriding preference for engaging in research activity that leads to publications, and thereby resources. The inadequate research capacity at the two universities has substantially limited their revenue generation from research.

Aside from academic staff, other organisational actors such as schools, institutes, and/or departments do not directly receive revenue as incentives for revenue generation. As a result, they do not perceive any incentive to take an active part in revenue generation from educational activities. Lack of incentive for units of the universities has led deans and academics department heads to have little interest in revenue generation from educational services. However, the offices of deans and department heads obtain their share of overhead costs for project management for some research projects. They mostly receive nonfinancial resources such as laboratory instruments, chemicals, books, ICT facilities, participation of project staff in international conferences, and other capacity building training for staff. Most research projects include compensation for better-equipped facilities, refurbished rooms, office equipment, scientific equipment, and/or travel grants.

\subsection{Conclusion}

This chapter presents an analysis of the data on the status of revenue generation in the Ethiopian case study universities, using the resource dependence perspective as its theoretical lens. The findings show that the Ethiopian case study universities were unable to diversify their revenue base significantly - to the level of ensuring financial health and sustainability - irrespective of volatilities that may influence any form of resource dependence negatively. We argue that any unforeseen underperformance by either the main state allocation or student tuition fees would financially destabilise the overall operations of the Ethiopian case study universities. It may also threaten their very survival. Although ASTU and HU have attempted to secure the largest amount of resources for the longest time possible by implementing revenue generating activities through education, research and consultancy, and other non-academic services and products, they have managed to earn only one-fifth of their recurrent budget from nongovernmental sources. In the subsequent paragraphs, we discuss why the Ethiopian case study universities operated in certain ways in terms of revenue generation. 
ASTU and HU were able to earn the largest volume of their nongovernmental resources by offering educational services, due to the rising social demand for higher education. The environment coupled with university specific strengths in terms of human and nonhuman resources positively influenced the Ethiopian case study universities to acquire resources by providing educational services at the undergraduate level. More importantly, the two most salient stakeholders of ASTU and HU, the Ethiopian government and the students, strongly support access to good quality higher education in order to reap the social and individual benefits from university education. Although there are no financial incentives from the national government to support academically able but financially challenged full-cost paying students, an un-easing demand for higher education along with rising tuition fees in Ethiopia hints that most stakeholders for educational services are comparatively price inelastic.

The Ethiopian case study universities pursued two prominent revenue generation strategies; adapting and altering strategies to maximize their revenue from educational services. The adaptive strategies employed by the case study universities include: horizontal and vertical differentiation of their educational programmes, opening new campuses in strategic locations, flexible class scheduling to help students combine work and study, and using different modes of delivery. There was a proliferation of programmes in social sciences and humanities, business and economics, and agriculture mostly at undergraduate level. The ultimate goal of the adaptive strategy is to expand educational services by promoting efficiency gains. As part of their altering strategy, the Ethiopian case study universities formed alliances with other educational organisations and invited external representatives onto their governing boards. The formation of alliances with other environmental actors enabled them to overcome shortages of non-human resources and reduce their initial investment capital. In spite of huge environmental demands for postgraduate education, lack of human and non-human resources at both universities has limited vertical differentiation at postgraduate level, particularly in areas that require infrastructure, laboratories, and workshops.

The findings showed that revenue generation from research and consultancy represented a very small fraction of the nongovernmental resources in the Ethiopian case study universities. Although both environmental factors and university specific conditions could help explain such a low performance in research, the best explanation comes from the internal context of the two universities, i.e. lack of qualified academic staff/researchers and inadequate nonhuman resources for conduct cutting edge research. In particular, the absence of financial support for research in the main state funding allocation has contributed to eroding research infrastructures at the two case study 
universities. Even though ASTU and HU, as part of their adaptive strategy, developed research entities such as institutes, centres and units alongside their traditional academic departments, and created administrative research support structures, this strategy currently incurs more costs than benefits. Creating organisational structures without having adequate research capacity has illustrated how organisational decision makers under conditions of uncertainty imitated the behaviour of other universities in their immediate or international environment, particularly those universities whom they knew and trusted. Moreover, the Ethiopian case study universities' attempts to form alliances and linkages with other organisations in their environment, as part of their altering strategy, has turned out to be less than effective as forming alliances is a matter of social capital or a win-win approach that operates based on the 'Matthew Effect'.

The findings also indicate that the Ethiopian case study universities obtained resources by providing non-academic products and services to their internal and external stakeholders. In this regard, the major revenue generation activities include renting university facilities, bookshops, medical services, accommodation, catering services, laboratory testing, agricultural products, and maintenance and repairs of computers and furniture. As the main customers for these services and products are the university community itself, this study acknowledged that there are real organisational and economic differences between the universities and other businesses in operating the non-academic services and products. ASTU and HU face numerous distinctive constraints and incentives in their pricing, costs, and offerings, as subsidising the services and products has become the norm. As no substantive strategic or philosophical debate need accompany a choice to rent university facilities to various stakeholders, the Ethiopian case study universities aspire to achieve efficiency in running their non-academic services.

As is evident from the findings presented in this chapter, the existing academic staff focused internal reward and incentives systems were unable to guide the academic community towards revenue generation. ASTU and HU provided financial rewards for those academic staff who directly participated in teaching full-cost paying students. No financial rewards were directly provided to administrative support staff or other office holders, including middle level managers, deans, and department heads, who directly or indirectly facilitated revenue generation. Although participation in revenue generation can sometimes indirectly lead to the recruitment and promotion of staff, revenue generation was not one of the steering tools or criteria in the universities' human resource policies. In short, faculty at the heart of the academic enterprise 
are, for the most part, still being trained, hired, and rewarded in traditional ways.

Finally, the current high enrolments in the full-cost paying programmes at the Ethiopian case study universities could be used to maximise financial gains at the expense of quality in the absence of robust quality assurance mechanism (Mulu Nega, 2012). The only way to maximize the benefits of revenue generation is to establish robust quality control mechanisms and develop new capabilities in terms of additional resources for universities to enable them to enter into postgraduate studies and research, and thereby respond to the dynamic environment with the full potential to acquire resources. The example of the College of Agriculture and Environmental Studies at HU, where the college engaged in revenue generation from undergraduate and postgraduate teaching, research and consultancy services, and selling agricultural products, suggests that in-house capacity in terms of qualified academic staff and other nonhuman facilities is important in diversifying the revenue base. Financial sustainability cannot be achieved in the Ethiopian context without sufficient and sustainable public funding. Equally, the idea of 'revenue generation' in public universities is appropriate as public funding can only support highquality university education when the system is relatively modest and inevitably elitist. We recognise that revenue generation is inevitable in the Ethiopian higher education landscape, but that inevitability needs to be managed in mission-focused and market-smart ways without imperilling core academic values or compromising the quality of education. 


\section{The Kenyan Case Study University}

\subsection{Introduction}

This chapter provides a wide range of data on the national development context of Kenya, its higher education system, and the Kenyan case study university in order to answer the basic questions of this study. The chapter is organised in line with the theoretical framework and research model discussed in Chapter 3, and the operationalisation of variables discussed in Chapter 4. Following this introductory section, we analyse the wider societal environment of the Kenyan case study university, in terms of the demographic and socio-economic context of the country. In the third section, we discuss the history and structure of the Kenyan higher education system, emphasising the size and shape, governance and management, and financing of higher education. The key characteristics of Jomo Kenyatta University of Agriculture and Technology (JKUAT) are provided in section four in line with the variables in Table 4.1. In section five, we identify JKUAT's external stakeholders and determine their salience in terms of regulatory powers and funding. The sixth section of this chapter explores the environments of JKUAT to identify key drivers, enablers, and barriers for revenue generation. In section seven, we analyse the revenue generation strategies of the Kenyan case study university. Finally, we draw some conclusions.

\subsection{Demographic and Socio-economic Context of Kenya}

The Republic of Kenya (hereafter Kenya) lies on the equator with the Indian Ocean to the south-east, Tanzania to the south, Uganda to the west, South Sudan to the north-west, Ethiopia to the north and Somalia to the north-east. The total area of Kenya is 582,650 km2. Kenya had eight provinces64 in 2011. The 2010 constitution of the country introduced two levels of government: national and counties (see Chapter 11 of the Constitution). The counties are constitutionally permitted to manage their own affairs and further their development. The Kenyan higher education system, like that of Ethiopia, always faces environmental changes. The principal features of the environmental factors that influence the Kenyan higher education system and

64 Central (11\%), Coast (8\%), Eastern (15\%), Nairobi (8\%), Nyanza (14\%), North Eastern $(6 \%)$, Rift Valley $(26 \%)$, and Western $(11 \%)$. The share of population is shown in brackets against each province. During data collection, there was a move to organize 47 counties. 
organisations are the dynamic changes in the demographic, socio-economic, and political contexts of the country.

Kenya had a population of around 41 million in 2010, representing 42 different ethnic groups. There is also a rapidly growing youth population in the country, as shown in Table 6.1.

Table 6.1: Key Population Statistics for Kenya

\begin{tabular}{|c|c|c|c|c|}
\hline $\begin{array}{l}\text { Total } \\
\text { Population } \\
\text { (2010) in } \\
\text { millions }\end{array}$ & $\begin{array}{l}\text { Proportion of } \\
\text { population } \\
\text { below the age } \\
\text { of } 15\end{array}$ & $\begin{array}{l}\text { Proportion of } \\
\text { population } \\
\text { between } \\
15 \text { and } 64\end{array}$ & $\begin{array}{l}\text { Proportion of } \\
\text { population } 65 \\
\text { or older }\end{array}$ & $\begin{array}{l}\text { Population } \\
\text { annual } \\
\text { growth rate }\end{array}$ \\
\hline 40.9 & $42.5 \%$ & $54.9 \%$ & $2.7 \%$ & $2.6 \%$ \\
\hline
\end{tabular}

Source: UNPF 2010

According to the Kenyan National Bureau of Statistics (2012), the primary school age population and the secondary age population respectively cover $25 \%$ and $9 \%$ of the total population of the country. The higher education age cohort is about $6 \%$ of the total population. This suggests that the Kenyan higher education system has huge demand for higher education services. We will return to the country's pre-higher education system in section 6.6.2.

Similarly, universities in Kenya operate in a fast changing economic environment. Table 6.2 provides data on GDP (or income) per capita and other selected economic development indicators for Kenya.

Table 6.2: Selected Economic Development Indicators for Kenya

\begin{tabular}{llll}
\hline $\begin{array}{l}\text { Gross domestic } \\
\text { product per }\end{array}$ & $\begin{array}{l}\text { Rank out of } 142 \\
\text { capita } \\
\text { current } \text { in }\end{array}$ & $\begin{array}{l}\text { Stage of } \\
\text { development } \\
\text { dollars I2010 }\end{array}$ & $\begin{array}{l}\text { Overall } \\
\text { competitive } \\
\text { ranking (out of } \\
142 \text { countries) }\end{array}$ \\
\hline 809 & 102 & Factor driven $^{66}$ & 102 \\
\hline
\end{tabular}

Source: WEF 2011-2012

The Kenyan economy can be characterised as a dual economy, having a small, relatively sophisticated urban economy based largely in Nairobi and a large,

65 Compared to Ethiopia's USD 350 and South Africa's USD 7158.

66 Kenya competes based on its factor endowments-primarily unskilled labour and natural resources. Companies compete based on price and sell basic products or commodities, with their low productivity reflected in low wages. 
under-developed rural economy (CHET, 2010). According to a World Economic Forum report (2011-2012), Kenya's innovative capacity is ranked 52nd, with high company spending on $R \& D$ and good scientific research institutions that collaborate well with the business sector. This innovative potential is supported by an educational system that, although educating a relatively small proportion of the population compared with most other countries (see Section 6.3), gets fairly good marks for quality $\left(51^{\mathrm{st}}\right)$ and for on-the-job training (54 $\left.4^{\text {th }}\right)$. Financial markets are well developed by international standards (26th) and a relatively efficient labour market (37th) also supports the economy. However, Kenya's overall competitiveness is held back by poor health conditions $\left(122^{\text {nd }}\right)$ and a difficult security situation (129th).

As shown in Chart 6-1, Kenya's economic growth has been irregular and fluctuating between 2007 and 2011. Following the successful implementation of the Economic Strategy for Wealth and Employment Creation, Kenyan economy grew by more than $6.1 \%$ in $2006 / 2007$, from virtual stagnation $(0.6 \%)$ in 2002 . Between 2007 and 2009, however, the growth of economy significantly slowed.

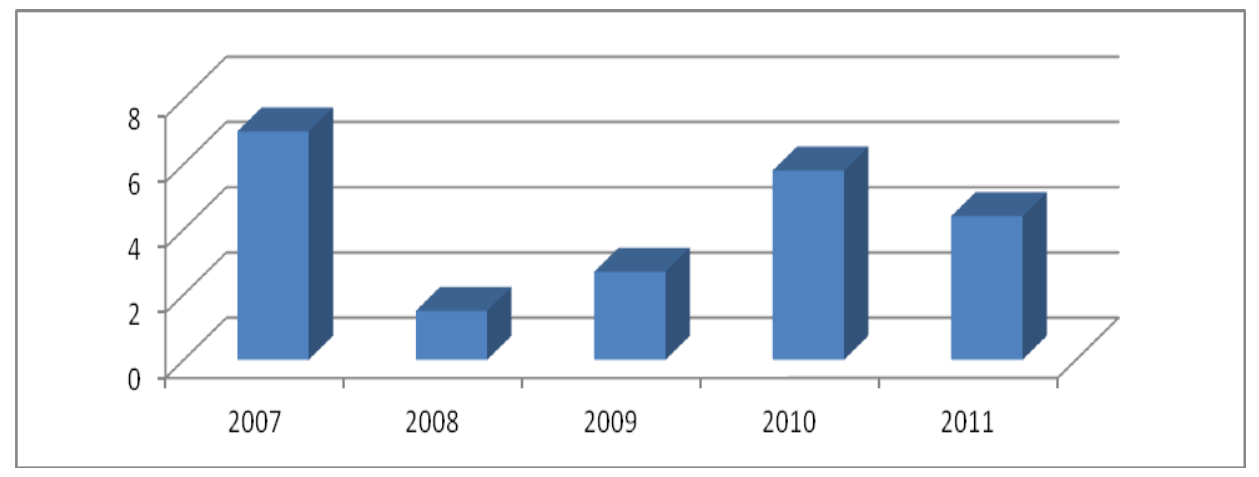

Chart 6-1 Real GDP Growth Rates, 2007-11

Source: accessed on 25 April 2013: http://www.africaneconomicoutlook.org/en/datastatistics/table-2-real-gdp-growth-rates-2003-2013/ or African Economic Outlook.

Agriculture is the mainstay of the economy. It currently accounts for $26 \%$ of GDP directly and another $25 \%$ indirectly, $65 \%$ of Kenya's total exports, $18 \%$ of formal employment, and 70\% of informal employment (GoK 2010:1). Tourism remains a leading earner of foreign exchange for the country (GoK, Vision 2030). For instance, tourism earnings rose to KSh 73.7 billion in 2010 from KSh 62.5 billion in 2009. Revenues from tourism are expected to rise to $22 \%$ of GDP by 2015 and remain at that level to 2030. The manufacturing sector contributes $10 \%$ of GDP. It currently employs 254,000 people, which represents $13 \%$ of total 
employment (GoK, 2007). An additional 1.4 million people are employed in the informal side of the industry.

There are many economic challenges influencing Kenyan higher education organisations.These include domestic budget deficits and chronic unemployment, and externally the global financial and economic crisis, and high international oil and commodity prices. According to the Kenyan Ministry of Finance (2012:20), the general government budget balance as a percentage of GDP in 2011 was -7.5 compared to Ethiopia's -1.3. The poverty level in Kenya is still relatively high, $48 \%$ in 2010, which is expected to fall to $42 \%$ in 2012 (IMF, 2012). The current economic environment in Kenya has led to reductions in the state budget for universities. Although the Kenyan government spends $1 \%$ of its GDP and about $13.7 \%$ of its total education budget on higher education (CHET, 2010:33), budgetary pressures are apparent at individual higher education organisations. As observed in national strategic plans and the manifestoes of political parties (see JKUAT, 2009:16-17), there is a political commitment to expanding good quality, well-resourced and governed higher education system. As it stands now, Kenyan higher education organisations operate in a financial crisis caused by decreased government support for individual universities.

\subsection{Higher Education System in Kenya at a Glance}

Higher education in the context of Kenya includes Universities, Polytechnics, Technical, Industrial, Vocational and Entrepreneurship Training (TIVET), Institutions of Science and Technology, diploma level Teacher Training Colleges, and other post-secondary education organisations. The objective of this section is to briefly discuss the Kenyan higher education system in terms of its size and shape, participation, governance and management, and financing.

\subsubsection{Size and Shape of the Kenyan Higher Education System}

The origins of higher education in Kenya can be traced back to Makerere University in Uganda, founded in 1922 during British colonial rule. Makerere University was established as a technical college for African students from the East African countries of Uganda, Kenya, and Tanganika. The foundation of the first higher education organisation in Kenya dates to 1947, when the colonial government sought to establish a technical and commercial institute in Nairobi (see Bailey et. al, 2011) that aimed at providing higher technical education for Kenya, Uganda, and Tanzania. In 1951, this concept received a Royal Charter, under the name of the Royal Technical College of East Africa. This College 
opened its doors to its first intake of students in 1956 (Ngome, 2000:360). The College became Royal College of Nairobi in 1961, based on the recommendation of a working party established in 1958. The Royal College of Nairobi became the University College of Nairobi and joined Makerere and Dar es Salaam Colleges to form the University of East Africa in 1964 following Kenyan independence in 1963. Because of nationalist pressure, mainly from Kenya and Tanzania, the University of East Africa was dissolved in 1970, with each of the three countries (Kenya, Uganda and Tanzania) establishing their own national universities. An Act of Parliament officially inaugurated the University of Nairobi (UoN) as the first Kenyan university in December 1970.

Pressure to increase higher education participation necessitated the establishment of more universities in different parts of the country. A Presidential Working committee, the Mackay Report, recommended the establishment of Moi University (MU) at $35 \mathrm{kms}$ from Eldoret town as the second university in 1984 (GoK, 1981). MU is known for its forestry and wildlife conservation studies, although it runs academic programmes in engineering, agriculture, physical sciences, medicine, and social sciences. The third university is Kenyatta University (KU) that has its beginnings in 1965 when the British government handed over the Templer Barracks to the Kenyan government. This barracks was converted to Kenyatta College, located on the outskirts of Nairobi along Thika Road. In 1975, it became a constituent college of the UoN, known as Kenyatta University College and then became an autonomous university in 1985.The university offers degree courses in physical and social sciences, business studies and environmental sciences. It is, however, renowned for its programmes in education for which it claims to be the leading education institution in Eastern and Central Africa.

Egerton University (EU) was the fourth public university, founded in 1987. Its history dates back to 1939 when Lord Maurice Egerton of Tatton, a settler farmer, donated 300 hectares of land from his estate to a school for training white settler youth for careers in agriculture. From a very small institution in the early 1940s, it grew into a college in 1950 and soon started offering certificate and diploma courses in agriculture and education. In 1979, the Government of Kenya and USAID funded the expansion of the college, which became a constituent college of the UoN. In 1987, it was upgraded to Egerton University. EU is best known for its agriculture programmes. The fifth university was Jomo Kenya University of Agriculture and Technology (JKUAT), one of the case study universities for this research. We shall discuss and analyse JKUAT in detail shortly (see Section 6.4). The six was Maseno University (MSU) that was established in 2000. Its history dates back to the first decade of the twentieth century, when a Church Missionary Society-established mission 
centre expanded to cater for learning and agricultural activities. Later, it became a teacher training college (Siriba Teacher Training College) and governmenttraining institute. In 1990, these two institutions merged to form Maseno University College, a constituent college of MU. In 2000, it became a fullyfledged university. Masinde Muliro University of Science \& Technology (MMUST) was the seventh public university in Kenya. It started to function in 1972, as Western College of Arts \& Applied Sciences, providing certificate and diploma courses in mechanical, electrical and electronic engineering as well as in agriculture, water, building, accounting, and finance. In 2002, it became a constituent college of MU and was renamed Western University College of Science \& Technology. In 2007, it was upgraded to become an autonomous university. Geographically, almost all Kenyan universities are located in Nairobi and Rift Valley provinces.

The government of Kenya has implemented a gentle expansion of universities, adding a few more institutions to an elite university system. Since 2007 however, Kenya has established 15 university colleges (http://www.che.or.ke/status.html, accessed on 2012-05-18). These include: Kisii University College (EU), Chuka University College (EU), Laikipia University College (EU), Kimathi University College of Technology (JKUAT), Mombasa Polytechnic University College (JKUAT), Meru University College of Science and Technology (JKUAT), Multi-Media University College of Kenya (JKUAT), Pwani University College (KU), Kabianga University College (MU), Narok University College (MU), Chepkoilel University College (MU), Karatina University College (MU), Bondo University College (MSU), Kenya Polytechnic University College (UoN), and South Eastern University College (UoN). Kenya is still in favour of developing institutions into universities after them first serving for an extended period as a college supervised by an old established university. The addition of the 15 new public higher education organisations means there are universities in all provinces except North-Eastern and Western provinces.

Apart from universities, there are a number of post-secondary institutions offering training at diploma and certificate levels. TIVET programmes are offered in Youth Polytechnics (YP), nineteen Technical Training Institutes (TTIs), fourteen Institutes for Technology (ITs), and two National Polytechnics (http://www.scienceandtechnology.go.ke/index.php/rad-

institutions/accrediratedtechnical-institutions accessed on 18 May 2012). A number of institutions spread across ten government ministries as well as private institutions offer TIVET programmes. Graduates from TIVET are awarded certificates and diplomas. In the field of teacher training, there are $28(71 \%)$ primary teacher training colleges and three diploma teacher-training 
colleges. Teacher training colleges form an important avenue for those who want to continue with their post-secondary education but fail to secure admission to the universities or other technical education institutions. Non-graduate healthcare professionals (e.g. nurses and clinical officers) are trained in 11 medical training colleges in various parts of the country (see Bailey et. al, 2011). Several other private commercial technical institutions, whose exact number is not known, operate in Kenya (ibid, p17). Kenya's higher education system has put an emphasis on formal academic education, which has been the main stumbling block for the TIVET sector.

Kenya is also home to private higher education institutions. The 1980s and 90s saw the emergence of private HEIs in Kenya (Ngome, 2000:364). According to Mugenda (2009), Kenya has about twenty-three private universities including branch campuses of foreign universities. These private universities have different statuses in terms of accreditation: Chartered ${ }^{67}$ universities (14); universities with Letters of Interim Authority68 (11); and universities with Certificates of Registration69 (2) (accessed on 2012-05-18: http://www.che.or.ke/status.html; see also Otieno 2010). The chartered universities have been fully accredited by a Commission for Higher Education (CHE). The registered universities are those that were offering degrees before the establishment of the CHE in 1985, and were issued with Certificates of Registration (CoR) after fulfilling the requirements set out in the Universities Rules, 1989. According to CHE policy, the issuance of CoR is a statement of the existence of the institutions and should in no way be construed to imply accreditation. Universities operating under Letters of Interim Authority (LIA) are those that applied to the CHE for their establishment and fulfilled

67 University of Eastern Africa, Baraton, 1991; Catholic University of Eastern Africa, Nairobi, 1992; Daystar University, Nairobi, 1994; Scott Theological College, 1997; United States International University, Nairobi, 1999; Africa Nazarene University, Nairobi, 2002; Kenya Methodist University, Meru, 2006; St. Paul's University, 2007; The Pan Africa Christian University, 2008; Kabarak University, 2008; and Strathmore University, Nairobi, 2008; Mount Kenya University, 2011; Africa International University, 2011; and Kenya Highlands Evangelical University, 2011.

68 Aga Khan University, Nairobi, 2002; Kiriri Women's University of Science \& Technology, Nairobi, 2002; Great Lakes University of Science \& Technology, Kisumu, 2002; Gretsa University KCA University, Nairobi, 2007; The Presbyterian University of East Africa, 2007; KCA university, 2007; Adventist University of Africa, 2008; Inoorero University, 2010; The East Africa University, 2010; Genco University; and Management University of Africa.

69 The East African School of Theology, 1989; and the Nairobi International School of Theology, 1989. 
requirements as stipulated in the Universities Rules, 1989 and were issued with LIA by the CHE. One of the private universities is exclusively for women (Kiriri Women's University), and two of them are trans-local (the United States International University and Aga Khan University). The private universities in Kenya are mainly theologically-based and offer comparatively few programmes, focusing on arts and commercial courses particularly business studies, ICT, and the social sciences. The majority of these institutions are limited in capacity, located in Nairobi province and catering for a small student population (with annual admissions ranging from 500 to 2000).

\subsubsection{Participation in University Education}

The Kenyan government has strived to increase participation in higher education over the last four decades. Beginning with just 571 students enrolled in Nairobi University College (Weidman, 1995), there were 180,978 students enrolled in Kenyan universities in 2011. The number of students in the Kenyan universities increased by $53 \%$, from 118,239 students in $2007 / 08$ to 180,978 students in 2010/11 (IMF, 2012). Enrolment at private universities remains low at $12.7 \%$ of total admissions (GoK, 2007:96), down from a high of $20 \%$ before the admission of self-sponsored students in public universities. Currently, more than half (around 52\%) of enrolments at public universities are in private entry schemes (parallel programmes). The rapid growth of student admissions through Module II programmes, largely explains the reduced private university share. The privatisation gains by public universities create hurdles for the private institutions.

The minimum qualification requirement for university admission in Kenya is a $\mathrm{C}+$ pass. However students must earn a grade point average on the Kenyan Certificate Secondary Examination (KCSE) significantly over the minimum eligibility requirements. Of the 50,000 students qualifying for admission each year, not more than 10,000 are admitted into the regular programme (CHET, 2010:18). For example, only 3\% of secondary school students entered university in 2007. The number of students who qualify but are not admitted to public universities increases every year, as shown in Table 6.4 (see Kigotho, 2000). 
Table 6.3: Admission trends in public universities

\begin{tabular}{cccccc}
\hline $\begin{array}{c}\text { Academic } \\
\text { Year }\end{array}$ & $\begin{array}{c}\text { Total form } \\
\text { 4 enrol- } \\
\text { ment }\end{array}$ & $\begin{array}{c}\text { No. } \\
\text { qualified } \\
\text { (c+ and } \\
\text { above) }\end{array}$ & $\begin{array}{c}\text { JAB } \\
\text { admis- } \\
\text { sions }\end{array}$ & $\begin{array}{c}\% \\
\text { qualified } \\
\text { admitted }\end{array}$ & $\begin{array}{c}\text { \% of form } \\
\text { 4 admitted }\end{array}$ \\
\hline $2002 / 03$ & 176,018 & 42,158 & 11,046 & $26.2 \%$ & $6.3 \%$ \\
$2003 / 04$ & 186,939 & 42,721 & 10,791 & $25.3 \%$ & $5.8 \%$ \\
$2004 / 05$ & 193,087 & 58,218 & 10,200 & $17.5 \%$ & $5.3 \%$ \\
$2005 / 06$ & 209,276 & 68,030 & 10,000 & $14.7 \%$ & $4.8 \%$ \\
\hline
\end{tabular}

Source: Otieno (2010)

By 2015, the number of students seeking university entry will be between 160,000 and 180,000 (see GRK, 2007). If the current trends continue, the number of students who will miss the opportunity to go to university will be over 100,000 by 2015 . Notwithstanding the expansion of universities in recent years, the capacity of the higher education sector in Kenya is still limited (World Bank, 1994; Weidman, 1995; Kigotho, 2000; Kabiru Kinyanjui, 2007). The ideal plan is to increase the proportion of those accessing university from the relevant cohort to at least $15 \%$ by 2020 , in order to have higher education access comparable to that of middle-income countries (Kabiru Kinyanjui, 2007:1-2; GRK, 2007).

\subsubsection{Higher Education Governance and Management in Kenya}

The Kenyan higher education system is steered by a number of regulatory frameworks (see Section 6.5.1) and regulators in order to influence or constrain the behaviour of universities, their students, and other actors in the higher education system to meet the expectations of society. In this subsection, we briefly introduce some of the key external actors in the Kenyan higher education landscape. The House of the Parliament of Kenya approves various statutes that regulate universities (see Chapter 8 of the constitution). The Ministry of Higher Education, Science, and Technology (MOHEST) is the main body in charge of policy formulation, implementation, evaluation and regulation of university education, TIVET, and issues related to national research, science and technological issues (see the Presidential Circular No. 1/2008 of 2008). The responsibilities of MOHEST are: i) policy formulation in collaboration with the CHE, a Higher Education Loans Board (HELB), and other relevant institutions and departments of the government; ii) co-ordination of plans and budgets from public universities in collaboration with CHE and other departments; iii) approval of the annual revenues and expenditures of 
universities (see the Universities Act, 2012; clause 38); iv) disbursement of grants and bursaries to local and overseas universities; v) coordination of admissions to public universities in liaison with Joint Admission Board (JAB); and vii) declaration of any institution to be a technical university, etc..

The Commission on Higher Education (CHE) is an intermediary body between the universities and the Kenyan government, with responsibility for overseeing quality assurance and the expansion of university education (see the Universities Act (Cap.210B) of 1985). The CHE has considerable statutory powers to run university education by defining admission requirements, programme length, qualification levels, staff qualifications, student enrolments, infrastructural facilities, and ethical standards governing the university community. The establishment of public universities through institutional Acts of Parliament did not, however, make public universities subject to the accreditation process of the CHE. The heavy involvement of the government itself in planning, budgetary matters and maintaining the quality of public universities seems to have denied CHE an active role as stipulated in the law (see Sifuna, 2006:187). CHE now presides over matters of quality assurance in private universities. Following the ratification of the 2012 Universities Act, the Commission for University Education (CUE) is the successor to the CHE (see Part II 4(2)).

Higher Education Loans Board (HELB) ${ }^{70}$ is an important stakeholder in the Kenyan higher education landscape; it tries to improve the access to higher education for people who have sufficient academic competence but are financially challenged, through a means testing ${ }^{71}$ approach. In this respect, it carries out loan recovery, establishes a revolving fund, and seeks additional funds from the private sector and donors (Otieno, 2004) in order to promote access to higher education for people from disadvantaged groups (see section 6.6.3.1). HELB works with a credit bureau and a government tax authority, a National Social Security Fund and a Government Computer Centre, Kenya Revenue Authority (KRA) and National Health Insurance Fund (NHIF) to recover loans by identifying loan recipients who are working in both the private

70 The loan issue was tabled for discussion in the policy of higher education in Kenya during the first planning phase (1964 to 1970). The Kenyan government introduced a student loan system in its higher education system in 1974 (see RoK, 1964:105; RoK, 1973; Woodhall, 1991).

71 Targets students who are orphaned as a result of HIV/AIDS and those who come from semi-arid and arid geographical areas such as Samburu, Turkana, West Pokot and other districts in Eastern and North Eastern provinces. 
and public sectors (Ngolovoi, 2006). The Joint Admissions Board (JAB) ${ }^{72}$ is another regulator of the Kenyan higher education system, which decides applications for all admissions to public universities for government sponsored undergraduate degree students. JAB regulates access to public higher education in Kenya through highly selective criteria according to which only candidates with a C+ grade in KCSE are eligible for admission to universities. The Board sets the entry cut off point $(\mathrm{CoP})$ for government-sponsored students from year to year. Students who attain the prescribed $\mathrm{CoP}$ are admitted into regular state supported programmes by the JAB.

The Ministry of Finance (MoF) is an important body in Kenyan higher education governance. It is responsible for regulating and managing the budgets and expenditure of all government financial resources (see Constitution of Kenya, Cap VII Sections 99-103). The MoF manages the Kenyan government's revenue, expenditure, and borrowing. MoF mobilises resources, including from donors, for other government organs including public universities to support the government's programmes and activities. More importantly, the MoF coordinates and assists public universities in the preparation of their annual national budget, influences the amount of funding that each university receives, and provides accounting, disbursements, and auditing services to universities.

National Council for Science and Technology (NCST) is a statutory institution, which was established in July 1977 by the Science and Technology Act. Cap. 250 of Kenya. The purpose of NCST is to advise the government on all matters related to scientific and technological activities, including determining the priority $^{73}$ areas in science, technology and innovation, coordination of research and experimental development, and enhancing collaboration and linkages among various actors (funding organisations, universities, etc.). For the higher education system, NCST coordinates and promotes research, science, and technology activities (GoK, 2007). It provides financial support for some strategically important research.

Inter-University Council for East Africa ${ }^{74}$ (IUCEA), as one of the regulators of the Kenyan higher education system, provides the scope and opportunity for

72 Is a non-statutory body made up of the Vice Chancellors, Deputy Vice Chancellors, Principals and Deans of the seven public universities and representatives from MOHEST.

73 In 1989, the Council outlined the national research priority areas and subsequently revised them in 2004.

74 EAC includes Burundi, Kenya, Tanzania, Rwanda and Uganda 
advancing higher education interests in the region. The main objectives of IUCEA are to: (i) facilitate networking among universities within East Africa, and with universities outside the region; (ii) provide a forum for discussion on matters relating to higher education in East Africa; and (iii) facilitate maintenance of internationally comparable education standards in East Africa to promote the region's competitiveness in higher education. The current systems of accreditation across the EAC are more or less harmonised. This means that the accreditation status of a university in one country can be easily recognised in other EAC countries. A higher education provider registered in one Partner State is allowed to operate in another country if the basic national requirements to operate in that country have been met.

\subsubsection{Financing Higher Education in Kenya}

Public universities in Kenya are considered state corporations, so they fall under the purview of State Corporations Act Cap 466. According to the 2012 Universities Act (clause 31), funds for a public university come from: (a) sums as may be granted to the university by parliament; (b) monies or assets as may accrue to or vest in the public university in the course of the exercise of its powers or the performance of its functions; and (c) all monies from any other source provided for or donated or lent to the public university with the approval of the Cabinet Secretary responsible for Finance and the Cabinet Secretary responsible for University Education. Government budgetary allocations to Kenyan education sector have progressively increased over the last few years. Nearly $73 \%$ of the government's social sector spending and about $40 \%$ of the national recurrent expenditure goes to education (MoE, 2008: viii). This translates to around $7 \%$ of GDP, which is one of the highest levels of expenditure on education in Africa (GoK, 2007: 95), with the average being 3.9\% for Sub-Saharan Africa (World Bank, 2010). The Kenyan government spends 1\% of its GDP, or about $13.7 \%$ of its total education budget, on higher education (CHET, 2010:33). This funding level is far greater than most of the poorest counties in Africa, which allocate approximately $0.63 \%$ of their GDP to higher education (World Bank, 2010:2).

Kenya employs an input-based budget as a method of allocating budgets to its public universities (World Bank, 2010:42). Officially, an undifferentiated ${ }^{75}$ unit

75 The method does not take into account the different costs of the various degree programmes. 
cost $^{76}$ system is used for allocating funds to public universities to educate all students admitted through JAB (see Pillay 2004, 2008; World Bank, 2010:4). This resource allocation mechanism generally gives universities discretion over internal allocation of funds (see Hauptman \& Salmi, 2006). However, the amount per student received by each university varies substantially. For instance in 2005, the funding per student for six Kenyan public universities ranged from US\$1,962 to US\$2,989 (Otieno 2008). The funding mechanism does not differentiate between expensive and inexpensive academic programmes. As a result, universities with relatively expensive programmes are under-funded compared to those universities with relatively cheap programmes. The assumed average cost of each degree programme is KSh 120,000 (US\$1,534) per year, of which the government covers KSh 70,000 (US\$895) for sponsored students (module I), leaving the remaining KSh 50,000 (US\$639) for students to raise from HELB or private sources. According to Ouma (2011:24), the Kenyan government has suspended state funding for capital expenditure, which has constrained renovations and the construction of new buildings to accommodate rising student numbers (see Sifuna, 2006). Since 2005, the government has had a small research fund to assist public universities in undertaking research on national development issues (Odhiambo, 2006). The government allocation for research was Kshs. 20 million in 2005 and KShs. 65 million in 2006.

In terms of budget allocation practices, all public universities are required to submit their annual budget to MOHEST. Budget allocations take into account the size, needs, and historical allocations of a given public university, but not projections of the actual needs of the universities (RoK, 1998; see Ouma, 2007). In some cases, however, Vice-Chancellors lobby heavily for enhanced allocations. Kabiru Kinyanjui (2006:47) pointed out that the approved budgets for universities are not well connected to results or performance in terms of quality of graduates, quality of research or effectiveness in resource management. The Kenyan budget allocation practice can thus be described as negotiated funding between university leaders and the MoF and MOHEST (Otieno 2008). The approved funds from the government treasury are usually released one month in arrears, resulting in what one interviewee described as a

76 In 1991, the government arrived at a historical figure of Kshs 120,000 for every student. From the Kshs 120,000, only Kshs 86,000 is paid as tuition fees with the government expected to contribute Kshs 70,000. Each student is expected to pay Kshs 16,000. The rest is distributed as follows: accommodation, Kshs. 7,000; book allowance, Kshs 9,000; and food allowance, Kshs 18,000. This unit cost was arrived at in 1991 (and was implemented as from 1995) and remains in place. 
hindrance to efficient administration of finance and running of programmes (see JKUAT, 2004, 2005). In the public expenditure review (PER) reports, universities have argued for the release of government grants on a quarterly basis (Ibid).

In the history of Kenyan higher education, there have been three higher education funding policies (see Ouma, 2007). These include the era of free higher education (1963-1974), the era of cost sharing, and the era of privatisation. Until the early 1970s, university education in Kenya was free and the full costs (both tuition and living expenses) were borne by the government (Weidman, 1995; RoK, 1973:72; Eshiwani, 1993). The importance of higher education for the social and economic development of the newly independent state and the desire to guarantee equality of opportunity in higher education were the main reasons for the policy of free higher education provision (Ouma, 2007:83). In return for their free higher education, graduates were required to work in the public sector for a minimum of three years. Economic expansion ${ }^{77}$ and political stability contributed to the implementation of this policy.

The 1973 economic difficulties ${ }^{78}$ coupled with rising oil prices resulted in a reduction of budgets from the Kenyan government to public organisations (see also Otiende, 1986; World Bank, 1988; RoK, 2001; 2003). This financial constraint brought about the implementation of structural adjustment programmes ${ }^{79}$ (SAPS) in Kenya (Eshiwani, 1990; World Bank; 1988). A significant change in financing higher education in Sub-Saharan Africa in general and in Kenya in particular was realised following a policy paper: Education in Sub-Saharan Africa: Policies for Adjustment, Revitalisation, and Expansion (World Bank, 1988). Condemning the 'needlessly' high cost of higher education in SubSaharan Africa countries, this World Bank policy paper recommended a sort of cost-sharing scheme through which beneficiaries of higher education make monetary contributions to their education (World Bank, 1988:77). The Kenyan government introduced cost-sharing at the university level in 1991 (see RoK,

77 Kenya's first decade after independence (1963-1973) was a period of economic prosperity (6.6\% of GDP growth) with significant foreign exchange reserves and high commodity prices (RoK, 1973; Swamy 1994).

78 Since 1973, Kenya has faced economic difficulties which have been linked to fluctuating prices for its major exports, low levels of technology, drought and famine, high population growth, collapse of the East African Community, high rates of urbanisation, increasing debt, land fragmentation, widespread poverty, disease and ignorance (Joseph Kipkemboi Rono, 2002:82).

79 The period of structural adjustment programmes (1986-1989). 
1998: 96); students were required to pay direct fees of US\$80 to US\$107 annually and total charges were raised to US\$ 667. The implementation of cost sharing in Kenya has gone hand in hand with a heavy subsidisation of the system (Ouma, 2007:82), however.

The Kenyan public universities have often faced financial challenges (Ngome, 2003:370). In response to this, almost all public universities engage in revenue generation and diversification from a variety of sources (Ouma, 2007; Nafukho, 2004; Kigotho, 2000). According to the World Bank (2010:76), Kenya's public universities self-generated resources on average accounted for approximately $39 \%$ of higher education revenue in 2007 . This figure is well above the average $28 \%$ nongovernmental revenue for African public universities. One of the most popular revenue generation strategies for public universities in Kenya is a dual track $^{80}$ system. This system was imported from Makerere University in Uganda, tested and legitimatised at the UoN in 1998, and then other Kenyan public universities followed that example to supplement their governmental funding (see Kiamba, 2004; Ouma, 2007). As part of their nongovernmental revenue, almost all public universities mobilise resources from external aid, mostly for funding research. For instance, Kenya received US\$ 5.5 million a year in the form of aid over the period of 2001-2006 (World Bank, 2010:98). Total donor support is expected to rise steadily from $3.9 \%$ of GDP in $2007 / 08$ to about $4.6 \%$ by 2012/13 (GOK, 2007). The recently launched Kenya Joint Assistance Strategy (KJAS), signed by the Government and development partners, will ensure this target is met.

\subsection{Key Characteristics - Jomo Kenyatta University of Agriculture and Technology}

Jomo Kenyatta University of Agriculture and Technology (JKUAT) is one of the seven established public universities in Kenya. The main campus of the university is located at Juja ${ }^{81}$ town, which is $36 \mathrm{kms}$ to the north-east of Nairobi along Nairobi-Thika Highway (close to the industrial towns of Thika and Ruiru). Plans for the establishment of Jomo Kenyatta College of Agriculture and Technology (JKCAT) began in 1977. A year later (in 1978), Mzee Jomo Kenyatta donated 200 hectares of farmland for the establishment of the College. JKCAT began admitting its first batch of students in 1981, as a Middle Level College with assistance from the Japanese Government. In 1982 the then President of Kenya, President Daniel Arap Moi, officially opened JKCAT. The first

\footnotetext{
80 Also Module II or parallel track or parallel programmes
}

${ }^{81}$ Small rural town 
graduation ceremony was held in 1984, awarding Diplomas in Agricultural Engineering, Food Technology and Horticulture. In 1988, the president declared JKCAT a constituent College of Kenyatta University through a legal Notice, under the Kenyatta University Act (CAP 210C). The name of JKCAT then changed to Jomo Kenyatta University College of Agriculture and Technology (JKUCAT). The university college admitted its first group of undergraduate degree students in 1989. JKUAT became a fully-fledged University through the JKUAT Act, 1994 and was inaugurated on 7 December 1994. JKUAT is now organised into two colleges, two faculties, two schools, four institutes, five constituent colleges, and seven campuses. In this section, interviews and documentary data concerning JKUAT are analysed in line with the research model in Chapter 3, and the operationalisation of key variables in Chapter 4 (see Table 4.1).

\subsubsection{Vision and Mission of Jomo Kenyatta University of Agriculture and Technology}

The vision of Jomo Kenyatta University of Agriculture and Technology is "to become a university of global excellence in training, research, and innovation for development" (see JKUAT's Strategic Plan (2009-2012). The mission of the University is "to offer accessible, quality training, research, and innovation in order to produce leaders in the fields of Agriculture, Engineering, Technology, Enterprise Development, Built Environment, Health, and other Applied Sciences to suit the needs of a dynamic world." Its functions and objectives as stipulated in the JKUAT Act, 1994 Part II (4) include:

- Facilitating directly or indirectly or in collaboration with other institutions of higher learning the implementation of the university's missions (i.e.; teaching, research and effective application of knowledge and skills to the life, work and welfare of citizens of Kenya);

- Participating in the discovery, transmission and preservation and enhancement of knowledge and stimulating the intellectual participation of students in the economic, technological, agricultural, professional and cultural development of Kenya; and

- Playing an effective role in the development of agriculture and technology in conjunction with industry and providing extension services to contribute to the social and economic development of Kenya. 


\subsubsection{Student Population and Areas of Specialisation at JKUAT}

Beginning with a tiny enrolment of less than 100 students in 1981, JKUAT enrolled 20,000 students in 2012. The total student enrolment at JKUAT grew by $538 \%$ between 2000 and 2012.

\section{Chart 6-2 Student Enrolment}

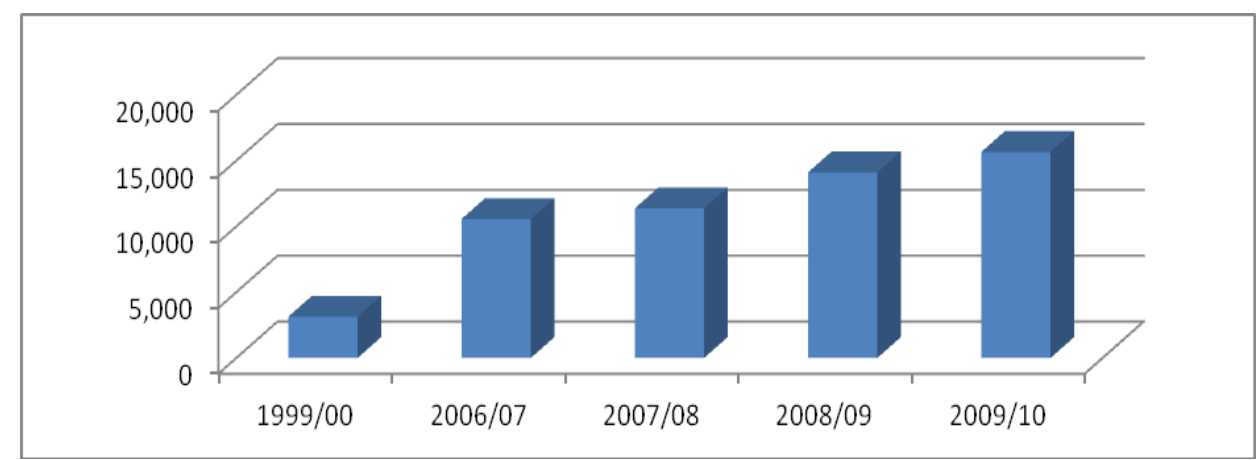

Chart 6-3 below shows JKUAT's student population by level of study in 2011/12.

Chart 6-3 Student Population by the level of degree in 2011/12

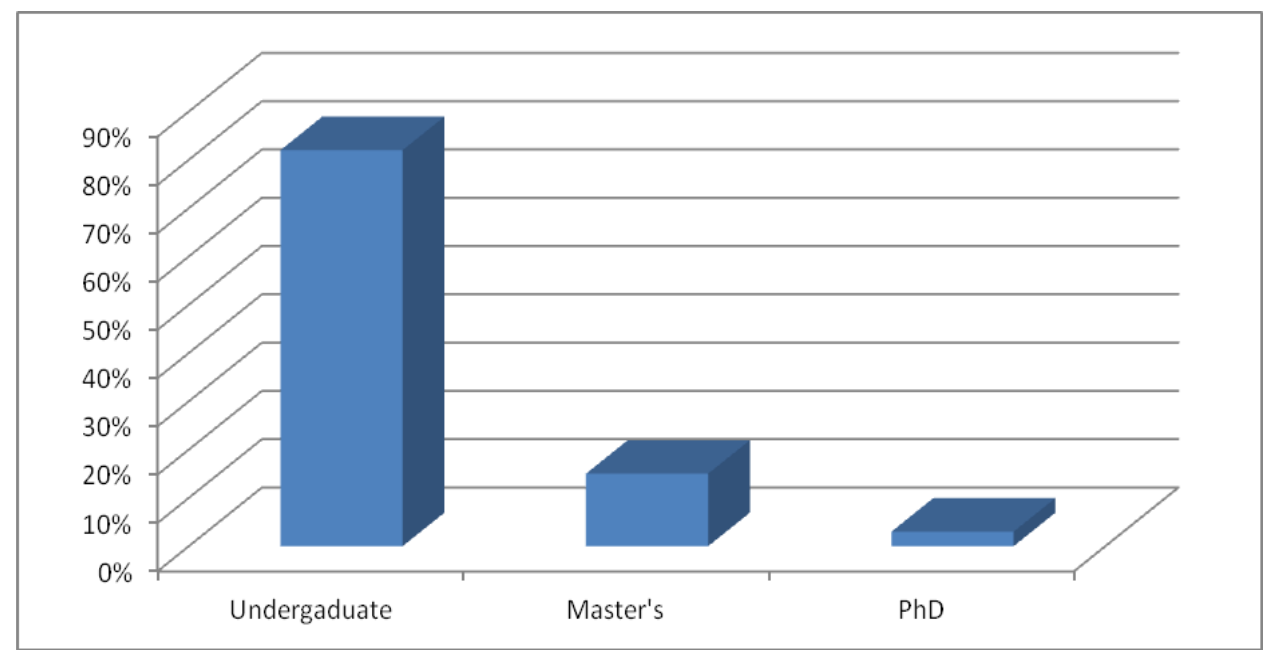

As indicated in Chart 6-3, the majority of students (82\%) at JKUAT are enrolled in undergraduate education. The proportion of Master's and PhD students in JKUAT's total enrolment was about $15 \%$ and 3\%, respectively in 2011. Table 6.4 
below shows the fields of study in which JKUAT's students were enrolled in 2011/12.

Table 6.4: Academic Programmes at JKUAT (2011/12)

\begin{tabular}{|c|c|c|c|c|c|c|c|}
\hline Academic Subunit & 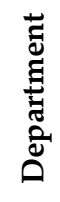 & Ưّ & 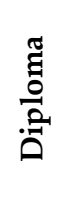 & 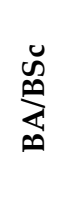 & $\sum_{\sum}^{\infty}$ & 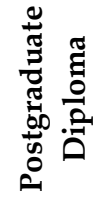 & 空 \\
\hline $\begin{array}{l}\text { College of Engineering and } \\
\text { Technology }(1994)^{82}\end{array}$ & 8 & & & 12 & 17 & & 17 \\
\hline College of Health Sciences ${ }^{83}$ (2001) & 2 & 1 & 2 & 7 & 15 & 2 & 15 \\
\hline $\begin{array}{l}\text { Institute of Computer Science \& } \\
\text { Information Technology (1998) }\end{array}$ & 2 & 1 & 1 & 3 & 2 & & \\
\hline $\begin{array}{l}\text { Institute for Energy and } \\
\text { Environmental Technology }{ }^{84}(1990)\end{array}$ & & & & & 3 & 1 & 1 \\
\hline $\begin{array}{l}\text { Institute for Biotechnology Research } \\
\text { (1994) }\end{array}$ & & 5 & & & 1 & & 2 \\
\hline $\begin{array}{l}\text { School of Architecture and Building } \\
\text { Sciences () }\end{array}$ & 3 & & 1 & 3 & 2 & & 1 \\
\hline $\begin{array}{l}\text { School of Human Resource } \\
\text { Development (2005) }\end{array}$ & 3 & 3 & 9 & 7 & 9 & - & 5 \\
\hline School of Law (2008) & 1 & & & 1 & & & \\
\hline Faculty of Agriculture (1981) & 4 & & 1 & 11 & 7 & & 2 \\
\hline Faculty of Science ${ }^{85}(1988)$ & 8 & 1 & 13 & & 9 & 1 & 9 \\
\hline
\end{tabular}

Source: accessed on 13 February 2013 http://www.jkuat.ac.ke/divisions/aa/

82 Contains three schools: School of Mechanical, Manufacturing and Material Engineering, School of Electrical, Electronic and Information Engineering, School of Civil, Environmental and Geospatial Engineering

83 Embraces Institute of Tropical Medicine and Infectious Diseases and department of medical laboratory sciences

84 Short courses programme in eight areas

85 Bridging Certificate in Mathematics/Physics/Biology/Chemistry 
The total number of programmes in JKUAT has grown rapidly over the last five years: 107 in 2005/06, 114 in 2006/07, 121 in 2007/08, and 152 in 2008/09. The university aims to offer 161 academic programmes by 2012 (JKUAT, 2012:22). Over $54 \%$ of the total students are enrolled on programmes in the hard sciences such as natural sciences, engineering and health, while the rest (46\%) are in the softer knowledge domains of humanities and social sciences, and law. Research is the founding mission of JKUAT. The university has predominantly undertaken research in agricultural fields, environment and technology, engineering and health.

\subsubsection{Internal Governance and Management at JKUAT}

JKUAT Act of 1994 defined the internal governance and management of the university (Part III, Article 10). Fig. 6.1 below presents the organisational structure of JKUAT.

\section{Figure 6-1 Organisational Structure of JKUAT}

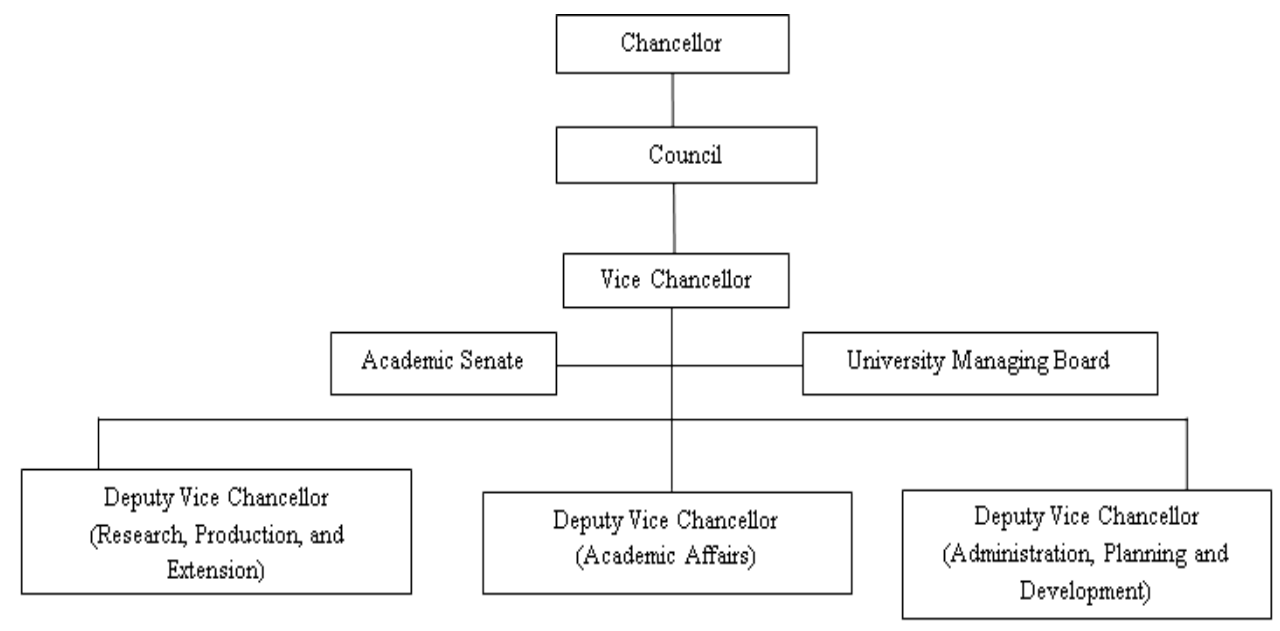

In addition to the positions shown in Fig. 6.1, more than 25 different offices are answerable to the university vice chancellor and her three deputy vice chancellors. Articles 10 to 21of JAKUAT Act 1994 state the key duties and responsibilities of positions in the structure indicated in Fig. 6.1. A Chancellor heads JKUAT (see Clause 11 (1\&2) of the 1994 JKUAT Act). The president of the country is automatically the chancellor of the university (Article 11, no.1) unless he sees it fit to appoint some other person to be the chancellor (Article 11, no.2). The Chancellor, as the honorary head and symbol of authority in the university, confers degrees and grants diplomas, certificates and other awards of the university. He/she directs an inspection of the university and gives advice to the 
Council that he considers necessary for the development of the university ((Article 11, no. 3 (a-d)).

The Council ${ }^{86}$ is the highest level of authority at JKUAT and comprises government officials and professionals who govern the university. The council's duties and responsibilities include: (i) administering the property and funds of the university; (ii) receiving donations, endowments, gifts, grants or other monies and making legitimate disbursements; (iii) providing for the welfare of the staff and students of the university; (iv) generating and raising funds for the purposes of the university from within and outside the country; (v) making regulations governing the conduct and discipline of the students; (vi) determining the maximum number of students to be admitted to the university; and (vii) entering into association with other universities, colleges or institutions of higher learning within or outside Kenya (see JKUAT Act, 1994 Part III clause 16). The council undertakes its responsibilities through twelve council committees ${ }^{87}$. There is a widespread belief among the university community that the heavy representation of government authorities (around $60 \%$ ) in the Council of JKUAT is a threat to organisational autonomy (see also Sifuna, 1998:192; Sifuna, 2006; Ngome, 2000:367).

The Vice Chancellor (VC), as the chief executive officer (CEO) of the university, is competitively appointed. $\mathrm{S} / \mathrm{he}$ is the academic and administrative head of the university with the overall responsibility for the direction, organisation and administration of the university's programmes (JKUAT Act, 1994 Part III Clause 12). The VC is directly responsible to the Council for the general conduct and discipline of the students and academic staff of the university (Article 12). The $\mathrm{VC}$ is the chairperson of the senate and the senior university management team. At JKUAT, the real decision making power in terms of finance, procurement, and human resource is vested in and concentrated at the office of the vicechancellor. The council appoints the three deputy vice chancellors through a

86 Consists of the VC, the deputy vice chancellors, the head of each constitute college, the principal of each college within the university, four persons elected by the senate from its members, two members each elected by the staff and student associations, the permanent secretaries in the ministries for finance, education, agriculture, technical training, and public works, the director of personnel management, the secretary to the commission, two persons appointed by the president to represent the private sector, two non-public officers representing the public interest, and two persons elected by the Alumni Association from among its members (Article 15).

87 Executive, Finance, Tender, Sealing, Building, Planning and Development, Terms of Services, Staff Appraisal, Appointment, and Promotions, Staff Disciplinary, Honorary Degree, Staff Housing Policy, and Staff Welfare. 
competitive recruitment process based on merit. The names of the deputy vice chancellors are the Deputy Vice Chancellor for Academic Affairs (DVC-AA), Deputy Vice Chancellor for Research, Production, and Extension (DVC-RPE), and the Deputy Vice Chancellor for Administration, Planning, and Development (DVC-APD). The DVCs exercise their power and duties under the general direction of the VC (JKUAT Act, 1994 Part III clause 13).

The division of DVC-AA is the largest unit at JKUAT, in charge of planning academic programmes, preparation of syllabuses, and running the overall teaching-learning processes. This office is also responsible for student affairs (i.e. admissions and records and welfare). The DVC-AA's other responsibilities include course regulations, timetables, examinations, certificates and transcripts, graduation, library services, student's attachment, capacity building and staff appraisals. The DVC-RPE co-ordinates research, production and extension activities. It manages the university's exhibitions, workshops, and seminars. This division is mandated to solicit research funds from stakeholders. It also facilitates JKUAT's income-generating activities. The DVC-ADP ${ }^{88}$ is responsible for corporate planning, human resource management (i.e. staff recruitment, training of administrative staff, promotions and discipline, personnel administration), financial and procurement management, health care services, registry administration, legal matters, transport, estates and central services. Each deputy vice chancellor has their own registrar who manages the day-to-day operation of their division.

The Senate is the leading body of the university in charge of academic matters (see JKUAT Act, 1994 Part III (17)). The VC, the Deputy VCs, the (deputy) head of each constituent college, the principal of each college within the university, the head of each faculty, the director of each institute, research centre or school, the chairman of each teaching department, the director of postgraduate studies, the university librarian, the registrars of the university, one representative of each faculty board, and two members elected by the students' association are members of the Senate at JKUAT (JKUAT Act, 1994 Part III). The senate is responsible to the university council and regulates all academic programmes and students affairs. The senate, in consultation with the council, determines admission issues (the minimum entrance qualification, the number of students, etc.), sets and ensures the content and academic standard of any course of study, and determines graduate profiles. As stipulated in JKUAT Act, 1994 Part III (18), JKUAT has a university management board (MB) that consists of the

88 Comprises seven departments such as Finance, Human Resource, Central Services, Halls of Residences, Catering and accommodation, Estates, and Transport. 
vice chancellor who is the chairperson, the deputy vice chancellors, the principals of the colleges, the finance officer, the registrars, and the student dean. The MB is responsible for the day-to-day management of the university. The university management board also advises the Council and the Senate on management, administration, and academic affairs.

Colleges, institutes, schools and faculties, and departments are organised under the Deputy Vice Chancellor for Academic Affairs (http://www.jkuat.ac.ke/ divisions/aa/, accessed on 26 February 2013). A College Management Board (CMB) whose members consist of the Principal as Chairman, the Deputy Principal, Deans of Faculties, Institutes, Schools and Centres, College Bursar and College Registrar as its members is responsible for the administrative functions of the College. Additionally, a College Academic Board (CAB) is responsible for the administration and management of the academic programmes of the College on behalf of senate. The Council, in consultation with the Chancellor, appoints a principal for each college within the university who is the academic and administrative head of the college under the general direction of the VC (Article 14). Faculties and departments are headed by deans and department chairs, respectively. At JKUAT, the dean's position is elective. The deans and department chairs enjoy a relatively high level of autonomy in the areas of education and research, but they are not in charge of finance, procurement, or human resource management. The Faculty Board (FB) and individual department assemblies are responsible for the academic affairs of their units.

JKUAT has an Alumni Association, which includes graduates of the university and other interested members and aims to mobilising resources (see JKUAT's strategic plan (2009-2012)). Another important body is JKUAT Enterprises (JKUATES), which is a fully owned enterprise. It is also a fully-fledged corporate body with the ability to research, market and commercialise the university's products and services. With four distinct divisions (i.e.; Enterprise Development Centre, Products, ICT, and Consultancy divisions), JKUATES aims to take the university to the people by handling the university's applied research contracts, consultancies, and short-term course work.

\subsubsection{Academic and Administrative staff at JKUAT}

There were 2050 academic and administrative staff in-post at JKUAT in 2012. Around $33 \%$ of them were academic staff. The academic staff include the VC, the DVCs, the heads of constitute colleges, the principals of colleges within the university, the university librarian, the librarian of each constituent college, the registrars, the lecturers, and all members of staff who are engaged in teaching 
or research or extension (JKUAT Act, 1994 Part III clause 20 (1)). The academic staff are thus the backbone of the university's business and their strengths are crucial in meeting the demands and expectations of a variety of environmental stakeholders. The success of a university is dependent on knowledge embedded in its senior staff, particularly academic and research staff, and other educational inputs (e.g. books and networks, laboratories, library, etc.). Chart 64 below gives a breakdown of academic staff by level of qualification.

Chart 6-4 Academic Staff Qualifications in 2012

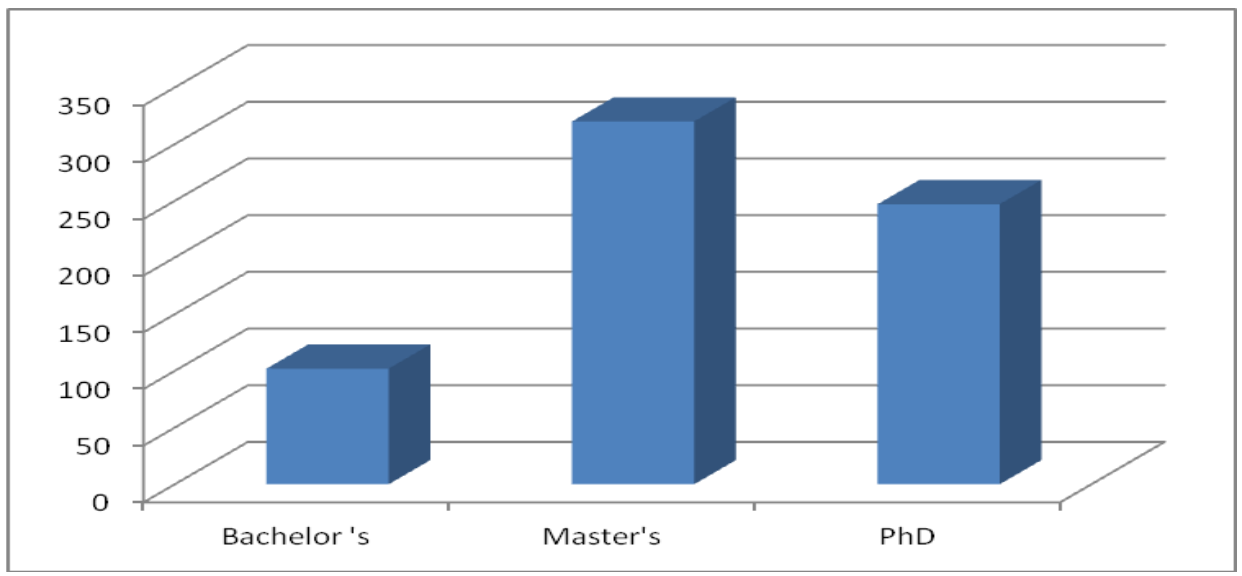

The university has full professors (4\%), associate professors (7\%), senior lecturers $(13 \%)$, lecturers $(32 \%)$, assistant lecturers or tutorial fellows $(30 \%)$, and graduate assistants (14\%). JKUAT does not allow bachelor holders to run classes independently. Academic staff holding higher scientific degrees are at the heart of the university and without them the university cannot function properly. Most interview respondents rated the qualifications and expertise of academic staff at JKUAT as adequate. One senior professor and the deputy vice chancellor reported that members of academic staff in high demand departments like the School of Human Resource Development, ICT, and Law generally have a heavy workload and are overstretched.

In 2012 there were more than 1381 support staff, more than twice the number of academic staff (1:2.06). The administrative support staff consist of administrative staff, technical support staff, and other non-academic technical staff employed in the teaching hospital of JKUAT (JKUAT Act, 1994 Part III clause $20(2)$ ). About $27 \%$ of JKUAT's administrative staff hold degrees, which range from Bachelor's to $\mathrm{PhD}$. Chart 6-5 below gives a breakdown of administrative support staff by level of qualification. 
Chart 6-5 Administrative Staff Qualifications in 2012

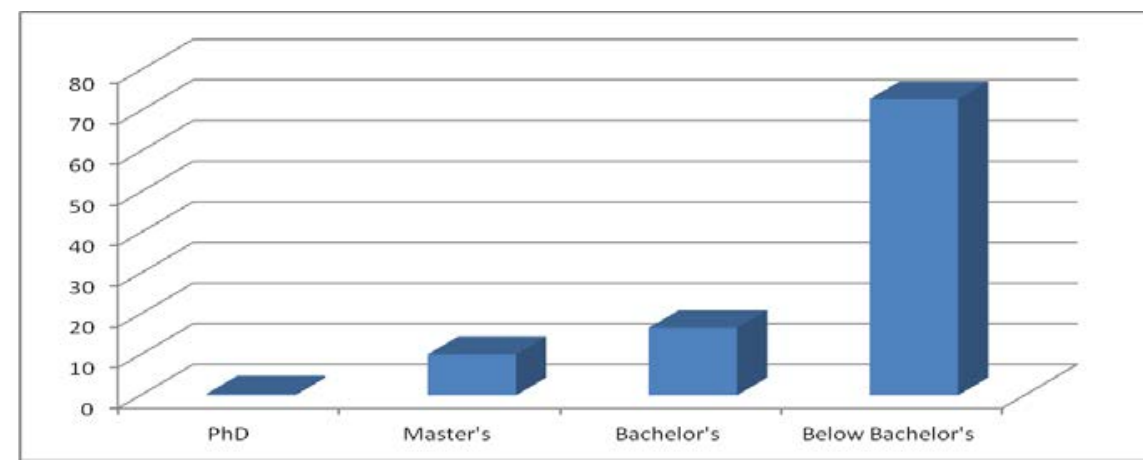

In all its operations, JKUAT is committed to adhering to international quality management standards. The university is now a holder of the ISO 9001:2008 certification and uses this method as its quality management standards. The ISO framework assists the university in ensuring a philosophy of continual improvement in all aspects of managing its businesses. It increases the effectiveness and efficiency of JKUAT through continual improvement in systems and products/services quality (http://www.jkuat.ac.ke/ ?s=ISO+9001\%3A2008 accessed on May 25, 2012). Additionally, formal negotiations on performance contracts take place between JKUAT and the MOHEST in every year (see Legal Notice No. 93 of 2004, Article 6). One of the challenges for JKUAT is shortages of academic and administrative staff. The number of in-post staff equals just $62 \%$ of the overall human capital requirement of the university. This figure is below the industry standard of not less than $85 \%$.

\subsubsection{Non-Human Resources and Facilities at JKUAT}

Generally the growth in infrastructures and facilities; viz. lecture halls, library, offices, laboratories, ICT, etc. at JKUAT has not been congruent with the corresponding increase in student population (JKUAT 2009: 22; Kabiru Kinyanjui, 2006:28). This results in large class sizes on most academic programmes. The books, journals, and sitting capacity available in the libraries are not sufficient to serve the increased number of students. Notably most of the libraries become congested leading up to and during the examination period, and do not meet the minimum benchmark ratio of 60 titles per student per degree programme. As a result, facilities have deteriorated due to overuse without the requisite resources and strategies for continuous maintenance and/or upgrading. Moreover, inadequate research infrastructure is one of the prominent issues holding back JKUAT's ability to engage in cutting-age 
research. The inadequate or total absence of capital budget exacerbates the problem (see Section 6.4.6). As a senior professor and a dean reported, stakeholders have many concerns about the quality of the rapidly expanding programmes, in view of limited physical resources, and a rapidly increasing student population. During the interviews, we repeatedly noted that the university's non-human resources were perceived as inadequate.

\subsubsection{Sources of Finance for JKUAT}

JKUAT receives resources from the Kenyan government and a variety of other stakeholders (non-finance ministry). The Kenyan government is the chief financer of the university. As stated in section 6.3, a single block grant or a single line item budget is used to allocate budget to the university. Disbursement of budget is made on monthly basis. The university is also required to report the utilisation of allocated budgets to the government on a quarterly basis. The government auditors may challenge budget management practices that deviate from civil service norms.

The financial allocation from government treasury has not been sufficient to cover the growing budgetary needs of the university (JKUAT, 2010). Between 2001 and 2005, for instance, the university, on average, received $69.58 \%$ of its total budget from the government treasury (Ouma, 2007). This level of funding did not remain in place in the period from 2006/07 to 2009/10. From 2006 to 2009, for instance, the governmental capitation for the university remained at KSh. 881 million (JKUAT, 2009:9), which promoted the notion of 'funding at a constant level'. As depicted in Chart 6-6 below, there were significant differences between actual and requested budgets for the university. 


\section{Chart 6-6 Budget Submission and Government funding of JKUAT in KShs (millions)}

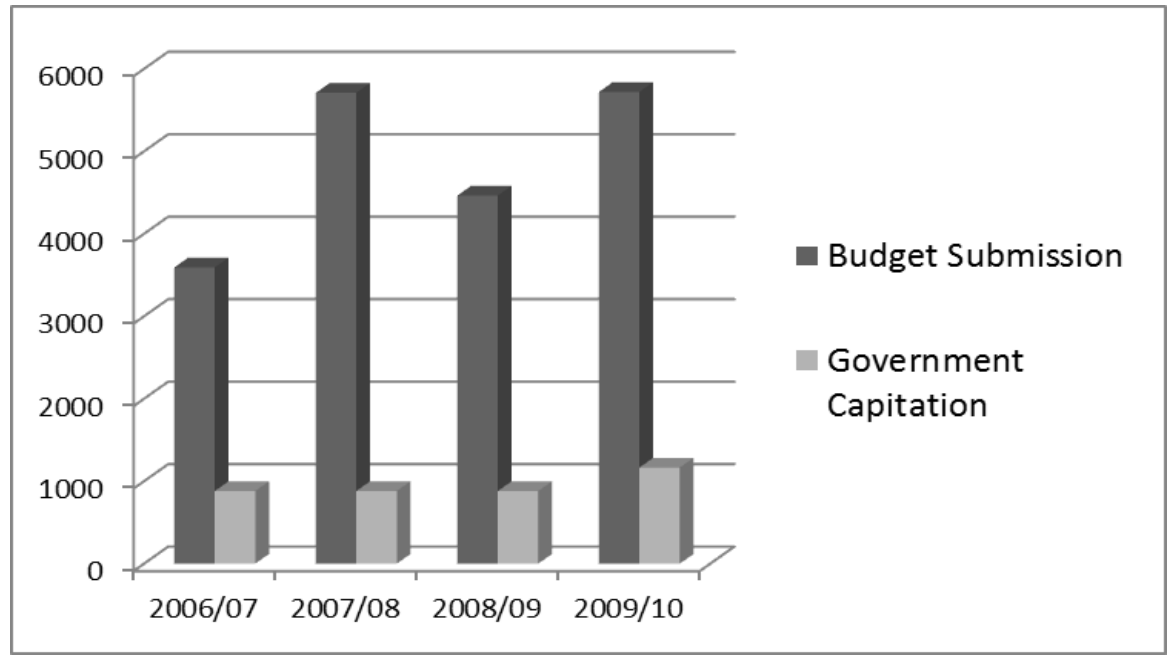

Sources: Reports of the Controller and Auditor General: 2006, 2008 and 2010

Between 2006 and 2009, the Kenyan government provided on average only 20\% of the budget requested by the university. The year after (in 2009/10), the capitation was KSh.1.12 billion, reflecting an increase of 32.2\% compared to the 2008/2009 allocation. However, this still did not match the budget requested, which was KShs. 5.7 billion.

The budget from the government is primarily meant to pay staff remuneration. Currently, it covers only $51 \%$ of the required expenditure. The rise in JKUAT expenditure is mostly attributed to an increase in lecturer salaries and housing allowances. Budget allocations for development expenditure have generally diminished. As reported by Ouma (2007:121), between 1996 and 2005, there were negligible allocations for development expenditure. For instance, in 2001, only $0.07 \%$ of the development expenditure was recorded from government treasury. Escalating costs coupled with inflationary pressures have made it difficult to sustain the operations of the university using only the governmental budget. The reports (1998-2003) of the Auditor General indicated that JKUAT was experiencing financial difficulties and in some cases "technically insolvent" (Ibid pp138-139).

JKUAT generates revenue from a variety of sources (non-MoF fund) that contribute to balancing the income structure of the university, as indicated in Chart 6-7. 
Chart 6-7 Governmental and Nongovernmental Revenues in KShs (millions)

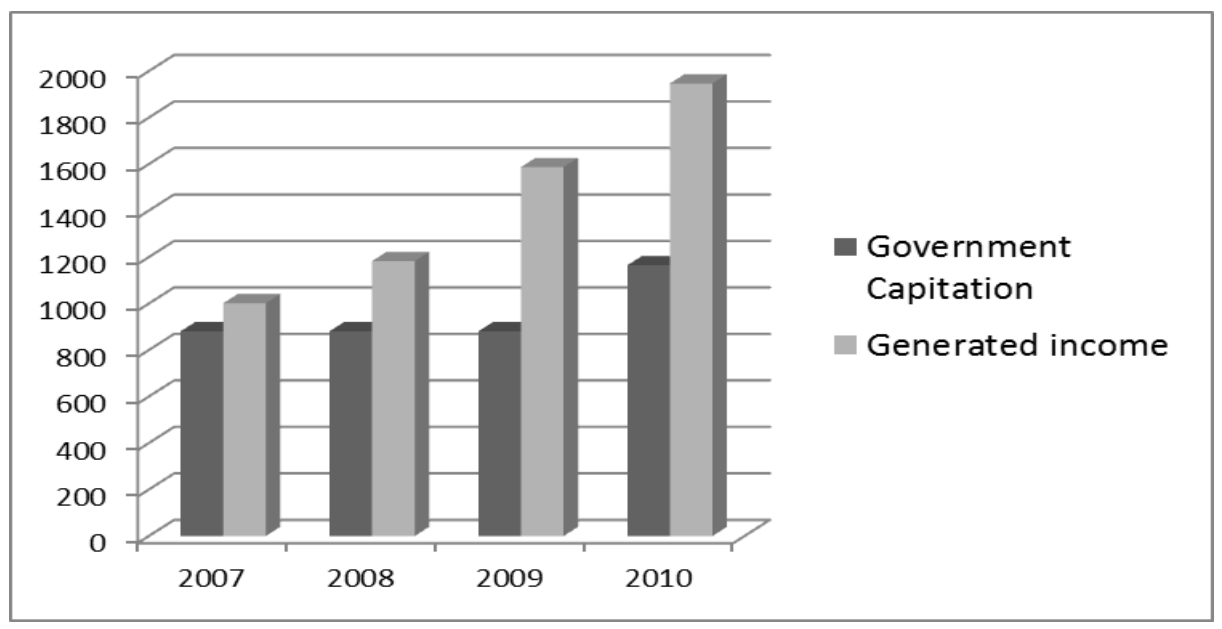

Sources: Reports of the Controller and Auditor General: 2006, 2008 and 2010 and JKUAT Strategic Plan (2009-2012).

Since 2005, JKUAT has managed to generate more revenue from nongovernmental sources than what it acquired from the main state allocation (JKUAT, 2010). JKUAT managed to generate KSh 5.8 billion between 2006/07 and $2009 / 10$, which is equivalent to $152 \%$ of the total government capitation (see JKUAT, 2004/05; 2005/06; 2006/07; 2007/08; 2008/09; 2009/10). Over the period $2006 / 07$ to $2009 / 10$, the amount of revenue generated increased by $108 \%$. Revenue from nongovernment sources increased by 19\% between 2006/07 and $2007 / 08$; and an increase of $52 \%$ was registered a year later, then $15 \%$ between 2008/09 and 2009/10. We shall discuss this matter in more detail later.

\subsection{External Environment of the Kenyan Case Study University}

This part of the chapter presents the findings of data analysis concerning the external environment of the Kenyan case study university. As discussed in section 6.2, the wider societal environment of the Kenyan higher education system has influenced the overall operations of JKUAT. We have already begun to analyse the immediate environment of the university in terms of the governance and management of higher education in Kenya in section 6.3. This part is the continuation of sections 6.2 and 6.3. The main purposes of this section are to explore the external environment of JKUAT to identify the key external stakeholders in the university; and determine stakeholder salience in terms of their regulatory powers and funding as perceived by the interview respondents (see Tables 4.3 and 4.4). 


\subsubsection{External Stakeholders in JKUAT}

Table 6.5 presents a variety of external stakeholders that influence the behaviour, actions, and policies of JKUAT (see JKUAT, 2009:14-15).

Table 6.5: Key External Stakeholders of JKUAT

\begin{tabular}{ll}
\hline Public Authorities & Other than Public Authorities \\
\hline $\begin{array}{l}\text { The House of the Parliament and the } \\
\text { president of Kenya }\end{array}$ & Students and their families \\
Ministry of Higher Education, & Donors (bilateral and multilateral) \\
Science and Technology (MOHEST) & \\
Ministry of Finance (MoF) & Professional associations \\
Commission for Higher Education & NGOs \\
(CHE) & \\
Higher Education Loans Board & Private higher education institutions \\
(HELB) & \\
National Council for Science and & Private Sector (i.e. business and \\
Technology & industry) \\
Inter-University Council for East & \\
Africa (IUCEA) & \\
Joints Admissions Board (JAB) & \\
Local and provisional authorities & \\
Public research institutes & \\
Other public post-secondary & \\
institutions/Universities &
\end{tabular}

These stakeholders can also be categorised as regulators, suppliers, customers, and competitors. One of the common characteristics of the stakeholders is that all stakeholders exert some sort of pressure on the actions and behaviour of the universities in order to promote their demands and expectations. Not all stakeholders are equally powerful and important in issuing sanctions and offering rewards for the universities. In explaining who really matters and what counts to JKUAT, we analyse stakeholder salience in terms of regulatory powers and funding in the subsequent subsections. 


\subsubsection{Stakeholder Salience in Terms of Regulatory Powers}

Table 6.6 below presents the regulatory powers of external stakeholders in the Kenyan case study university, as perceived by the interview respondents.

Table 6.6: Stakeholder salience in terms of regulation at JKUAT

\begin{tabular}{ll}
\hline Stakeholder & $\begin{array}{l}\text { Degree of salience } \\
\text { (most, more, salient, less) }\end{array}$ \\
\hline Government & Most Salient \\
Donors & More Salient \\
Professional associations & Salient \\
\hline
\end{tabular}

The Kenyan government includes all actors that are categorised under 'public authorities' in Table 6.6. The duties and responsibilities of the public authorities were briefly discussed in section 6.3.3. As a state corporation, JKUAT is subject to many regulatory frameworks and policies that collectively influence its behaviour and actions (see Table 6.7 below).

Table 6.7: Key Regulatory Frameworks of JKUAT

\begin{tabular}{|l|l|}
\hline Vision 2030 (2008-2030) & The Universities Act, 2012 \\
\hline State Corporations Act Cap 466 & $\begin{array}{l}\text { JKUAT Act, 1994 (repealed in } \\
\text { 2012) }\end{array}$ \\
\hline $\begin{array}{l}\text { The Kenya Education Sector Support } \\
\text { Programme (KESSP) 2005-2010 (MEST, } \\
\text { 2005) }\end{array}$ & $\begin{array}{l}\text { Sessional Paper No. 1 of 2005 on } \\
\text { Education, Training and Research }\end{array}$ \\
\hline $\begin{array}{l}\text { The Ministry of Higher Education, } \\
\text { Science and Technology (MOHEST) } \\
\text { Strategic Plan 2008-2012 }\end{array}$ & $\begin{array}{l}\text { The Science, Technology and } \\
\text { Innovation Bill (MOHEST 2009) }\end{array}$ \\
\hline $\begin{array}{l}\text { Guidelines on performance contracting } \\
\text { by the public sector reform and } \\
\text { performance contracting secretariat }\end{array}$ & $\begin{array}{l}\text { EAC Treaty on Education and the } \\
\text { sector policy and strategy }\end{array}$ \\
\hline IUCEA development plan 2006 & JKUAT strategic plan 2009-2012 \\
\hline Legal Notice No. 93 of 2004 & \\
\hline
\end{tabular}

One of the most important regulatory frameworks for the Kenyan case study university is the JKUAT Act, 1994 which was repealed in 2012 and replaced by the Universities Act, 2012. The Act, among other things, defines the degree of 
freedom the university has to steer itself. An analysis of the autonomy of JKUAT in academic, organisational, staffing, and financial matters (Table 4.4) is made in the following subsection in order to explore the link between revenue generation and the degree of organisational autonomy.

\subsubsection{The 1994 JKUAT Act and Organisational Autonomy}

The analysis of the autonomy of JKUAT mainly focuses on JKUAT Act, 1994, which was used as the legal framework for the university from 1994 to May 2012. Whenever necessary and appropriate, we may refer to the new Universities Act, 2012. JKUAT Act, 1994 did not allow the university to pursue additional income streams. Nor did the Act prevent the university from acquiring resources from nongovernmental sources. The universities Act, 2012, however, acknowledges revenue generation as legitimate income for the Kenyan public universities. Table 6.8 below indicates the level of JKUAT's academic autonomy.

Table 6.8: Academic Autonomy of JKUAT

\begin{tabular}{lc}
\hline Aspect & Autonomy \\
\hline $\begin{array}{l}\text { Freedom to select and admit parallel undergraduate } \\
\text { students (BA/BSc) and postgraduate students (MA/MSc } \\
\text { and PhD) }\end{array}$ & Yes \\
$\begin{array}{l}\text { Freedom to select and admit regular students } \\
\text { Freedom to decide on parallel student numbers }\end{array}$ & No \\
Freedom to introduce degree programmes & Yes \\
Freedom to terminate degree programmes & Yes \\
$\begin{array}{l}\text { Freedom to design programmes } \\
\text { Freedom to decide modes of instruction and delivery }\end{array}$ & Yes \\
$\begin{array}{l}\text { Ability to charge tuition fees for government sponsored } \\
\text { students }\end{array}$ & Yes \\
$\begin{array}{l}\text { Ability to charge tuition fees for nongovernment } \\
\text { sponsored students }\end{array}$ & No \\
\hline
\end{tabular}

Table 6.9 presents the status of financial autonomy in the Kenyan case study university. 
Table 6.9: Financial Autonomy

\begin{tabular}{lc}
\hline Aspect & Autonomy \\
\hline Generation and deployment of monetary resources & Yes \\
Ability to keep surplus & Yes \\
$\begin{array}{l}\text { Ability to charge tuition fees for government sponsored } \\
\text { students }\end{array}$ & No \\
Ability to charge tuition fees for nongovernment & \\
sponsored students & Yes \\
Lump-sum or block grant funding & Yes \\
Ability to set pricing of research \& consultancy services & Yes \\
Ability to own buildings & Yes \\
Ability to borrow money & No \\
Leasing of university facilities & Yes \\
\hline
\end{tabular}

The degree of perceived autonomy in staffing is presented in Table 6.10 below.

Table 6.10: Autonomy with respect to staffing

\begin{tabular}{lc}
\hline Aspect & Autonomy \\
\hline Freedom to decide on recruitment procedures & Yes \\
Freedom to decide on promotion of academic staff & Yes \\
Freedom to decide on promotion of administrative staff & No \\
Freedom to decide on dismissal of staff & Yes \\
Setting pay for academic staff & No \\
Setting pay for administrative staff & No \\
Working conditions for university staff & Yes \\
\hline
\end{tabular}

Concerning organisational autonomy, JKUAT was free to decide on its internal governance and decision-making structures as well as introduce new academic structures such as faculties, departments, research centres, etc. To summarise, while JKUAT enjoys autonomy in academic, organisational, and financial aspects it still lacks sufficient autonomy in staffing matters. The inability of JKUAT to control its overall salary costs and limited autonomy to borrow money on the financial market negatively affects its ability to pursue certain goals, including revenue generation. 


\subsubsection{Other Regulation Tools used by Donors and Professional Organisations}

Donors such as the World Bank, IMF, UNESCO, EU, and WTO influence the higher education system in Kenya (Ouma, 2007). As reported by Ouma (2007), donors use a very coercive approach to influence the Kenyan public universities including through technical assistance. They (donors) force most Sub-Saharan African countries including Kenya to incorporate their policy thinking into their national and sectorial development agenda. Funding schemes are the first instrument through which the international donors make their agenda attractive (see Section 6.3.4). Compliance with the demands of international donors, and/or imitating the organisational structure of the most developed countries is, sometimes but not always, one of the safest ways to access international loans and assistance. Donors can also influence African higher education systems through research. There are two widely cited examples in this regard (see Chapter 2). The relative neglect of higher education in Africa in general and in Kenya in particular came after the conclusion that the highest rates of return for Africa came from primary-level education (Lulat, 1988). The 1980s new loan policies by the World Bank, the Structural Adjustment Programme, led to deep financial cuts to the Kenyan higher education sector.

Additionally, several professional associations influence the Kenyan higher education system. Kenya has a strong tradition of involvement by professional associations in higher education affairs. The country uses professional associations to assure the quality of its higher education through external accreditation of professional courses and/or the recognition of graduates' right to practice their professions. This involvement is more common in engineering, medicine and law, professions where a license is needed to work, than in more academic fields (e.g., philosophy or history) of study or career oriented fields (e.g. business studies). Professional associations have an influence or play regulatory roles over the content of curriculum, pedagogy, mode of delivery, and facilities of the programmes.

\subsubsection{Stakeholder Salience in Terms of Funding}

The findings in this research revealed that one of the tools by which stakeholders influence the behaviour of JKUAT is through funding. The relative importance of the external stakeholders in the university in terms of the magnitude of the (potential) resources provided to the university as perceived by the interview participants is indicated in Table 6.11. 
Table 6.11: Stakeholder Importance in Terms of Funding at JKUAT

\begin{tabular}{ll}
\hline Stakeholder & $\begin{array}{l}\text { Degree of salience } \\
\text { (most, more, salient, less) }\end{array}$ \\
\hline $\begin{array}{l}\text { Public Authorities } \\
\text { Students (and their parents) }\end{array}$ & $\begin{array}{l}\text { Most } \\
\text { Dont } \\
\text { multilateral) }\end{array}$ \\
$\begin{array}{l}\text { Ministries, provisional and } \\
\text { Local authorities }\end{array}$ & Salient \\
Business \& Industry & Less \\
\hline
\end{tabular}

The Kenyan government is the most powerful and important stakeholder in JKUAT. The budget allocated to JKUAT from the Kenyan government is the most sustainable and second largest part of the funding structure of the university. The second most important stakeholder to the university is the students. In 2010, about $54 \%$ of total recurrent revenue for JKUAT came from tuition fees (see Table 6.12). A variety of student support schemes, including the HELB, facilitate poor and financially challenged but academically able students in gaining access to higher education (see section 6.3). Students can also bear part of their tuition and living costs themselves. As the demand for higher educational services in Kenya keeps growing (see Section 6.6.2), revenue from student tuition fees is forecast to rise in the future.

The third most important stakeholder in JKUAT is the donors (both bilateral and multilateral donors), also called development partners. The major bilateral donors include Japan (JICA), Germany (GTZ and DAAD scholarship), the USA (American chemical society) and Norway (NUFU fund). The multilateral donors consist of the World Bank, UNDP, UNESCO, FAO, WHO, ADB, and the like. In the last four to five years, donors provided the fourth largest volume of financial resource to JKUAT (see section 6.6.2). Donors' money can be allocated

89 The governmental authorities include the House of the Parliament and the Office of the President, Ministry of Higher Education, Science, and Technology (MOHEST), Ministry of Finance (MoF), Commission for Higher Education (CHE), Higher Education Loans Board (HELB), National Council for Science and Technology (NCST), Inter-University Council for East Africa (IUCEA), and Joint Admissions Board (JAB). These actors collectively influence the methods of resource allocation to JKUAT. 
for research grants, institutional capacity building (for the development of physical infrastructure and human resource base), strengthening and twinning arrangements, North-South partnership research programmes, etc.. Financial support from donors for research and human resource development is quite common. Most donors offer opportunities for universities to bid for projects on a competitive basis, in accordance with certain specifications or agreements (World Bank, 2010).

Several ministries or offices that run development programmes in the areas of environment, education, health, roads, statistics, agriculture, economic sector, police force, business and industries, etc. are key service partners for JKUAT. These stakeholders offer opportunities for JKUAT to be involved in contract education and research, tailor-made short courses, and consultancy activities. For instance, governmental bureaus have been sponsoring their employees to upgrade their knowledge and skills at JKUAT by annually committing money for capacity building. There are also instances where JKUAT engages in locality-specific research that has led to various types of research collaboration in energy, agriculture, health, construction, education, ICT, business and economics, and the like. Research and development organisations within government ministries or departments also collaborate with JKUAT on joint research projects, exchange programmes, and in sharing critical equipment and other resources (JKUAT, 2009:15). The formation of county level administrations in Kenya has already necessitated and will continue to enhance the need to create strong implementation capacities at grass-roots level for sustained economic development.

Industrial firms are currently the least salient stakeholder for JKUAT. Most manufacturing firms in Kenya are family-owned and the vast majority of them are small (see section 6.2). Nearly 50\% of manufacturing firms in Kenya employ 50 workers or less. There are few medium or large-sized firms. The top three manufacturing subsectors account for $50 \%$ of the sector's GDP, $50 \%$ of exports, and $60 \%$ of formal employment. The bulk of Kenya's manufactured goods (95\%) are basic products such as food, beverages, building materials and basic chemicals. Only $5 \%$ of manufactured items, such as pharmaceuticals, are skillintensive. JKUAT finds it difficult to engage in large-scale research-intensive collaboration and consultancy with such industrial firms. Most industrial firms are very limited in articulating their needs, knowledge absorption, and capacity to pay for the service rendered. Nor do they have a tradition of collaborating with the university. This does not mean that there is no interdependence between JKUAT and industrial firms. There are a few examples of the involvement of industrial stakeholders in JKUAT activities (JKUAT, 2009:15) in the form of (i) improving graduates skills, (ii) joint research and development 
projects, (iii) retraining and re-skilling their employees, (iv) short-term training customised for the needs of industry, and (v) solutions to industrial and operational problems through consultancy services.

\subsection{Revenue Generation at the Kenyan Case Study University}

This section closely analyses the interdependence between JKUAT and its environment in the process of resource exchanges. First, it presents the volume of resources that the university received from each resource provider from 2006 to 2010 and briefly discusses what the resource providers received in return for their resources. Second, it presents the findings of data analyses concerning drivers for revenue generation. The final part of the section explores key enablers for and barriers to revenue generation at the Kenyan case study university.

\subsubsection{Status of Revenue Generation at JKUAT}

As has indicated in Chart 6-6, the volume of nongovernmental revenue at JKUAT has surpassed its direct public funding since 2005. Table 6.12 below shows JKUAT's sources of nongovernmental revenue from 2006 to 2010.

Table 6.12: Nongovernmental Funds by source (in million KShs)

\begin{tabular}{|c|c|c|c|c|c|}
\hline Sources & 2006 & 2007 & 2008 & 2009 & 2010 \\
\hline Student fees (JAB) & 209.70 & 294.69 & 219.91 & 236.23 & 288.10 \\
\hline $\begin{array}{l}\text { Student fees (Self } \\
\text { Sponsored) }\end{array}$ & 460.50 & 621.33 & 876.10 & $1,158.22$ & $1,439.00$ \\
\hline $\begin{array}{l}\text { Bilateral and } \\
\text { multilateral donors }\end{array}$ & 21.40 & 21.50 & 22.60 & 92.75 & 128.00 \\
\hline $\begin{array}{l}\text { Business \& Industry } \\
\text { (Consultancy) }\end{array}$ & - & - & - & 2.11 & - \\
\hline Any other Sources & 53.42 & 64.03 & 64.53 & 98.00 & 91.90 \\
\hline Total & 745.02 & $1,001.55$ & $1,183.14$ & $1,587.31$ & $1,947.00$ \\
\hline
\end{tabular}

Sources: Reports of the Controller and Auditor General: 2006, 2008 and 2010 and JKUAT Strategic Plan (2009-2012).

JKUAT solicits resources from a variety of sources: public and private organisations, multilateral organisations and bilateral countries, internal and local sources, and/or individual customers (JKUAT, 2010:6). JKUAT's nongovernmental funds have grown rapidly from 2006 to 2010. Although direct 
public funding continues to be the most important revenue source for the university, JKUAT has managed to shift its revenue sources from heavy dependence on the government to greater reliance on an array of sources. Student fees and the marketing of university facilities appear to hold immediate promise for revenue generation. The university solicits resources from local and international, public and private sources as far as resources can be obtained from legitimate sources without compromising its missions (see JKUAT, 2009:14).

In return for their resources, the stakeholders receive both academic and nonacademic services and products from the university. These include: (i) teaching (degree programmes, centres or campuses initiated for the sole purposes of revenue generation) including short-term training and other bridging courses; (ii) research outcome Income Generating Units (IGUs) (i.e. commercialisation of research outputs) and consultancy offering professional services at a fee; and (iii) non-academic services, including catering, chemistry products centre, food products centre, farm and tailoring. These revenue generation activities are congruent with the mission of the university and are embedded in the overall academic strategy of the university (JKUAT, 2010:40).

Chart 6-8 below indicates that JKUAT acquired the largest volume of resources by offering educational services to a variety of stakeholders.

Chart 6-8 Revenue from Educational Services as a percentage of Nongovernmental Revenue

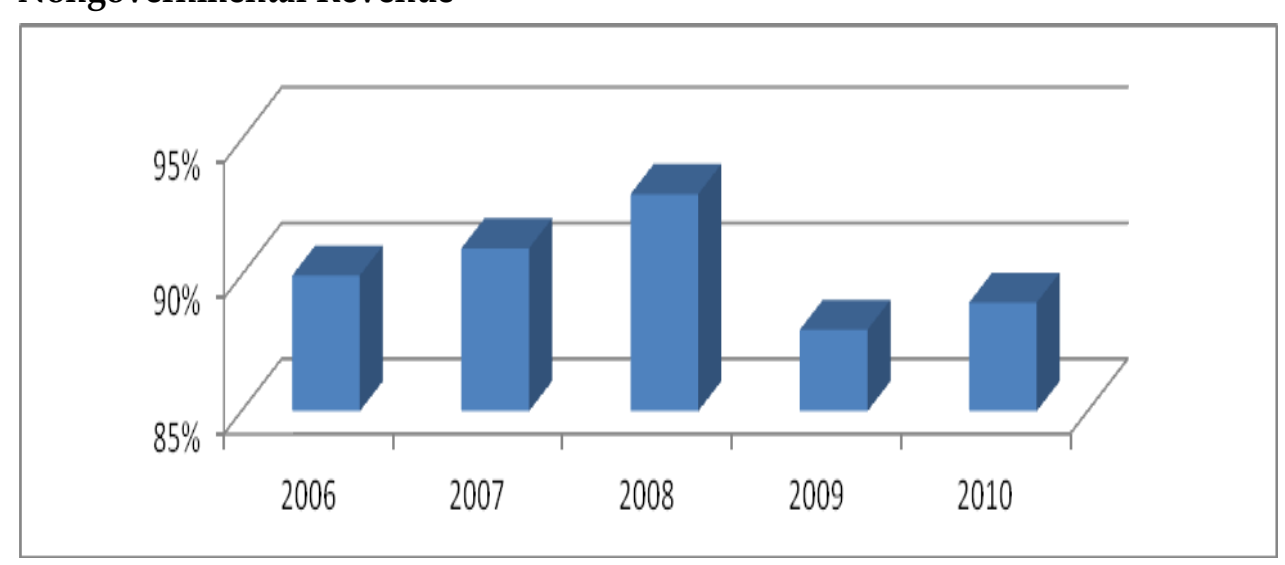


The government-sponsored $\mathrm{JAB}^{90}$ students and parallel students pay tuition fees to the university for their educational services. In the last five to six years, revenues from state-subsidised JAB students have been fluctuating. JKUAT runs self-sponsored fee-paying programmes to overcome or compensate for diminishing public resources. Since 2002, parallel programmes have steadily grown to become the most significant source of nongovernment revenue for JKUAT (see Table 6.13 above). Due to stiff competition among universities in Kenya for full-fee paying students, JKUAT is often reluctant to increase fees for fear of losing students to universities charging lower fees. In return for resources, students demand and expect (i) quality and affordable programmes, (ii) conformance of programmes to relevant professional regulatory bodies, (iii) variety of academic programmes, (iv) defined programme schedules, (v) safe accommodation, health and recreation facilities, (vi) affordable and good quality catering services, and (vii) a healthy, safe and secure environment (JKUAT, 2009:14-15).

JKUAT does not have a vibrant research tradition nor a tradition of cuttingedge scientific research and development. Nonetheless, the university undertakes some research and consultancy activities in order to acquire resources from its stakeholders, as shown in Chart 6-9 below.

Chart 6-9 Revenue from Research and Consultancy as a percentage of Nongovernmental Revenue

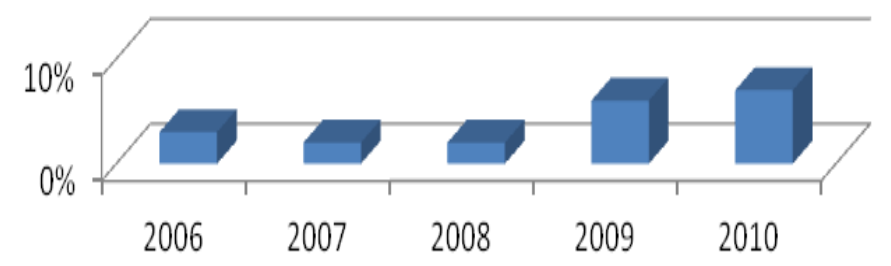

The university has been able to acquire resources for research from a number of bilateral and multilateral donors and from the government research council (NCST).This volume of earned revenue for research and consultancy services steadily increased from 2007 to 2010, but represented around 5\% of the total nongovernmental revenue in 2010. In return for their resources, donors require performance reports or demand the university meets certain conditions associated with the resources provided. Currently, the university mobilises

90 The average cost of each degree programme for JAB students is covered by the government as well as the beneficiary students. 
resources to carry out its research agenda than undertakes research to acquire resources from stakeholders.

Revenue from non-academic services such as bank interest, catering and accommodation services, bookshops, rental income, restaurants, stocks, commercial investments (farms and hotels), health services, printing and photocopying, etc. represents less than $5 \%$ of the total nongovernment budget as shown in Chart 6-10.

\section{Chart 6-10 Revenue from Non-academic Services as a percentage of Nongovernmental Revenue}

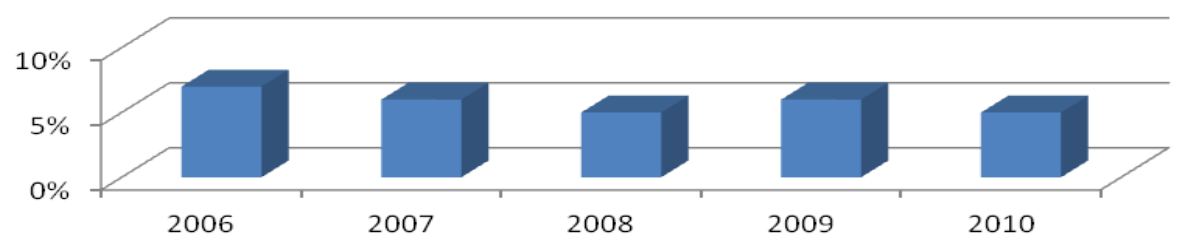

Although JKUAT promotes a full cost policy for revenue generation from nonacademic services, this policy is difficult to enforce. There is a general perception in the academic community that non-academic services and products where the university community is a direct beneficiary have to be heavily subsidised.

\subsubsection{Drivers for Revenue Generation at JKUAT}

In the context of Kenya, the continued growth in demand for university education, research, short-term courses, and consultancy services within Kenya and EAC and COMESA region are important drivers for revenue generation. In this regard, huge market opportunities for rolling out JKUAT programmes in neighbouring countries, and national and international job opportunities for JKUAT graduates are key drivers for engaging in revenue generation, as reported by the interview respondents. The demands for JKUAT's academic programmes are linked to the socio-economic development levels of Kenya, which are much higher than in neighbouring countries (CHET, 2010). According to a World Economic Forum report (2011-2012), Kenya's innovative capacity is ranked $52^{\text {nd }}$, with high company spending on R\&D and good scientific research institutions that collaborate well with the business sector. For innovative potential, Kenya gets fairly good marks for quality (51 $\left.1^{\text {st }}\right)$ as well as for on-the-job training $\left(54^{\text {th }}\right)$. These and similar factors may offer more opportunities for Kenyan public universities to attract international students and researchers. 
The general economic context of Kenya is an important driver for revenue generation, since pressures on public budgets have led to reductions in public funding for universities (see JKUAT, 2009). Threats like the decline of government financial contributions for universities and unstable Kenyan economic conditions force JKUAT to seek additional sources of revenue. Fluctuations in the growth of the economy negatively affect the resources that the Kenyan government can make available for its higher education system (see Ouma, 2007; Sifuna, 2006). There is now a wide spread understanding in the university community that public funding alone will not be sufficient to respond to the growing demand for higher education, while delivering a level of quality that provides students with the skills necessary to succeed in current and future labour markets. As a result, heavy dependence on a single funder (e.g. public funding) is risky for JKUAT. Risk mitigation is a powerful driver for the strategic pursuit of new funding sources for the university (JKUAT, 2009).

The continued expansion of the demand for higher education in Kenya also constitutes an important driver for revenue generation. Kenya, like Ethiopia, faces the situation of growing demand for higher education due to a rapid expansion in its youth population and an expanding pre-higher education system, as shown in Table 6.13 below.

Table 6.13: Student Enrolment in Pre-Higher Education System in Kenya

\begin{tabular}{lcc}
\hline \multirow{2}{*}{ Education Level } & Number (in millions) in & Number (in millions) in \\
& $\mathbf{2 0 0 7}$ & $\mathbf{2 0 1 0 / 1 1}$ \\
\hline Pre-primary & 1.70 & 2.20 \\
Primary (1-8) & 8.25 & 9.38 \\
Secondary (9-12) & 1.51 & 1.70 \\
\hline
\end{tabular}

Source: IMF (2012); GoK (2003:95); and GoK (2007)

In Kenya, an 8-4-4 education structure (i.e.; 8 years of Primary Education, 4 years of Secondary Education, and 4 years of University Education) has been in place since 1985 (MoE, 2008). Primary school Net Enrollment Ratio (NER) increased from $73.7 \%$ in 2000 to $91.4 \%$ in 2010. According to Kenya Education Sector Support Programme (2005:12), Kenya plans to achieve Education for All (EFA) by 2015. The gross secondary education enrolment rate was $59.5 \%$ in 2009 (compared to Ethiopia's 34.4\%). In recent years, the rate of transition from primary to secondary has registered particularly impressive growth, from 41.7\% in 2002 to 60\% in 2005 (GoK Vision 2030:94), and 72.5\% in 2010/11. According to the Mid Term Plan (2008-2012), this transition rate should reach 75\% by 2012 (GoK, Vision 2030). The government has also committed itself to 
building 560 new secondary schools by 2012. The overall growth of the student population in Kenya coupled with the recently introduced government policy of free secondary education has led to the growth in demand for higher education (JKUAT, 2009:20).

The Kenyan higher education system can generally be characterised as "supplyconstrained", as the demand for higher education outstrips the capacity of the system. The cut-off point for admission ${ }^{91}$ to university depends on the total public university student capacity which has been around 10,000 students for several years. In 2011, the system accommodated only about $20 \%$ of those who met the minimum entry requirements. Such a low level of participation in higher education $(4.6 \%)$ has already led to shortages of skilled labour in Kenya, which was identified as one of the major challenges for the realisation of Vision $2030^{92}$ (GoK, 2007). Kenya plans to increase the transition rate from secondary to university level education from $8 \%$ to $15 \%$ (Ibid, p99), in order to reach a level of $20 \%$ of young people participating in higher education by 2030 .

Similarly, changes to demand in the labour force (notably the creation of 15 university colleges in Kenya) have created a need for more university graduates trained for highly specialised occupations at postgraduate levels (Master's and $\mathrm{PhD}$ ). There is also a growing demand from international students for postgraduate education at the Kenyan universities. This implies increasing pressure for more training to be available at Master's and PhD levels. The demand for postgraduate education is an important driver for revenue generation. According to Vision 2030 (GoK, 2007:23), the country's global competitiveness will depend on the ability to create a human resource base that is constantly re-training and accessing technological learning within employment. Recognising that $21^{\text {st }}$ century knowledge becomes obsolete faster than at any other period in human history, the ministries and local offices are required to embrace lifelong learning and constantly retool their employees to remain relevant in the future. The growth of knowledge contributes to the rise of lifelong learning in society. As a result, the need for frequent retraining

91 At the end of the fourth year in secondary education, students are required to sit for the Kenya Certificate of Secondary Examination (KCSE) and admission to higher education is determined based on their results.

92 The country's new development blueprint covering the period 2008-2030 aims to transform Kenya into an industrialising middle-income country providing a high quality of life to all its citizens by the year 2030 (GRK 2007:1). The implementation of Vision 2030 is based on five-year planning horizons as medium-term rolling plans, the first phase of which covers the period 2008-2012. 
throughout professional careers has become an important driver for revenue generation at JKUAT.

Kenyans are aware of the significant role university education plays in enabling the nation to benefit from the global economy (GoK, 2007). Research and increased technology applications can help to address the challenges that Kenya faces. The Kenyan Vision 2030 proposes intensified application of STI in all sectors to raise productivity and efficiency. A new incentive structure to support the use of STI in specialised research centres, and universities is proposed. More resources are to be devoted to scientific research, enhancing the technical capabilities of the workforce, and raising the quality of teaching of mathematics, science and technology in schools, polytechnics and universities. Universities are expected to build capacity for generation, adaption, and utilisation of knowledge and innovations to create the enabling conditions for socio-economic development (Ibid, p 96). This drives JKUAT to opt for revenue generation.

\subsubsection{Factors that Enable or Hinder Revenue Generation at the Kenyan Case Study University}

The interview respondents and documentary evidence at JKUAT widely acknowledged a number of factors that enable or erect barriers to revenue generation within and outside the University. Those environmental and university specific factors that enable or obstruct revenue generation efforts at JKUAT are investigated below.

\subsubsection{Environmental Factors that Enable or Hinder Revenue Generation at JKUAT}

The Kenyan aspiration to become an industrialised middle-income country by 2030 is one of the factors that creates opportunities to expand university education (GRK 2007: 1\&31). The realisation of this objective is subject to the country's capacity to produce highly trained human capital that will help to carry out and support this transformation (ibid, p96). Other policy and strategy documents such as the Kenya Education Sector Support Programme (KESSP) 2005-2010 (MHEST 2005), the Ministry of Higher Education, Science and Technology Strategic Plan 2008-2012 (MHEST 2008), and the Science, Technology and Innovation Bill (MHEST 2009) urge Kenyan universities to reorient their education and research to help realise Vision 2030.The Kenyan government's commitment to expansion of higher education culminated in the development of the new Universities Act, 2012. The 2012 Universities Act openly acknowledges earned revenue from sources other than the national 
government as legitimate revenue for public universities. Any unexpended balance of the grant made to JKUAT may be carried forward from one year to the next and be spent as the university chooses (Clause 40). The 1994 JKUAT Act did not prevent the university from pursuing additional revenue streams.

The findings in this chapter show that the degree of autonomy granted by the regulatory framework enables or hinders the capacity of JKUAT to generate additional revenue. JKUAT's autonomy in terms of academic, organisational, and financial matters is a key enabler for revenue generation. According to one senior leader and a finance officer, the existing government resource allocation mechanism gives flexibility and autonomy in financial management (see Salmi and Hauptman, 2006), which enables revenue generation. However, the university's inability to set staff salaries and its inability to borrow money from financial markets are perceived as barriers to revenue generation. JKUAT's freedom to enter into partnership with other organisations in the environment, ability to organise itself the way it wishes, freedom in internal allocation of resources, and its overall academic autonomy are important enablers for pursuing and developing additional funding streams. It is also hoped that the fresh Charter that the University was granted in February 2013 as per Universities Act No. 42 of 2012 will further enhance the autonomy of JKUAT (http://www.jkuat.ac.ke/2013/03/president-awards-jkuat-fresh-charter/ accessed on 1 March 2013).

One of the most important incentives for revenue generation at JKUAT is the implementation of "dual track tuition policies". To that end, the existence of diversified criteria for admission of full-cost paying students is a crucial enabler for revenue generation (see Table 6.14 below).

Table 6.14: Admission Criteria of Students

\begin{tabular}{ll}
\hline $\begin{array}{l}\text { Desired education } \\
\text { level }\end{array}$ & Requirements \\
\hline Certificate & $\mathrm{C}-$ \\
Diploma & $\mathrm{C}$ \\
Degree & $\mathrm{C}+$ \\
Master's & Bachelor's degree at 1st or 2nd upper class or lower + \\
& $\begin{array}{l}\text { 2yrs work experience or pass }+5 y \text { yrs experience or } \\
\text { other qualification considered equivalent by Senate }\end{array}$ \\
$\mathrm{PhD}$ & Relevant Master's degree \\
\hline
\end{tabular}

Source: http://www.jkuat.ac.ke/service-charter/admission-of-students/ accessed on March 09, 2013). 
The Kenyan government influences revenue generation by public universities through funding mechanisms. The growing provision of student loans and bursaries are important enablers for revenue generation. The establishment of the HELB ${ }^{93}$ (see World Bank, 2010:84 for operational summary of HELB) is one of the mechanisms that foster revenue generation at JKUAT. HELB ${ }^{94}$ ensures that academically able but financially challenged students are able to participate in higher education and JKUAT earns tuition fees revenue by admitting loan holders. Other schemes like Constituency Development Fund ${ }^{95}$ (CDF), Local Authority Transfer Fund, and a Constituency Aids Fund are enablers for revenue generation. Needy students from various constituencies can apply for bursaries, which account for $10 \%$ of the total CDF (GoK, 2006). The existence of various strategic partnerships and collaborative opportunities with local and international organisations and higher education organisations (see section 6.3) in the university's task environment enables the university to foster revenue generation by forming alliances. However, affordable and competitive academic programmes in other universities are threats for revenue generation.

A lot of supportive polices are available for fostering revenue from research activities in Kenya. Kenya's vision 2030 recognises research and development $(R \& D)$ as one of the key strategies for the economic growth and competitiveness of the country (see Vision 2030 for Kenya; MHEST strategic plan, 2008). This overall policy direction is amplified in other strategic plans such as the MHEST strategic plan (MOHEST, 2008:25-26), and the Science, Technology and Innovation Bill (MOHEST 2009). In terms of financing research, government funding allocations for research at public universities are largely inadequate, limiting research capacity. This limited funding for research is an important barrier to generating revenue from research. For example, JKUAT acquired

93 HELB offers: (i) loans for undergraduate and postgraduate (Master's \& PhD) studies, (ii) bursaries for undergraduate studies, and (iii) scholarships for postgraduate studies. The MOHEST disburses about KShs. 82 million in each financial year to HELB.

94 The Loans Board pays often about KShs 8,000 per student for tuition costs directly to the university (Ngolovoi, 2006). The remaining loaned funds are paid to the student through his or her bank account for food and lodging costs and other living expenses.

95 Constituency Development Fund (CDF) was introduced in 2003 with the passage of CDF Act 2003. At least $2.5 \%$ of government revenue will be allocated to the fund, which is geared towards the alleviation of poverty and promotion of local development. The CDF increased from Kshs 1.26 billion in 2003/04 to 14.3 billion in 2010/11. Almost Kshs. 60 billion has been channelled through CDF since its inception. CDF contributes over $10 \%$ to all development in Kenya. 
about KShs. 65 million for research from NCST through competitive funding mechanisms between 2009 and 2011, which was perceived as too little by the Deputy Vice Chancellor of Research, Production, and Extension (accessed in February 2013 http://jkuat.ac.ke/divisions/rpe/wp-content/uploads/2011/04/ NCST-Grants-2011.pdf).

A number of international organisations like AICAD, EU, Japan, Germany, USAID, DFID, FARA, RUFORUM, and DAAD have endeavoured to offset the shortfall of research funding (JKUAT, 2009). For instance, JKUAT negotiated a KShs. 500 million fast food processing plant within the university with a Japanese firm. Other major sources are uni-brain consortium (USD 2mil) for agro-business incubators, EU's beans projects (KShs30mil) and banana project (USD1 mill), and other Japanese funded project (1million USD). This shows that JKUAT's research funds from donors supersede its national research budget. The availability of donors to fund research at JKUAT is an important incentive to search for additional revenue from donors. There are several models for research funding cooperation between the university and donors. The cooperation ranges from a project-based collaboration to long-term structured strategic partnerships. A common way of funding research at JKUAT is supporting dozens of projects by either directly funding JKUAT or faculties or departments within the university or even individual researchers or groups of researchers within a faculty. In most cases, the university is forced to implement a variety of uncoordinated projects which has led to huge administrative costs. The diversity of instruments and associated rules, heavy administrative processes and accountability requirements were reported by senior leaders to be barriers for fostering revenue generation from donor funding if other feasible alternatives existed.

The underdevelopment of the manufacturing sector in Kenya is an important barrier to revenue generation from research and consultancy. Most manufacturing firms in Kenya are family-owned and the vast majority of Kenyan industrial firms are small (see Section 6.2). Medium and large firms are limited. The top three manufacturing subsectors account for $50 \%$ of the sector GDP, $50 \%$ of exports, and $60 \%$ of formal employment. According to the Deputy Vice Chancellor for Academic Affairs, most industrial firms are very limited in articulating their needs, knowledge absorption, and capacity to pay for the service rendered. Nor do they have a tradition of collaborating with the university. JKUAT finds it difficult to engage in large-scale research-intensive collaboration and consultancy with small industrial firms, which was reported to be a barrier for revenue generation. Moreover, Kenya's ability to attract international students and researchers may be held back by poor health conditions (122 $\left.{ }^{\text {nd }}\right)$ and the country's security situation (129'th) (WEF, 2011-2012). 
The advancement of ICT in Kenya is an important enabler for revenue generation in universities. The information technology and modern telecommunication has a significant impact on how students learn, how academic staff teach and conduct research, and how administrators manage their organisations. Most public universities in Kenya embrace and seek out modern pedagogical approaches such as e-learning and video conferencing. ICT alters and enlarges traditional tasks of teaching and research by changing forms of cooperation within and between universities and with other organisations in the environment. Applications of modern technology in the management of academic organisations means they transcend the obstacles of time and location and are able to learn more about their stakeholders, and respond to stakeholder demands and expectations with possible increases in efficiency and effectiveness. Science, Technology and Innovation, supported to a large extent by ICT, has become a major driving force for economic change in many nations and Kenya is likely to benefit.

\subsubsection{University Specific Factors that Enable or Hinder Revenue Generation}

The findings of this research identify a number of internal enablers for and barriers to revenue generation at the Kenyan case study university. One of the most important enablers for revenue generation at JKUAT is changes in the attitudes of the university community. The senior university leaders and middle level managers and academics who participated in the interviews reported that most university members have positive attitudes towards revenue generation and positive attitudes towards relations with external stakeholders for revenue generation. The old negative attitudes towards revenue generation as diverting academics from their core mission/activities have gradually vanished at JKUAT. As a result, revenue generation is rooted and embedded in the overall academic mission, policies, plans and strategies of the university (see JKUAT, 2009). The formulation of an "Income Generating Units Policy" of JKUAT is an important step forward in that regard.

The internal governance structures and decision-making processes of the university are usually considered adequate for embarking on a successful revenue generation strategy. JKUAT maintained a 'deliberative' structure of committees for revenue generation, that play steering roles by combining the traditional academic model of collective collegial decision-making and strong organisational leadership for effective and efficient coordination. The participation of the academic community in overall governance and management of revenue generation is ensured through the Income Generation Unit (IGU) committee, with senior academics chairing the committees. As 
reported by one registrar, the governance, and decision making structure for revenue generation still works well, and the university has not needed to make immediate changes.

Almost all interview respondents rated the qualification and competence of human resources (i.e.; academic and administrative staff) at JKUAT as strength of the university in developing and engaging in successful revenue generation strategies and activities. The proportion of staff with doctoral degrees was $37 \%$ at JKUAT in 2011 (see Chart 6-4). Nevertheless, the heavy involvement of the senior academic staff in teaching and administrative tasks limited the opportunities for engaging in research and PhD supervision. Similarly, JKUAT has adequate professional managerial expertise and competence for fostering revenue generation except in the area of procurement. The use of a transformative leadership style by the senior leadership, the implementation of the system of performance contracting, and ISO 9001:2008 QMS certification have all been important enablers for revenue generation. The national policy on service delivery and the adoption service charter at the university have also contributed (http://www.jkuat.ac.ke/service-charter/ accessed on January 2013).

One of the important barriers for revenue generation of JKUAT is the inadequate non-human resources (see section 6.4.5). Growth in infrastructure has not been congruent with the increase in student population (JKUAT, 2009:22-23). Lack of national investment in research and capital also exacerbates the problem. As it stands today, the university has inadequate lecture halls, library, offices, laboratories, hostels, and other facilities.

The availability of seed money to start new or expand existing revenue generation activities is an important enabler for income diversification. Accordingly, the strategic plan of JKUAT (2009-2012) indicates that the university has allocated KShs. 42 million over three years (2009/10-2011/12) or KShs. 14 million per year in order to grow its revenue streams (JKUAT, 2009:62; see also JKUAT, 2010: 6).

\subsection{Revenue Generation Strategies of the Kenyan Case Study University}

In the preceding sections, we have explored the external environment and the characteristics of JKUAT in line with the research model in Chapter 3 and the variables used for empirical testing in Chapter 4 . On the basis of the analysis, we have identified several drivers of, enablers for, and barriers to revenue generation at JKUAT. In this section, we will examine the university's revenue generation strategies. As stated in the strategic plan (2009-2012) of JKUAT, generating and effectively managing financial resources is the third strategic 
objective of the university (see JKUAT, 2009). In this regard, several revenue generation strategies have been formulated to ensure the financial sustainability of the university.

\subsubsection{Differentiation of Services and Products for Revenue Generation}

The environment of JKUAT contains a variety of stakeholders with diverse demands whose very specific needs for university services are under-served (see sections 6.6). The university has unique resources and capabilities, which enable it to satisfy the needs and expectations of its salient stakeholders to some degree (see section 6.4). One of the university's revenue generation strategies is the differentiation of its services and products to reach as many stakeholders as possible. As far as this strategy is concerned, any subunit (e.g. college, campus, faculty, department, or institute) of the university is allowed to initiate an Income Generating Unit (JKUAT, 2010:12). Revenue generation activity can originate from research or teaching or from any other source such as university management or Council (Ibid, p12). In the subsequent subsections, we explore JKUAT's differentiation strategy in relation to each revenue generation activity.

\subsubsection{Differentiation in Educational Services and Creation of Academic Units for Revenue Generation}

As discussed in section 6.6, JKUAT has huge demand for its academic programmes from Kenya and EAC and other international students. In response to this demand, the university has differentiated its academic programmes as depicted in Table 6.15. These academic programmes were launched in the spirit of becoming market or demand-driven.

Table 6.15: Differentiation in Academic Programmes of JKUAT

\begin{tabular}{ll}
\hline Year & Number of Academic programmes \\
\hline $2005 / 06$ & 107 \\
$2006 / 07$ & 114 \\
$2007 / 08$ & 121 \\
$2010 / 11$ & 152 \\
$2011 / 12$ & 161 \\
\hline
\end{tabular}


Revenue generation has come to characterise virtually all academic departments at JKUAT (see Table 6.5), although it has not been uniform. Some programmes attract more fee-paying students than others. It has been most evident in the school of Human Resource Development, and most difficult to expand to those disciplines that require huge investments. Whenever possible and appropriate, JKUAT takes a first move advantage by launching new programmes immediately after the demand is identified. A good example of this is opening several certificate and diploma courses for county governance following the restructuring of the Kenyan government (see section 6.2).

A vertical differentiation strategy reaches out to diverse students who seek specialties at different educational levels, as shown in Table 6.16 below.

Table 6.16: Vertical Differentiation at JKUAT

\begin{tabular}{l}
\hline Level \\
\hline Bridging Course \\
Certificate \\
Diploma \\
Degree \\
Postgraduate diploma \\
Master's \\
PhD
\end{tabular}

The creation of new satellite campuses in many towns and cities in Kenya and outside is an important strategy for JKUAT moving its educational services closer to (potential) clients and thereby attracting and accommodating the soaring demand for higher education (see Table 6.17).

Table 6.17: Names of Satellite Campuses of JKUAT

\begin{tabular}{ll}
\hline \multicolumn{2}{c}{ Satellite Campuses } \\
\hline Karen & Taita Tveta \\
Nairobi & Nakuru CBD \\
Nairobi Central Business District & Kitale CBD \\
(CBD) & \\
Mombasa CBD & Kisii CBD campuses \\
Arusha (Tanzania), & \\
\hline
\end{tabular}


JKUAT is the first public university in East Africa to open a campus in another country. The legal framework of the Inter-University Council has facilitated the opening of Arusha campus for East Africa (IUCEA). In a bid to internationalise its student population, JKUAT has attracted students from the East Africa region, Zambia, Malawi, Botswana, Eretria, Ethiopia, Southern Sudan, Sudan, and even from as far as Germany and Sweden.

The recently established constituent colleges of JKUAT might advance its revenue generation (see Table 6.18) by taking university education closer to its customers.

Table 6.18: Constituent Colleges of JKUAT

\begin{tabular}{ll}
\hline \multicolumn{2}{c}{ Constitute College } \\
\hline Taita Taveta University College & $\begin{array}{l}\text { Mombasa polytechnic university } \\
\text { college }\end{array}$ \\
$\begin{array}{l}\text { Dedan Kimathi University College } \\
\text { Meru University College of Science } \\
\text { and Technology }\end{array}$ & \\
\hline
\end{tabular}

To address the educational demands of students who want to combine work and study, JKUAT has scheduled its academic programmes at different times. Although undergraduate parallel students were initially required to attend lessons in the evenings and weekends, as in Ethiopia (see Chapter 5), JKUAT now has a policy of teaching parallel students and JAB sponsored students together on a full-time basis, in order to create capacity for efficient use of resources and admitting more postgraduate students. As a result, weekends are reserved for postgraduate students (Master's and PhD), whose numbers have been growing rapidly over the last five years.

As part of its educational services, JKUAT offers short and bridging courses to a variety of stakeholders. Several short courses in the areas of business, construction, and energy and environmental technology have been offered for employees from different (non-) government offices and industrial firms. The business courses consist of entrepreneurship skills, human resource management, business information technology, conflict resolution and negotiation, public relation, procurement and logistics, office management for secretaries, community development, business communications, finance and accounting, business law, ICT policy and many others. In 2011, for instance, JKUAT and the Public Procurement Oversight Authority (PPOA) entered into a Memorandum of Understanding to train procurement and supply chain staff in 
Civil Service and State Corporations for one year. Popular courses in construction include project management; site management, labour-based road construction techniques, project financing, arbitration, and contracts administration, computer aided engineering design and drafting, research methodology, environmental impact assessment of construction projects, sustainable road construction, sustainable building materials and construction, and new and emerging materials and technologies in construction. The major courses in the areas of energy and environmental technology include environmental impact assessment, occupational health, safety and environment, biogas energy technology, cleaner production, pollution and waste management, solar energy technology, environmental leadership programme, energy management, wind energy technology, and energy audits.

Similarly, JKUAT offers bridging courses for high school graduates whose average matriculation grade is below the minimum required for automatic university admission (i.e. a $\mathrm{C}+$ ) or who have scored the required minimum grade but then had inferior grades in subjects considered core for the course desired by the student. The bridging courses offered include English, Mathematics, Physics, Biology, chemistry, and Kiswahili. The aim of running these courses is to guarantee a constant flow of parallel students for future courses and to generate revenue through the bridging courses themselves.

Forming alliances and consortia with other organisations is one of the strategies for overcoming a shortage of human and non-human resources to foster revenue generation. According to JKUAT's strategic plan, the university will increase the number of collaborations at a rate of $10 \%$ per annum over the period 2009 to 2012 (JKUAT, 2009; JKUAT, 2010:6). There are examples of collaborations in almost all academic units, in the form of sharing staff, guest lectures, joint research projects, etc. The main approaches to overcoming the inadequate facilities (JKUAT, 2009:22) at the main (Juja) campus include lobbing private entrepreneurs to construct hostels, and establishing franchises with other middle-level colleges for JKUAT programmes. JKUAT persuaded local entrepreneurs to construct hostels for rent in the university's vicinity. This partnership has been facilitated by the Juja Community Development Committee (formed in 2005), which is organised under the department of university community collaboration and is hosted by the division of RPE. While the entrepreneurs bring financial resources, the university develops blueprints for hostel construction and provides supervision services during the actual construction. This partnership results in provision of more secure, affordable, and comfortable hostels for the university's student population. It has also strengthened the amicable relationship between the Juja community and JKUAT. Another strategy which has been extensively used for expanding IGU 
teaching is franchises or co-ventures with non-degree awarding middle level, mostly proprietary colleges. JKUAT is a clear 'leader' when it comes to coventures with private, mostly for profit, non-university institutions in Kenya, (http://www.jkuat.ac.ke/academic-programmes-2/. accessed in January 2013). In these ventures, students enrolled in the franchised colleges are awarded degrees, diplomas, and certificates by JKUAT.

\subsubsection{Differentiation in Research and Consultancy Services and Creation of Research Entities}

With some history of success in research, JKUAT has tried to differentiate its research and consultancy services to meet the demands of various salient stakeholders. This differentiation strategy has been supported by establishing research institutes, centres, and units (see Chart 6-11) that result in dual operating structure along with academic departments.

\section{Chart 6-11 Number of Research Institutes, Centres, and Units at JKUAT}

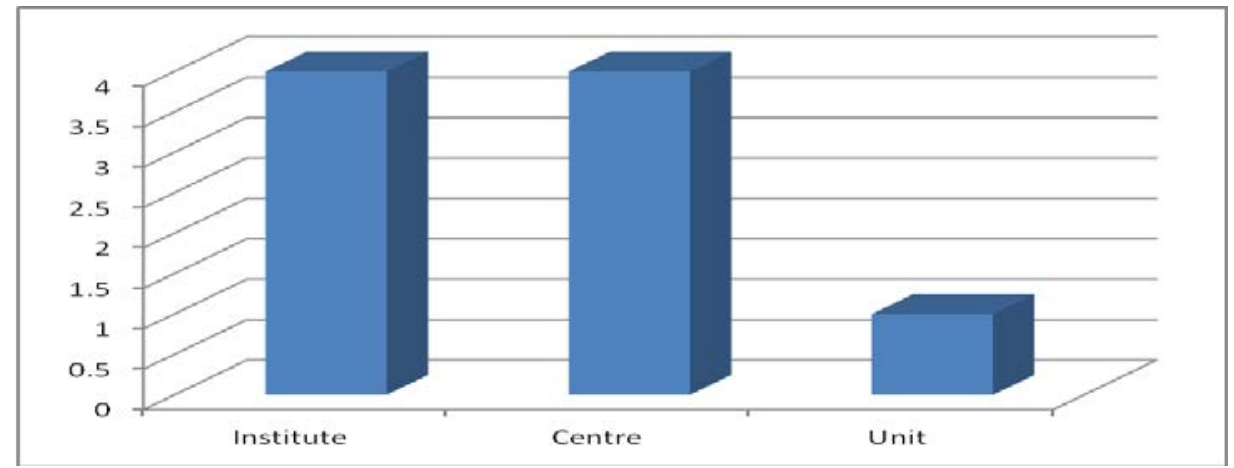

The university tries to produce new products in the areas of food, chemistry, biotechnical, engineering and horticulture in its engineering workshop, horticulture nursery, biotechnology centre, botany tree nursery, chemistry products centre, food technology centre, and software development (see JKUAT, 2010:9). For instance, JKUAT's food technology centre produces products like confectionery, beverages, and juices, and soft-drinks, yoghurt, and different types of mushroom for revenue generation. The chemistry products centre also produces products like soaps, detergents, and paints for sale.

Some of the key institutes that foster revenue generation at JKUAT include: Biotechnology Research (IBR), Energy \& Environmental Technology (IEET), Computer Science and Information Technology (ICSIT), and Tropical Medicine and Infectious Diseases (ITROMID). These academic entities are organised as research entities, which are built outside core disciplinary departments and link 
with stakeholders. Internally they work closely with the university's researchers, while externally they collaborate with other scientists from local and international research institutes or stakeholders. The academic entities also provide educational services. The growing use of these academic entities results in a dual operating structure of departments and institutes, strongly indicating the university's intention to generate revenue from research IGUs.

The IBR produces a variety of fast-maturing and disease-free planting materials like avocado, grafted mango seedlings, passion-fruit vine seedlings, pawpaw seedlings, and tissue-cultured banana seedlings, and tissue culture aloe-vera seedlings. Other products are organic farming products, compost manure products, bio-pesticides, and briquettes (bio-charcoal). IBR secures some external funding to support its research activities from NCST, Bill and Melinda Gates foundation, and Alexander von Humboldt foundation. The ICSIT performs research in the area of ICT, and produces up-to-date and innovative research to provide appropriate ICT solutions to the Kenyan ICT industries. ITROMID is the coordinating centre for all departments engaged in HIV/AIDS activities including AIDS Control Unit, and University Hospital. The College of Engineering and Technology (COETEC) is one of the academic units that engages heavily in revenue generation. The COETEC has a Research, Innovation, and Consultancy Triangle that consists of Engineering workshops, Consultancy and Professional Development Centre, and Industrial or Community Liaison Office. The Sustainable Materials Research and Technology Centre (SMARTEC), a multi-disciplinary centre, focuses on research related to civil engineering, building technology and eco-technology. SMARTEC has developed a walking tractor and tricycle in its workshops as well as housing constructed from local eco-materials (i.e. wall blocks, floor tiles, paving tiles, roofing tiles). During the data collection, the university is in the process of establishing an industrial and technology park to complement the existing engineering facilities and engage in revenue generation.

JKUAT undertakes a variety of consultancy activities in its colleges, faculties, schools, and institutes. The university's consultancy services are particularly concentrated in the areas of engineering and technology, agriculture and environment. Material or sample tests in Civil Engineering laboratories for clients; for instance, water testing in NEMA accredited Environmental Engineering laboratory, material testing in Structural or Materials Engineering laboratory and soil mechanics laboratory are frequently used forms of consultancy. JKUAT also offers consultancy services in infrastructural projects such as roads and bridges, airports, port development and related near-shore structures. 
JKUAT wants to form linkages and partnerships with industry, offshore universities, research and development institutions, among others, for joint research projects (JKUAT, 2009:46). The university often develops proposals for research through linkages and collaborations with other organisations in order to achieve optimal staffing and facilities to undertake research effectively (http://www.jkuat.ac.ke/r-d-and-technology-transfer/ accessed in February 2012). These partnerships enable the university to overcome its inadequate research facilities such as laboratories, workshops, and libraries. Similarly, JKUAT has co-opted potential competitors into allies in the struggle for research funds, allowing each to and exploit the complimentary assets that they bring into the arrangement. In this regard, we observed more collaboration in the areas of health, where ITROMID of JKUAT shares resources with research organisations such as Kenya Medical Research Institute (KEMRI). The department of chemistry has also been in constant collaboration with the public and private universities and research institutions such as ICIPE, KEFRI, KEMRI, and KARI amongst others.

\subsubsection{Differentiation of Non-Academic Services and Products for Revenue Generation}

JKUAT responds to huge internal and external markets by differentiating its non-academic services and products as indicated in Table 6.19 below.

Table 6.19: Diversifying Non-academic Services for Revenue Generation

\begin{tabular}{|l|l|}
\hline Academic credentials & Alumni fees \\
\hline ID card & Agricultural products ${ }^{96}$ \\
\hline Bookshops & Industrial products \\
\hline Conference hall and venue hire & Medical services \\
\hline $\begin{array}{l}\text { Material or sampling testing in } \\
\text { laboratories }\end{array}$ & $\begin{array}{l}\text { Residences or housing services } \\
\text { (guest houses and dormitories) }\end{array}$ \\
\hline Sport facilities & Leasing university property \\
\hline Catering services & Computer assembling \\
\hline Repair and maintenance of furniture & Day care centre and model schools \\
\hline Investment income & \\
\hline
\end{tabular}

96 JKUAT engages in selling several agricultural products such as: poultry and poultry products, dairy products, live beef animals and beef, pig and pork, small live animals (sheep and goats) and products, horticulture products, improved seeds and the like to in-and off-campus communities. 
The growth of JKUAT has necessitated provision of these on-campus services in order to meet the demands of their internal and external customers. JKUAT also established Jomo Kenyatta University of Agriculture and Technology Enterprises (JKUATES) as an income generating enterprise with its own legal personality for fostering revenue generation and avoiding unfair competition with the private sector.

\subsubsection{Creation of Administrative Support Structures for Stakeholder Management}

JKUAT pursues a strategy of creating administrative support structures to support stakeholder management that leads to revenue generation. As in the Ethiopian case study universities, two approaches have generally been implemented. The first method focuses on using the existing organisational structures to enhance efficiency and reduce costs. The second method is establishing new organisational structures dedicated to revenue generation. At its strategic apex, the Deputy Vice Chancellor for Research, Production and Extension (DVC-RPE) is the custodian of IGU policy in terms of overseeing its implementation (see JKUAT, 2010:1). The members of Income Generating Units Committee (see Table 6.20below) promote collegial steerage for the university's revenue generation agenda.

Table 6.20: Members of IGUs Committee of JKUAT

\begin{tabular}{|c|c|}
\hline \multicolumn{2}{|c|}{ Position } \\
\hline $\begin{array}{l}\text { Deputy Vice Chancellor for Research, } \\
\text { Production and Extension (DVC-RPE) } \\
\text { (Chairperson) }\end{array}$ & Directors of institutes and schools \\
\hline $\begin{array}{l}\text { Deputy Vice Chancellor for Academic } \\
\text { Affairs }\end{array}$ & $\begin{array}{l}\text { Three Registrars under the Three } \\
\text { Deputy VCs }\end{array}$ \\
\hline $\begin{array}{l}\text { Deputy Vice Chancellor for } \\
\text { Administration, Planning and } \\
\text { Development Division }\end{array}$ & Finance Officers \\
\hline $\begin{array}{l}\text { Principals of JKUAT } \\
\text { campuses/colleges }\end{array}$ & Chief Medical Officer \\
\hline Deans of faculties & University Chief Librarian \\
\hline Chief Production Officer (secretary) & Legal Officer \\
\hline $\begin{array}{l}\text { Managers of Income Generating Units } \\
\text { (IGUs) }\end{array}$ & $\begin{array}{l}\text { Managing director of enterprises } \\
\text { (JKUATES) }\end{array}$ \\
\hline
\end{tabular}


This committee exists to: (i) coordinate all IGUs, (ii) provide IGU policy and resources, (iii) approve budgetary support to IGUs, (iv) coordinate capacity building programmes for IGUs, and (v) monitor and evaluate the performance of IGUs and their activities on a monthly and quarterly basis (Ibid, p7). The committee operates according to the university's Income Generating Units Policy (IGUs policy).

Various outreach administrative units operating as crosscutting offices (see Table 6.21) have been involved in establishing better university-environment relationships and helping to raise revenue.

Table 6.21: Crosscutting Offices Fostering Revenue Generation

\section{Office}

- Department of Finance

- Human Resource Department

- Directorate of Performance Contract and Appraisal

- Corporate Planning

- Alumni and International Students Office

- Legal Services

These offices have not necessarily been established by the university solely with the objective of generating revenue, but they offer potential for revenue generation. By optimising tasks in the existing offices, they enable the university to achieve efficiency measures and reduce administrative costs. The offices indicated in Table 6.21 provide administrative support services in the areas of need identification, marketing the university's services and products, proposal writing and costing, legal and contract support, and financial and human resource matters. Wherever and whenever the volume and complexity of work calls for additional administrative support units, the senior university leaders respond by opening additional units. In this respect, a finance unit has been seconded at RPE to manage financial matters for IGUs. The IGU/IGA prepares a statement of accounts and disbursement schedule in liaison with the IGU accountant placed at RPE division and submits this to DVC-RPE. The DVC-RPE scrutinises the statement of accounts and submits it to the VC. The $\mathrm{VC}$ in consultation with the internal audit office approves the statement of accounts and disbursement schedule, and forwards it to DVC-APD for onward submission to the finance office for disbursements. All generated revenue is 
centrally kept in the IGU Account located at and managed by the division of RPE (or DVC-RPE).

Along with these crosscutting offices, the university has set up specific offices for each revenue generation activity; namely, education, research, and nonacademic services. In order to foster revenue generation from educational services and short courses, JKUAT has set up a variety of administrative support offices, as indicated in Table 6.22 below.

Table 6.22: Administrative Entities in Charge of Education and Short-term Courses at JKUAT

\section{Office}

- Deputy Vice Chancellor for Academic Affairs

- Registrar for Academic Affairs

- Three Deputy Registrars: Admission, Programmes and Training, and for Examination

- Planning and Control Section

- Colleges, Institutes, Schools and Faculties, and Departments

- Continuing Education Programme (CEP)

- Extension, Training and Community-Oriented Section

The university's division of academic affairs controls all revenue generation from educational activity and short courses. This division plans academic programmes, prepares syllabuses, admits students, and offers examinations, certificates and transcripts, and library services, among other things. The Deputy Registrar for Programmes and Training of DVC-AA facilitates the needs identification survey, which is an entry point for launching new academic programmes in accordance with the standards of CHE and IUCEA. Upon approval of the proposed programmes by the Senate and Council, the section of deputy registrar for Admission and Marketing of DVC-AA, in collaboration with the academic units concerned, develops a plan that outlines target markets, strategies, and tactics for attracting students on JKUAT campuses and CEP centres. JKUAT heavily advertises its programmes in print and electronic media, and through fora such as agricultural shows, trade fairs, CHE exhibitions, and by directly addressing to high school students. CEP deals with the co-ordination and general administration of academic programmes at the approved centres for providing the university's programmes. 
Students are flexibly admitted in JKUAT's programmes in January, April, and August. Once students are told they have been accepted to JKUAT, the Academic Affairs Division works closely with the Finance Department on financial matters. The policy of forcing students to settle their tuition and application fees for a semester in one lump at the time of registration was repealed in 2007/08. Students of JKUAT are now able to pay their tuitions and fees in instalments (three or four times within a semester) for easing their financial burdens.

Short-term courses are organised by the Extension, Training and Communityoriented Section (ETC) of JKUAT in conjunction with academic departments. These courses are processed by filling in a form obtainable from RPE division. This form is designed to gather information on the nature of courses, a client and its contact details, professional team members involved in offering courses, start and completion dates for the envisaged short courses, and details of expenditure (estimated cost, amount of fees for the courses, estimated total expenditure, estimated net surplus). The completed form is co-signed by the relevant department, DVC-RPE and by the VC within two working days. After approval by the VC, the RPE Division and ADP division provide the necessary financial support and logistical services (e.g. transportation, catering, and accommodation) for the implementation of the short-term course.

As in its educational activity education, the Kenyan case study university has an operational research structure that manages the research activity of the university and its IGAs (see Table 6.23).

Table 6.23: Administrative Support Entities Fostering Revenue Generation from Research and Consultancy Services

\section{Office}

- Deputy Vice Chancellor for Research, Production and Extension

- Directorate of Research Services

- Directorate of Linkages

- Directorate of Production

- Directorate of Extension and Technology Transfer

- Research Monitoring and Evaluation Committee 
The Directorate of Research Services is charged with formulating relevant research policy guidelines. It serves as a link between the divisions of RPE and Academic Affairs. This directorate, in conjunction with the Directorate of Extension and Technology Transfer, evaluates discoveries and innovations that may qualify for scaling up and commercialisation. The directorate of Research Services provides expert guidance on how to develop proposals for funding, and encourages the development of research and innovation proposals for external funding. The directorate carries out intellectual property audits, and advises researchers on patenting matters to enable staff to maximise the returns from their research. Moreover, it mobilises researchers from various academic disciplines to respond to calls for proposals made by various granting organisations.

Additionally, JKUAT has a Directorate of Linkages to facilitate its linkages and partnerships with other organisations. The university also established a Directorate of Production to pilot and scale up innovations from the Directorate of Research Services. This directorate provides policy guidelines on the operation and management of IGUs. The Directorate searches for potential investors, venture capitalists or angel investors who can support the scaling up of university innovations and develops partnerships or linkages.

The Directorate of Extension and Technology Transfer conducts and coordinates university exhibitions at agricultural shows, open days, exhibitions, technical meetings and other fora. Since 2005, JKUAT has held an annual Scientific, Technological, and Industrialisation Conference ${ }^{97}$ in order to popularise its services and products. It also has responsibility for marketing patented innovations by contracting with firms that can potentially license the innovation for commercialisation purposes.

The university's products are sold to internal and external customers. The internal market is an existing market where the main customers are the university's staff and students. IGUs can delegate their responsibility for selling to JKUATES. In the latter arrangement, the IGU will negotiate service fees with

97 The objectives are to: (i) provide a forum through which JKUAT will highlight the ongoing contributions it is making to society, (ii) create a forum for constantly improving the University's approach to development-oriented scientific research, (iii) provide a forum for research peers from local and international institutions to discuss, share and publish vital information, (iv) provide an opportunity for the industrial/business sectors and policy makers to interact with researchers, to get new ideas and products for infusion into the production system and research, and (v) help policy makers to appreciate the need for substantial and long-term investment in scientific research, innovation and industrialisation. 
JKUATES. JKUATES may buy the research products directly from IGUs at wholesale price and sell them to the university community. The external market is the primary responsibility of JKUATES. JKUATES is expected to prepare a marketing plan that addresses such issues as marketing, pricing, target markets, existing and potential competitors, marketing budget and a promotional mix for reaching out to customers based on a mutual agreement between IGUs and JKUATES. JKUATES currently sells a number of IBR products (see Table 6.23).

The development of research entities such as institutes, centres and units as well as a number of administrative offices at the Kenyan case study university, without adequate supporting research capacity, illustrates how the university has imitated the behaviour of other actors in its environment, particularly those actors whom it knew and trusted. This illustrates how the university has tried to imitate the organisational structures of research intensive universities without considering its own capacity. This may lead to huge administrative costs for the university.

The consultants or the units that have initiated consultancy activities are required to fill in a consultancy form obtainable from RPE division. This form is designed to gather information on the nature of consultancy including the expected outputs or products, the client and their contact details, project leader and professional team members involved in the consultancy, start and completion dates, and details of expenditure. The completed consultancy form is co-signed by the consultant, DVC-RPE and the VC. The VC's signature equated to approval for the planned consultancy activity. All pre-consultancy activities are processed within two working days. After approval by the VC, the RPE division facilitates the implementation of the consultancy project by providing transport and initial payments where necessary and handling other logistical matters.

The division of Administrative, Planning and Development (DVC-APD) and other offices under the leadership of this division manage all of JKUAT's nonacademic revenue generation activities (see Table 6.24). 
Table 6.24: Entities Fostering Revenue Generation from Non-Academic Services and Products

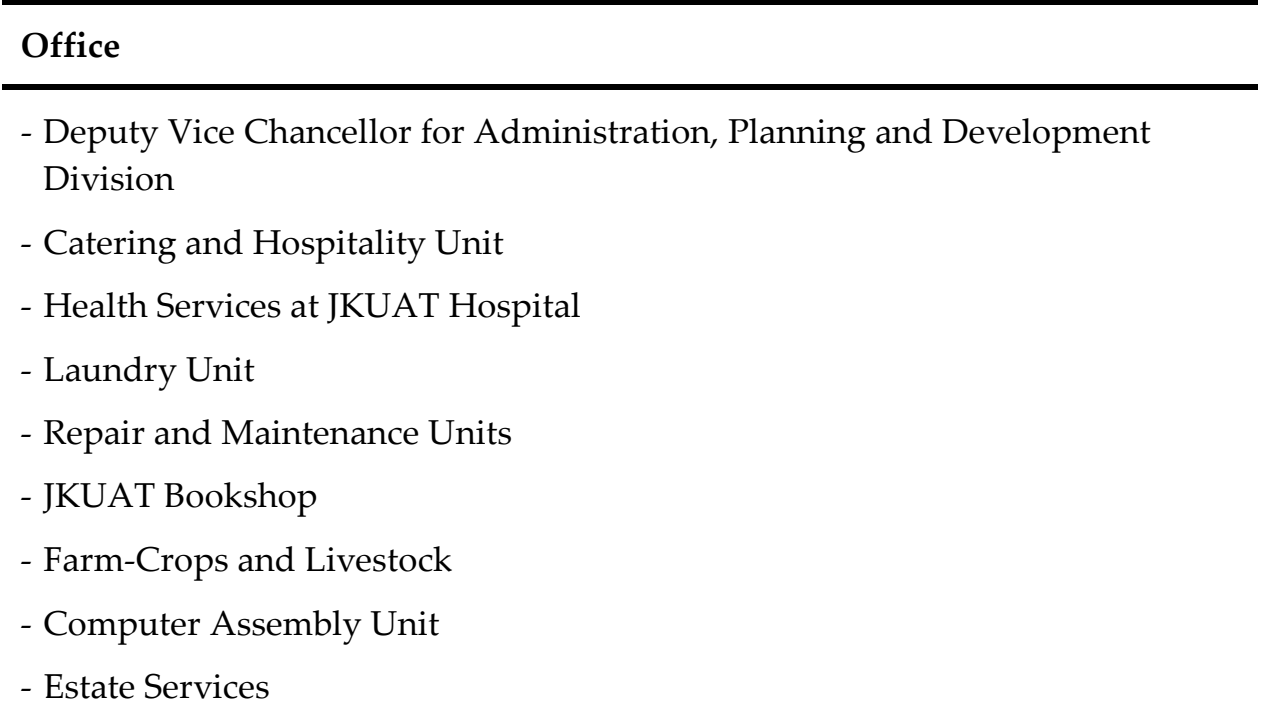

Although the IGU policy states that each revenue generation initiative must, after an investing setup phase, be run with a positive balance of income and expenditure based on a full cost consideration, this policy has not been fully applied. This is because the key customers are often the university community, who like to have subsidised services and products. For instance, almost all cafeterias on campuses are highly subsided and promote the notion of "feed yourself from the work place". The unofficial principle is to motivate the university community to reduce staff turnover.

\subsubsection{Decisions Concerning Internal Resource Allocation Mechanisms and Human Resource Policies for Revenue Generation}

As stated earlier, JKUAT's revenue generation agenda is rooted and embedded in the overall academic mission, policies, plans and strategies of the university (see JKUAT, 2009). The Income Generating Units Policy of the university is a major internal regulation that determines internal resource allocation and human resource matters for fostering revenue generation. It provides a framework for the planning and administration of revenue generation activities in the university. More specifically, the IGU policy tries to establish modalities for the coordination and monitoring of IGUs, encourage exploitation of potential business opportunities through resource maximisation, provide 
guidelines on establishment of IGUs, ensure high ethical standards and best practice while running the businesses, and provide guidelines for the sharing of IGU revenues and surpluses (JKUAT, 2010). The formulation of the policy itself can be considered an indicator of the leadership's commitment to revenue generation.

JKUAT maintains the IGA fund with annual budget allocations which to provide seed money or initial start-up capital to support both new IGU development and growth of the existing IGUs (Ibid p 6). Some of this seed money comes from a $20 \%$ levy on the gross income from each revenue generation activity. This cross-subsidisation represents an interesting lever to keep the organisation together and ensure an improved attitude towards revenue generation. Between 2005 and 2010, JKUAT allocated KShs. 135.76 million to IGAs (accessed in February 2013 http://jkuat.ac.ke/divisions/rpe/wpcontent/uploads/2011/04/JKUAT-FUNDED-RESEARCH-PROJECTS.pdf). In 2008/09 alone, Ksh. 13.53 million was disbursed for new and existing IGAs from nongovernmental sources. The seed money also comes from the budget that JKUAT receives from the main governmental support.

A business plan is an entry point for any revenue generation activity at JKUAT. The plan comprises a business description, market and marketing strategy, production details (e.g. requirements and costs, forecasts of production vis-à-vis sales, and financial start up and operational costs), human resources (e.g. responsibilities and pay), business risk and mitigation strategies, and action plan. Accepted business plans are loaned seed money for starting up the revenue generation activity. The university and the IGU make an agreement about utilisation of the seed money. Resources are allocated according to the detailed budget breakdown that is shown in the accepted business plan. In most cases, money is allocated for recruitment of additional staff, procurement of goods and services, rewarding staff, and capacity development. JKUAT is aware that engaging in revenue generation requires sufficiently qualified human resources (i.e. both academic and administrative staff), who are adequately rewarded. However revenue generation is not a major criterion for recruitment, promotion, or dismissal of academic and administrative staff. The criteria by which faculty and administrators judge academic work remain unchanged and persist in prioritising conventional forms of education and research. In order to ensure an adequate supply of academic staff to run its programmes, JKUAT employs part-time academic staff from outside of the university, and invites guest lecturers (see Section 6.7.6). JKUAT's inability to set staff salaries hinders its capacity to attract and retain experienced and qualified staff. This challenge is more obvious in those disciplines where the 
private sector offer much higher salaries and/or better career prospects (e.g. business and economics, law, and medicine).

The university community will only support revenue generation if they perceive it as useful and rewarding in monetary or nonmonetary terms. The senior university leaders offer rewards to increase the academic community's commitment to revenue generation. The incentive mechanisms exist at two levels: rewarding staff directly, and providing incentives at subunit/institute level or central level. The income distribution for teaching services is shown in Table 6.25.

Table 6.25: Income Distribution for Teaching Services (Internal Actors)

\begin{tabular}{lc}
\hline Unit & $\begin{array}{c}\text { Teaching (balance after 20\% } \\
\text { deduction) }\end{array}$ \\
\hline Direct Service Providers & $35 \%$ \\
Department & $10 \%$ \\
College/Campus/Faculty/School/Institute & $5 \%$ \\
Library & $1 \%$ \\
Vice Chancellor's Office & $1 \%$ \\
Central Administration & $31 \%$ \\
RPE Division & $3 \%$ \\
Colleges/campuses & $2 \%$ \\
Academic Division & $2 \%$ \\
Administrative Division & $2 \%$ \\
Development Fund & $3 \%$ \\
Staff Welfare & $2.5 \%$ \\
Student Welfare & $2.5 \%$ \\
Total & $\mathbf{1 0 0} \%$ \\
\hline
\end{tabular}

Similarly, the university has a set of incentive mechanisms to increase the academic community's commitment to revenue generation from research and consultancy activities, as indicated in Table 6.26. 
Table 6.26: Sharing Ratios for Research among Internal Actors

\begin{tabular}{|c|c|c|c|c|}
\hline Type & Inventor & University & Collaborators & \\
\hline $\begin{array}{l}\text { With third party } \\
\text { involvement }\end{array}$ & $30 \%$ & $60 \%$ & $10 \%$ & \\
\hline $\begin{array}{l}\text { Without third party } \\
\text { involvement }\end{array}$ & $40 \%$ & $60 \%$ & & \\
\hline \multicolumn{5}{|c|}{ Distribution of the university's $60 \%$} \\
\hline $\begin{array}{c}\text { Central } \\
\text { Administration }\end{array}$ & Faculty & Department & IPO & $\begin{array}{l}\text { Research } \\
\text { Fund }\end{array}$ \\
\hline $21 \%$ & $3 \%$ & $18 \%$ & $6 \%$ & $12 \%$ \\
\hline
\end{tabular}

Source: JKUAT Intellectual Property Policy (JKUAT, 2006:21-23)

JKUAT also has a set of financial incentives (see Table 6.27) to increase the university community's commitment to generating revenue from consultancy services. 
Table 6.27: Income Distribution for Consultancy Services (Internal Actors)

\begin{tabular}{|c|c|c|c|}
\hline \multirow{2}{*}{ Unit } & \multicolumn{3}{|c|}{ Sourced or initiated by } \\
\hline & Employee & Department & University \\
\hline $\begin{array}{l}\text { Direct Service } \\
\text { Providers }\end{array}$ & $65 \%$ & $40 \%$ & $50 \%$ \\
\hline Department & $5 \%$ & $25 \%$ & $3 \%$ \\
\hline $\begin{array}{l}\text { College/Campus/Fa } \\
\text { culty/School/Institu } \\
\text { te }\end{array}$ & $3 \%$ & $5 \%$ & $2 \%$ \\
\hline Library & $1 \%$ & $1 \%$ & $1 \%$ \\
\hline $\begin{array}{l}\text { Vice Chancellor's } \\
\text { Office }\end{array}$ & $1 \%$ & $1 \%$ & $1 \%$ \\
\hline $\begin{array}{l}\text { Central } \\
\text { Administration }\end{array}$ & $8 \%$ & $11 \%$ & $10 \%$ \\
\hline RPE Division & $3 \%$ & $3 \%$ & $3 \%$ \\
\hline Colleges/Campuses & $2 \%$ & $2 \%$ & $2 \%$ \\
\hline Academic Division & $2 \%$ & $2 \%$ & $2 \%$ \\
\hline $\begin{array}{l}\text { Administrative } \\
\text { Division }\end{array}$ & $2 \%$ & $2 \%$ & $2 \%$ \\
\hline Development Fund & $3 \%$ & $3 \%$ & $19 \%$ \\
\hline Staff Welfare & $2.5 \%$ & $2.5 \%$ & $2.5 \%$ \\
\hline Student Welfare & $2.5 \%$ & $2.5 \%$ & $2.5 \%$ \\
\hline Total & $100 \%$ & $100 \%$ & $100 \%$ \\
\hline
\end{tabular}

Similarly, the university has introduced an incentive mechanism for those actors who participate in revenue generation from non-academic services and products, as shown in Table $6.28 .20 \%$ of gross income from non-academic services is kept to serve as contribution to the IGA Fund and for the development of facilities. Where applicable, direct and indirect costs are recovered before declaration of surplus. 
Table 6.28: Income Distribution for Non-Academic services (Internal Actors)

\begin{tabular}{lc}
\hline Unit & $\begin{array}{c}\text { Non-Academic Services (balance } \\
\text { after 20\% deduction) }\end{array}$ \\
\hline Direct Service Providers & $35 \%$ \\
Department & $10 \%$ \\
College/Campus/Faculty/School/Institute & $5 \%$ \\
Library & $1 \%$ \\
Vice Chancellor's Office & $1 \%$ \\
Central Administration & $31 \%$ \\
RPE Division & $3 \%$ \\
Colleges/Campuses & $2 \%$ \\
Academic Division & $2 \%$ \\
Administrative Division & $2 \%$ \\
Development Fund & $3 \%$ \\
Staff Welfare & $2.5 \%$ \\
Student Welfare & $2.5 \%$ \\
\hline Total & $\mathbf{1 0 0} \%$ \\
\hline
\end{tabular}

In terms of research capacity development, JKUAT uses its nongovernmental revenues (about KShs. 50 million per year) - mainly from educational activity on research capacity building to expand its ability to attract resources from donors and NCST. From 2005-2012, for example, JKUAT allocated Kshs. 114 million for research and another KShs. 56.43 million for innovation projects. (http://rmis.jkuat.ac.ke/research/?title=Home\%3EResearch\&section=home\&sho $\mathrm{w}=$ research;http://rmis.jkuat.ac.ke/research/?title=Home\%3EInnovations\&sectio $\mathrm{n}=$ home\&show=innovation accessed in February 2013). In the 2008/09 fiscal year, JKUAT disbursed Kshs. 30.15 million for research and Kshs.11 million for innovation projects (JKUAT, 2009:23). Each year, JKUAT funds an average of 25 research and 10 innovation projects. The purpose of the fund is to support the application of new ideas and skills in turning research results into innovations (value creation) to bring them closer to the market. 


\subsection{Conclusion}

This chapter presents an analysis of the data on the status of revenue generation in the Kenyan case study university, using the resource dependence perspective as its theoretical lens. The findings show that although JKUAT was able to earn a majority of its resources (around 63\% of the entire budget in 2010) from nongovernmental sources, it has still not diversified its revenue base to a level which ensures financial health and sustainability. Any unforeseen underperformance by either the main state allocation or student tuition fees could financially destabilise the overall operations of the university, threatening its very survival. While JKUAT has tried to secure resources from education, research and consultancy, and other non-academic services and products, the university earned almost all of its nongovernmental revenue from educational services. In the subsequent paragraphs, we discuss why the Kenyan case study university operated in certain ways in relation to each revenue generation activity.

JKUAT obtained the vast majority (around $89 \%$ ) of its nongovernmental resources from the provision of educational services. The environment, coupled with its own specific strengths in terms of human resources, positively shaped JKUAT's ability to obtain resources by providing educational services within Kenya, EAC, and COMESA region. The adequate regulatory framework (i.e., academic, financial and organisational autonomy), and the growing provision of students' loans and bursaries for academically able but financially challenged students also contributed to this. Notably, the two most salient stakeholders of the university (i.e. the Kenyan government and the students)'s high levels of motivation to reap the social and individual benefits of university education have led to burgeoning demand for access to good quality higher education.

JKUAT has pursued two major revenue generation strategies, adapting and altering strategies, to maximise the resources it earns from educational services. The adapting strategy employed by the university includes horizontal and vertical (seven tiers) differentiation of academic programmes, opening new campuses and constituent colleges in strategic locations within and outside Kenya, flexible class scheduling to help students combine work and study, flexible payment arrangement for students, multiple admission schedules, and using different modes of delivery (e.g. weekends for postgraduate students). As part of the altering strategy, JKUAT is one of the most prominent public universities in Kenya to intensively form alliances with other education organisations (particularly middle level colleges) to overcome shortages of resources or reduce initial investment capital. Although most proliferation of programmes was in social sciences and humanities at undergraduate level, 
JKUAT has also made remarkable progress in achieving differentiation in postgraduate education. However the university still needs better infrastructure, laboratories, and workshops as well as additional qualified human resources in order to respond adequately to the soaring demand for postgraduate education from Kenyan and international students.

The findings indicate that revenue generation from research and consultancy and postgraduate education represent a very small fraction (about $5 \%$ ) of the nongovernmental resources in the Kenyan case study university. Although both environmental factors and university specific conditions provide justification for only acquiring small amount of resources from these activities, the best explanation comes from JKUAT's inadequate research infrastructure. In particular, the limited financial support for research from the main state allocation has contributed to eroding research infrastructures at JKUAT. As part of its adaptive strategy, JKUAT created research entities such as institutes, centres and units alongside traditional academic departments, and also created administrative support structures to foster revenue generation from research and consultancy services. Although the performance of these research entities has gradually been improving, in terms of producing improved agricultural products, food and beverages, detergents, and other industrial products, the creation of dedicated structures for research currently costs rather than benefits the university. Creating organisational structures without adequate research capacity illustrates how organisational decision makers have imitated the behaviour of other universities in their immediate or international environment, particularly those universities whom they knew and trusted. Moreover, like the Ethiopian case study universities, the formation of alliances and linkages with other organisations has been less effective than it might have been due to the limited in-house nonhuman research capacity.

The findings in this chapter indicate that JKUAT obtained around $4 \%$ of its nongovernmental revenue by providing non-academic services and products to their internal and external stakeholders. In this respect, revenue generation activities include catering services, laundries, conference facilities, repair and maintenance, bookshop, hospital services, farm (crops and livestock), and computer assembly. These non-academic activities raise marginal revenue while remaining relatively important factors in creating an enabling environment for teaching and research at the university. As the main customers for the non-academic services are the university community itself, this study acknowledges that there are real organisational and economic differences between universities and other businesses in operating non-academic services and products. Notably, JKUAT faces numerous distinctive constraints and 
incentives in their pricing, costs, and offerings, as subsidising the services and products has become the norm.

The results in this chapter reveal that JKUAT has well established stakeholder management structures and reward systems for linking up with outside stakeholders and increasing the commitment of internal actors to revenue generation. The participatory leadership style pursued by the senior university leaders, competent administrative support staff, and the implementation of ISO 9001:2008 QMS for improving stakeholder management and service delivery enable many administrative support units to function properly and thereby create a structured approach to stakeholder management. One of the most successful strategies for increasing the commitment of the academic community to revenue generation is internal reward mechanisms (often finance) for individual staff and units. Although participation in revenue generation can sometimes indirectly lead to the recruitment and promotion of staff, revenue generation is not one of the steering tools or criteria in the human resource policies of the university.

The current high levels of enrolment in the full-cost paying programmes at JKUAT might be a motivation to maximise financial gains at the expense of quality in the absence of robust quality assurance mechanisms for public universities in Kenya. This is an important time to establish a robust quality assurance mechanism that protects customers against highly financially motivated individual and organisational actors. The New Universities Act, 2012 recognises that Kenyan public universities engage in revenue generation from a variety of sources (other than the main state appropriations) as a legitimate activity. JKUAT needs to develop new capabilities to enter into research and consultancy activities in order to respond to the current dynamic environment. We recognise that revenue generation is inevitable in the Kenyan higher education landscape, but this needs to be managed in mission-focused and market-smart ways without imperiling core academic values and compromising the quality of education. 


\section{The South African Case Study University}

\subsection{Introduction}

The objective of this chapter is to analyse the environment and the South African case study university in line with the theoretical framework and research model in Chapter 3, and the operationalisation of the key variables in Chapter 4. The chapter is organised in eight sections. Following this introductory section, the second section presents the background and contextual information about the socio-economic and political context of South Africa. The third section discusses the South African higher education system in terms of access, governance and management, and financing. A profile of Nelson Mandela Metropolitan University (NMMU) and its organisational environment are analysed in the fourth and fifth sections, respectively. The sixth section explores the drivers, enablers, and barriers to revenue generation. The seventh section analyses NMMU's revenue generation strategies. Finally, we draw conclusions of the chapter.

\subsection{Socio-Economic, and Political Context of South Africa}

The Republic of South Africa (hereafter South Africa) lies at the southern end of the African continent and occupies an area of $1.22 \mathrm{~km}^{2}$. The country is bounded by the Indian Ocean to the east and the Atlantic Ocean to the west. To the north lie Namibia, Botswana, Zimbabwe, Mozambique, and Swaziland while South Africa totally encloses Lesotho. Following the 1994 elections (post-apartheid regime), South Africa was organised into nine provinces: the Eastern Cape, Free State, Gauteng, KwaZulu-Natal, Limpopo, Mpumalanga, Northern Cape, North West, and Western Cape. Like the Ethiopian and Kenyan case study universities (see Chapters 5 and 6), the South African case study university always faces environmental changes, which bring both pressures and opportunities. The findings in this chapter indicate that changes in demographic, economic, and political factors in the wider societal environment influence the overall operations of the South African higher education system in general and NMMU in particular. With respect to demographic factors, the South African population is still growing gently. Table 7.1 presents some key population statistics for South Africa. 
Table 7.1: Key population statistics of South Africa

\begin{tabular}{|c|c|c|c|c|}
\hline $\begin{array}{l}\text { Total } \\
\text { Population }^{98} \\
(2010) \text { in } \\
\text { millions }\end{array}$ & $\begin{array}{l}\text { Proportion of } \\
\text { the } \\
\text { population } \\
\text { below the } \\
\text { age of } 15\end{array}$ & $\begin{array}{l}\text { Proportion of } \\
\text { population } \\
\text { aged } \\
\text { between } 15 \\
\text { and } 64\end{array}$ & $\begin{array}{l}\text { Proportion of } \\
\text { population } \\
\text { aged } 65 \text { or } \\
\text { older }\end{array}$ & $\begin{array}{l}\text { Population } \\
\text { annual } \\
\text { growth rate }\end{array}$ \\
\hline 50.5 & $30.1 \%$ & $65.2 \%$ & $4.6 \%$ & $1.2 \%$ \\
\hline
\end{tabular}

Source: South African Statistics, 2012

The growth in the youth population leads to huge opportunities for educational services. According to South African Statistics (2012), the primary school age population and the secondary age population respectively contain about $20 \%$ and $9 \%$ of the total population of the country. The higher education age cohort accounts for $8 \%$ of the total population. This suggests a high demand for educational services at all levels, including higher education.

South Africa is the biggest economy in Africa, and the $29^{\text {th }}$ largest in the world. It is an efficiency-driven middle-income country and it is the second largest economy in the BRICS countries, after China. South Africa has a highly developed, largely metropolitan economy that co-exists with a relatively under-developed, largely non-urban economy. Table 7.2 depicts some economic development indicators for South Africa.

Table 7.2: Selected economic development indicator of South Africa

\begin{tabular}{llll}
\hline $\begin{array}{l}\text { Gross domestic } \\
\text { product per } \\
\text { capita in current }\end{array}$ & $\begin{array}{l}\text { Rank out of 142 } \\
\text { countries }\end{array}$ & $\begin{array}{l}\text { Stage of } \\
\text { development } \\
(2011-12)\end{array}$ & $\begin{array}{l}\text { Overall } \\
\text { competitive } \\
\text { ranking (out of } \\
142 \text { countries) }\end{array}$ \\
\hline 7,158 & 66 & Efficiency driven & 50 \\
\hline
\end{tabular}

Source: World Economic Forum (WEF)'s Global Competitiveness Index (GCI) 2011-2012

According to the World Economic Forum (2011-2012), South Africa does reasonably well in more complex areas such as business sophistication (38th) and innovation (41st), benefiting from good scientific research institutions (30th) and strong collaboration between universities and the business sector in innovation (26th) (ibid). However, among the most significant challenges for

98 Comprises 79.5\% Africans, 9\% Whites, 9\% Coloureds and 2.5\% Indians or Asians in 2011 (South African Statistics, 2012). 
the nation are unemployment and poverty, with about $40 \%$ of South African households still living below the poverty line of about Rand 480 per person per month (Dinokeng Scenarios, 2009). Unemployment remains chronically high (between 25 and 40\%), and income and other inequalities continue to increase, especially within the black African population. The country has one of the world's highest levels of inequality with a Gini coefficient of 0.7 (National Development Plan Vision 2030).

From 2007 to 2011, the South African economy grew irregularly, as depicted in Chart 7-1.

\section{Chart 7-1 Real GDP Growth Rates, 2007-11}

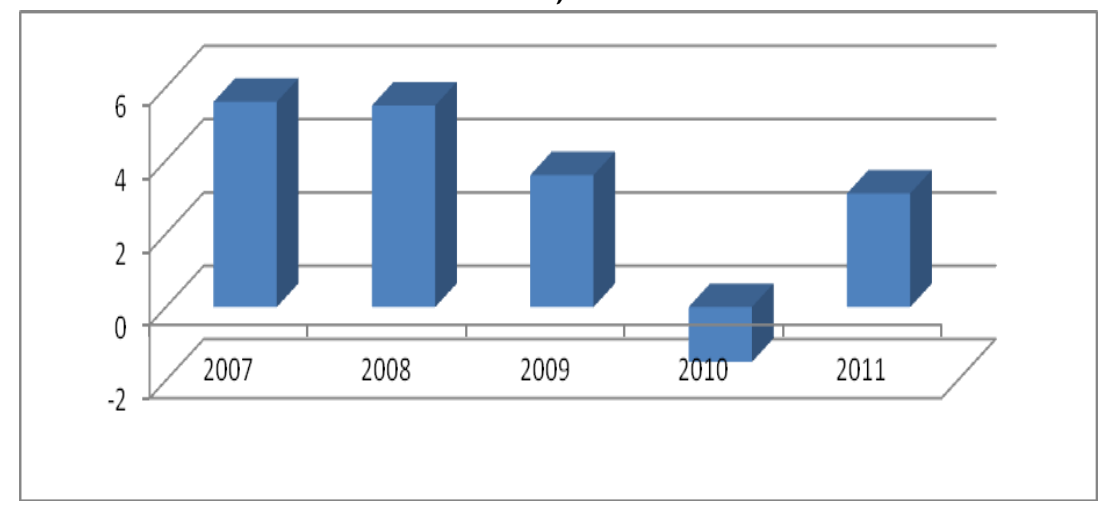

Source: accessed on 25 April 2013: http://www.africaneconomicoutlook.org/en/datastatistics/table-2-real-gdp-growth-rates-2003-2013/ or African Economic Outlook.

The real GDP growth of the country had been decreasing from 2007-2010 consistently, if modestly. In 2011, South Africa witnessed a positive economic growth, however. Aspects of the economy are highly sophisticated, with strong mining, financial and industrial sectors, and a good infrastructure (National Development Plan Vision 2030). The country is well endowed with mineral resources, with large shares of the global supply of platinum group metals, gold, diamond, manganese, iron ore, coal, and uranium. In 2011, for instance, GDP by sector shows that agriculture contributed $2.5 \%$, industry $31.6 \%$, and the service sector $65.9 \%$ (WEF, 2011-12). This suggests that the structure of the labour market in South Africa leans towards services, trade, and knowledgeintensive industries, where most employment positions require higher education degrees. There is also a political commitment to expand good quality higher education, as indicated in several economic development policies and strategic plans (see Section 7.4; see also CHET, 2010). The country enjoys a good 
digital infrastructure ${ }^{99}$, which effectively supports the operation of higher education organisations as well as their participation in international research networks.

\subsection{The South African Higher Education System}

South Africa has one of the longest experiences with higher education in Africa. Higher education in South Africa means all learning programmes leading to qualifications higher than grade $12^{100}$ in terms of the NQF as outlined in the South African Qualifications Authority Act (SAQA), 1995 (Act 58 of 1995). Higher education is offered by Further Education and Training Colleges, the Sectoral Education and Training Authorities (SETAs), and by Universities on a full-time, part-time or distance basis. A higher education institution may, subject to its institutional statute and the Higher Education Act 101 of 1997, award diplomas and certificates and confer degrees. The following subsections contain an analysis of access, governance and management, and the financing of the higher education system in South Africa.

\subsubsection{Size and Shape of the South African Higher Education System}

Higher education began in South Africa with the establishment of the University of the Cape of Good Hope (UCGH) in 1873. The South African higher education organisations were moulded into sharply stratified race and class divisions. According to Subotzky (2003:546), apartheid racial ideology generated historically white universities (HWUs) and historically black universities (HBUs) and fifteen technikons (of which seven were historically white, seven historically black, and one a distance education technikon). The eleven HWUs are Cape Town, Natal, Rhodes, Witwatersrand, Free State, Port Elizabeth, Potchefstroom, Pretoria, Rand Afrikaans, Stellenbosch, and UNISA. The HBUs consist of North West, Fort Hare, University of the North, Transkei, Venda, Zululand, Durban Westville, the Western Cape, MEDUNSA, and Vista University. Under this highly unequal set of functionally differentiated higher education organisations, the HBUs were fundamentally disadvantaged in terms of financial resources, human resources, infrastructure, material resources, research capacity, and academic credibility because of the apartheid legacy

99 ICT is one of the five enabler pillars that is included in the Global Innovation Index (GII).

100 'Grade 12 ' means the highest grade at which education is provided by a school as defined in the South African Schools Act, 1996 (Act 84 of 1996) 
(CHET, 2010). After the end of apartheid, a series of Acts and policies were developed to redress organisational inequalities, and enable the country to engage beneficially in the competitive global economy (see Section 7.5). One of the policy directions in the South African higher education landscape was the development of new institutional types through mergers.

There are currently 23 universities in South Africa, which include 11 universities (defined as such during the apartheid period and remain so); six universities of technology (the former technikons or technical universities); and six comprehensive universities (merged universities and technikons). In addition, two institutions in Northern Cape and Mpumalanga serve as administrative hubs coordinating higher education provision through partnerships with universities elsewhere. The eleven traditional universities offer various formative and professional bachelor's degrees as well as a small number of diplomas and certificates at undergraduate level. These universities offer provision at honours, master's and doctoral levels, as well as a limited number of postgraduate diplomas and certificates. The universities of technology offer a number of undergraduate diplomas that are vocationally oriented, as well as a bachelor of technology degree. Postgraduate provision at universities of technology is limited to a relatively small number of master's and doctoral programmes. The comprehensive universities offer a combination of traditional university and university of technology programmes. No new universities have been established since the advent of democracy in South Africa, although there is government commitment to developing two Institutes of Higher Education in Mpumalanga and the Northern Cape into full universities.

The end of apartheid also heralded a growth in both local and international private higher education organisations in the country. The size and shape of the private higher education institutions are not known precisely, due to data limitations. According to the SAQA database, there are at least 362 for-profit and not-for-profit private higher education institutions. Some findings show that there are between 8,000 and 12,000 private post-school education and training institutions in South Africa (CHET, 2010). In 2011, there were 87 private higher education institutions offering the award of whole qualifications at levels 5 to 8 (i.e., certificates, diplomas, or degrees) registered with the Department of Higher Education and Training (DHET). They are geographically concentrated in the provinces of Gauteng, Western Cape, and KwaZulu-Natal. The most prominent international providers of higher education with campuses in South Africa are Australian universities, Monash University and Bond University (CHET, 2010). The most popular types of qualification offered by private higher education institutions are undergraduate 
certificates, diplomas, and bachelor degrees. Private higher education institutions of South Africa are relatively small in size, their student enrolment figures range from fewer than 20 students to approximately 15,000 students.

\subsubsection{Participation in the South African Higher Education System}

Access to higher education has been expanding in South Africa in recent decades. Enrolment as a proportion of the $20-24$ year-old cohort was $17 \%$ in 2012. This participation rate is lower than that for comparable middle-income countries, although much higher than the average of $6 \%$ for Sub-Saharan African countries.

Table 7.3: Higher education organisations and total enrolment in 2010 in South Africa ${ }^{101}$

\begin{tabular}{lllll}
\hline $\begin{array}{l}\text { Number of } \\
\text { public } \\
\text { universities }\end{array}$ & $\begin{array}{l}\text { Number of } \\
\text { Private } \\
\text { HEIs }\end{array}$ & $\begin{array}{l}\text { Total } \\
\text { enrolment }\end{array}$ & $\begin{array}{l}\text { Gross tertiary } \\
\text { enrolment } \\
\text { rate }\end{array}$ & \begin{tabular}{l}
$\begin{array}{l}\text { Quality } \\
\text { education } \\
\text { system ranking } \\
\text { (out of 142 } \\
\text { countries) }\end{array}$ \\
\hline 23
\end{tabular} \\
\hline 114 & 837,779 & 15.4 & 133 \\
\hline
\end{tabular}

Source: WEF 2011-2012 and National Statistics

The overall enrolment at private higher education organisations was around $10 \%$ of the total admissions in 2011 . The 837,779 students in the 23 universities in 2010 represented an increase of almost 70\% since the advent of democracy; there were 495,356 students of all types in 1994. In 2010, nearly two-thirds (62\%) of the students were enrolled in contact-based study, with the remainder enrolled in distance education. Of the distance education students, $83 \%$ were at the University of South Africa. A large number of young people (nearly 0.6 million in 2007) have attempted matriculation but failed to get a university entrance pass (ibid.).

South Africa is also a major African destination for international students. In 2011, there were more than 68,000 international students enrolled in South African universities. Nearly 40,000 of them are contact students, while others are distance education students. According to Salmi (2012), the poor security situation remains an important obstacle to attracting and retaining as many

101 South Africa has 87 registered and 27 provisionally registered private higher education organisations. 
international students and academic staff (including researchers) as possible in South Africa.

The country envisages increasing participation rates ${ }^{102}$ to more than $30 \%$ by 2030. Enrolments in the higher education sector, including private higher education, will have to increase to 1.62 million from 0.84 million in 2010. This is more than a $70 \%$ increase. The establishment of two new universities is proposed, to expand the capacity of the higher education sector. The South African higher education system suffers from lack of efficiency. Close to a third of the 2005 cohort of students dropped out before finishing their degree. Only $27 \%$ graduated in the regular four-year period and only $51 \%$ had completed their studies after 6 years (CHET 2012: www.chet.org.za/data). The higher education system in South Africa is heavily criticised for gender, racial and other inequalities with regard to access to educational opportunities and success (2012 Green Paper). In terms of race, for example, only two-thirds of all students in higher education were African in 2009. Notwithstanding this significant progress in expanding access, the participation rate for African and Coloured students is still only 13\% (National Planning Commission, 2012).

\subsubsection{Governance and Management of the South African Higher Education}

In this section, we are concerned with the external governance and management of the South African higher education system. Since 1994, a number of laws and policies have been formulated to govern and manage the higher education system in South Africa (see Section 7.4.2). One of the most significant laws for steering the system is the Higher Education Act No. 101 of 1997.The Department of Higher Education and Training (DHET) ${ }^{103}$ is the government department responsible for all post-school education and training. It determines the scope and range of operations of public and private higher education institutions (Act 101 of 1997, Article 3). With regard to university education, the DHET determines policy on higher education after consulting the Council on Higher Education (CHE). Its main responsibilities include planning, coordinating, monitoring, and managing the system. The DHET, after consulting the CHE and with the concurrence of the Minister of Finance, determines policy on the funding of public higher education. It also allocates public funds to public universities. The funding mechanism for higher education in South Africa is an important steering tool and heavily depends on

\footnotetext{
102 The National Plan for Higher Education set a target of $20 \%$ participation in higher education rate 2016 (see DHET strategic plan 2010-14).

103 Was formed in May 2009.
} 
national and institutional plans. We shall return to this issue in sections 7.34 and 7.4.3. The National Student Financial Aid Scheme (NSFAS) Act No. 56 of 1999 provides the legal basis for the granting of loans and bursaries to eligible students attending public higher educational institutions, as well as for the administration of such loans and bursaries.

The Minister of HET has executive responsibility for the National Qualifications Framework Act No. 67 of 2008. This Act establishes a National Qualifications Framework (NQF), South African Qualifications Authority (SAQA), and the CHE. The NQF is the principal instrument through which national education and training qualifications are recognised and quality assured. One of the objectives of NQF is to create a single integrated national framework for learning achievements and to enhance the quality of education and training (ibid, Article 5). The NQF is organised in a series levels of learning achievement that are arranged in ascending order from one to ten. It facilitates the mobility of students across borders and among institutions of higher learning by standardising university qualifications and bringing about greater harmonisation with cross-border/international qualifications. The SAQA and the CHE seek to achieve the objectives of the NQF by developing an integrated national framework. Specifically, the SAQA is responsible for the development of policy and criteria for registering standards and qualifications in the NQF on the recommendation of the CHE (see NQF Act 67 of 2007 Article 13). The primary body with a direct role in the quality assurance of university education is the CHE. It is also responsible for the development and management of a Higher Education Qualifications Framework (HEQF).

Act 101 of 1997 establishes a statutory Council on Higher Education (CHE), which advises the Minister of Higher Education and Training and is responsible for quality assurance. All higher education institutions are regulated through an accreditation system led by the CHE and its implementation arm, the Higher Education Quality Committee (HEQC). The HEQC is legally mandated to close down programmes and even whole institutions that have failed to meet specific quality assurance standards. The CHE through its permanent committee, the Higher Education Quality Committee (HEQC): (i) promotes quality assurance in higher education; (ii) audits the quality assurance mechanisms of higher education institutions; and (iii) accredits programmes of higher education. The HEQC is deemed to be accredited by SAQA as an Education and Training Quality Assurance body primarily responsible for higher education. The CHE and the HEQC must comply with the policies and criteria formulated by SAQA in terms of section 5(1) (a) (ii) of the South African Qualifications Authority Act, 1995 (Act 58 of 1995). The South African Qualifications Authority has overall oversight of the NQF and maintains collaborative relationships with the three 
Quality Councils (QCs) for Higher Education, General and Further Education and Training, and Trades and Occupations respectively. The QCs have responsibility for standards development and quality assurance. We shall return to the internal governance and management of the South African case study university in section 7.5.

\subsubsection{Higher Education Financing in South Africa}

Several features of the South African higher education financing framework are somewhat advanced and unique in the African context. According to Act 101 of 1997 Article 40, a public university can receive money from a variety of sources. These include (a) funds allocated by the Minister; (b) any donations or contributions received by the organisation; (c) money raised by the organisation; (d) money raised by means of loans and overdrafts; (e) income derived from investments; (f) money received for services rendered to any other organisation or person; (g) money payable by students for higher education programmes provided by the university; (h) money received from students or employees of the institution for accommodation or other services provided by the institution; and (i) other receipts from whatever source. In terms of tuition fees, the council may discriminate in a fair manner between students who are not citizens or permanent residents of the Republic and students who are citizens or permanent residents of the Republic when determining the amount payable;

South African public universities are financed principally by government subsidy, student tuition fees (fee recovery), and other revenue from a variety of sources such as private and government contracts, donor and alumni support, and investments. There is a serious public commitment to spending on higher education in South Africa. As a percentage of the education budget, for instance, higher education spending increased from $4 \%$ in 1996 to $14.5 \%$ in 2008 (CHET, 2010). Similarly, the government's total university budget as a percentage of GDP increased from $0.68 \%$ in 2004 to $0.75 \%$ in 2011 . This figure is, however, still far below the OECD average of $1.3 \%$. The public budget remains insufficient to catch up with the rising costs of provision of university education and research (CHET, 2010; Ouma, 2007; Duncan 2009). For instance, government funding of higher education declined by $3.1 \%$ in real terms from 2000 to 2004 (Wangenge-Ouma and Cloete 2008). During this period, the total state spending per FTE student declined by R515 per annum. The current funding level can support a planned annual growth of $2.8 \%$, and therefore does not allow for the expansion and demand as evidenced by the current annual growth of $4.6 \%$ (see CHET, 2010). 
South Africa's funding formula combines performance-based formulas, earmarked funding, and block grants. The approach distributes the funds made available by government in ways that advance policy priorities. The national government pays universities for delivering teaching and research services specified in government-approved plans. Block grants comprise (a) teaching funds calculated by student enrolment and costs per student for different subject matter categories, (b) teaching funds based on agreed teaching outputs (for example, improved graduation rates), (c) research funds for agreed outputs, and (d) institutional factor funds for enrolling students from disadvantaged groups, maximising enrolment capacity, and attaining enrolment consistent with government-designated priority areas. Institutions are informed in advance of the total amount of the block grant they will receive. Earmarked funds are designated for specific purposes. In the main, these are for the national student financial aid scheme (NSFAS), research development, foundational programmes, teaching development, approved capital projects, and interest payments on approved loans.

Not all higher education institutions are equally dependent on the state for funding and nor are they equally affected by the shortfall in the main state budget. Some universities receive slightly more than $30 \%$ of their total income from the government, while others receive around 65\% (Cloete \& Wangenge-Ouma, 2008). We shall discuss the methods of allocating higher education budget to universities in South Africa in Section 7.4.2. Almost all higher education organisations are dependent on the second source of revenue, known as the fee-paying component. This source comprises 30\% to $40 \%$ of their revenue (CHET, 2010). Revenue from tuition fees increased from 15\% in 1996 to $32 \%$ in 2008 (Ibid). Unlike many higher education systems in Africa, the South African system is firmly based on cost recovery through fees. The NSFAS is used to ensure access for financially disadvantaged students. The third source of revenue for public universities is called the 'third-stream' and comes from a variety of sources. This revenue source constituted $23 \%$ and $27 \%$ of total revenue in 2004 and 2007, respectively. An interesting feature of this aspect of financing is that universities are not penalised with lower state funding if they raise third-stream revenue. Nor does DHET take revenues raised from student fees and other private sources in to account when distributing government budget to individual universities.

\subsection{Key Characteristics of Nelson Mandela Metropolitan University}

NMMU is one of the six comprehensive universities and was established through the merging of the Port Elizabeth campus of Vista University into the 
University of Port Elizabeth (UPE) in January 2004, and the subsequent merging of the Port Elizabeth Technikon (PET) and UPE in January 2005. Before their union, each institution had significant experience in higher education provision: Port Elizabeth Technikon (1882), the University of Port Elizabeth (1964), and Vista University's Port Elizabeth campus (1983). NMMU is now a mediumsized university located in the Eastern Cape Province at Port Elizabeth city. A brief profile of the university is presented in the subsequent subsections in line with the theoretical framework in Chapter 3, and the operationalisation of key variables in Chapter 4.

\subsubsection{Vision and Mission of the University}

The vision of NMMU is to be a dynamic African university, recognised for its leadership in generating cutting-edge knowledge for a sustainable future. Its mission is to offer a diverse range of quality educational opportunities that will make a critical and constructive contribution to regional, national, and global sustainability (NMMU, 2008). To achieve its vision and mission, the university ensures that:

- It is committed to promoting equity of access and opportunities to give students the best chance of success in their pursuit of lifelong learning and diverse educational goals.

- It provides a vibrant, stimulating, and richly diverse environment that enables staff and students to reach their full potential.

- It develops graduates and diplomats to be responsible global citizens capable of critical reasoning, innovation, and adaptability.

- It creates and sustains an environment that encourages and supports a vibrant research, scholarship and innovation culture.

- It engages in mutually beneficial partnerships locally, nationally and globally to enhance social, economic, and ecological sustainability.

\subsubsection{Student Population of NMMU}

NMMU is predominantly an undergraduate university that has various entry and exit points for ensuring accessibility and student mobility in order to be responsive and flexible for its diverse customers. The university offers a wide range of programmes to students, including undergraduate and postgraduate awards and other qualifications such as certificates and diplomas. Chart 7-2 below shows NMMU's total student population by level of study. 
Chart 7-2 Headcount Total Students from 2006 to 2010

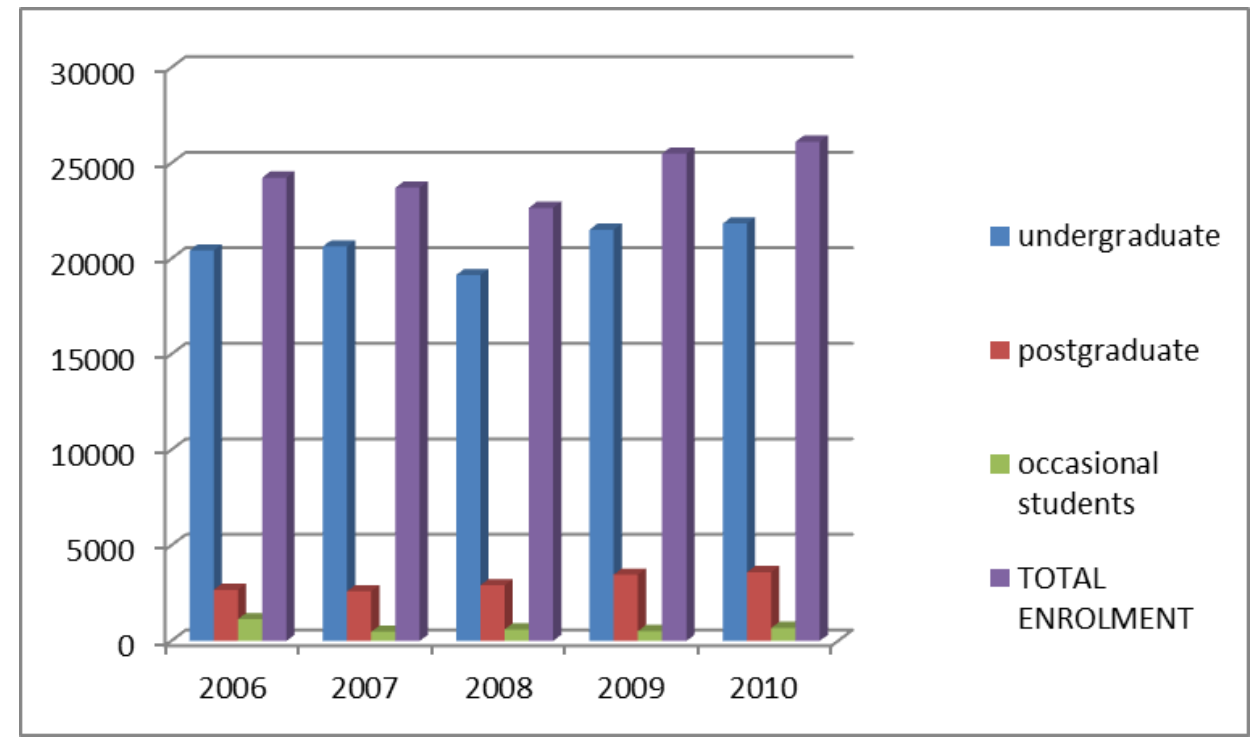

While the majority of students at NMMU are undergraduates, NMMU is progressively increasing enrolments at the postgraduate level in order to achieve a sufficiently diverse postgraduate population by attracting postgraduate students within South Africa and overseas. An analysis of enrolment trends from 2001 to 2010/11 shows that the proportion of postgraduate students in NMMU's total enrolment was 11\% in 2001 and $14 \%$ in 2010/11. Since 2005, the most significant growth has taken place at the Master's (i.e. $10.3 \%$ average annual growth) and Doctoral (i.e. 10.6\% average annual growth) levels. According to the interviewees, undergraduate students living "out of commuting distance" from NMMU are far less likely to attend the university than students living "within commuting distance", the effect being particularly marked for students from lower-income families. In 2009, for instance, $71 \%$ of all NMMU students were from the Eastern Cape Province. As reported by one senior leader, "a majority of undergraduate students of NMMU are from disadvantaged schooling backgrounds and in need of academic development and support interventions to enhance their chances of success at higher education level". Additionally, overseas students now represent a substantial percentage (10\% in 2011) of the student body of NMMU. Chart 7-3 below depicts the distribution of students at the seven campuses of the University. 
Chart 7-3 Proportion of total headcount enrolments by campus in 2010

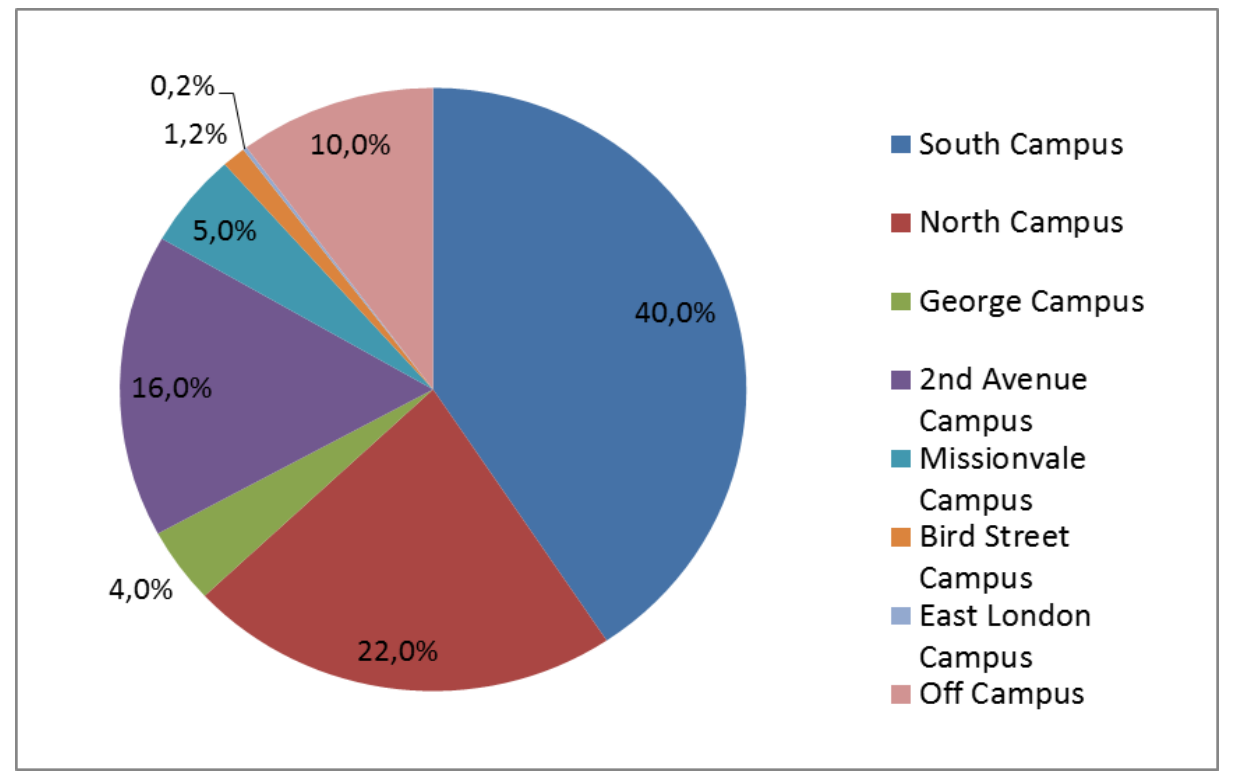

\subsubsection{Disciplinary Areas and Academic Units of NMMU}

The South African case study university provides several academic programmes in accordance with the HEQF as indicated in Chart 7-4.

Chart 7-4 Percentage of overall enrolments by major fields of study in 2010

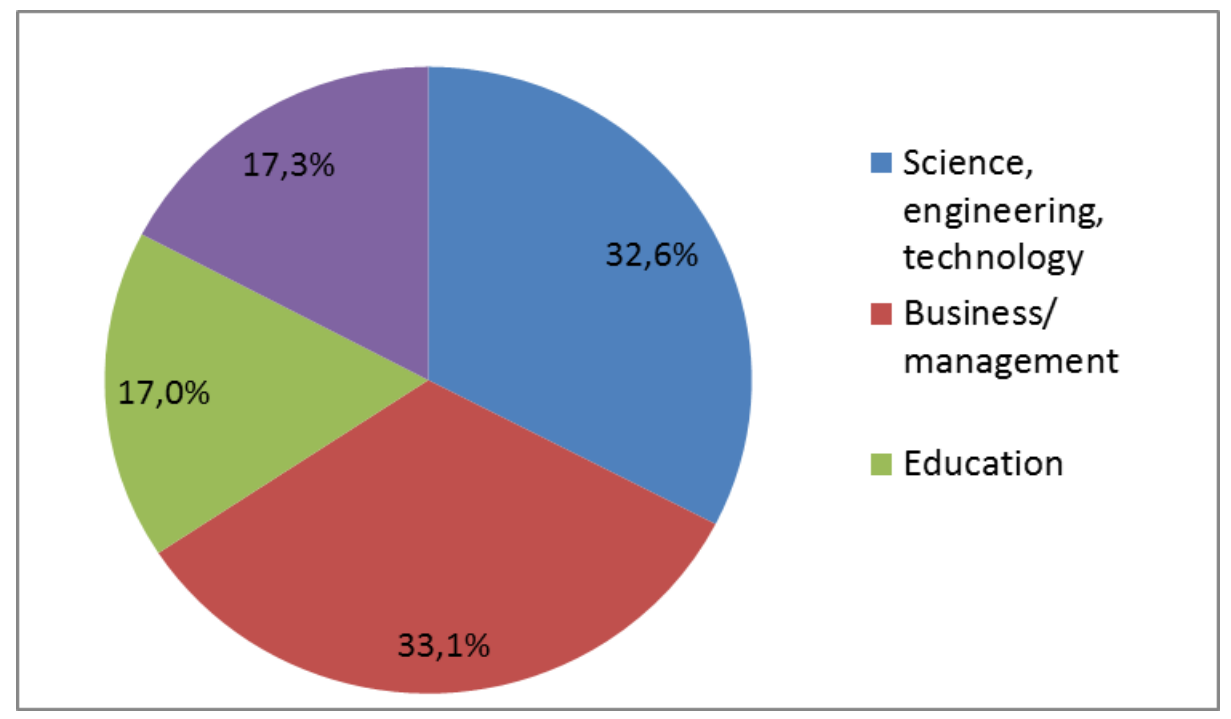


Since 2005, NMMU has been rapidly expanding its academic programmes into science and technology and business management. The proportion of SET programmes at NMMU rose from 18\% in 2001 to 32.6\% in 2010. NMMU now also offers programmes in the Built Environment and Information Technology, Health Sciences, and Law. The university offers a range of training from shortterm non-accredited or accredited courses to nationally recognised qualifications leading to employment or further education.

\subsubsection{Internal Governance and Management of NMMU}

Figure 7-1 NMMU Management Structure

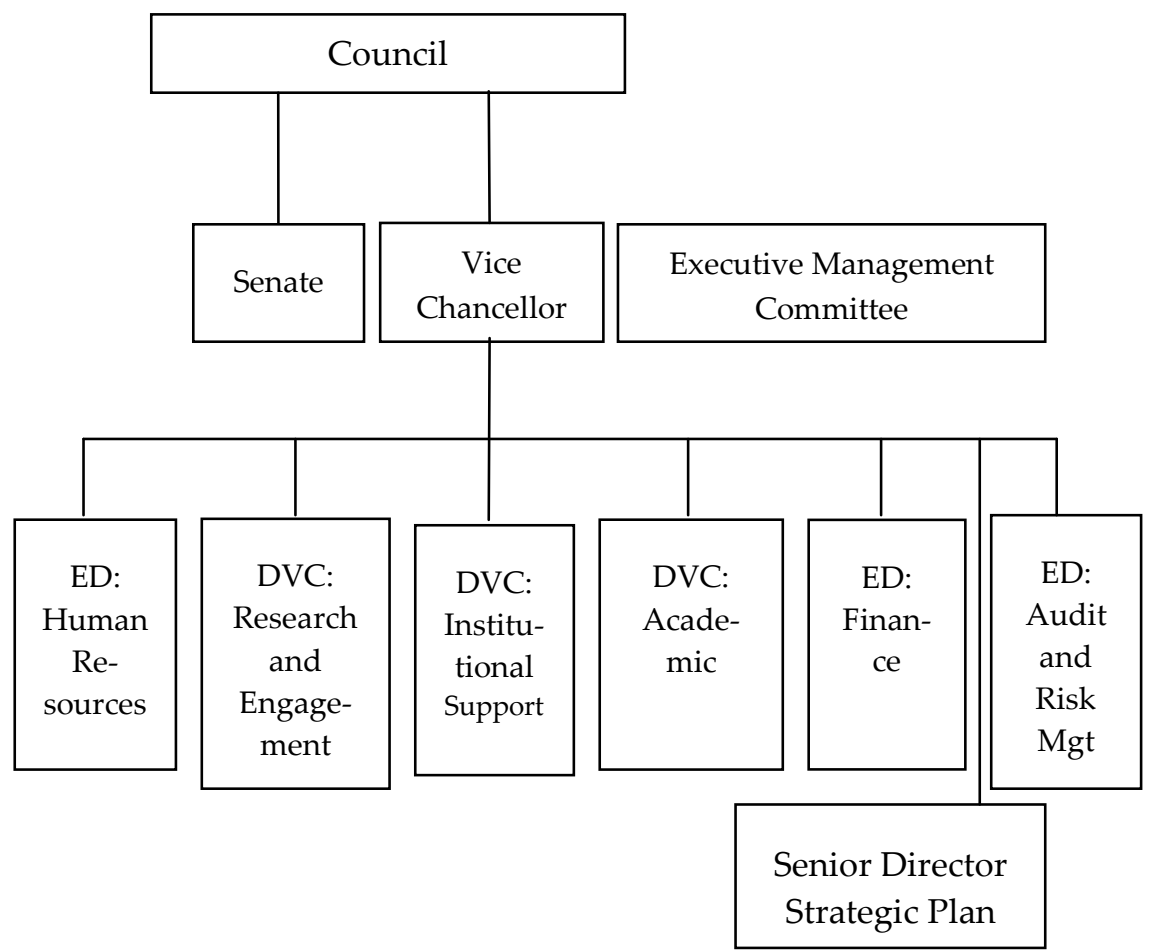

The Higher Education Act has implications for internal governance and management of NMMU (See Higher Education Act 101 of 1997 Article 26 No.2). The internal governance structures of NMMU include a governing council, senate, the university vice chancellor with an executive management committee, deputy vice chancellors, executive deans, department heads, and usually some form of student representation (see Act 101 of 1997 Article 26 No.2). Fig. 7.1 shows NMMU's internal governance and management structure. 
The Chancellor is the titular head of the University. The Council has responsibility for setting the mission and goals of the university, the approval of its policies and procedures, the oversight its resources, as well as an informed understanding of programmes and activities of NMMU (Statue 2006 Article 4 No.3; Act 101 of 1997). Members of the Council come from government, renowned professionals drawn from various fields of knowledge and experience, industry, the community, academic staff, and students. The Council has a number of committees with defined roles, for example, an executive committee, a governance committee, finance and facility committee, a human resources committee, an audit and risk committee, and a remuneration committee (NMMU's statute Article 15). The Vice-Chancellor is often a member of the above-mentioned committees. The senate is comprised of senior academics, executive management, executive deans, and other internal stakeholder representatives. The senate is responsible for academic matters and is accountable to the council. The senate appoints its executive committee and a faculty board for each faculty in order to undertake its functions properly.

Responsibility for operational matters and the day-to-day running of the university is vested in the Vice-Chancellor. The Vice-Chancellor is the academic head and chief executive and accounting officer of the university. He is responsible for the management and administration of the university. The ViceChancellor is accountable to the council on all matters pertaining to his key performance areas. He is responsible for allocating resources, formulating internal policies, structure and staff of the university, monitoring employee performance, and motivating and rewarding employees in accordance with the statute of the university. The Executive Management Committee assists the Vice-Chancellor in the management and administration of the university. This committee comprises of the Vice-Chancellor, deputy vice chancellors, the executive directors, Registrar, and Head of Organisation Transformation and Equity. The Executive Management Committee can establish committees, known as management committees, to perform any of its functions.

Like HU in Ethiopia and JKUAT in Kenya (see Chapters 5 and 6), NMMU typically maintains a 'deliberative' structure of committees for ensuring academic participation in organisational decision-making processes. The committee approach, in addition to improving access to information, plays a key role in building consensus that facilitates policy implementation. This web of interlocked central committees has become the heart of NMMU's capacity to steer itself.

The senior university leadership are linked to the academic departments by a chain of mid-level academic managers (deans or executive deans, directors). 
The university organises itself as seven faculties with seven executive deans who report to the Deputy Vice-Chancellor responsible for the academic affairs. The faculties contain diverse academic units, including a range of schools and/or departments (see Table 7.4). There are no schools in the Law and Health Sciences faculties. The George campus houses two schools: the School of Natural Resource Management (Saasveld) and the School of Business and Social Sciences (York Street Campus). There are two Campus Principals at Missionvale and George.

Table 7.4: Academic Entities

\begin{tabular}{ll}
\hline Academic Entities & Number \\
\hline 1. Faculties & 7 \\
1.1. Schools & 23 \\
1.1.1. Departments & 70 \\
2. Institutes & 4 \\
3. Centres & 8 \\
4. Units & 17 \\
\hline
\end{tabular}

Source: http://departments.nmmu.ac.za/ accessed on October 2013)

The academic managers at NMMU perform a number of academic related tasks under the supervision of the senate. They play a significant role in academic affairs such as curriculum, teaching and learning, and examinations, under the close guidance and approval of the senate. The mid-level academic managers also collect information on the performance of their colleges, faculties, schools or institutes. There are also a number of research and education committees (e.g. research, technology, and innovation (RTI) committee) at different levels. The university has a discipline-centred academic base that should be reasonably research-focused. Many academic departments are developing additional structures such as institutes, centres and units (Chart 7-16). This results in the co-existence of academic departments with various interdisciplinary entities, creating dual operating structures within the university in order to address external demands from stakeholders.

NMMU has created administrative units to assist with administrative tasks (e.g. a unit to assist academics with research applications; a department to deal with accountability requirements); technology and knowledge transfer offices; teaching and learning centres; and offices to advise students on career and other 
issues. A variety of non-academic \& support entities such as administration and management (12 offices), research support departments (4 offices), corporate and operations (15 offices, student-oriented departments (14 offices), centres (7 offices), and units (7 offices) have been established as non-academic administrative support offices (http://departments.nmmu.ac.za/Non-academic-support-entities accessed on 15 October, 2013). In the balance between central control and faculty or departmental autonomy in terms of financial, procurement and human resource management, NMMU is relatively centralised.

\subsubsection{Academic and Administrative staff at NMMU}

In 2010 NMMU had 1611 staff, of which 36\% were academic staff, 17\% were professional staff, and the remaining $40 \%$ were support staff. The administrative support staff of NMMU actually outnumbered their academic counterparts by a wide margin: 1: 1.89 in 2010. There were 574 academic staff who performed the basic work of education and research in 2010/11.

\section{Chart 7-5 Academic Staff Volume and Composition in 2010/11}

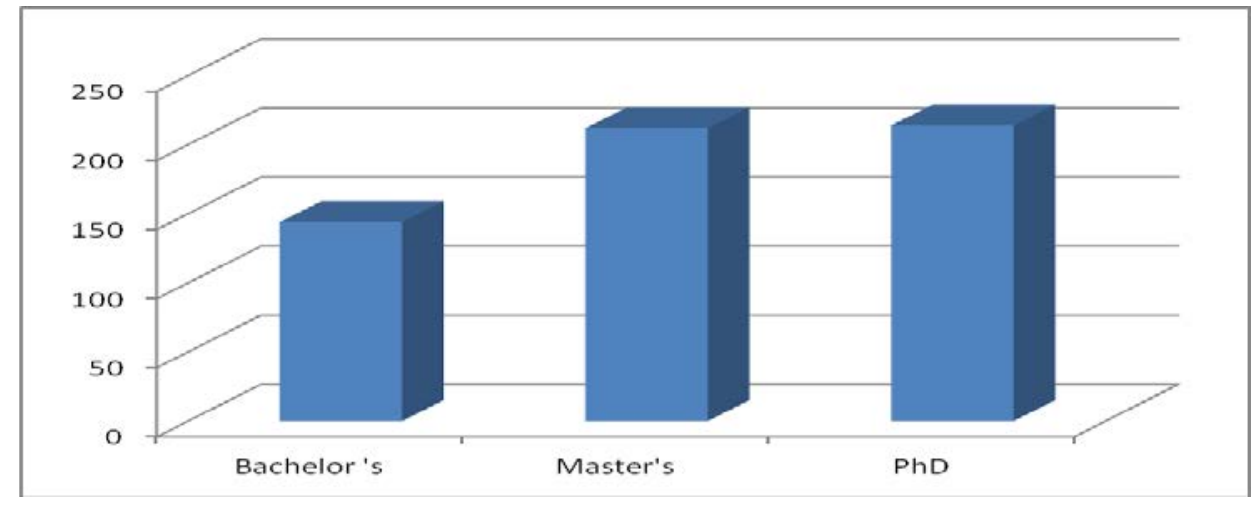

About $99 \%$ of academic staff were South African, while the remaining 7(1\%) were international staff. It is interesting to note that at NMMU, in South Africa which accounts for a large proportion of all research conducted by African universities, $38 \%$ of academic staff had doctoral degrees ${ }^{104}$ in 2011. This figure is below the average for universities which have a strong focus on research. $\mathrm{PhD}$ holders, by virtue of their training and educational attainments, are typically responsible for initiating and undertaking research, supervising graduate

104 The percentage of academic staff with Doctoral qualifications has increased from $31.2 \%$ in 2005 to $38 \%$ in 2011. 
students, and holding senior management positions. Data from NMMU showed that permanent staff with doctoral degrees produced $83 \%$ of research outputs. NMMU slightly exceeded the Higher Education Funding Framework benchmark for comprehensive universities of 0.93 weighted research outputs per permanent academic staff member per annum with a weighted research output of 0.95 in 2009 as compared to 0.77 in 2005.

In South Africa, the NRF rating is an important tool for steering the behaviour of academic staff. Only $12 \%$ of NMMU's permanent academic staff held NRF rating in 2011. The number of NMMU National Research Foundation (NRF) rated researchers has grown from 57 and 64 in 2009 and 2010 respectively to 66 in 2011. Although natural science is still the major contributor of rated researchers and aggregate research unit output, other faculties do contribute, as shown in Table 7.5 below.

Table 7.5: Number of Rated Researchers per Faculty/Division in 2011

\begin{tabular}{|c|c|c|c|c|c|c|c|}
\hline Faculty/Division & A & B & $\mathrm{C}$ & $\mathbf{P}$ & Y & L & TOTAL \\
\hline Arts & & & 4 & & & & 4 \\
\hline Business and Economic Sciences & & & 2 & & 1 & 2 & 5 \\
\hline Education & & & 3 & & & 1 & 4 \\
\hline $\begin{array}{l}\text { Engineering, the Built } \\
\text { Environment and Information } \\
\text { Technology }\end{array}$ & & 2 & 9 & & & 1 & 12 \\
\hline Health Sciences & & 1 & 2 & & & & 3 \\
\hline Law & & & 1 & & 1 & & 2 \\
\hline Science & 2 & 4 & 25 & & 1 & 2 & 34 \\
\hline $\begin{array}{l}\text { Higher Education Access and } \\
\text { Development Services }\end{array}$ & & & 1 & & & & 1 \\
\hline Sport Bureau & & & 1 & & & & 1 \\
\hline Total & 2 & 7 & 48 & 0 & 3 & 6 & 66 \\
\hline
\end{tabular}

CHET's research found that NMMU's ratio between doctoral graduates and permanent academic staff was $6.6 \%$ in 2007. Moreover, each permanent academic staff member currently publishes one research article every three years $(0.34$ per year). In 2010, 15(2.6\%) of the permanent academic staff were involved in commercialisation of research products. In 2011, NMMU was awarded four DST/NRF Research Chairs as part of the South African Research 
Chairs Initiative (SARChI). One of the key staffing issues is, according to one senior director, that more than $50 \%$ of staff are aged 45 or above, and an aging academic population is a point of concern for the university. Moreover, the rapid expansion of enrolment at NMMU has not been accompanied by an equivalent expansion in the number of academics, causing increased teaching loads for the academic staff.

The complexity, diversity, and specialisation of non-academic work has increased over time. NMMU therefore employed 1037 administrative support staff in 2010.

\section{Chart 7-6 The Proportion of Administrative Support Staff, by Category in} 2011

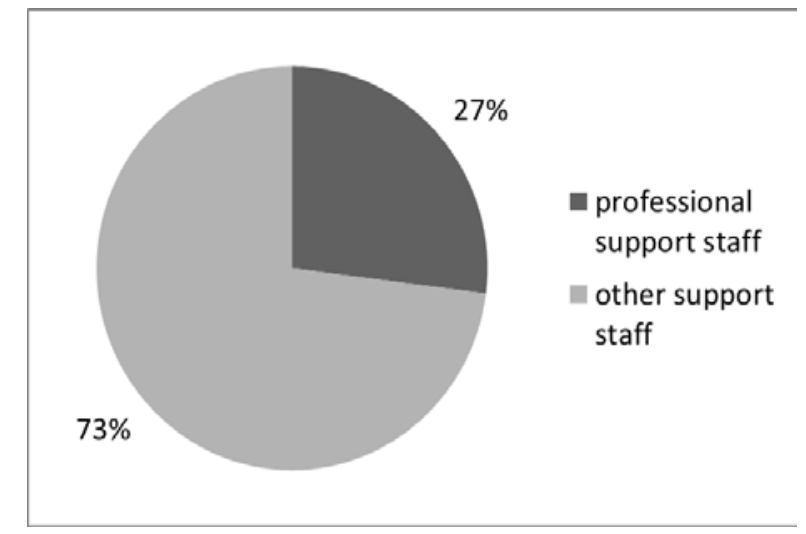

The university has also grown aware of the need for new professional management in the support offices to reduce the administrative burden on academics, and free them to concentrate on their core tasks. Although $27 \%$ of the administrative staff are professional support staff, several senior academics who could have been performing education and research tasks are still involved in administrative tasks. This has led to an increasingly blurred boundary between academics and administrators at NMMU.

\subsubsection{Non-Human Resources or Facilities at NMMU}

NMMU's non-human resources are rated as adequate by our interviewees. NMMU received the highest rating for its efforts to provide its students with a supportive campus environment including facilities and services such as career advising, student counselling, ICT-enabled learning, academic peer support, and so forth among higher education organisations participating in the assessment of campuses. Additionally, the University received the highest rating for its efforts to provide high-quality ICT services to support teaching 
and learning (the Council for Higher Education, 2009) and housing services in South Africa. In particular, the university has adequate research infrastructures in the areas of applied Chemistry, Process Development (InnoVenton), Friction Stir Welding, IT, health, and physics. Some of the important research support and facilities at the university include:

- The availability of the only high-resolution transmission electron microscope in Africa, funded by the National Research Foundation.

- The establishment of a new Chemical Fuels Technology Centre at InnoVenton, in collaboration with major industrial players including PetroSA, CSIR, and Sasol.

- Adequate research capacity in the area of Automotive Engineering (i.e. to design and develop a small racing vehicle).

- The Automotive Components Technology Station (ACTS) is currently involved in a multi-million rand research project in support of the local nuclear industry, which could result in reduced costs and increased reliability through research aimed at developing specialised platforms for using friction stir welding as a possible weld repair procedure.

However there are areas where more investment is urgently required. According to one senior director, half of NMMU's lecture venues are not technology-enabled and a large proportion of laboratory equipment is ageing.

\subsubsection{Sources of Finance for NMMU}

The funds of NMMU consist of funds allocated by the government, and revenue raised from other nongovernment sources such as donations or contributions, loans and overdrafts, income derived from investments and money received for services rendered to stakeholders (see Article 40 of Act 101 of 1997). The South African government subsidises NMMU directly but the university received significant revenue from other sources. The status of revenue generation at NMMU is discussed in detail in Section 7.6. 
Table 7.6: Recurrent Budget by Source R'000

\begin{tabular}{|c|c|c|c|c|c|}
\hline Revenue & 2006 & 2007 & 2008 & 2009 & 2010 \\
\hline $\begin{array}{l}\text { State } \\
\text { appropriations }\end{array}$ & 428,663 & 470,458 & 462,072 & 495,973 & 560,056 \\
\hline $\begin{array}{l}\text { Tuition and other } \\
\text { fee income }\end{array}$ & 228,939 & 251,808 & 278,312 & 328,552 & 382,828 \\
\hline $\begin{array}{l}\text { Income from } \\
\text { contracts for } \\
\text { research }\end{array}$ & 21,692 & 25,679 & 46,477 & 61,787 & 71,438 \\
\hline $\begin{array}{l}\text { Sales of goods \& } \\
\text { services }\end{array}$ & 31,447 & 34,488 & 29,532 & 29,646 & 32,990 \\
\hline $\begin{array}{l}\text { Private gifts and } \\
\text { grants }\end{array}$ & 75,861 & 111,768 & 156,165 & 152,298 & 205,232 \\
\hline $\begin{array}{l}\text { Interest \& } \\
\text { dividends }\end{array}$ & 26,731 & 51,409 & 91,082 & 77,858 & 54,589 \\
\hline $\begin{array}{l}\text { Total Recurrent } \\
\text { Revenue }\end{array}$ & 813,333 & 945,610 & $1,063,640$ & $1,146,114$ & $1,307,133$ \\
\hline
\end{tabular}

Source: NMMU (2011)

The amount of nongovernmental funds at NMMU is higher than the governmental contribution, and the role of government in terms of financing the university is gradually diminishing. NMMU can be described best as a "publicly supported university" or a "privately funded public university".

No capital budget has been given to NMMU in recent decades. The university identified a blockage in the maintenance of buildings and expensive teaching and research equipment as one of its developmental challenges (NMMU, 2008). In the financial data, we were unable to include nonmonetary (in-kind) and immaterial resources. In general, the surplus/deficit indicators of NMMU suggest that the university has achieved financial health in the last four years (2008-2011). We shall return to this issue in section 7.6.

\subsection{The External Environment of Nelson Mandela Metropolitan University}

This part of the chapter presents the findings of the data analysis concerning the external environment of the South African case study university. This is a continuation of sections 7.2 and 7.3. In this section, we closely explore the 
immediate or task environment of NMMU to identify the external stakeholders of the university; and determine stakeholder salience in terms of regulatory powers and funding, as perceived by the interview respondents (see Tables 4.3 and 4.4).

\subsubsection{The External Stakeholders of NMMU}

Several stakeholders operate in the task environment of NMMU as regulators, suppliers, customers, and competitors. Table 7.7 below presents the external stakeholders in NMMU.

Table 7.7: Key External Stakeholders in NMMU

\begin{tabular}{ll}
\hline Governmental Stakeholders & Other Stakeholders \\
\hline $\begin{array}{l}\text { National Planning Commission and } \\
\text { the Department for Performance }\end{array}$ & Students and their families \\
Monitoring and Evaluation & \\
Department of Higher Education and & Donors (bilateral and multilateral) \\
Training (DHET) & \\
Council on Higher Education (CHE) & Professional associations \\
South African Qualifications Agency & NGOs \\
(SAQA) & \\
Department of Science and & Private higher education institutions \\
Technology (DST) & \\
Department of Trade and Industry & Private sector (i.e.; business and \\
(DTI) & industry) \\
Department of Economic & \\
Development & \\
Department of National Treasury & \\
Ministry of Labour & \\
National Research Foundation & \\
Local and provisional authorities & \\
Public research institutes & \\
Other public post-secondary & \\
institutions/Universities &
\end{tabular}


One common characteristic of the stakeholders is that they exert some sort of pressure on the actions, and behaviour of the universities in order to promote their own demands and expectations. However not all stakeholders are equally powerful and important in issuing sanctions and offering rewards for the universities. In explaining who really matters and what counts to NMMU, we analyse stakeholder salience in terms of regulatory powers and funding in the following subsections.

\subsubsection{Stakeholder Salience in Terms of Regulatory Powers}

The study documents that universities in South Africa are steered by government agencies and other stakeholders such as donors and professional associations. The degree of importance of the three regulators of NMMU as perceived by the interview respondents is shown in Table 7.8.

Table 7.8: Stakeholder Salience in terms of Regulatory Powers of NMMU

\begin{tabular}{ll} 
Stakeholder & $\begin{array}{l}\text { Degree of salience } \\
\text { (most, more, salient, less) }\end{array}$ \\
\hline Government & Most Salient \\
Donors & Salient \\
Professional associations & Salient \\
\hline
\end{tabular}

The South African government represents all stakeholders that are categorised under 'public authorities' in Table 7.7. However, as stated in section 7.3.3, the Department of Higher Education and Training (DHET), NQF ${ }^{105}$, the SAQA, and the CHE (see NQF Act 67 of 2008) are the most important public authorities in steering the South African higher education system to intended directions. The South African government uses a number of regulatory frameworks and policies (see Table 7.9 below) to influence the behaviours and actions of NMMU.

${ }^{105}$ Higher education qualifications occupy six levels of the NQF, namely, levels 5 to 10. Levels 5 to 7 comprise undergraduate qualifications (with the exception of the professional Bachelor's degree at Level 8) and levels 8 to 10 accommodate postgraduate qualifications. 
Table 7.9: Key Regulatory Framework for NMMU

\begin{tabular}{|l|l|}
\hline Higher Education Act 101 of 1997 & $\begin{array}{l}\text { National Development Plan Vision } \\
2030\end{array}$ \\
\hline $\begin{array}{l}\text { National Qualifications Framework } \\
\text { Act } 67 \text { of } 2008\end{array}$ & $\begin{array}{l}\text { Medium Term Strategic } \\
\text { Frameworks (MTSF) of 2004-2009 } \\
\text { and 2009-2014 }\end{array}$ \\
\hline $\begin{array}{l}\text { Higher Education Quality Framework } \\
\text { of Government Notice No.928 of 2007 }\end{array}$ & $\begin{array}{l}\text { Technology and Innovation } \\
\text { Strategy }\end{array}$ \\
\hline $\begin{array}{l}\text { Skills Development Act No. 97 of 1998 } \\
\text { The Human Resource } \\
\text { Development Strategy of South } \\
\text { Africa 2010-2030 }\end{array}$ \\
\hline $\begin{array}{l}\text { National Industrial Policy Framework } \\
\text { (2007) }\end{array}$ & $\begin{array}{l}\text { National Research Foundation Act } \\
\text { No 23 of 1998) }\end{array}$ \\
\hline
\end{tabular}

NMMU is required to demonstrate conformity with these laws and policies in order to acquire legitimacy for its behaviour and the outcomes of its actions, thus sustaining its operation and securing a regular flow of public resources. One of the key regulation tools is the Higher Education Act 101 of 1997. This Act is analysed below in order to explore the autonomy of NMMU.

\subsubsection{The Higher Education Act 101 of 1997 and Organisational Autonomy}

The South African government directly regulates its universities through the Higher Education Act 101 of 1997. The Higher Education Act allows public universities to be involved in revenue generation (see Higher Education Act 101 of 1997 Article 40). This law defines NMMU's level of autonomy, which determines the capacity of NMMU to generate additional revenue. The level of autonomy is analysed in the four dimensions of organisational autonomy (see Table 4.4), to show the link between revenue generation and the degree of organisational autonomy as perceived by the interviewees and shown in the documentary evidence. This is shown in Table 7.10 below. 
Table 7.10: Academic Autonomy of NMMU

\begin{tabular}{lc}
\hline Aspect & Autonomy \\
\hline $\begin{array}{l}\text { Freedom to select and admit students (both } \\
\text { undergraduate or postgraduate) }\end{array}$ & Yes \\
$\begin{array}{l}\text { Freedom to decide on overall student numbers } \\
\text { Freedom to introduce degree programmes }\end{array}$ & Yes \\
Freedom to terminate degree programmes & Yo \\
$\begin{array}{l}\text { Freedom to design content/ standards \& curricula for } \\
\text { programmes }\end{array}$ & No \\
$\begin{array}{l}\text { Freedom to decide modes of instruction and delivery } \\
\text { Ability to charge tuition fees }\end{array}$ & Yes \\
Ability to set priorities for research & Yes \\
$\begin{array}{l}\text { Freedom to determine charging levels for research and } \\
\text { consultancy works }\end{array}$ & Yes \\
Freedom to generate revenue from research & Yes \\
\hline
\end{tabular}

The South African government sets out the minimum admission requirements for university education (i.e. Higher Certificate, Diploma and Degree studies) and requires the NC (V) Level 4. Although the introduction of new academic programmes requires approval by public authorities in South Africa, most respondents did not see this as a barrier to revenue generation.

NMMU's level of financial autonomy is shown in Table 7.11 below.

Table 7.11: Financial Autonomy at NMMU

\begin{tabular}{lc}
\hline Aspect & Autonomy \\
\hline Generation and deployment of monetary resources & Yes \\
Ability to keep surplus & Yes \\
$\begin{array}{l}\text { Ability to charge tuition fees for government sponsored } \\
\text { students }\end{array}$ & Yes \\
$\begin{array}{l}\text { Ability to charge tuition fees for nongovernment } \\
\text { sponsored students }\end{array}$ & Yes \\
Lump-sum or block grant funding & Yes \\
Pricing of research \& consultancy services & Yes
\end{tabular}




\begin{tabular}{lc}
\hline Aspect & Autonomy \\
\hline Ability to own buildings & Yes \\
Ability to borrow money & No \\
Ability to lease of university facilities & No \\
\hline
\end{tabular}

Table 7.12 below presents NMMU's perceived degree of autonomy in the dimension of staffing.

Table 7.12: Autonomy with respect to staffing

\begin{tabular}{lc}
\hline Aspect & Autonomy \\
\hline Freedom to decide on recruitment procedures & Yes \\
Freedom to decide on promotion of academic staff & Yes \\
Freedom to decide on promotion of administrative staff & No \\
Freedom to decide on dismissal of staff & Yes \\
Freedom to set pay for academic staff & No \\
Freedom to set pay for administrative staff & No \\
Freedom to set working conditions for university staff & Yes \\
\hline
\end{tabular}

In terms of organisational autonomy, NMMU has been granted autonomy with respect to internal governance. The university is free to decide on its internal governance and decision-making structures and/or is free to introduce new academic structures (faculties, departments, research centres). Under the Higher Education Act 101 of 1997, the South African case study university enjoys considerable autonomy in terms of internal governance, financial autonomy and academic autonomy. However its staffing autonomy is very limited.

\subsubsection{Other Regulation Tools Used by Donors and Professional Organisations}

Donors and professional organisations shape NMMU indirectly. The influence of donors on the South African higher education system, although limited, comes through international institutions like the World Bank, IMF, WTO, and the like (Ouma, 2007). Higher education has increasingly become a (private) good that is subjected to the conditions of the GATS agreements. Reporting on donors' influence on public universities in South Africa, Ouma (2007) indicated that it is more normative than coercive. Several professional associations which 
are registered by the SAQA (National Qualifications Framework Act No. 67 of 2008 Article 13i (i-ii)) seek to further their particular professions by upholding the relevance and quality of programmes, and by maintaining and enforcing standards of training and ethics in their professions.

\subsubsection{Stakeholder Salience in Terms of Funding at NMMU}

Table 7.13 below depicts stakeholder salience on the basis of the magnitude of the (potential) resources provided to NMMU, as perceived by the university interviewees.

Table 7.13: Stakeholder Importance in Terms of Funding at NMMU

\begin{tabular}{ll}
\hline Stakeholder & $\begin{array}{l}\text { Degree of salience (four scales: } \\
\text { most, more, salient, less) }\end{array}$ \\
\hline $\begin{array}{l}\text { Public Authorities } \\
\text { Students (and their parents) }\end{array}$ & Most \\
$\begin{array}{l}\text { Donors (bilateral and multilateral) } \\
\text { Ministries, provisional and Local } \\
\text { authorities }\end{array}$ & Salient \\
Business \& Industry & More \\
\hline
\end{tabular}

The government of South Africa is the most important funder of NMMU. In 2010 , for instance, about $43 \%$ of the university's total budget came directly from the government. The second most important stakeholder in NMMU, in terms of funding, is the students. In 2010, about 30\% of NMMU's total recurrent revenue was received in the form of tuition fees (see Table 7.6). Since the demand for university education is expected to grow in South Africa (see Section 7.5.2), revenue from student tuition fees is projected to rise proportionally in the future. Several student support schemes, including the NSFAS, facilitate poor and disadvantaged but academically able students in gaining access to higher education. Students and their families also share the burden of higher education costs through the payment of tuition fees, or by covering some of the student's living costs.

Donors are the third important stakeholder in NMMU, because of their capacity to influence regulations and funding. In 2010, private gifts and grants accounted for $16 \%$ of NMMU's total recurrent revenue (see Table 7.6). Several bilateral and multilateral donors contributed to financing higher education in South Africa. Between 2001-06, for instance, the annual average direct and 
indirect commitments for higher education in South Africa were US\$ 17.4 million and US\$ 3.1 million respectively (World Bank, 2010: 98). Additionally, since 2000, seven American foundations, the Ford, Carnegie, Rockefeller, MacArthur, Hewlett, Mellon, and Kresge foundations, and the Partnership for Higher Education in Africa have made significant investments in African universities including those in South Africa. Between 2000 and 2008, for instance, the partnership foundations contributed an aggregate of US\$354 million towards higher education initiatives in seven countries from which the South African higher education system greatly benefited (World Bank, 2010).

The South African government has increasingly recognised the important role of universities in regional and national development. The growing recognition of universities as economic engines has the potential to put NMMU in the spotlight and bring the university closer to industry. Government policies and other financial schemes have been encouraging the university to interact more closely with provisional authorities and local communities to stimulate the socio-economic development of the country. South Africa's MTSF 2009-2014 provides examples of this strategy, aimed at stimulating regional socioeconomic development. There are now opportunities for interactions through teaching, research, short courses, consultancy, and other forms of 'service'. Ministries, provisional and local authorities may choose a university as the first candidate for offering services in terms of capacity building and short-term training. Increased demand for retraining and retooling employees in business or government represents a potential source of revenue for NMMU. Various governmental and industrial actors have special funds for this.

In South Africa, several opportunities for collaborations between universities and industry are available in the areas of promoting problem-solving, knowledge transfer and product development, tailor-made short-term training, research and consultancy, and joint R\&D (NMMU, 2008). In this regard, the Ten-Year Innovation Plan of DST (DST 2008) proposes transforming South Africa's resource-based economy into a knowledge-based economy, in support of the government's broad developmental agenda. This may be achieved through, among other things, human capital development, knowledge generation and exploitation (R\&D), and knowledge infrastructure to connect research results and socio-economic outcomes (ibid, viii-6). NMMU has been benefiting from this policy direction and from the economic environment of South Africa, which is characterised by both a considerable number of multinational industrial firms, and a growing number of small and mediumsized firms. 


\subsection{Revenue Generation by the South African Case Study University}

This section closely analyses the interdependence between NMMU and its environment in the process of resource exchanges. First, it presents the volume of resources that the university received from each resource provider from 2006 to 2010 and briefly discusses what the resource providers received in return for their resources. Second, it presents the findings of data analyses concerning drivers for revenue generation. The final part of the section explores key enablers for and barriers to revenue generation at NMMU.

\subsubsection{Status of Revenue Generation at NMMU}

Revenue raised from nongovernmental sources increased between 2006 and 2010, as shown in Chart 7-7 below.

\section{Chart 7-7 Revenue from Nongovernmental Sources as a Percentage of} Recurrent Budgets

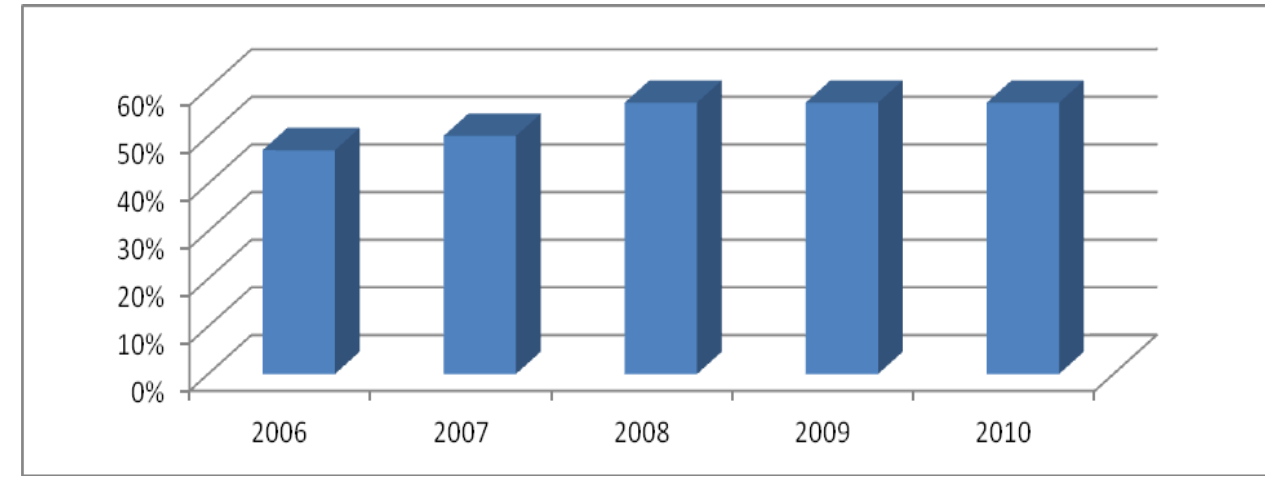

The volume of nongovernmental revenue at NMMU has been greater than its direct public funding since 2008. However, direct public funding continues to be the most important and predictable revenue source for the university. In return for resources from its resource providers, the university offers educational services including short courses, commercialises research and consultancy services, and sells other non-academic services. According to NMMU's Vision 2020, the university's financial position reflects a healthy balance sheet with sufficient reserves underpinned by positive cash flows and the anticipated generation of a R1 billion endowment fund by 2020. These reserves grow with fair returns on investments through a conservative investment approach to support deferred maintenance, replacement of assets and infrastructure. Revenue streams are diversified to ensure that NMMU is not totally reliant on government subsidies and fees. 
Students' financial contributions represent a significant revenue source at NMMU. From 2006 to 2010, growth in revenue from tuition fees fluctuated, as shown in Chart 7-8.

Chart 7-8 Revenue from Education Services as a percentage of Nongovernmental Revenue

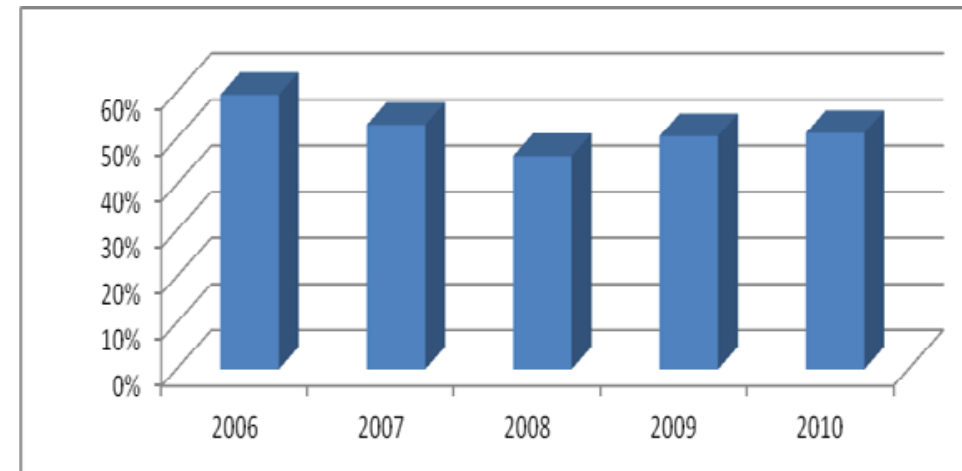

Many interviewees believe that student financial contributions are a feasible alternative to state support as they are predictable under the current huge demand for higher education in South Africa and other countries in the region (see Section 7.5.2). This source also enables the university to invest in its core missions.

One of the strategic objectives of NMMU, outlined in Vision 2020, is to increase and diversify the external and internal financial resources available to support research-related activities. Chart 7-9 indicates that revenue earned through research and consultancy services represents around one third of total nongovernmental revenue in 2010 and this grew consistently from 2006 to 2010.

Chart 7-9 Revenue from Research and Consultancy Services as a Percentage of Nongovernmental Revenue

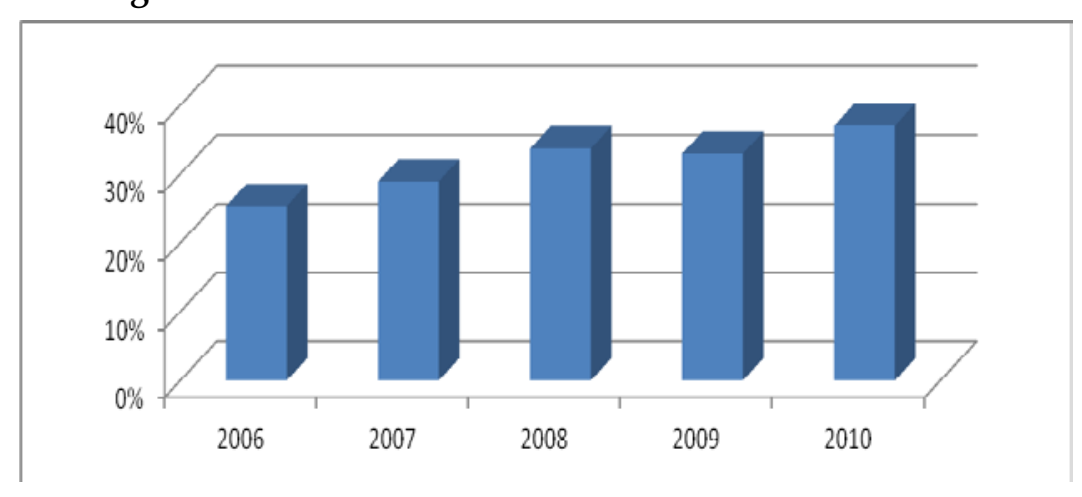


In Chart 7-9, we have included all revenue earned through contract research, and private gifts and grants. NMMU's vibrant research tradition or a tradition of cutting-edge scientific research and development are the main reasons for such an achievement for acquiring revenue from research outcomes. According to CHET (2010:120), for instance, NMMU had the equivalent of USD 7,600 in research funding per permanent academic staff member in 2007. Research output units have also shown grown in recent years, from 224.01 units in 2009 to 255.51 in 2010. Between 2010 and 2012, NMMU's research output subsidy, a crucial benchmark for research performance, grew from R59 million to R78 million in 2012 (NMMU, 2012). This is because of an increase in publications in ISI and IBSS indices from 116 in 2010 to 189 in 2011.

NMMU received about $10 \%$ of its nongovernment budget (see Chart 7-10 below) by providing non-academic services and products such as renting out university facilities and retail business (sales of goods and services).

Chart 7-10 Revenue from Non-academic Services as a Percentage of Nongovernmental Revenue

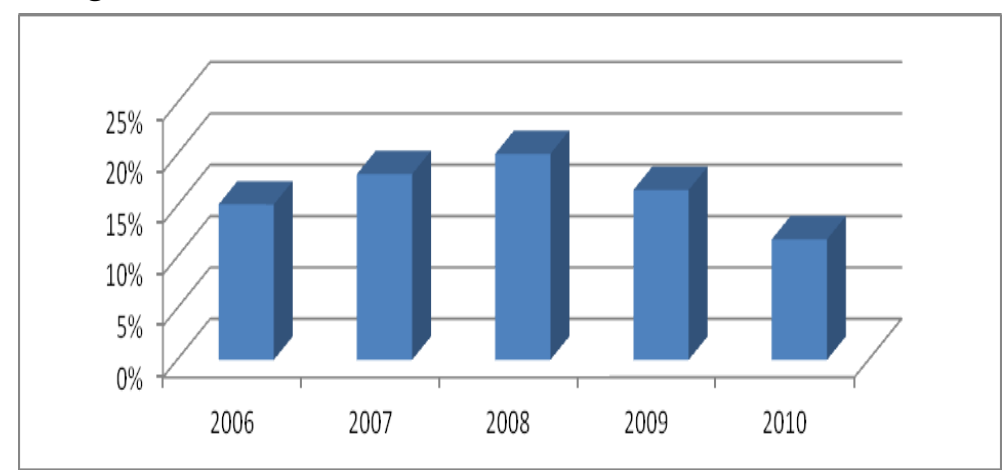

Although NMMU promotes a full cost policy for revenue generation from nonacademic services, this policy is not enforced. There is a general perception among the academic community that activities where the university community is a direct beneficiary have to be heavily subsidised.

\subsubsection{Drivers for Revenue Generation}

The general socio-economic and political context of South Africa is an important driver for revenue generation at NMMU. The basic thrust of the Presidency's Medium Term Strategic Framework (MTSF) for 2009-2014 is to improve the conditions of life for all South Africans through identifying opportunities for new areas of growth and economic participation and progressively setting the country on a higher and more sustainable growth 
trajectory. According to the South African Vision 2030, South Africa has highlevel skills shortages or a so-called 'skills deficit', which constitutes a significant constraint to ensuring a knowledge-based economy (see also NMMU, 2008:2). A firm emphasis on strengthening the human resource base of the country by ensuring a broad-based focus on developing education, skills and training initiatives at all levels is one of the strategic priorities identified in the MTSF. The strategic plan (2010/11-2014/15) of the Department of Science and Technology (DST) has identified the need to increase the number and improve the equity profile of honours, master's, doctoral and postdoctoral graduates in an attempt to contribute to developing the next generation of researchers and academics in South Africa. The internationalisation policy has also provided opportunities for the university to expand its activities, for instance, fostering "cross border" research collaboration, which has become an important way of increasing income in recent years.

Developmental policies in South Africa (see Table 7.9) drive certain types of exchange and cooperation, for instance, between academia and other sectors, which also has an effect on revenue generation by universities. The South African higher education system is urged to fulfil a crucial role in producing higher-level trained human resources that may sustain development in the country and the African continent. The DHET strategic plan indicates that South Africa should become a preferred destination for international students and staff, particularly those wishing to pursue postgraduate studies and research. Similarly, the International Education Association of South Africa (IESA) encourages universities in South Africa to exploit increasing opportunities for the recruitment of international students. IESA states that this can be facilitated through the integration of international and intercultural elements into higher education's core business in a manner that addresses national needs and strengthens institutional curricular and outreach programmes, inter alia. All these critical policies drive NMMU to engage in revenue generation.

In the South African higher education setting, pressure on public budgets leads to reductions in public funding related to capital investment in NMMU (see NMMU, 2008). This is the most widely mentioned driver for revenue generation for the university. Public universities are at the stage of believing that public funding alone will not be sufficient to respond to the growing demand for access to higher education while delivering a level of quality that provides students with the skills necessary to succeed in current and future labour markets. There is now a widespread consensus among the academic community that heavy dependence on a single funder (e.g. public funding) is risky. Distrustful views on how teaching and research funding will evolve in 
the future also reinforce the perception that spreading risks is crucial. Risk mitigation is a powerful driver for the strategic pursuit of new funding sources for NMMU. Revenue generation is thus part of a strategy to make funds available for academic development, be it teaching or research activities.

Revenue generation supports the expansion of the university's missions by providing new resources to enable the achievement of new or existing tasks. In today's South Africa, public universities are asked to strive for excellence in teaching, research and innovation, by offering opportunities to diverse groups of learners, and providing the optimal creative environment for the talented young researchers. As discussed earlier, these increased expectations are often not matched with significant additional revenue. The South African case study university provides an example of mission expansion dependent on the generation of third party funding. For instance, income derived from tuition fees has also allowed the university to create research support positions on a permanent basis, something that is difficult to achieve exclusively through projects of limited duration. Essentially, the development of the research mission of the university seems to depend on the university's ability to obtain more leeway in its staff expenditure and unblock funds with no strings attached.

A strong motivation for NMMU to diversify its income also lies in wishing to avoid the administrative burden that often comes with public funding. Revenue generated through commercial or fundraising activities is perceived as being comparatively easier to manage and can be allocated internally without restrictions. Several interviewees mentioned that, earned revenues often lead to rationalised and simplified funding modalities, which in turn foster revenue generation as there is no deterrent from multiple and complex requirements. Finally, revenue generation may also enhance the competitiveness of the South African case study university.

\subsubsection{Factors that Enable or Hinder Revenue Generation at NMMU}

In this subsection, we identify the environmental factors and university specific conditions that enable or obstruct revenue generation at the South African case study university. First, we analyse the environmental factors that enable or hinder revenue generation at NMMU, followed by the university specific factors. 


\subsubsection{Environmental Factors that Enable or Hinder Revenue Generation at NMMU}

The South African government plays a key role in supporting revenue generation by providing the right framework conditions. The legal recognition of revenue generation as one of the legitimate roles of public universities in South Africa in Act 101 of 1997 is an important step forwards for revenue generation. Universities' capacity to generate additional revenue is related to the degree of autonomy granted by this act (see section 7.5.2.1). The findings on the degree of autonomy at NMMU show that the university enjoys significant autonomy in organisational, financial, and academic dimensions. In particular freedom in the generation and deployment of monetary resources, the block grant funding system, the ability to charge tuition fees, freedom to set the price of research \& consultancy services and freedom in the recruitment and promotion of academic staff are some key enablers for revenue generation. Nonetheless, the university's autonomy in staffing matters is limited. NMMU is unable to set the salary levels of its academic and administrative staff. Nor is it able to borrow money from financial markets. These are key barriers to revenue generation for NMMU. They often impede the university's capacity to make the necessary large-scale initial investment to engage in large-scale revenue generation activities.

Public authorities and other external stakeholders, particularly the South African government, enable or hinder NMMU's revenue generation strategies through policies and funding modalities. The existence of national incentives for education and research enables certain types of cooperation between the university and other stakeholders in the environment. The South African Ten-Year Innovation Plan (DST 2008) states that progress towards a knowledge-based economy is driven by four elements: human capital development, knowledge generation and exploitation (R\&D), knowledge infrastructure, and enablers to address the "innovation chasm" between research results and socio-economic outcomes. Concerning university education, one of the most important factors that pushes students to obtain a university degree is their higher chance of employment after receiving university degrees. The unemployment rate for those with university degrees is only $3 \%$, for those with matric it is $28 \%$, but for those without matric it is over $60 \%$ (NMMU, 2008).

Among the strategic priorities identified in the MTSF for 2009-2014 is strengthening the human resource base of the country by ensuring a broadbased focus on developing education, skills and training initiatives at all levels to overcome the country's current 'skills deficit'. Importantly, South African universities in general and NMMU in particular have huge opportunities, 
arising both locally and internationally, for expanding access to higher education. Locally, the progress achieved in the pre-higher education system (i.e.; General Education and Training (GET) ${ }^{106}$, also known as compulsory education (Grades 1-9), and Further Education and Training (FET) ${ }^{107}$ or noncompulsory education (grades 10-12)) offer more opportunities for expanding undergraduate education (see Section 3(1) of the South African Schools Act of 1996). There were 12.3 million learners in ordinary schools ${ }^{108}$ (Department of Basic Education, 2013) in 2011. The Eastern Cape Province, where the South African case study university is situated, contributes $16 \%$ of the total learners, and about $22 \%{ }^{109}$ of the ordinary schools are found in this province. The gross enrolment ratios of the GET band (grades R-9) and the FET band (grades 10-12) were $92 \%$ and $80 \%$, respectively in 2011. The South African pre-higher education system will have to expand to achieve universal GET and FET. Vision 2030 suggests that in the future about $80 \%$ to $90 \%$ of every cohort of learners will successfully complete the full 21 years of schooling, of whom $80 \%$ successfully pass the exit exam by 2030 . This will lead to increasing demand for university education, from which NMMU can generate revenue.

Vision 2030 also outlines plans to increase the higher education participation rate to more than $30 \%$, double the number of scientists and increase the numbers of African and female postgraduates, especially at $\mathrm{PhD}$ level, and improve research and innovation capacity. The National Plan for Higher Education set a goal of $20 \%$ participation by 2016 . In 2030, $75 \%$ of university academic staff are expected to hold $\mathrm{PhDs}$, since $\mathrm{PhD}$ graduates, as staff or postdoctoral fellows, are the dominant drivers of new knowledge production within the higher education and science innovation system. The ageing profile of the professoriate in South Africa and for the "brain drain" caused by the emigration of highly skilled academics and researchers is an important driver for expanding postgraduate education. The launch of a variety of undergraduate programmes at both private and public HEIs offers more opportunities for expanding postgraduate studies. A larger share of the working population also needs to refresh their skills and knowledge through short-term courses, due to the rapid expansion of knowledge itself. This has created huge opportunities for

106 The GET includes: foundation phase (Grades R to 3), intermediate phase (Grades 4 to 6), and senior phase (Grades 7 to 9).

107 The FET means all learning and training programmes leading to qualifications from levels 1 to 4 of the South African National Qualifications Framework (NQF). It includes grades 10 to 12 and learners in FET colleges.

108 All schools from grades $\mathrm{R}$ or 1-12

109 The highest percentage (24\%) were found in KwaZulu- Natal followed by the Eastern Cape with $(22 \%)$, while the Northern Cape had the lowest number of schools in 2011. 
short-term courses and refresher programmes. These are crucial in providing improved opportunities for lifelong learning and continuous professional development for a diverse range of learners, through diversifying the current modes of delivery and intensifying strategies to implement blended or electronic learning (NMMU, 2008).

The DHET strategic plan indicates that South Africa should become a preferred destination for international students and staff, particularly those wishing to pursue postgraduate studies and research (see International Education Association of South Africa (IESA). The South African universities now see admitting international students (particularly from SADC countries) both as a means to grow their revenue sources and to increase their reputation and quality (NMMU, 2008:14-16). NMMU will have to continue recruiting talented international students and staff in an effort to harness these benefits.

Despite having huge student population seeking educational services, the poor quality of schooling received by a significant section of the population leading to poor student preparedness ${ }^{110}$ has been reported as one of the barriers to revenue generation. It also limits access to higher education in South Africa (CHET, 2010:22). The Eastern Cape, from where NMMU's student population is predominantly drawn (e.g. about $71 \%$ in 2009) is known for its poor schoolleaving certificate results. Student success rates are below the national benchmark of 80\% (NMMU's Vision 2030). Schools in South Africa are ranked into quintiles ${ }^{111}$ based on the resources available to them, starting with Quintile 1 (the poorest schools) and up to Quintile 5 (the best-resourced schools). In this scale, $42.8 \%$ of all schools in the Eastern Cape were in Quintiles 1 and 2, while only $28.6 \%$ were in Quintiles 4 and 5 in 2009.

110 The South African education system was racially segregated and highly unequal in terms of intra-racial budgetary and resource allocations. As a result, historically white schools had the advantage of decades of infrastructural investment and access to well-trained and qualified teachers, while high teacher-pupil ratios, unqualified and under-qualified teachers and a lack of books, libraries and laboratories characterised historically black schools.

111 The quintile ranking takes into consideration factors like income level, unemployment rate, and the level of educational attainment (literacy rate) of the surrounding community. 
Table 7.14: Levels of Achievement in Matric Examinations

\begin{tabular}{lcccc}
\hline Area & $\begin{array}{c}\text { National } \\
\text { Senior } \\
\text { Certificate } \\
\text { (NSC) }\end{array}$ & $\begin{array}{c}\text { Higher } \\
\text { Certificate } \\
\text { (HC) }\end{array}$ & Diploma & $\begin{array}{c}\text { Bachelor } \\
\text { degrees }\end{array}$ \\
\hline $\begin{array}{l}\text { Eastern } \\
\text { Cape }\end{array}$ & $0.3 \%$ & $32.4 \%$ & $40 \%$ & $27.3 \%$ \\
$\begin{array}{l}\text { South } \\
\text { Africa }\end{array}$ & $0.20 \%$ & $28 \%$ & $39 \%$ & $33 \%$ \\
\hline
\end{tabular}

Table 7.14 indicates that the Eastern Cape is delivering more HC and Diploma passes than the national average, and well below the national average for Bachelor's degree passes.

The South African government influences revenue generation through the modalities under which it delivers funding to universities. Most of the HE budget from the national treasury (see section 7.3.4) is set aside for funding the National Student Financial Aid Scheme (NSFAS). The NSFAS provides a sustainable financial aid system for study loans and bursaries for academically deserving and financially needy students. As this loan programme has both cost sharing and access-participation objectives, it is one of the enablers for revenue generation. In 2011, the funds made available through NSFAS were Rand 6 billion and this is expected to continue growing. Furthermore, other governmental departments, companies, foundations and other organisations provide financial assistant to students. In 2011, for instance, a Finance Officer reported that about 70 financial sources ${ }^{112}$ worked with NMMU.

A lot of support structures and incentives are available for research activities in South Africa. Research and development (R\&D) is increasingly recognised as a key strategy for the economic growth and competitiveness of the country (see MTSF for South Africa; DST strategic plan, 2008). The DHET Strategic Plan identifies the following outputs which are needed to address the relevant Medium Term Strategic Framework (MTSF) priority:

112 Includes, among others, vice chancellor's scholarship, bursaries awarded by diverse company sponsors and various departments of government such as education, social development, disability, water affairs, agriculture, forestry and fisheries, cooperative governance, health, national treasury, etc. 
Increase research, development, and innovation in human capital for a growing knowledge economy, with a particular focus on postgraduate degrees, deepening industry and university partnerships, as well as increased investment into research development and innovation, especially in the areas of science, engineering, and technology.

Similarly, South Africa's Ten-Year Innovation Plan (DST 2008) aims to transform the country into a knowledge based economy, in which the production and dissemination of knowledge leads to economic benefits and enriches all fields of human endeavour. This plan aims to increase the number of patents and products developed by South African universities and other research institutions. DHET's Strategic Plan indicates that if South Africa is to build academic capacity for the future, its higher education system must focus on post-graduate study and research. Table 7.15 depicts DHET's research oriented strategic issues.

Table 7.15: Research Oriented Strategic Issues - DHET

\begin{tabular}{|c|c|c|c|}
\hline Strategic goal & Goal Attainment & $\begin{array}{l}\text { Strategic } \\
\text { objectives }\end{array}$ & Strategic Target \\
\hline $\begin{array}{l}\text { Goal 4: Expand } \\
\text { research, } \\
\text { development } \\
\text { and innovation } \\
\text { capacity for } \\
\text { economic } \\
\text { growth and } \\
\text { social } \\
\text { development. }\end{array}$ & $\begin{array}{l}\text { Expand research, } \\
\text { development and } \\
\text { innovation capacity } \\
\text { for economic growth } \\
\text { and social } \\
\text { development by } \\
\text { increasing the } \\
\text { number of post- } \\
\text { graduate students in } \\
\text { higher education and } \\
\text { by increasing support } \\
\text { to industry- } \\
\text { university } \\
\text { partnerships by } 2014 .\end{array}$ & $\begin{array}{l}\text { To develop and } \\
\text { enhance the } \\
\text { research } \\
\text { capacity and } \\
\text { productivity of } \\
\text { universities by } \\
2014 .\end{array}$ & $\begin{array}{l}\text { - } 142,325 \text { postgraduate } \\
\text { graduates } \\
\text { - } 15,837 \text { master's } \\
\text { graduates } \\
\text { - 5,772 doctoral } \\
\text { graduates } \\
\text { - } 34,613 \text { publications } \\
\text { - Ratio of research } \\
\text { output units per } \\
\text { instructional/ research } \\
\text { staff } 1.42\end{array}$ \\
\hline
\end{tabular}

Source: DHET's Strategic Plan (2010/11-2014/15), p42

Along with the supportive policies on university research, a variety of financial incentives to foster revenue generation from research activities are available for NMMU, as shown in Chart 7-11 below. 
Chart 7-11 Major flows of funding for R\&D (South Africa, 2009/10) (R millions)

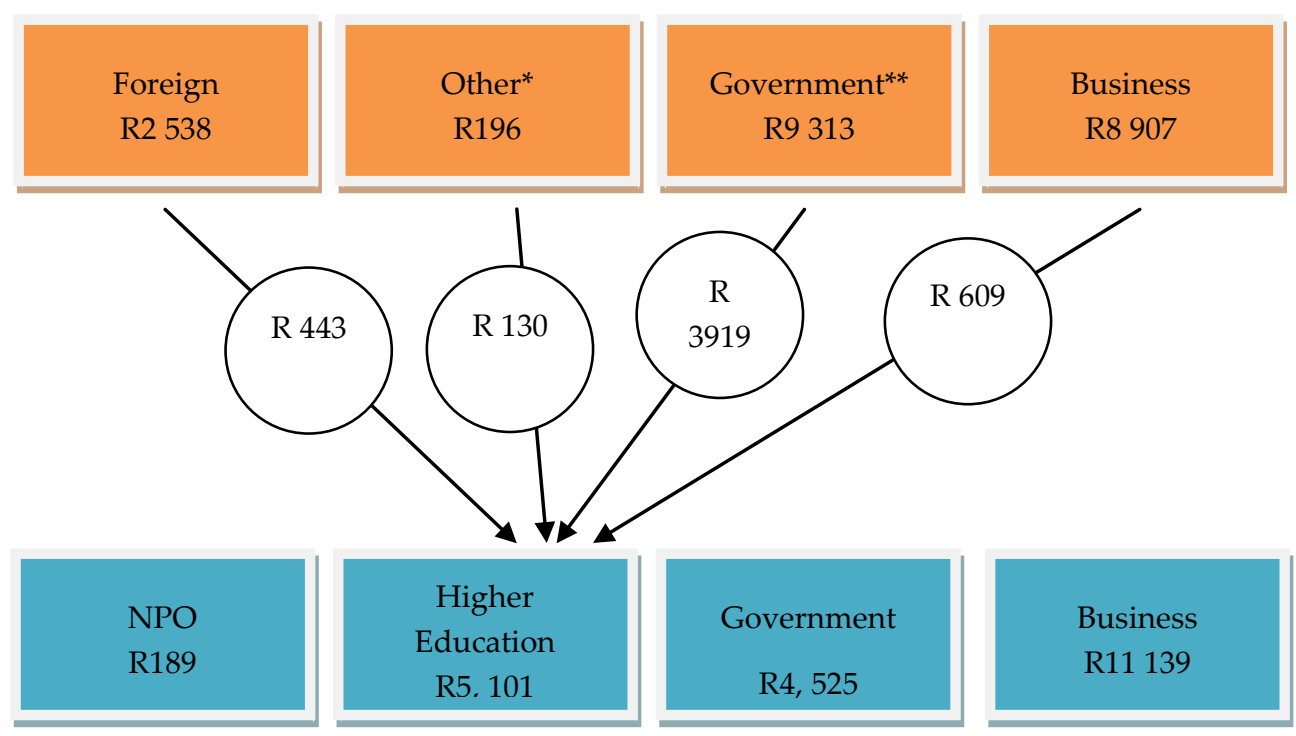

Source: National Survey of Research and Experimental Development High-level Key Results (2009/10 Fiscal Year): Department of Science and Technology Republic of South Africa (p23)

* Other includes contributions from Higher Education, Not for- profit organizations $\mathrm{NPO}$ and individual donations

** Government includes Science Councils

The 2009/10 R\&D survey recorded that South Africa's Gross Expenditure on Research and Development (GERD) amounted to Rand 20.9 billion. The GERD as a percentage of Gross Domestic Product (GDP) was $0.87 \%$. The South African government was the largest source of domestic funds for R\&D in 2009/10, contributing $44.4 \%$ of the total funding. While higher education and science councils received $84.2 \%$ of the total government funding, the business sector received $15.4 \%$ of the funds. The business sector was the second largest funder of R\&D, financing $42.5 \%$ of all R\&D performed in the country. The business sector financed $91.4 \%$ of its own R\&D activities and $8.2 \%$ of funds from this sector supported $R \& D$ in government, higher education and science councils. Research contracts are primarily provided by external for-profit organisations, mainly industrial firms, for specific deliverables to be achieved within set deadline. The location of NMMU in the neighbourhood of some relatively large industrial firms, offers the university numerous opportunities to gain research 
contracts. Foreign funding of R\&D increased from R 2.394 billion in 2008/09 to R2.538 billion in 2009/10 and the business sector received $60.6 \%$ of this funding.

Chart 7-11 indicates that NMMU's research funds come through research grants, contracted research, and research donations. Research grants are primarily provided by non-industry or not-for-profit bodies such as government, NGOs and foundations, for a specific goal or deliverable, mostly dealing with basic or fundamental research. The government has increasingly prioritised areas of knowledge that have the potential to contribute to the national economy through research excellence, relevance, and innovation. In this respect, the block grant funding from the state comprises research money for agreed outputs consistent with government-designated priority areas. NMMU has benefited financially from creative state-level mechanisms that stimulate research and development. The formula rewards research outputs in the form of ProQuest International Bibliography of Social Science IBSS, and M\&D Incentive funding (see DHET Journal Lists).

NMMU also earns resources from the National Research Foundation (NRF) and the Medical Research Council, which are incentive mechanisms to foster revenue generation. As an independent government agency, the NRF promotes and supports research in all fields of knowledge through (i) awarding funding on a competitive basis, (ii) establishing a healthy balance between strategydriven versus demand-pull funding, (iii) creating merit-based and rigorous peer review, (iv) using PhDs as a driver, (v) cross-fertilisation of talent within the National System of Innovation, (vi) effective, goal-oriented resource allocation, (vii) fairness, transparency and accountability, and (viii) transformation and excellence (NRF Act No. 23 of 1998). The NRF rating system is a key driver in the NRF's aim to build a globally competitive science system in South Africa by benchmarking the quality of South African researchers against the best in the world. NRF ratings are allocated based on a researcher's recent research outputs and impact as perceived by international peer reviewers. This rating system encourages researchers to publish high quality outputs in high impact journals/outlets. Rated researchers acting as supervisors impart cutting-edge skills to the next generation of researchers. NRF's Institutional Research Development Programme (IRDP) assists higher education organisations in the development and enhancement of their research culture, environment, ethos, and practice to become world-class African universities in order to deliver the skills required by the national system of innovation. The main objectives of the IRDP are to increase the quality of PhDs and other research outputs, which are key enablers for revenue generation. Linked to this, it seeks to promote staff development, increase the number of rated researchers, and facilitate institutional partnerships. With the financial 
benefits from NRF, come some constraints: a need for detailed financial reporting, less than $10 \%$ of the total budget to be spent on overhead costs, and no permanent staff salary costs from research grants. However, NRF does cover expenses like student bursaries, project running costs, and equipment.

Various bilateral and multilateral donors, NGOs, and foundations are the main sources of funds for research at NMMU. Research donations are primarily provided by funders with a philanthropic or public good perspective, where the funders do not benefit directly from the outcomes of the research, and no specific research deadlines or deliverables are required. NMMU has received such donations from, for example, estates, philanthropists, and alumni. Research donation is very common at NMMU, and is typically run through the NMMU Trust. There are typically no detailed financial reporting requirements beyond, for example, provision of the names of bursary recipients. No overhead costs are generally allowed, but the funding may be used for salaries, depending on the type of donation. Donor funding does not also allow any profit to be made by the university, but benefits it in other ways. The funding often offers important opportunities to investment in research facilities, and enhances cooperation among researchers (social contacts). It benefits the university by bringing postgraduate students, equipment, capacity, etc. and enhancing the social contacts of the university. Detailed and stringent financial and activity reporting are generally required for research grants, which interviewees regarded as an unattractive part of the funds.

\subsubsection{University Specific Factors that Enable or Hinder Revenue Generation at NMMU}

Several university specific conditions influence revenue generation at NMMU. As a comprehensive university, NMMU is legally mandated to offer university education, to undertake research and offer community services to a variety of stakeholders. The university has well diversified academic programmes, having various entry and exit points for ensuring accessibility and student mobility (see section 7.4). This provides a unique opportunity to address the demands and expectations of its various stakeholders. In terms of research, the university continuously establishes a vibrant research and innovation environment, strengthening and enhancing its engagement in various forms of basic and applied research, technology transfer, and commercialisation. The existing capacity (see research achievement of NMMU, 2011) of the university is an important enabler for revenue generation.

One of the enablers for revenue generation at NMMU is its internal governance structures and decision-making processes, which interviewees considered adequate to embark on a successful revenue generation strategy. In this respect, 
the composition of the university council, whose membership is drawn from governmental authorities, the university, and the private sector, is a crucial step in revenue generation, linking the university with its various stakeholders. Large governance bodies under the principle of collegial representation and strong executive leadership tend to be supportive of revenue generation. The committee structure of the university (see Section 7.3.4) plays a steering role by combining the traditional academic model of collective collegial decisionmaking along with strong organisational leadership for effective and efficient coordination of the university. This web of interlocked central committees has become the heart of NMMU's capacity to steer itself. University senates and committee structures generally offer real opportunities for staff participation in university decision-making processes.

The qualified and motivated academic staff, and managerial expertise and competence of NMMU are important enablers for developing and engaging in successful revenue generation strategies and activities. The proportion of the total academic staff with doctorates was $38 \%$ in 2011 . There is also a steadily increasing number of NRF rated researchers, which is an important enabler for revenue generation from research and consultancy activities (see Section 7.4.5 and Table 7.5). Nevertheless, some interview respondents reported that the academic workload in teaching students did not allow for the possibility of heavily engaging in research and $\mathrm{PhD}$ supervision.

This study clearly shows that NMMU has reasonably good research management capacity that can help faculty to prepare successful project proposals, make research inputs available in a timely fashion, and to negotiate with diverse external stakeholders (partners) to secure funding. Similarly, NMMU has grown aware of the need for specialised professional management to reduce the administrative burden on academics and free them to concentrate on their core tasks (education and research), which is found to be an important enabler for revenue generation.

As a historically white university, NMMU has adequate physical resources and research facilities (see Section 7.4.2). For instance, the university's accommodation enables it to enrol more learners. The availability of such facilities influences enrolment planning at faculty and campus levels and it is an important enabler for fostering revenue generation from educational services. Although in 2011 a significant proportion of NMMU students (87\%) resided in off-campus accommodation, they are able to benefit from the university's investment in residences if they wish to. As indicated in section 7.5, the university has heavily engaged in research in the areas of science, technology, and health, which are connected to its state of the art laboratories and 
workshops, which in return serve as the basis for revenue generation from research and consultancy activities. In general, NMMU, with accumulated advantages in research infrastructures (human and nonhuman), is able to prevail in competitive domains, and its success reinforces those advantages. This phenomenon is the "Matthew effect", where success brings more success.

NMMU has been constantly growing in terms of student population, academic and administrative support staff, visitors from overseas universities, and other stakeholders. This necessitates offering various non-academic services on university campuses. Students require food, accommodation, medical and other non-academic services from the university. Graduating students like to have academic certificates whenever they wish to send their official diplomas abroad for further education and employment. The replacement of lost IDs is another service that students demand. The university community needs cafeteria services on campuses. They also wish to conduct a number of workshops, conferences, trainings, etc. all of which require facilities that range from having state-of the art conferences centres to small meeting rooms. Most short-term training courses are offered in the conference centres. Participants at diverse meetings may need bed and restaurant services on campuses. There need to be facilities to host visitors (guest lecturers and researchers) from all departments/colleges. Several external customers strongly desire to receive various products and services from the university that is situated in their region. Firstly, many organisations and individuals would like to use the university laboratories for tests such as soil tests, material/sample testing in Civil Engineering laboratories, water, etc.. Secondly, external customers need the facilities of the university for conferences, exhibitions, or conventions. The availability of adequate non-human resources to meet these diverse needs is an important enabler for revenue generation.

\subsection{Revenue Generation Strategies at the South African Case Study University}

The objective of this section is to explore the types of revenue generation strategies formulated by the South African case study university to exploit environmental opportunities and its own strengths by overcoming outside threats and inside weaknesses to enable revenue generation. According to NMMU's Strategic Plan, one of the university's six strategic priorities is to formulate and implement a financial growth and development strategy to enhance the long-term sustainability and competitiveness of the university (NMMU, 2008:23). Under this strategic priority, the growth and diversification of income streams to support the attainment of NMMU's strategic goals is one 
of the strategic goals of the university. There are three strategic objectives (optimising student fees and subsidy income, securing more robust alternative revenue streams, and mobilising academic units, NMMU Trust and Alumni Relations for fund-raising), and their respective outputs (see Vision 2030 ${ }^{113}$ ). Revenue generation at NMMU is thus rooted and embedded in the overall academic mission, policies, plans, and strategies of the university. Moreover, a separate financial growth and development plan (2011-2020) was prepared in order to give the university a healthy balance sheet with sufficient reserves underpinned by positive cash flows and the generation of a R1 billion endowment fund.

\subsubsection{Differentiation of Products and Services for Revenue Generation}

The analysis in this chapter indicates that NMMU has broad streams of demand for university education, contract research, and other non-academic products and services from a variety of stakeholders. One of its strategies is a differentiation strategy, to meet the requirements of resource provider in return for resources. NMMU's Vision 2030 indicates that the university is actively responding to a range of scarce skill areas at national, regional, and local levels through a combination of its academic programme portfolio at under- and postgraduate levels, and its research, innovation, and engagement initiatives (NMMU, 2008). The differentiation strategy has been possible because of the academic autonomy of the university (see section 7.5.2.1). In the subsequent subsections, we explore NMMU's differentiation strategy of NMMU.

\subsubsection{Differentiation of Educational Services and Creation of Academic Units for Revenue Generation}

For acquiring the resources indicated in Chart 7-8, NMMU differentiated its academic programmes, offering certificates, diplomas, and degrees up to doctoral levels of the HEQF to address the academic proficiencies and interests of students and their academic interests and career aspirations (see Chart 7-12).

\footnotetext{
113 Information for formulating the strategic plan was gathered through 'environmental scanning'. A SWOT analysis was carried out to inform the strategic plan.
} 
Chart 7-12 Total Headcount Enrolment by Qualification Type

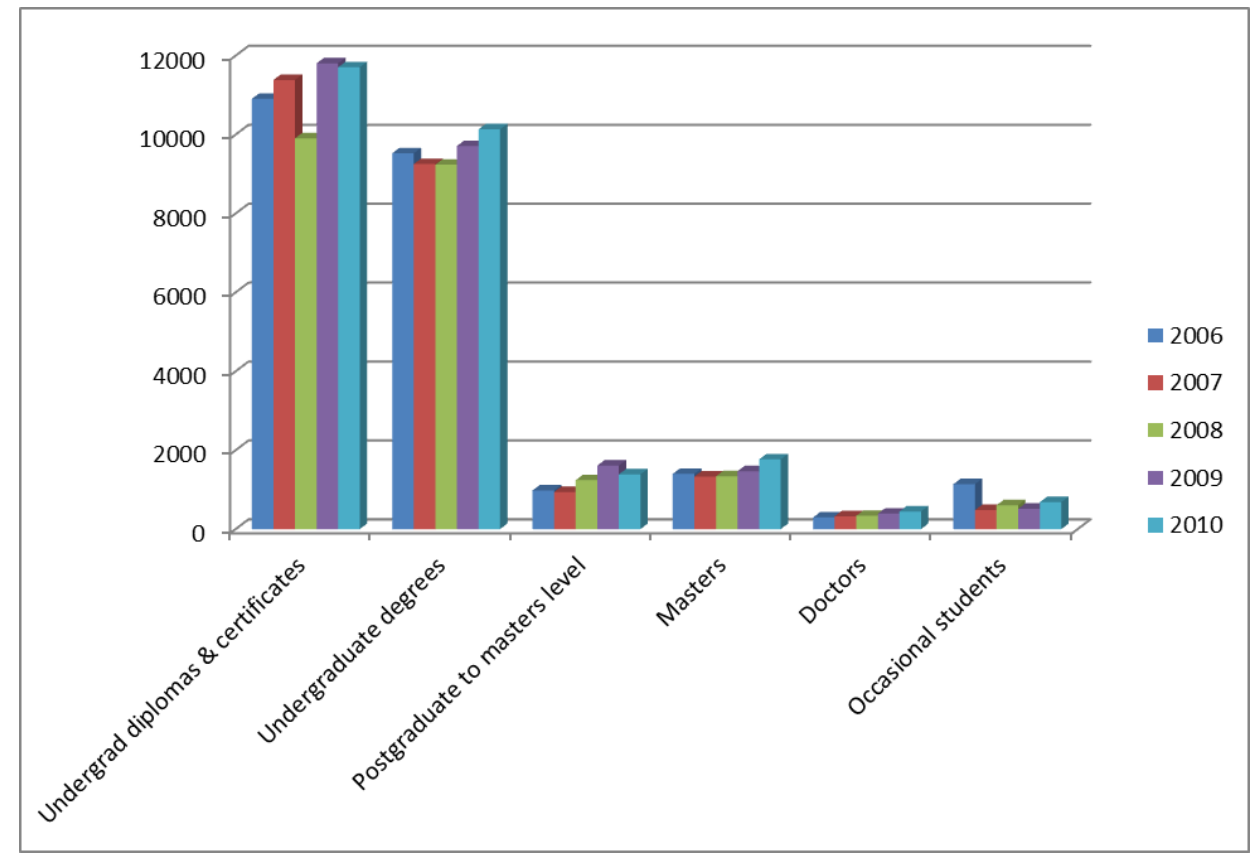

The university has been able to accommodate the soaring demand for higher education by moving its educational services closer to (potential) clients in seven campuses (see sections 7.4.2, 7.4.3 and 7.4.4; Table 7.4). Educational choices at NMMU are expanding and the conditions in which programmes are offered are diversifying. Most of the students at NMMU come from the Eastern and Southern Cape but the university also attracts students from other provinces in South Africa and as well as international students (10\% in 2010). NMMU follows both vertical and horizontal differentiation strategies to reach a broad range of students who seek its educational services. The university targets both students seeking degree programmes and non-degree pre-and post-baccalaureate certification. More differentiation in programmes was, however, observed for undergraduate programmes than at postgraduate level.

The university currently has four different access routes through which applicants may be admitted into a programme at the university. These include:

- Applicants meet the university's minimum admissions requirements and are admitted directly.

- Applicants do not meet the university's minimum admission requirements, but meet the requirements to be referred for further assessment, and are accepted based on their satisfactory performance on the Access Assessment Battery (AAB). 
- Applicants are admitted based on appropriate post-school qualifications or studies.

- $\quad$ Applicants are admitted based on Recognition of Prior Learning (RPL).

Additionally, NMMU has designed and implemented flexible modes of delivery and access routes to enable non-conventional learners to pursue higher education studies in pursuit of lifelong learning. NMMU therefore has contact students, distance students, and short course students. The highest proportion of NMMU students in each year is contact students, as shown in Chart 7-13.

Chart 7-13 NMMU Contact Students Enrolments, 2007 - 2011

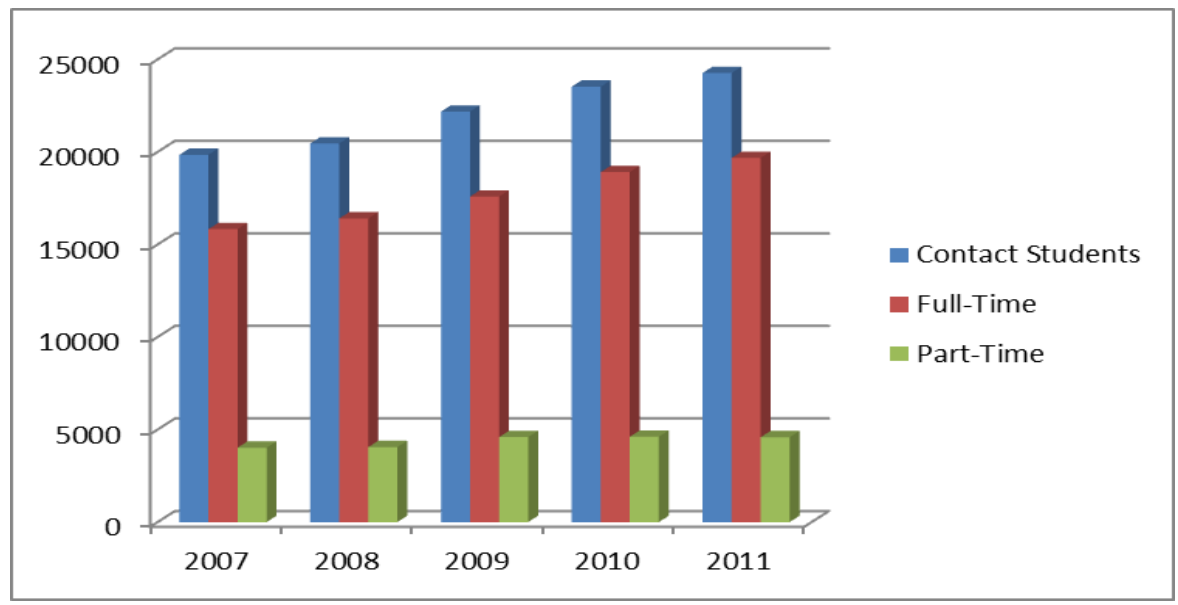

Chart 7-14 below shows the number of students at NMMU enrolled in distance education.

Chart 7-14 NMMU Distance Students Enrolments, 2007 - 2011

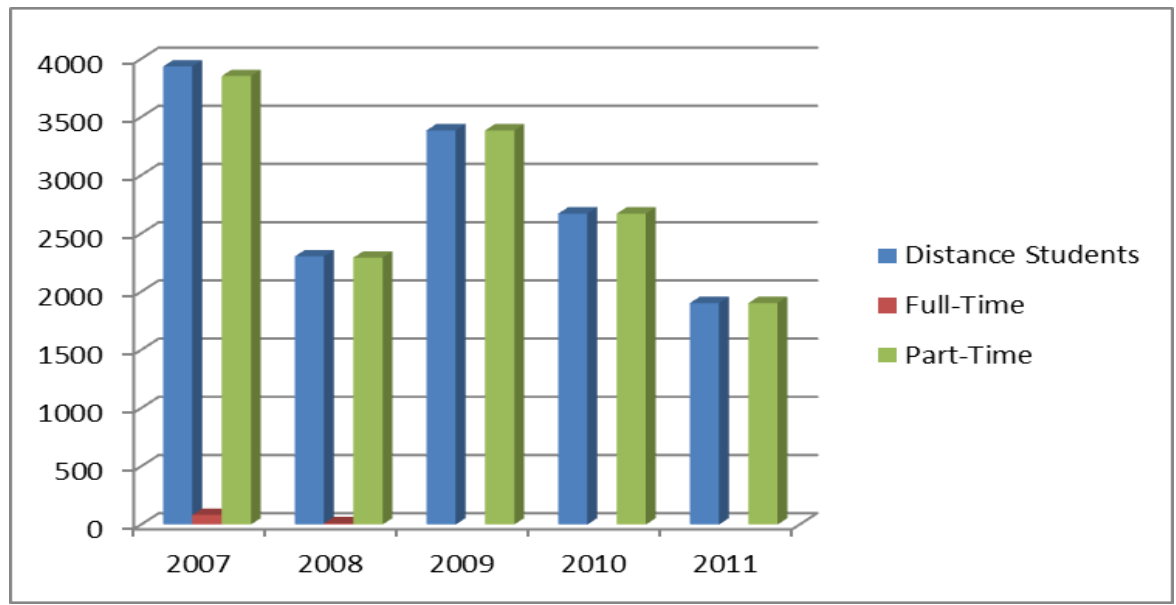


Rapid progress in information and communication technologies fostered the development of new ways of learning, such as distance learning and independent study. The development of print, audio-visual, and broadcast media contributed to this.

NMMU also provides its diverse stakeholders (notably mature learners) with a wide range of short learning programmes (SLPs) and skills training to acquire and develop practical skills and experience that meet particular workplace and professional development needs. The short courses may or may not award credits, depending on the purpose of the programmes. Chart 7-15 below shows the short course enrolment trend at NMMU.

Chart 7-15 NMMU Short Course Students Enrolments, 2007 - 2011

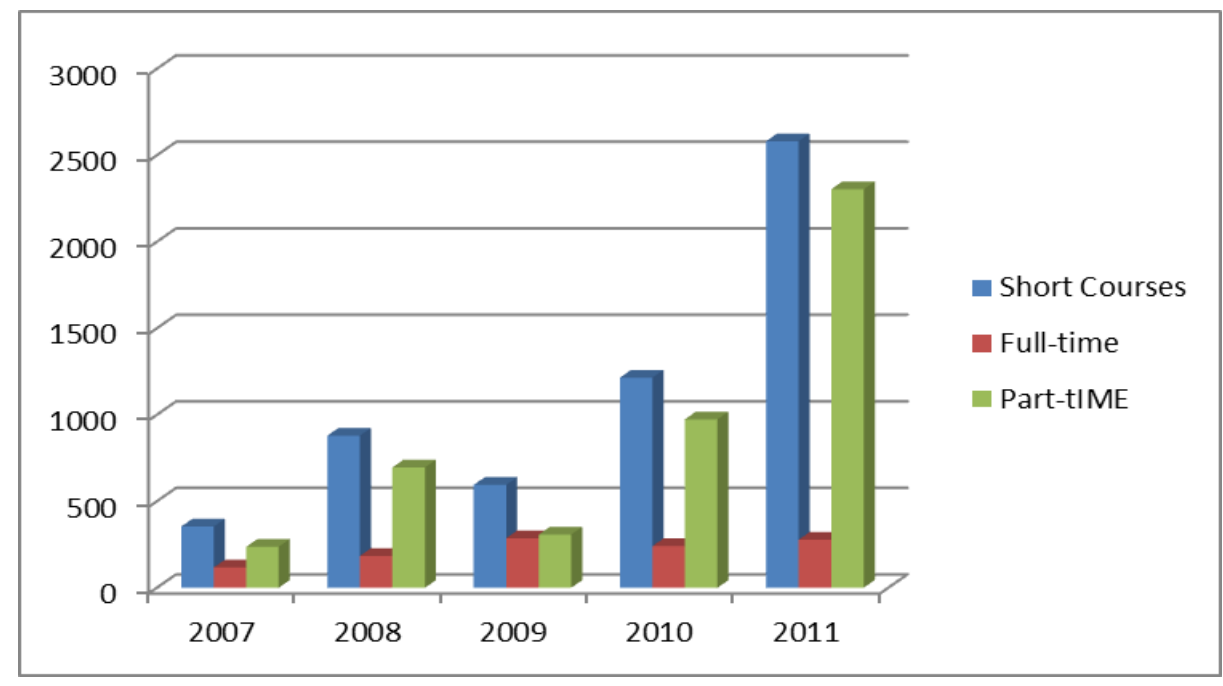

There are 56 diverse short courses offered in 2011/12

(http://continuingeducation.nmmu.ac.za/Course-Content---A-Z-List-of-short-courses).

One of NMMU's revenue generation strategies is forming alliances and consortia with other actors in the environment to foster revenue generation from educational services. The university develops partnerships with various post-secondary providers, including the public and private Further Education and Training (FET) sector, to ensure that students who wish to enrol for qualifications at NMMU may do so (in terms of appropriate admission requirements and agreements that allow them to progress onto an appropriate NMMU qualification). This collaborative alliance has been used by the university to gain access into new markets and improve its competitiveness. It often reduces early outlays for content development, technical infrastructure (e.g., lecture halls, library, offices, laboratories, hostels, and other educational 
inputs) and marketing, and partnerships can provide the capital needed for generating revenue quickly. The university has created franchises or collaborations with other middle-level colleges.

\subsubsection{Differentiation of Research and Consultancy Services and Creation of Academic Units for Revenue Generation}

As has been shown in Chart 7-9, earned revenue from research and consultancy services as a proportion of total nongovernmental revenue increased from 2006 to 2010. This achievement is a result of NMMU's vibrant research and innovation environment that responds to its local, national, continental, and global knowledge economy. Table 7.16 below presents the diverse research themes of the university, which meet the research and consultancy requirements of a variety of stakeholders.

Table 7.16: NMMU Research Themes in 2011

\begin{tabular}{ll}
\hline Research Themes & Driver \\
\hline Biodiversity Conservation and & Prof. Graham Kerley \\
Restoration & \\
Coastal Marine and Shallow Water & Dr Derek du Preez \\
Ecosystems & Prof. Rossouw von Solms \\
Cyber Citizenship & Prof. Velile Notshulwana \\
Democratisation, Conflict and Poverty & Prof. Maarten de Wit \\
Earth Stewardship Science & Prof. Rosa du Randt \\
Health and Wellbeing & Prof. Denise Zinn \\
Humanising Pedagogies & Prof. Danie Hattingh \\
Manufacturing Technology and & \\
Engineering & Prof. Jan Neethling \\
Nanoscale Characterisation and & \\
Development of Strategic Materials & Prof. Paul Webb \\
Science, Mathematics and Technology & Prof. Ernest van Dyk \\
Education for Society & Prof. Kobus van Wyk \\
Sustainable Human Settlements & Prof. Hendrik Lloyd \\
Sustainable Local Economic & \\
Development & \\
\hline
\end{tabular}

Source: NMMU 
While NMMU continues to value disciplinary research, it encourages multi-, inter- and trans-disciplinary projects that are able to address complex and multi-faceted problems through the interaction between various disciplinary perspectives or by moving beyond current disciplinary configurations. The University plays a leading role in innovation activities that contribute to national research and development needs, the provincial growth and development plan (PGDP), and the regional system of innovation (RIS) in the Eastern Cape.

NMMU has established institutes, centres, and units that mainly focus on conducting research, offering short-term training, engaging in teaching (notably postgraduate students), and providing consultancy services in response to the demands of stakeholders, to acquire resources (see Chart 7-16 below).

\section{Chart 7-16 Number of Research Institutes, Centres, and Units at NMMU}

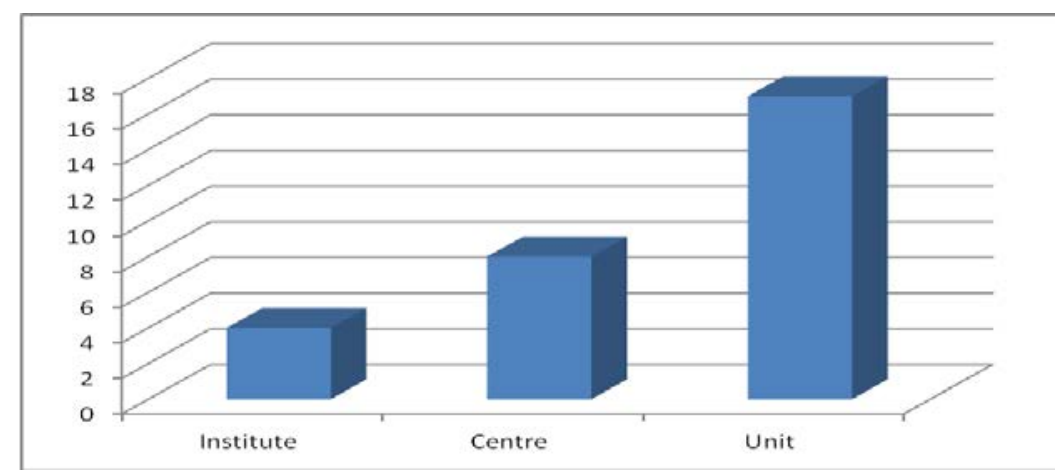

The university is moving to a dual structure of basic units in which traditional academic departments are supplemented by the research entities shown in Chart 7-16, in order to reach across old university boundaries and link the university with various stakeholders to promote collaborative and interdisciplinary approaches to research. Externally, the entities serve as venues for establishing stable and enduring relationships with stakeholders in order to develop predictable flows of resources. Internally, the research entities work closely with traditional academic departments, for example with researchers and postgraduate students by sharing resources. In other words, they create opportunities for collaborations between academic staff and/or between faculty members in different disciplines by bringing together a new mix of people to solve new problems in unusual ways. This shows that the research entities actually operate much like mediating bodies situated between the university and external stakeholders. As a result, they are seen favourably by senior leaders because they can enhance the university profile and indicate their compliance with environmental demands. Additionally, NMMU has created 
business-incubators or science and technology parks as part of improving research and consultancy initiatives and has facilitated academic start-up firms in order to take advantage of low-cost real estate to provide affordable rentals to aspiring commercial enterprises.

We will now provide some examples of the research achievements of the institutes. Some of the research institutes at NMMU include Institute for Sustainable Government and Development (incorporating the Law Clinic), the Institute for Advanced Manufacturing and Engineering Research, the Institute for Information and Communication Technology Advancement, and, InnoVenton. The centres at NMMU consist of the Management Development Centre, the Telkom Centre of Excellence, the Centre for African Conservation Ecology, the Centre for Energy Research, the Centre for the Advancement of Non-Racialism and Democracy, and the Centre for Educational Research, Technology, Innovation, and its subunits. Automotive Components Technology Station (ACTS) at NMMU is a multi-disciplinary advisory centre for the automotive component and related manufacturing industries in Southern Africa (particularly in the Eastern Cape region). ACTS provides support to small and medium enterprises in the automotive component manufacturing industry in order to improve innovation and competitiveness, with the aim of making the South African automotive industry more globally competitive. About $50 \%$ of ACTS funding comes from income generated through projects, services and training for industry. ACTS has signed an agreement with DST/TIA for a three-year funding cycle (2009-2012). Another research entity is InnoVenton or NMMU Institute of Chemical Technology, which was awarded a Technology Station by the Department of Science and Technology's Tshumisano programme. The institute's research activities are organised into two main themes, namely product development and process development. InnoVenton is funded entirely by external funds, either through grants such as from the DST through the Tshumisano Trust, contract research for external clients, selling expert services to industry, or by dividend/royalty income from commercialisation projects. Other research entities such as Pebble Bed Modular Reactor Project in the science faculty, Agro-Processing Project, Maths Development, etc. are all funded by government agencies and industrial firms.

As part of increasing its research capacity sustainably, in 2011 NMMU launched the Centre for High Resolution Transmission Electron Microscopy (HRTEM) focusing on material science, and the ESKOM funded Centre for Expertise in Forecasting. The university has a number of leading Research Chairs, funded from both public and private sources to concentrate on research and development in specific fields such as automotive engineering, nanophotonics, social sciences, HIV/AIDS and mathematics education 
NMMU has a strategy of forming alliances and consortia with other organisations to meet the research and consultancy demands of its stakeholders. NMMU has formed linkages and partnerships with national and international research and development organisations, industries, and other in country and overseas universities in order to further strengthen its human and nonhuman resources such as qualified academic staff, research facilities (i.e., laboratories, workshops, and libraries), and other physical plants for enhancing capabilities and reducing costs. The NMMU Internationalisation Committee constantly reviews the range, depth, and quality of the university's partnerships. In this respect, NMMU has formed various research based linkages and collaborations with other organisations in its environment (accessed on 20 October 2011 http://international.nmmu.ac.za/GlobalLinkages/Global-Partnerships).

The university enhances its postgraduate studies, and the research skills of its Master's and PhD students by creating international research opportunities in which students spend time at partner universities, thereby sharing in the knowledge pool as well as infrastructure of those universities. Makerere University in Uganda and NMMU have an academic postgraduate and research collaboration in Mathematics, Applied Mathematics and Economics. University of Oldenburg in Germany collaborates with NMMU on PhD research in areas of renewable energy. University of North Carolina, Wilmington and NMMU have an exchange agreement for political studies. The mechatronics and robotics for advanced production technology joint research work plan is a co-operation between the NMMU and Reutlingen University (RU) in Germany. One of NMMU's oldest partnerships is with St. Cloud State University in St Cloud, Minnesota and involves on staff and student exchanges, focusing on the development of higher education and professional skills. Currently, NMMU is paying particular attention to new research opportunities with Brazil, India, and China. The University has also benefitted from its membership of the successful Erasmus Mundus consortium, involving five South African Universities in partnership with a number of European Universities (Leuven, Freie Universität Berlin, Pierre et Marie Curie, Karolinska Institutet, Masaryk, Granada and Amsterdam), enabling exchange opportunities for staff and students in exciting research projects.

NMMU has well-established linkages with industry to promote problem-solving, knowledge transfer and product development (NMMU 2008: 44). It has many such projects with Sasol, Eskom, Kumba, MTN, CSIR, SMMEs, etc. It also collaborates with industrial firms in the areas of Automotive Components Technology and Automotive Engineering and provides support to SMMEs in the Eastern Cape through the Small Business Unit (ibid.). 
7.7.1.3. Differentiation of Non-Academic Products and Services for Revenue Generation

NMMU provides essential facilities and services to a variety of customers to support its core business of teaching and learning and create an enabling living and learning experience on all its campuses. In this regard, NMMU has extensively diversified its non-academic services in order to meet the demands of their internal and external customers, as shown in Table 7.17.

Table 7.17: Diversifying Non-Academic Services for Revenue Generation

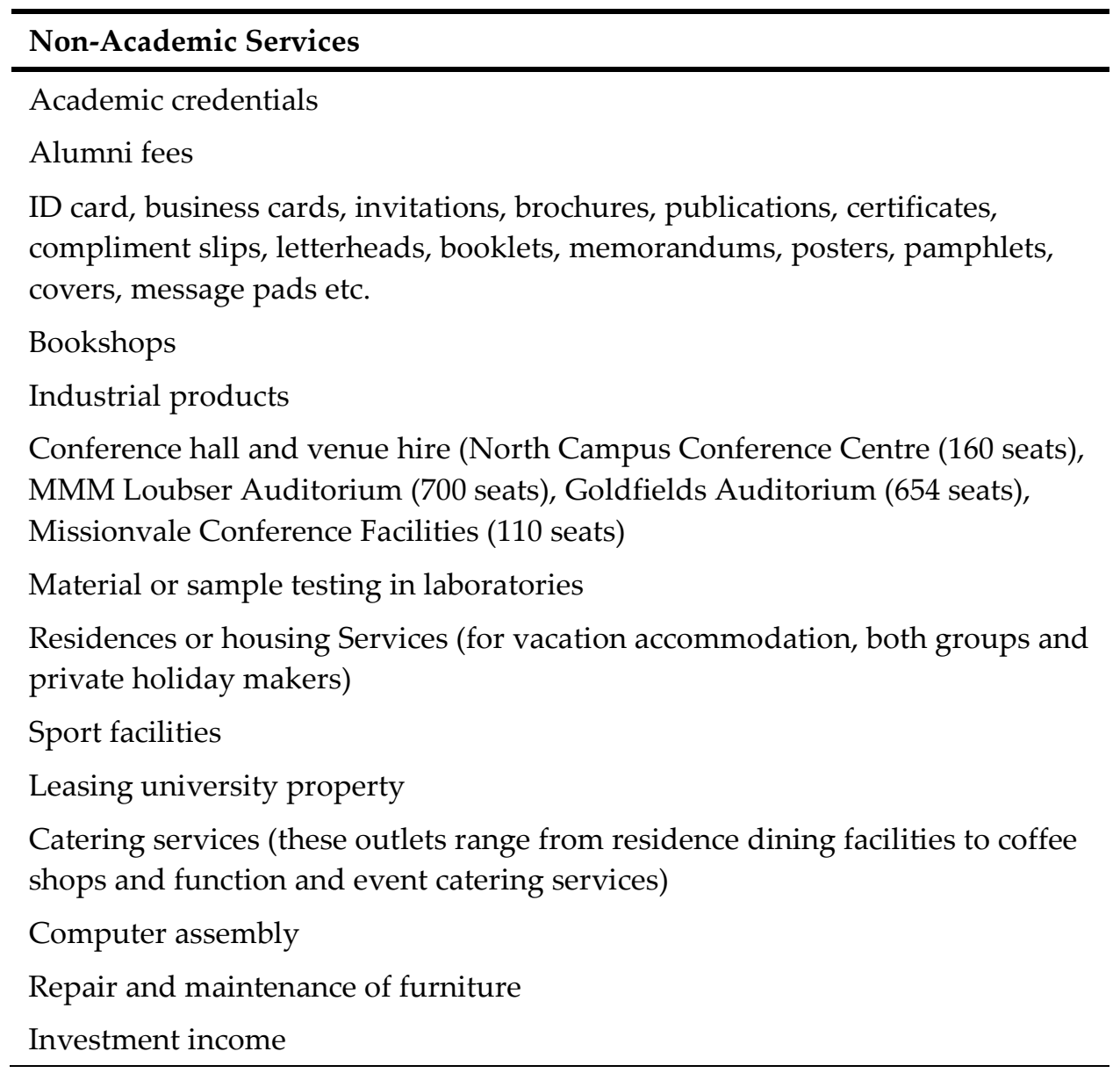

The "raison d'être" of these activities is not necessarily to generate income, but as far as possible to not run at a loss. 


\subsubsection{Creation of Administrative Support Structures for Stakeholder Management}

NMMU has set up numerous structures and positions for revenue generation in order to manage its stakeholders efficiently and effectively by using its organisational autonomy (see section 7.5.2.1). Two approaches have generally been employed to manage the huge amount of administrative work accompanying the university's revenue generation activities. The first approach is to use the existing organisational structures to enhance efficiency and reduce costs. The second is to establish new organisational structures dedicated to revenue generation within the university. At its strategic apex, a Deputy Vice Chancellor for Research and Engagement coordinates all revenue generation. A committee or a team comprising different university community members assists the office of the deputy vice chancellor in terms of revenue generation. The committees bring the decision-making processes to large governance bodies under the principle of collegial representation or increasingly shared governance and leadership. In other words, NMMU has developed a strong central leadership fused with traditional academic notions in the process of revenue generation.

Additionally, various outreach administrative units operating as crosscutting offices (see Table 7.18 below) help raise revenue from different stakeholders, and establish better university-environment relationships or manage resource dependencies.

Table 7.18: Crosscutting Administrative Support Offices for Fostering Revenue Generation

\begin{tabular}{l}
\hline Office \\
\hline - Directorate of Finance \\
- Directorate of Human Resources \\
- Strategic Planning, Marketing and Corporate Relations \\
- Office for International Education \\
- Legal Services \\
- Support Services
\end{tabular}

These offices are not necessarily established by the university solely with the objective of generating revenue, but they offer the potential for revenue generation. The offices provide administrative support services in the areas of need identification, marketing the university's services and products, 
supporting proposal writing and costing, providing legal and contract support, and handling financial and human resource matters, among other things. Offices like International Education, and Strategic Planning, Marketing and Corporate Relations foster both internal and external communication revenue generation at NMMU. The external communication aims to make key stakeholders aware of the range of activities that are undertaken by the university. The internal communication aims to involve the broader university community (e.g. leadership, academic staff, and administrative staff) in the process of revenue generation.

As indicated in Table 7.19, NMMU has established a variety of administrative support offices to foster revenue generation from educational services and short courses.

Table 7.19: Administrative Entities in Charge of Education and Short-courses

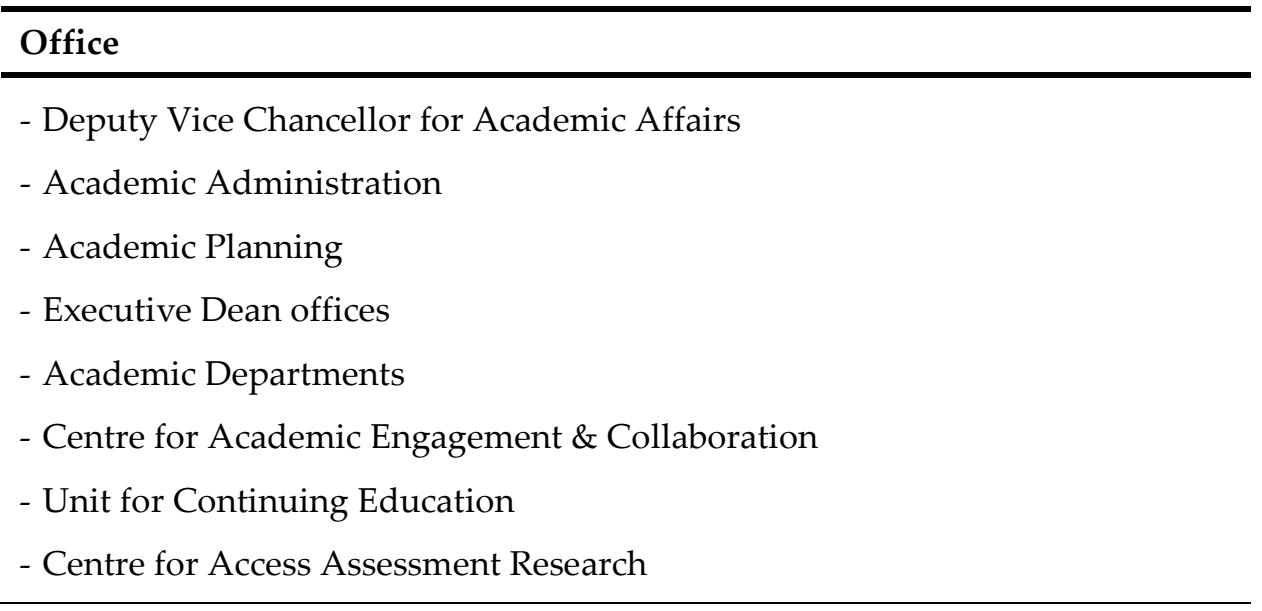

The offices are in charge of planning academic programmes, preparation of syllabuses, admission of students, examinations, certificates and transcripts, library services, student attachment and training of academic staff and appraisals. The Academic Planning Department plays a facilitation role in the process of programme development, approval, accreditation, and registration with the DHET, HEQC, and SAQA. Upon the approval of the academic programmes, the Department of Academic Administration undertakes such matters as academic applications and admission, the registration process, planning and generation of lecture timetables, running of examinations, graduation planning, faculty administration, student records, student systems support and training, publication of annual general and faculty prospectuses, and drafting and publication of the annual academic calendar. The Centre for 
Academic Engagement \& Collaboration (CAEC) is the umbrella unit whose focus is the formation and regulation of academic engagement partnerships with a variety of stakeholders. The Marketing and Corporate Relations department, in collaboration with the university's Higher Education Access and Development Services, and faculties ensure effective packaging and communicating of the programme mix and admission requirements. The Office for International Education strives to attract as many international students as possible. NMMU heavily advertises its programmes in both print and electronic media, on websites, at trade fairs and at exhibitions by employing a userfriendly promotion and marketing strategy including directly addressing high school students. Those applicants who do not meet the university's minimum admission requirements are referred for further assessment to the Centre for Access Assessment Research, which provides research based quality assessment.

NMMU has created a Unit for Continuing Education that provides a support structure for faculties to enhance their capacity to offer short-learning programmes (SLPs). This unit provides adult learners with an opportunity to acquire or develop their skills base by marketing, coordinating and administering the short learning programmes offered by the various faculties of the NMMU. The Academic Affairs Divisions closely work with finance offices on financial matters. Financial services are provided from the central office to ensure that all moneys are properly accounted for in accordance with legal and financial regulations. Other departments, such as Strategic Planning, Procurement, and Human Resources ensure the timely availability of resources and services for running the academic programmes.

Table 7.20 below shows administrative support offices that manage the research and consultancy services of NMMU.

Table 7.20: Administrative Support Offices for Fostering Revenue Generation from Research and Consultancy Services

\begin{tabular}{l}
\hline Office \\
\hline - Deputy Vice Chancellor for Research and Engagement \\
- Department of Research Management \\
- Department of Research Capacity Development \\
- Department of Innovation Support and Technology Transfer \\
- Centre for Academic Engagement and Collaboration \\
- Office for International Education \\
\hline
\end{tabular}


These research entities work alongside a number of committees such as an RTI committee, a Capital Equipment Committee, and a Publication Committee in order to ensure that researchers at NMMU spend optimum time on academic matters without being burdened with administrative tasks. The administrative support offices for research and consultancy are both outward facing and inward facing. As far as the outside world is concerned, they serve as a liaison between the university and its stakeholders, and seek to match faculty expertise with the research needs of the stakeholders in the environment. Marketing and promotion and bidding for funds are some methods of doing that. For instance, the International Education Office at NMMU works in collaboration with environmental stakeholders (i.e. universities and research organisations) to offset a lack of human and nonhuman resources in some research themes. The Department of Innovation Support and Technology Transfer also provides support for start-up companies through business incubators, research parks, and venture capital funds. Inward-facing functions include the dissemination of information to internal actors (academic and administrative staff) and stimulating and regularising academic unit involvement in research and consultancy.

The department of Research Capacity Development (RCD) focuses on capacity development for researchers by rendering financial assistance to postgraduate and postdoctoral candidates from NMMU, and offering staff funding and development opportunities. The department of Innovation Support and Technology Transfer handles the issues of intellectual property (IP) and commerciality for the invitations. In terms of innovation, it assists researchers in obtaining and negotiating external research-related grants and contracts, and provides some funding for those projects that may have a commercialisable IP. It encourages researchers to disclose their inventions, undertakes IP identification and protection, monitors and manages NMMU's IP portfolio, facilitates the license or assignment of NMMU's IP to NMMU's wholly owned company, Innovolve (Pty) Ltd. NMMU RTI committee ensures that the central and faculty RTI Committees support and/or recommend projects for funding which are aligned with the academic and research focus areas of NMMU and/or the research activities of a research unit, centre or institute. Additionally, NMMU provides consultancy services to industry and governmental and nongovernmental offices in order to contribute to national and regional economic and social development.

Revenue generation from non-academic activities requires a wide range of specialist skills as seen in Table 7.21 below. 
Table 7.21: Entities Fostering Revenue Generation from Non-Academic Services and Products

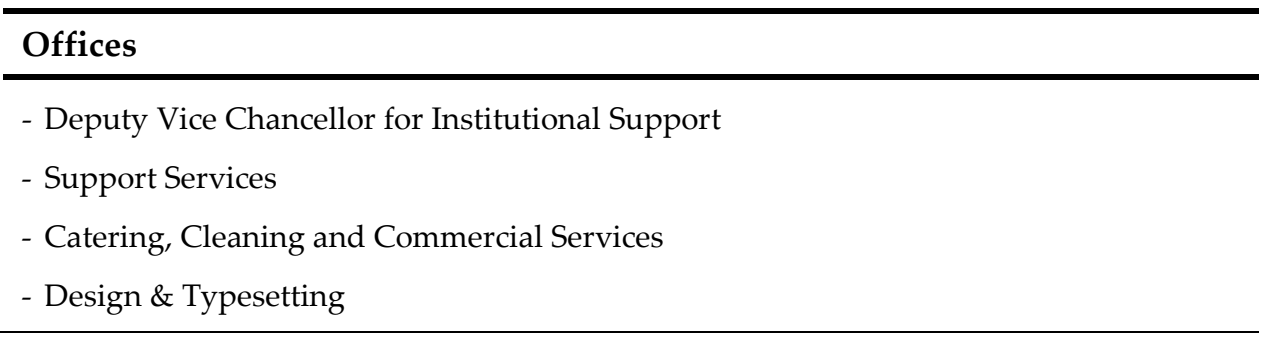

The Office of Deputy Vice Chancellor for Institutional Support is in charge of offering overall policy leadership for fostering revenue from non-academic services. The administrative support offices indicated above offer their services to customers in order to reduce costs and achieve efficiency. In principle, NMMU is committed to running the non-academic services and products to cover their costs plus a contribution to the general pot of earned revenue. In practice, however, most of the non-academic activities listed in Table 7.16 bring little net income and sometimes don't cover their operating costs, because services are under-priced and heavily subsidised to create an enabling working environment for staff. It is widely believed that the availability of services at reasonable prices (often subsidised) on campuses contributes to attracting and retaining senior academic and administrative staff.

\subsubsection{Internal Resource Allocation Mechanisms}

An internal resource allocation mechanism is one strategy for aligning the university's revenue generation agenda with the immediate interests of particular internal actors. It is an important tool for senior university leaders to influence or constrain the behaviour of internal actors to achieve the revenue generation goals of the university. In this respect, the following four policies on revenue generation were identified as steering tools.

- Policy for the management of third stream income generated by NMMU Conferences, Seminars and Workshops;

- Policy and procedures for approval and signing of research-related contracts;

- Framework for the support and funding of research activities at NMMU by the university; and

- $\quad$ Policy for the Management of Short Learning Programmes. 
These policies collectively determine the internal resource allocation mechanisms of the university in terms of coordinating human and non-human resources, resource utilisation, and the distribution of earned revenue among diverse internal actors.

One of the preconditions for engaging in revenue generation activities is a business plan. This business plan, among other things, comprises a business description, market and marketing strategy, production details (i.e. requirements and costs, forecasts of production vis-à-vis sales, and financial start up and operational cost), human resources including responsibilities and pay, business risk and tackling strategy, and action plan. NMMU promotes the principle that revenue generation must lead to financial and non-financial returns. The policies stipulate that clients should, in principle, pay the full cost for products and services. This should include an appropriate surplus. This is not to say that decisions regarding any prospective initiative for revenue generation are considered only in financial terms. The university has the right to do a particular piece of research or teaching primarily because it is academically and socially worthwhile.

One of the aims of these policies is to state how seed money is made available to foster revenue generation. NMMU allocates seed money or initial capital to support new or existing revenue generation activity. The seed money comes from two sources: main governmental support and earned revenue. In most cases, trust funds are pulled together to fund such initiatives. Allocation of the money to any promising revenue generation activity is made in line with the university's resource allocation model, described below.

\section{(a) Corporate Resource Allocation Model (Corporate RAM)}

The NMMU Corporate RAM includes: (i) estimated revenue resources (Council Funded), (ii) top-slice for institutional overheads and strategic allocations, (iii) allocated earmarked income, (iv) allocated salary block funding, and (v) allocated operating block funding. Revenue streams are identified and best estimates/ calculations/ forecasts are made for DHET subsidy, student contributions, and other revenue such as investment income, Office for International Education, conference centres or facilities or vacation accommodation, rentals \& services, and reimbursement of trust fund operational expenditure and bursary allocation. This top slice of funding represents the first (executive) level of strategic intervention in the financial plan. Included in the top-slice block are: Corporate overheads (external audit fees, bank charges, insurance, municipal rates and services, contract security, contract cleaning, grounds maintenance contracts), library books \& periodicals 
allocation for new \& replacement items, capital maintenance projects, provision for depreciation, leave provision write-ups, interest \& redemption on building loans, strategic allocations, DHET Infrastructure \& Missionvale Projects, and central management (MANCO) commitments.

All earmarked income is allocated according to the applicable business plan, contract or agreement: residences, conference centre /facilities/ vacation accommodation, earmarked portion of application \& registration fees, foundation programmes, and Trust Fund contributions towards administrative expenditure, International Office allocation, and earmarked allocations of Investment Income (i.e. unspent IOP Funds). An entry point for any nonacademic services and products is a business plan that must be approved by the senior university leaders and appropriate committees. Each revenue generation initiative must, after the setup phase, be run with a positive balance of income and expenditures based on a full cost consideration or at least must not be making a loss. The idea is to create an enabling working environment for the university community. Moreover, the university considers student diversity and access for disadvantaged students as intrinsically important to their missions-that is, these factors enter the equation when setting prices. Administrative and Academic Support salary block allocations are calculated on the cost of the council approved staffing structure. Provision is made for a remuneration contingency to fund adjustments to staffing costs including annual salary increase costs. The Administrative and Academic Support operating block allocations are distributed on a zero based budgeting principle informed by the budget directives and management resolutions for that budgeting cycle.

\section{(b) Academic Resource Allocation Model (Academic RAM)}

NMMU has an academic resource allocation model that provides incentives for revenue generation from educational services including short courses. Academic activities are mainly funded from DHET subsidy and student contributions. NMMU receives its core funding through block grant budgeting which awards the university freedom to reallocate the funds between various activities or emerging opportunities as it sees fit. This Academic RAM is based on the council funded revenue streams that a faculty generates which include fees, teaching input subsidy, teaching output subsidy, and research output subsidy, as shown in Table 7.21. These streams are weighted based on the revenue they generate. A factor is then calculated for each faculty by determining their share of each stream. A total weighted factor is then 
calculated, which is used to determine faculties' share of the applicable academic block allocation.

Table 7.22: NMMU Academic Resource allocation Model

\begin{tabular}{|c|c|c|c|c|c|c|}
\hline \multirow[t]{2}{*}{$\begin{array}{l}\text { Academic } \\
\text { Units }\end{array}$} & \multicolumn{3}{|c|}{$\begin{array}{l}\text { Subsidy Block Allocation } \\
\text { for Year (n) }\end{array}$} & \multirow{2}{*}{ 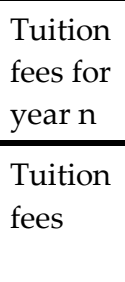 } & \multirow{2}{*}{$\begin{array}{l}\text { Total } \\
\text { income }\end{array}$} & \multirow{2}{*}{$\begin{array}{l}\text { Academic } \\
\text { Salary } \\
\begin{array}{l}\text { Block } \\
\text { amount }\end{array}\end{array}$} \\
\hline & $\begin{array}{l}\text { Teaching } \\
\text { input } \\
\text { subsidy }\end{array}$ & $\begin{array}{l}\text { Output } \\
\text { subsidy }\end{array}$ & $\begin{array}{l}\text { Research } \\
\text { output } \\
\text { subsidy }\end{array}$ & & & \\
\hline Faculty & & & & & & \\
\hline
\end{tabular}

\section{(c) Capital Budget Allocation Model}

The capital budget is distributed from a zero base. The guideline for the academic share of the capital budget is $70 \%$ with $30 \%$ for Administrative and Academic Support. The Capital Resource Allocation Committee (CRAC) utilises three sub-committees to assist it in the evaluation process for teaching \& research, computer equipment, furniture and other equipment. The committees are required to recommend " $\mathrm{A}$ " priorities to CRAC for funding and evaluate all requests for capital budget.

\subsubsection{Human Resources Policies for Revenue Generation}

The South African case study university wants to have sufficiently qualified and motivated human resources, both academic and administrative, in order to foster its revenue generation agenda. NMMU has tried to attract and retain senior academic staff, who preferably hold PhDs, using traditional academic criteria determined by the academic community. Nevertheless, recruiting high quality candidates (PhDs, associate professors, or full professors) was reported as challenging in certain fields such as engineering, business and economics studies, computer sciences, energy, etc. given the competitive salaries in the private sector. NMMU has devised a number of alternative strategies to limit the challenges in the recruitment of senior academic staff. The University employs part-time academic staff from outside, and invites guest lecturers from other overseas and in-country universities to ensure an adequate supply of academic staff for running full-fee paying programmes. They develop joint local and international exchanges in research, recruit senior academics from other countries and offer postdoctoral scholarships for students, among other things. 
One of the relatively successful strategies has been joint research projects with different universities, due to NMMU's in-house human and nonhuman capacity. Most senior researchers may act like magnets in attracting able faculty (through social capital) from other universities. NMMU offers 10 international and 10 domestic postdoctoral scholarships a year, to improve its research capacity.

An important strategy for acquiring the capacity for revenue generation is investing in staff development through providing support for emerging researchers, postgraduate students, and postdoctoral fellows to become research active. NMMU has heavily invested in its research facilitiesreconstituting departments, regrouping research teams, constructing expensive new physical plants, investing in promising faculty, etc.

Revenue generation has not been a major criterion for promotion or dismissal of both academic and administrative staff. The criteria by which faculty and administrators judge academic work remain unchanged and persists in prioritising conventional forms of education and research. However, the use of teaching as a criterion for staff performance evaluation provides an incentive to stick to the revenue generation agenda. Similarly, NMMU offers promotion to academic staff based on the number and quality of publications. By its very nature, research is more closely linked to faculty reward and compensation policies than teaching, which fuels the staff's desire to take part in worldstandard research wherever possible and appropriate. Faculty below the level of full professors undertake research to ascend the career ladder. Even the behaviour of senior professors at NMMU has been steered by the longestablished 'publish or perish' policy. In this regard, NMMU respects peer review and disciplinary norms. The role of peer review remains strong and perhaps has even been strengthened, since universities now focus not only on peer-reviewed publications, but also on peer-reviewed research evaluations of academic departments, the results of which influence funding or revenue generation.

NMMU has a set of incentive mechanisms for each revenue generation activity in order to increase the academic community's commitment to its revenue generation agenda. According to the policies, there are a diversity of incentive mechanisms (monetary and nonmonetary), mostly operating by rewarding staff directly or through providing incentives at faculty/institute level. For education, the university uses market incentives to reward individuals who directly or indirectly make an extra effort to generate revenue from educational services. This financial incentive has fostered higher levels of faculty involvement in revenue generation from educational activities. This incentive scheme is highly 
influential in shaping the behaviours of faculty (notably early-career faculty) to engage in revenue generation. NMMU also has an explicit reward system for their administrative support staff who directly or indirectly engage in generating revenue from educational services.

With respect to short learning programmes (SLPs), remuneration for NMMU staff and part-time lecturers offering short courses is determined by the SLPs policy. NMMU staff who are presenters of SLPs are remunerated in terms of a secondary appointment, unless the SLPs forms part of their normal workload. The rate of remuneration per hour may vary but must fall within the parameters of the fixed scale set by the NMMU. In the event of remuneration rates exceeding the fixed scale, the Dean must provide a written explanation, which is attached to the SLP salary claims form. Remuneration is determined by factors like the course development required, course content, level of the SLP, expertise required, etc.. Remuneration is then agreed by the Dean and the Lecturer, based on a decision by the Faculty Management Committee. On completion of the course, a fee based on the gross income of each SLP is charged by NMMU, as a contribution to administrative and infrastructural costs. The levy charged on the gross income of each SLP is $15 \%$. The levy is divided between the Institution (10\%) and the Faculty $(5 \%)$. Once all operational expenses, levies, and remuneration have been deducted, the allocation of surplus funds is made by the FMC.

A framework is used to reward research and consultancy activities at NMMU. The framework clearly states that that academic staff who undertake research and consultancy activities retain some of the generated income according to a distribution factor. The South African system uses a points system for rewarding productive scientists with financial bonuses. Resources are allocated to two categories of researchers, namely established researchers (via incentives and a small number of specialised support categories e.g. support for research entities) and emerging researchers (via the top-up of NRF grants and an internal Research Development Fund). In this regard, a 2:1 funding partnership was agreed between NMMU and Thuthuka top-up in order to support womanin-research; black academics (REDIBA); and researchers-in-training. The NMMU top-up is limited to a maximum of R50,000 per year for SET and R35 000 for SSH applicants. Support for the second group results in more black and female staff members becoming productive researchers. The research activities of staff members who fall outside these two groups are financially supported by Faculty RTI Committees. Individual researchers get incentives from publications, Master's, and PhD supervision at NMMU. For the publication output subsidy, thirty percent of the Rand value of a unit is paid into the research account in the name of the researcher. Thirty percent of this amount 
can be given as a single-payment, non-pensionable bonus to researchers, as a taxable personal award. A single-payment, non-pensionable bonus is also applied to researchers as a taxable personal award or as a non-taxable research grant, each time the individual is successfully rated in a normal five-year cycle.

As NRF rating brings about a variety of opportunities for academic staff and researchers, NMMU's academic staff are motivated to acquire NRF rating. NRF ${ }^{114}$ rating remains one of the most important benchmarks of excellence in research at universities in South Africa and in many instances the research status of a university is determined by the number (and level) of NRF rated staff members. The rating system encourages researchers to publish high quality outputs in high impact journals/outlets, which is usually accompanied by academic promotion other than financial rewards. The monetary value attached to NRF rating and the bonus is $A=R 50 k, B$ \& $P=R 30 k, C=R 20 k, Y=R 10 k$ and $\mathrm{L}=\mathrm{R} 5 \mathrm{k}$. In terms of rewards for staff producing research for postgraduate students qualifying for DHET research output subsidy, $70 \%$ goes to the supervisor/promoter and $30 \%$ to the co-supervisor(s)/co-promoter(s) unless both parties agree on a different split. The incentive schemes have increased the number of scientific publications and thereby the volume of NMMU's revenue from research.

An academic's chances of getting a salary increase or promotion is often centred on his/her research production in refereed publications or the volume of competitive grants brought in from research councils. Although not fully enforced, publish-or-perish logic dominates NMMU's assessments of faculty performance. Targets are based on the assumption that a permanent academic should publish at least one research article every two years. The ratio at NMMU suggests that each permanent academic can publish one research article every three years.

Additionally, the senior university leaders have encouraged academic staff to engage into research or/and build research capacity by creating competitively awarded internal funding pools, supported by cross department subsidies and

114 A researcher may submit his/her research portfolio via the Research Office to the National Research Foundation (NRF) for evaluation. The NRF rates the researcher in one of the following categories: A, B, C, P, Y or L. NRF rated researchers generate a substantial amount of $1^{\text {st }}$ stream income for the institution through research publications and the training of master's and doctoral students and also generate $3^{\text {rd }}$ stream income through their engagement with commerce and industry. NRF Broad Investment Areas include next generation, emerging researchers, established researchers strategic investment, and infrastructure. 
existing resources. NMMU has created a Strategic Research Fund (SRF) to invest in research projects and infrastructures. Academics are encouraged to apply for funding from the SRF. Five (5) or fewer awards are granted annually to research entities (units, centres and institutes), with a monetary value of up to R100,000 each. The funding is seed funding for research entities needing development to enable them to be nationally or internationally competitive. Internally, this has enabled the university to raise the levels of research funding support across the system, whilst particularly targeting support for Research Development and Teaching Replacement Grant funding for emerging and next generation researchers. The university has also invested in 19 Postdoctoral Fellowships in 2011. These interventions, among others, are crucial for the renewal of NMMU's research capabilities for the next generation.

Academic units such as departments and faculties also get many benefits from research and consultancy activities, which fosters revenue generation from these activities. The benefits consist of staff development programmes, professional conference participation by staff, library acquisitions, and the provision of equipment and vehicles. Departments and faculties that do research are included in the sharing formula based on income generation performance. For instance, twenty percent of the Rand value of a unit for publication output subsidy is allocated to the RTI Committee. Fifty percent of this amount is to be transferred to faculties to fund RTI activities. This funding scheme is intended to support research units, centres, and institutes, and researchers who do not qualify for support from the NMMU RTI Committee and the running costs of projects. Academic support units such as HEADS also qualify if they have a functional RTI Committee. The remaining fifty percent is used to fund research activities supported by the NMMU RTI Committee. This does not preclude Research Management (RM) from submitting an annual operating budget for expenditures associated with the RTI Committee. NRF top-up reserve fund for equipment is used to provide top-ups to purchase expensive research equipment co-funded by NRF. Moreover, the central management of NMMU levies $15 \%$ of the total research project budget where possible. This research levy further splits as $5 \%$ to indirect ${ }^{115}$ cost recovery and $10 \%$ to the Strategic Research Fund. The case study university uses its earned revenue to fund a new research fellowship scheme for young faculty by crosssubsidising internally. This strategy reinforces all internal actors' involvement in fostering the universities' research and consultancy agenda.

115 Generally called overhead costs, these are real costs but are difficult to determine exactly; they include such things as legal costs, financial administration, human resource administration, rent, security, water and lights, access to libraries, insurance, maintenance, use of brands and names, etc.. 
The senior university leaders have formulated a workload policy to address mission drift in teaching or research (NMMU 2008:64). Academic staff workload models have at least $20 \%$ of time allocated to research. In general, the sharing of revenue and surplus at NMMU recognises contributions at individual, department, faculty, administrative unit, and university level, which has been found to be an important factor for revenue generation.

\subsection{Conclusion}

Revenue generation has increasingly become one of the survival mechanisms for financial sustainability in the South African higher education landscape. The results in this chapter show that the South African case study university has gained most of its resources (around 60\% of the entire budget in 2011) from nongovernmental sources since 2008. NMMU has diversified its revenue base to include student contributions, contract research and other non-academic activities including philanthropic funding more successfully than the Ethiopian and Kenyan universities discussed in Chapters 5 and 6. Thus, there is a perceptible trend towards distributed resource dependence at NMMU..

Student tuitions fees represent the highest contribution of NMMU's income structure. The environment of the South African case study university, coupled with NMMU's specific strengths in terms of its human resources, welldifferentiated academic programmes, adequate internal governance and management and reward system positively influenced the South African case study university to acquire resources by providing educational services to diverse stakeholders. In particular, the availability of growing demand for educational services from within the country, SADC and internationally, the incentives in the regulatory framework (i.e. high degree of financial, academic and organisational autonomy), and financial incentives for students in the form of loans and bursaries from various stakeholders are the most important factors in obtaining resources from a variety of stakeholders. Notably, the two most salient stakeholders of the university (i.e.; the South African government and the students)'s motivation to reap the social and individual benefits of university education has led to increasing demand for opening access to good quality higher education.

NMMU devised both adapting and altering strategies for acquiring resources by providing educational services. As part of its adaptive strategy, the university has differentiated its academic programmes horizontally and vertically (six tiers) to meet the soaring demand for university education from diverse groups of learners at cost-recovering (or higher) tuition fee levels. Another category of adapting strategy includes opening seven campuses in 
strategic locations in different places in the country, and using different pedagogical modes (e.g. contact, or distance). As part of the altering strategy, NMMU has formed alliances with other educational organisations (particularly middle level colleges) in its environment to take its educational services closer to potential students. Although most proliferation of programmes was in social sciences and humanities at undergraduate level, NMMU made remarkable progress in achieving differentiation in postgraduate education as well.

The findings in this chapter indicate that revenue generation from research and consultancy represented about 35\% of NMMU's nongovernmental resources. Both environmental factors and university specific conditions explain how the university managed to obtain more than one third of its nongovernmental revenue by offering research and consultancy services. The environment of NMMU consists of several stakeholders in research and consultancy services, such as the South African government including science councils, business and industry, not for-profit organisations (NPO) and individual donors, and foreign donors that allocate resources for having research and consultancy services in an exchange. Similarly, freedom to set priorities for research, determine charging levels for their research and consultancy, and freedom to generate revenue from research outputs and consultancy services are all legal and policy incentives to acquire resources by providing research and consultancy. As part of its adaptive strategy, NMMU has created research entities such as institutes, centres, and units alongside traditional academic departments, as well as research administrative support structures that are run and owned by the senior professors who hold NFR rating. Moreover, the South African case study university has formed alliances and linkages with other organisations (e.g., universities and research entities) in the environment that have further enhanced its revenue. This remarkable achievement is primarily a result of NMMU's capability in terms of human and nonhuman resources, along with the external opportunities for revenue generation from research and consultancy services.

The findings in this chapter show that NMMU obtained around $10 \%$ of its nongovernmental revenue by providing non-academic services and products to its internal and external stakeholders. The non-academic revenue generation activities consist of alumni fees, printing services, bookshops, conference hall and venue hire, testing services, accommodation, sport facilities, catering services, computer assembly, repair and maintenance of furniture and investment. These revenue generation activities, while improving the campus service experience for the university community, also help to generate revenue. As the main customers for the non-academic services are the university community itself, this study acknowledges that there are real organisational 
and economic differences between the university and other businesses in offering non-academic products and services.

The results in this chapter show that NMMU has well established stakeholder management structures and reward systems for linking up with external stakeholders and increasing internal actors' commitment to revenue generation. The participatory leadership style pursued by the senior university leaders and the university's competent administrative support staff have enabled the university to create a structured approach to stakeholder management. At NMMU, the administrative backbone fuses managerial and traditional academic values through several committees which include trusted peers. NMMU Trust is one of the organisational structures responsible for acquiring additional resources in innovative and dynamic ways to support the university's strategic plan. One of the most successful strategies for increasing the commitment of the academic community to revenue generation is the University's internal reward mechanism for individual staff and units. Although participation in revenue generation can sometimes indirectly lead to the recruitment and promotion of staff, revenue generation has not been one of the steering tools or criteria in the university's human resource policies.

Revenue generation is a dynamic process that requires additional capability to serve a rapidly changing organisational environment which is full of opportunities for acquiring resources. While NMMU has made remarkable progress in generating additional funding from diverse stakeholders, there is still a belief among the academic community that resources from nongovernmental sources can supplement, but not replace public budgets. Revenue generation is inevitable in the South African higher education landscape, but that inevitability needs to be managed in mission-focused and market-smart ways without imperilling core academic values or compromising the quality of education. 


\section{Comparative Analysis}

\subsection{Introduction}

In Chapters 5-7, we have analysed data on revenue generation at four SubSaharan African public universities in three countries. The results showed that each case study university has a complex organisational story in terms of revenue generation, which has been influenced by the contextual peculiarities of the university and unique features of their organisational characters. This chapter presents a comparative analysis of the similarities and differences between the four case study universities based on the research model depicted in Chapter 3, and the operationalisation of the key variables in Chapter 4. It focuses of four main issues. First, we provide a synthesis and analysis of the similarities and differences in the environments of the four case study universities. Second, we compare and contrast unique features of the organisational characters of the case study universities. Third, we identify key drivers, enablers for and barriers to revenue generation across the case study universities. Fourth, we consider the similarities and differences in the four universities' revenue generation strategies. Finally, we draw conclusions based on the findings.

\subsection{The environments of the case study universities: similarities and differences}

As the conceptual approach of the study focuses on the interactions between the environment, university specific conditions, and revenue generation strategies and activities, this section compares and contrasts the environmental contexts of the case study universities. Following the list of variables provided in Chapter 4, the comparison covers the following basic issues: the wider societal environment, the immediate environment, external stakeholders, and stakeholder salience in terms of regulatory powers and funding (see Chapter 4 Tables 4.2, 4.3 and 4.4). The ultimate goal of this section is to investigate the extent to which the environments of the case study universities influence their revenue generation efforts. 


\subsubsection{The wider societal environment}

As discussed in Chapter 4 (see Table 4.2), the wider societal environment that influences higher education includes demographic trends, overall economic conditions, and political commitment to higher education. The analysis of the case studies in Chapters 5-7 showed that demographic trends in the three sampled countries positively influence the external demand for higher education. There has been rising social demand for higher education in Ethiopia, Kenya, and South Africa due to high rates of population growth, and rapidly growing school age populations (see Table 8.1 below).

Table 8.1: Key Population statistics for sampled countries

\begin{tabular}{lccccc}
\hline Country & $\begin{array}{c}\text { Total } \\
\text { Population } \\
\text { (2010) in } \\
\text { millions }\end{array}$ & $\begin{array}{c}\text { Proportio } \\
\text { n of } \\
\text { populatio } \\
\mathbf{n} \text { below } \\
\text { the age of } \\
\mathbf{1 5}\end{array}$ & $\begin{array}{c}\text { Proportio } \\
\text { n of } \\
\text { populatio } \\
\text { n between } \\
\mathbf{1 5} \text { and } \mathbf{6 4}\end{array}$ & $\begin{array}{c}\text { Proportion } \\
\text { of } \\
\text { population } \\
\mathbf{6 5} \text { or older }\end{array}$ & $\begin{array}{c}\text { Populati } \\
\text { on } \\
\text { annual } \\
\text { growth } \\
\text { rate }\end{array}$ \\
\hline Ethiopia & 85.0 & $41.5 \%$ & $55.2 \%$ & $3.3 \%$ & $2.6 \%$ \\
Kenya & 40.9 & $42.5 \%$ & $54.9 \%$ & $2.7 \%$ & $2.6 \%$ \\
South & 50.5 & $30.1 \%$ & $65.2 \%$ & $4.6 \%$ & $1.2 \%$ \\
Africa & & & & & \\
\hline
\end{tabular}

Source: UNPF, 2010

The results of the analysis in the case study chapters show that the number of pre-higher education graduates (and particularly an increase in secondary school and technical and vocational education enrolment) automatically increases the number of candidates seeking to enter higher education. In Ethiopia, around $31 \%$ of students graduating from preparatory schools and TVET will access higher education, as indicated in the Growth and Transformation Plan (MoFED, 2010). This means that there will be an annual intake of 467,000 undergraduate students by 2015 . Likewise, Kenya plans to raise the transition rate from secondary level to university from $8 \%$ to $15 \%$ in order to reach $20 \%$ higher education participation by 2030 from $4.6 \%$ in 2008. In South Africa, about $80 \%$ of all students enrolled in secondary education successfully pass the exit exam by 2030 . The national plan for higher education of South Africa sets a goal of $20 \%$ participation by 2016 , from the current $15 \%$. The number of undergraduates across the three countries has also rapidly increased demand for postgraduate education. The annual intake for postgraduate programmes (Master's degrees and PhDs) in Ethiopia will reach 
16,100 students by 2015, up from 10,734 in 2009/10. In South Africa, $75 \%$ of university academic staff are expected to hold PhDs by 2030. Kenya wishes to rapidly increase graduate enrolments to staff its 15 newly established universities.

The current economic environments of the case study universities generally invite them to play a role in terms of education and research (see Table 8.2).

Table 8.2: Selected economic development indicators

\begin{tabular}{lcccc}
\hline Country & $\begin{array}{c}\text { Gross domestic } \\
\text { product per capita } \\
\text { in current US } \\
\text { dollars/2010 }\end{array}$ & $\begin{array}{c}\text { Rank out of } \\
\mathbf{1 4 2} \\
\text { countries }\end{array}$ & $\begin{array}{c}\text { Stage of } \\
\text { development } \\
\text { (2011-12) }\end{array}$ & $\begin{array}{c}\text { Overall } \\
\text { competitive } \\
\text { ranking (out of } \\
\text { 142 countries) }\end{array}$ \\
\hline Ethiopia & 350 & 140 & Factor driven & 106 \\
Kenya & 809 & 123 & Factor driven & 102 \\
South & 7,158 & 66 & $\begin{array}{c}\text { Efficiency } \\
\text { driven }\end{array}$ & 50 \\
Africa & & & &
\end{tabular}

Source: WEF 2011-2012

Chart 8-1 below shows that our sampled countries have generally had good recent economic performances (IMF, 2011). South Africa is the highest-ranked country in Sub-Saharan Africa and the second-placed among the BRICS economies, after China. Recently Ethiopia has been one of the most rapidly growing non-oil economies in Africa.

Chart 8-1 Real GDP growth rates, 2007-11

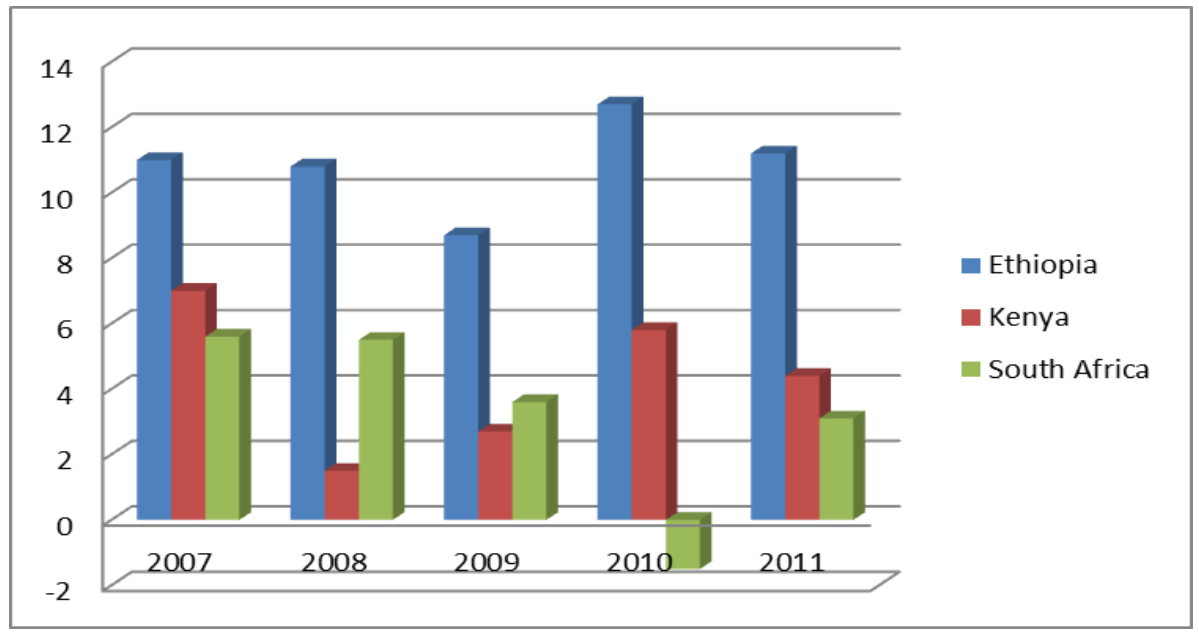

Source: accessed on 25 April 2013: http://www.africaneconomicoutlook.org/en/datastatistics/table-2-real-gdp-growth-rates-2003-2013/ or African Economic Outlook. 
While the growth in the Ethiopian economy enables the country to invest more in the case study universities, revenue from state appropriations remains the same or has reduced in the Kenyan and South African case study universities. Compared to the agriculture-based economies of Ethiopia and Kenya, that often need human resources at the intermediate level and in agriculture (see World Bank, 2010:132), the service and industrial based economy in South Africa ${ }^{116}$ may require a workforce who have university degrees. A move to develop industrialised knowledge-based economies in all three countries over the next 20 to 30 years may lead to expanded access to higher education. Additionally, the rapidly growing economies in the three countries have already brought significant changes within the employment market and paved the way for higher education to become one of the preconditions for high rates of employment compared to pre-higher education graduates. In South Africa, for example, the unemployment rate for those with university degrees is only $3 \%$, for those with matric it is $28 \%$, but for those without matric it is over $60 \%$ (NMMU, 2008).

With regard to political matters, the governments of the three countries have all endorsed the role of higher education in national development. Universities are recognised as strategic ingredients for national development and they are required to contribute to national productivity through the production of a well-educated workforce and research. There are political commitments to the expansion of good quality higher education across the sample countries, backed up by huge investments in their higher education systems. The three countries have maintained their public investment in higher education over recent decades, allocating approximately $0.75 \%$ to $1 \%$ of their gross domestic products (GDP) and around $14 \%-32 \%$ of public expenditure on education to the higher education systems. This suggests that the wider societal environments of the four case study universities invite them to play a role in expanding educational services and research, which may lead to revenue generation.

\subsubsection{The immediate environment of the four universities: similarities and differences}

In this subsection, we compare and contrast the task environments of the case study universities, where their products or services (i.e. academic degrees and other educational and research services) are exchanged for resources. As indicated in Table 8.4 below, the four case study universities engage in transactions with similar organisations and groups of individuals (or simply

116 In 2011, for instance, South Africa's GDP by sector shows that agriculture contributed $2.5 \%$, industry $31.6 \%$, and the service sector contributed 65.9 . 
stakeholders) with different capabilities to influence their actions and behaviours in the process of acquiring resources (see Chapters 5-7). The stakeholders consist of regulatory agencies, key suppliers, product consumers (customers), and competitors. One stakeholder group can play one or more of these roles. For instance, national governments can be regulatory bodies and consumers as the same time. The degree to which the stakeholders influence the four universities varies from one university to another. The concept of stakeholder analysis is used to assist us in classifying stakeholders and determining stakeholder salience, which in turn enables us to understand the ways the senior university leaders behave towards the needs and expectations of a given stakeholder. As stated in Chapters 3 and 4, a stakeholder's ability to exercise powers and/or the criticality of the provided (potential) funds for the universities are used as tools in determining the interactions between a given stakeholder and the universities. In the subsequent subsections, we discuss stakeholder salience in terms of funding and regulatory powers as revealed in the findings of each case study university.

\subsubsection{Stakeholder salience in terms of funding}

With respect to funding, five main stakeholders provide resources to the case study universities. The relative importance of these stakeholders to the universities in terms of the magnitude of the money provided, and their potential to provide funding in the future, is indicated in Table 8.4 below.

Table 8.4: Stakeholder salience in terms of funding

\begin{tabular}{lcccc}
\hline Stakeholder & ASTU & HU & JKUAT & NMMU \\
\hline $\begin{array}{l}\text { Public Authorities } \\
\text { Students (and their parents) }\end{array}$ & ++++ & ++++ & ++++ & ++++ \\
$\begin{array}{l}\text { Donors (bilateral and } \\
\text { multilateral) }\end{array}$ & ++ & +++ & ++++ & +++ \\
$\begin{array}{l}\text { Ministries, Regional and Local } \\
\text { authorities }\end{array}$ & ++ & ++ & ++ & ++ \\
$\begin{array}{l}\text { Business \& Industry } \\
\text { Key: }\end{array}$ & + & ++ & +++ & +++ \\
\hline
\end{tabular}

Key: ++++ the most salient +++more salient ++ salient + less salient

The national governments of the three countries were rated as the most salient stakeholders in all of the case study universities, due to their serious commitment to spending on their higher education systems. As a percentage of the education budget, higher education spending equalled $31.7 \%$ in Ethiopia, 
$14 \%$ in Kenya, and 15\% in South Africa. The national governments use different funding schemes or resource allocation mechanisms to influence the behaviour of their universities (see section 8.2.4) in the process of acquiring resources. Students are the second most important stakeholder for the Ethiopian and South African case study universities, while they are the most salient stakeholders for the Kenyan case study university. JKUAT generated the largest share of its revenues from student tuition fees in the last five years (see Section 8.3.1.1), even more than its main government source. Population growth and rapidly expanding pre-higher education systems (notably increases in secondary graduates) create more opportunities for the case study universities to offer educational services to acquire resources. In other words, more accessible secondary education means more students entitled to various types of higher education in their lifetimes. We shall return to this issue in section 8.2.2.3.

Ministries (non-finance ministry), regional and local authorities were found to be the third most salient stakeholders for the case study universities, except for ASTU. The resources from these public authorities are expected to grow rapidly in the future. The Ethiopian Growth and Transformation Plan (GTP), Kenya's Vision 2030, and the Medium Term Strategic Frameworks (MTSF) for 2009-2014 in South Africa all position universities as strategic assets to encourage the economic competitiveness of their respective countries, regions, and hometowns. Universities in these countries are required to offer teaching, research, short courses, and consultancy services to improve the national implementation capacity. Special funds for capacity building and research have also been earmarked. The representation of government authorities on the boards or councils of the case study universities is a way of strengthening the universities' contributions to national and regional demands.

Donors (both bilateral and multilateral) are the fourth most salient stakeholder category for the case study universities, because of their influence on funding. The annual share of direct and indirect support for Ethiopia, Kenya, and South Africa is shown in Table 8.5 below. 
Table 8.5: Aid to higher education, annual average commitments, 2001-06

\begin{tabular}{lcc}
\hline Country & $\begin{array}{c}\text { Amount of direct aid in US\$ } \\
\text { (million) }\end{array}$ & $\begin{array}{c}\text { Amount of indirect aid in } \\
\text { US\$ (million) }\end{array}$ \\
\hline Ethiopia & 11.3 & 8.3 \\
Kenya & 5.5 & 5.4 \\
South & 17.4 & 3.1 \\
Africa & & \\
\hline
\end{tabular}

Source: World Bank (2010: 98)

For decades, research and development in African universities has been supported by aid that consist of fellowships for training for research capacity building, research grants to individuals and teams, institution building, strengthening and twinning arrangements, North-South partnership research programmes are a key funding form (see World Bank, 2010; Gaillard, 2000). This is particularly important in Ethiopia and Kenya, where there are limited or no government funds for research. Private foundations (e.g. the Ford, Carnegie, Rockefeller, MacArthur, Hewlett, Mellon, and Kresge foundations and the Partnership for Higher Education in Africa) have also played an important role in financing higher education in Africa. Between 2000 and 2008, for instance, the partnership foundations contributed an aggregate of US\$354 million to higher education initiatives in seven countries (World Bank, 2010), benefitting the Kenyan and South African higher education systems. Moreover, NMMU and to a limited extent JKUAT have developed fundraising activities and are targeting philanthropic sources. This is not the case in Ethiopia.

Table 8.4 shows that business and industry is the third salient stakeholder for NMMU, whereas it is the least salient stakeholder for the Ethiopian and Kenyan case study universities. Ethiopia and Kenya's industries are often small to medium-scale firms using low technology inputs, while the relatively large industries are subsidiaries of international companies which draw upon the inhouse R\&D capabilities of their parent company (see also Munyoki et al., 2011). As a result, ASTU, HU, and JKUAT face many challenges in collaborating with these small industrial firms. The key challenges are that all or most technology is imported, and R\&D concepts are not fully understood by the personnel of the small industrial firms. Some opportunities for collaborations between universities and industrial firms are available in the areas of tailor-made shortterm training, consultancy, and identification of technology needs rather than cooperation in the areas of research and development. NMMU is in a completely different setting, with several opportunities for university-industry cooperation. This is because of the economic environment of South Africa that 
is characterised by both a considerable number of multinational industrial firms, and a growing number of small and medium-sized firms. The concentration of car production industrial firms in Port Elisabeth, where NMMU is situated, has led to an intense collaboration between the university and industrial firms (see CHET, 2010).

\subsubsection{Stakeholder salience in terms of regulatory powers}

The stakeholder's power to influence the four universities is indicated in Table 8.6.

Table 8.6: Stakeholder Salience in Terms of Regulations

\begin{tabular}{lcccc}
\hline Stakeholder & ASTU & HU & JKUAT & NMMU \\
\hline Government & ++++ & ++++ & ++++ & ++++ \\
Donors & +++ & +++ & +++ & ++ \\
Professional & + & + & ++ & ++ \\
associations & & & & + \\
\hline
\end{tabular}

Key: ++++ the most salient +++more salient ++ salient + less salient

The national governments here represent a wider group of public authorities listed in Chapter 5 (see Table 5.12) for the Ethiopian case study universities, Chapter 6 (Table 6.6) for the Kenyan case study university, and Chapter 7(Table 7.7) for the South African case study university. The governments are the most salient stakeholders in terms of their regulatory powers across the case study universities. The Ministry of Education in Ethiopia, the Ministry of Higher Education, Science and Technology (MOHEST) in Kenya, and the Ministry of Higher Education and Training in South Africa are the most prominent stakeholders influencing their respective higher education systems. There are also so-called "intermediate" or "buffer" agencies that carry out particular functions like accreditation and strategic leadership. Compared to the Ethiopian and Kenyan higher education systems, the quality assurance body in South Africa is strong and powerful. NMMU is mainly regulated through an accreditation system led by a statutory body, the Council on Higher Education, and its implementation arm, the Higher Education Quality Committee (HEQC).

Several regulatory tools are used (see Tables 5.14, 6.8 and 7.9 in Chapters 5, 6 and 7 respectively) to influence the actions and behaviour of the case study universities. The key regulation tools are: the Higher Education Proclamation 650/2009 for Ethiopia, the Universities Act, 2012 and JKUAT Act, 1994 (repealed in 2012) for Kenya, and the Higher Education Act 101 of 1997 for South Africa. 
All universities are required to demonstrate conformity with the law in order to acquire legitimacy for their behaviours and outcomes of their actions, thus sustaining their operations and securing a regular flow of public resources. The Ethiopian and South African governments legally allow their public universities to be involved in revenue generation. The Kenyan case study university was neither allowed nor denied permission to pursue additional revenue streams prior to 2012. The newly ratified Universities Act of Kenya openly acknowledges earned revenue from sources other than the government as legitimate revenue for Kenyan public universities. In this research, we considered four dimensions of autonomy (finance, staffing, education and research, and internal governance) to explore the link between revenue generation and the degree of organisational autonomy, based on the perceptions of the interviewees and documentary evidence (Table 4.4). The empirical findings are presented below.

Table 8.7 below shows the dimensions of academic autonomy that facilitate revenue generation in the case study universities. 
Table 8.7: Autonomy with Respect to Academic Matters

\begin{tabular}{|c|c|c|c|c|}
\hline Aspect & ASTU & HU & JKUAT & NMMU \\
\hline $\begin{array}{l}\text { Freedom to select and admit parallel }{ }^{117} \\
\text { undergraduate students (BA/BSc) and } \\
\text { postgraduate students (MA/MSc and } \mathrm{PhD})\end{array}$ & + & + & + & + \\
\hline Freedom to select and admit regular students & - & - & - & + \\
\hline $\begin{array}{l}\text { Freedom to decide on parallel student } \\
\text { numbers }\end{array}$ & + & + & + & + \\
\hline Freedom to introduce degree programmes & + & + & + & - \\
\hline Freedom to terminate degree programmes & + & + & + & + \\
\hline Freedom to design programmes & + & + & + & - \\
\hline $\begin{array}{l}\text { Freedom to decide modes of instruction and } \\
\text { delivery }\end{array}$ & + & + & + & + \\
\hline $\begin{array}{l}\text { Ability to charge tuition fees for government } \\
\text { sponsored students }\end{array}$ & - & - & - & + \\
\hline $\begin{array}{l}\text { Ability to charge tuition fees for } \\
\text { nongovernment sponsored students }\end{array}$ & + & + & + & + \\
\hline Freedom to set priorities for their research & + & + & + & + \\
\hline $\begin{array}{l}\text { Freedom to determine charging levels for } \\
\text { research and consultancy work }\end{array}$ & + & + & + & + \\
\hline $\begin{array}{l}\text { Ability to generate revenue from research } \\
\text { and consultancy services }\end{array}$ & + & + & + & + \\
\hline
\end{tabular}

Key: + present - absent

The findings suggested that the four case study universities enjoy substantial academic autonomy. The higher education laws allow universities to find and exploit niches in the academic market place, and thereby create opportunities for the sale of academic services (education and research).

The findings with respect to the financial autonomy of the four universities are depicted in Table 8.8 below.

${ }^{117}$ No such students at NMMU 
Table 8.8: Financial Autonomy

\begin{tabular}{|c|c|c|c|c|}
\hline Aspect & ASTU & HU & JKUAT & NMMU \\
\hline $\begin{array}{l}\text { Generation and deployment of } \\
\text { monetary resources }\end{array}$ & + & + & + & + \\
\hline Ability to keep financial surpluses & - & - & + & + \\
\hline $\begin{array}{l}\text { Ability to charge tuition fees to } \\
\text { government sponsored students }\end{array}$ & - & - & - & + \\
\hline $\begin{array}{l}\text { Ability to charge tuition fees to } \\
\text { nongovernment sponsored students }\end{array}$ & + & + & + & + \\
\hline Lump-sum or block grant funding & - & - & + & + \\
\hline $\begin{array}{l}\text { Ability to set prices for research \& } \\
\text { consultancy services }\end{array}$ & + & + & + & + \\
\hline Ability to own buildings & + & + & + & + \\
\hline Ability to borrow money & - & - & - & - \\
\hline Ability to lease university facilities & + & + & + & - \\
\hline
\end{tabular}
Key: + YES - NO

The degree of financial autonomy is perceived as being lower in the Ethiopian case study universities as ASTU and HU cannot use their core budget to fund revenue generation (see Chapter 5). We will return to this issue in section 8.2.5.

Table 8.9 below depicts the degree of perceived autonomy in terms of staffing. 
Table 8.9: Autonomy with respect to staffing

\begin{tabular}{|c|c|c|c|c|}
\hline Aspect & ASTU & HU & JKUAT & NMMU \\
\hline Freedom to decide on recruitment & + & + & + & + \\
\hline $\begin{array}{l}\text { Freedom to decide on promotion of } \\
\text { academic staff }\end{array}$ & + & + & + & + \\
\hline $\begin{array}{l}\text { Freedom to decide on promotion of } \\
\text { administrative staff }\end{array}$ & - & - & - & - \\
\hline Freedom to decide on dismissal of staff & + & + & + & + \\
\hline $\begin{array}{l}\text { Freedom to set salaries for academic } \\
\text { staff }\end{array}$ & - & - & - & - \\
\hline $\begin{array}{l}\text { Freedom to set salaries for } \\
\text { administrative staff }\end{array}$ & + & - & - & - \\
\hline $\begin{array}{l}\text { Freedom to determine working } \\
\text { conditions for staff }\end{array}$ & + & + & + & + \\
\hline
\end{tabular}

Key: + YES - NO

All four case study universities are unable to set salary scales for their staff. However, according to the interviewees, the inability to control the overall salary costs prevented the Ethiopian case study universities from attracting and retaining qualified and motivated academic and administrative staff.

The four case study universities were granted autonomy with respect to internal governance as shown in Table 8.10.

Table 8.10: Autonomy with respect to internal governance

\begin{tabular}{lcccc}
\hline Aspect & ASTU & HU & JKUAT & NMMU \\
\hline $\begin{array}{l}\text { Freedom to decide on internal } \\
\text { governance and decision-making }\end{array}$ & + & + & + & + \\
structures/bodies & & & & \\
$\begin{array}{l}\text { Freedom to introduce new academic } \\
\text { structures (faculties, departments, } \\
\text { research centres) }\end{array}$ & + & & & \\
\hline
\end{tabular}

Key: + YES - NO 
Table 8.6 in the previous section also depicts the regulatory powers of donors and professional organisations over the four case study universities. The regulatory powers of donors in developing countries are naturally indirect, and are often mediated by international institutions like the World Bank, IMF, WTO, etc. These actors have played a steering role in higher education systems through three mutually inter-related policy lines of deregulation, liberalisation, and privatisation (Castells, 2000, cited in van der Wende, 2002). In this regard, the international donors have promoted a reduction in central state regulative and intervening roles, and a trend toward outcomes steering. Sub-Saharan African governments were encouraged to incorporate donors' agendas into their national policies and plans. For instance, higher education is increasingly regarded as a private good, which is subject to the conditions of the GATS agreements. Donors bind their financial loans and assistance to conditions that require developing countries to comply with and implement the institutional framework of developed countries. Ethiopian ${ }^{118}$ and Kenyan universities have encountered donor steering through coercively imposed financially motivated policies (see Chapters 5 and 6), while the donors have normatively influenced the South African public university (see Chapter 7; see also Ouma, 2007). Most interview respondents reported that donor funding schemes were more difficult to access and more complex to manage than their governmental budgets. The challenges include excessive reporting requirements, technical financial requirements (e.g. separate bank accounts for every project), and cofunding arrangements in some projects. Similarly, the professional associations seek to promote their particular professions and exert pressure on universities to improve the relevance and quality of degree programmes, and maintain and enforce standards of training and ethics in their vocational degree programmes. The cumulative effect of regulatory powers and funding explains the degree to which the four universities give priority to the demands of their external stakeholders. The national governments are the most salient stakeholders in the four universities.

\subsubsection{Funding schemes}

Although funding schemes explain organisational autonomy in terms of financial matters discussed above, we want to analyse this separately in this subsection. The methods of governmental budgetary allocations for the case study universities are presented in Table 8.11.

118 There were several conditionalties in the World Bank funded Post secondary Education Project. 
Table 8.11: Methods of Allocating Government Funds to Universities

\begin{tabular}{|c|c|c|c|}
\hline Method & Ethiopia & Kenya & South Africa \\
\hline Line-item budgeting & $\checkmark$ & & \\
\hline $\begin{array}{l}\text { Input-based budgeting (block } \\
\text { grant) }\end{array}$ & & $\checkmark$ & \\
\hline $\begin{array}{l}\text { Funding Formula based block } \\
\text { grant }\end{array}$ & & & $\checkmark$ \\
\hline Earmarked funds & & & $\checkmark$ \\
\hline Competitive funding & $\checkmark$ & & $\checkmark$ \\
\hline
\end{tabular}

Source: World Bank (2010:42)

The methods of allocating government funds to universities in Kenya and South Africa permit internal resource allocation by the universities themselves. Kenya employs input-based budgeting, which in principle makes use of the actual costs per student in prior years as reported by higher education organisations. This approach is open to subsequent negotiations between university administrators and the Ministry of Finance, causing substantial variations between universities in the amount of money received per student. In any case, public universities in Kenya are free to allocate their block grant as they see fit.

In South Africa where several funding schemes are employed (see Table 8.11above), the national government allocates budgets to universities in ways that advance policy priorities. Funding pays universities for delivering teaching and research services specified in government-approved plans. Block grants comprise (a) teaching funds calculated by student enrolment and costs per student for different subject matter categories, (b) teaching funds based on agreed teaching outputs (for example, improved graduation rates), (c) research funds for agreed outputs including research master's, doctorates and publications, and (d) an institutional factor fund for enrolling students from disadvantaged groups. This makes enrolment consistent with governmentdesignated priority areas. Earmarked funds are designated for specific purposes, such as the national student financial aid scheme (NSFAS), research development, foundational programmes, teaching development, approved capital projects, and interest payments on approved loans. The advantages of funding modalities in South Africa are its predictability, incentives for 
efficiency, capacity to operate within hard budget constraints, and promotion of organisational autonomy and equity.

One of the interesting advantages of enhancing access to higher education in Kenya and South Africa is the student support schemes. The National Student Financial Aid Scheme (NSFAS) in South Africa and the Higher Education Loans Board (HELB) in Kenya provide incentives to students to enrol in higher education. The national governments of Kenya and South Africa pay a certain amount per student directly to the case study universities to cover tuition fees, in order to decrease the cost of education for students and thereby improve access to higher education. As the investment in higher education made by the student is less dependent on their wealth, poor and disadvantaged but academically able students are encouraged to gain access to higher education.

Ethiopia's method of funding follows relatively rigid rules and restricts spending to particular items and regulates the extent to which funds may be switched from one line item to another. MoFED pre-allocates university budgets to cost items and/or activities so that it has a greater steering power over universities. This method has significantly impeded ASTU's and HU's capacity to manage their funds as they see fit and curtailed efficiency and responsiveness. Unlike Kenya and South Africa, the Ethiopian system does not have student support schemes for non-regular full cost paying students. The system does not create equality of opportunity for academically able but financially challenged students to access higher education.

\subsection{Characteristics of the case study universities: similarities and differences}

As discussed in Chapters 5 to 7 , the four case study universities have different histories, settings, and profiles that are linked to their mission statement, disciplinary configuration or specialisations, internal governance and management, and their human and nonhuman resources (see Table 4.1 in chapter 4). Each university's development is in itself a complex organisational story. Table 8.12 below provides some university specific conditions that are extracted from Table 4.7 in Chapter 4. 
Table 8.12: Selected university specific conditions

\begin{tabular}{|c|c|c|c|c|}
\hline Position & ASTU & HU & JKUAT & NMMU \\
\hline $\begin{array}{l}\text { Type of } \\
\text { University }\end{array}$ & $\begin{array}{l}\text { Comprehensi } \\
\text { ve University }\end{array}$ & $\begin{array}{l}\text { Comprehensi } \\
\text { ve University }\end{array}$ & $\begin{array}{l}\text { Comprehensi } \\
\text { ve University }\end{array}$ & $\begin{array}{l}\text { Comprehensi } \\
\text { ve University }\end{array}$ \\
\hline Mission & $\begin{array}{l}\text { Teaching, } \\
\text { Research, } \\
\text { and } \\
\text { Community } \\
\text { services }\end{array}$ & $\begin{array}{l}\text { Teaching, } \\
\text { Research, } \\
\text { and } \\
\text { Community } \\
\text { services }\end{array}$ & $\begin{array}{l}\text { Teaching, } \\
\text { research, and } \\
\text { Community } \\
\text { services }\end{array}$ & $\begin{array}{l}\text { Teaching, } \\
\text { Research, } \\
\text { and } \\
\text { Community } \\
\text { services }\end{array}$ \\
\hline $\begin{array}{l}\text { Total student } \\
\text { population } \\
\text { in 2010/11 }\end{array}$ & 19,516 & 30,634 & 20,000 & 26,119 \\
\hline Founded & 1983 & 1952 & 1994 & 2005 \\
\hline Emerged as & $\begin{array}{l}\text { Technical } \\
\text { University }\end{array}$ & $\begin{array}{l}\text { Agricultural } \\
\text { University }\end{array}$ & $\begin{array}{l}\text { Agricultural } \\
\text { and } \\
\text { Technology } \\
\text { University }\end{array}$ & $\begin{array}{l}\text { Technical } \\
\text { University }\end{array}$ \\
\hline Location & Urban & Rural & Rural & Urban \\
\hline
\end{tabular}

The results of this study indicate that all the case study universities have paid due attention to revenue generation in their mission statements. As comprehensive universities, the four universities offer a variety of programmes to address the educational requirements of different types of students (see Table 13 below). 
Table 8.13: Discipline mix at case study universities

\begin{tabular}{lcccc}
\hline Disciplinary field & ASTU & HU & JKUAT & NMMU $^{119}$ \\
\hline Engineering and Technology & $\checkmark$ & $\checkmark$ & $\checkmark$ & $\checkmark$ \\
Natural and Computational Science & $\checkmark$ & $\checkmark$ & $\checkmark$ & $\checkmark$ \\
Medicine and Health Sciences & $\checkmark$ & $\checkmark$ & $\checkmark$ & $\checkmark$ \\
Agricultural and Life Sciences & $\checkmark$ & $\checkmark$ & $\checkmark$ & $\bullet$ \\
Business and Economics & $\checkmark$ & $\checkmark$ & $\checkmark$ & $\checkmark$ \\
Social and Humanities & $\checkmark$ & $\checkmark$ & $\checkmark$ & $\checkmark$ \\
\hline
\end{tabular}

Key: $\checkmark$ Available $\bullet$ Not-available

Knowledge is clustered in each university within faculties, schools, and/or colleges. The narrower groupings, which are the basic building blocks or operating units, are generally known as departments, institutes, centres and/or units. Since the four case study universities have dozens departments, they are multiversities. There are two distinct tiers in the mode of knowledge organisation at the four case study universities: undergraduate and postgraduate education. All the universities are predominantly undergraduate teaching universities, with limited engagement in postgraduate education and research. In comparison with the Ethiopian case study universities, the Kenyan and South African universities have engaged in more postgraduate education and research, as depicted in Chart 8-2 below.

Chart 8-2 Total number of students in 2011/12

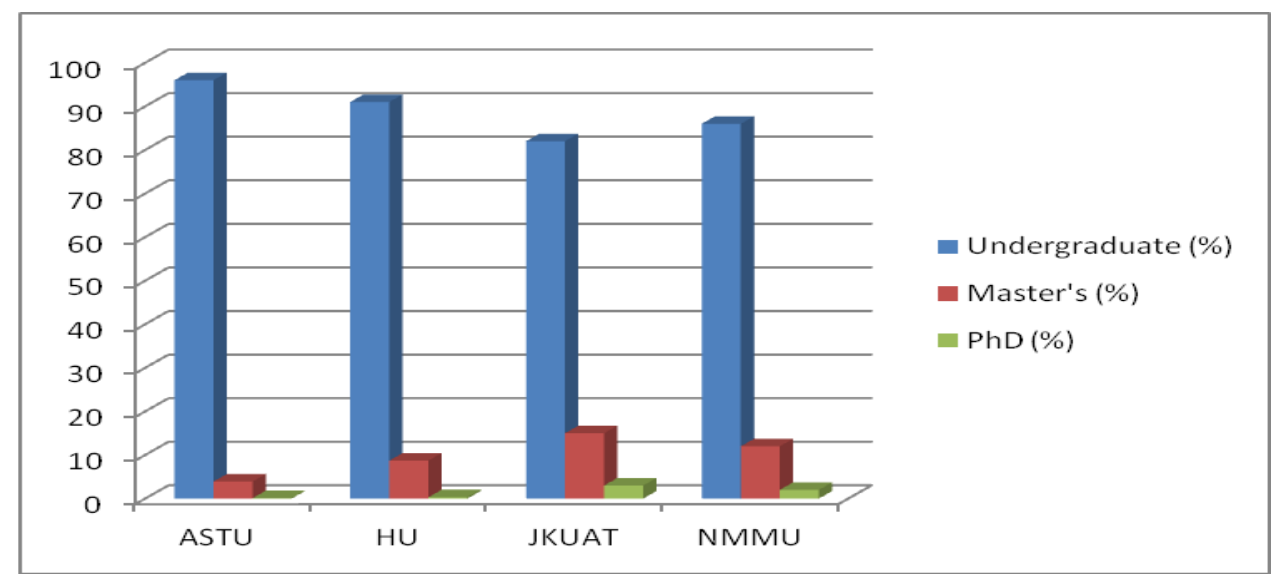

119 It does not have a faculty of agriculture. Agriculture related courses such as agricultural management and forestry are offered under the faculty of science. 
While research activities frequently take a back seat to fulfilling the evergrowing demand for teaching and there are inadequate research capabilities in the Ethiopian and Kenyan case study universities, NMMU has vibrant research traditions and it engages heavily in cutting-edge research activity. This suggests that with the exception of NMMU, the universities rarely developed researchled academic departments. University lecturers at NMMU are required to publish in recognised journals in order to boost research ratings, funding, and their prestige.

With respect to their internal governance structures and decision-making processes, we have identified at least four levels of authority across the case study universities. From top to bottom, the first layer of authority is Councils in the cases of JKUAT and NMMU or Boards in the cases of the Ethiopian case study universities. Decision-making approval of internal policies, resources, and strategic and annual plans are vested in the boards or councils. The second level is the authority of presidents or vice chancellors, who are heads of administration/management as well as academic leaders. At all the case study universities, their presidents, or vice chancellors are legally urged to act as CEOs, promoting efficiency and effectiveness. There have been calls for stronger leadership and centralisation of managerial authority at all the case study universities. As a result, there is, at least rhetorically, a movement away from collegial towards managerial styles of organisational governance and management, limiting the powers of academic senates to advisory roles on academic matters. Yet, the formal powers of the president/vice chancellor differ from one case study university to another. Although the direction of steering was towards 'academic leadership and management', all but ASTU maintained the parallel structures of 'administration' and 'academic policy-making and leadership' which were brought together through the committee system. In other words, all but ASTU still have large governance bodies under the principle of collegial representation alongside the legally enhanced strong executive leadership. HU, JKUAT, and NMMU typically maintain a 'deliberative' structure of committees, with senior academics chairing the committees. This web of interlocked central committees has become the heart of NMMU's capacity to steer itself. The utilisation of senates in major decisionmaking process at JKUAT and NMMU, and the committee structures, generally offer ample opportunities for staff participation in university decision-making processes. At $\mathrm{ASTU}^{120}$, the president himself is in charge of major decisions related to all aspects of the university. This personal leadership faced

${ }^{120}$ In the case of ASTU, however, almost all decisions are made by the managing board (notably the president). 
opposition from the academic community. One of the discernible trends across the case study universities has been the absence of devolution of decisionmaking powers in terms of finance, human resource, and procurement.

The third level aggregates the operating units and functions as part of the university. As discussed in the case study chapters, this level of authority refers to the roles of deans, or executive deans in the case of NMMU, and/or directors. The mid-line academic managers at the four case study universities perform a number of tasks on academic matters under the supervision of their respective senates. The responsibilities of deans and academic department heads have mainly been limited to academic matters such as the contents of the curriculum, teaching and learning issues, examinations, and research affairs. The centralised decision-making processes and structures in terms of finance, human resources, and procurement issues may come at the expense of reducing the responsiveness of the low-level units to rapidly changing opportunities in the environments, as reported by the deans and department heads. The new role of 'Director of Corporate Services' or similar, has been emerging, mirroring arrangements that already exist in some European universities. Recruitment to this position, as well as a range of specialist professional roles such as Director of Finance, Direct of Human Resources, or Director of Marketing and Public Relations, is increasingly likely to be from outside the higher education sector, to for strengthen the central steering capacity. The fourth level is the lowest major operating unit; namely, the department, institute, centre, and/or unit. As with the deans, the duties of academic department heads have mainly been limited to academic matters. Individual professors exercise extensive supervision of the work of students and often of that of junior faculty as well.

Various steering tools are employed in aligning the immediate interests of particular internal actors (e.g. academic staff, administrative staff, senior managers, and other office heads in the universities) with the overall missions of the universities. All the case study universities have policies that guide decisions specific to their operations. These include strategic plans, senate legislation, and other academic and non-academic policies. In contrast to the Ethiopian and Kenyan case study universities, NMMU has several such policies that define the rules of the game in the overall operation of the university. The policies enable it to coordinate its human and non-human resources, resource utilisation, and reward system effectively and efficiently.

In terms of staffing matters, while the Kenyan and South African case study universities have qualified and motivated academic staff and managerial expertise and competence, the Ethiopian case study universities suffer from shortages of qualified academic staff and professional managers. Chart 8-3 
presents the academic staff volume and composition (in terms of staff qualifications) in the four case study universities.

Chart 8-3 Academic staff volume and composition in 2010/11

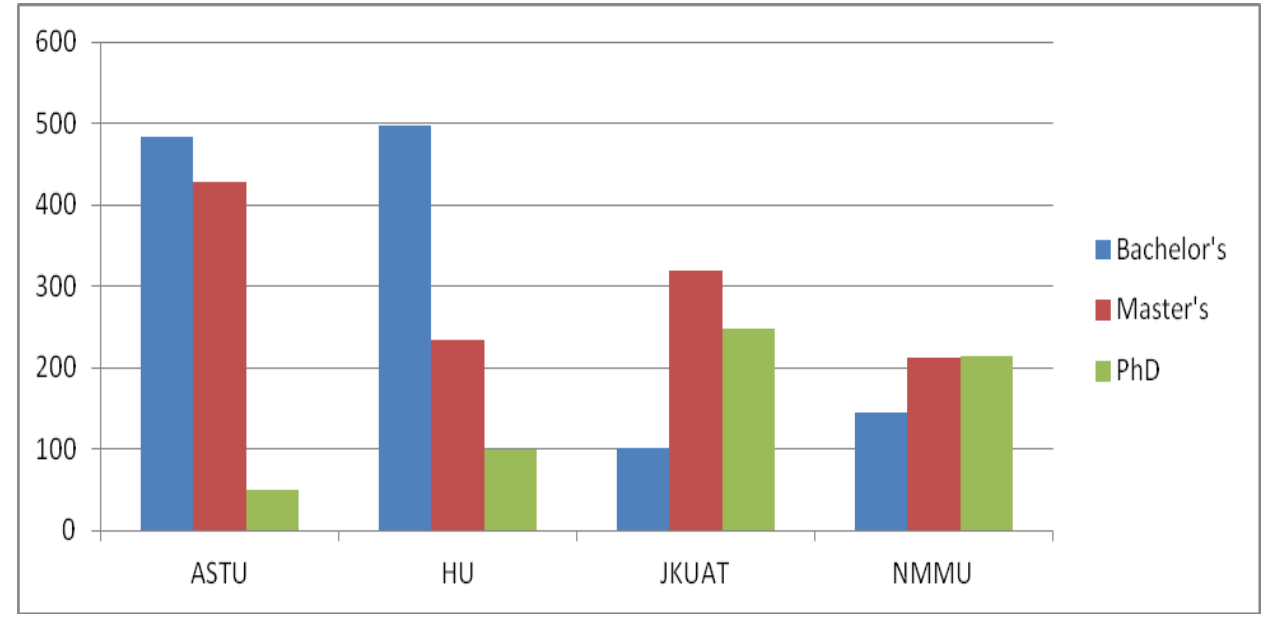

The proportion of academic staff with a PhD ranges from 5\% at ASTU to $38 \%$ at NMMU. To varying degrees, most faculties and colleges in the Ethiopian case study universities suffer from a lack of qualified staff, particularly at PhD level. The staff is characterised by young, inexperienced, and often insufficiently trained staff who lack the capacity to carry out research or supervise postgraduate students. Ensuring an adequate supply of quality academics is more challenging in disciplines in which the private sector offers much higher salaries and/or better career prospects. Such disciplines typically include computer sciences, business and economic studies and engineering. The migration of many talented academics to wealthier parts of the world, compounded by low academic salaries in Ethiopia, leaves many universities with few qualified academics. Low calibre academics are unable to attract new high calibre academics from elsewhere. Another pressing challenge is that staff often spend too little time on their main job because of second jobs and/or moonlighting to compensate for their low salaries. Additionally, several senior staff have more administration work and fewer teaching and research activities, while the junior faculty are knowledge workers. As a result, university capacity for research in Ethiopia and to some extent in Kenya is steadily eroding. This lack of qualified personnel, more than the lack of funds, is an obstacle to contracting or collaborating with stakeholders for revenue generation. JKUAT and NMMU have comparatively well qualified academic staff who can initiate and undertake research and supervise students as well as hold senior management positions in academic units. 
The case study universities employed large numbers of administrative support staff; the ratio of academic to non-academic staff was 1:2.3 for ASTU, 1:2.4 for HU, 1:2.07 for JKUAT and 1: 1.89 for NMMU in 2010. While the number of staff in support positions is high, the managerial expertise and professionalisation of the staff varies widely. JKUAT and NMMU were able to attract and retain specialised professional support managers, but HU lacks the professional managers needed to staff the administrative posts at intermediate positions. The latter uses its senior academic staff to run and coordinate administrative tasks. Although the Ethiopian case study universities have grown aware of the need for specialised professional management, the salary levels for support staff do not allow them to attract and retain professional managers. Several senior academics who could have been performing education and research tasks are heavily involved in administrative tasks that could otherwise be carried out by specialised support staff.

Chart 8-4 below shows that the four case study universities obtained resources from the main state allocation and other nongovernmental sources.

\section{Chart 8-4 Percentage of governmental recurrent budgets and nongovernmental revenue from 2007-2010}

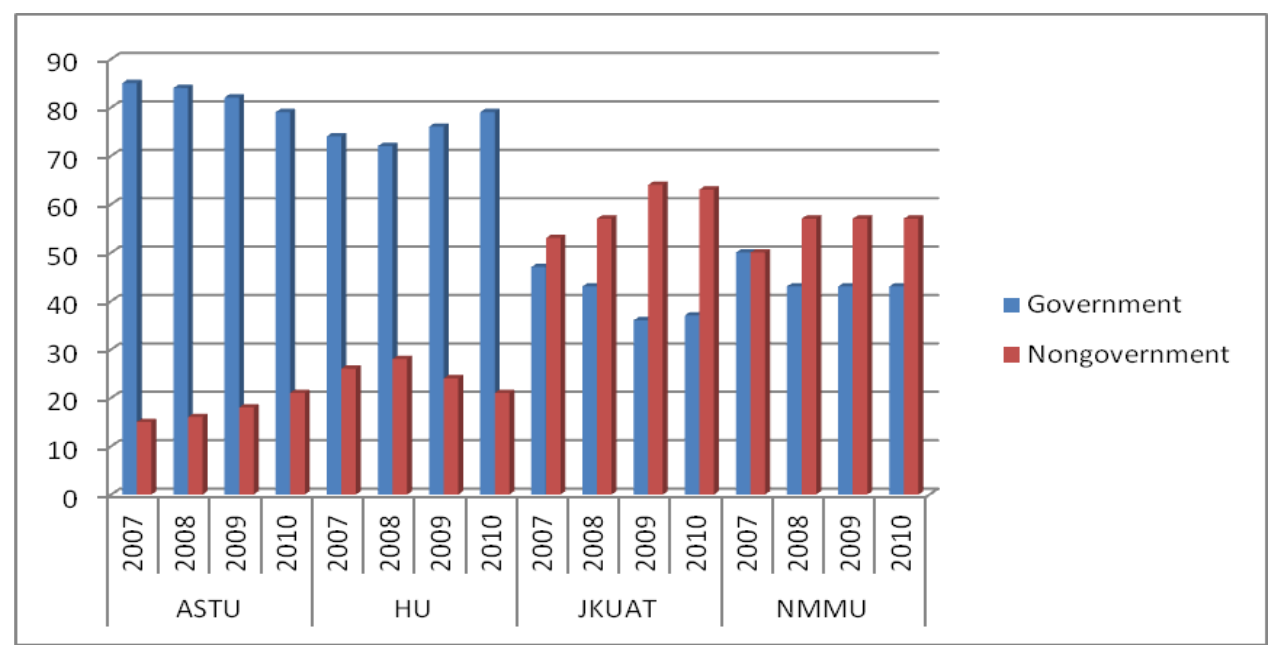

We shall return to income from all nongovernmental sources in section 8.5. Whereas JKUAT and NMMU obtained less government support as a share of the whole and more support from nongovernmental sources (particularly nonfinancial ministry), the Ethiopian case study universities still obtained most of their recurrent and capital budgets from the main state allocation. The Kenyan and South African governments suspended state funding for capital 
expenditure at JKUAT and NMMU, respectively, from 2007-2010, due to financial constraints. As a result of capital resource allocations, the physical infrastructure at ASTU and HU has been significantly enlarged by a series of construction phases on campuses, to increase admission capacity. However, no research funds were allocated to the Ethiopian case study universities from their national government prior to 2012/13.

To varying degrees, all except NMMU reported lack of adequate facilities in the face of ever-increasing student enrolments. On the one hand, the Ethiopian and Kenyan case study universities operate with over-crowding in classrooms and dormitories, a shortage of teaching materials and laboratories, deterioration of physical facilities, inadequate ICT equipment and computers, and inadequate library stocks. This is particularly a severe case at the Kenyan case study university, as JKUAT has faced serious challenges in the construction of new buildings to accommodate rising student numbers and to carry out renovations of the existing infrastructures. Long years of neglect in financing university research have left the Ethiopian and Kenyan case study universities with weak research infrastructures and equipment, and made them reliant on donors for research funds. The available laboratories at ASTU, HU and even at JKUAT are equipped for teaching purposes. On the other hand, NMMU has state of the art laboratories that enable it to engage in research in the areas of science, technology, and health. The research capacity and capability of the university serves as the basis for revenue generation activity from research.

\subsection{Revenue generation in the four case study universities}

This section compares the similarities and differences in revenue generation at the four case study universities. The first subsection compares the sources and shares of earned revenues across the case studies. The similarities and differences in the drivers for revenue generation across the universities are examined in the second subsection. In the third subsection, we compare and contrast the factors that enable or hinder revenue generation within and outside the case study universities. Although the revenue generation strategies of the universities could have been part of this section, they are discussed separately in section 8.5.

\subsubsection{Status of Revenue Generation at the Case Study Universities}

In the preceding sections ( 8.2 and 8.3 ) of this chapter, we reported that the four case study universities face growing demand for their services amid financial constraints from the main state budgets. All case study universities have, with 
varying levels of success, responded to the financial problems by constructing a portfolio of stakeholders to share rising costs. The analysis in this subsection is primarily based on the data collected from the case study universities and national budget proclamations. Chart 8-5 below presents the share of nongovernmental revenue in the total recurrent budget of the four case study universities from 2007 to 2010.

\section{Chart 8-5 Nongovernmental Revenue as a Percentage of Recurrent Budgets}

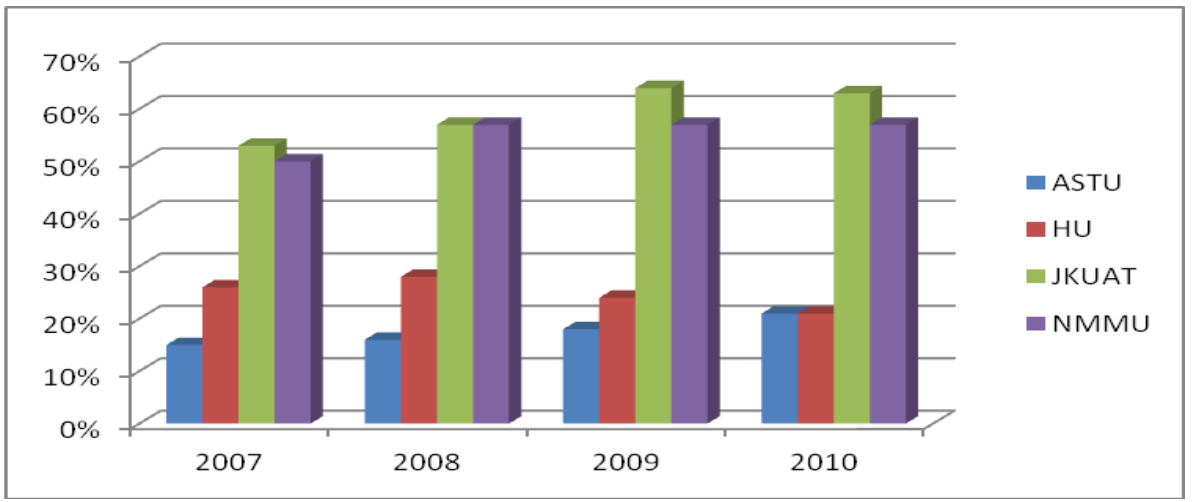

The financial data shown in chart 8-5 above does not include the monetary value of in-kind resources received by the four universities from diverse stakeholders. Moreover, we have faced substantial financial data problems for the Ethiopian case study universities because of a lack of transparency and a perceived fear of penalisation with lower state financing. As a result, our financial data does not allow us to reach solid conclusions. At JKUAT and NMMU, the proportion of nongovernmental funds surpassed the governmental sources (see Chart 8-4). The role of the government in financing is gradually diminishing, and therefore JKUAT and NMMU can best be described as "publically supported universities".

The four case study universities received the highest share of nongovernmental revenues from various stakeholders in return for their educational services and short courses, as shown in Chart 8-6 below. 


\section{Chart 8-6 Revenue from educational services as a percentage of total nongovernmental revenue}

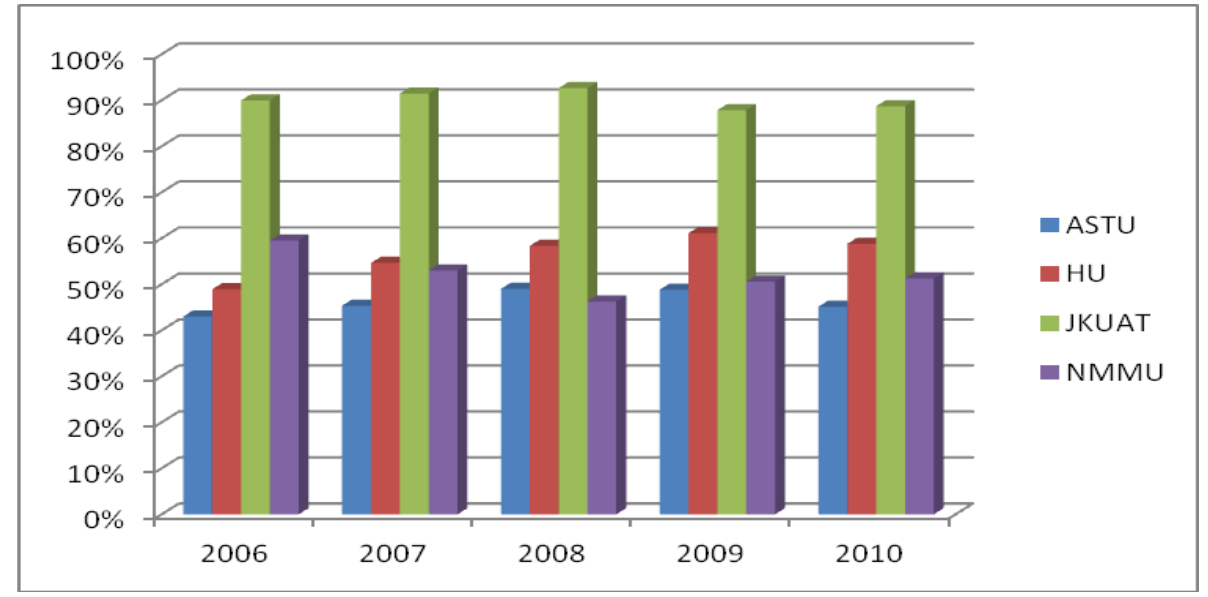

Financial contributions from students constitute the most directly available and sustainable revenue source, and therefore they are the most attractive complement to state support. With various levels of emphasis and performance, all case study universities received nongovernmental revenues from different stakeholders in return to their research and consultancy services, as indicated in Chart 8-7 below.

Chart 8-7 Revenue from research and consultancy services as a percentage of total nongovernmental revenue

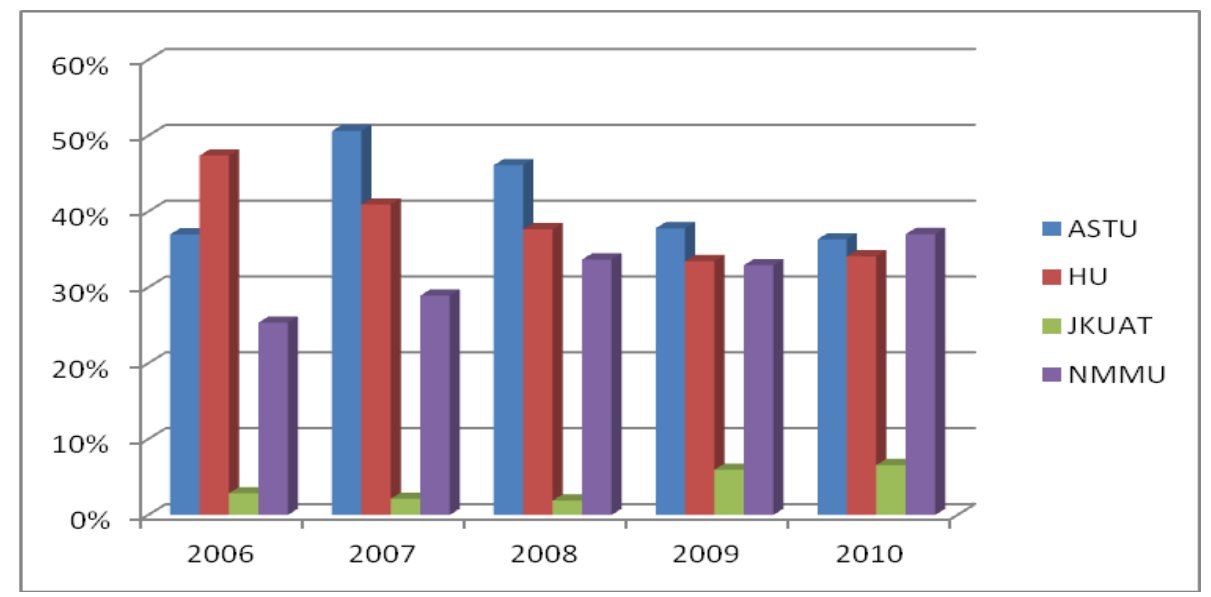

All the case study universities generate funds to conduct research than undertake research to generate revenue. Except NMMU, the universities do not have a vibrant research tradition or a tradition of cutting-edge scientific 
research and development. The achievements of the Ethiopian case study universities in earning close to $40 \%$ of their nongovernmental income from research and consultancy services did not reflect their real research traditions and capacity. The majority of research funds of ASTU and HU were obtained from international donors (notably the World Bank and NUFFIC) as per multiyear agreements between the donors and the Federal Ministry of Education and without facing any external competition. NMMU truly supplements its core funding from research and consultancy services because of its research tradition and research facilities. They are able to provide research and consultancy services to industry, government, and nongovernment offices.

The third category of nongovernmental revenue comprises the management of conference facilities, catering and accommodation, and a variety of earned revenue from self-supporting operations on campuses. Revenue from nonacademic services and products is indicated in Chart 8-8 below.

\section{Chart 8-8 Revenue from non-academic services as a percentage of nongovernmental revenue}

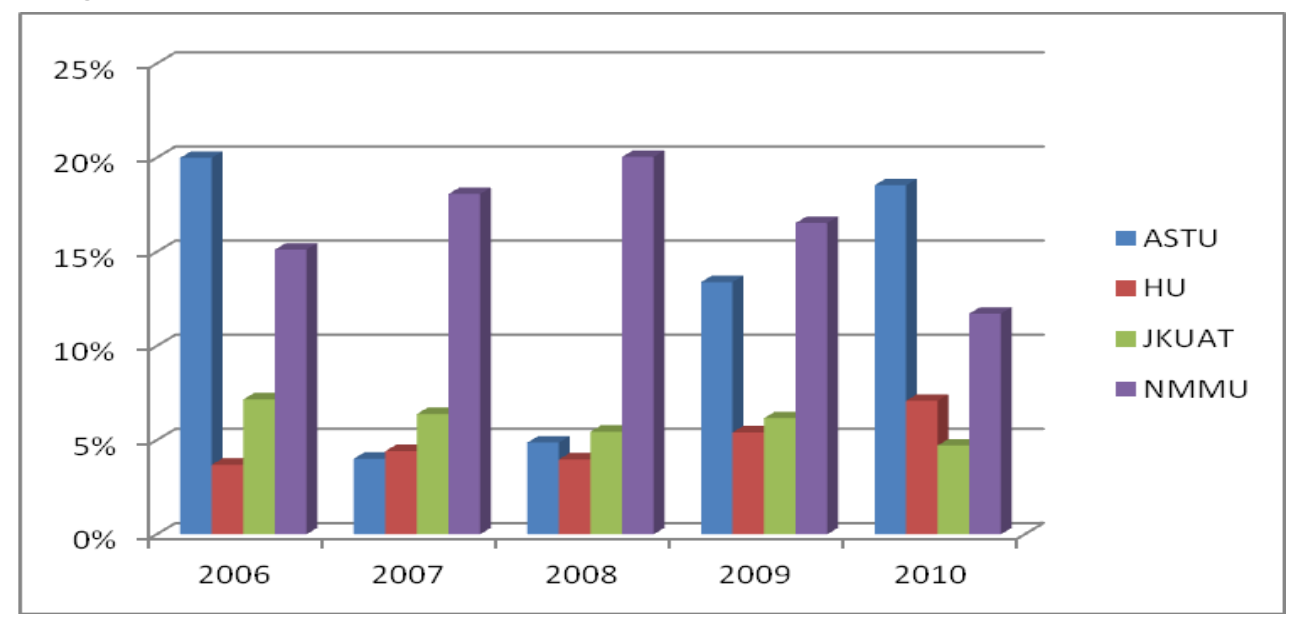

\subsubsection{Drivers of Revenue Generation at the Case Study Universities}

The findings of this study reveal that drivers of revenue generation across the case study universities were similar (see Chapters 5-7). The higher education systems in the three countries have been gradually moving from a minor cost in governmental budgets to a major expenditure because of student and knowledge growth. The cost of staff, learning and research materials, catering and accommodation services, coupled with inflationary pressures has made it very difficult to sustain university operations. Despite declarations of intent to 
increase spending on higher education, it is not very likely that public expenditure can grow significantly across the three countries, and therefore it will not be able to keep up with rapidly inflating costs. One of the most important drivers for revenue generation is thus a reduction or stagnation in public budgets for the universities. Heavy dependence on a single funder or state has become a risky matter (see Chapters 5 to 7) so risk mitigation is a powerful driver for revenue generation, forcing the case universities to raise revenue from alternative resource providers in the environment.

The general socio-economic and political contexts of the sampled countries are important drivers for revenue generation. As discussed in section 8.2, university education and research has increasingly been recognised as a key tool for development in the national strategic plans of Ethiopia, Kenya, and South Africa (see Growth and Transformation Plan for Ethiopia, Vision 2030 for Kenya, and Medium Term Strategic Framework for South Africa). In this regard, several sectoral policies and strategic plans drive certain types of cooperation, for instance between academia and regional or local governments, academia and business, and between academia and ministries, which has an effect on income diversification for universities. As it stands now, more students and different types of students seek to obtain higher education certificates, diplomas, and degrees from the case study universities, which drives universities to generate revenue by providing educational services. Equally, globalisation and internationalisation play a role in fostering opportunities to generate revenue from international students, most notably at the Kenyan and South African universities. The international environment of the case study universities has provided opportunities for fostering cross border research collaboration, which has also become a driver for revenue generation at the case study universities. The availability of many international organisations and donors, which provide resources for research at the case study universities, is a strong incentive to increase collaborative research activities across borders.

One of the strong motives for ASTU and HU to engage in revenue generation lies in their desire to avoid the administrative burden that often comes with public funding. Nongovernmental revenues are perceived as being easier to manage and can be allocated internally without restrictions. Revenue generation supports the expansion of the universities' missions by providing new resources to foster, for example, research tasks. Another strong motivation for the case study universities to generate revenue lies in their internal growth. The four case study universities have been constantly growing in terms of student population, academic and administrative support staff, visitors from 
overseas universities, and other stakeholders, which has an effect on their revenue generation agenda.

\subsubsection{Factors that Enable or Hinder Revenue Generation at the Case Study Universities}

The purpose of this subsection is to identify those factors that enable or erect barriers to revenue generation in the four case study universities. The subsection consists of two parts. The first part compares those environmental factors that enable or hinder revenue generation at the case study universities. The second part deals with university specific factors that enable or hinder revenue generation at the four universities.

\subsubsection{Environmental Factors that Enable or Hinder Revenue Generation in the Case Study Universities}

The findings of the study show that revenue generation at the case study universities has been influenced by the opportunities and threats in the environments of the case study universities (see Chapters 5 to 7 ). This study documented that the overall socio-economic and political context of the sampled countries, discussed in section 8.2 , invite the case study universities to play a vital role in the overall development of the countries. In particular, the aspirations of Ethiopia and Kenya to become middle-income countries within the coming 20 to 25 years necessitates an improvement in their human capital through expanding access to higher education. The spectacular progress achieved in the areas of primary and secondary school participation, and the expansion in vocational education (see Tables 5.20 in chapters 5, 6, and 7 respectively and 6.14, and Section 7.6.3.1) in all three countries has raised social demand for higher education. As stated in the strategic development plans of the three countries, more of the working population need to refresh their skills and knowledge through short courses, which allows the case studies to generate resources by providing short courses and refresher programmes.

The provision of more places in undergraduate education by both private and public higher education organisations offers more opportunities for expanding postgraduate provision, as shown in Table 8.14 below. 
Table 8.14: Higher education organisations and total enrolment in 2010

\begin{tabular}{lcccc}
\hline Country & $\begin{array}{c}\text { Public } \\
\text { universities }\end{array}$ & Private & $\begin{array}{c}\text { Total } \\
\text { Enrolment }\end{array}$ & $\begin{array}{c}\text { Gross tertiary } \\
\text { enrolment rate }\end{array}$ \\
\hline Ethiopia $^{121}$ & 31 & 65 & 467,843 & 3.6 \\
Kenya $^{122}$ & 22 & 27 & 180,978 & 4.1 \\
South Africa $^{123}$ & 23 & 114 & 837,779 & 15.4 \\
\hline
\end{tabular}

Source: WEF 2011-2012 and National Statistics

The continued expansion of the demand for higher education across the globe constitutes a driver of revenue generation for JKUAT and NMMU. The Kenyan and South African case study universities have already started to admit international students to expand their sources of revenue. African and Asian countries are lucrative markets for NMMU.

The national governments of the three countries play a key role in supporting revenue generation by providing the right framework conditions. The higher education laws in Ethiopia and South Africa urge public universities to engage in revenue generation. Public universities in Ethiopia are required to generate a minimum of $5 \%$ of their overall budget from nongovernmental sources as stated in the Education Sector Development Programme IV of Ethiopia (MoE, 2010). Although the Kenyan case study university was neither formally allowed nor prohibited from revenue generation activities, the heavy involvement of JKUAT in revenue generation indicates that the importance of the legal basis for revenue generation may have been overstated. Conversely, we argue that JKUAT might not pursue additional revenue streams if the regulatory frameworks directly prohibited it.

The findings in the case study chapters show that revenue generation in universities is enabled or obstructed by the degree of autonomy granted by the regulatory framework in which the case study universities operate. As discussed in section 8.2.3, the four case study universities enjoy substantial academic and organisational autonomy, which enables them to engage in revenue generation. Nonetheless, the variations in their levels of financial and

121 Includes only universities under the auspice of MOE.

122 Only the seven universities and the 15 university colleges are included. Other Youth Polytechnics, nineteen Technical Training Institutes, fourteen Institutes for Technology, other two National Polytechnics, 11 medical training colleges, etc. are not counted.

123 South Africa has 87 registered and 27 provisionally registered private higher education organisations. 
staffing autonomy (see Tables 8.8 and 8.9) influenced their revenue generation. The findings of this study show that freedom in the generation and deployment of monetary resources, the block grant funding system of Kenya and South Africa, the ability to charge tuition fees for nongovernment sponsored students, freedom to set charging levels for research \& consultancy services and freedom in recruiting and promoting academic staff are important enablers for revenue generation. This study also identified the inability to borrow money from financial markets, line item budgeting in Ethiopia, and the inability to set the salary levels of academic and administrative staff as important barriers to revenue generation. For example, the Ethiopian case study universities are prohibited from reallocating funds between budget heads without passing stringent approval procedures, which has proved to be one of the major obstacles in the implementation of a sustainable revenue generation strategy. Similarly, the inability to borrow money from capital markets has become a barrier to engaging in large-scale revenue generation.

This study found that government financial initiatives have created opportunities for the case study universities to engage in revenue generation. Noting the low average incomes in Africa, the three countries all implemented a form of student lending scheme. In this regard, Kenya and South Africa have developed student loan schemes for higher education (see Chapters 6 and 7) that enable academically able but financially challenged students to participate in higher education. The loan programmes have both cost sharing and accessparticipation objectives, which is one of the enablers for revenue generation at JKUAT and NMMU. In South Africa, most of the earmarked government budget is set aside for funds for the National Student Financial Aid Scheme (NSFAS). About 70 financial assistant providers ${ }^{124}$ from government offices, companies, foundations and other organisations offer financial assistance to NMMU students (see Chapter 7). Similarly, in Kenya, HELB offers loans and bursaries, and scholarships for needy students (see Chapter 6). Higher education students can also seek support from the Constituency Development Fund. In Ethiopia, there are no financial schemes like HELB and NSFAS that address the financial challenges of full-cost paying students. This could prevent the poorest students from participating in higher education.

As part of their national development policies and strategies, the sampled countries recognise the role of higher education in national growth through

124 Includes, among others, vice chancellor's scholarship, bursaries awarded by diverse company sponsors and various departments of government such as education, social development, disability, water affairs, agriculture, forestry and fisheries, cooperative governance, health, national treasury, etc.. 
generating new technology and innovation. The South African government has increasingly prioritised areas of knowledge that have the potential to contribute to the national economy, under the banner of building research excellence, relevance, and innovation. The data analysis shows that NMMU has several incentives to foster revenue generation from research and consultancy activities, as shown in Chart 7-12. First, NMMU's block grant funding comprises research money for agreed outputs consistent with governmentdesignated priority areas. Second, the university can earn resources from the National Research Foundation (NRF) and the Medical Research Council. Third, NMMU has numerous opportunities for research contracts with industry and the private sector. The ostensible political commitments to university research and technology transfer by the Ethiopian and Kenyan governments have not been translated into funding incentives. Government allocations for research have generally been non-existent for ASTU and $\mathrm{HU}^{125}$. The Kenyan government has set aside very small amounts of research funding for its public universities since 2005. This research fund was reportedly too small to motivate public universities to generate revenue from this source (See Chapter 6). Inadequate public funding for research has limited the ability of public universities in Ethiopia and Kenya to invest in research facilities and equipment, and thereby hindered their overall research capacity. Moreover, the absence of big researchintensive industrial firms that allocate money for university research (see section 8.2.2) prevents the Ethiopian and Kenyan case study universities forming strategic alliances with business and industry.

The availability of various donor funds (both bilateral and multilateral donors, NGOs, and foundations) to offset the lack of government funding for research has been an important enabler for revenue generation (Table 8.5). Compared to the Ethiopian and Kenyan case study universities, NMMU has more opportunities to earn private gifts and grants from donors. For instance, the university receives donations from estates, philanthropists, and alumni. Research donation is, however, very uncommon at the Ethiopian and Kenyan case study universities, since giving financial support to public universities is uncommon in the two countries. Moreover, the excessive complexity of the rules and reporting obligations tied to most donor funds hinder universities from diversifying their funding streams from international donors.

${ }^{125} \mathrm{HU}$ obtained some research funding (about USD 0.8 million yearly) from the Ethiopian Institute of Agricultural Research (EIAR) as the nationally funded projects. 


\subsubsection{University Specific Factors that Enable or Hinder Revenue Generation at the Case Study Universities}

The findings in this chapter identify several university specific factors that enable or obstruct revenue generation at the four case study universities. Engaging in diverse missions is in itself an important enabler for generating revenue from diverse sources. As comprehensive universities, the four case study universities offer a variety of academic programmes to address the demands of various students who seek educational services. Through research, they can earn resources by creating and/or applying valuable knowledge to solve societal problems. The universities can also disseminate knowledge that leads to revenue generation. However, inadequate research capacity at the Ethiopian and Kenyan case study universities is an important barrier to revenue generation.

The results of this study indicate that the internal governance and management of the case study universities influence their revenue generation. One of the factors that creates an enabling environment for revenue generation is the composition of the university Councils at JKUAT and NMMU or Boards at ASTU and HU, whose membership is drawn from governmental authorities, the university, and the private sector. This representation of various stakeholders creates an opportunity for promoting the interactions between the universities and their diverse stakeholders. The strong commitment to revenue generation by the senior university leaders of the four universities is another important factor that determines the capacity of the case study universities to generate nongovernmental revenues. The Kenyan and South African ${ }^{126}$ case study universities have formulated policies that provide frameworks for managing their revenue generation activities. The findings indicate that the absence of policies dedicated to revenue generation at the Ethiopian case study universities was one of the barriers to revenue generation. The availability of capital to start-up feasible initiatives is an important condition for revenue generation at all case study universities. The inadequate seed money for a sustainable revenue generation strategy at the Ethiopian case study universities is a major obstacle to engaging in large-scale revenue generation activities. The governance structures and decision-making processes of HU, JKUAT, and NMMU were found to be adequate to embark on a successful revenue generation strategy. In particular, large governance bodies under the principle

${ }^{126}$ NMMU's policies include: the management of third stream income generated by NMMU conferences, seminars and workshops, the management of short learning programmes, policy on research contracts, and policy on research funding which are part of its revenue generation agenda. 
of collegial representation through a 'deliberative' structure of committees and strong executive leadership tend to be supportive to revenue generation. In fact, the web of interlocked central committees has become the heart of NMMU's capacity to steer itself and this offers real opportunities for revenue generation. Conversely, the experience at ASTU shows that revenue generation will not prosper in a top-down approach.

The results of this study also indicated that qualified and motivated academic staff and managerial expertise and competence matter in developing a successful revenue generation strategy. In this respect, the four case study universities demonstrate significant variations (see section 8.3) in the capabilities of their human resources. Comparatively, JKUAT and NMMU have sufficiently qualified human resources that enable them to offer education and research services for revenue generation. Conversely, the low proportion of $\mathrm{PhD}$ holders at the Ethiopian case study universities is a barrier to initiating and undertaking research, supervising graduate students, and holding senior management positions (see Chart 8-3). The absence of highly qualified academic staff at ASTU and HU is a major barrier to attracting new high calibre academics from elsewhere through alliance formation with other organisations in the environment. The Ethiopian case study universities need high quality professional managers to reduce the administrative burden on academics and free them to concentrate on their core tasks (education and research), which lead to revenue generation.

Compared to the Ethiopian and Kenyan case study universities, NMMU has been equipped with the state of the art equipment and research facilities (see chapter 7 section 7.4.6), which enable it to engage in cutting-edge research in the areas of science, technology, and health. To varying degrees, however, the Ethiopian and Kenyan case study universities reported a lack of adequate facilities for research in the face of ever-increasing student enrolments. The limited facilities are also organised and equipped for teaching purposes. Notably, the Kenyan case study university pointed out that over-crowded classrooms, shortages of teaching materials and laboratories, deterioration of physical facilities, inadequate ICT equipment and computers, and inadequate library stocks are key barriers to revenue generation. Long years of neglect in financing university research in Ethiopia and Kenya have left the case study universities with weak research infrastructures and equipment. Thus, the inadequate research infrastructures at ASTU, HU, and JKUAT were reported to be key barriers to revenue generation, limiting their ability to meet demand in the areas of research and consultancy. However, the physical infrastructure of the Ethiopian case study universities does allow them to increase their admission capacity for full-cost paying students. 


\subsection{Revenue Generation Strategies at the Four Case Study Universities}

This section attempts to compare the similarities and differences in the case study universities' revenue generation strategies. At the case study universities, revenue generation has been accorded great attention as a strategy for financial security in their strategic plans ${ }^{127}$. All the case study universities reported that they planned to increase non-public funding in the future to compensate for decreases in public funds. The comparative strategies for revenue generation are discussed below.

\subsubsection{Differentiation of Academic and Non-Academic Products and Services for Revenue Generation}

One of the major strategies used for revenue generation by the four case study universities is differentiation of academic and non-academic services and products in order to address the demands and expectations of as many stakeholders as possible. The high degree of academic and organisational autonomy that the four universities enjoy reinforces the implementation of this differentiation strategy. In the following sections the differentiation strategy is explored for each revenue generation activity, namely, education and shortcourse services, research and consultancy services, and non-academic services and products.

\subsubsection{Differentiation of Educational Services and Short Courses for Revenue Generation}

The findings in this study indicate that all the case study universities have differentiated their educational services and short-courses to meet the requirements of various stakeholders, as discussed in section 8.2. In order to meet the demands and expectations of stakeholders, all universities involve different academic units (i.e. schools, faculties, departments, and institutes) in revenue generation. Although the amount of money earned has not been uniform across all academic departments and programmes, revenue generation from full-cost paying students has become a characteristic feature of all academic departments in the universities. Most of the expansion in

${ }^{127}$ Information for formulating strategic plans was gathered through 'environmental scanning'. A SWOT analysis was carried out. Diverse experts including external consultants were involved in developing the strategic plans to gather knowledge of multiple facets of internal and external conditions. The growth and diversification of revenue streams is identified as one of the strategic issues in JKUAT's strategic plan (200-2012), NMMU's vision 2020, ASTU's framework and HU's BPR study. 
programmes has taken place in the humanities and social sciences where huge capital investments for machinery, laboratories, workshops, and heavy-duty equipment are not required. Within the social sciences and humanities, schools of business and economics have numerous opportunities for generating revenue. Additionally, education-specific strategies and tactics such as diversification in terms of levels, duration, modes of delivery, and target groups have been formulated, to reach as many students as possible. One of the strategies employed to reach different types of students is vertical differentiation of programmes, as shown in Table 8.15.

Table 8.15: Levels of degrees, diplomas, and certificates offered at the case study universities

\begin{tabular}{|c|c|c|c|}
\hline ASTU & HU & JKUAT & NMMU \\
\hline $\begin{array}{l}\text { Bridging } \\
\text { Course }\end{array}$ & $\begin{array}{l}\text { First } \\
\text { Degree }\end{array}$ & Bridging Course & Certificate \\
\hline \multirow[t]{7}{*}{ First Degree } & Master's & Certificate & Diploma \\
\hline & $\mathrm{PhD}$ & Diploma & $\begin{array}{l}\text { First Degree }\left(1^{\text {st }} \text { and }\right. \\
\text { professional })\end{array}$ \\
\hline & & Degree & $\mathrm{M}$ tech \\
\hline & & $\begin{array}{l}\text { Postgraduate } \\
\text { diploma }\end{array}$ & Honours degrees \\
\hline & & Master's & Postgraduate Diploma \\
\hline & & $\mathrm{PhD}$ & Master's ( 1 or 2 years) \\
\hline & & & $\mathrm{PhD}$ \\
\hline
\end{tabular}

This strategy targets not only students seeking degree programmes but also students seeking certificates at pre-and post-baccalaureate levels. The Ethiopian universities are not legally allowed to offer diploma ${ }^{128}$ and certificate level programmes. Provision of undergraduate programmes has grown more than postgraduate provision at the case study universities. For instance, despite huge demand for computer sciences, engineering, law, and business and economic studies at postgraduate level, the universities barely offer PhDs in these areas. One of the main reasons for this is the lack of senior academics who could teach and supervise students. Inadequate research facilities and low salaries (notably at ASTU and HU) also contribute. The extensive vertical differentiation at

${ }^{128}$ Diploma programme is now part of the TVET sector in Ethiopia. 
JKUAT and notably at NMMU (see Table 8.15 above) allows the universities to address the educational requirements of various stakeholders at different levels of preparation. The vertical differentiation in agricultural fields at HU was one of its strategies for overcoming the competition for full-cost paying undergraduate students from newly established universities in its vicinity (see Chapter 5).

Several education-specific strategies have been employed by the case study universities to overcome inadequate educational inputs. These include pooling resources to undertake a specific educational activity, expanding their education services into new markets, and/or developing an advantage over a competitor. Running classes at times when the facilities and staff within the departments are usually idle is one of the strategies for revenue generation, as shown in Table 8.16.below. This strategy allows students to combine work and study.

Table 8.16: Programme scheduling

\begin{tabular}{cccc}
\hline ASTU & HU & JKUAT & NMMU \\
\hline Evening & Evening & Evening & Evening \\
Weekend & Weekend & Weekend & Weekend \\
Summer & Summer & & Summer \\
& Distance & & Distance \\
\hline
\end{tabular}

This strategy was devised to overcome the inadequate facilities in terms of lecture halls, library, offices, laboratories, hostels, and other educational inputs, and to take educational services closer to potential customers. The summer programmes at ASTU and HU target employers who can upgrade their staff's skills during a break time for regular students. The programmes are facilitated by the representation of regional and local authorities on the boards of the Ethiopian case study universities. As part and parcel of their expansion strategy, all the universities have established new campuses (seven at JKUAT, five at NMMU, three at $\mathrm{HU}$, and two at ASTU) in strategic locations to accommodate the soaring demand for higher education. JKUAT also opened a new overseas campus in Tanzania. Rapid progress in information and communication technologies has fostered the development of new ways of learning, such as distance learning and independent study.

The four universities have created franchises or collaborations with other colleges in their environments. The universities share facilities with other education providers (see Table 8.14) to make optimal use of the facilities (e.g., 
lecture halls, library facilities, laboratory spaces) of alliance organisations in order to enrol more full-cost paying students. The strategy of forming alliances reduces early outlays for content development, technical infrastructure, and marketing costs. At JKUAT, partnerships with other learning organisations are the main additions to the revenue generation archetype, where the third party resells JKUAT's courses in new markets. In other words, the university uses outside parties (colleges and even universities) to deliver educational services traditionally provided by themselves to achieve dual advantages, i.e. to be competitive in that environment while, at the same time, saving money. JKUAT also lobbies private entrepreneurs to construct hostels that enable the university to overcome shortfalls related to facilities and thereby accommodate more students on its main campus (Juja).

The four case study universities offer a variety of short courses in the areas of energy, business and economics, engineering and technology, agricultural sciences, biotechnology, statistics, and the like. ASTU and JKUAT also provide bridging courses for those students whose average matriculation grade may be below the minimum requirements for automatic university admission or who may have scored the required minimum grade but then had inferior grades in subjects considered core for the course desired by the student. The differentiation strategies for research and consultancy and non-academic services are briefly explained in the subsections that follow.

\subsubsection{Differentiation of Research and Consultancy Services for Revenue Generation}

The four case study universities have tried to diversify their thematic research areas according to their strategic plans and research strategies in response to environmental opportunities for research and consultancy services (see sections 8.2 and 8.4). ASTU mainly desires to conduct research in the areas of energy, tropical medicine, technical and vocational education, agriculture, and ICT. HU's thematic research covers agricultural sciences, law, social science, education, language, and health. Agriculture is the powerhouse for research at HU. JKUAT's research focuses mainly on food, chemistry, biotechnology, ICT, engineering and horticulture products. More specifically, JKUAT plans to undertake research in its engineering workshop, horticulture nursery, botany tree nursery, food technology centre, chemistry products centre, and software development centre. NMMU's focus research areas include health and wellness, automotive technology, energy, chemical technology (InnoVenton), economic and business development, material sciences, infrastructure and process development for industrial firms, advanced manufacturing and engineering research, ICT for development and telecoms, environmental and natural 
resource management, culture, communication and language, leadership, governance and democracy as well as law, education, and infrastructure and human settlement development.

In this regard, alongside their traditional academic departments, the universities have established research entities to promote contract education, contract research, and consultancy as shown in Chart 8-9.

Chart 8-9 Number of Research institutes, centres, and units at the case study universities

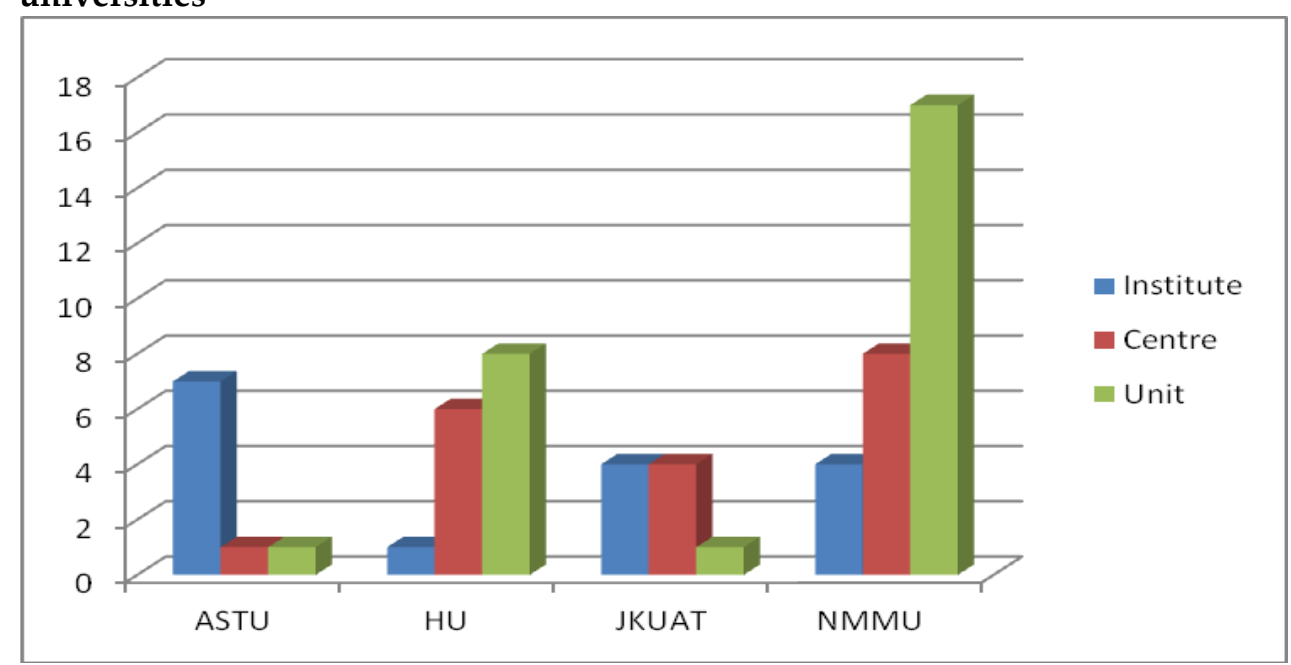

The research entities are required to respond to emerging external opportunities for revenue generation. These entities are generally, but not always, multi-or trans-disciplinary. They reach across old university boundaries in order to link up the universities with various stakeholders. Internally, they work closely with traditional academic departments by sharing resources, but also operate much like mediating bodies situated between the university and external stakeholders. Externally, the research entities serve as venues for collaboration between the universities and their stakeholders (e.g., national governments, research institutes, donors, and industrial firms). However, the creation of these research entities at the Ethiopian and Kenyan case study universities without adequate research capacity has illustrated how the senior leaders of the universities, under conditions of uncertainty, imitated the behaviour of other actors in their environment, particularly those actors whom they knew and trusted (see section 8.2). The research entities at NMMU foster revenue generation from research and consultancy (see Chart 8-6). Moreover, all the case study universities, except $\mathrm{HU}$, have created business-incubators or science and technology parks as part of their initiatives to improve research and 
consultancy or to facilitate academic start-up firms in order to take advantage of low-cost real estate to provide affordable rentals to aspiring commercial enterprises.

With varying levels of success, all the case study universities have formed linkages and partnerships with selected national and international research organisations, industry, and other in country and overseas universities in order to augment their human and nonhuman resources capacity in terms of qualified academic staff, and research facilities. This strategy has been very successful at NMMU (and to some degree at JKUAT) where there was already the critical inhouse qualified human capacity. The inadequate research capacity in terms of qualified human resources across several academic units of the Ethiopian case study universities (and to some degree at JKUAT) makes alliance arrangements for research less fruitful. This suggests that forming alliance with other organisations is a matter of social capital. The main lesson is that the Ethiopian and Kenyan case study universities still seek their own valuable, rare, inimitable, and non-substitutable resources to enter into postgraduate studies and research, and thereby compete in the markets created in the current dynamic environment.

\subsubsection{Differentiation of Non-Academic Products and Services for Revenue Generation}

All the case study universities have diversified their non-academic services, as shown in Table 8.15, in order to meet the demands of their internal and external customers. 
Table 8.15: Diversifying non-academic services for revenue generation

\begin{tabular}{|c|c|c|c|c|}
\hline Activity & ASTU & HU & JKUAT & NMMU \\
\hline Academic credentials & $\checkmark$ & $\checkmark$ & $\checkmark$ & $\checkmark$ \\
\hline Alumni fees & $\bullet$ & $\bullet$ & $\checkmark$ & $\checkmark$ \\
\hline ID card & $\checkmark$ & $\checkmark$ & $\checkmark$ & $\checkmark$ \\
\hline Bookshops & $\bullet$ & $\checkmark$ & $\checkmark$ & $\checkmark$ \\
\hline Agricultural products ${ }^{129}$ & $\checkmark$ & $\checkmark$ & $\checkmark$ & $\bullet$ \\
\hline Industrial products & - & $\bullet$ & $\checkmark$ & $\checkmark$ \\
\hline Conference hall and venue hire & $\checkmark$ & $\checkmark$ & $\checkmark$ & $\checkmark$ \\
\hline Medical services & $\checkmark$ & $\checkmark$ & $\checkmark$ & $\bullet$ \\
\hline $\begin{array}{l}\text { Material or sampling testing in } \\
\text { laboratories }\end{array}$ & $\checkmark$ & $\checkmark$ & $\checkmark$ & $\checkmark$ \\
\hline $\begin{array}{l}\text { Residences or housing services } \\
\text { (guest houses and dormitories) }\end{array}$ & $\checkmark$ & $\checkmark$ & $\checkmark$ & $\checkmark$ \\
\hline Sport facilities & $\checkmark$ & $\checkmark$ & $\checkmark$ & $\checkmark$ \\
\hline Leasing university property & $\checkmark$ & $\checkmark$ & $\checkmark$ & $\checkmark$ \\
\hline Museum & $\bullet$ & $\checkmark$ & $\bullet$ & • \\
\hline Catering services & $\checkmark$ & $\checkmark$ & $\checkmark$ & $\checkmark$ \\
\hline Computer assembly & $\checkmark$ & $\checkmark$ & $\checkmark$ & $\checkmark$ \\
\hline Repair and maintenance of furniture & $\checkmark$ & $\checkmark$ & $\checkmark$ & $\checkmark$ \\
\hline Day care centre and model schools & $\bullet$ & $\checkmark$ & $\checkmark$ & $\bullet$ \\
\hline Investment income & - & - & $\checkmark$ & $\checkmark$ \\
\hline
\end{tabular}

Key: $\checkmark$ Available $\bullet$ Not-available

129 ASTU engages in large-scale agricultural production such as meat, dairy, grains, honey, horticultural crops, fruits, etc. HU sells agricultural products including: poultry and poultry products, dairy products, live beef animals and beef, pig and pork, small live animals (sheep and goats) and products, horticulture products, improved seeds and the like to in-and off-campus communities. Similarly, JKUAT engages in selling agricultural products such as: poultry and poultry products, dairy products, live beef animals and beef, pig and pork, small live animals (sheep and goats) and products, horticulture products, improved seeds and the like to in-and off-campus communities. 
The geographical locations of HU and JKUAT offer them better opportunities to engage in different revenue generation in areas where needs are not currently met by the private sector. Although the four universities are in principle committed to running the products and services shown in Table 8.15 to cover their full costs plus a contribution to the general pot of earned revenue, in practice, they barely cover their full costs because services are under-priced and highly subsidised to create an enabling working environment for staff. In the best cases, the "raison d'être" of these activities is not to generate income, but as far as possible to not run at a loss. The identification of the full costs of all university activities is also difficult because revenue generation activities still share some resources with the universities core activities. In the long run, feebased services at the case study universities can raise legal and philosophical issues about unfair competition with the private-sector, which contributes to the taxes that fund the operations of the case study public universities.

\subsubsection{Creation of Administrative Support Structures for Stakeholder Management}

The second major strategy used by all case study universities was to strengthen their steering capacity for efficient and effective stakeholder management. This strategy appeared in different forms and levels of centralisation or decentralisation across the case study universities. As part of strengthening their steering capacity, the case study universities created administrative units that promote contract education, contract research and consultancy, and other non-academic matters and handle 'relationship management'. These structures are required to improve communication, create stable and clear organisational structures, and increase the commitment of all internal and external actors to ensuring relationship management that leads to revenue generation. Two approaches were generally used for this, namely: (i) using the existing organisational structures to implement revenue generation policies to enhance efficiency and reduce costs, and (ii) establishing new organisational structures dedicated to revenue generation within the university. Autonomy with respect to internal governance allows the universities to set up numerous structures and positions for revenue generation as discussed in the following paragraphs.

One of the strategies is the formation of stronger line authority. All the case study universities mandate one of the vice presidents/deputy vice chancellors to oversee or strategically lead their revenue generation efforts, as indicated in Table 8.16 below. 
Table 8.16: Office in charge of revenue generation at the strategic apex

\begin{tabular}{lll}
\hline University & Level & Position \\
\hline ASTU & Vice President & $\begin{array}{l}\text { International Relations, Corporate } \\
\text { Communications, and Fund Raising }\end{array}$ \\
HU & Vice President & $\begin{array}{l}\text { Institutional Development and } \\
\text { Community Engagement }\end{array}$ \\
JKUAT & $\begin{array}{l}\text { Deputy Vice } \\
\text { Chancellor } \\
\text { NMMU }\end{array}$ & $\begin{array}{l}\text { Deputy Vice } \\
\text { Chancellor }\end{array}$ \\
\hline
\end{tabular}

At all the case study universities except ASTU, the administrative backbone fused new managerial values with traditional academic values through committees or teams. The committees or teams comprise different university community members and assist the senior positions in charge of revenue generation. The existence of revenue generation committees or teams enables the three universities to organise their decision-making processes in large governance bodies under the principle of collegial representation or increasingly shared governance and leadership. This approach worked best where academics who are trusted by peers serve on revenue generation committees. The absence of such a committee at ASTU hinted that revenue generation was seen as hard managerialism, a very top-down command led approach.

The senior leaders at all the case study universities are well aware of the amount of work that is created by revenue generation. In responding to these administrative tasks, several outreach administrative units operating as crosscutting offices (see Table 8.17) were created to support revenue generation and establish better university-environment relationships. 
Table 8.17: Key support offices dealing with revenue generation

\begin{tabular}{llll}
\hline ASTU & HU & JKUAT & NMMU \\
\hline - Finance and & - Finance, & - Financial & - Directorate of \\
Accounting & Procurement & Administration & Finance \\
- Human & and Property & - Human & - Directorate of \\
Resources & Management & Resource & Human \\
- Legal Matters & - Human & Management & Resource \\
- Public & Resource & - Corporate & - Strategic \\
Relations & Management & Planning & Planning \\
- International & - Strategic & - Directorate of & - Marketing and \\
Office & Planning, & Performance & Corporate \\
& Monitoring, & Contracting & Relations \\
& and Evaluation & and Appraisal & - Legal Services \\
& - Promotion and & - Purchasing & - Management \\
& Marketing & Department & Information \\
& - Legal Support & - Transport & - Transformation, \\
& and Intellectual & Division & Monitoring and \\
& Right & - Estates and & Evaluation \\
& Protection & Central & - Support \\
& & Services & Services \\
& & - Corporate & - Office for \\
& & communication & International \\
& & office & Education \\
\hline & & & \\
& & & \\
& & &
\end{tabular}

Some of the offices shown in Table 8.17 were not necessarily established solely with the objective of generating revenue, but they offer support for revenue generation. By optimising tasks in the given structures, the senior university leaders try to achieve efficiency without extensive decentralisation of their financial, human resource and procurement management at faculty and departmental levels. Collectively these offices deal with stakeholders in the environments in order to facilitate linkages at different levels and to address issues of accountability (i.e. in terms of compliance and reporting) once linkages are made.

Communication (both internal and external communication) plays an essential role in fostering revenue generation at the four universities. External 
communication aims to make external stakeholders aware of the range of activities that the case study universities undertake for revenue generation. This makes the much-needed link between the internal activities of universities and the outside world by highlighting opportunities for collaboration. The four case study universities now heavily advertise their programmes in both print and electronic media, on websites, through fora such as agricultural shows, trade fairs and exhibitions and by directly addressing high school students. One or more dedicated units conduct marketing activities along with academic departments and faculties. For instance, at NMMU, the Marketing and Corporate Relations (MCR) department in collaboration with the university's Higher Education Access and Development Services (HEADS) and the academic faculties make a significant effort to ensure effective packaging and communicating of the programme mix and admissions requirements. NMMU and JKUAT use a user-friendly format for their promotional and marketing materials. Internal communication targets the broader university community in order to achieve cooperation between the leadership and academic and administrative staff. Through internal communication the entire university community is made aware of the purposes, aims, and actions pursued to raise nongovernmental revenue.

Along with the university-wide positions indicated in Tables 8.16 and 8.17, many outreach support offices with the specific mission of assisting revenue generation have been established. Table 8.18 below presents the key offices in charge of administrative support functions to foster revenue generation from educational services and short courses. 
Table 8.18: Key support offices dealing with revenue generation from educational services and short-courses

\begin{tabular}{llll}
\hline \multicolumn{1}{c}{ ASTU } & \multicolumn{1}{c}{ HU } & \multicolumn{1}{c}{ JKUAT } & \multicolumn{1}{c}{ NMMU } \\
\hline - Vice President for & - Vice President & - Deputy Vice & - Deputy Vice \\
Academic Affairs & for Academic & Chancellor for & Chancellor for \\
and & Affairs & Academic & Academic \\
Undergraduate & - College of & Affairs & Affairs \\
Studies & Continuing & - Registrar for & - Academic \\
- Institute of & and Distance & Academic & Administration \\
Continuing and & Education & Affairs and & - Centre for \\
Distance & - Consultancy & Deputy & Academic \\
Education & and Short- & Registrars & Engagement \& \\
- Further Training & Term Training & & Collaboration \\
Institute & Office & & - Higher \\
& & & Education \\
& & & Access and \\
& & & Development \\
& & & Services \\
& & & - Unit for \\
& & & Continuing \\
& & & Education \\
& & & - International \\
& & & Education \\
\hline
\end{tabular}

These administrative support offices are in charge of planning of academic programmes, preparation of syllabuses, admissions of students, examinations, certificates and transcripts, library services, etc.. Unlike JKUAT and NMMU, ASTU and HU established a separate university-wide college (HU) and institute (ASTU) that deal with revenue generation from educational services. The outreach offices work closely with other administrative support offices on financial matters, strategic planning, procurement, and human resource management for fostering revenue generation from educational activities. Similarly, the four case study universities involve different offices to facilitate revenue generation from research and consultancy services and establish better university-environment relationships (see Table 8.19). 
Table 8.19: Key support offices dealing with revenue generation from research and consultancy services

\begin{tabular}{|c|c|c|c|}
\hline ASTU & HU & JKUAT & NMMU \\
\hline $\begin{array}{l}\text { - Vice President } \\
\text { for Research } \\
\text { and } \\
\text { Postgraduate } \\
\text { Studies } \\
\text { - Knowledge and } \\
\text { Technology } \\
\text { Interchange } \\
\text { - Research and } \\
\text { Publication } \\
\text { Office } \\
\text { - Technology } \\
\text { Innovation } \\
\text { Centre }\end{array}$ & $\begin{array}{l}\text { - Vice President } \\
\text { for Research } \\
\text { Affairs } \\
\text { - Research } \\
\text { Group } \\
\text { - Research } \\
\text { Partnerships } \\
\text { - Research } \\
\text { Promotion and } \\
\text { Marketing } \\
\text { - Legal Support } \\
\text { and Intellectual } \\
\text { Rights } \\
\text { Protection } \\
\text { - Consultancy } \\
\text { and Short- } \\
\text { Term training } \\
\text { office } \\
\text { - Estate and } \\
\text { Facility } \\
\text { Management }\end{array}$ & $\begin{array}{l}\text { - Deputy Vice } \\
\text { Chancellor for } \\
\text { Research, } \\
\text { Production and } \\
\text { Extension } \\
\text { - Directorate } \\
\text { Research } \\
\text { Services } \\
\text { - Directorate of } \\
\text { Production } \\
\text { - Directorate of } \\
\text { Linkages } \\
\text { - Directorate of } \\
\text { Extension and } \\
\text { Technology } \\
\text { Transfer }\end{array}$ & $\begin{array}{l}\text { - Deputy Vice } \\
\text { Chancellor for } \\
\text { Research and } \\
\text { Engagement } \\
\text { - Department of } \\
\text { Research } \\
\text { Management } \\
\text { - Department of } \\
\text { Research } \\
\text { Capacity } \\
\text { Development } \\
\text { - Department of } \\
\text { Innovation } \\
\text { Support and } \\
\text { Technology } \\
\text { Transfer } \\
\text { - Office for } \\
\text { International } \\
\text { Education } \\
\text { - RTI committee } \\
\text { - Capital } \\
\text { Equipment } \\
\text { Committee } \\
\text { - Publication } \\
\text { Committee }\end{array}$ \\
\hline
\end{tabular}

Some of the administrative support offices shown in Table 8.19 were not necessarily established solely with the objective of generating revenue, but they do offer support for revenue generation. They are both outward facing and inward facing. As far as the outside world is concerned, they were established to serve as a liaison between the universities and their stakeholders, and to match faculty expertise with the research needs of stakeholders in the environment. Knowledge and Technology Interchange at ASTU, Research 
Partnerships at HU, Linkage at JKUAT, and International Education at NMMU are intended form collaborations with other universities and research organisations in the environment of the universities in order to offset the lack of qualified human resources and research facilities. Inward-facing functions include the dissemination of information to internal actors (academic and administrative staff) and stimulating academic unit involvement in research and consultancy. In the case of NMMU, its RTI committees at central and faculty levels support and/or recommend projects for funding which are aligned with the academic and research focus areas of the university. The support functions include support for proposal writing, contracting support, financial support, HR support, linkages, and the like. The administrative support structures indicated in Table 8.19 might have paid off if the Ethiopian and Kenyan case study universities had been research-oriented universities with core qualified faculty, and environmental incentives for research. However, here this move is simply an isomorphic approach in which the universities try to replicate the practices of more prestigious research-intensive universities, creating significant administrative costs.

Revenue generation from non-academic activities also requires a wide range of specialist skills (see Table 8.20).

Table 8.20: Key Support Offices Dealing with Revenue Generation from Non-Academic Services

\begin{tabular}{cccc}
\hline ASTU & HU & JKUAT & NMMU \\
\hline Vice President for & Vice President for & Deputy Vice & Deputy Vice \\
International & Institutional & Chancellor for & Chancellor for \\
Relations, Corporate & Development and & Administration & Institutional \\
Communication and & Community & Health Care & Support \\
Fund Raising & Engagement & Services & Support \\
International Office & Farm & Estates and other & Services \\
Social Services & Management & central services & Audit and Risk \\
Compound Services & Office & JKUAT & Management \\
& & Enterprises & \\
\hline
\end{tabular}

As shown in Table 8.20 above, the offices of Vice Presidents/Deputy Vice Chancellors are in charge of offering overall policy leadership for fostering revenue from non-academic services. Offices like finance, human resources, 
procurement, and marketing are all involved in generating revenue from nonacademic serves to reduce costs and achieve efficiency.

\subsubsection{Decisions Concerning Internal Resource Allocation Mechanisms and Human Resource Policies for Revenue Generation}

The third major strategy focuses on using internal resource allocations and human resource policies to stimulate internal actors to engage in revenue generation activities. The four universities have identified revenue generation as one of their strategic priorities for ensuring financial sustainability. In order to address this, all the case study universities formulated policies (though less so in the Ethiopian case study universities) that guide specific decisions about revenue generation. The policies are roadmaps that help in coordinating human and nonhuman resources, resource utilisation, and distribution of revenue among diverse internal actors. The Income Generation Unit Policy (IGU policy) at the Kenyan case study university and the four revenue generation related policies at NMMU provide frameworks for the planning and administration of revenue generation activities, modalities for coordination and monitoring, exploitation of potential business opportunities, establishment of income generation units, and guidelines for sharing of revenues and surpluses. At all the case study universities, one of the preconditions for engaging in revenue generation activities is a business plan. This business plan serves as a starting point for revenue generation activity and as a way of ascertaining the feasibility and profitability of revenue generation activities. The business plan and the policies for revenue generation require a needs identification study before launching any revenue generation activities. One of the problems with most needs identification studies at the Ethiopian and Kenyan case study universities was that they were not properly conducted. Individual academic staff members, motivated by financial gain, often make decisions about launching revenue generation activities.

The business plan, along with the policies for revenue generation, defines the internal resource allocation mechanisms and staffing for revenue generation activities at the case study universities. The availability of capital to start-up feasible initiatives and the ability to use resources with a considerable amount of autonomy is a prime condition for revenue generation. The leadership of the four universities plays a role by creating a positive climate for revenue generation through financial support. Any promising revenue generation initiatives, be it for new activities or for expanding existing programmes, are given seed money, mostly in the form of loans. The seed money covers the costs of feasibility studies for new academic programmes, research projects, and/or 
advertising and marketing them, or supporting implementation. We now ask the question 'what are the sources of seed money or initial capital to support revenue generation?' Two alternatives are available for JKUAT and NMMU, while there is only one option for ASTU and HU. JKUAT and NMMU receive their core governmental funds in a way that allows the universities to decide internal funding allocations (see also section 8.2.4). Seed money can therefore easily come from the main governmental support. They can also use a portion of their earned revenue for pre-investment. However, ASTU and HU cannot use their core budget for this purpose because of the excessive bureaucracy and complexity in the Ethiopian government's funding (see section 8.2.5), particularly in the case of line item budgeting. The vast majority of seed money at ASTU and HU comes from their earned revenues. As the overall volume of generated revenue is comparatively low, the Ethiopian case study universities have often faced shortages of seed money to expand their revenue generation activities. Their inability to borrow money from capital markets under any circumstances is also a barrier to engaging in large-scale revenue generation activities. The seed money typically operates like an investment funds, expecting the recipient units to repay the money through the returns on the initial investment. At NMMU, trust funds are pulled together to fund such initiatives. JKUAT supports new revenue generation initiatives through revolving funds.

The academic and administrative staff will only engage in revenue generation as long as they perceive its usefulness and have the opportunity to enjoy monetary and non-monetary rewards (see Chapter 3). The senior university leaders offer rewards (both monetary and non-monetary) to increase the staff's commitment to revenue generation. The incentive mechanisms exist at two levels: rewarding staff directly, and/or providing rewards to subunits. JKUAT and NMMU offer incentives for individual staff, departments, colleges, and central university offices that are directly or indirectly involved in revenue generation, in order to increase their commitment to the revenue generation agenda. The Ethiopian case study universities do not have such a sharing ratio for rewarding actors who are directly or indirectly involved in revenue generation. Nor did they directly reward administrative support staff or subunits. The absence of reward mechanisms for administrative support staff and middle and operational level offices at the Ethiopian case study universities has been reported as a main cause for lack of support for revenue generation from these internal actors. The nonmonetary rewards include flexible working hours, training, pleasant working environment, and sabbaticals. Revenue generation from legitimate missions of the university now embraces many aspects, even entire units, of the case study universities. In Massy's (2009) 
words, the case study universities follow the motto of becoming mission centred and market smart in their revenue generation agenda.

The four universities demonstrate that human resource development and high quality managerial skills and practices are essential for successful revenue generation. Engaging in revenue generation requires qualified academic and administrative staff. With varying degrees of success, the four universities have used a variety of strategies to gain the necessary capacity. Although the universities are free to decide on the recruitment and promotion of academic staff as well as determine working conditions for staff, ASTU and HU were unable to attract and retain qualified academic and administrative staff due to their inability to set staff salaries. Revenue generation is not a criterion for recruitment of staff. One of the strategies devised to foster the human resource capacity of a university is creating partnerships with other research institutes and universities, thereby sharing the expertise of their partners. NMMU also offers financial support to postdoctoral students in order to enhance its research capacity. All the case study universities are free to decide on promotion of their academic staff but none of them use revenue generation as a major criterion for the promotion of academic staff. The criteria by which faculty and administrators judge academic work remain unchanged and persist in prioritising conventional forms of education and research. As the promotion of academic staff is usually decided on the number and quality of publications, this has indirectly fostered revenue generation from research at NMMU.

One of the strategies that ASTU devised to attract and retain professional managers was lobbying the Ethiopian government to allow the university to decide the salary scale for its senior administrative staff. This special privilege created the capacity to improve its stakeholder management. JKUAT and NMMU have been able to recruit professional managers to carry out the required support services. The introduction of performance contracting ${ }^{130}$ and the formulation of service charters following public service reforms in Kenya substantially improved the university's service delivery capacity. JKUAT's ISO 9001:2008 QMS certifications also contributed to that end.

\subsection{Conclusion}

This chapter attempted to compare and contrast revenue generation at the four case study universities situated in three Sub-Saharan African countries using

130 Performance contract is a management tool aimed at improving efficiency and effectiveness in the management of public services. 
the resource dependence perspective as its theoretical lens. With varying levels of success in revenue generation, all the case study universities have been able to win revenue from multiple sources. Nonetheless, there are variations in the distribution of resource dependence at the four universities. While the Kenyan and South African case study universities obtain the majority of their financial resources from the nongovernmental sources (around 57\%-60\% in 2010), the Ethiopian case study universities are still largely dependent on government funding (around $80 \%$ of their recurrent budget in 2010). With regard to nongovernmental resources, student tuition fees were uniformly the largest source of revenue across all case study universities. However, revenue from research and consultancy services varies between universities. While research and consultancy services are the second most important source of nongovernmental revenue for NMMU, they are the least important and sustainable source of nongovernment revenue for the Ethiopian and Kenyan case study universities. This variation is attributed internally to their research capacity in terms of human and nonhuman resources, and externally to environmental opportunities for research and consultancy. In terms of nonacademic products and services and products, ASTU and NMMU obtained between $10 \%-17 \%$ of their nongovernmental revenue by providing nonacademic products and services, but the figures were below $7 \%$ for $\mathrm{HU}$ and JKUAT.

With various levels of success and achievements, the four case study universities devised both adapting and altering strategies for acquiring resources from education, research and consultancy, and non-academic services. In terms of education and short-term training services, the key adapting strategies across all the case study universities include differentiation of educational services (horizontally and vertically), opening (satellite) campuses in strategic locations, devising diverse modes of delivery (face to face or distance), and differentiation of student population in terms of their study period (weekdays, weekends, summer, or evening). Some of these strategies focused on using the existing resources of the universities as efficiently as possible. The four universities also formed strategic alliances with other educational organisations to create additional capabilities that pragmatically increased their range of viable responses to diverse types of students who wish to use their educational services. The presence of regional or provisional authorities on the boards or councils of the case study universities, as well as the formation of a strong alumni association by JKUAT, also enabled the case studies to have preferential access to resources by offering educational services and short courses to regional or provisional stakeholders. 
Concerning research and consultancy services, all the case study universities identified their research priority areas, established research entities alongside their traditional academic departments, and created research management offices as part of their adapting strategies. However, unlike NMMU, the development of several research entities such as institutes, centre and units at Ethiopian and Kenyan case study universities along with different research management structures took place without adequate research capacities. This has illustrated how organisational decision makers, under conditions of uncertainty, imitated the behaviour of other actors in their environment, particularly those actors whom they knew and trusted. These research structures may have paid off if the three case studies had had highly qualified and experienced academic staff within the organisations. With regard to the altering strategy, all the universities tried to form alliances with other higher education organisations and research institutes to foster their research implementation capacity. The alliance arrangement can be practical and fruitful when universities have their own critical in-house capacity in terms of human and nonhuman resources which enables them to work with other parties. NMMU is an example of this, particularly its ability to prevail in competitive domains in terms of research success and its ability to work with a number of alliance organisations in a win-win fashion, which reinforces those advantages.This is not the case in the Ethiopian and Kenyan case study universities. This may be described as the "Matthew effect", where success brings more success at NMMU. The lack of qualified personnel and inadequate research infrastructure in the Ethiopian and Kenyan case study universities, more than the lack of environmental opportunities in terms of policy incentives and funding, are the main obstacles to revenue generation from research and consultancy services.

The four case study universities have also taken practical measures to improve communication, create stable and clear organisational structures, and increase commitment to 'relationship management' or 'stakeholder management'. Structurally, they have established outreach administrative units that promote contract education, contract research, short-term training, consultancy and other non-academic services and products in order to manage resource dependencies. Although all the case study universities tried to pursue efficiency gains by optimising some administrative tasks without establishing additional offices, the opening of diverse administrative support units adds to the organisational complexity of the universities. The establishment of various research entities and research management units at the Ethiopian and Kenyan case study universities incurs more costs than benefits with the current limited research capacity. In managing their revenue generation, three of the four 
universities (all but ASTU) formed a decision-making body with representation from senior leaders, mid-level managers, and academic staff as a set of interrelated committees along with stronger line management authority. The committee approach enabled the universities to fuse managerial values with traditional academic ones. Moreover, all except the Ethiopian case study universities staffed their administrative support offices with professional managers, which led to adequate managerial expertise and competence for stakeholder management. In this regard, while HU suffered from a lack of managerial expertise and competence to run its administrative support units, ASTU had relatively more capacity, which came from lobbying for additional autonomy to set the salary for its key administrative support functions. The four universities also followed similar patterns in aligning internal actors to their revenue generation agenda by providing financial and nonfinancial incentives. While the financial rewards target individuals in the Ethiopian case study universities, they focus on all internal actors, be they individuals or subunits such as faculty or departments, who directly or indirectly participate in revenue generation at the Kenyan and South African case study universities. Moreover, all the case study universities allocate seed money for expanding the existing revenue generation activities or launching new initiatives.

A number of environmental and university specific factors influence the revenue generation strategies and activities of the case study universities, though the types and nature of the influences vary across the case study universities. In other words, not all universities have the same potential or opportunities to explore new revenue sources because of their differences in terms of environmental factors and university specific conditions. With regard to external environment, the key factors that influence revenue generation from educational services across all the case study universities include the rising social demand for higher education, an adequate legal framework to provide educational services in return for resources and the academic and organisational autonomy of the universities. However, while financial incentives like HELB in Kenya and NSFAS in South Africa offer support to academically qualified, but financial challenged students and enable NMMU and JKUAT to generate revenue from educational services, the absence of such a financial scheme is a barrier in the Ethiopian context. Regarding research, the policy frameworks across all the case study universities encourage engagement in research for revenue generation. There are also demands for research and technology transfer in the three countries' national plans. However, the limited or absent funds for research at the Ethiopian and Kenyan case study universities has prevented them from investing in expensive state-of-the-art equipment like that of the South African case study university. 
Internally, the widely divergent fields of study in the academic departments of all the case study universities, and their human and nonhuman resources created an opportunity to meet the educational requirements of different types of students, who seek various types of education. While social science departments (notably business and economics) have commonly become a source of revenue first and most fully at all the case study universities, science and technology departments commonly lag behind to some degree. The lack of qualified staff is an obstacle to offering postgraduate study at the Ethiopian case study universities. Concerning research and consultancy services, there are clear differences among the case study universities in terms of the qualification mix of academic staff, professionalisation of managers, and non-human resources for generating revenue from research and consultancy services. Whereas the Ethiopian and Kenyan universities were unable to engage in cutting-edge research activities because of a lack of highly qualified staff (notably at ASTU and HU) and inadequate research facilities, the South African case study university, as a historically white university, has accumulated advantage in research infrastructure.

For non-academic services, as the main customers for non-academic services are the university community itself, this study acknowledges that there are real organisational and economic differences between the universities and other businesses in operating the non-academic services and products. Notably, all the case study universities have tried to overcome distinctive constraints and incentives in their pricing for third stream income opportunities. As no substantive strategic or philosophical debate need accompany a choice to offer non-academic products and services, the four case study universities aspire to achieve efficiency in running their non-academic services.

In short, with varying levels of success, there has been a general trend towards reduced financial dependence on national governments. Although all the case study universities have managed to reduce resource dependence on their national governments to some extent, the Ethiopian and the Kenyan case study universities did not diversify their revenue base to the level of ensuring financial sustainability and a sudden reduction in any one source of resources could destabilise their operations. More and diverse resources (both human and nonhuman) are still required to develop new capabilities at the Ethiopian and Kenya case study universities that can then be leveraged in response to the changing environment. 


\section{$9 \quad$ Conclusions and Reflections}

This chapter deals with the conclusion and reflections of the study, and in particular, uses the evidence offered in Chapters 5 to 7 and the comparison developed in Chapter 8 to demonstrate the study's contribution to the field. The empirical data and analysis in this thesis have focused primarily upon the question of how universities in Sub-Saharan Africa have attempted to generate revenue as a means of moving towards financial sustainability. This has been part of a larger research agenda motivated by understanding the issue of financial sustainability and the various choices that universities and policy makers make when seeking financial sustainability for higher education organisations and systems whilst ensuring their higher education systems continue to evolve to meet their national needs in terms of skills and research. In this concluding chapter, we therefore expand the scope of our discussions from the immediate comparison of the four universities in three Sub-Saharan African countries, to a more general discussion of revenue generation and financial sustainability in higher education, as both an academic and a policy concern.

This chapter has four major sections. Section 9.1 summarises the research motivation and the approach taken, and revisits the four research questions posed in section 1.3. Section 9.2 uses the empirical stylised facts developed within the comparative analysis in Chapter 8 to answer the four research questions and then moves on to a brief discussion of the immediate issues they raise in light of the literature review in Chapter 2. Section 9.3 outlines the substantive contribution of this thesis in theoretical and policy terms. The section reflects on the answers emerging in Section 9.2, in terms of the wider debates regarding revenue generation as an appropriate tool for achieving financial sustainability in higher education. In subsection 9.3.1, we return to the initial theoretical framework, resource dependence theory, and reflect on what this exploratory study suggests. Subsection 9.3.2 considers the practicalities of using revenue generation to deliver financial sustainability for higher education in comparison with the five other potential solutions for overcoming financial challenges identified in section 2.4; reflects on those circumstances under which it is the best solution and what can be done to optimise its use to ensure sustainability is delivered. The chapter concludes with a brief coda which reflects on how the methodology could be adopted and improved in further study in Section 9.4. 
Although the empirics are extremely partial, covering four universities in three Sub-Saharan countries with no claim to generalisation, it is possible to discern a distinct model for the use of revenue generation in practice that is quite distinct from the way it is used in developed countries. This suggests that more work may be required to understand financial sustainability in the context of developing countries. Future research may thus seek to further specify this developing world model of financial sustainability. Higher education policy makers, and other stakeholders including donors, may wish to reflect more explicitly on those differences when learning from experiences from elsewhere.

\subsection{Revenue Generation in Practice in Higher Education in Sub-Saharan Africa}

\subsubsection{Financial Sustainability: Revenue Diversification In a Time of Expanding Student Numbers}

The purpose of this study is to contribute to our understanding of how SubSaharan African public universities can achieve financial sustainability by diversifying their resources to continue to accommodate the growth in higher education enrolment (see section 1.1). As this study is conducted in SubSaharan African countries, where universities operate within the context of rapid enrolment growth and strong commitment to public financing of higher education, but paradoxical decline in public expenditure per student, the findings of the study contribute to existing knowledge on achieving financial sustainability.

The findings of a study carried out by the World Bank (2010) indicate that the capacity for public investment in higher education at national level meets only $33 \%$ to $40 \%$ of the total financial requirements of Sub-Saharan African universities. Most African countries are struggling with the policy challenge of balancing the need to raise educational participation while managing the costs of their higher education systems. Systems created on an elite basis for highly restricted participation are unable to deal adequately with expansions in student numbers, yet such an expansion of students is necessary to promote GDP growth and improve economic performance.

This is a worldwide phenomenon and universities operating in different countries have been looking for possible solutions for delivering financial sustainability. In most countries, shortfalls in government funding (Massy, 2009; Shattock, 2003; Clark, 1998; Hearn, 2003; Marginson \& Rhoades, 2002) combined with globalisation and internationalisation (Williams, 2009; Ouma, 
2007; Guerrero-Cano, Kirby, \& Urbano, 2006), risk management (Clark, 1998; Massy, 2009; EUA, 2011), organisational autonomy (EUA, 2011), and mission expansion (Clark, 1998; EUA, 2011) have become major drivers for searching for alternative solutions to achieving financial sustainability. There have been a range of responses across developing countries, but these responses have tended to be highly reactive and opportunistic, rather than based on a comprehensive evaluation of the costs and benefits of the various choices available to policy makers. Likewise, the academic debate has been very general, often drawing on developed world responses, rather than reflecting the different socio-economic and political contexts of developing countries.

Revenue generation is increasingly becoming one of the most important strategies for achieving financial sustainability in universities operating in different socio-economic and political environments or at extremely dissimilar stages of industrial and technological development (Jongbloed, 2003; Clark, 1998; Massy, 2009; Liu, 2007; Riechi, 2003; Ouma, 2007). African universities' self-generated resources, on average, account for approximately $28 \%$ of their recurrent budgets (World Bank, 2010). However, revenue generation itself is an area of serious debate, both scholarly and by the public, which is of significant interest for conceptual and empirical research. Hence, the main question addressed by this research (see section 1.3) is:

How can Sub-Saharan African public universities improve their financial sustainability by diversifying their resources while continuing to accommodate the growth in higher education enrolment?

This overarching research problem was broken down into the following four specific research questions:

1. What theory can assist us in understanding the enablers for and barriers to revenue generation for Sub-Saharan African universities?

2. What is the actual practice of revenue generation in Sub-Saharan African public universities?

3. What are the enablers for and barriers to revenue generation in SubSaharan African public universities?

4. Given what we know from theory and international practice, how can barriers be overcome and enablers be introduced for revenue generation in Sub-Saharan African universities? 


\subsubsection{The Wicked Issues of Revenue Generation in Universities as Complex Organisations}

This research has tried to contribute to academic debates about how to deal with these urgent financial pressures, which are found in different socioeconomic and political contexts across the globe. In this regard, Section 2.4 identified six kinds of response that may be introduced at the level of the system: providing additional funding, capping student numbers, liberalising/ privatising, raising efficiency, cost sharing and revenue-generation. There are thus a range of choices open to policy-makers and academic institutional leaders trying to make their higher education systems, or universities, financially sustainable. There has however been little debate about which circumstances make one solution preferable to another in a particular context.

This research has explored one of these solutions, namely giving universities increased freedom to generate revenue, to diversify their revenue base at the level of the organisation and ultimately to reduce their dependence on public funding. There are a range of ways in which universities can exploit their existing assets to generate additional revenue, from educational services/shortterm courses to research/consultancy, facility rental and product sales (see section 2.8).However, the customers and market demands for these activities may be very different from the teaching and research activities which are universities' current core mission.

To generate revenue, universities may have to change what they do to meet customers' needs, and this can also have effects on their nature, in terms of their mission, the balance of activities they undertake, the staff in their organisation, and the way the institution is organised. There appears to be a trade-off between the benefits that revenue generation can bring, and the potential negative outcomes such as shifting academic priorities, compromising educational excellence, unfair competition with the private sector, and market distortion (see section 2.11). It is therefore necessary to understand universities are not simply businesses, but organisations seeking to achieve their goals in a wider environmental context.

For this research, we developed a conceptual model using Resource Dependence Theory to understand revenue generation in universities (see Section 3.1). This theory suggests that revenue generation exposes universities to a much wider range of stakeholders with interests and resources (see Section 3.2). Where universities have a great deal of power and self-determination, then external stakeholders have limited opportunities to dictate universities' activities and therefore the university is not threatened. However, in situations where external stakeholders are more powerful, better resourced or more 
legitimate, then there is the real concern that universities may be compelled to meet the needs of their external partners at any cost (see section 3.3). We argue that this may be financially sustainable in the short-term but in the long-term it is just as unsuited to meeting the skills needs of Sub-Saharan African countries as a system where universities do not have enough finance.

Our conceptual model suggests that universities have to accommodate their stakeholders' interests, depending on their relative power, whilst ensuring that they deliver their core activities. The balancing of interests between university and stakeholders depends on the characteristics of the university as well as the wider organisational environment in which the university operates. The interactions between university characteristics and organisational environment influence both the strategies that universities are able to formulate and their success in revenue generation. The research looks at how these two independent variables, university characteristics and organisational environment, affect universities' revenue generation strategies and activities.

\subsubsection{Study Approach, Method and Results}

The research questions listed above were addressed based on a review of the literature in Chapter 2, a theoretical framework and research model provided in Chapters 3 and 4, and empirical data derived from the case study universities in Chapters 5 to 8 using a qualitative research approach. A critical review of the scholarly literature was undertaken to conceptualise revenue generation and map the state of revenue generation in universities. The theoretical framework derived from resource dependence theory provides a useful conceptual tool for understanding the case study universities' strategic responses to their financial challenges. It also provides a lens to explain how environmental factors and university specific conditions influence revenue generation strategies and activities.

As revenue generation by public universities is a multifaceted phenomenon, it requires the collection and analysis of data drawn from diverse sources and different actors using multiple methods. Accordingly, we gathered data through interviews from four public universities in three Sub-Saharan African countries (Ethiopia, Kenya, and South Africa). The four universities included in this study were Adama Science and Technology University and Haramaya University in Ethiopia, Jomo Kenyatta University of Agriculture and Technology in Kenya, and Nelson Mandela Metropolitan University in South Africa. 
We conducted 67 semi-structured interviews with purposefully selected participants from the four case universities (see Annex I). Respondents ranged from senior university leaders to frontline actors (see Table 4.8) who were directly or indirectly involved in their university's revenue generation agenda. Additionally, we collected documentary evidence from national laws, regulations, development strategies and plans, and from websites of the case study universities and their stakeholders, which more or less represent views of their external stakeholders. The documentary evidence mainly covers the period 2007/08-2010/11.Furthermore, we observed as on-lookers on what was going on in the offices, classrooms, laboratories, and the premises of university campuses with respect to revenue generation. In terms of data analysis, a content analysis, an analysis at the level of individual case study universities, and a comparative analysis across the four case study universities were undertaken to answer the basic research questions.

By comparing four universities in Sub-Saharan Africa, we have been able to understand the complexities of moving towards revenue generation. The four universities chosen have sufficient similarities to allow meaningful comparison: they are publically funded and have a recognised position within their national systems, they are comprehensive in terms of the subjects they offer, they all have the potential to generate revenue and they have been active - in various ways - in revenue generation. At the same time, their responses in terms of strategy and activity have been rather different, allowing for a closer comparison of their activities.

There have been a range of responses from the universities (see section 8.6), with both adaptive and altering strategies being used to improve their revenue generation (see subsections 9.2.2.1 and 9.2.2.2 below for further discussions). As shown in this study, revenue generation is to some extent dependent on the research strengths of the university and yet all the universities have adopted a similar set of strategies (including strategic alliances with other organisations) to create internal revenue generation capacity. All four universities have experienced profound structural pressures from revenue generation, with the majority of the universities developing new structural arrangements to deal with those pressures, including the creation of revenue generation-related committees. At the same time, despite policy aspirations to improve university revenue generation and engage more effectively with the economy, the level of resources generated has not significantly shifted the basis for the sustainability of the sector - revenue generation funds itself but does not necessarily represent a new and more sustainable approach to university financing. 
There has been a degree of diversification in the courses offered by the universities, as that is less dependent on the research base. The most popular new courses established were in social sciences, business and management, because these had relatively limited investment requirements, and were also greatly in demand from students due to their contribution to graduate employability. Our research shows that Sub-Saharan African universities have evolved in response to the pressure to generate revenue. Questions remain about the extent to which universities have felt pressured to make changes to generate revenue at all costs, or whether universities were able to exploit their assets, create sustainable investments and use revenue generation activities as an increasingly important element of a sustainable university finance system.

\subsection{Balancing Growing Student Enrolments and Revenue Generation in Sub-Saharan Africa}

\subsubsection{Enablers For and Barriers to Revenue Generation: a Theoretical Framework}

The study's first research question was about the organisational theory that underlies the conceptualisation of the relationships between universities and their environments in the process of acquiring resources.

1. What theory can assist us in understanding the enablers for and barriers to revenue generation in Sub-Saharan African universities?

The starting point for the theoretical analysis was the need to deal with the key issues at the heart of revenue generation in universities. Revenue generation is not the core mission for universities, rather it is a means to an end, to enable universities to deliver their core activities (teaching, and in some cases also research and community service). When universities wish to generate revenue, they must make changes in their overall operations, including internal structures, in response to the requirements of resource providers. These changes may involve both risks and opportunities. For example, if all university staff set up their own companies, then teaching will be forced onto less qualified or inexperienced employees, which will adversely affect the quality of the education and/or the value of their main outputs. If universities manage to earn additional resources without compromising their core missions, this will lead to academic development, be it in teaching or research activity. If universities are engaging in revenue generation, then they will be responding to their external environments or the needs of diverse stakeholders. It is, therefore, necessary to adopt a theoretical framework that helps us to understand this 
interdependency between universities and their environment in the process of acquiring resources.

In our search for organisational theories that fit the topic under study, we carried out a literature review, as discussed in Chapter 2. Chapter 2 concludes that the existing research outcomes in the area of revenue generation have insufficient complexity in models and richness in data to enable us to understand the interdependent processes across many different actors, agents, and higher education organisations involved in revenue generation. The subject of revenue diversification by organisations of higher learning is still undertheorised and subject to ongoing debate, and is thus yet to achieve theoretical and empirical agreement among stakeholders. However, the literature review in Chapter 2 contains some important insights into factors that influence revenue generation by universities across the globe. A synthesis of the review of literature shows that revenue generation is all about acquiring resources from external stakeholders and is influenced by university specific factors and external conditions (Clark, 1998; Etzkowitz, 2003). The key university specific factors include the commitment of senior university leadership (Clark, 1998, 2001; Williams, 1992; Lapworth, 2004; Stamoulas, 2006; Askling et al., 1999), internal resource allocation models (Massy, 1996, 2003; Jongbloed, 2003), qualifications and commitment of academic staff (CHET, 2011; Massy, 2003; Dill, 2003), stakeholder management capacity (Cloete \& Maassen, 2006; Sporn, 2006; Gumport \& Sporn, 1999), and the reward system (Kirby, 2005; Shattock, 2003). Externally, revenue generation is dependent on the laws, incentives and policies shaped by government authorities (OECD, 2008; EUA, 2011; Mowery et al., 2001; Hellsmark et al., 2003), the surrounding industry (Gulbrandsen \& Smeby, 2005), and the regional conditions (Friedman \& Silberman, 2003). The resource allocation models employed by public authorities for the financing of their universities, along with their accompanying financial regulations may provide incentives for public universities to engage in revenue generation (EUA, 2011; Gumport \& Sporn, 1999).

The main insights from the literature review conclude that universities as organisations are not completely self-contained or in complete control of the conditions of their own existence, but must engage in exchanges and transactions with other groups or organisations in their environment to acquire resources (see also Scott, 1992; Hall 1999). We thus characterise organisations as open systems that support themselves by exchanging resources with their environment (Meyer \& Scott, 1992). The environment within which the organisation is embedded not only offers opportunities for acquiring resources, but simultaneously imposes constraints on the range of actions available to the focal organisation (Tolbert, 1985). This suggests that organisational choice is 
constrained by a range of environmental pressures, and organisational survival depends on an organisation's responsiveness to external demands and expectations. In this regard, organisations are capable of choosing strategies in response to demands and expectations from their environment (Oliver, 1991). Establishing a balance between environmental demands and internal factors in universities (in our case) is an important issue in formulating strategies to manage the relationship between universities and their environments in the process of acquiring resources (Gumport \& Sporn, 1999; Clark, 1998, 2004; Lawrence \& Lorsch, 1986; Dill, 2003).

Resource dependence theory provides useful insights into how organisations shape their relationships with the environment in the process of acquiring resources essential for their survival. In line with this theoretical perspective, universities as organisations aim to secure a steady flow of resources, anticipating developments in their environment, responding to threats and opportunities. Resource dependence theory suggests that the organisation must respond to some discontinuity or lack of fit that arises between the organisation and its environment in the process of acquiring resources. Universities will seek to decrease the level of uncertainty around resources and expand their resource base by formulating and implementing strategies for their survival. This suggests that the strengths and weaknesses of a university itself can influence their choice of strategies and the types of activities undertaken to acquire resources.

Resource dependence theory provides the basis for the research model formulated in this study (see Figure 9.1 below). There is a bi-directional relationship between the university and its environment, and, in the light of this, particular strategies are formulated and possible activities are chosen. The intended outcomes of the activities are revenue streams that help to secure the survival of the university. Successful revenue generation activity may also result in the development of legitimate and trust-based relationships between the university and the key stakeholders in its environment. Success (or lack of success) in generating revenue may trigger an adaptation of the university's strategies, leading to a revision of the university's strategies and relationships with its stakeholders. 
Figure 9-1 Research model restated

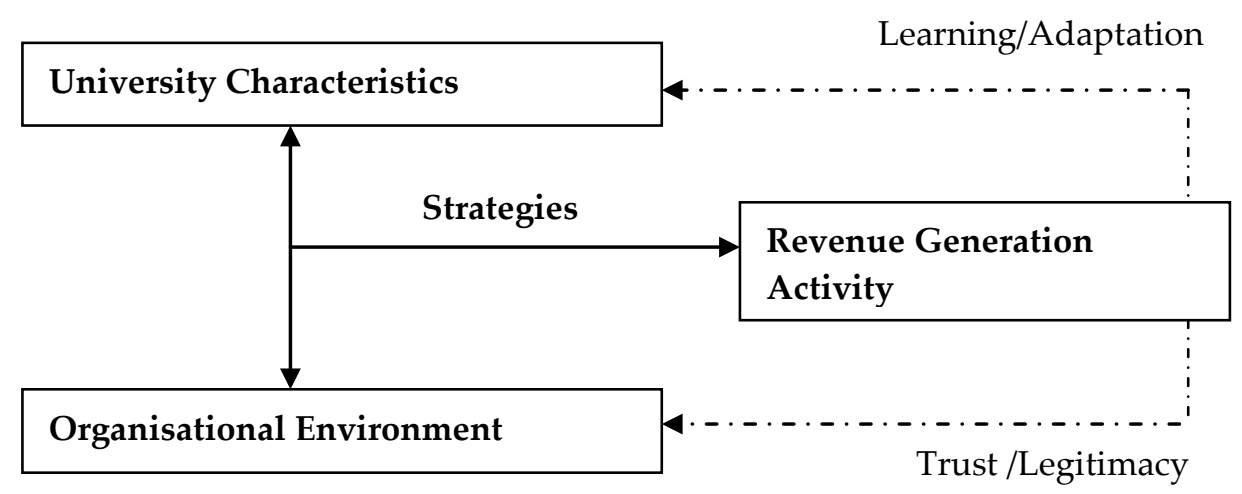

The characteristics of the university and the external environment, comprise the independent variables of the study. The two independent variables are expected to influence the strategies that a university may choose to secure resources. The focus of this research is on university strategy, which is one of the dependent variables. A wide spectrum of strategies, broadly categorised as adapting and altering strategies, may be considered by the university in order to acquire resources for its survival. The choice of revenue generation strategies and the activities that result from these strategies form the dependent variables.

\subsubsection{Universities' Revenue Generation Practices in Sub-Saharan Africa}

Our second sub-question focuses on the existing empirical studies concerning revenue generation practices used by universities in the context of Sub-Saharan Africa.

2. What is the actual practice of revenue generation in Sub-Saharan African public universities?

The review of the existing empirical studies presented in chapter 2 showed that there has been limited research on revenue generation in the context of public universities in Sub-Saharan Africa. Our literature review thus primarily covers the work of scholars who have directly or indirectly explored the practice of revenue generation in other parts of the world. A synthesis of the scholarly literature on higher education financing around the world shows that most higher education systems face the challenge of designing sustainable funding models (EUA, 2011; Clark, 1998; Massy, 2003; Johnstone, 1998; Beliakov et al., 1998; Jongbloed, 2004; Clark, 2004; Rizzo, 2004; OECD, 2008; World Bank, 2010; Bermal et al., 2003; Shen\& Li, 2003; Ziderman, 2003; Varghese, 2009). As we 
have indicated in subsection 9.1.1, the capacity for public investment in higher education at the national level in Africa meets only 33 to $40 \%$ of their total financial requirements (see World Bank, 2010). Revenue generation is now widely recognised as one strategy for achieving financial sustainability in universities (Jongbloed, 2003; Clark, 1998; Massy, 2009; Liu, 2007; Riechi, 2003; Ouma, 2007).

Universities in Africa manage to generate around $28 \%$ of their recurrent budgetfrom sources other than their recurrent government allocation (World Bank, 2010). Universities undertake both academic and non-academic activities to generate such external resources (Clark, 1998; Shattock, 2003; Jongbloed, 2003; Johnstone, 1998; Leslie \& Slaughter, 1997; Williams, 1992; Liu, 2007; CHET, 2011; EUA, 2011; Hearn, 2003) from a diverse array of stakeholders. The most prominent source of external revenue across the globe is tuition fees paid by students (EUA, 2011; OECD, 2008; Williams, 1992). Revenue from applied research and consultancy are other examples of income sources for universities, particularly in technologically advanced regions (Leslie \& Slaughter, 1997). Obviously, variations in revenue generation exist from one university to another in the same or different countries, and among departments and programmes within the same university (Clark, 2004). Studies show that although revenue generation is one mechanism to achieve financial sustainability, it cannot replace public funding (see EUA, 2011).

Chapter 8 attempted to compare and contrast the revenue generation efforts of the four case study universities situated in three Sub-Saharan African countries, using the resource dependence perspective as the theoretical lens. Section 8.4 considered revenue generation in the four case study universities, and highlighted how all four universities face financial constraints, making financial sustainability a key concern for them. Against a back-drop of stagnating or falling public budgets, revenue generation has been driven by the desire to mitigate the risk of dependence on a single resource provider. In this regard, all of the universities were successful to some degree, although the resources acquired were not always sufficient to allow investment in the resources that would strengthen the knowledge core (teaching/ research/infrastructure) at the heart of that service provision.

The results are synthesised in section 8.6. The findings of the study revealed that, with different degrees of emphasis and success, all the case study universities exchanged their academic (i.e. education and research) and nonacademic products and services to acquire resources from diverse stakeholders. The most obvious point in this analysis is that all the universities generated revenue from multiple sources, with student fees being the most prominent; the 
capacity to generate resources from research and consultancy depends both on internal factors (academic and administrator knowledge) and external demands and opportunities. A key finding is that the universities themselves had changed their internal operations and structures to generate revenue, using both adapting and altering strategies to acquire resources through education, research and consultancy, and non-academic services (Gumport \& Spon, 1999; see also section 3.3.3). The research revealed that the four case study universities have formulated various revenue generation strategies, which can be broadly categorised into adaption and altering strategies.

\subsubsection{Adapting Strategies}

The primary focus of adapting strategies was on using existing resources as efficiently as possible, through a range of diversifications in the offer of existing services and activities. The universities adapted and changed their services to fit environmental requirements, for example by creating many kinds of higher education provision to meet a much wider range of target audiences than the single traditional learner route. They assessed the needs of their salient stakeholders, defined their market segments, and then adapted their services and products to meet some of these needs. In this context, the universities were primarily responding to their environmental requirements.

The findings in this study demonstrated that the key strategies used for revenue generation from education and short-term training services included differentiation of educational services (horizontally, in terms of the spectrum of programmes, and vertically, in terms of the level of programmes), opening (satellite) campuses in strategic locations, devising diverse modes of delivery (face to face teaching, or distance education), and differentiation of the student population in terms of their study period (weekdays, weekends, summer, or evening). Similarly, all the case study universities identified their research priority areas, established research entities alongside their traditional academic departments, and created research management offices as part of their adapting strategies to acquire resources from research and consultancy services. Establishing research entities such as institutes, centres and units without having adequate research capacity illustrated how organisational decision makers imitated the behaviour of other actors in their environment, as observed at the Ethiopian and Kenyan case study universities.

At the corporate level, all the case study universities have taken practical measures to improve communication, create stable and clear organisational structures for 'relationship management' or 'stakeholder management', and increased staff commitment by setting up incentive schemes as part of their 
revenue generation strategies. Structurally, they have established outreach administrative units that promote contract education, contract research, shortterm training, consultancy and other non-academic products and services. In managing their revenue generation, all but Adama Science and Technology University formed a decision-making body constituted of representatives from senior leaders, middle managers, and academic staff, which created an opportunity for fusing managerial values with traditional academic values. The four universities have also followed similar patterns in aligning internal actors to their revenue generation agenda by providing financial and nonfinancial incentives. While the financial rewards target individuals in the Ethiopian case study universities, they focuses on all internal actors, be it individuals or subunits, who directly or indirectly participate in revenue generation in the Kenyan and South African case study universities. All the case study universities allocate some seed money for expanding existing revenue generation activities or starting new initiatives.

Other organisational responses targeted stakeholder and relationship management, setting up outreach units to create new kinds of services (training, consultancy and other non-academic services). Introducing this plethora of new units introduced new organisational complexity and thus worked against improving institutional efficiency.

\subsubsection{Altering Strategies}

In terms of altering strategies, the four universities attempted to alter the system of constraints and dependencies confronting them in their respective environments through forming alliances, co-opting, and/or lobbying for deregulation or reregulation. The study revealed that the four case study universities formed strategic alliances with other educational organisations to create additional capabilities that pragmatically increased their range of viable responses to diverse types of students who wished to use their educational services. Similarly, all the universities tried to form alliances with other higher education organisations and research institutes to foster their research capacity as part of their altering strategies. In other words, alliances with other research organisations (universities and research institutes) formed a key strategy for improving their own in house capacity. However, such alliance arrangements are only practical and fruitful when universities ensure their own critical inhouse capacity in terms of human and non-human resources, as observed in the South African case study university. It was clear that where these initiatives were failures, this was primarily because of internal problems with insufficient 
qualified personnel and inadequate infrastructure, rather than a lack of policy incentives and funding.

The presence of regional or provisional authorities on the boards or councils of the case study universities, as well as the formation of strong alumni associations, were employed as altering strategies to gain preferential access to resources by offering educational services and short courses to regional or provincial stakeholders. In some cases, the senior university leaders lobbied for additional autonomy in terms of staffing (i.e. freedom to set salaries for administrative staff) (see Table 5.19).

\subsubsection{Enablers For and Barriers to Revenue Generation}

The findings in this study revealed that our case study universities have all diversified their revenue structure to some degree. The proportion of nongovernmental funds of all but the Ethiopian case study universities exceeded the total budgets from their respective national governments. However, with the exception of the South African case study university, they have not diversified their revenue base to the level of ensuring financial sustainability, as a sudden decrease in any one source of resource could destabilise their operations. As not all universities have the same potential and opportunities for exploring new income sources, this study attempted to identify the factors that enable or erect barriers to revenue generation by universities.

3. What are the enablers for and barriers to revenue generation in SubSaharan African public universities?

The research identified factors, both specific to universities and in their wider environmental contexts that influenced revenue generation strategies and activities. The main environmental contexts were (rising) demand for higher education, the legal framework surrounding the core funds for universities, as well as the universities' academic and organisational autonomy. The main internal factors affecting revenue generation were subject mix (business studies being popular), research strengths, and commercialisation infrastructure.

\subsubsection{Enablers and Barriers External to the Universities}

The findings of this study revealed that in the university's environment, the types and nature of stakeholders, the regulatory framework (including dimensions of organisational autonomy), funding and incentive schemes influence the capacity of universities to generate additional revenue. The study 
indicated that while the regulatory frameworks in which the case study universities operate allow them to generate revenue, the limited degree of financial and staffing autonomy granted to the universities (notably the Ethiopian case study universities) hinder their revenue generation efforts. In this respect, inability to reallocate funds as the universities see fit, inability to borrow money on the capital market, and inability to decide on the volume and salary levels of their staff are the key barriers to engaging in large-scale revenue generation efforts.

This study identified inadequate funding and incentive schemes as possibly being the main obstacle to revenue diversification in universities. Funding incentives set by public authorities should reflect the diverse missions and profiles of universities not focus exclusively on rewarding education activities as in the cases of Ethiopian and Kenyan universities. The limited or absent upfront investment in university research infrastructures hinder revenue generation at these universities. South Africa has a range of targeted support funds for research, including research funds for graduate students and rewards for research publications, which provide opportunities for universities to generate additional research funding. Moreover, student support schemes such as the National Student Financial Aid Scheme in South Africa and the Higher Education Loan Board in Kenya facilitate poor and disadvantaged but academically able students gaining access to higher education. These funding schemes provide the university with opportunities to generate revenue from students.

The study also showed that inadequate resource allocation mechanisms and funding modalities have a negative effect and create powerful disincentives for universities to seek additional funding sources. An excessive administrative burden, including complex rules and reporting obligations associated with public or private and donor sources, is one hurdle which deters universities from diversifying their funding streams. The funding modalities that are particularly unfavourable to universities include line item budgeting, which tends to create conditions that stand in the way of the universities' income generation potential. Similarly, a diversity of instruments and associated rules, heavy administrative processes and accountability requirements deter our case study universities from participating in some donor funding schemes.

\subsubsection{Enablers and Barriers Internal to the Universities}

The findings of this study demonstrated that leadership commitment to revenue generation, internal governance and management processes, absence of sufficiently qualified and motivated academic staff and professional managers, 
and inadequate non-human resources influence revenue generation across the case study universities. Senior university leadership's huge commitment to revenue generation, which we witnessed in this study, is of paramount importance for seeking additional revenue streams. The adequacy of structures and decision-making processes facilitates universities' revenue diversification efforts. In particular, a deliberative structure of committees along with strong organisational leadership is a key enabler.

The study revealed that lack of properly qualified academic staff - as measured by the number of PhD holders - is an important barrier to revenue generation in the Ethiopian case study universities. The proportion of academic staff with doctorates is an indication of the research capability of academic staff and their potential to engage in revenue generation beyond the teaching of self-funded (fee-paying) students, as shown in the case of the South African case study university. The findings of this study also indicated that the potential for revenue generation depends on the ability of universities to offer good quality services to their internal and external stakeholders. The inadequate administrative support capacity at the Ethiopian case study universities is an obstacle to revenue generation. At operational level, properly qualified/experienced staff are needed particularly in the areas of procurement management, fundraising, human resources, communication, and financial management.

With regard to non-human resources, universities suffering from a lack of research facilities and proper laboratories and equipment are often unable to initiate research-based revenue generation activities, as observed in the Ethiopian and Kenyan case study universities. Their capacity in terms of physical facilities and infrastructure affects their potential to engage in postgraduate education and research, particularly in those academic programmes that require considerable investment in laboratories, machinery and other physical facilities. The example of Nelson Mandela Metropolitan University shows that heavy upfront investment in research facilities and infrastructure enables the university to earn revenue from research and postgraduate educational services.

\subsubsection{Recommendations for Enhancing Revenue Generation}

Overall, revenue generation in the context of Sub-Saharan African universities is constrained by a multitude of interrelated factors in both the internal and external environments, as indicated in section 9.2.3 above. This implies that there is a need for improvement in both the internal and external environments of the universities to bring positive changes in current revenue generation 
practice. By combining the arguments from section 9.2.3 with additional material from Chapter 8, it is possible to answer the fourth research question indicated below.

4. Given what we know from theory and international practice, how can barriers be overcome and enablers be introduced for revenue generation in Sub-Saharan African universities?

\subsubsection{Effective Revenue Generation by Sub-Saharan African Universities}

The findings of this research revealed that our case study universities have been diversifying their revenue structure to some degree, but have largely been unable to do so to the level of ensuring financial sustainability. The major university specific barriers for achieving financial sustainability through diversifying the funding structure include lack of sufficiently qualified and motivated academic and administrative staff, shortages of non-human resources, and inadequate support and incentives for revenue generation. On this basis, it is possible to characterise the universities that are effective in generating revenue in four ways. These four characteristics form the basis for an ideal type model of an effective "revenue-generating university" (in the particular context of Sub-Saharan African Anglophone public universities), in contrast to the archetypal single-funder dependent model.

The first element is that there is a clear growth model for the use of the resources, that is to say that the resources that are generated are invested in core university assets that contribute to the main missions of teaching and research. With the exception of the South African university, we observed that the research bases of the case study universities seem to be quite weak, and therefore effective revenue generation needs to ensure that some of the resources that flow into the university provide not only administrative funding, but also 'pump prime' new research activities, creating and expanding the university's knowledge base. There is also a need to ensure that the link between teaching and research is maintained when this happens so that students benefit from the improving knowledge levels of academic staff.

The second element is that there is strong leadership within the university to ensure an effective balancing of stakeholder interests. In subsection 8.2.2.1, we identified that the move to revenue generation increases the university's exposure to a wider array of stakeholder interests, public authorities, students, donors, and business/ industry. The need for a strong, integrative investment growth model requires that there is a single strategic centre that can balance out internal interests (and conflicts) and take decisive action to maximise the ways in which the universities meet these stakeholders' needs. Whilst this idea is not 
novel, what is clear empirically is that existing university management could well be improved; therefore, in our ideal type, there is a continuous improvement of leadership and management capacity through training.

The third element of an effective revenue generating university is that the responsibility for revenue generation is devolved to and felt by staff at all levels. In situations where university employees are not directly exposed to financial signals from their stakeholders, it is all too easy to revert to a businessas-usual model, i.e. the single funder dependent model. Therefore, the third key element of our model is designing and implementing effective resource allocation models that provide incentives for revenue generation at faculty and departmental levels (see section 8.5.3). This needs to give academic and administrative staff the opportunity to receive monetary rewards for their efforts. At the same time, it needs to ensure that there is a central revenue stream that serves to create seed money and capital for new ideas that cannot be funded out of recurrent revenue.

The final element is that revenue generation needs to be embedded into the organisational structures of the university, and in particular, in the human resource side. This ensures that academics and administrative staff are able to share in the non-monetary benefits of revenue generation. These may include flexible work hours, training, a pleasant working environment, and sabbaticals. Although none of the case study universities used revenue generation as a measure for staff recruitment or promotion, effective revenue generation sees revenue generation being well-aligned with recruitment and promotion criteria, in areas such as strengthening research activities (which indirectly supports revenue generation activity in research and technology transfer).

\subsubsection{Creating an Optimal Environment for University Revenue Generation}

The findings of this study identify a number of hurdles for revenue generation in the environments of universities, particularly in their regulatory frameworks. An effective revenue generating university is one that manages itself to respond effectively to signals from external stakeholders about what they value and are prepared to pay more for. But at the same time, it is also dependent on the quality of the signals coming in from the outside environment, as well as the regulatory freedom that it has to respond in a timely way to stakeholders' needs. In subsection 8.2.2.1 we identified that public authorities are the most salient stakeholders for all universities, and therefore we also argue that there is much that these public authorities can do to ensure that they give their universities the best chance to respond effectively, and to optimise the benefits 
of revenue generation, increasing the overall quality of university knowledge activities.

Although effective revenue generating universities are those where there is considerable autonomy, for public universities that is not something that the universities are fully able to decide for themselves. In subsection 8.2.2.2, we pointed out that there appears to be a correlation between university autonomy in the areas of finance and staffing, and revenue-generation capacity. This fits intuitively with the idea in subsection 9.2.4.1 that flexible resource allocation models and strong central leadership support revenue generation activity. Therefore, those public authorities which are best supporting university revenue generation activity are those which have delivered reforms which give universities autonomy to take decisions, and at the same time hold the universities more strictly accountable for the exercise of those freedoms in meeting overall public policy goals.

Alongside shifting the regulatory burden on universities in ways that give universities new freedoms to generate revenue, public authorities can also directly stimulate revenue generation by encouraging it via the resources they provide to universities. There are a variety of methods that can be used to ensure that public funding is stimulating and not discouraging revenue generation. Part of this can be done by using funding formulas, competitive funding and/or earmarked funding as mechanisms of resource allocations. Given that revenue generation is also dependent on excellence, governments should also seek to stimulate that, and notably, ensure that there is adequate public funding provided (e.g. through loans) for all qualified students to go to university.

A third set of activities that public authorities may seek to encourage is cooperation and interaction between universities and external bodies. Given the relatively underdeveloped nature of connections between universities and external stakeholders, and the need to generate expertise in working with external partners, this suggests that universities should be encouraged to work with those partners that are most proximate to them. One form of proximity here would be geographical, working with regional and local communities, businesses and authorities. These kinds of local co-operation on the one hand help directly to contribute to the diversification of offer which is central to the adapting strategies (see subsection 9.2.2.1) and on the other hand help the universities to build up management and shared infrastructure for supporting co-operation around revenue generation (see 9.3.3.1)

Finally, this study revealed that donor funding schemes are among the most complex funding programmes available to universities because of the diversity 
of instruments and associated rules, the heavy administrative processes and the accountability requirements. In order to set desirable incentive mechanisms to foster revenue diversification from international donors, we recommend simplification of funding schemes by streamlining eligibility conditions and accountability requirements to reduce the administrative burden on universities. There is a need to create mechanisms to support universities applying to funding programmes.Learning from the experiences of Europe, simplification of rules and procedures as well as moving towards funding on a full cost basis appearsto be a sustainable solution in the long-run.

\subsection{Reflections on Theory and Policy Practice}

In this section, we reflect on how the results from our empirical investigations relate to current debates on revenue generation by public universities and on some elements of the chosen theoretical framework. This is followed by a reflection on the policy practice in the context of Africa.

\subsubsection{Reflections on the Theoretical Framework}

This part deals with the extent to which resource dependence theory is able to explain the overall revenue generation efforts of universities in Sub-Saharan Africa. First, we reflect on possible conceptual avenues for understanding financial sustainability that retain the strengths or value of resource dependence theory in our research. Second, we present some limitations of the theory in light of alternative - or complementary - theories that stress non-monetary concepts and values that may influence organisational strategies and activities.

\subsubsection{The Value of Resource Dependency Theory for Understanding Revenue Generation in Sub-Saharan African Universities}

This research was guided by the theoretical framework derived from resource dependence theory. The main contribution of the theoretical outline described in Chapter 3 was the structure it brought to the research. Resource dependence theory served as the framework for identifying the study's key variables and guided the research procedures; i.e. data collection and analysis, interpretation and discussion of the results, reflecting on research findings and drawing conclusions. As stated by Pfeffer \& Salanick (2003), the resource dependence perspective is all about the connection between environment, organisation, and organisational decisions or actions for acquiring and maintaining resources that are essential for the survival of organisations. Thus, the theory proved to be helpful in suggesting such variables as organisational environment, university 
characteristics, strategies, activities, and resources, as detailed in Chapter 4. By illustrating all these variables, the search for the connections between these variables was more organised and simplified.

Resource dependence theory also proved to be useful in investigating a number of nested levels of organisational environment in terms of the distribution of power and resources (Pfeffer \& Salancik, 2003; Nienhüser, 2008). Grounded in an open-system theory, the theory argues that an organisation is dependent on those organisations or entities in its environment that control critical resources for its survival (Pfeffer \& Salancik, 1978, 2003; Aldrich, 1979; Scott, 1992a). One of the fundamental assumptions of the theory is that the organisational environment not only provides critical resources needed by the organisation, but is also a source of constraints to acquiring that resource (Nienhüser, 2008). The theory proved to be important in analysing different dimensions of organisational environment, focusing on the task environment (Scott, 1992a; Scott, 2003:211) to explore opportunities and constraints embedded in the environment. According to resource dependence theory, those actors who control critical resources have power, and that power influences the behaviour and actions of the resource recipient organisation (Nienhüser, 2008; Pfeffer \& Salancik, 1978). In this study, resource dependence theory hinted at the importance of stakeholders in the organisational environment, their powers and motives (Pfeffer \& Salancik, 1978; see also Oliver, 1991) and ways of enforcing their interests in a broader and oversimplified way. A stakeholder theory, a more refined theory for prioritising stakeholder claims and reconciling the sometimes contradictory interests of stakeholders (see Enders, Jongbloed, \& Salerno, 2008), was applied to complement our main theory and overcome the shortfalls in the resource dependence perspective. We have relied on stakeholder theory for studying stakeholder salience in terms of regulatory powers and funding (see Freeman, 1984; Enders, Jongbloed, \& Salerno, 2008). In general, however, as long as power in and around the organisation is seen as important in driving dependence relations and resource exchange, the resource dependence perspective may provide useful insights (see Davis \& Cobb, 2009).

Resource dependence theory assumes an active role of organisations in their struggle for survival (Aldrich, 1979; Pfeffer \& Salancik, 1978; Scott, 1992b; Davis $\&$ Cobb, 2009). This theory argues that organisations, as rational actors, strive to maximise their resources by reducing their dependence upon others, while at the same time making others dependent on them (Berman, Phillips, \& Wicks, 2007; Davis \& Cobb, 2009; Nienhüser, 2008). The resource dependence perspective seeks to understand internal organisational dynamics by looking at the internal distribution of power (Nienhüser, 2008) as one of the factors that influences organisational actions and behaviour. In our research, the theory 
suggested an examination of both individual and organisational actors who control important resources or power in order to advance their demands (Pfeffer \& Salancik, 1978). More importantly, resource dependence theory explicitly stresses the importance of management, as noted by Nienhüser (2008). Pfeffer and Salancik (2003) suggest that leaders and managers have a decision-making and legitimising role, besides the function of perceiving and interpreting the environment (see also Nienhüser, 2008; Berman, Phillips, \& Wicks, 2007). Following the insights of the resource dependence perspective, we examined the roles of senior leaders and managers in scanning their organisational environment, analysing their organisations, formulating revenue generating strategies and policies, and entering into the actual exchange relationships with resource providers in order to manage resource dependence (see Berman, Phillips, \& Wicks, 2007; Davis \& Cobb, 2009; Nienhüser, 2008). The theory suggests that organisations must have a certain level of autonomy (Hall, 1999: 281) or discretion that permits them to decide on strategies for resource exchange. The theory therefore pointed at the need for exploring different basic dimensions of autonomy in the context of universities.

The resource dependence perspective also provides a means to interpret the strategies available to the university's management in handling resources and exchange relationships with the environment (Berman, Phillips, \& Wicks, 2007; Pfeffer \& Salancik 2003; Nienhüser, 2008). The theory allows for a detailed analysis of strategies for acquiring resources that lead to ensuring organisational survival (Nienhüser, 2008; Oliver, 1991). The resource dependence perspective suggests two broad strategies to address dependence (see Davis \& Cobb, 2009). On the one hand, organisations can adapt and change to fit environmental requirements (see subsection 9.2.2.1 above). On the other hand, organisations can attempt to alter the environment so that it fits the capabilities of the organisations (see subsection 9.2.2.2 above). The two broad strategies include the following options: closely collaborating (or even merging) with other organisations, diversifying services and products, creating new organisational structures, co-opting important others through interlocking directorates, and engaging in lobbying activities to influence matters such as regulations (Pfeffer \& Salancik, 1978; Davis \& Cobb, 2009).

The application of resource dependence theory is not new to higher education. In particular, this theory has been applied in empirically oriented studies of higher education (Huisman, 1997; Volkwein, 1986; Leslie \& Slaughter, 1997). There are also higher education studies in which resource dependence theory has been combined with neo-institutional theory (see Goedegebuure et. al.2006; Gornitzka, 1999; Zomer, 2011; Leisyte, 2007). This suggests that resource 
dependence theory may offer important insights into strategy building and decision-making in higher education.

\subsubsection{The Limitations of Resource Dependence Theory}

Although resource dependence theory has much to offer in explaining the behaviour and actions of organisations, as discussed in subsection 9.3.1.1, the chosen theoretical perspective had some limitations, especially with respect to its capacity for explaining empirical phenomena such as the universities' strategic responses. We recognise that human behaviour and organisational strategies can never be fully explained by market mechanisms or maximisation of resources (see Nienhüser, 2008). Some key findings of this research that do not conform to the assumptions of the resource dependence perspective are discussed in the subsequent paragraphs.

Following Nienhüser (2008), we argue that the resource dependence theory is too limited in scope if one attempts to interpret the behaviour, actions and strategies of organisations in a too materialistic, objective or rational way. The findings of our study revealed that the case study universities, although operating in different institutional fields, have shown similar strategic responses to achieving financial sustainability, seemingly without calculating their immediate economic advantages or efficiency gains. The strategic responses to dealing with financial pressures include pursuing revenue generation as an adaptive strategy (see section 8.4), with different universities adopting similar structures but without having equal internal capabilities or equal external opportunities for revenue generation (see subsection 8.5.1.2).We also came across the case of different universities devising similar internal governance systems (see section 8.5.2).

With regard to revenue generation as an adaptive strategy across the universities, the work of Westphal \& Zajac (2004) offers some new insights. These authors take a neo-institutional perspective and suggest that organisational policies and practices (such as revenue generation in our case) can acquire legitimacy by the mere fact that they are widely adopted elsewhere and conform to the dominant practices within their organisational field (Westphal \& Zajac, 2004: 430; Delmas\&Toffel, 2008: 1027). This suggests that revenue generation is increasingly becoming one of the strategic responses in higher education systems and universities in both developed and developing countries that are dealing with financial pressures (see chapters 2 and 8). Revenue generation practices are becoming consistent with prevailing institutional logics, as is the case in several higher education systems across the globe; they are progressively being institutionalised as an appropriate strategic 
response to financial austerity (see Westphal \& Zajac, 2004; Clark, 1998). Conformity with the collective norms around the operations of universities appears to be one explanation for engaging in revenue generation (see Oliver, 1991), even for universities operating at different stages of socio-economic development and in extremely dissimilar political environments.

The findings of our research showed that the case study universities, in order to ensure financial sustainability, emulated the strategies of other universities in the global higher education world, in particular of those universities whom they knew and trusted (DiMaggio and Powell, 1983; Oliver, 1991; Ashworth et al., 2007; Greenwood \& Hinings, 1996; Delmas \& Toffel, 2008). A case in point is the creation of research entities and research management structures at the Ethiopian and Kenyan case study universities without there being adequate supporting research capacity (see subsection 8.5.1.2) to lead to economic gains. These structures were created and organised in certain ways, not because this form of governance and organisation had been analysed and found to facilitate efficiency and effectiveness for acquiring resources in their contexts, but rather because it is regarded as the appropriate response in organising oneself for revenue generation. In fact, the case study universities incurred additional costs in pursuing this strategy. This suggests that the universities' actions and behaviour were influenced and shaped by the existing rules, norms, and logics in their environment (see DiMaggio \& Powell, 1983; Ashworth et al., 2007; Greenwood \& Hinings, 1996; Delmas \& Toffel, 2008). This type of copying or emulating behavious shows how organisational strategies and practices converge through a legitimising process(see sections 8.5.1.2 and 8.5.2), known as isomorphism (see DiMaggio \& Powell, 1983; Ashworth et al.,2007). These non-monetary motives exhibited by organisations in response to their financial challenges can thus best be explained using a neo-institutional perspective (DiMaggio \& Powell, 1983; Meyer \& Rowan, 1977; Scott, 1987b; Greenwood \& Hinings, 1996).

Alongside the broad similarities in the strategies and activities of the case study universities, we also observed variations in some strategies and in the pace of implementation (see section 5.7.2; section 8.5). Institutional logics (Alford \& Friedland, 1991; Greenwood et al., 2011) can serve as an instrument to explore what beliefs are represented by relevant stakeholder groups and what these stakeholders value as legitimate actions and outcomes for higher education organisations. The existence of competing (and shifting) institutional logics in organisations and their environment may account for the variation in practices across different organisations - including differences in the revenue generation strategies employed. Ocasio and Thornton(2008) explain how competing institutional logics may induce heterogeneity in organisational strategies, 
actions and behaviours (see also Alford \& Friedland, 1991; Westphal \& Zajac, 2004). The institutional complexity implied by the competing logics poses a challenge for the organizational leadership. The leadership will have to identify what kind of institutional logics relevant stakeholders on the system level as well as on the institutional level adhere to. Academic staff will for example have different values than managerial staff. There might also be differences in ideas about the future direction of higher education by ministries, the management of higher education institutions, as well as among local authorities and regional industries interested in the innovative capacities of higher education. Policy makers and industry may focus more on the employability of graduates and stress the role of higher education in boosting the economy, while other groups may stress that higher education should support the social differentiation and contribute to the building of elites in society. The heterogeneity in the strategic responses of the two Ethiopian case study universities in their internal governance and management towards revenue generation, despite facing a similar regulatory environment, can be explained by using institutional logics as a theoretical lens. One could take the example presented by Scott et al. (2000) in their study of institutional change in health care organisations and translate it to higher education organisations and argue that the higher education field is shaped by the institutional logics of the market, the logic of the democratic state, and the professional logic of academia (see also Ocasio \&Thornton, 2008). Similar to the field of medical care, the degree to which, for instance, the institutional logic of the academic profession is prevailing in university governance may have implications for the universities' revenue generation strategies and activities (see Clark, 1983).

Our empirical findings suggest that formulating a strategy for acquiring resources without having adequate in-house capacity (see section 9.2.3) is a necessary but not sufficient condition for revenue generation. The question that follows is "what kinds of in-house capacity are needed?" Resource dependence theory does not provide answers to this question. One of the reasons is that the core concept of 'resource' is not defined in a way that allows one to make differences among types of resources. A similar argument was made by Kraaijenbrink, et al., (2010) in their overview article on the resource-based view of the firm. Resources may include all assets (tangible and intangible), capabilities, routines, organisational processes, attributes, information, and knowledge that are owned or controlled by the organisation that enable the organisation to formulate and implement strategies that improve its efficiency and effectiveness (see also Barney, cited in Kraaijenbrink, 2010). Clearly, it might be more helpful to make a distinction between the various types of resources, and distinguish between those resources that are inputs to the 
organisation and the capabilities that enable the organisation to select, deploy, and organise such inputs (see Kraaijenbrink, p, 358). As argued by Sirmon et al., (2007) and illustrated in our empirical research, it appears that building new capabilities is more difficult in environmental contexts that are characterised by high uncertainty and a high variability of munificence. Having human and nonhuman resources in adequate volumes and of sufficient quality can serve as a springboard in allowing universities to diversify their resource base and enter into postgraduate studies and research.

In general, revenue generation in public universities is at best a means to an end - the university is not seeking to make a profit as a public organisation - the four case study universities were trying to deliver high-quality teaching and research. These activities are partly motivated by institutional logics and values and that are not readily reducible to financial or accounting values. There is always a need to understand revenue generation in this wider context and link it where possible to research strengths, as well as community services including regional development (see section 9.2.4). The integration of resource dependence theory with insights from neo-institutional theory, institutional logics, and the resource-based view can help in making a deeper examination of the factors that shape the strategic responses of universities in terms of revenue generation. Further research on financing higher education in developing countries might therefore take on board divergent values, logics and resources next to economic motives in understanding the operations of universities as complex organisations.

\subsubsection{Reflections on policy practice}

In this section, we consider the practicalities of using revenue generation to deliver financial sustainability for universities, along with the five other potential solutions for overcoming financial challenges (see section 2.4). We also suggest what can be done to optimise the use of revenue generation to ensure the financial sustainability of universities. First of all, we argue that closing the gap between enrolment and resource availability projections through capping the growth in enrolments, is not a politically or economically feasible measure in the context of Sub-Saharan African countries, where there is an increasing school age population and a low higher education participation rate (around $6 \%$ ). Most African countries are too poor to ignore the rising social demand for access to higher education, which will support more knowledge-intensive growth in Africa (see OECD, 2008; World Bank, 2009; World Bank, 2010). Higher education is the most durable investment that Africa needs to enhance its overall development (see World Bank, 2010). In expanding their higher education 
enrolment, most African countries realise that their vast potential wealth can only be unlocked by sharply increasing the number of its young people graduating from higher education (World Bank, 2012).

Creating an optimal organisational environment and effective internal conditions for revenue generation in universities is necessary if revenue generation is to lead to sustainable financing of higher education in Africa (see section 9.2.4). The creation of such external and internal enabling conditions for revenue generation in universities goes along with the other four potential solutions: mobilisation of additional public budgets, the development of a private higher education sector, cost sharing, and efficient use of available resources, as discussed in Section 2.4.We suggest that these policy options may be used in combination to achieve financial sustainability in universities depending on the conditions and constraints in each Sub-Saharan African country. The main advice in this regard is that the policy instruments should not be judged in isolation from one another; rather they should be combined and adapted to the specific national conditions in order to find an optimal balance between economic requirements, social needs, political imperatives, access and quality considerations, and financial resources. Revenue generation in universities should generally be understood within the complex environment of supranational, national and organisational policies. Policy makers should be aware that these solutions are contentious too.

The findings of this study show that the capacity of universities to diversify and broaden their funding base is limited by inadequate human and non-human resources (see subsection 8.6). African countries have to find ways to sustain the costs of establishing high-quality research and postgraduate universities to diversify their resource base. African countries which wish to foster revenue generation in their public universities could choose to invest the much needed additional funding to strengthen universities. The overall implication of mobilising additional resources from governmental sources is to create additional capabilities that may help universities to engage in large scale revenue generation. Although government budgets in African countries are already stretched thinly over many sectors, we argue that the possibility of mobilising additional resources should not be disregarded since education spending as a share of gross domestic product (GDP) in Africa varies widely from one country to another. According to the World Bank (2010:120), education spending as a share of gross domestic product (GDP) ranges from $8 \%$ to $40 \%$, with a 46 -country average of $20.9 \%$. Similarly, the World Bank study reports that the share of the higher education budget in the total education budget ranges from $4.1 \%$ to $39.1 \%$, with a 39 -country average of $21.2 \%$.Thus, an increase in the share allotted to the education budget in general and to higher 
education in particular is more justifiable in the case of countries that spend a smaller portion of their overall budget on education. We argue that those countries which are close to achieving universal primary education have leverage to channel a significant portion of their education budget to higher education.

As universities are embedded in nation states, national governments remain crucial in steering them. This study indicated that national governments can provide universities with a certain amount of autonomy and not interfere with organisational policies and activities for broadening their funding base, so long as universities are accountable for their actions. The capacity of universities to generate additional income relates to the degree of financial and staffing autonomy granted by the regulatory framework in which they operate (see section 8.6). In particular, they should manage their own budget and use the resources they generate in accordance with their development objectives. The results of this study revealed that public authorities influence revenue generation and diversification strategies through the modalities under which they deliver funding to the universities. An incentive for African governments to use may be the inclusion of specific criteria in earmarked funding, formula funding, performance contracts, and competitive funding instead of line item budgeting. Rationalisation of resources and increasing the autonomy of higher education institutions are sensitive topics and may face political resistance. The issue of accountability has to be clearly articulated and monitored, whenever more organisational autonomy is granted.

Cost sharing is one of the solutions that enable African governments to attract additional resources from the beneficiaries of higher education (Johnstone, 1998). The issue of cost sharing in higher education is, however, contentious in many African countries because of ongoing debates about the social and individual benefits of higher education (World Bank, 2010), absence of adequate information to provide means-tested financial assistance, and limited data on the price responsiveness of students (see Vossensteyn, 2005). One option in this regard is that any cost-sharing policy should be accompanied by loans to students from low-income backgrounds. As the major source of revenue is from tuition fees paid by students (see EUA, 2011; OECD, 2008; Williams, 1992; section 8.4), revenue generation in universities is thus partly contingent on the cost sharing policy of each country.

The findings of this study showed that some African universities, including our case study universities, have begun to attract international students and run campuses in other African countries (see chapters 6 and 7). Opening higher education markets to domestic and transnational providers enables African 
countries to meet the growing demand for higher education that the public sector is unable to respond to (Altbach \& Teferra, 2004; Saint, 1992). As long as there is an adequate regulatory framework, the availability of cross-border higher education markets may help to diversify revenue and absorb part of the increase in the number of students. Governments should ask in what disciplines the private sector provides a cost-effective alternative to the public sector, in order to maximise their complementarity and partnerships for addressing the rising social demand for access. African governments should also establish accreditation and certification mechanisms that protect consumers and ensure the quality of the services offered whenever this policy option is chosen.

As this study addresses organisational level policies, we reflect on institutional level polices while considering the practical implications these policies have for revenue generation in universities. This study shows that each university has its own way of responding to financial pressure. There is no 'one size fits all' solution, as we indicated in subsection 9.2.4. However, we can suggest some policy issues, which may be beneficial to universities that aim at shaping or (re)considering their revenue generation strategies. Apparently, revenue generation has been progressively bringing some universities to acquire substantial resources from diverse stakeholders in response to their financial challenges. This suggests that revenue generation itself is gradually becoming a legitimacy strategy to achieving financial sustainability by the mere fact that it is widely adopted across several universities in the globe. One can argue that it may be difficult to prohibit the existence of revenue generation in universities. However, the feasible option seems to be to find ways of reducing the wicked issues of revenue generation in universities. Universities seeking to further their revenue generation efforts should address a critical question related to organisational missions. As rightly noted by Harman \& Harman (2003), "When ideas for new revenue streams may be promising in a business sense but threatening organizational mission, the best choice may be to walk away". Using Massy's (2009) words, universities must be 'mission-centred and marketsmart' in their revenue generation efforts.

As each university faces a distinctive context shaping its choices, there is no one best approach to decision making about revenue initiatives. Nevertheless, we suggest that a number of general considerations and guidelines relating to revenue generation or revenue generation policy are of paramount importance for strategic management of revenue generation. These policies should indicate what universities will and will not do to generate revenue. The strategic analysis should ensure that the ultimate goal of any revenue-diversification effort must be the generation of new net returns, not simply the generation of new revenue. Leaders in universities should make clear from the start that the 
university will withdraw from failing enterprises or revenue generation activities. Potential returns may be non-financial and can come in the short or long term. Effective decision making on any prospective initiative should thus be university specific and consider factors not easily monetised.

The findings of this study show that pursuing revenue generation might lead to an extra workload, which necessitates additional human and non-human resources. A workload policy at organisational level is needed. Appointing new staff based on the university-specific workload policy is necessary to foster revenue diversification (EUA, 2012). Moreover, incentive measures are required to mobilise both organisational actors and individual actors towards revenue generation. Bases of apportionment should be according to the policy and benefit both the participants and the university community as a whole. There will be a need to consider revenue generation as one of the criteria for recruitment and promotion of staff. Similarly, there should be an internal resource allocation model that fosters revenue generation. Decentralisation of financial and staffing matters as well as procurement management to colleges or departments may be considered in light of the foreseen additional administrative costs that it will incur on the university.

More efficient use of available resources means achieving efficiency in the operation of universities including a reduction in the cost of production (Bleiklie et al., 2000; Hauptman, 2009; Woodhall, 1995). Although the room for efficiency improvement in the context of Sub-Saharan African public universities is getting narrower as a result of surging enrolment (World Bank, 2009), we argue that better management of university resources is not a one-off activity. Rather, it has to be considered in the day to day operation of universities. Above all, the efficient use of available resources provides assurance to salient stakeholders that their resources are being put in good use. The main reflection here is that this efficiency policy can best be enforced in higher education systems and universities where there is an adequate leadership and management system and a reliable and effective information, evaluation, and monitoring system (World Bank, 2010).

Finally, universities could consider seeking partners or forging alliances with other organisations in their environments to improve their revenue generation. In all revenue generating activities, the quality of education and research should not be compromised. There have to be quality assurance mechanisms that lay down formal rules. An organisational level policy for fostering revenue generation in universities is possible when there is capable, engaged, and competent leadership, academic and administrative support staff, and adequate governance and management structures. Thus, leadership, management and 
skill development that progressively build the overall organisational capacity matter enormously when developing a successful revenue generation strategy.

\subsection{Coda: Reflections on Methodology and Future Potential Research Avenues}

\subsubsection{Methodological Reflections}

This study was conducted using a cross-national comparative study and a multiple comparative case study approach on a selection of four universities. The multiple case study design enabled us to examine universities operating in different African settings as well as within one national setting (the two Ethiopian case study universities). Four universities, four distinct places, conditioned by national and local contexts, different origins and developmental trajectories, and the commitment of particular internal actors to revenue generation were critically examined. This approach has given us more information regarding the development of various types of revenue generation strategies in universities operating in three distinct socio-economic and political settings. This enables us to place the findings in a comparative perspective and to learn which enablers and barriers are particularly relevant for universities operating in different settings. It brought valuable insights into revenue generation in terms of shared or differing features across the four universities. Studying four case study universities with three different national settings was the absolute maximum number of cases possible with the study's time and budget limitations. We are well aware of the fact that one of the familiar problems in this approach is the extent and depth of the study. Although a single in-depth case study, accompanied by a large number of interviews, might have provided additional information on the perspective of different groups in the university, we can convincingly make theoretical generalisations using the multiple case study approach employed in this study. More importantly, the multiple case study approach has enabled us to include the dimensions that we have identified, due to the typology in Chapter Four.

In terms of data collection, we used different methods such as interviews, documentary evidence, and direct observations. Our research method was simple. During visits to each case study university, we conducted a dozen taped interviews with academic staff, administrators, and support staff (see Table 4.8) who were directly or indirectly involved in the revenue generation activity of their case study universities. Discussions with the interviewees yielded an understanding of the core elements of the revenue generation 
strategies in their organisations, and how the university's revenue generation efforts are enabled or obstructed by university specific conditions and environmental factors. During the interviews, an attempt was made to link the interview data with the analytical framework of the study in a complex way. We have primarily used official documents for the description of the case studies. The additional documentary data collected on the spot gave us the opportunity to obtain data on finance, policies, legal framework, strategic plans, and financial and performance reports. It enabled a comparative analysis of the universities based on quantitative and qualitative data. The use of documentary evidence has permitted us to obtain the broadest possible information and to obtain comparable data. Overall, the use of multiple methods of data collection has proved very complementary, as one method was able to fill the gaps left by others.

\subsubsection{Openings for Further Research}

Although we have used in-depth case studies, we suggest some avenues for further research. Given the comparative nature of this study and the broad nature of the subject of financing higher education, it might not be possible to probe the subject in greater depth and breadth. First, the scope of the study could be extended to validate the applicability of the conceptual framework and generate further empirical insights in a comparative way. There are several opportunities for this. The number of countries could be expanded to include other African countries such as Anglophone, Francophone, and Lusophone countries. Of course, comparing with countries from other continents -the emerging economies (e.g. BRICS) - would be very interesting. Another area of study could be to include private universities.

Second, additional insights could be gained by extending the research to include all parts of the model shown by broken lines, such as trust and legitimacy relationships with the environment, as well as learning, and adaption by the focal university. Thirdly, we could also consider looking more closely at one university to gain an in-depth understanding of revenue generation among several departments. In addition, it would be interesting to combine the resource dependence perspective with other theories such as new institutional theory, institutional logics, and the resource based view to investigate several environmental and university specific conditions that influence revenue generation strategies and activities in universities. Finally, it would be interesting to carry out a follow-up study (longitudinal approach) and revisit the countries and universities that are included in this thesis. By including the above-mentioned areas, the empirical breadth of our study might 
have been expanded, but despite of this we hope that our study in its present form and depth has contributed to a better understanding of the practice of revenue generation in Sub-Saharan African universities. 


\section{References}

Abagi, O. (2001). Situational Analysis of Education in Kenya. Background Document Prepared for Action Aid Kenya.

Abbott, M., \& Doucouliagos, C. (2003). The efficiency of Australian Universities: A data envelopment analysis. Economics of Education Review, 22, 89-97.

Aina, A.T. (2004). Introduction: How Do We Understand Globalisation and Social Policy in Africa? In Aina, A.T., Chachage, S.L.C., \& Annan-Yao, E. (eds.), Globalisation and Social Policy in Africa (pp. 1-20). Pretoria: UNISA Press.

Aina, J.F.A., Goma, L.K.H., \& Johnson, G.A. (1996). The African Experience with Higher Education. Accra: Association of African Universities.

Albrecht, D., \& Ziderman, A. (1995). Financing Universities in Developing Countries. Washington, D.C.: The Falmer Press.

Aldrich, H. (1979). Organizations and Environments. Englewood Cliffs, NJ: Prentice-Hall.

Aldrich, H.E., \& Pfeffer, J. (1976). Environments of Organizations. Annual Review of Sociology, 2, 79-105.

Alford, R., \& Friedland, R. (1991). Bringing society back in: Symbols, practices, and institutional contradictions. In Powell, W.W., \& DiMaggio, P.J. (eds.), The New Institutionalism in Organizational Analysis (pp. 232-263). Chicago: University of Chicago Press.

Allen, T.J., Chevalier, A., O'Shea, R.P., \& Roche, F. (2005). Entrepreneurial orientation, technology transfer and spinoff performance of U.S. universities. Research Policy, 34(7), 994-1009.

Allison, G.T., \& Zelikow, P. (1999). Essence of Decision: Explaining the Cuban Missile Crisis ( $2^{\text {nd }}$ ed.). New York: Addison Wesley Longman.

Altbach, P.G. (1991). The Academic Profession. In Altbach, P.G. (ed.), International Higher Education. An Encyclopedia (pp. 23-47). New York, London: Garland Publishing, Inc.

Altbach, P.G. (2001). Academic freedom: international realities and challenges. Higher Education, 41, 205-219.

Altbach, P.G. (2002). Knowledge and Education as International Commodities: The Collapse of the Common Good. International Higher Education, 28, 2-5.

Altbach, P.G., \& Teferra, D. (2004). African Higher Education: Challenges for the 21st Century. Higher Education, 47(1), 21-50.

Altenburg, T. (2010). Industral Policy in Ethiopia. Economic Geographer, Deutsches Institut für Entwicklungspolitik (DIE). 
Amaral, A., Dill, D.D, Jongbloed, B.W.A., \& Teixeira, P. (eds.) (2004). Markets in higher education - Rhetoric or Reality? Dordrecht, Boston, London: Kluwer Academic Publishers.

Amaral, A., Jones, G.A., \& Karseth, B. (2002). Governing Higher Education: National Perspectives on Institutional Governance. Dordrecht/Boston/London: Kluwer Academic Publishers.

Anderson, D., \& Johnson, R. (1998). University Autonomy in Twenty Countries. Canberra: Department of Employment, Education, Training and Youth Affairs.

Anderson, M.A. \& Ashby, E. (1966). Universities: British, Indian, African. A study in the Ecology of Higher Education. London: Weidenfeld and Nicolson.

Anderson, M.S., Anderson, K.S., Blumenthal, D., Campbell, E.G, \& Jones, L.M. (2001). Entrepreneurship, secrecy, and productivity: a comparison of clinical and non-clinical life sciences faculty. Journal of Technology Transfer, 26(3), 233-245.

Andrews, K. (1980). The Concept of Corporate Strategy (2nd ed.). Dow-Jones Irwin.

Arbo, P. \& Benneworth, P. (2007). Understanding the Regional Contribution of Higher Education Institutions: A Literature Review. Paris: Organisation for Economic Co-operation and Development.

Arikan, A.M., \& Barney, J.B.(2001). The resource-based view: Origins and implications. In Hitt, M.A., Freeman, R.E., \& Harrison, J.S. (eds.), Handbook of strategic management (pp. 124-188). Oxford: Blackwell.

Arora, A., Experton, W., \& Johnstone, B. (1998). The financing and Management of Higher Education. A Status Report on World Reforms. Washington DC: World Bank.

Asgedom, A. (2007). Academic Freedom and Development of Higher Education in Ethiopia: The case of Addis Ababa University (PhD Thesis). East Anglia: Faculty of Education, University of East Anglia.

Ashworth, R., Boyne, G., \& Delbridge, R. (2007). Escape from the Iron Cage? Organizational Change and Isomorphic Pressures in the Public Sector. Journal of Public Administration Research and Theory, 19, 165-187.

Askling, B., Bauer, M., \& Marton, S. (1999). Swedish Universities towards selfregulation: A new look at institutional autonomy. Tertiary Education and Management, 5, 175-195.

Assefa, T., \& Gebre-Egziabher, T. (2007). Decentralization in Ethiopia. Addis Ababa: Forum for Social Studies.

ASTU (2009). Research Strategic Plan (2009-2012). Unpublished. Adama, Ethiopia.

ASTU (2011/12). ASTU'S Five-Year Strategic Plan (2011/12-2015/16). Unpublished. Adama, Ethiopia. 
Audretsch, D.B., \& Lehmann, E.E. (2005). Do University policies make a difference? Research Policy, 34(3), 343-347.

Audretsch, D., Lehrmann, E., \& Warning, S. (2005). University Spillover and new firm location. Research Policy, 34; 1113-1122.

Bailey, T., Bunting, I, Cloete, N., Maassen, P., \& Pillay, P. (2011). Universities and Economic Development in Africa. Wynberg (SA): Centre for Higher Education Transformation (CHET).

Bailey, T., Cloete N., Maassen P., Muller, J., Pillay P., \& Pinheiro R. (2010). Higher Education and Economic Development: Analytical Framework. Cape Town: Centre for Higher Education Transformation

Baldini, N., et al. (2006). Institutional Changes and the Commercialization of Academic Knowledge: A Study of Italian Universities' Patenting Activities between 1965 and 2002. Research Policy, 35, 518-532.

Ballou, K. (1998). A concept analysis of autonomy. Journal of Professional Nursing, 14(2), 102-110.

Banya, K., \& Elu, J. (2001). The World Bank and Financing Higher Education in Sub-Saharan Africa. Higher Education, 42(1), 1-34.

Barr, N. (1998). The Economics of the Welfare State. Oxford: Oxford University Press.

Barrow, C.W. (1993). Will the fiscal crisis force higher ed to restructure? Thought and Action: The NEA Higher Education Journal, 9(1), 7-24.

Bauer, M., Bleiklie, I., Henkel, M., \& Kogan, M., Kogan, M. (eds.) (2006). Transforming Higher Education. A Comparative Study (2nd ed.). Dordrecht: Springer.

Becher, T., \& Kogan, M. (1992). Process and Structure in Higher Education (2nd ed.). London: Routledge.

Becher, T., \& Trower, P.R. (2001). Academic Tribes and Territories: Intellectual enquiry and the culture of disciplines ( $2^{\text {nd }}$ ed.). Philadelphia: The Society for Research into Higher Education \& Open University Press.

Begg, D., Dornbusch, R. Dornbusch, R., \& Fischer, S. (1991). Economics. (3rd ed.). London: McGraw-Hill.

Beliakov, S., Lugachyov, M., \& Markov, A. (1998). Financial and Institutional Change in Russian Higher Education (Working Paper No. DP98/05). Centre for Economic Reform and Transformation, Department of Economics, HeriotWatt University.

Benneworth, P., \& Jongbloed, B.W.A. (2009). Who matters to universities? A stakeholder perspective on humanities, arts and social sciences valorisation. Higher Education, 59(5), 567-588.

Benneworth, P., \& Sanderson, A. (2009). Building institutional capacity for HEI regional engagement in a sparse innovation environment: a case study of Knowledge House. Higher Education Management and Policy, March 2009. 
Berdahl, R. (1990). Academic freedom, autonomy and accountability in British universities. Studies on Higher Education. 15. (2): 169 - 180.

Berdahl, R. (1999). Universities and Governments in the 21st Century. In Braun, D., \& Merrien F.-X. (eds.), Towards a New Model of Governance for Universities? A Comparative View. London, Philadelphia: Jessica Kingsley Publisher.

Berglund, E. (2008). I Wanted to Be an Academic, Not A Creative. Notes on Universities and the New Capitalism. Ephemera: Theory and Politics in Organization, 8(3), 232-23.

Bergmann, B.R. (1991). Bloated administration, blighted campuses. Academe Nov.-Dec., 12-15.

Bermal, F., Kitaev, I., Nadurata, T., \& Resurrection, V. (2003). Student Loans in the Philippines: Lessons from the Past. Bangkok: UNESCO-IIEP.

Berman, S.L., Phillips, R. A., \& Wicks, A.C. (2005). Resource Dependence, Managerial Discretion and Stakeholder Performance, Academy of Management Proceedings, Meeting Abstract Supplement, B1-B6.

Bernal, J. D. (1969). Science in History (Vol. 2). The scientific and industrial revolutions. Cambridge, Mass.: C.A. Watts.

Bernasconi, A. (2005). University Entrepreneurship in a Developing Country: The Case of the P. Universidad Católica de Chile. 1985-2000. Higher Education, 50 (2), 247-274.

Beverwijk, J.M.R. (2005). The Geneses of a System. Coalition Formation in Mozambican Higher Education, 1993-2003 (thesis). Enschede: CHEPS/UT.

Beyer, J. (1981/82). Ideologies, values, and decision making in organizations. In Nystrom, P.C., \& Starbuck, W.H. (eds.), Handbook of organizational design (Vol. 2). Remodeling organizations and their environments (pp. 166-202). New York: Oxford University Press.

Billiet, J. (1996): Theoretical Dimensions and Measurement Models of Attitudes towards Ethnic Minorities. Leuven: ISPO-bulletin 1996/23.

Birley, S. (2002). Universities, Academics, and Spinout Companies: Lessons from the Imperial. International Journal of Entrepreneurship Education, 1(1), 133-53.

Birley, S., \& Nicolaou, N. (2003a). Academic networks in a trichotomous categorisation of university spinouts. Journal of Business Venturing, 18(3), 333359.

Birley, S., \& Nicolaou, N. (2003b). Social networks in organizational emergence: the university spinout phenomenon. Management Science, 49(12), 1702-1725.

Bleiklie, I., Høstaker, R., \& Vabø, A. (2000). Policy and Practice in Higher Education: Reforming Norwegian Universities. London, Philadelphia: Jessica Kingsley Publisher.

Bok, D. (2003). Universities in the Marketplace: The Commercialization of Higher Education. Princeton, NJ: Princeton University Press. 
Boucher, G., Conway, C., \& Van Der Meer, E. (2003). Tiers of Engagement by Universities in their Region's Development. Regional Studies, 37(9), 887-897.

Boyer, E.L. (1990). Scholarship Reconsidered: Priorities for the Professoriate. Princeton, NJ: Carnegie Foundation for the Advancement of Teaching.

Bozeman, B., Kirkland, J., \& Rahm, D. (2000). University-Industry RED Collaboration in the United States, the United Kingdom, and Japan. Dordrecht: Kluwer Academic Publishers.

Brennan and Shah (1994). Higher Education Policy in the United Kingdom. In Goedegebuure, L., et. al (eds.), Higher Education Policy. An International Comparative Perspective (pp. 290-314). Oxford: Pergamon.

Bryman, A. (2007). Effective leadership in higher education: A Literature Review. Studies in Higher Education, 32(6), 693-710.

Bryson, J. (1995/96). Strategic Planning for Public and Nonprofit Organizations. San Francisco: Jossey-Bass.

Bundy, C. (2004). Under new management? A critical history of managerialism in British universities. In Walker, M., \& Nixon, J. (eds.), Reclaiming universities from a runaway world. Berkshire: Open University Press.

Callaert, J., Debackere, K., Ranga, M., \& Zimmermann, E. (2004). Combining entrepreneurial and scientific performance in academia: towards a compounded and reciprocal matthew-effect? Research Policy, 33(3), 425-441.

Cameron, K. (1984). Organizational adaptation and higher education. Journal of Higher Education, 55(2), 122-144.

Cameron, K. (1983). Strategic responses to conditions of decline: Higher education and the private sector. Journal of Higher Education, 54(4), 359-380.

Canton, E., \& van der Meer, E. (2001). Economics of higher education. In CBP/CHEPS, Higher Education Reform: Getting the Incentives Right. Den Haag: SDU.

Carroll, B. (2006). Harnessing Private Monies to Fuel University Growth: A Case Study of Makerere University. Presented at DBSA/HSRC/Wits/NEPAD Conference: "Investment Choices for Education in Africa", Johannesburg, 19-21 September.

Castells, M. (1996). The Rise of the Network Society. Oxford \& Malden: Blackwell Publishers.

Cave, M. (1994). Why Students Need (Consumer) Protection. Royal Economic Society Newsletter, 87(October), 18-20.

Chabotar, K.J. (1989). Financial Ratio Analysis Comes to Nonprofits. The Journal of Higher Education, 60(2), 188-208.

Chaffee, E.E. (1985). The concept of strategy: From business to higher education. In Smart, J. (ed.), Higher Education: Handbook of Theory and Research (Vol. I). New York: Agathon. 
Chandler, A.D. (1962). Strategy and Structure. Chapters in the History of the Industrial Enterprise. Cambridge, MA: MIT Press.

Charles, D.R. (2006). Universities as key knowledge infrastructures in regional innovation systems. Innovation 2006, 19(1), 117-130.

Charles, D.R. (2003). Universities and territorial development: reshaping the regional role of English universities. Local Economy, 18(1), 7-20.

Chiesa, V., \& Piccaluga, A. (2004). Explotation and diffusion of public research: the case of academic spinoff companies in Italy. Research and Development Management, 30(4), 329-339.

Chun, M., \& Gumport, P.J. (1999). Technology and higher education. In Altbach, P., Berdahl, R., \& Gumport, P.J. (eds.), American Higher Education in the 21st Century: Social, Political and Economic Challenges. Baltimore: Johns Hopkins University Press.

Clark, B.R. (1979). The Many Pathways of Academic Coordination. Higher Education, 8(3).

Clark, B.R. (1983). The higher education system: Academic organisations in crossnational perspective. Berkeley: University of California Press.

Clark, B.R. (1995). Complexity and differentiation: The deepening problem of integration. In Dill, D.D., \& Sporn, B. (eds.), Emerging Patterns of Social Demand and University Reform: Through a Glass Darkly. Oxford: Pergamon.

Clark, B.R. (1998). Creating Entrepreneurial Universities; Organizational Pathways of Transformation. Oxford: Pergamon.

Clark, B.R. (2001). The Entrepreneurial University: New Foundations for Collegiality, Autonomy, and Achievement. Higher Education Management, 13(2).

Clark, B.R. (2003). Sustaining Change in Universities: Continuities in Case Studies and Concepts. Tertiary Education and Management, 9(2), 99-116.

Clark, B.R. (2004). Sustaining Change in Universities: Continuities in case studies and concepts. London: SRHE/OUP.

Clarysse, B., \& Moray, N. (2004). A process study of entrepreneurial team formation: the case of a research-based spinoff. Journal of Business Venturing, 19, 55-79.

Cloete, N., Bunting, L., \& Bunting, I. (2002): Transformation Indicators Applied to Two South African Higher Education Institutions. Pretoria: CHET.

Cloete, N., Fehnel, R., Gibbon, T., Maassen, P., Moja, T., \& Perold, H.(2002): Transformation in Higher Education: Global Pressures and Local Realities. Cape Town: Juta.

Cloete, N., \& Maassen, P. (2006). Global reform trends in higher education. In Cloete, N., Fehnel, R., Maassen, P., Moja, T., Perold, H., \& Gibbon, T. (eds.), Transformations in higher education: Global pressures and local realities in South Africa (pp. 7-33). Cape Town: JUTA. 
Cloete, N., \& Ouma, G.W. (2008). Financing higher education in South Africa: Public funding, Non-government Revenue and Tuition fees. South African Journal of Higher Education, 22 (4), 906-919.

Coaldrake, P., \& Stedman, L. (1999). Academic Work in the Twenty-first Century. Changing roles and policies. Department of Education, Training and Youth Affaires, Canberra, Australia.

Coase, R. (1960). The Problem of Social Cost. Journal of Law and Economics 3(1), 144.

Cohen, M.D., \& March, J.G. (1974). Leadership and Ambiguity: The American College President. Boston: Harvard Business School Press.

Considine, M., \& Marginson, S. (2000). The Enterprise University: Power, Governance and Reinvention in Australia. Cambridge: Cambridge University Press.

Cooksey, B., Levey, L., \& Mkude, D. (2003). Higher Education in Tanzania: A Case Study. Oxford: James Curry.

Corbin, J., \& Strauss, A. L.(1990). Basics of qualitative research. Newbury Park, CA: Sage.

Court, D. (1999). Financing Higher Education in Africa, Makerere: The Quiet Revolution. New York and Washington: Rockefeller Foundation and the World Bank.

Covalski, M.A., \& Dirsmith, M.W. (1983). Strategy, external communication and environmental context. Strategic Management Journal 4, 137-151.

Central Statistic Agency (2008). Ethiopia: Statistical Abstract. Addis Ababa: Government of Ethiopia.

Currie, J., DeAngelis, R., de Boer, H., Huisman, J., \& Lacotte, C. (2003). Globalizing practices and university responses: European and Anglo-American differences. Westport, CT: Praeger.

Cyert, R.M., \& March, J.G. (1992). A Behavioral Theory of the Firm (2nd ed.). Englewood Cliffs, NJ: Prentice-Hall.

DACST (1996). White Paper on Science and Technology. Pretoria: Department of Arts, Culture, Science and Technology.

Dahl, R.A. (1957). The Concept of Power. Behavioral Science, 2(3), 201-215.

David G, Duane Ireland, Hitt, R, Michael A, \& Sirmon. Managing Firm Resources in Dynamic Enviroments to Create Value: Looking inside the Black Box. Academy of Management Review, Vol. 32, No. 1, 273-292.

Davies, J.L. (2001). The emergence of entrepreneurial cultures in European Universities. Higher Education Management, 13(2), 25-45.

Davis, G.F., \& Cobb, J.A. (2009). Resource Dependence Theory: Past and Future. Research in the Sociology of Organizations, 28, 21-42. 
Debackere, K., \& Veugelers, R. (2005). The role of academic technology transfer organizations in improving industry science links. Research Policy, 34(3), 321342.

De Boer, H. (2000). Institutional Governance: Consequences of Changed Relationships between Government and University. Paper presented at an IMHE Seminar, Tokyo.

De Boer, H., \& Goedegebuure, L. (2009). The changing nature of the academic deanship. Leadership, 5(3), 347-364.

De Boer, H., \& Dennert, H. (2002). Resource Management in Higher Education. Presentation for the Engineering Education in Indonesia (EEDP) workshop, Enschede: CHEPS.

de Vries, P., \& Koelman, J. (1999). Marketisation, Hybrid Organisations and Accounting in Higher Education. In Jongbloed, B., Maassen, P., \& Neave, G. (eds). From the Eye of the Storm. Higher Education's Changing Institution (pp. 165-187). Dordrecht: Kluwer Academic Publishers.

Del Campo, A.A., Hill, R.C.,Keller, R.T., \& Sparks A., Sparks A. (1999). The transfer and commercialization of University-developed Medical Imaging Technology: opportunities and problems. IEEE Transactions on Engineering Management, 46(3), 289-299.

Delmas, M.A., \& Toffel, M.W. (2008). Organizational Responses to Environmental Demands: Opening the Black Box. Strategic Management Journal, 29(10) 1027-1055

Denzin, N. \& Lincoln, Y. (2003). Strategies of Qualitative inquiry (2 $2^{\text {nd }}$ ed.) Thousand Oaks, CA: Sage.

DHET (2010). Strategic Plan 2010/11 - 2014/15. Pretoria: Department of Higher Education and Training.

Di Gregorio, D., \& Shane, S. (2003). Why do some universities generate more start-ups than others? Research Policy, 32(2), 209-227.

Dijstelbloem, H., Spaapen, J., \& Warmelink, F. (2007). Evaluating research in context. A method for comprehensive assessment. The Hague: Consultative Committee of Sector Councils for Research and Development (COS).

Dill, D.D. (1992a). Academic administration. In Clark, B.R. \& Neave, G.R. (eds.), The Encyclopedia of Higher Education (Vol. 2) (pp. 1318-1329). Oxford: Pergamon.

Dill, D.D. (1992b). Organization and administration of higher education. In Alkin, M.C., Linden, M., Noel, J., \& Ray, K. (eds.), Encyclopedia of Educational Research (Vol. 3). New York: Macmillan.

Dill, D.D. (1997a). Higher education markets and public policy. Higher Education Policy, 10(3-4), 167-185. 
Dill, D.D. (2001). The regulation of public research universities: Changes in academic competition and implications for university autonomy and accountability. Higher Education Policy, 14(1), 21-35.

Dill, D.D. (2003). Allowing the Market to Rule: The Case of the United States. Higher Education Quarterly, 57(2), 136-158.

Dill, D.D. (2007). Are public research universities effective communities of learning? The collective action dilemma of assuring academic standards. In Geiger, R.L., Colbeck, C.L., Williams, R.L., \& Anderson, C.K. (eds.), Future of the American public research university (pp. 187-203). Rotterdam: Sense Publishers.

Dill, D.D., \& Sporn, B. (1995a). The implications of a postindustrial environment for the university: An introduction. In Dill, D.D., \& Sporn, B. (eds.), Emerging Patterns of Social Demand and University Reform: Through a Glass Darkly. Oxford: Pergamon.

Dill, D.D., \& Sporn, B. (1995b). University 2001: What will the university of the twenty-first century look like? In Dill, D.D., \& Sporn, B. (eds.), Emerging Patterns of social demand and University Reform: Through a glass darkly. Oxford: Pergamon.

DiMaggio, P.J., \& Powell, W. (1983). The Iron Cage Revisited: Institutional Isomorphism and Collective Rationality in Organizational Fields. American Sociological Review, 48(2), 147-60.

DiMaggio, P.J., \& Powell, W. (1991). The Iron Cage Revisited: Institutional Isomorphism and Collective Rationality in Organizational Fields. In Powell, W., \& DiMaggio, P.J. (eds.), The New Institutionalism in Organizational Analysis (pp. 63-83). Chicago: University of Chicago Press.

DoE (1997). Education White Paper 3: A Programme for the Transformation of Higher Education (General Notice 1196 of 1997). Pretoria: Department of Education

DoE - National Treasury (2008). Review of Funding and Resource Requirements of the Public Higher Education System. Pretoria: Joint Committee on Higher Education Financing

DoE (2009). Human Resource Development Strategy of South Africa 2010-2030. Pretoria: Department of Education

Donaldson, L. (1995). American anti-management theories of organization: A critique of paradigm proliferation. Great Britain: Cambridge University Press.

Dooley, L., \& Kirk, D. (2007). University-industry collaboration. Grafting the entrepreneurial paradigm onto academic structures. European Journal of Innovation Management, 10(3), 316-332.

Douglass, J.A., \& Keeling, R. (2008). The Big Curve: Trends in University Fees and Financing in the EU and US (Research \& Occasional Paper Series: CSHE.19.08). Centre for Studies in Higher Education. University of California, Berkeley. 
Drucker, P.F. (1997). The future that has already happened. Harvard Business Review, Sept.-Oct., 20-24.

DST (2008). Ten-Year Innovation Plan. Pretoria: Department of Science and Technology.

DTI (2010). Industrial Policy Action Plan 2010/11-2012/13. Pretoria: Department of Trade and Industry.

GoRSA (1997). Higher Education Act 101 of 199.

Government of South Africa (1994). The Reconstruction and Development Programme. Pretoria: Office of the PresidentDuczmal, W. (2006). The Rise of Private Higher Education in Poland: Policies, Markets, and Strategies (doctoral dissertation). University of Twente, Enschede.

Duncan, J. (2009). Third Stream Income at South African Universities. Grahamstown: Centre for Higher Education Research, Teaching and Learning, Rhodes University.

Eastman, J.A. (2007). Revenue Generation and Organisational Change in Higher Education: Insights from Canada. Higher Education Management and Policy, 18(3), 55-81.

Eichele, H. (2007). Setting up Adama University. A Framework. Unpublished. Release 1.1. Adama, Ethiopia.

Eichele, H. (2008). Setting up Adama University. A Framework. Unpublished. Release 1.1.1. Adama, Ethiopia.

Eisemon, T. (1992). Private initiatives in higher education in Kenya. Higher Education, 24(2), 157-175.

Enders, J. (2004). Higher Education, internationalisation, and the nation-State: Recent developments and challenges to governance theory. Higher Education, 47, 361-382.

Enders, J. (2007). The Academic Profession. In Forest, J.F., \& Altbach, P.G. (eds.), International Handbook of Higher Education (pp. 5-21). Dordrecht: Springer.

Enders, J., \& Fulton, O. (2002). Blurring boundaries and blistering institutions: An introduction. In Enders, J. \& Fulton, O. (eds.), Higher education in a globalising world (pp. 1-14). Dordrecht/Boston/London: Kluwer.

Enders, J., Jongbloed, B., \& Salerno, C. (2008). Higher education and its communities: Interconnections, interdependencies and a research agenda. Higher Education, 56, 303-324.

Ernste, H. (2007). The international network university of the future and its local and regional impacts. In Harding, A., Scott, A., Laske, S., \& Burtscher, C. (eds.), Bright satanic mills: Universities, regional development and the knowledge economy. Ashgate: Aldershot.

Etzioni, A. (1964). Modern Organizations. Englewood Cliffs, NJ: Prentice-Hall.

Etzkowitz, H. (1993). Enterprises from Science: The origins of Science-based Regional Economic Development. Minerva, 31(3), 326-360. 
Etzkowitz, H. (1998). The norms of entrepreneurial science: cognitive effects of the new university-industry linkages. Research Policy, 27(8), 823-833.

Etzkowitz, H. (2003). Research groups as 'quasi-firms': the invention of the entrepreneurial university. Research Policy, 32, 109-121.

Etzkowitz, H. (2004). The evolution of the Entrepreneurial University. International Journal of Technology and Globalization, 1, 64-77.

Etzkowitz, H. (2008). The Triple Helix. University- Industry- Government, Innovation in Action. Routledge. London

Etzkowitz, H., \& Leydesdorff, L. (eds.) (1997). Universities and the Global Knowledge Economy: A Triple Helix of University-Industry-Government Relations. London: Cassell.

Etzkowitz, H., \& Leydesdorff, L. (2000). The dynamics of innovation: from the National Systems and "Mode 2" to a Triple Helix of university-industrygovernment relations. Research Policy, 29, 109-23.

Etzkowitz, H., Gebhardt, C., \& Terra, B.R.C., \& Webster, A. (2000). The future of the university and the university of the future: evolution of ivory tower to entrepreneurial paradigm. Research Policy, 29(2), 313-330.

European Commission and Federal Ministry of Economy and Labour of Austria (2001). Benchmarking Industry-Science Relations. The Role of Framework Conditions. Final Report. Vienna/Mannheim, June 2001.

Estermann, T., \& Pruvot, E.B. (2011). Financial Sustainable Universities II. European Universities Diversifying Income Streams. Brussels: European University Association.

Estermann, T., Nokkala, T., \& Steinel, M. (2011). University Autonomy in Europe II. Brussels: European University Association.

Fahey, L., King, W., \& Narayanan, V. (1981). Environmental Scanning and Forecasting in Strategic Planning: The State of Art. Long Range Planning, 14(1), 32-39.

Fahey, L., \& Narayanan, V. (1986). Macro-environmental Analysis for Strategic Management. St. Paul, MN: West.

Fairweather, J.S. (1988). Entrepreneurship and Higher Education: Lessons for Colleges, Universities, and Industry. ASHE-ERIC Higher Education Report No. 6. Washington, D.C.: Association for the Study of Higher Education.

FDRE (1995). Constitution.

FDRE (2003). Higher Education Proclamation (No 351/2003). Addis Ababa: Negarit Gazeta.

FDRE (2005). Public Procurement law. Addis Ababa: Negarit Gazeta.

FDRE (2006). Budget Proclamation. Addis Ababa: Negarit Gazeta.

FDRE (2007). Budget Proclamation. Addis Ababa: Negarit Gazeta.

FDRE (2007). Federal Civil Servants Proclamation (No. 515/2007). Addis Ababa: Negarit Gazeta. 
FDRE (2008). Budget Proclamation. Addis Ababa: Negarit Gazeta.

FDRE (2008). Cost-sharing Regulation No.154/2008. Council of Ministers. Addis Ababa: Negarit Gazeta.

FDRE (2009). Budget Proclamation. Addis Ababa: Negarit Gazeta.

FDRE (2009). Higher Education Proclamations (No 650/2009). Addis Ababa: Negarit Gazeta.

FDRE (2010). Budget Proclamation. Addis Ababa: Negarit Gazeta.

FDRE (2011). Budget Proclamation. Addis Ababa: Negarit Gazeta.

Fielden, J. (2007). Global Trends in University Governance. World Bank Education Working Paper Series 9. Washington: The World Bank.

Flyvbjerg, B. (2006). Five Misunderstandings about Case-Study Research. Qualitative Inquiry, 12(2), 219-245.

Fogel, D.S., \& Gnyawali, D.R. (1994). Environments for Entrepreneurship development: Key Dimensions and Research Implications. Entrepreneurship: Theory and Practice, 18, 43-62.

Fombrun, C.J. (1996). Reputation: Realizing Value from the Corporate Image. Cambridge, MA: Harvard Business School Press.

Freeman, R.E. (1984). Strategic management: A stakeholder approach. Boston: Pitman

French, J.R.P. \& Raven, B. (1960). Five Bases of Power An Empirical Investigation. Journal of Applied Psychology, 76 (1), 106-114.

Friedman, J., \& Silberman, J. (2003). University Technology Transfer: Do Incentives, Management, and Location Matter? Journal of Technology Transfer, 28(1), 17-30.

Gaillard, J. (2000). Science in Africa at the Dawn of the 21st Century: Country Report; Tanzania. Brussels: European Commission.

Galbraith, J. (1977). Organizational Design: An Information Processing View. Reading, MS: Addison-Wesley.

Galaskiewicz, J., \& Marsden, P. (1978). Inter-organizational resource networks: Formal patterns of overlap. Social Science Research 7, 89-107.

Geiger, R.L. (1991). Private Higher Education. In: Altbach, P.G. (ed.), International Higher Education. An Encyclopedia. New York, London: Gerland Publishing.

Geiger, R.L. (2002). The American university at the beginning of the twenty-first century: Signposts on the path to privatization. In Adams, R.M. (ed.), Trends in American and German Higher Education (pp. 33-84). Cambridge: American Academy of Arts and Sciences.

Geiger, R.L. (2004). Knowledge and Money: Research Universities and the Paradox of the Market Place. Standford: Stanford University Press.Gemmell, N. (1997). Externalities to higher education: A review of the new growth literature. Report 8 
in: The National Committee of Inquiry into Higher Education, www.leeds.ac.uk/ncihe/r8_129.htm.

Gibbons, M. (1998). Higher Education Relevance in the 21st Century. Washington, D.C.: The World Bank.

Gibbons, M., Limoges, C., Nowotny, H., Schwartzman, S., Scott, P., \& Trow, M. (1994). The New Production of Knowledge: the dynamics of science and research in contemporary societies. London: Sage.

Goddard, J., \& Puukka, J. (2008). The engagement of higher education institutions in regional development: an overview of the opportunities and challenges. Higher Education Management and Policy 20 (2), 11-41.

GOK (2004). Economic Recovery Strategy for Wealth and Employment Creation 20032007. Nairobi: Ministry of Planning and National Development.

GOK (2005a). Kenya Education Sector Support Programme 2005-2010: Delivering quality education and training for all. Nairobi: Ministry of Education, Science and Technology.

GOK (2005b). Millennium Development Goals in Kenya: Needs and costs, Nairobi: Ministry of Planning and National Development (MPND). Available at: http://www.ke.undp.org/KenyaMDGNeedsAssessment.pdf.

GOK (2007). Kenya Vision 2030: A globally competitive and prosperous Kenya. Nairobi: Ministry of Planning and National Development and the National Economic and Social Council (NESC).

Goldin, C., \& Margo, R.A. (1992). The Great Compression: The Wage Structure in the United States at Mid- Century. The Quarterly Journal of Economics, 107 (1), 1-34.

Goedegebuure et al., (eds.) (1994). Higher Education Policy, an International Comparative Perspective. London: Pergamon.

Goldin, C., \& Margo, R.A. (1992). The Great Compression: The Wage Structure in the United States at Mid- Century. The Quarterly Journal of Economics, 107 (1), 1-34.

Gomm, R. , \& Hammersley, M. (2000). Introduction. In Gomm, R., Hammersley, M., \& Foster, P. (eds.), Case Study Method: Key Issues, Key Texts (pp. 1-16). London: Sage.

Gornitzka, A. (1999). Governmental policies and organisational change in higher education. Higher Education, 38, 5-31.

Gornitzka, A. \& Maassen, P. A. M. (1998). University Autonomy in Europe: Changing Paradigms in Higher Education Policy. Vienna: University of Vienna.

Gornitzka, A., \& Maassen, P. (2000). Hybrid steering approaches with respect to European higher education. Higher Education Policy, 13, 267-285.Graham, G. (2002). Universities. The Recovery of an Idea. Thorverton: Imprint Academic. 
Greenwood, R., Kodeih, F., Lounsbury, M., Micelotta, E.R., \& Raynard, M.(2011). Institutional Complexity and Organizational Responses. The Academy of Management Annals, 5 (1), 317-371.

Greenwood, R., \& Hinings, C.R. (1996). Understanding Radical Organizational Change: Bringing together the Old and the New Institutionalism. Academy of Managemenl Review, 21(4), 1022-1054.

Grix, J. (2004). The Foundations of Research. New York: Palgrave Macmillan.

Guerrero-Cano, M., Kirby, D.A., \& Urbano, D. (2006). A Literature Review on Entrepreneurial Universities: An Institutional Approach. Working paper presented at the 3rd Conference of Pre-communications to Congresses. Business Economic Department. Autonomous University of Barcelona.

Gulbrandsen, M., \& Smeby, J. (2005). Industry funding and university professors' research performance. Research Policy, 34(6), 932-950.

Gumport, P., \& Pusser, B. (1995). A case of bureaucratic accretion: Context and consequences. Journal of Higher Education, 66(5), 493-520.

Gumport, P., \& Pusser, B. (1997). Restructuring the academic environment. In Peterson, M.W., Dill, D.D., \& Mets, L.A. (eds.), Planning and Management for a Changing Environment: A Handbook on Redesigning Postsecondary Institutions. San Francisco: Jossey-Bass.

Gumport, P. \& Sporn, B. (1999). University restructuring: The role of economic and political forces. In Smart, J. (ed.), Higher Education: Handbook of Theory and Research (Vol. XIV). New York: Agathon.

Guskin, A.E. (1994a). Reducing student costs and enhancing student learning: The university challenge of the 1990s. Part I: Restructuring the administration. Change 26(4), 23-29.

Hackman, J. (1985). Power and centrality in the allocation of resources in colleges and universities. Administrative Science Quarterly, 30, 61-77.

Hall, R.H. (1999). Organizations. Structures, Processes and Outcomes (7th edition ed.). Upper Saddle River: Prentice Hall.

Haramaya University (2004). Ten Years Strategic Plan (2004/05-2013/14). Haramaya University, Dire Dawa, Ethiopia.

Haramaya University (2008a). Reengineered Core Business Process: LearningTeaching. Unpublished. Haramaya University, Dire Dawa, Ethiopia.

Haramaya University (2008b). Redesigned Core Business Process: Research and Community Engagement. Unpublished. Haramaya University, Dire Dawa, Ethiopia.

Haramaya University (2008c). Business Process Reengineering Study for Procurement, Finance, and Property Administration. Unpublished. Haramaya University, Dire Dawa, Ethiopia.

Haramaya University (2008d). Business Process Reengineering for Human Resource Management. Unpublished. Haramaya University, Dire Dawa, Ethiopia. 
Haramaya University (2011). Finance, Procurement and Property Management department of HU.Harman, G., \& Harman, K. (2003). Institutional Mergers in Higher Education: Lessons from International Experience. Tertiary Education and Management, 9(1), 29-44.

Hartley, J.F. (1994). Case Studies in Organizational Research. In Cassell, C., \& Symon, G. (ed.), Qualitative Methods in Organizational Research. London/Thousand Oaks/New Delhi: Sage Publications.

Hasan, A. (2007). Independent Legal Status and Universities as Foundations. A paper prepared for the Ministry of Science, Technology and Higher Education of Portugal, Paris.

Hauptman, A.H., \& Salmi, J. (2006). Innovations in Tertiary Education Financing: A Comparative Evaluation of Allocation Mechanisms. Education Working Paper Series, Number 4. Washington, D.C.: World Bank.

Helsabeck, R.E. (1973). The compound system: A conceptual framework for effective decision-making in colleges. Berkeley, CA: Center for Research and Development in Higher Education.

Hatch, M.J. (1997). Organization theory: Modern symbolic and postmodern perspectives. New York, NY: Oxford University Press.

Hauptman, A.M. (2007). Higher Education Finance: Trends and Issues. In James Forest, J.F., \& Altbach, P.G. (eds.), International Handbook of Higher Education (pp. 83-106). Dordrecht: Springer.

Hearn, J.C. (2003). Diversifying Campus Revenue Streams. Opportunities and Risks. American Council of Education, Center for Policy Analysis.

Henkel, M. (1997). Academic values and the university as corporate enterprise. Higher Education Quarterly, 51(2), 134-143.

Henrekson, M., \& Rosenberg, N. (2001). Designing efficient institutions for science based entrepreneurship: lesson from the US and Sweden. Journal of Technology Transfer, 26(3), 207-231.

Heyneman, S.P. (1999). The sad story of UNESCO's education statistics. International Journal of Educational Development, 19, 65-74.

Hinchcliff, J. (2000). The globalisation of education. Paper presented at the Technological Education and National Development Conference, April 2000. Abu Dhabi, United Arab Emirates. ED447296.

Hinchliffe, K. (1985). Issues Related to Higher Education in Sub-Saharan Africa. Washington, D.C.: World Bank.

Hitt, M.A., Ireland, R.D, \& Sirmon, D.G. (2007). Managing firm resources in dynamic environments to create value: Looking inside the black box. Academy of Management Review, 32(1), 273-292.

Holliday, A. (2002). Doing and Writing Qualitative Research. London: Sage Publications. 
Huberman, A., \& Miles, M. (1994). Qualitative data analysis. Thousand Oaks, CA: Sage

Huisman, J. (1995). Differentiation, diversity, and dependency in higher education. A theoretical and empirical analysis. Utrecht: Lemma.

Huisman, J. (2007). The Anatomy of Autonomy. Higher Education Policy 20, 219221.

IAU (2010). Guide to Higher Education in Africa (5 ${ }^{\text {th }}$ edition). London: Palgrave Macmillan.

IHEP (2007). Regional Universities and Civil Society Development. A Symposium and Study Tour. Washington: IHEP.

IMF (2011). World Economic Outlook database, April. Available at http://www.imf.org/external/pubs/ft/weo/2011/01/weodata/index.aspx.

IMF (2012). Kenya: Poverty Reduction Strategy Paper-Progress Report. IMF Country Report No. 12/10. Washington, D.C.: International Monetary Fund Publication Services.

Jacob, M., Hellsmark, H., \& Lundqvist, M. (2003). Entrepreneurial transformations in the Swedish University system: the case of Chalmers University of Technology. Research Policy, 32(9), 1555-1569.

Jacobs, D. (1974). Dependency and Vulnerability: An Exchange Approach to the Control of Organizations. Administrative Science Quarterly, 19, 45-59.

Jacobs, B., \& van der Ploeg, F. (2006). Getting European Universities into Shape. Badia Fiesolana: European University Institute.

Jensen, R.A., \& Thursby, M.C. (2001). Proofs and prototypes for sale: the licensing of university inventions. American Economic Review, 91(1), 240-259.

JKUAT (2004). Report of the Controller and Auditor General on the financial statements of Jomo Kenyatta University of Agriculture and Technology for the year ended 30th June 2004.

JKUAT (2006). Intellectual Property Policy. Unpublished.

JKUAT (2006). Report of the Controller and Auditor General on the financial statements of Jomo Kenyatta University of Agriculture and Technology for the year ended 30th June 2006.

JKUAT (2008). Report of the Controller and Auditor General on the financial statements of Jomo Kenyatta University of Agriculture and Technology for the year ended 30th June 2008.

JKUAT (2009). JKUAT strategic plan (2009-2012). Jomo Kenyatta University of Agriculture and Technology, Juja/Nairobi, Kenya.

JKUAT (2010). Report of the Controller and Auditor General on the financial statements of Jomo Kenyatta University of Agriculture and Technology for the year ended 30th June 2010.

JKUAT (2010). Income Generating Units Policy. Unpublished. Jomo Kenyatta University of Agriculture and Technology, Juja, Kenya. 
JKUAT (2010). Intellectual Property Policy (IPP). Unpublished. Jomo Kenyatta University of Agriculture and Technology, Juja, Kenya.

Johnson, R.B. (1997). Examining the validity structure of qualitative research. Education, 118 (2), 282-292.

Johnson, B.L., (1995). Resource Dependence Theory: A Political Economy Model of Organization. Available: http://webpages.edu/ adkin109/resdept.html. Accessed 20 October 2004.

Johnson, G., \& Scholes, K. (1999). Exploring Corporate Strategy (5th ed.). London: Prentice Hall.

Jónasson, J.T. (2008). Inventing Tomorrow's University. Who is to take the Lead? Bologna: Bononia University Press.

Jongbloed, B.W.A. (2000). The Funding of Higher Education in Developing Countries. In Jongbloed, B., \& Teekens, H. (eds.), The Financing of Higher Education in Sub-Saharan Africa. Utrecht: Cheps/Lemma.

Jongbloed, B.W.A. (2003). Marketisation in Higher Education, Clark's Triangle and the Essential Ingredients of Markets. Higher Education Quarterly, 57(2), $110-135$.

Jongbloed, B.W.A. (2004). Mapping University-Business Interactions. A research proposal to identify indicators of interaction. Unpublished paper.

Jongbloed, B.W.A., \& Koelman, J. (2004). Vouchers for higher education? Center for Higher Education Policy Studies, Netherlands.

Jongbloed, B.W.A., \& Venniker, R. (2001). When Factory meets Faculty: University-industry co-operation in the US. In: CPB \& CHEPS, Higher Education Reform: Getting the incentives right (pp. 119-134.). The Hague: SDU.

Jongbloed, B.W.A., \& Van der Sijde, P.C. (2008a). Over het slechten van barrières voor kennistransfer tussen Universiteit en MKB. Tijdschrift voor Hoger Onderwijs, 26(3), 167-179.

Jonhstone D.B. (1998). Worldwide Reforms in the Financing and Management of Higher Education. Center for Comparative and Global Studies in Education, State University of New York, Buffalo, available at www.gse.buffalo.edu/org/IntHigherEdFinance/publReformsFinMan.html

Jonhstone, D.B. (2001). Responses to Austerity: The Imperatives and Limitations of Revenue Diversification in Higher Education. The Welsh Journal of Education [Special International Issue], 11(1), 18-36.

Johnstone, D.B. (2003). Cost Sharing in Higher Education: Tuition, Financial Assistance, and Accessibility. Czech Sociological Review, 39(3), 351-74.

Johnstone, D.B. (2004). The Economics and Politics of Cost Sharing in Higher Education: Comparative Perspectives. Economics of Education Review, 20(4), 403-10. 
Johnstone, D.B. (2006). Financing Higher Education: Cost-sharing in International Perspective. Boston College Center for International Higher Education. Boston: ICHEFAP and Sense Publisher.

Johnstone, D.B., \& Marcucci, P. (2010). Financing higher education Worldwide: Who pays? Who should pay? Baltimore: The Johns Hopkins University Press.

Judd, C.M., Kidder, L.H., \& Smith, E.R.(1991). Research methods in social relations (6 ed.). Fort Worth: Holt, Rinehart, and Winston.

Judge, T.A., \& Robbins, S.P. (2008). Essentials of Organizational Behavior (9 $9^{\text {th }}$ ed.). Upper Saddle River: Pearson Prentice Hall.

Keast, D. (1995). Entrepreneurship in Universities: Definitions, Practices and Implications. Higher Education Quarterly, 49(3): 248-266.

Keller, G. (1983). Academic strategy: The management revolution in American higher education. Baltimore: The Johns Hopkins University Press.

Kellow, N., \& Sutton, J. (2010). An Enterprise Map of Ethiopia. London: International Growth Center.

Kiamba, C. (2005). Entrepreneurialism and Adaptability in Kenyan Universities in the Face of Declining Donor and Government Support. A paper presented at the Nuffic Conference on "The changing landscape" at the Hague on 23-25 May 2005.

Kiamba, C (2004). Privately sponsored students and other income generating activities at the University of Nairobi. Journal of Higher Education in Africa, $2(2), 53-74$.

Kigotho, W. (2000). Arap Moi Sets up Private College. The Times Higher Education Supplement . March 31, 2000.

Kinyanjui, K. (2007). The Transformation of Higher Education in Kenya: Challenges and Opportunities. A Paper Presented at the 'Mijadala on Social Policy, Governance and Development in Kenya' sponsored by Development Policy Management Forum on 9 July, 2007 at Nairobi Safari Club.

Kirby, D.A. (2002a). Entrepreneurship. Maidenhead: Mcgraw-Hill.

Kirby, D.A. (2005). Creating Entrepreneurial Universities in the UK: Applying entrepreneurship theory to practice. Journal of Technology Transfer, 31(5), 599603.

Kirby, D.A. (2006). Creating entrepreneurial universities in the UK: Applying entrepreneurship theory to practice. Journal of Technology Transfer, 31(5), 599603.

Kirk, J., \& Miller, M.L. (1986). Reliability and validity in qualitative research. Beverly Hills, CA: Sage Publications.

Kirp, D.L. (2003). Shakespeare, Einstein and the Bottom Line: The Marketing of Higher Education. Boston: Harvard University Press

Kirp, D.L., \& Roberts, P.S. (2002). Mr. Jefferson's university breaks up. The Public Interest, 70-84. 
Kluge, S. (2000). Empirically Grounded Construction of Types and Typologies in Qualitative Social Research. Forum Qualitative Sozialforschung, 1(1), 1-11.

Koelman, J., \& Venniker, R. (2001). Public funding of academic research: the Research Assessment Exercise of the UK. In CPB \& CHEPS (eds.), Higher Education Reform: Getting the Incentives Right (pp. 101-117). Sdu Uitgevers: Den Haag.

Kohtamäki, V. (2009). Financial Autonomy in Higher Education Institutions Perspectives of Senior Management of Finnish AMK Institutions. Tampere: Tampere University Press.

Koivula, J., \& Rinne, R. (2009). The dilemmas of the changing university. In Shattock, M. (ed.), Entrepreneurialism in Universities and the Knowledge Economy: Diversification and organizational change in European higher education (pp. 183-199). London: Sage.

Kraaijenbrink, J., Groen, A.J., \& Spender, C. (2010). The Resource-Based View: A Review and Assessment of Its Critiques. Journal of Management, 36(1), 349372.

Kwiek, M. (2008). Academic Entrepreneurship vs. Changing Governance and Institutional Management Structures at European Universities. Policy Futures in Education, 6(6), 757-770.

Lapworth, S. (2004). Arresting decline in shared governance: Towards a flexible model for academic participation. Higher Education Quarterly, 58(4), 299-314.

Laukkanen, M. (2000). Exploring Alternative Approaches in High-level Entrepreneurship Education: Creating Micro-mechanisms for Endogenous Regional Growth. Entrepreneurship and Regional Development, 12, 25-47.

Lawrence, P.R., \& Lorsch, J.W. (1986). Organization and Environment: Managing Differentiation and Integration. Boston: Harvard Business School Press.

Lee, K., \& Sherer, P.D. (2002). Institutional Change in Large Law Firms: a resource dependency and institutional perspective. Academy of Management Journal, 45, 102-119.

Lee, Y.S. (1996). Technology transfer and the research university: a search for the boundaries of university-industry collaboration. Research Policy, 25, 843863.

Leisyte, L. (2007). University governance and academic research: case studies of research units in Dutch and English universities (doctoral dissertation). Enschede: University of Twente.

Leslie, L.L. (1995). What drives higher education management? The new era in financial support. Journal for Higher Education Management, 10(2), 5-16.

Leslie, L.L., \& Slaughter, S. (1997). Academic Capitalism: Politics, Policies, and the Entrepreneurial University. Baltimore: Johns Hopkins Press.Levine, A. (2000a). Restructuring higher education to meet the demands of a new century. Twenty- 
second annual Pullias Address. Los Angeles: University of Southern California.

Levine, S., \& White, P.E. (1961). Exchange as a Conceptual Framework for the Study Inter-organizational Relationships. Administrative Science Quarterly, 5(4), 583-601.

Levy, D.C. (1986a). Private and Public: Analysis and Ambiguity in Higher Education. In Levy, D.C. (ed.), Private Education: Studies in Choice and Public Policy (pp. Xxxx). New York: Oxford University Press.

Li, W., \& Shen, H. (2003). A Review of the Student Loan Scheme in China. Bangkok: UNESCO-IIEP.

Link, A.N., \& Scott, J.T. (2005). Opening the ivory tower's door: An analysis of the determinants of the formation of U.S. university spin-off companies. Research Policy, 34(7), 1106-1112.

Liu, Y. (2007). Revenue Diversification: A comparison of Russian and Chinese Higher Education. Higher Education in Review, 4, 21-42.

Lockett, A., \& Wright, M. (2005). Resources, capabilities, risk capital and the creation of university spin-out companies. Research Policy, 34(7), 1043-1057.

Lockett, A. et al. (2004). Assessing the relative performance of U.K. University technology transfer offices: parametric and non-parametric evidence. Research Policy, 34(3), 369-384.

Lockett, A. et al. (2005). The creation of spin-off firms at public research institutions: managerial and policy implications. Research Policy, 34(7), 981993.

Lucas, R. (1988). On the Mechanics of Economic Development. Journal of Monetary Economics, 22, 3-42.

Lulat, Y.G-M. (1988). Review Article: Education and National Development: The Continuing Problem of Misdiagnosis and Irrelevant Prescriptions. International Journal of Educational Development 8(4), 315-328.

Lynton, E.A. (1995). Making the case for professional service. Washington, DC: American Association for Higher Education Forum on Faculty Roles and Rewards.

Maak, T. (2007). Responsible Leadership, Stakeholder Engagement, and the Emergence of Social Capital. Journal of Business Ethics, 74, 329-343.

Maassen P., \& Potman, H. (1990). Strategic decision making in higher education. An analysis of the new planning system in Dutch higher education. Higher Education, 20(4), 393-410.

Maassen, P.A.M., \& van Vught, F.A. (1994). Alternative models of governmental steering in higher education; an analysis of steering models and policy instruments in five countries. In Goedegebuure, L. \& Vught, F.V. (eds.), Comparative policy studies in higher education (pp. 35-63). Utrecht: Lemma 
Mahoney, J.T. (1995). The management of resources and the resource of management. Journal of Business Research, 33(2), 91-101.

Mamdani, M. (2007). Scholars in the Marketplace: The dilemmas of neo-liberal reform at Makerere University 1989-2005. Pretoria: HSRC Press.

Mansfield, E. (1991). Academic research and industrial innovation. Research Policy, 20(1), 1-12.

Marginson, S. (2007). Global University Rankings: Implications in General and for Australia. Journal of Higher Education Policy and Management, 29(2), 131142.

Marginson, S. \& Rhoades, G. (2002). Beyond national states, markets, and systems of higher education: A glonacal agency heuristic. Higher Education, 43, 281-309.

Marshall, C., \& Rossman, G. (1997). Designing qualitative research (2nd ed.). London: Sage.

Martin, M., \& Sanyal C. B. (2006). Financing higher education: International perspectives, Higher Education in the world: the Financing of Universities. Palgrave Macmillan.

Massey, D., \& Quintas, P., \& Wield, D. (1992). Academic-industry links and innovation: questioning the science park model. Technovation, 12(3), 161-175.

Massy, W.F. (1996). Productivity issues in higher education. In Massy, W. (ed.), Resource Allocation in Higher Education. Ann Arbor: The University of Michigan Press.

Massy, W.F. (2003). Honoring the Trust: Quality and Cost Containment in Higher Education. Bolton, MA: Anker Publishers.

Massy, W.F. (2004). Markets in Higher Education: Do They Promote Internal Efficiency? In Teixeira, P., Jongbloed, B., Dill, D.D., \& Amaral, A. (eds.), Markets in Higher Education: Rhetoric or Reality? Dordrecht: Kluwer Academic Publishers.

Massy, W.F. (2009). Academic Values in the Marketplace. Presented at the V. Conference for University Management, Pontifica Universidad Católica de Chile, January 8, 2009.

Materu, P. (2007). Higher Education Quality Assurance in Sub-Saharan Africa. Status, Challenges, Opportunities, and Promising Practices. Washington DC: World Bank.

Mcinnis, C. (2001). Promoting academic expertise and authority in an entrepreneurial culture. Higher Education Management, 13(2), 45-57.

McNay, I. (1995). The Regional Dimension in the Strategic Planning of Higher Education. Higher Education Quarterly, 48(4), 323-336.

McNay, I. (1999). Changing Cultures in UK Higher Education. In Braun, D., \& Merrien, F.X. (eds.), Towards a New Model of Governance for Universities? A Comparative View. London/Philadelphia: Jessica Kingsley. 
Mets, L.A., \& Peterson, M.W. (1987). An evolutionary perspective on academic governance, management, and leadership. In Peterson, M.W., \& Mets, L.A. (eds.), Key Resources on Higher Education Governance, Management, and Leadership (pp.xxxx). San Francisco: Jossey-Bass.

Meyer, J. W., \& Rowan, B. (1977). Institutional organizations: formal structure as myth and ceremony. American Journal of Sociology, 80(2): 340-363.

Meyer, J.W., \& Scott, W.R. (1983). Organizational Environments: Ritual and rationality. Beverley Hills, CA: Sage.

Meyer, J.W., \& Scott, W.R. (1991). The rise of training programs in firms and agencies: An institutional perspective. In Staw, B.M., \& Cummings, L.L. (eds.), Research in Organizational Behavior 13 (pp. 297-326). Greenwich, CT: JAI Press.

Meyer, J. W., \& Scott, W.R. (1992). Organisational environments: ritual and rationality. Beverly Hills (CA): Sage.

Miclea, M. (2004). "Learning to do" as a pillar of education and its links to entrepreneurial studies in higher education: European contexts and approaches. Higher Education in Europe, 29(2), 221-231.

Middlehurst, R. (2004). Changing Internal Governance: A Discussion of Leadership Roles and Management Structures in UK Universities. Higher Education Quarterly, 58(4), 258-279.

Mintzberg, H. (1979). The Structuring of Organizations: A Synthesis of the Research. Englewood Cliffs, NJ: Prentice-Hall.

Mintzberg, H. (1983). Structures in Fives: designing effective organizations. Englewood Cliffs: Prentice Hall

Mintzberg, H. (1994). The Rise and Fall of Strategic Planning. London: Prentice Hall.

Mintzberg, H., \& Waters, J.A. (1985). Of strategies, deliberate and emergent. Strategic Management Journal, 6(3), 257-272.

Mitroff, I. (1983). Stakeholders of the Organizational Mind. San Francisco: JosseyBass.

MHEST (2004). Development of Education in Kenya. Gaborone: Ministry of Education Science and Technology

MHEST (2005). Kenya Education Sector Support Programme 2005-2010: Delivering Quality Equitable Education and Training to all Kenyans. DRAFT, April 2005. Nairobi: Ministry of Higher Education, Science and Technology

MHEST (2008). Strategic Plan 2008-2012: Quality Higher Education, Science, Technology and Innovation for National Prosperity and Global Competitiveness. Revised Edition, 2008. Nairobi: Ministry of Higher Education, Science and Technology

MHEST (2009). Science, Technology and Innovation Bill. Nairobi: Ministry of Higher Education, Science and Technology 
MoE (1997). Yekefitegna Temeherete Yewedefit Aktacha Tenate. Future Directions of Higher Education (Amaharic Version, Draft). Unpublished. Addis Ababa: Federal Democratic Republic of Ethiopia

MoE (2002). Education Sector Development Programme II (ESDP-II). Programme Action Plan (PAP). Unpublished. Addis Ababa University. Addis Ababa: Federal Democratic Republic of Ethiopia.

MoE (2004). Report of the Higher education System Overhaul Committee. Addis Ababa: Federal Democratic Republic of Ethiopia.

MoE (2005). Education Sector Development Programme III (ESDP-III) 2005/062009/10. Programme Action Plan (PAP). Unpublished. Addis Ababa: Federal Democratic Republic of Ethiopia

MoE (2008). Annual Intake and Enrollment Growth and Professional and Program Mix of Ethiopian Public Higher Education: Strategy and Conversion Plan, 2008/09-2011/12. Unpublished. Addis Ababa: Federal Democratic Republic of Ethiopia.

MoE (2010). Education Sector Development Program ESDP IV (2010/11-2014/15). Addis Ababa, Ethiopia

MoE (2011). Education Statistics Annual Abstract. Addis Ababa: Federal Democratic Republic of Ethiopia.MoFED (2002). Ethiopia: Sustainable Development and Poverty Reduction Program. Addis Ababa: Federal Democratic Republic of Ethiopia.

MoFED (2010). Growth and Transformation Plan (GTP) 2010/11-2014/15. Addis Ababa: Federal Democratic Republic of Ethiopia.

MoFED (2010). Budget Administration. Ministry of Finance and Economic Development. Addis Ababa, Ethiopia.

MoFED (2010). Disbursement directive. Ministry of Finance and Economic Development. Addis Ababa, Ethiopia.

Mohamed, H. (2010). Towards Establishing Global Measures for Organizational Task Environment. Assessment \& Evaluation in Higher Education. International Review of Business Research Papers, 6(6), 246 -258.

Mohrman (2003). Creating a Strategic Human Resources Organization. Stanford University Press. Stanford, California.

Mok, K. H. (2005). Fostering entrepreneurship: changing role of government and higher education governance in Hong Kong. Research Policy, 34(4), 537554.

Molm, L.D. (2001). Theories of Social Exchange and Exchange Network. In Ritzer, G., \& Smart, B. (eds.), Handbook of Social Theory (pp. 260-272). London: Sage.

Mowery, D.C., Nelson, R.R., Sampat, B.N., \& Ziedonis, A.A. (2001). The growth of patenting and licensing by the U.S. universities: an assessment of the effects of the Bayh-Dole act of 1980. Research Policy, 30(1), 99-119. 
Mowery, D.C., Nelson, R.R., Sampat, B.N., \& Ziedonis, A.A. (2004). Ivory Tower and Industrial Innovation. University-industry technology transfer before and after the Bayh-Dole act in the United States. Palo Alto, CA: Stanford University Press. Mowery, D.C., \& Sampat, B.N. (2005). The Bayh-Dole act of 1980 and university-industry technology transfer: a model for other OECD governments? Journal of Technology Transfer, 30(1-2), 115-127.

Mugenda, O. (2009). Higher education in Kenya: Challenges and opportunities. Unpublished paper.

Mulu Nega(2012). Quality and Quality Assurance in Ethiopian Higher Education: critical issues and practical implications. Enschede: University of Twente, Enschede.

Munyoki, J., Kibera, F., \& Ogutu, M. (2011). Extent to which university-industry linkage exists in Kenya: A study of medium and large manufacturing firms in selected industries in Kenya. Business Administration and Management, 1(4), 163-169.

Musisi, N.B. (2001). A Reflection and Taking Stock of Innovations at Makerere University. Paper Presented at a Conference Organised by Ford Foundation, 'Innovations in African Higher Education', 1-3 November, Nairobi.

Musisi, N.B., \& Muwanga, N.K. (2003). Makerere University in transition, 19932000: Opportunities and challenges. Oxford: James Curry.

Nadler, D.A., \& Tushman, M.L. (1997). Competing by Design. The Power of Organizational Architecture. Oxford: Oxford University Press.

Nafukho, F.M. (2002). The Market Model of Financing State Universities in Africa: Some Innovative Lessons from Kenya. Unpublished. Paper presented at a Conference on the theme: African Universities in the 21' Century. Organized by University of Illinois at Urbana Champaign and the Council for the Development of Social Science Research In Africa. April 25-27, 2002.

Nafukho, F.M. (2004). The Market Model of Financing State Universities in Kenya: Some Innovative Lessons: In Zeleza, P.T., \& Olukoshi, A. (eds), African Universities in the twenty-first Century (Vol. I) (pp. 126-139). Pretoria: UNISA Press.

Neave, G. (1998). The Structuring of Organizations: A Synthesis of the Research. Englewood Cliffs, NJ: Prentice-Hall.

Neave, G., \& van Vught, F.A. (1994). Government and higher education relationships across three continents: the winds of change. Oxford: IAU; Pergamon.

Nelles, J., \& Vorley, T. (2008). (Re)conceptualising the academy: Institutional development of and beyond the Third Mission. Higher Education Management and Policy, 20(3), 109-126.

Newman, J. (2000/1). Modernising governance: New labour, policy and society. London: Sage. 
Ngolovoi, M. (2006). Means testing of student loans in Kenya. Presented at the Comparative and International Higher Education Policy: Issues and Analysis Workshop: University at Albany.

Ngome, C.K. (2003). Kenya. In Teferra, D., \& Altbach, P.G. (eds), African Higher Education: An International Reference Handbook. Bloomington, IN: Indiana University Press.

Ngome, C.K. (2000). Private Universities in Kenya. Unpublished.

Nienhüser, W. (2008). Resource Dependence Theory. How Well Does It Explain Behavior of Organizations? Management revue, 19(1+2), 9-32

NMMU (2006). Statue of the Nelson Mandela Metropolitan University. Unpublished. Port Elizabeth: Nelson Mandela Metropolitan University.

NMMU (2007). Policy on the Management of Private Work. Unpublished. Port Elizabeth: Nelson Mandela Metropolitan University.

NMMU (2007). Policy and Procedure for Approval and Signing of Research-related Contracts. Unpublished. Port Elizabeth: Nelson Mandela Metropolitan University.

NMMU (2007) Research, Technology and Innovation Strategy. Unpublished. Port Elizabeth: Nelson Mandela Metropolitan University

NMMU (2009). Vision 2020 Directional Statements, Strategic Priorities, Goals and Objectives. Port Elizabeth: Nelson Mandela Metropolitan University.

NMMU (2009). Policy for the Management of Third Stream Income Generated by NMMU Conferences, Seminars and Workshops. Unpublished. Port Elizabeth: Nelson Mandela Metropolitan University.

NMMU (2010). Financial Growth and Development Plan (FGDP) 2011-2020. Unpublished. Port Elizabeth: Nelson Mandela Metropolitan University.

NMMU (2010). Framework for the support and funding of research activities at NMMU by the NMMU RTI Committee. Unpublished. Port Elizabeth: Nelson Mandela Metropolitan University.

NMMU (2010). Policy on Short Learning Programmes. Unpublished. Port Elizabeth: Nelson Mandela Metropolitan University.

NMMU (2011). NMMU Research and Innovation Report 2011. Port Elizabeth: Nelson Mandela Metropolitan University.

NMMU (2012). Budget Guidelines. Unpublished. Port Elizabeth: Nelson Mandela Metropolitan University.

Obong, Q.O. (2004). Academic dilemmas under neo-liberal education reforms: A review of Makerere University, Uganda. In Zeleza, P.T., \& Olukoshi, A. (eds.), African Universities in the twenty-first century. Pretoria: UNISA Press.

Ocasio, W., \& Thornton, P.H. (2008). Institutional logics. In R. Greenwood, C. Oliver, K. Sahlin, \& R. Suddaby (Eds.), The SAGE handbook of organizational institutionalism (pp. 99-129). London: Sage.

OECD (1993). Employment Outlook. Paris: OECD. 
OECD (1998). Fostering entrepreneurship. Paris: OECD.

OECD (1998). Human Capital Investment, An International Comparison. Paris: OECD.

OECD (1998). Redefining Tertiary Education. Paris: OECD.

OECD (2002). Education at a Glance: OECD Indicators 2002. Paris: OECD.

OECD (2005). Higher Education Management and Policy. Special Issue: Entrepreneurship. Volume 17, No. 3. Paris: OECD. In particular 'Entrepreneurial Universities and the Development of Regional Societies: A Spatial View of the Europe of Knowledge (pp. 59-86).

OECD (2007). Entrepreneurship. Journal of Education Management and Policy, 17(3). Journal of the Programme on Institutional Management in Higher Education. OECD Publishing.

OECD (2008). Tertiary Education for the Knowledge Society. Paris: Organisation for Economic Cooperation and Development

Oketch, M.O. (2000). Costing and Financing Higher Education for Development in Sub-Saharan Africa: Kenya's case. International Education Journal, 4(3),1-10.

Oketch, M.O. (2003). Market Model of Financing Higher Education in SubSaharan Africa: Examples from Kenya. Higher Education Policy, 16(3), 313 332.

Oliver, C. (1991). Strategic Responses to Institutional Processes. Academy of Management Review, 16, 145-179.

Oosterbeek, H. (1995). Sociaal leenstelsel voor financiering van studie. Economisch Statistische Berichten, 19-4-1995, 376-379.

Ordorika, I. (2003). The limits of university autonomy: power and politics at the Universidad National Autonoma de México. Higher Education, 46(3), 361388.

Osborn, R.N. (1971). Organizational Effectiveness: A Model and a Test. Unpublished dissertation, Kent State University.

Otieno, W. (2004). Student Loans in Kenya: Past Experiences, Current Hurdles, and Opportunities for the Future. Journal of Higher Education in Africa, 2(2), 75-99.

Otieno, W. (2008). Access and Equity in Higher Education: Assessing Financing Policies in Kenya. Washington, DC: Partnership for Higher Education in Africa.

Otieno, W. (2010). Higher Education Financing in Kenya. In Pillay, P. (ed), Higher Education Financing in East and Southern Africa (pp.xxxx). Cape Town: African Minds

Ouma, G. W. (2007). Reducing resource dependence on government funding: The case of public universities in Kenya and South Africa. Unpublished doctoral dissertation. University of Cape Town. 
Ouma, G.W. (2011). Managing Resource dependency difficulties in African higher education: the case of multiple exchange relationships in Kenyan and South African public universities. Higher Education policy, 24, 167-184.

Owen-Smith, J., \& Powell, W.W. (1998). Universities and the market for intellectual property in the life sciences. Journal of Policy Analysis and Management, 17, 253-277.

Patton, M.Q. (1987). How to Use Qualitative Methods in Evaluation. Newbury Park London/New Delhi: Sage Publications.

Patton, M.Q. (1990). Qualitative Evaluation and Research Methods. London: Sage.

Patton, M.Q. (2002). Qualitative evaluation and research methods. Thousand Oaks, CA: Sage.

Pettigrew, A., \& Whipp, R. (1991). Managing Change for Competitive Success. Oxford: Blackwell Publishers.

Pfeffer, J. (1981). Power in organizations. Boston: Pitman.

Pfeffer, G., \& Salancik, G.R. (1978). The External Control of Organisations: A Resource Dependence Perspective. New York: Harper and Row.

Pfeffer, G., \& Salancik, G.R. (2003). External Control of Organisations: A Resource Dependence Perspective. Stanford: Stanford University Press.

Pillay, P. (2010). Linking higher education and economic development. Implications for Africa from three successful systems. Cape Town: CHET.

Porter, M.E (1979). Strategic Planning. George Steiner. Free Press.

Porter, M.E. (1980). Competitive Strategy. Techniques for analyzing industries and competitors. New York: Free Press.

Porter, M.E. (1996). What is Strategy? Harvard Business Review, 74(6), 61-78.

Power, M. (1994a). The Audit Society. In Hopwood, A., \& Miller, P. (eds.), Accounting as Social and Institutional Practice (pp. 299-316). Cambridge: Cambridge University Press.

PSA (2004). Medium Term Strategic Framework 2004-2009. Pretoria: Presidency of South Africa.

PSA (2008b). Towards an Anti-Poverty Strategy for South Africa: A discussion document. Pretoria: Policy Coordination and Advisory Services, Presidency of South Africa.

PSA (2009a). Medium Term Strategic Framework 2009-2014. Pretoria: Presidency of South Africa

Ramirez, F.O., Riddle, P. (1991). The Expansion of Higher Education. In: Altbach, P.G. (ed.), International Higher Education: An Encyclopedia (pp. 91106). New York: Garland.

Ramsden, P. (1998). Managing the effective university. Higher education Research and Development, 17(3), 347-370.

Richards, L. (2005). Handling Qualitative Data. A Practical Guide. London: Sage Publications. 
Riechi, R.O.A. (2003). Revenue Diversification in Kenya's Public Universities and Implications for Efficiency and Equity: An Analysis of Educational Finance in the African Context. Unpublished Doctoral Dissertation. Jawaharlal Nehru University.

Rizzo, P. (2004). A (Less Than) Zero Sum Game? State Funding for Public Higher Education: How Public Higher Education Institutions Have Lost. Unpublished Doctoral Dissertation. Cornell University.

RoK (1964). Development Plan, 1964-1970. Nairobi: Government Printer.

RoK (1973). Development Plan, 1974-78. Draft Chapter on Education. Nairobi: Government Printer.

RoK (1985). The Universities Act (Cap.210B) of 1985

RoK (1986). Sessional Paper No.1 of 1986: Economic Management for Renewed Growth. Nairobi: Government Printer.

RoK (1994). Jomo Kenyatta University of Agriculture and Technology Act 1994, No. 8 of 1994. Nairobi, Kenya.

RoK (2007). Kenyan Vision 2030. Nairobi, Kenya.

RoK (2008). The Presidential Circular No. 1/2008 of 2008.

RoK (2010). Constitution of Kenya.

RoK (2012). The Universities Act, 2012.

RoK (2012). Kenyan National Bureau of Statistics. Nairobi.

Röpke, J. (1998). The Entrepreneurial University, Innovation, academic knowledge creation and regional development in a globalized economy. Working Paper Department of Economics, Philipps- Universität Marburg, Germany: 15.

RoSA (1995). The South African Qualifications Authority Act (SAQA), 1995 (Act 58 of 1995).

RoSA (1997). Higher Education Act 101 of 1997.

RoSA (1998). Skills Development Act No. 97 of 1998.

RoSA (1998). National Research Foundation Act No 23 of 1998.

RoSA (1999). The National Student Financial Aid Scheme (NSFAS) Act No. 56 of 1999.

RoSA (2007). Higher Education Quality Framework of Government Notice No.928 of 2007.

RoSA (2007). National Industrial Policy Framework (2007).

RoSA (2007). National Qualifications Framework Act No. 67 of 2008; NQF Act 67 of 2007.

RoSA (2012). National Development Plan Vision 2030 Green Paper; National Planning Commission, 2012.

Rothaermel, F.T., Agung, S.D., \& Jiang, L. (2007). University entrepreneurship: a taxonomy of the literature. Industrial and Corporate Change, 16, 1-101.

Saint, W. (1992). Universities in Africa: Strategies for Stabilization and Revitalization. Washington, D.C: World Bank. 
Saint, W (2003). Higher Education Development in Ethiopia: Pursuing the Vision. New York: World Bank.

Salmi, J. (2007). Autonomy from the State vs Responsiveness to Markets. Higher Education Policy, 20(3), 223-42

Salmi, J. (2012). Unleashing the Potential of South African Universities Assessing the Tertiary Education Ecosystem. A short report produced for the Centre of Higher Education Transformation (CHET).

Salter, B., \& Tapper, T. (2004). The external pressure on the internal governance of universities. Higher Education Quarterly, 56(3), 245-256.

Sanyal, B. (1998). Diversification of Sources and the Role of Privatisation in Financing Higher Education in the Arab States Region. Paris: UNESCO-IIEP.

Sawyerr, A. (2002a). The Public Good in African Higher Education: Select Issues for Policy. Keynote Speech. Higher Education at the Crossroads: A Policy Consultation on Higher Education in Africa. Accra: AAU. 30 - 41.

Sawyerr, A. (2004). Challenges Facing African Universities: Selected issues. Accra: Association of African Universities

Sayer, A. (1992). Methods in Social Science. A Realist Approach (2nd ed.). London: Rutledge.

Schneider, A. (1999). Master's degrees, once scorned, attract students and generate revenue. The Chronicle of Higher Education, 45(37), A12-13.

Schulte, P. (2004). The Entrepreneurial University: A Strategy for Institutional Development. Higher Education in Europe, 29(2), 187-191.

Scott, W.R. (1987a). The adolescence of institutional theory. Administrative Science Quarterly, 32, 493-511.

Scott, W.R. (1987b). Organizations: Rational, Natural, and Open Systems (2nd edition). Englewood Cliffs, New Jersey: Prentice-Hall.

Scott, W.R. (1992a). The organization of environments: Network, cultural, and historical elements. In Meyer, J.W., \& Scott, W.R. (eds.), Organizational Environments: Ritual and Rationality. London: Sage.

Scott, W.R. (1992b). Organizations: Rational, Natural, and Open Systems (3 ${ }^{\text {rd }}$ ed.). Englewood Cliffs, NJ: Prentice Hall.

Scott, W.R. (2003). Organizations. Rational, Natural, and Open Systems (5 $5^{\text {th }}$ ed.). New Jersey: Prentice Hall.

Scott, W. R., et al. (2000). Institutional Change and Health Care Organizations: From Professional Dominance to Managed Care. Chicago: University of Chicago Press.

Shattock, M. (2000). Strategic Management in European Universities in an age of increasing institutional reliance. Tertiary Education and Management, 6, 93104.

Shattock, M. (2003). Managing Successful Universities, Society for Research into Higher Education. Berkshire, England: Open University Press. 
Shattock, M. (2004). Entrepreneurialism and the transformation of Russian universities. Paris: International Institute for Educational Planning.

Shattock, M. (2005). European Universities for Entrepreneurship: Their Role in the Europe of Knowledge. The Theoretical Context. Higher education management and policy, 17(3), 13-25.

Shattock, M. (ed.) (2009). Entrepreneurialism in Universities and the Knowledge Economy. Diversification and Organizational Change in European Higher Education. Society for Research in Higher Education and the Open University Press.

Shea, J. (2000). Does parents' money matter? Journal of Public Economics, 77, 155184.

Siegel, D.S. (ed.) (2006a). Technology Entrepreneurship: Institutions and Agents Involved in University Technology Transfer (Vol. 1). London: Edgar Elgar:.

Siegel, D.S., Westhead, P., \& Wright, M. (2003c). Assessing the impact of university science parks on research productivity: exploratory firm-level evidence from the United Kingdom. International Journal of Industrial Organization, 21(9), 1357-1369.

Sifuna, D.N. (1998). The Governance of Kenyan Public Universities. Research in Post-Compulsory Education, 3(2), 175-211.

Sifuna, D.N. (2006). A Review of Major Obstacles to Women's Participation in Higher Education in Kenya. Research in Post-Compulsory Education, 11(1), 85105-

Silverman, D. (2000). Doing Qualitative Research. A Practical Handbook. Thousand Oaks, CA: Sage

Smart, J. (ed.), (1999). Higher Education: Handbook of Theory and Research (Vol. I). New York: Agathon.

Sotirakou, T. (2004). Coping with conflict within the entrepreneurial university: Treat or challenge for heads of departments in the UK higher education context. International Review of Administrative Sciences, 70(2), 345-372.

Sporn, B. (1995a). Adaptation processes at universities: Organizational implications of a complex environment. Tertiary Education and Management 1(1), 72-76.

Sporn, B (1999). Adaptive University Structures: An Analysis of Adaptation to Socioeconomic Environments of US and European Universities. London: Jessica Kingsley.

Sporn, B. (2001). Building Adaptive Universities: Emerging Organizational Forms Based on Experiences of European and US Universities. Tertiary Education and Management, 7(2), 121-134.

Sporn, B. (2006). Governance and Administration: Organizational and Structural Trends. International Handbook of Higher Education, 18, 141-157. 
Stake, R.E (2000). Case Studies. In Denzin, N.K., \& Lincoln, Y.S. (eds.), Handbook of Qualitative Research (2nd ed.). Thousand Oaks, CA: Sage.

Stamoulas, A. (2006). Greece before the Bologna Process: Confronting or Embracing Quality Assurance in Higher Education? Higher Education Policy, 19(4), 433-455.

Steiner, G. (1979). Strategic Planning. Free Press.

Stensaker, B. (2004). The blurring boundaries between accreditation and auditthe case of Norway. In Schwarz, S. \& Westerheujden, D.F. (eds), Accreditation in the framework of evaluation activities. Current situation and dynamics in Europe. Dordrecht: Kluwer Academic Press.

Strauss, A. L. (1987 [2003]). Qualitative Analysis for Social Scientists. Cambridge: Cambridge University Press.

Subotzky, G. (1999). Alternatives to the Entrepreneurial University: New Modes of Knowledge Production in Community Service Programs. Higher Education, 38(4); 401-440.

Subotzky, G. (2003). South Africa. In Teferra, D. \& Altbach, P. (eds.), African Higher Education: An International Reference (pp. 545 - 562). Bloomington \& Indianapolis: Indiana University Press.

Suchman, M.C. (1995). Managing legitimacy: Strategic and institutional approaches. Academy of Management Review, 20, 571-610.

Tang, P.J.G., \& Van Ewijk, C. (2000). Efficient progressive taxes and education subsidies. CPB Research Memorandum, No. 170.

Task Force on Higher Education and Society (2000). Higher education in developing countries: Peril or promise. Washington: World Bank.

Teshome, Y. (2005). Policy Development in Higher Education in Ethiopia and the Role of Donors and Development Partners. Paper presented at the International Expert Meeting-Formulas that work: Making Higher education Support More effective; The Hague, The Netherlands, 23-24, May, 2005.

Teshome, Y. (2007). The Ethiopian Higher Education: Creating Space for Reform. Addis Ababa: St Mary's University College Printing Press.

Teulings, C. (2000), Onderwijs: een nuttige maatschappelijke investering? Socialisme en Democratie, 57(9), 405-410.

Thomas, H. (1995/6). Strategic Planning. In Warner, D. \& Palfreyman, D. (eds.), Higher Education Management (pp. 33-46). Buckingham: SRHE and Open University Press.

Thompson, J.D. (1967). Organizations in Action. New York: McGraw-Hill.

Tolbert, P.S. (1985). Institutional environments and resource dependence: Sources of administrative structure in institutions of higher education. Administrative Science Quarterly 30, 1-13. 
Tolbert, P.S., \& Zucker, L.G. (1996). The institutionalization of institutional theory. In Clegg, S., Hardy, C., \& Nord, W.R. (eds.), Handbook of Organization Studies (pp. 175-190). London and Thousand Oaks: Sage Publications.

Tregoe, B.B., \& Zimmerman, J.W. (1980). Top Management Strategy. New York: Simon and Schuster.

Trow, M.A. (1973). Problems in the Transition from Elite to Mass Higher Education. Berkeley, CA: Carnegie Commission on Higher Education.

Trow, M.A. (1983). Reorganizing the biological sciences at Berkeley. Change, 15(8), 44-53.

UNESCO (2007). Main transformations, challenges and emerging patterns in Higher Education Systems. UNESCO Forum on Higher Education, Research and Knowledge Occasional Paper Series. Paper no. 16. Paris: UNESCO.

UNPF (2010). The State of World Population 2010. United Nations Population Fund (UNFPA).

Vaira, M. (2004). African Higher Education: Challenges for the 21st Century. Higher Education, 47(1), 21 - 50.

Van der Wende, M.C. (2002). Higher education globally. Towards new frameworks for higher education research and policy. In The CHEPS Inaugurals 2002 (pp. 2969). Enschede: Twente University Press.

Verhoest, K., Bouckaert, G., Peters, B.G., \& Verschuere, B. (2004). The study of organisational autonomy: a conceptual review. Public Administration and Development 24, 101-118.

Varghese, N.V. (2004). Incentives and Institutional Changes in Higher Education. Higher Education Management and Policy Volume 16, No. 1.

Varghese, N.V. (2009). Higher Education Reforms Institutional Restructuring in Asia. IIEP UNESCO.

Vedovello, C. (1997). Science parks and university-industry interaction: geographical proximity between the agents as a driving force. Technovation, 17(9), 491-502.

Volkwein, J. F. (1986). Campus autonomy and its relationship to measures of university quality. Journal of Higher Education, 57(5), 510-524.

Vossensteyn, H. (2005). Perceptions of student price-responsiveness. Enschede: CHEPS.

Wagaw, T. (1990). The Development of Higher Education and Social Change: An Ethiopian Experience. East Lansing: Michigan State University Press.

Weber, M. (1947). The theory of social and economic organization. New York: Free.

WEF (2011-12) The Global Competitiveness Report 2009-2010. Geneva: World Economic Forum.

Weick, K (1976). Educational organizations as loosely coupled systems. Administrative science Quarterly, 21, 1-19 
Weidman, J.C. (1995). Diversifying Finance of Higher Education Systems in the Third World: The Cases of Kenya and Mongolia. Education Policy Analysis Archives, 3(5), 1-13.

Westphal, J.D, \& Zajac, J. E. (2004). The Social Construction of Market Value: Institutionalization and Learning Perspectives of Stock Market Reactions. American Sociology Review, 69, 433-457.

Williams, G.L. (1992). Changing Patterns of Finance in Higher Education. Burkingham: Open University Press.

Williams, G.L. (1995). The "marketization" of higher education: Reforms and potential reforms in higher education finance. In Dill, D. D., \& Sporn, B. (eds.), Emerging Patterns of Social Demand and University Reform: Through a Glass Darkly. Oxford: Pergamon.

Williams, G. (ed.) (2003). The enterprising university. Reform, excellence and equity. Burkingham: Open University Press.

Williams, G. (2009). Finance and entrepreneurial activity in higher education in the knowledge society'. In Shattock, M. (ed.), Entrepreneurialism in Universities and the Knowledge Economy (pp. 9-33). Open University Press. McGraw-Hill Education.

Wondimu, H. (2003). Ethiopia. In Teferra, D., \& Altbach, P. (eds.), African Higher Education: An International Reference Handbook. Bloomington: University of Indiana Press.

Wondwosen Tamrat (2008). The Anatomy of Private Higher Education in Ethiopia. Addis Ababa: St. Mary's University College Printing Press.

Woodhall, M. (1991). Education and Training Under Conditions of Economic Austerity and Restructuring. Paris: UNESCO, Bureau for the Coordination of Operational Activities.

Woodhall, M. (1995). Financial Diversification in Higher Education: A Review of International Experience and Implications for African Universities. Higher Education Policy 8(1), 16-23.

World Bank (1986). Financing Education in Developing Countries: Exploration of Policy Options. Washington, DC: World Bank.

World Bank (1988). Education in Sub-Saharan Africa: Policies for Adjustment, Revitalization, and Expansion. Washington, DC: World Bank.

World Bank (1994). Higher Education: The Lessons of Experience. Washington, DC: World Bank.

World Bank (2000). Higher Education in Developing Countries: Peril and Promise. The Task force on Higher Education and Society. Washington, DC: World Bank.

World Bank (2002). Constructing Knowledge Societies: New Challenges for Tertiary Education. Washington, DC: World Bank. 
World Bank (2004a). Higher Education Development for Ethiopia: Pursuing the Vision. Washington, DC: World Bank, Human Development Department, Africa Region.

World Bank (2004b). Country Status Report: Ethiopia. Washington, DC: World Bank, Human Development Department, Africa Region.

World Bank (2005). Post-secondary Education Project Cr. 3984. Washington, DC: World Bank.

World Bank (2009). Accelerating Catch-up Tertiary Education for Growth in SubSaharan Africa. Washington, DC: World Bank.

World Bank (2010). Financing Higher Education in Africa. Washington, DC: World Bank.

Yin, R.H (1994). Case Study Research: Design and Methods (2nd ed.). Beverly Hills, CA: Sage Publishing.

Yin, R.K. (2003). Case study research: Design and methods. Thousand Oaks: Sage Publications Inc.

Ylinenpää, H. (2001). Science Parks, Clusters and Regional Development. Paper presented at 31st European Small Business Seminar in Dublin, Sept 12-14. Luleå: Luleå University of Technology; Department of Business Administration and Social Sciences.

Zhou, C., (2008). Emergence of the entrepreneurial university in evolution of the triple helix. Journal of Technology Management in China, 3(1), 109-126.

Ziderman, A. (2003). Student Loans in Thailand: are they Effective, Equitable, Sustainable? Bangkok: UNESCO-IIEP.

Zomer, A.H (2011). Do spin-off companies make academics' heads spin? The impacts of research-based spin-off companies on the production of scientific knowledge. Enschede: University of Twente. 


\title{
Nederlandstalige samenvatting
}

\author{
De aanleiding
}

Het zorgdragen voor voldoende financiële middelen - en daarmee het bewerkstelligen van financiële bestaanszekerheid - is een van de belangrijkste uitdagingen voor universiteiten, zowel in de ontwikkelde landen in de westerse wereld als in de ontwikkelingslanden in Afrika en Azië. Dit onderzoek gaat in op de vraag welke keuzes universiteiten daarbij maken, welke strategieën ze daarbij hanteren en hoe de beleidsmakers in de omgeving van universiteiten de bestuurders en medewerkers van universiteiten aanzetten om actief op zoek te gaan naar aanvullende financiële middelen. Universiteiten wereldwijd worden geconfronteerd met toenemende studentenaantallen terwijl hun budgetten daarmee niet altijd meegroeien. En dit terwijl het belang van universiteiten voor de ontwikkeling van individuen en de samenleving groot is - vooral nu goederen en diensten een steeds grotere kennis- en technologiecomponent bezitten.

Dit dissertatieonderzoek kijkt vooral naar universiteiten in Afrika - twee universiteiten uit Ethiopië, één uit Kenia en één uit Zuid Afrika. Met name in Sub-Sahara Afrika zijn universiteiten in de afgelopen decennia geconfronteerd met een snelle groei in de instroom van studenten. De financiële bijdrage die de overheid per student beschikbaar stelt is echter sterk gedaald. Daardoor voldoen de publieke investeringen in het hoger onderwijs bij lange na niet meer aan de behoeften van de meeste Afrikaanse universiteiten. De Wereldbank schat dat de bijdrage slechts een derde tot $40 \%$ van de behoefte dekt (World Bank, 2010). De bestaande stelsels voor hoger onderwijs in Afrika zijn nog vooral gestoeld op het idee dat hoger onderwijs is bedoeld voor - en tegemoet komt aan de eisen van - een nationale elite. Toch is hoger onderwijs ook in Afrika cruciaal voor de verdere ontwikkeling van de nationale welvaart en het verbeteren van de economische prestaties. Desalniettemin ligt de prioriteit van veel overheden in Sub-Sahara Afrika niet bij het hoger onderwijs en wordt van de universiteiten verwacht dat zij in grote zelf zorgdragen voor voldoende financiële middelen.

Gelet op deze situatie is het verwerven van financiële middelen één van de belangrijkste strategieën voor het bewerkstelligen van de financiële bestaanszekerheid van de universiteiten in Sub-Sahara Afrika. Ook in andere landen in de wereld is dit overigens het geval (Clark, 1998; Jongbloed, 2003; Riechi, 2003; Liu, 2007; Ouma, 2007; Massy, 2009), maar in Afrika zijn de 
omstandigheden uiteraard veel meer uitdagend. Uiteraard is de overheid immer nog de belangrijkste bron van inkomsten, maar steeds meer wordt de universiteit uitgedaagd - en zelfs opgelegd - om inkomsten te genereren uit bronnen als collegegelden van studenten, korte cursussen, contractonderzoek, dienstverlening aan derden, consultancy en donaties (van ontwikkelingsorganisaties, buitenlandse overheden en non-profitorganisaties).

De uitdagingen bij het genereren van inkomsten zijn het onderwerp van deze dissertatie - daarbij gaan we zowel in op praktische vragen als op wetenschappelijke kwesties. Dat laatste om te onderzoeken hoe, in het licht van de uiteenlopende stelsels van wet- en regelgeving en de verschillen in economische omstandigheden, de voorwaarden en de obstakels voor inkomstenverwerving door universiteiten beter kunnen worden begrepen.

\section{Onderzoeksvragen}

De centrale onderzoeksvraag van deze studie is:

Op welke wijze kunnen universiteiten in Sub-Sahara Afrika hun financiële bestaanszekerheid verbeteren en tegelijk het hoofd bieden aan de sterke stijging van hun studentenaantallen en welke rol speelt een diversificatie van de financiële middelen daarbij?

Deze vraag valt uiteen in de volgende deelvragen:

1) Welke theorie staat ons ter beschikking voor het begrijpen van de voorwaarden voor en de barrières bij het genereren van inkomsten door universiteiten in Sub-Sahara Afrika?

2) Hoe ziet de praktijk van het genereren van inkomsten eruit bij de openbare universiteiten in Sub-Sahara Afrika?

3) Welke voorwaardenscheppende structuren, maatregelen en omstandigheden zien we rondom de verwerving van middelen door universiteiten in Sub-Sahara Afrika? En welke obstakels ondervinden de universiteiten hierbij?

4) Gelet op wat we weten van de theorie en de internationale praktijk rondom financiële middelenverwerving, hoe kunnen barrières worden overwonnen en voorwaarden worden geschapen voor het genereren van inkomsten door universiteiten in Sub-Sahara Afrika?

Conceptueel model

Ons theoretisch kader is gebaseerd op een theorie rondom het gedrag van organisaties: de resource dependence theorie (Pfeffer \& Salancik, 1978). Deze biedt een bruikbaar conceptueel kader voor het bestuderen van de interne en externe aspecten van de middelenverwerving door universiteiten en hun strategische 
antwoorden op de financiële uitdagingen. Volgens deze theorie hebben externe actoren (belanghebbenden, of stakeholders) die beschikken over hulpbronnen die voor de organisatie van belang zijn een sterke, dan wel minder sterke invloed op de organisatie. Dit beïnvloedt het gedrag van de organisatie (Nienhüser, 2008). De theorie benadrukt het belang van de stakeholders in de omgeving van de organisatie, hun bevoegdheden, hun motieven (zie ook: Oliver, 1991) en de manier waarop deze hun belangen naar voren brengen. Aan de resource dependence theorie (RDT) voegen we de stakeholder theorie toe om een analyse te kunnen maken van de wijze waarop de organisatie haar stakeholders prioriteert en de (soms tegenstrijdige) belangen van stakeholders met elkaar verzoent (zie Jongbloed, Enders \& Salerno, 2008). De invloed die een bepaalde stakeholder bezit komt onder meer naar voren in de (wettelijke, regelgevende) bevoegdheden van de stakeholder en de potentiële financiële middelen waar deze over beschikt (Freeman, 1984; Davis \& Cobb, 2009).

De RDT veronderstelt een actieve rol van de organisatie bij verzekeren van haar voortbestaan (Aldrich, 1979; Pfeffer \& Salancik, 1978; Scott, 1992b; Davis en Cobb, 2009; Nienhüser, 2008). In het RDT perspectief is de interne verdeling van de macht daarbij een van de factoren die het organisatorische gedrag beïnvloedt (Nienhüser, 2008). De rol van het leiderschap en management van de organisatie is dan van groot belang. Pfeffer en Salancik (2003) stellen dat leiders en managers een besluitvormende en legitimerende rol hebben en daarbij de omgeving van de organisatie in ogenschouw nemen (zie ook Nienhüser, 2008; Berman, Robert en Wicks, 2007). RDT veronderstelt dat organisaties een zekere mate van autonomie moeten hebben om te kunnen beslissen over middelenverwerving of -ruil (Hall, 1999). Autonomie kent diverse dimensies en deze zullen een rol spelen bij de middelenverwerving door universiteiten.

De RDT biedt het perspectief waarin de mogelijke inkomstenstrategieën van het universitaire management kunnen worden geïnterpreteerd (Berman, Robert \& Wicks, 2007; Pfeffer \& Salancik, 2003; Nienhüser, 2008; Oliver, 1991). RDT wijst op twee typen strategieën om de afhankelijkheid van de omgeving mee te adresseren (zie Davis \& Cobb, 2009): een strategie van aanpassing (aan de omgeving) en een strategie van beïnvloeding van de omgeving om te bewerkstelligen dat deze beter aansluit bij de capaciteit en wensen van de organisatie. Binnen deze brede strategieën passen de volgende opties: nauwe samenwerking (via allianties of fusies) met andere organisaties, diversificatie van aangeboden diensten, creëren van nieuwe organisatiestructuren, coöptatie van belangrijke derden door middel van in elkaar grijpende besturingsorganen, en lobbyactiviteiten om regelgeving te beïnvloeden (Pfeffer \& Salancik, 1978; Davis \& Cobb, 2009). 
De RDT biedt het kader voor ons onderzoek en wijst op de onderlinge relaties tussen factoren en variabelen als de organisatorische omgeving, capaciteit (en andere kenmerken) van de universiteit, gekozen strategieën, ondernomen activiteiten, en beschikbare middelen. Deze samenhangende variabelen vormen de basis van ons onderzoeksmodel (zie onderstaande figuur).

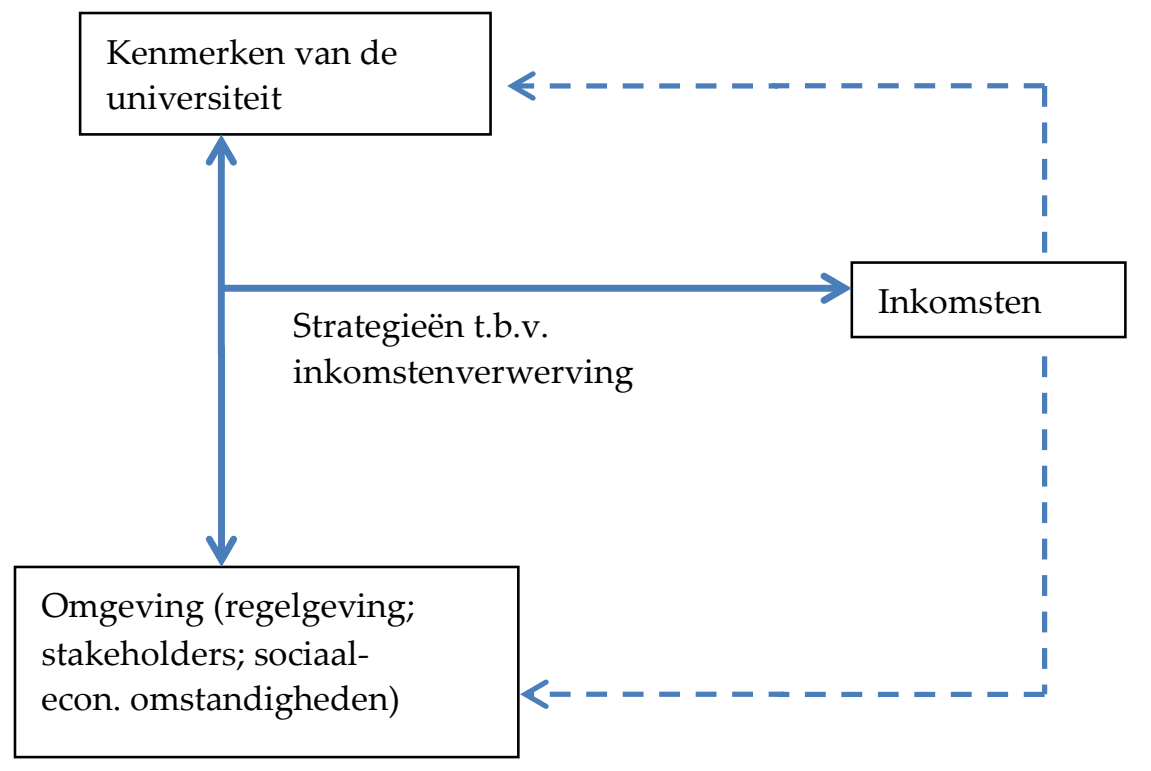

onderzoeksmodel

Er is een tweezijdige relatie tussen de universiteit en haar omgeving. Deze in aanmerking genomen, kiest de universiteit haar strategieën om inkomsten te verwerven. Daaruit resulteren (met wisselend succes) inkomsten die terugvloeien naar universiteit en omgeving. Deze activiteiten leiden tot meer financiële bestaanszekerheid, meer legitimiteit en meer vertrouwen bij de stakeholders van de universiteit. Met de resultaten van de ondernomen activiteiten tracht de universiteit haar voortbestaan te verzekeren en haar ambities te realiseren. Gebleken succes (of gebrek daaraan) kan tot een aanpassing van de gekozen strategieën leiden, hetgeen kan vragen om een herziening van de relaties met de stakeholders van de universiteit.

De kenmerken van de universiteit en de omgeving zijn de onafhankelijke variabelen in onze studie. De focus in ons onderzoek ligt op de strategie van de universiteit en de daaruit resulterende activiteiten om inkomsten te verwerven - de afhankelijke variabelen. Een breed spectrum van strategieën, variërend van 
aanpassings- tot veranderingsstrategieën, staat de universiteit ter beschikking om middelen te verwerven ten behoeve van haar voortbestaan.

\section{Methodologie}

Om onze onderzoeksvragen te beantwoorden hebben we een aantal case studies gemaakt van universiteiten - universiteiten opererend in een verschillende nationale context. Via een selectie van vier cases is inzicht verkregen in de inkomstenstrategieën van verschillende universiteiten. De onafhankelijke variabelen en de context verschillen per universiteit en maken het mogelijk de invloed daarvan te bestuderen (Yin, 2003; Miles \& Huberman, 1994; Grix, 2004). Vier openbare universiteiten uit drie landen in Sub-Sahara Afrika - Ethiopië, Kenia en Zuid-Afrika - zijn geselecteerd voor ons onderzoek. De keuze van de landen is ingegeven door de wens om voldoende variëteit in (externe, interne) omstandigheden over de cases te bewerkstelligen (zie Patton, 1987, 2002; Silverman, 2000). Het belangrijkste criterium voor de keuze van de landen was het verschil in niveau van ontwikkeling in het hoger onderwijs en in ontwikkeling van de economie. De landen verschillen aanzienlijk wat betreft de mogelijkheden en wetgeving voor universiteiten om inkomsten te genereren. Zuid-Afrika is een relatief ontwikkelde economie, die meer kansen biedt voor universiteiten om inkomsten uit diverse bronnen te verwerven uit onderwijs-, onderzoek- en adviesactiviteiten. Vergeleken daarmee zijn Ethiopië en Kenia meer factor-gedreven economieën, met relatief meer beperkte en beperkende condities voor universiteiten om middelen te mobiliseren uit diverse bronnen.

Uit Ethiopië zijn twee openbare universiteiten geselecteerd: Adama Science and Technology University (ASTU) en Haramaya University (HU). Uit Kenia is de Jomo Kenyatta University of Agriculture and Technology (JKUAT) afkomstig. De Nelson Mandela Metropolitan University (NMMU) is gesitueerd in ZuidAfrika. Meer dan vier case studies bleek niet mogelijk, gelet op de tijd en het budget voor onze studie. De vier universiteiten zijn in verschillende mate actief in het genereren van inkomsten. Het zijn alle vier brede universiteiten wat betreft de disciplines en faculteiten die ze in huis hebben. Het staat de universiteiten in verschillende mate vrij om middelen te genereren buiten de reguliere overheidsbekostiging om. De case studie universiteiten zijn uiteraard niet representatief voor Sub-Sahara Afrika, maar kunnen wel dienen om strategieën voor inkomstenverwerving te onderzoeken en te detecteren die zich onderscheiden van de strategieën en modellen die elders in de wereld in gebruik zijn. 
De kwantitatieve en kwalitatieve gegevens voor ons onderzoek zijn afkomstig uit meerdere bronnen: ten eerste uit literatuuronderzoek en desk research naar inkomstenverwerving in Sub-Sahara Afrika en daarbuiten, en, ten tweede, uit de informatie verzameld bij de vier case studie universiteiten. Met een groot aantal sleutelfiguren uit de universiteiten zijn interviews gehouden en er zijn stukken verzameld bij de vier universiteiten. Ook zijn documenten verzameld en bestudeerd om zicht te krijgen op de omgeving van de universiteit en de belangrijkste partijen in de omgeving daarvan. We hebben 67 semigestructureerde interviews afgenomen. De respondenten varieerden van bestuurders aan de top tot managers, onderzoekers en personeelsleden op de werkvloer. De verzamelde gegevens zijn geanalyseerd, zowel op het niveau van instelling als in vergelijkende zin - tussen de vier case studie universiteiten.

\section{De eerste twee onderzoeksvragen beantwoord}

De empirische gegevens en analyses in dit onderzoek zijn vooral gericht op de vraag welke strategieën de universiteiten in Sub-Sahara Afrika hebben gehanteerd om inkomsten te genereren als middel op weg naar financiële bestaanszekerheid. Het gaat dan met name om de inkomsten verkregen naast de reguliere bekostiging (de rijksbijdrage) van de nationale overheid. We presenteren nu de belangrijkste bevindingen van onze studie.

literatuuronderzoek

Onze eerste onderzoeksvraag betreft organisatietheorieën die bruikbaar zijn voor het conceptualiseren van de relaties tussen universiteiten en hun omgeving, met name wat betreft het verwerven van middelen. Uit onze literatuurstudie bleek dat de bestaande onderzoeksliteratuur veelal onvoldoende rekening houdt met de veelheid en complexiteit van relaties die er bestaan op het gebied van middelenstromen. Adequate theorieën voor het begrijpen van de onderlinge afhankelijkheid tussen de vele verschillende actoren en organisaties betrokken bij inkomstenverwerving te modelleren zijn schaars en vaak op empirisch weinig rijk materiaal gebaseerd. Diversificatie van inkomsten door organisaties van het hoger onderwijs is weinig onderzocht zeker in Afrika (uitzonderingen daargelaten, zie: Ouma, 2011; Cloete et al., 2011, 2015). Er is veel discussie over het onderwerp, maar weinig consensus over theorie en empirie van strategieën voor inkomstenverwerving. Het inzicht dat oprijst uit de literatuur is dat universiteiten als open organisaties zich noodgedwongen bezighouden met het onderhouden van (financiële) relaties met de buitenwereld om in hun voorbestaan te kunnen voorzien (zie ook Scott, 1992; Hall, 1999). Universiteiten zijn open organisaties die in verbinding staan 
met en transacties doen met hun omgeving (Meyer \& Scott, 1992). Deze omgeving biedt niet alleen kansen voor het verwerven van middelen, maar legt tegelijk ook beperkingen op aan het handelingsrepertoire van de organisatie (Tolbert, 1985). De literatuur wijst erop dat het verwerven van middelen van externe stakeholders mede wordt beïnvloed door factoren die specifiek zijn voor de universiteit in kwestie (Clark, 1998; Etzkowitz, 2003). De resource dependence theorie kan ons inzicht verschaffen in de vraag hoe en waarom universiteiten als organisaties relaties met de omgeving inrichten om middelen te verwerven die essentieel zijn voor hun voortbestaan.

Omdat de academische literatuur naar de empirie van inkomstenverwerving door publieke universiteiten in Sub-Sahara Afrika schaars is hebben we verder gekeken naar deze praktijk in andere delen van de wereld. Uit de wetenschappelijke literatuur over de financiering van het hoger onderwijs blijkt dat veel landen voor de uitdaging staan een meer duurzaam systeem voor de bekostiging van hun hoger onderwijs te ontwerpen (EUA, 2011; Clark, 1998; Massy, 2003; Johnstone, 1998; Beliakov et al., 1998; Jongbloed, 2004; Clark, 2004; Rizzo, 2004; OECD, 2008; World Bank, 2010; Kitaev et al., 2003; Shen \& Li, 2003; Ziderman, 2003; Varghese, 2009). Daarbij is het stimuleren van inkomstenverwerving door universiteiten een vaak voorkomende beleidsdoelstelling: universiteiten worden uitgedaagd middelen te verwerven buiten hun reguliere rijksbijdrage om (Clark, 1998; Jongbloed, 2003; Riechi, 2003; Liu, 2007; Ouma, 2007; Massy, 2009).

Universiteiten in Afrika slagen erin om ongeveer $28 \%$ van hun jaarlijkse inkomsten te genereren uit externe middelen, dat wil zeggen uit bronnen anders dan de student-afhankelijke bijdrage van hun overheid (Wereldbank, 2010). Daartoe ondernemen universiteiten zowel academische als nietacademische activiteiten voor een diverse verzameling stakeholders (Clark, 1998; Shattock, 2003; Jongbloed, 2003; Johnstone, 1998; Slaughter \& Leslie, 1997; Williams, 1992; Liu, 2007; CHET, 2011; EUA, 2011; Hearn, 2003). Wereldwijd is de meest voorkomende bron van externe middelen het collegegeld dat studenten betalen voor hun opleiding of voor aanvullend onderwijs (EUA, 2011; OECD, 2008; Williams, 1992). Opbrengsten uit contractonderzoek en consultancy vormen een andere bron van inkomsten, met name in regio's waarin de bedrijvigheid meer kennis- en technologiegedreven is (Leslie \& Slaughter, 1997). Uiteraard bestaan er grote variaties tussen landen, tussen universiteiten en tussen verschillende afdelingen (faculteiten, disciplines) daarbinnen (Clark, 2004), maar nergens vormt het genereren van externe inkomsten een vervanging voor de overheidsfinanciering (zie EUA, 2011). 
In respons op de financiële krapte in de hoger onderwijssector gaan overheden over op een van de volgende strategieën: het beperken van de studentenaantallen, liberalisering en privatisering van hoger onderwijs, efficiëntieverhoging, verhoging van de financiële bijdragen van studenten en het stimuleren van externe middelenverwerving. Uit de beschikbare studies blijkt dat het genereren van externe inkomsten door de universiteiten spanningen op kan roepen. Academische prioriteiten kunnen gaan verschuiven met mogelijk nadelige gevolgen voor de kwaliteit van het onderwijs, en er kan oneerlijke concurrentie met de particuliere sector optreden. Hoe universiteiten hiermee omgaan vereist een goed begrip van de universiteit als organisatie met een publieke taak in een omgeving die vele claims op haar doet.

\section{Onderzoeksvaag 3: resultaten uit de case studies}

In alle vier case studie universiteiten is het bevorderen van de financiële bestaanszekerheid aan de orde. De case studie universiteiten hanteren alle een diversificatiestrategie om zo door middel van een spreiding over meerdere inkomstenbronnen risico's te spreiden en de financiële weerbaarheid te vergroten. Zowel bij JKUAT (de universiteit uit Kenia) als NMMU (uit Zuid Afrika) is het aandeel van de externe middelen groter dan dat van de reguliere overheidsbijdrage, maar alleen bij de laatstgenoemde instelling is de diversificatie zodanig dat er gesproken zou kunnen worden van een relatief hoge mate van financiële bestaanszekerheid. De twee Ethiopische universiteiten (ASTU en HU) zijn nog in zeer hoge mate afhankelijk van één geldschieter, de rijksoverheid, en daarmee sterk gevoelig voor een afname van de rijksbijdrage. De vier case studie universiteiten zijn alle, in verschillende mate en met verschillende mate van succes, actief in het vermarkten van hun academische en niet-academische diensten. Daarmee verwerven ze middelen van diverse 'klanten' (zeg stakeholders). Collegegelden vormen de relatief meest omvangrijke bron van externe inkomsten. Het genereren van middelen uit onderzoek en consultancy blijkt af te hangen van een aantal interne en externe factoren. De interne factoren hebben te maken met de capaciteit - de kennisbasis, academische vaardigheden, maar ook de administratieve expertise - die aanwezig is om onderwijs en onderzoek te kunnen vermarkten. De externe factoren hebben te maken met de behoefte vanuit de markt en de in de omgeving aanwezige bedrijven en organisaties. Om daarop in te spelen hebben universiteiten hun interne structuren en werkprocessen aangepast; ze hanteren strategieën zowel gericht op aanpassing aan en beïnvloeding van de omgeving. Dit om externe middelen te verwerven via het aanbieden van diensten op het 
gebied van onderwijs, onderzoek en advieswerk (Gumport \& Sporn, 1999). We gaan nu in op deze twee typen van strategieën.

strategieën gericht op aanpassing

In het kader van de strategieën gericht op aanpassing aan de omgeving proberen universiteiten hun middelen zo efficiënt mogelijk in te zetten en een diversificatie in hun aanbod van diensten en activiteiten te bewerkstelligen. Daarmee spelen ze in op de behoeften in hun omgeving. Zo creëren ze naast hun reguliere programma's bijvoorbeeld nieuwe opleidingen en cursussen gericht op nieuwe doelgroepen. Daartoe voeren ze een behoefte-onderzoek uit en bepalen ze hun meest belangrijke stakeholders. Ze beoordelen de behoeften van de belangrijkste stakeholders, bepalen hun marktsegmenten, en passen dan hun diensten en producten aan.

Veel van deze strategieën zijn gericht op het genereren van inkomsten uit onderwijs en kortlopende trainingen en cursussen. Deze productdifferentiatie uit zich horizontaal, in termen van het spectrum van programma's, en verticaal, in termen van het niveau van de programma's. Ook starten universiteiten nieuwe (satelliet-) campussen op strategische locaties, passen ze hun onderwijsvorm aan (bijvoorbeeld: onderwijs op afstand, in het weekend, de avonduren of in de zomermaanden) om zich op nieuwe groepen van studenten te kunnen richten. De vier universiteiten hebben in wisselende mate hun onderzoekzwaartepunten geïdentificeerd en daartoe onderzoekinstituten opgezet naast de faculteiten. Ook hebben ze interne dienstonderdelen opgezet om de inkomstenverwerving te ondersteunen en de contacten met de buitenwereld te onderhouden. We merken op dat het starten van dergelijke entiteiten niet altijd voldoende doordacht is. De expertise en bezetting schiet soms tekort en een adequate basis en traditie wat betreft onderzoek ontbreekt in sommige gevallen. Dit duidt erop dat beslissingen tot differentiatie en diversificatie eerder een uiting zijn van imitatiegedrag dan van een weldoordachte, rationele strategie. We denken deze 'imitatiestrategie' te bespeuren bij de twee Ethiopische universiteiten en de JKUAT (Kenia).

Op het corporate niveau hebben de case studie universiteiten praktische maatregelen genomen om de communicatie te verbeteren en structuren voor 'relatiebeheer' of 'stakeholder management' opgezet. Ook prikkelen ze hun academische staf door middel van regelingen en stimuleringsmaatregelen om inkomsten te genereren. Ze zetten eenheden op die zich bezighouden met outreach, contractonderwijs, contractonderzoek, korte opleidingen, advieswerk, en zelfs het aanbieden van niet-academische producten en diensten. Daartoe hebben drie van de vier universiteiten een besluitvormend orgaan opgezet met daarin bestuurders en academici vanuit de instelling. Dit orgaan identificeert 
kansen en initiatieven gericht op inkomstenverwerving en bespreekt de voors en tegens. De vier universiteiten hanteren zowel financiële en niet-financiële beloningen om de aandacht van de academische staf te richten op inkomstenverwerving. In het geval van de Ethiopische case studie universiteiten is de financiële beloning op de direct betrokken individuen gericht; bij de Keniaanse en Zuid-Afrikaanse universiteiten betrekt de beloning daar ook andere eenheden en personen bij. Alle case studie universiteiten stellen seed money ter beschikking voor initiatieven en structuren rondom middelenverwerving. Een en ander leidt echter tot een aanzienlijke vergroting van de organisatorische complexiteit, soms met nadelige gevolgen voor de efficiëntie.

strategieën gericht op beïnvloeding

De vier universiteiten hanteren eveneens strategieën om hun omgeving te veranderen en zo hun mogelijkheden te vergroten en de beperkingen die ze ervaren weg te nemen. Deze strategieën omvatten onder andere het vormen van allianties met andere instellingen, de coöptatie van leden in bestuursorganen, en het lobbyen voor aangepaste regulering door de overheid. De vier case studie universiteiten hebben strategische allianties met andere onderwijsorganisaties opgezet om nieuwe groepen van studenten te bereiken die van hun onderwijsdiensten gebruikmaken. Allianties met universiteiten of onderzoeksinstituten zijn soms ook bedoeld om de eigen onderzoekcapaciteit te vergroten of te upgraden. Uit de case studies blijkt echter dat dergelijke allianties op dit gebied alleen vruchtbaar zijn wanneer de case studie universiteit ook zelf werkt aan de eigen kritische massa in termen van onderzoek en voldoende menselijk en niet-menselijk kapitaal ter beschikking stelt. De Zuid-Afrikaanse NMMU universiteit illustreert dit punt. Teleurstellingen op dit punt blijken vooral te worden veroorzaakt door een gebrek aan voldoende gekwalificeerd personeel en infrastructuur.

Een strategie om buitenstaanders lid te doen zijn van universitaire bestuursorganen kan zijn ingegeven door de wens om gemakkelijker toegang te verkrijgen tot nieuwe marktsegmenten of om beperkingen in wetgeving weg te nemen. Coöptatie van vertegenwoordigers van regionale autoriteiten, bedrijven of alumni in de universitaire raden of bestuursorganen van de case studie universiteiten is een strategie gericht op beïnvloeding van de buitenwereld en een weg om preferentiële toegang te krijgen tot nieuwe hulpbronnen. De aanwezigheid van dergelijke vertegenwoordigers kan nieuwe mogelijkheden bieden voor het verzorgen van educatieve diensten en korte cursussen aan regionale of provinciale partijen. In een ander geval (ASTU) hebben universitaire bestuurders gelobbyd voor meer autonomie van de universiteit op 
het gebied van personeelsbeleid en arbeidsvoorwaarden voor het eigen personeel.

\section{Voorwaarden en barrières voor middelenverwerving}

Niet elke universiteit bezit dezelfde mogelijkheden en kansen om nieuwe inkomstenbronnen aan te boren. Er kunnen omstandigheden zijn die het genereren van externe inkomsten stimuleren, maar ook belemmeringen die in de weg staan. Deze factoren vallen uiteen in externe factoren (d.i. gesitueerd buiten de universiteit) en interne factoren (binnen de universiteit).

externe voorwaarden en barrières

In de omgeving van de universiteit spelen de volgende (externe) factoren een rol bij het resultaat van strategieën en acties gericht op externe middelenverwerving: de soort en aard van de stakeholders, de wettelijke regelgeving, inclusief de mate van autonomie die de universiteit bezit, de bekostiging van de universiteit (naar aard en omvang) en het bestaan van eventuele stimuleringsregelingen die universiteit aanzetten (dan wel beperken) bij inkomstenverwerving. De case studies illustreren dat de algemene wettelijke kaders in de drie landen niet beperkend zijn, maar dat er op het gebied van de financiële en personele autonomie voor de Ethiopische case studie universiteiten wel degelijk barrières bestaan. Zo ondervinden deze universiteiten belemmeringen bij het inzetten van budgetten, het herverdelen van fondsen over begrotingsposten, kunnen ze geen beroep doen op de kapitaalmarkt voor het aangaan van leningen, en zijn ze niet in staat te beslissen over het volume en de salarissen van het universitaire personeel.

In het geval van de universiteiten uit Ethiopië en Kenia zijn de financiering en de stimuleringsregelingen volledig gericht op de onderwijsfunctie van de universiteit. Er bestaat vrijwel geen aandacht voor de andere functies van de instelling, zoals onderzoek, maatschappelijke dienstverlening en het stimuleren van de toegankelijkheid van het hoger onderwijs voor studenten uit sociaaleconomisch zwakke milieus. Het ontbreken van publieke bekostiging voor onderzoekers of onderzoekinfrastructuur staat het genereren van externe inkomsten uit onderzoek in de weg. Zuid-Afrika, daarentegen, heeft een breed scala aan instrumenten op het gebied van (financiële) ondersteuning van onderzoek, inclusief beurzen voor studenten en beloningen voor wetenschappelijke publicaties, die de mogelijkheden voor universiteiten om aanvullende financiering van het onderzoek te vinden aanzienlijk vergroten. Bovendien kent het land studiefinanciering vanuit de National Student Financial Aid Scheme. In Kenia verschaft de Higher Education Loan Board studiefinanciering 
om de intrede in het hoger onderwijs te vergemakkelijken voor studenten uit arme en achtergestelde milieus. Het gebrek aan dergelijke regelingen in Ethiopië betekent dat universiteiten in dat land verstoken blijven van studenten die anders wellicht betaalde cursussen zouden volgen aan de universiteit.

Een andere barrière voor middelenverwerving is het bestaan van ingewikkelde administratieve regelingen en zware verantwoordingslasten rondom inkomstenverwerving. Deze bureaucratie bestaat rondom zowel inkomsten uit publieke als private bronnen, inclusief schenkingen door buitenlandse donoren. Deze lasten maken dat universiteiten soms afzien van inspanningen om middelen binnen te halen en aanvullende financieringsbronnen te zoeken. Het bestaan van gedetailleerde voorschriften voor de besteding van publieke en private middelen legt aanzienlijke beperkingen op aan de handelingsvrijheid van universiteiten.

interne voorwaarden en barrières

De volgende factoren, gesitueerd binnen de universiteit, zijn van invloed op het resultaat van de strategieën en acties gericht op externe middelenverwerving: de betrokkenheid van het leiderschap van de instelling (zowel op topniveau als bij het middenkader), het bestaan van (adequate, dan wel minder adequate) interne beleidsprocessen en procedures rondom het genereren van externe middelen, het aanwezig zijn (of het gebrek aan) voldoende gekwalificeerd en gemotiveerd academisch personeel en professionele managers, en het ter beschikking staan van materiële en infrastructurele voorzieningen op het gebied van trainings- en onderzoeksfaciliteiten. Uit de case studies blijkt dat een cruciale rol wordt gespeeld door het universitaire leiderschap bij het aanjagen van externe middelenverwerving. Uit onze case studies blijkt verder dat structuren, commissies en besluitvormingsprocessen rondom de diversificatie van diensten en inkomsten soms tekortschieten of afwezig zijn. Een adequate interne structuur van commissies, gecombineerd met sterk leiderschap, blijkt een essentiële factor te zijn bij inkomstenverwerving.

Uit de case studies blijkt dat een gebrek aan gekwalificeerd wetenschappelijk personeel - zoals onder andere blijkend uit het aantal gepromoveerden - een grote barrière is bij het genereren van inkomsten door de Ethiopische universiteiten. Een gebrek aan onderzoeksvaardigheden en onderzoekscapaciteit beperkt het genereren van externe inkomsten uit onderzoek. Veel universiteiten in Sub-Sahara Afrika lijden sterk onder het gebrek aan onderzoeksfaciliteiten, laboratoria en apparatuur. Daartegenover staat het voorbeeld van de Nelson Mandela Metropolitan University, waar via gerichte investeringen in onderzoek en infrastructuur de universiteit de mogelijkheden heeft gecreëerd om inkomsten uit onderzoek en uit post- 
graduate onderwijs te verdienen. In Ethiopië en Kenia zijn de externe middelen voornamelijk afkomstig uit collegegelden die worden betaald door studenten die geen door de overheid bekostigde plaats op de universiteit hebben weten te bemachtigen.

Uit het geval van de Zuid-Afrikaanse case studie universiteit (NMMU) komt ook duidelijk naar voren dat de mogelijkheden voor het genereren van inkomsten sterk afhankelijk zijn van de kwaliteit van (eerder) geleverde diensten. De gebrekkige administratieve ondersteuning in het geval van de Ethiopische universiteiten is een beletsel bij het aangaan en afwikkelen van contracten met externe partijen en daarmee een belemmering voor het genereren van inkomsten. Hier is het probleem dat naar behoren gekwalificeerd en ervaren personeel schaars is voor gebieden als inkoopmanagement, fondsenwerving, human resources, communicatie en financieel beheer.

reflecties ten aanzien van de theorie

Onze studie laat zien dat de resource dependence theorie zijn beperkingen heeft. Dit in het bijzonder wat betreft de mogelijkheid tot het verklaren van empirische fenomenen als de keuzes voor meer uitgewerkte strategische reacties van universiteiten op ontwikkelingen in de buitenwereld. Uiteraard kunnen menselijk gedrag en organisatiestrategieën nooit volledig worden verklaard door marktmechanismen of economische motieven (zie Nienhüser, 2008). Uit ons onderzoek blijkt echter wel dat onze case studie universiteiten bepaalde typen van strategische respons aan de dag leggen, ook al zijn ze actief in uiteenlopende institutionele omgevingen. De strategische reacties duiden niet altijd op calculatief gedrag of afwegingen van economische aard. De strategische reacties op uitdagingen of kansen in de omgeving zijn vaak te interpreteren als een strategie van aanpassing aan de omgeving die niet op een adequaat fundament van interne capaciteiten of expertise is gestoeld. Het antwoord van universiteiten op financiële uitdagingen is, zoals we hieronder zullen betogen, in sommige gevallen beter te interpreteren aan de hand van een neo-institutioneel perspectief, of vanuit de theorie van de institutional logics (Zajac \& Westphal, 2004; Delmas \& Toffel, 2008; Ashworth et al., 2007; Greenwood \& Hinings, 1996; Thornton \& Ocasio, 2008).

De empirie suggereert dat het hebben van een strategie voor het verwerven van externe middelen wel een noodzakelijke maar geen voldoende voorwaarde is voor het succes bij inkomstenverwerving. Het aanwezig zijn van adequate interne (menselijke en materiële) capaciteit is cruciaal. Deze hulpbronnen dienen in voldoende mate en in voldoende kwaliteit aanwezig te zijn om te dienen als springplank bij product- en inkomstendiversificatie. Deze vaststelling duidt erop dat een resource-based view (Kraaijenbrink et al., 2010) 
ook als een theoretische lens voor het interpreteren onze resultaten kan worden gebruikt. Ook wijzen de case studies erop dat een combinatie van de resource dependence theorie met de neo-institutionele theorie, institutional logics en de resource-based view zeer wel bruikbaar zou zijn als nader onderzoek zou moeten worden gedaan naar de keuze voor een uitgewerkte middelenstrategie. Nader onderzoek zou daarmee, naast economische en financiële motieven, ook in kunnen gaan op waarden, normen en aspecten van cultuur binnen de universiteit als complexe organisatie.

\section{Onderzoeksvraag 4: aanbevelingen voor middelenverwerving}

Deze dissertatie toont aan dat het genereren van externe inkomsten door universiteiten in Sub-Sahara Afrika sterk wordt beperkt door een veelheid van onderling gerelateerde factoren in zowel de interne als de externe omgeving van de universiteit. Om de middelenverwerving te stimuleren zal het bewerkstelligen van een stimulerende organisatorische omgeving en het scheppen van effectieve interne condities nodig zijn. Dit is vooral van belang wil op termijn de financiering van het hoger onderwijs in Sub-Sahara Afrika meer duurzaam en toekomstbestendig zijn. De totstandbrenging van dergelijke interne en externe condities kan niet zonder een vergroting van de publieke middelen voor hoger onderwijs in Sub-Sahara Afrika, aangezien de sector momenteel aanzienlijk op de proef wordt gesteld door een groei van de studentenaantallen die ver uitstijgt boven de beschikbare publieke budgetten.

Een uitlaatklep kan worden gevonden in de (verdere) ontwikkeling van een private hoger onderwijssector, het (verder) verhogen van de collegegelden, en een meer efficiënt gebruik van de beschikbare middelen. Deze beleidsopties zullen zeker moeten worden ingezet, maar daarnaast zal de financiële bestaanszekerheid van de universiteiten in Sub-Sahara Afrika afhankelijk zijn van de voorwaarden en beperkingen waar de universiteiten mee te maken hebben bij het genereren van externe middelen. Dit in combinatie met een stabiele en adequate publieke bekostiging. Het belangrijkste advies dat we op basis van de internationale praktijk en onze case studies kunnen aandragen is dat de verschillende beleidsinstrumenten en factoren niet los van elkaar moeten worden beoordeeld en ingezet, maar dat ze alleen in combinatie en toegespitst op de specifieke (nationale, regionale) situatie in Sub-Sahara Afrika tot een succesvol resultaat kunnen leiden.

Alleen met een slimme mix kan een adequate balans tussen economische eisen, sociale behoeften, politieke gegevenheden, overwegingen van kwaliteit en toegankelijkheid, en - niet onbelangrijk - beschikbare financiële middelen worden gevonden. Verwerving van externe middelen door universiteiten is altijd ingebed in een complexe realiteit van nationale, internationale, regionale 
en organisatorische (beleids-)omstandigheden. Beleidsmakers moeten zich ervan bewust zijn dat elke keuze omstreden zal zijn in dit krachtenveld.

We hebben via onze case studies vastgesteld dat de overheid de stakeholder is waar de meeste aandacht en tijd naar uit gaat. Het is de overheid die de condities en het speelveld in zeer sterke mate bepaalt. Daarom is het ook de overheid die universiteit de kansen en prikkels moet geven om effectief te kunnen reageren op behoeften in de samenleving en - als uitvloeisel daarvan het genereren van financiële middelen. Het verdienen van geld kan echter nooit het ultieme doel zijn; uiteindelijk moet het gaan om het verhogen van de algehele kwaliteit van de op kennis (via onderwijs en onderzoek) gerichte activiteiten van de universiteit.

\section{Slotobservaties}

De case studies tonen aan dat de mogelijkheden van universiteiten in SubSahara Afrika om een diversificatie van diensten en middelen tot stand te brengen wordt beperkt door het gegeven dat er onvoldoende menselijk en immaterieel kapitaal aanwezig is. Afrikaanse universiteiten zullen aanvullende middelen moeten genereren voor het opbouwen van onderzoekscapaciteit en faciliteiten voor het trainen van post-graduate studenten. Daarvoor zijn aanzienlijke investeringen nodig en zullen binnen het onderwijsbudget meer middelen voor hoger onderwijs moeten worden gevonden - zeker in landen waar de deelname aan het primair onderwijs richting 100\% gaat. Naast extra financiële middelen is expertise nodig: op organisatorisch gebied en voor de ondersteuning van activiteiten gericht op diensten die extra middelen doen binnenkomen.

Men dient te beseffen dat de overheidsbudgetten krap zijn, vooral in Afrikaanse landen. Het hoger onderwijs dient te wedijveren met een groot aantal andere beleidsvelden. Daarom zal het mobiliseren van aanvullende publieke middelen moeten worden gecombineerd met externe middelen - uit contractactiviteiten, cursussen en donaties van westerse landen. De kunst is de ene activiteit, respectievelijk geldstroom, te gebruiken als hefboom voor de andere.

Universiteiten zijn ingebed in natiestaten, en de nationale regeringen blijven van cruciaal belang bij hun aansturing. Onze studie laat zien dat nationale overheden de universiteit een zekere mate van autonomie moeten gunnen ten aanzien van beslissingen binnen de universiteit, met name op het gebied van financiën en personeel. Dit dient uiteraard gepaard te gaan met het afleggen door de universiteit van verantwoording over activiteiten, middelen en prestaties. Universiteiten moeten zoveel mogelijk hun eigen financiën kunnen 
beheren in overeenstemming met ontwikkelingsdoelstellingen die mede zijn geaccordeerd door de overheid.

De overheid kan universiteiten ook stimuleren om externe middelen te genereren door de publieke bekostiging die ze verschaft aan de universiteit. Er bestaat een veelheid van methoden die hiervoor kunnen worden gebruikt. Zo kan de overheid in bekostigingsformules stimulansen (premies) inbouwen, middelen in competitie ter beschikking stellen, dan wel gerichte, geoormerkte financiering als mechanisme inzetten. Gelet op het feit dat het genereren van inkomsten sterk afhankelijk is van de kwaliteit van geleverde diensten, moeten overheden juist de kwaliteit van onderwijs en onderzoek stimuleren. Onderdeel daarvan is ervoor te zorgen dat ook studenten over voldoende financiële middelen kunnen beschikken en een beroep kunnen doen op studiefinanciering. Verspilling van publieke middelen zal daarbij moeten worden voorkomen - bij universiteiten en studenten. Onderwerpen als inefficiënties, tekortschietende kwaliteit, vergroting van vrijheid en gebrekkige verantwoording zijn echter gevoelige onderwerpen en kunnen politieke weerstand oproepen.

Overheden kunnen de samenwerking tussen universiteiten en externe partijen aanmoedigen. Gelet op de relatief onderontwikkelde aard van interacties tussen universiteiten en externe stakeholders, en de noodzaak om kennis te genereren in het werken met externe partners, ligt het voor de hand dat de universiteiten in eerste instantie moeten worden gestimuleerd om samen te werken met partijen in hun (geografische) nabijheid. Dit kan uitmonden in samenwerking met regionale en lokale gemeenschappen, bedrijven en overheden. Deze lokale samenwerking draagt enerzijds bij aan de diversificatie van het aanbod van universiteiten en maakt deel uit van strategieën gericht op aanpassing aan de omgeving. Aan de andere kant helpt de samenwerking bij het opbouwen van managementexpertise en gedeelde infrastructuur.

Het vergroten van de private financiële bijdragen (in de vorm van collegegelden) aan het hoger onderwijs is een van de opties die overheden ook in Afrika - ter beschikking staan bij het genereren van extra middelen voor het hoger onderwijs (Johnstone, 1998). De kwestie van de verdeling van de kosten in het hoger onderwijs is echter zeer omstreden - en niet alleen in Afrikaanse landen. Er worden stevige debatten gevoerd over de maatschappelijke en individuele baten van het hoger onderwijs (World Bank, 2010). Daarbij ontberen ontwikkelingslanden veelal adequate informatie ten aanzien van de inkomenspositie van burgers; informatie die essentieel is bij het verstrekken van studiefinanciering. 
Vooralsnog lijken veel Afrikaanse landen de markt voor hoger onderwijs open te stellen voor binnenlandse en buitenlandse private aanbieders. Dit stelt de Afrikaanse landen in staat aan de groeiende vraag naar hoger onderwijs te voldoen; een vraag waaraan de publieke sector niet in adequate mate kan voldoen (Altbach \& Teferra, 2004; Saint, 1992). Overheden dienen zich daarbij wel af te vragen wat de kwaliteit is van het private hoger onderwijs. Accreditatie en certificering dienen de consument te beschermen en te garanderen dat het aanbod kwalitatief aan de maat is.

Uit de case studies is gebleken dat de regelingen rond donorgelden tot de meest complexe behoren waar het gaat om externe middelenverwerving. De regels, administratieve processen en verantwoordingseisen vormen een complexe constellatie. Om universiteiten te blijven prikkelen donormiddelen binnen te halen zou een vereenvoudiging van de financieringssystemen, subsidievoorwaarden en verantwoordingseisen kunnen worden overwogen. Er is eveneens behoefte aan mechanismen om de universiteiten te ondersteunen bij het aanvragen van donormiddelen.

Elke universiteit heeft zijn eigen manier van reageren op de financiële uitdagingen. $\mathrm{Er}$ is geen 'one size fits all' oplossing. Het opstarten van inkomstenverwerving is inmiddels een geaccepteerde activiteit in universiteiten; het is een legitimerende strategie ook richting overheid; en legitiem bij het verkrijgen van meer financiële bestaanszekerheid. Weerstand tegen de inkomstenverwerving kan worden weggenomen door de ondernemende (marktgerichte) activiteiten van de universiteit zoveel mogelijk aan te laten sluiten bij de missie van de universiteit. Elke universiteit heeft daarbij te maken met een eigen omgeving en context, die mede bepalend is voor haar keuzes ten aanzien van de strategie. Algemene overwegingen en richtlijnen hierbij zullen moeten uitgaan van de stelregel dat elke inspanning op het gebied van inkomstendiversificatie een netto rendement moet opleveren, niet alleen in de zin van nieuwe inkomsten, maar in de zin van baten die uitstijgen boven de kosten. Het universitaire bestuur moet vanaf het begin duidelijk maken dat de universiteit zich zal terugtrekken uit activiteiten of instituten die geen aanwijsbare baten opleveren. Potentiële baten kunnen ook niet-financieel van aard zijn en zich voordoen op de korte dan wel lange termijn. De besluitvorming over nieuwe initiatieven zal dus specifiek voor de universiteit zijn en vaak te maken hebben met factoren die niet gemakkelijk in geld zijn uit te drukken. Een beleid op instellingsniveau ter bevordering van het genereren van inkomsten is alleen mogelijk wanneer de universiteit beschikt over bekwaam, professioneel en betrokken personeel - op academisch en administratief niveau. Personeel dat wordt aangestuurd door adequate 
bestuurs- en management structuren, inclusief stimuleringsregelingen op het gebied van inkomstenverwerving.

De case studies tonen aan dat het nastreven en het genereren van externe middelen kan leiden extra werkdruk die aanvullende personele en materiële capaciteit vereist. Het aanstellen van nieuwe medewerkers kan daarbij noodzakelijk zijn (EUA, 2012). Bovendien zijn stimuleringsmaatregelen nodig om afdelingen en individuele medewerkers in beweging te brengen. Beloningen voor inkomstenverwerving moeten zijn gebaseerd op het uitgangspunt dat zowel het individu als de universitaire gemeenschap als geheel moet profiteren van de gegenereerde middelen. Inspanning en succes van een individu bij het genereren van inkomsten kan als een van de criteria worden meegenomen bij de werving en bevordering van personeel. Ook moet het interne allocatiemodel van de universiteit het genereren van inkomsten bevorderen.

Er is sterk leiderschap nodig binnen de universiteit om een effectieve afweging van belangen van stakeholders te waarborgen. We hebben bij de case studie universiteiten waargenomen dat door ondernemende activiteiten de universiteit meer wordt blootgesteld aan de wensen en belangen van een veelheid van stakeholders, zoals overheden, studenten, donoren en het bedrijfsleven. Dit roept om een sterke, integratieve visie op de ontwikkeling van de universiteit, vanuit een duidelijk strategisch leiderschap, dat interne belangen (en conflicten) kan verenigen op een zodanige wijze dat de universiteit voldoet aan de behoeften van deze stakeholders. Het zal duidelijk zijn dat het bestaande universitaire leiderschap en het instellingsmanagement in Sub-Sahara Afrika op dit gebied kan worden verbeterd. Door middel van training zullen vaardigheden en organisatorische capaciteit rondom het genereren van externe middelen geleidelijk moeten worden opgebouwd.

Middelen die resulteren uit strategieën voor inkomstenverwerving dienen te worden geïnvesteerd in de universiteit en bij te dragen aan de belangrijkste opdracht van de universiteit: het zorgdragen voor onderwijs en onderzoek. Met name het vermogen van de universiteiten in Sub-Sahara Afrika om onderzoek te doen is zwak, met uitzondering van de Zuid-Afrikaanse case studie universiteit. Derhalve zal een deel van de gegenereerde externe middelen moeten toevloeien naar nieuwe onderzoeksactiviteiten om de universitaire kennisbasis te vergroten. Daarbij zal ervoor gezorgd moeten worden dat een koppeling tussen onderwijs en onderzoek blijft gehandhaafd, opdat studenten profiteren van de verbetering van de kennisbasis van het wetenschappelijk personeel. 
In een universiteit met een effectieve strategie rondom middelenverwerving wordt de verantwoordelijkheid voor het genereren van inkomsten overgedragen aan - en gevoeld door - het personeel op alle niveaus. Als medewerkers van de universiteit niet in aanraking komen met de behoeften en financiële signalen van hun stakeholders zullen ze genegen zijn terug te vallen op een business-as-usual model, dat wil zeggen dat ze zich blijven richten op hun enige en belangrijkste financier - de overheid. Daarom is een belangrijke uitdaging het ontwerpen en implementeren van een effectief intern allocatie- en beloningsmodel, waarin prikkels voor het genereren van inkomsten zowel bij de faculteiten, departementen als individuen worden gevoeld. Dit model moet academisch en administratief personeel de mogelijkheid geven om geldelijke beloningen te ontvangen voor hun inspanningen om externe middelen te genereren. In dit model zal ook een inkomstenstroom vanuit het centrale niveau moeten zijn ingebouwd om aanjaagsubsidies te verschaffen voor initiatieven die niet uit de rijksbijdrage kunnen worden gefinancierd. Nog belangrijker is dat het genereren van inkomsten moet worden ingebed in de organisatiestructuur van de universiteit - in het bijzonder aan de human resource kant. Dit moet eraan bijdragen dat academici en administratief personeel in staat zijn om te delen in de voordelen van het genereren van inkomsten. Mogelijke voordelen kunnen zijn: flexibele werktijden, persoonlijke opleidingsplannen, adequate werkfaciliteiten, en apparatuur voor het uit te voeren werk. Verder merken we op dat activiteiten gericht op het verwerven van externe middelen uiteraard niet ten koste mogen gaan van de kwaliteit van het onderwijs en het onderzoek.

We hopen dat onze studie een beter begrip tot stand heeft gebracht van de uitdagingen waar universiteiten in Sub-Sahara Afrika voor staan en dat met de hier gedane aanbevelingen een verstandig beleid rondom middelenverwerving kan worden ingericht. Tenslotte spreken we de hoop uit dat de conclusies van deze studie zullen bijdragen aan het verbeteren van de toekomst van de universiteiten in Sub-Sahara Afrika. Ze verdienen het! 


\section{Annex}

\section{Interview Schedule}

\section{Questions}

What are the key resource providers for the university? Please rate the following in terms of importance and indicate where this importance has changed in recent years:

1. Central government (including funding councils \& national research council's)

2. Regional/local government

3. Students (regular vs self-funded)

4. Donors (international/WB, bilateral countries, others)

5. Business \& industry (local vs other)

Looking at these five categories, what do you consider to be the most significant developments in the funding for this university in recent years? Please make a distinction between public and private funding.

- What is the share of revenues from non-governmental sources ('external funding') in total recurrent income?

- Have these income streams been increasing or declining in the last five years?

- What are the activities that provide additional resources over and above the core funding received from the public authorities?

- What is the most important activity in this respect?

- Does the university have an explicit objective/strategy with respect to generating funds from sources other than the public authorities (= revenue diversification)? Is this documented somewhere? 
- What have been the drivers for such revenue diversification? Would you say these are mostly internal or external? In other words, is it government or donors that call for revenue generation or do the initiatives (if any) come from individual units and academics working in the university?

- Does the initiative for revenue generation activity (RGA) lie with the central or the decentral level in the university? In other words, is this RGA a topdown or a bottom-up issue?

- Does the university regard itself as being successful in generating external resources (e.g. compared to other universities)? If so, what is the evidence? Are you doing anything to learn from best practices in terms of RGA?

- What do public authorities (e.g. Ministry of Education or Finance) do to help your university to diversity its funding?

- How does the university monitor its potential for engaging in partnerships with external/regional stakeholders that eventually may bring additional resources to the university?

- Did your university in recent years adjust its internal resource allocation arrangements (= internal budgeting procedures) in order to generate external revenues? In what way? For instance, do academic departments that engage in such RGA reap part of the benefits from the resources they generate?

- Do you feel the internal resource allocation arrangements in your university are critical in RGA? In what way?

\section{Human resources policy}

- Did your university in recent years adjust its human resource policies \& regulations in order to generate external revenues? In what way? For instance, have you made any changes in selection or promotion (evaluation criteria) for academic staff?

- Is the success of academics in generating external funding used as part of the promotion criteria?

- Do you provide any (financial/salary, in-kind) benefits to those academics that are successful in RGA?

- Does successful engagement in revenue generation lead to better working conditions for staff (e.g. activity portfolio; participation in conferences; better research facilities)? 


\section{Differentiation in education}

- Have you ever made any changes in your programme supply or modes of educational delivery in order to generate additional resources from external sources?

\section{Differentiation in research}

- Did your university make any changes in its research activities/portfolio in order to generate additional resources? Which, and for which clients/stakeholders?

- Did this imply a shift in focus of research towards more applied research, user-driven research (=research that is explicitly focusing on external needs)?

- Have there been or are there currently research co-operations between your university and stakeholders that bring in significant additional resources? Of what kind are they?

\section{Autonomy}

- Are universities legally allowed to generate revenues from nongovernmental sources?

- What part of legislation is particularly restrictive to RGA and why?

- Can you please indicate if any specific national policies or regulations have been introduced over the past decade in your country with the aim of enabling the RGA (external funding) of universities? Did your university (or the body representing the universities in your country) ever argue/lobby for revised legislation or widening opportunities for RGA? Was there any role played by donors in this regard?

\section{Financial autonomy}

- To what extent can the university freely decide on the following matters:

- Generation and deployment of monetary resources received as a result of providing teaching, research and consultancy services to clients other than the regular students funded by the public authorities

- Setting or differentiating tuition fees for students;

- pricing of research \& consultancy services offered by the university; 
- borrowing funds on the capital market

- renting out of university facilities and providing (non-education) services to students (e.g. dormitories, meals);

- Please answer this by rating the above on a five-point scale: strongly disagree (1), disagree (2), neither agree nor disagree (3), agree (4) or strongly agree(5).

- To what extent do you regard the issue of financial autonomy to be important for the generation of resources from non-governmental sources?

\section{Autonomy in the dimension of Education}

- To what extent can the university freely decide on the following matters:

- Admission and selection of students

- Introducing or eliminating degree programmes;

- setting the standards \& curricula for such programmes and other diploma courses and contract education services;

- deciding on their modes of instruction and delivery

- Setting priorities for research and non-education services

- Please answer this by rating the above on a five-point scale: strongly disagree (1), disagree (2), neither agree nor disagree (3), agree (4) or strongly agree(5).

- To what extent do you regard the issue of autonomy in this educational area to be important for the generation of resources from non-governmental sources?

\section{Autonomy in the area of human resources}

- To what extent can the university freely decide on the following matters: relating to academic staff and support staff:

- selection, promotion, and dismissal of employees

- setting the pay \& working conditions for its employees

- Please answer this by rating the above on a five-point scale: strongly disagree (1), disagree (2), neither agree nor disagree (3), agree (4) or strongly agree(5). 
- To what extent do you regard the issue of staffing and human resources to be important for the generation of resources from non-governmental sources?

\section{Autonomy w.r.t. internal governance}

- To what extent can the university freely decide on matters relating to setting up its internal governance structure:

- Deciding on (and introducing) internal governance and decision-making structures/bodies (e.g. committees, boards, advisory bodies)

- Introducing new structures (faculties, departments, research centres) and engaging in collaborative partnerships with other (public \& private) organisations

- Please answer the above by rating the issues on a five-point scale: strongly disagree (1), disagree (2), neither agree nor disagree (3), agree (4) or strongly agree(5).

- To what extent do you regard the issue of internal governance to be important for the generation of resources from non-governmental sources?

- In your view, are the existing governance structures and decision-making processes adequate (appropriate) to enable the university to embark on a successful revenue generation strategy?

\section{More on governance}

- Have you included external representatives to sit on/play role in university's decision-making bodies with an eye towards encouraging or developing the generation of external resources?

- Did your university create alliances or consortia with other organizations (universities, companies, etc) with an eye towards encouraging or developing the generation of external resources?

- Did your university invite guests/persons from outside/abroad to collaborate in teaching and research activities help generate greater revenue for this university? Are there any collaborations between the university and other higher education institutions in RGA?

- Is the university currently characterized with a decentralized governance structure or a centralized one?

- What is your view on the matter of devolving decision making towards lower hierarchical levels? Do you feel that decentralizing some decision- 
making (e.g. financial or staffing) to faculty/ academic department level can be conducive to RGA? Why / How?

\section{Units, structures, alliances}

- What resources, dedicated functions or dedicated structures did your university introduce in recent years in order to encourage RGA?

- What organizational mechanisms (e.g. new academic units; i.e. departments; education and research centres, continuing education, language \& ICT training centre, etc) have been established to generate external revenues? Have any existing units been merged or integrated in order to do so?

- Have any administrative units or organizational support units (e.g. Technology Transfer Office, university enterprises, unit for fundraising, projects coordination units, donations office, etc) been established for generating new revenues for the university?

\section{Infrastructure}

- Have you introduced new policies or regulation with respect to the university's use of space, infrastructure or facilities in order to enhance existing and prospective revenues?

\section{Capacity}

- In your view, are the existing non-human resources (laboratories, libraries, workshops, etc) sufficient for engaging in revenue-generating initiatives? Or are they a barrier to such activity?

- In terms of their level of expertise and training, are the existing academic staff capable for engaging in RGA?

- What about the level of training and expertise of support staff?

- Did you provide training to academics and/or support staff already in place to professionalize them and familiarize them with RGA?

- What have been the effects of the growth of RGA on the academic activities of this university? Did the university in any way have to compromise its services, the diversity of its programmes, or the quality thereof? In other words, does RGA come at the expense of the core academic activity of 
academics (their teaching \& research)? Were there any cases of fraud or unfair competition?

- Were there any external reviews (or audits) carried out that looked at the effects of revenue generation activity?

\section{Overlooking all of these issues...}

- Can you please identify the external enablers and barriers for RGA in this university? First enablers, then barriers.

- Can, you identify the internal barriers for engaging in revenue generation activities? What are the key strategies to overcome the barriers?

Finally, please mention any issues that you feel are important but were not mentioned?

\section{Revenues obtained broken down by source of funding}

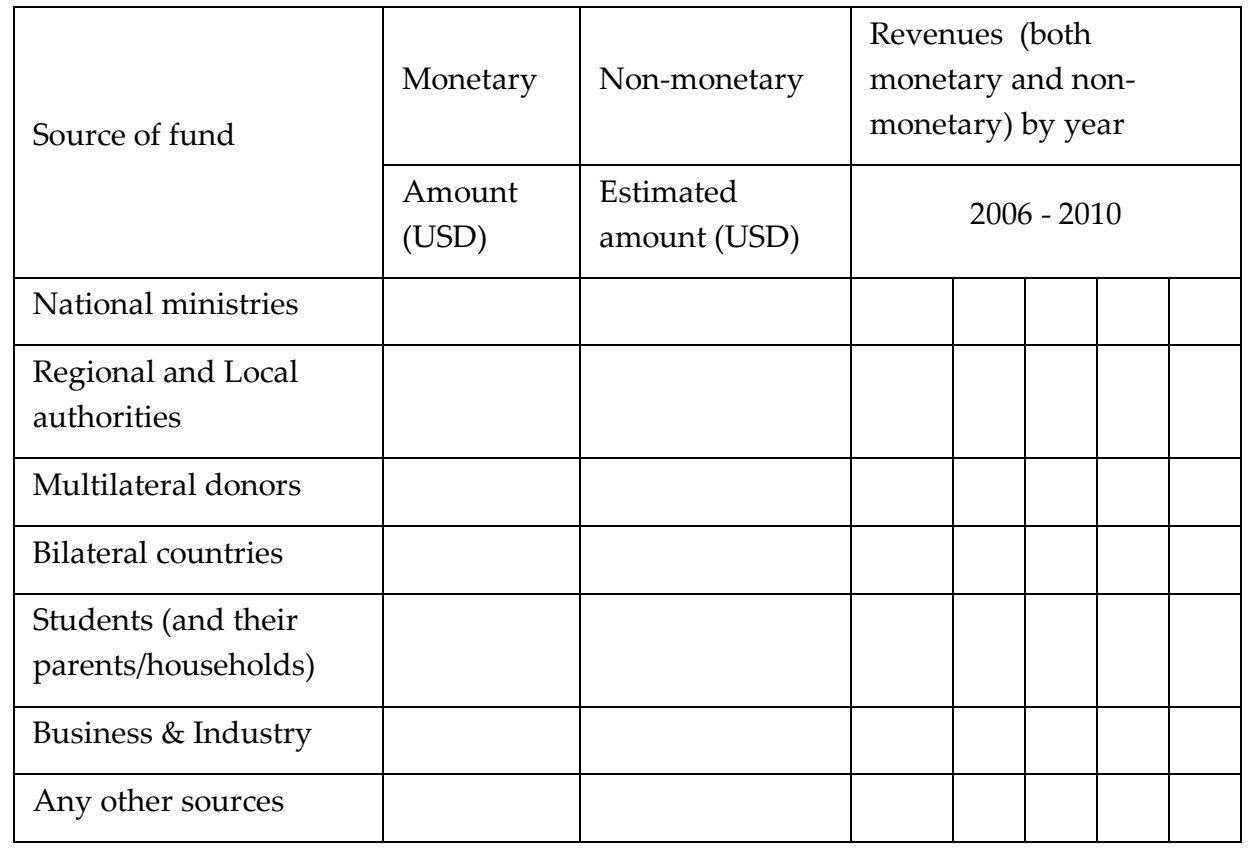


